\title{
Animal symbolisé, animal exploité : du Paléolithique à la Protohistoire
}

Sandrine Costamagno,

Lionel Gourichon, Catherine Dupont, Olivier Dutour, Denis Vialou (dir.)

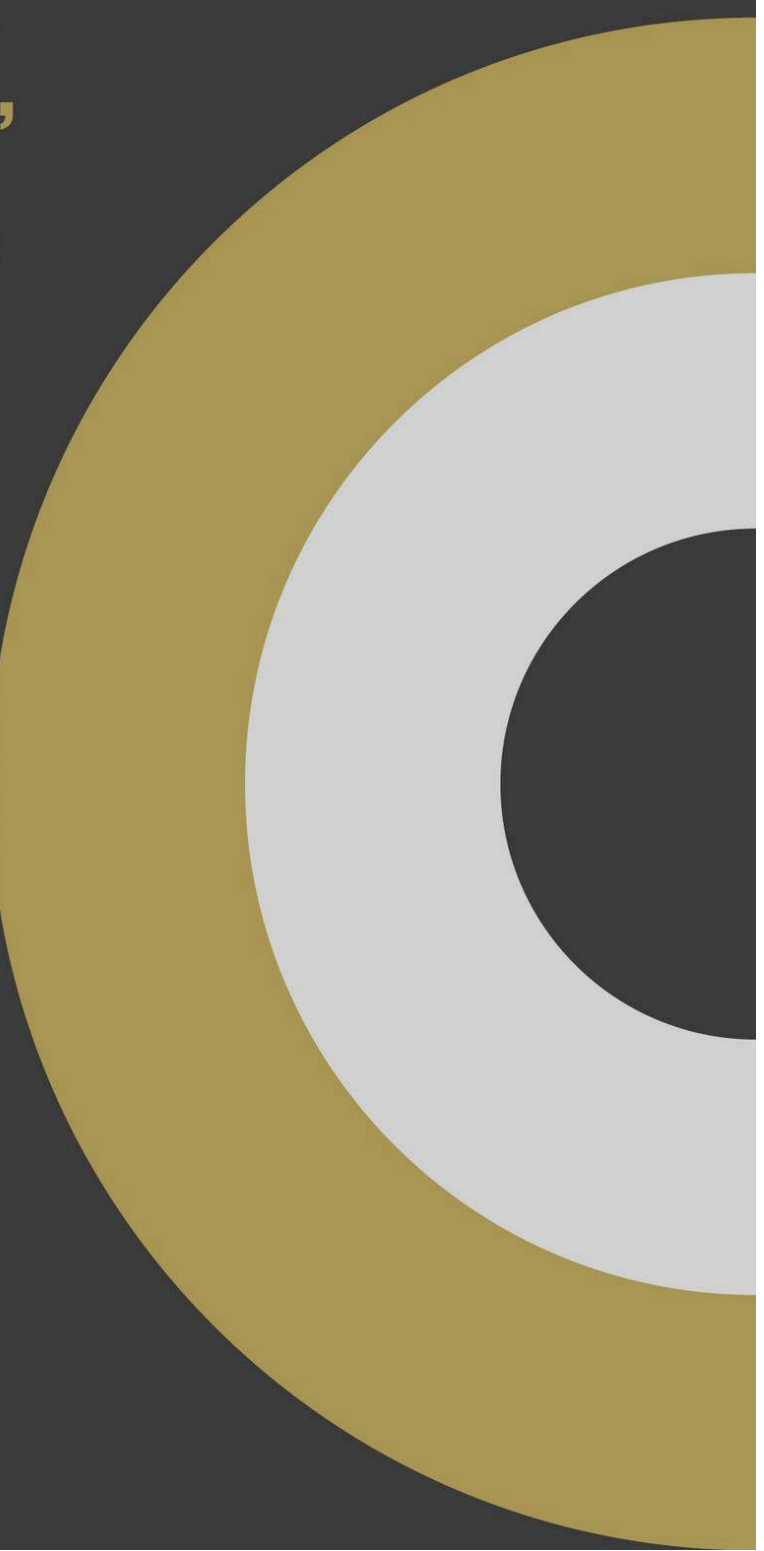




\title{
Animal symbolisé, animal exploité : du Paléolithique à la Protohistoire
}

\author{
Sandrine Costamagno, Lionel Gourichon, Catherine Dupont, Olivier Dutour \\ et Denis Vialou (dir.)
}

DOI : $10.4000 /$ books.cths. 4278

Éditeur : Éditions du Comité des travaux historiques et scientifiques Année d'édition : 2018

Date de mise en ligne : 22 janvier 2019

Collection : Actes des congrès nationaux des sociétés historiques et scientifiques

ISBN électronique : 9782735508860

\section{Sbooks}

http://books.openedition.org

\section{Référence électronique}

COSTAMAGNO, Sandrine (dir.) ; et al. Animal symbolisé, animal exploité : du Paléolithique à la

Protohistoire. Nouvelle édition [en ligne]. Paris : Éditions du Comité des travaux historiques et scientifiques, 2018 (généré le 10 décembre 2020). Disponible sur Internet : <http://

books.openedition.org/cths/4278>. ISBN : 9782735508860. DOI : https://doi.org/10.4000/books.cths. 4278.

Ce document a été généré automatiquement le 10 décembre 2020.

(C) Éditions du Comité des travaux historiques et scientifiques, 2018

Conditions d'utilisation:

http://www.openedition.org/6540 
Les dix-neuf textes que comporte ce volume sont issus du colloque organisé dans le cadre du 141 ème Congrès du CTHS «L'animal et l'homme » qui s'est déroulé à Rouen du 11 au 16 avril 2016. Proposé par la section préhistoire et protohistoire du CTHS, ce colloque avait pour objectif d'aborder les relations Homme/Animal sous ses multiples facettes, depuis le Paléolithique jusqu'à l'Âge du Fer. La trentaine de communications proposée lors de ces journées a porté sur cinq grandes thématiques "L'animal ressource ", "Entre chien et loup : de la bête féroce à l'animal familier ", «Les animaux vus et perçus par les Paléolithiques », «La vie et la mort partagée », «Pré-histoire des échanges de pathogènes ».

\section{SANDRINE COSTAMAGNO}

\section{Archéozoologue}

Directrice de recherche au CNRS

CNRS - TRACES - UMR 5608, Université Toulouse 2 Jean Jaurès

Secrétaire de la Section de Pré-Protohistoire du CTHS

\section{LIONEL GOURICHON}

\section{Archéozoologue}

Chargé de recherche au CNRS

Université Côte d'Azur, CNRS, CEPAM (UMR 7264), Nice

\section{CATHERINE DUPONT}

Archéozoologue - Archéomalacologue

Chargé de recherche au CNRS

CNRS - CReAAH - UMR 6566, Université de Rennes

Membre de la Section de Pré-Protohistoire du CTHS

\section{OLIVIER DUTOUR}

Paléopathogiste - Bioanthropologue

Directeur d'Etudes EPHE, Université PSL

Chaire d'anthropologie biologique Paul Broca

PACEA-UMR 5199, CNRS-Université de Bordeaux

Président de la Section de Pré-Protohistoire du CTHS

\section{DENIS VIALOU}

Préhistorien, spécialiste de l'art

Professeur émérite au département de Préhistoire du Muséum national d'Histoire naturelle

Membre émérite de la Section de Pré-Protohistoire du CTHS 
SOMMAIRE

Animal symbolisé, animal exploité : du Paléolithique à la Protohistoire
Sandrine Costamagno, Lionel Gourichon, Catherine Dupont, Olivier Dutour et Denis Vialou

L'exploitation de l'Ours au Paléolithique : un point sur la question

Dominique Armand

Introduction

Méthode

Résultats et discussion

Quels ours et quand?

Chasse ou charognage?

Différents types d'exploitation

Conclusions et discussion

Quelle place pour le Mammouth dans l'économie des Gravettiens d'Arcy-sur-Cure (Yonne, France) il y a environ 27000 ans cal BP?

Nejma Goutas et Jessica Lacarrière

Introduction

Le mammouth au Gravettien, en France : état de la recherche

Préambule méthodologique

Remise en contexte historique des recherches sur Arcy

Des industries gravettiennes particulières...

Présentation du corpus osseux

Discussion sur l'origine des restes de mammouth exploités dans le Gravettien d'Arcy

Conclusion

Le Renne (Rangifer tarandus), pilier de l'économie dans le Magdalénien supérieur de Peyrazet (Creysse, Lot)

Sandrine Costamagno, Jean-Marc Pétillon, Solange Rigaud, Delphine Kuntz, Véronique Laroulandie et Mathieu Langlais

Présentation du gisement

Matériel et méthode d'étude

Résultats

Les produits animaux recherchés

Discussion et conclusion

L'utilisation des petits gibiers au Tardiglaciaire : le cas de Rochereil (collection Jude, Dordogne)

Jean-Baptiste Mallye, Véronique Laroulandie, Peggy Bonnet-Jacquement, Myriam Boudadi-Maligne, Mathieu Langlais, Elena Man-Estier, Carole Vercoutère et Patrick Paillet

Le site de Rochereil : contexte et nouveaux travaux

Datations ${ }^{14} \mathrm{C}$ AMS

La mésofaune de Rochereil

Conclusion

Subsistance en zone côtière durant le Middle Stone Age en Afrique du Nord : étude préliminaire de l'unité stratigraphique 8 de la grotte d'El Mnasra (Témara, Maroc)

Émilie Campmas, Amel Chakroun, Driss Chahid, Arnaud Lenoble, Larbi Boudad, Mohamed Abdeljalil El Hajraoui et Roland Nespoulet

Spécificité géomorphologique de la région de Témara

Unité stratigraphique 8 de la grotte d'El Mnasra

Exploitation des ressources animales

Fonction du site et occupation du territoire côtier

Conclusion 
Perles discoïdes en coquille marine et en roche de l'âge du Bronze dans le Centre-Ouest de la France : l'exemple du Mas de Champ Redon à Luxé

Caroline Mougne, Catherine Dupont, Querré Guirec, Patricia Semelier et Valérie Audé

Présentation du site

Matériel et méthode

Résultats

Discussion

Polyvalence de l'élevage au IV millénaire avant notre ère sur l'habitat ceinturé de Wallendorf «Hutberg» (Saxe-Anhalt, Allemagne)

Svenja Höltkemeier

Cadre général

Matériel et méthodes

Résultats par espèce

Discussion

Animal, homme et pathogènes. Préhistoire d'une relation complexe

Olivier Dutour

Introduction

L'Homme, l'Animal et les Pathogènes, une question d'actualité

Préhistoire des pathogènes humains et de l'interface homme-animal-environnement

L'interface « naturelle » des premiers Hominines (7 à 4 millions d'années)

L’interface « ressource » des premiers Hominidés (4-2 millions d'années)

L'interface « prédateur augmenté » du genre Homo (2,5 millions d'années - 12000 ans)

L'interface de production de l'Homo sapiens au Néolithique (12 à 5000 ans)

L'interface diffusée de la protohistoire à nos jours

\section{Loups, chiens et sociétés du Paléolithique supérieur}

Myriam Boudadi-Maligne, Jean-Baptiste Mallye, Jean-Christophe Castel, Jean-Georges Ferrié, Laurent Crépin, Delphine Kuntz, Carole Vercoutère, Marie-Cécile Soulier et Sandrine Costamagno

Méthode et corpus d'étude

Résultats

Discussion et conclusions

Loups et chiens au Néolithique et au Moyen Âge en France méditerranéenne

Vianney Forest et Isabelle Rodet-Belarbi

Au Moyen Âge

Au Néolithique

Une vie de chien auprès des premiers éleveurs agriculteurs du Néolithique ancien en Europe occidentale

Rose-Marie Arbogast

Introduction

Le chien sur les sites du Néolithique ancien danubien

Les restes de chien du site de Herxheim

Conclusion

Ritual use of dogs and wolves in the Late Bronze and Early Iron Age in the South-Eastern Alpine region. New evidence from the archaeo(zoo)logical perspective

Brina Škvor Jernejčič et Borut Toškan

Introduction

Dog and wolf remains in funerary contexts

Dog and wolf remains in settlement contexts

Conclusions 
Une réflexion épistémologique sur les interprétations des relations Homme-animal dans les sépultures préhistoriques issues de fouilles anciennes : l'exemple de la nécropole mésolithique de Téviec (Saint-Pierre-Quiberon, Morbihan)

Pauline Fontan

Introduction

La difficile reconnaissance des premières sépultures préhistoriques

La nécropole de Téviec (1928-1930)

Place et statut de l'animal dans la nécropole de Téviec

Conclusion

Place et rôle de l'animal dans les pratiques funéraires au Cerny : l'exemple de la nécropole néolithique de Fleury-sur-Orne (Calvados)

Emmanuel Ghesquière et Lamys Hachem

Introduction

Contexte chrono-culturel

Les sépultures de la nécropole de Fleury-sur-Orne

Les dépôts animaux dans les sépultures de Fleury-sur-Orne

Les monuments de Fleury-sur-Orne

Synthèse sur les dépôts animaux de Fleury-sur-Orne et mise en perspective culturelle

Conclusion

Homme Vs animal : une même intention cultuelle dans les dépôts domestiques du second Âge du Fer dans le Bassin Parisien?

Valérie Delattre et Ginette Auxiette

L'amorce d'une réflexion pluridisciplinaire : pour en finir avec la « sépulture de relégation »

laténienne

Des humains, des mobiliers spécifiques... et des animaux pour une même pratique

De troublantes similitudes de traitement

Conclusion

L'homme et l'animal dans les fosses du Mormont (Eclépens, Vaud, Suisse, vers 100 av. notre

ère)

Patrice Ménie

Présentation de quelques fosses

Des associations homme animal volontaires ou fortuites?

Les associations homme animal dans les fosses

Les associations homme animal dans les ensembles mobiliers

Synthèse

Les mandibules de cheval de l'abri Duruthy (Sorde-l'Abbaye, Landes) : contexte archéologique et mise en perspective ontologique au sein du Magdalénien des Pyrénées

Clément Birouste, François-Xavier Chauvière, Frédéric Plassard et Morgane Dachary

Duruthy

Les mandibules de Duruthy dans leur contexte archéologique

Analyse

Les représentations animales de la grotte Margot (Thorigné-en-Charnie, Mayenne) : essai de synthèse

Tiphaine Guigon et Romain Pigeaud

Présentation des grottes de la vallée de l'Erve

L'art de Margot : inventaire et analyse

Méthodologie

Résultats de l'étude stylistique : une homogénéité au sein de chaque thème?

Bilan

Comparaisons 
Bouquetin peint : bouquetin chassé. L'art mobilier animalier de l'Abri Dalmeri (Préalpes orientales italiennes, Épigravettien récent) dans son contexte archéologique

Élisa Legrand

Stratigraphie et datations

Faune et paléo-environnement

L'habitat épigravettien (figure 5)

Les pierres peintes

La faible variabilité du choix du support

L'homogénéité de la technique

La thématique

Les déterminées (figure 8)

Les indéterminées (figure 9)

Considérations sur la thématique zoomorphe de l'Abri Dalmeri 


\section{NOTE DE L'ÉDITEUR}

Les articles de cet ouvrage ont été validés par le comité de lecture des Éditions du Comité des travaux historiques et scientifiques dans le cadre de la publication des actes du $141^{\mathrm{e}}$ Congrès national des sociétés historiques et scientifiques tenu à Rouen en 2016. 


\title{
Animal symbolisé, animal exploité : du Paléolithique à la Protohistoire
}

\author{
Sandrine Costamagno, Lionel Gourichon, Catherine Dupont, Olivier Dutour \\ et Denis Vialou
}

Les dix-neuf textes que comporte ce volume sont issus du colloque organisé dans le cadre du $141^{\text {ème }}$ Congrès du CTHS «L'animal et l'homme » qui s'est déroulé à Rouen du 11 au 16 avril 2016. Proposé par la section préhistoire et protohistoire du CTHS, ce colloque avait pour objectif d'aborder les relations Homme/Animal sous ses multiples facettes, depuis le Paléolithique jusqu'à l'Âge du Fer. La trentaine de communications ${ }^{1}$ proposée lors de ces journées a porté sur cinq grandes thématiques "L'animal ressource ", "Entre chien et loup : de la bête féroce à l'animal familier », "Les animaux vus et perçus par les Paléolithiques », "La vie et la mort partagée », "Pré-histoire des échanges de pathogènes ".

2 Peau, viande, moelle, plume, os, coquille, l'animal est pourvoyeur de ressources variées qui ont été largement utilisées par l'Homme au fil du temps. Au-delà de l'alimentaire, l'animal tient une place prépondérante dans la sphère technique et l'univers symbolique des sociétés humaines. D’abord marqueur identitaire puis, plus récemment, source de richesse et sans doute de prestige, l'animal et les restes fauniques qui nous sont parvenus constituent une clé d'entrée essentielle à une meilleure compréhension des modes de vie de ces populations du passé. Pour les périodes les plus anciennes, les animaux terrestres ont souvent été considérés sous un angle strictement alimentaire, mais des découvertes récentes et l'examen de collections anciennes à la lumière de nouvelles approches élargissent désormais la gamme des ressources utilisées tant par l'Homme de Néandertal en Europe que par les premiers hommes modernes en Afrique, témoignant d'une relation à l'Animal plus complexe que celle habituellement envisagée. À l'inverse, les ressources marines ont souvent été exclues des registres alimentaires de l'Homme du Paléolithique, car nettement plus visibles dans la sphère symbolique. Or, plusieurs études récentes montrent que les invertébrés marins ont été sous-estimés dans la sphère économique de ces populations. La chaîne d'exploitation globale de l'animal est une clé d'entrée privilégiée comme le montrent de nombreux articles du volume. Au travers d'une vaste synthèse à l'échelle de l'Europe, la 
contribution de Dominique Armand s'interroge sur les indices taphonomiques mobilisables pour la mise en évidence d'une chasse à l'ours ou plus modestement d'une utilisation de certaines ressources de ce carnivore au Paléolithique. L'ours des cavernes semble jouer un rôle plus prégnant au Paléolithique moyen qu'au Paléolithique supérieur, témoignant probablement d'un statut particulier pour les populations néandertaliennes. La place du mammouth dans les modes de vie des chasseurscueilleurs gravettiens d'Arcy-sur-Cure (Goutas et Lacarrière) et celle du renne pour les groupes magdaléniens de l'abri de Peyrazet (Costamagno et collaborateurs) sont abordées en tenant compte des registres techniques et alimentaires. À Arcy-sur-Cure, l'ivoire de mammouth récupéré sous sa forme sub-fossile constitue un matériau de choix pour les populations gravettiennes, au contraire des ossements. Les preuves d'une exploitation alimentaire de ce mégaherbivore sont en revanche plus ténues et les ossements présents sur le site indiquent plutôt une utilisation de ces éléments à des fins techniques principalement comme billots. À Peyrazet, le renne apparaît comme l'espèce-clé, apportant toutes les ressources - alimentaires, techniques, ornementales et probablement symboliques - nécessaires au groupe magdalénien ayant occupé l'abri. Sur ce site, sans doute dédié à des activités de couture, la faible part prise par les petits gibiers contraste nettement avec ce qui est observé sur le site tardiglaciaire de Rochereil (Mallye et collaborateurs). Si du Magdalénien à l'Azilien, on observe une rupture au sein du cortège des petits gibiers (spermophile, harfang, lagopède d'abord, lapin ensuite), la faible masse de viande fournie par ces animaux aux regards des ressources pourvues par les ongulés, notamment au Magdalénien, interroge réellement sur la finalité de cette consommation. L'élargissement du régime alimentaire est aussi discuté au travers de l'exemple de la grotte d'El Mnasra (Campmas et collaborateurs). Dans les niveaux MSA, à côté des ongulés terrestres, des coquillages marins ainsi que d'autres ressources d'origine marine ont été exploités à des fins alimentaires mais aussi ornementales, témoignant d'une adaptation ancienne au milieu côtier. L'article de Caroline Mougne et collaborateurs sur les perles discoïdes retrouvées en contexte sépulcral à l'Âge du Bronze montre aussi une exploitation de coquilles marines à des fins, cette fois-ci, strictement ornementales, mettant en jeu une différenciation sociale en fonction de l'âge des individus. Pour ces périodes, les ressources animales se diversifient par d'autres biais, notamment grâce à l'élevage. Sur le site de Wallendorf, daté de la fin du Néolithique, les études menées par Svenja Höltkemeier témoignent ainsi de l'importance de l'élevage bovin pour l'alimentation mais également à des fins motrices. Son importance symbolique est aussi perceptible par des symboles fourchus retrouvés sur des céramiques et en contexte architectural monumental. Les ovins et tout particulièrement les béliers jouent aussi une place prépondérante dans l'univers symbolique de ce groupe régional. La mise en place de ce mode de vie néolithique serait à l'origine d'une émergence massive de pathogènes se développant en raison d'une plus grande proximité avec les animaux d'élevage ou de compagnie.

Depuis plus d'une dizaine de milliers d'années qu'il accompagne les groupes humains sur tous les continents, l'histoire du chien est d'une grande complexité et se distingue de celle des autres animaux domestiques par l'extraordinaire diversité des relations qui ont pu se nouer entre l'Homme et ce grand canidé. Ressource alimentaire occasionnelle, courante ou rituelle, auxiliaire du berger ou du chasseur, protecteur de son maitre ou gardien du campement, mascotte ou souffre-douleur, pourvoyeur de matières premières (peau, poil, os, dents) pour la confection d'outils ou de parure, animal de salon ou de ferme, de somme ou de trait, simple éboueur ou compagnon de 
jeu, le rôle tenu par le chien dans les différentes cultures humaines présente des facettes multiples que notre propre expérience et la riche documentation ethnographique et historique disponible permettent en partie d'appréhender. Cependant, pour les périodes anciennes et plus encore quand on remonte aux origines de la domestication du loup, la tâche de l'historien, ou de l'archéologue, s'avère plus compliquée comme le rappelle dans ce volume la contribution de Myriam BoudadiMaligne et ses collaborateurs à travers une recherche centrée sur le Paléolithique du Sud-Ouest de la France. En effet, malgré son omniprésence, qui peut être attestée sur un site archéologique par des traces indirectes comme des coprolithes ou des ossements d'animaux mâchonnés ou partiellement digérés, le chien reste pourtant l'un des animaux domestiques les plus insaisissables par la rareté de ses restes osseux. On trouvera ceux-ci parfois mêlés à des vestiges alimentaires, ou bien sous la forme de parties animales transformées à des fins artisanales, mais aussi comme squelettes plus ou moins complets que l'Homme aura pris soin d'inhumer à part ou pour accompagner les défunts. Pour le Paléolithique, de telles archives s'avèrent clairsemées et ce n'est qu'à partir de la fin du Magdalénien que l'intensité de la relation entre l'Homme et le Chien se fait vraiment sentir.

4 Pour pister les traces de ce chien à partir de ses ossements, si peu abondants soient-ils, il existe plusieurs types d'approches complémentaires (biométrie, taphonomie, paléogénétique, biochimie moléculaire, etc.) qui permettent d'obtenir des informations touchant non seulement à son aspect physique, ses caractéristiques biologiques, mais aussi, grâce à l'analyse des contextes archéologiques, aux activités anthropiques dont il a pu faire l'objet. Dans le premier cas, pour faire suite à l'article de Myriam BoudadiMaligne et collaborateurs, l'étude de Vianney Forest et Isabelle Rodet-Belarbi sur le gabarit des grands canidés de la France méridionale montre ici toute la difficulté à distinguer le chien du loup sur la base seule de la taille des éléments squelettiques, même pour des périodes récentes, bien loin des tout débuts de la domestication, en raison de l'apparition progressive de morphotypes domestiques de grand format. Pour ce qui concerne l'étude des données contextuelles des découvertes, la contribution de Rose-Marie Arbogast sur la cynophagie dans un site du Sud-Ouest de l'Allemagne datant du Néolithique ancien révèle des pratiques de consommation qui ne peuvent être réduites à celles des animaux d'embouche habituels (porc, bœuf, mouton ou chèvre) mais sont plutôt liées à des évènements exceptionnels comme des contextes de crises sociales ou économiques. Enfin, la diversité de la place du chien dans les sociétés humaines, avec la présence discrète et occasionnelle de son congénère sauvage, le loup, est également illustrée dans ce volume par l'étude de Brina Škvor Jernejčič et Borut Toškan sur les sociétés de l'Âge du Bronze et du Fer en Slovénie, à travers différents témoignages en rapports avec des pratiques rituelles et symboliques associées à la mort (sépulture, offrandes) ainsi qu'à l'espace domestique ou collectif.

5 Car si l'animal fait partie intégrante de la vie de l'Homme à la fois pour la source de nourriture qu'il produit, parfois sa compagnie mais aussi pour sa force ou quantité de produits secondaires qu'il fournit, il partage également de façon récurrente sa mort. Ainsi, les associations hommes et animaux découvertes en contextes archéologiques sépulcraux sont fréquentes. Elles se présentent sous des formes parfois bien difficiles à interpréter, car se cachent derrière elles une multitude de scénarios et de rapports entre l'Homme et l'Animal. L'exemple de la nécropole mésolithique de Téviec proposé par Pauline Fontan témoigne d'une diversité de rapport à l'animal. Les sépultures sont creusées dans un dépotoir composé de déchets d'animaux (coquillages marins, 
poissons, oiseaux, mammifères marins et terrestres, crustacés). D'autres restes animaux composent les sépultures. Ils ont été interprétés par les archéologues qui les ont fouillés dans la première moitié du $\mathrm{xx}^{\mathrm{e}}$ siècle comme des offrandes, des totems, des objets façonnés et des parures. Ces interprétations sont dépendantes des systèmes de représentation des archéologues qui décrivent ces populations préhistoriques et sont amenées à évoluer en fonction des courants de pensée et des méthodes de fouille. Ainsi, les études de cas proposées par Emmanuel Ghesquière et Lamys Hachem, Valérie Delâtre et Ginette Auxiette ainsi que Patrice Méniel et qui s'étendent du Néolithique à l'Âge du Fer placent l'animal au cœur de l'analyse. Dès la fouille, la position des pièces squelettiques des animaux et des humains est prise en compte ainsi que les structures dans lesquelles ces vestiges osseux sont découverts. Ces observations de terrain révèlent la diversité des mises en scène réalisées. Si des restes d'animaux ont pu être associés au cadavre humain, un os isolé humain peut aussi accompagner un animal entier. Selon les études de cas proposées des restes de moutons, de bovins ou de chevaux sont déposés dans les tombes. Ils le sont soit sous la forme de pièces de viande, d'animaux complets ou quasi complets (exemple de prélèvements de bucrane ou de phalanges), voire d'os ou de fragments osseux. Si certains d'entre eux évoquent des offrandes alimentaires, ou l'exposition de trophées, d'autres gestes décrits par l'analyse archéozoologique s'avèrent plus complexes à interpréter. Ainsi, les dépôts animaux présents dans la nécropole Cerny de Fleury-sur-Orne mettent en exergue un traitement différentiel des bovins et des ovins - reliefs de repas pour les premiers, offrandes pour les seconds - témoignant sans nul doute d'un statut différent dans la symbolique de ces groupes (Ghesquière et Hachem). Au second Âge du Fer, les dépôts conjoints de restes animaux et humains à l'intérieur de silos révèlent une même intention cultuelle. Pour Valérie Delattre et Ginette Auxiette, ces offrandes, loin de s'inscrire dans une logique guerrière, seraient le reflet d'un échange saisonnier entre l'Homme et l'invisible, visant à invoquer les forces de fertilité et renouveau. L'association des restes humains et animaux dans les fosses du Mormont datées de la fin de l'Âge du Fer est au cœur des réflexions menées par Patrice Méniel. Ce site tout à fait exceptionnel par son ampleur témoigne d'une diversité de pratiques cultuelles qu'il est encore très difficile de décrypter. Au Paléolithique, à l'exception des os fichés dans les parois des grottes, les dépôts d'ossements sont rares et l'abri de Duruthy constitue à ce titre une réelle singularité. Clément Birouste et collaborateurs, grâce à une reprise du matériel osseux et des archives de fouilles, ont démontré le caractère intentionnel de l'accumulation de mandibules et de statuettes de chevaux signalée par R. Arambourou qui a fouillé le site dans la seconde moitié $\mathrm{du} \mathrm{xx}^{\mathrm{e}}$ siècle. Cette association vient conforter l'importance du cheval dans le Magdalénien pyrénéen. Discutant sur cette base, du régime ontologique de ces sociétés, les auteurs proposent de s'extraire de l'opposition « Nature »/»Culture » pour poser un regard renouvelé sur ces sociétés.

6 Depuis la découverte des représentations pariétales et mobilières d'animaux du temps des mammouths, s'est en effet imposée une approche naturaliste, exprimée en termes de réalisme figuratif, voire comportemental. Nous prêtons aux chasseurs-artistes paléolithiques nos regards de savants: le monde animal est considéré comme homogène, se prêtant à des classifications de plus en plus précises. Nous ne voyons plus la gent animale selon nos sensations poétiques ou enfantines, mais selon les caractères anatomiques et les liens phylétiques des animaux observés par les zoologues, paléontologues, généticiens... Et si les Paléolithiques n'avaient ni expérimenté, ni exprimé la savante objectivité visuelle des hommes et des caméras de notre temps? 
Pourquoi toutes ces figures animales indéterminées et indéterminables qui abondent souvent sur les parois de grottes? Et quels sont donc ces bisons magdaléniens démesurément bossus de la grotte périgourdine de Font-de-Gaume ou ces mammouths aurignaciens au corps déformé en arc de vastes viaducs? Et si toute cette faune représentée n'était qu'illusion comme le seraient, comme le sont, des panneaux assemblant sans ordre ni vraisemblance naturelle des chevaux, rennes, bouquetins, bisons, aurochs ou rhinocéros laineux, des silhouettes incomplètes et indicibles? Il est urgent d'engager un débat de fond sur les conceptions figuratives et les modes d'expression des Préhistoriques, un débat sur l'approche générale ou habituelle du bestiaire paléolithique se proclamant naturaliste, lointain relent d'un positivisme scientifique dépassé. Comme le montrent les contributions de Thiphaine Guiguon et Romain Pigeaud d'une part et d'élisa Legrand d'autre part, les faunes représentées dans la grotte Margot ou celle de l'abri Dalmeri témoignent largement d'une liberté figurative, d'une indépendance $d u$ réel vu ou vécu. Les artistes paléolithiques donnèrent à l'animal une dimension le projetant dans l'imaginaire, le méta-physique. La contribution de Clément Birouste et collaborateurs nous incite à nous extraire de notre perception moderne occidentale, permettant d'interpréter sous un jour nouveau l'art paléolithique. Nos conceptions matérialistes qui nous incitent à voir dans l'animal " une simple ressource à l'humanité, en tant que réservoir à calories et/ou à symboles » (Birouste et collaborateurs) doit être désormais dépassée afin d'envisager le rapport des sociétés préhistoriques au monde animal dans d'autres perspectives ontologiques.

Pour conclure, nous tenons à remercier les membres de la Section de Préhistoire et Protohistoire ainsi que l'ensemble des organisateurs du $141^{\text {ème }}$ Congrès du CTHS. Nous associons l'ensemble des intervenants à ces remerciements car ils ont permis la tenue de journées très enrichissantes grâce à la qualité scientifique de leurs présentations et aux échanges conduits tout au long des séances. La publication des actes de ce colloque n'aurait pu être menée à terme sans l'investissement et l'aide de Francine Fournaux, chargée de la coordination opérationnelle du Congrès, David Simon, responsable de l'édition numérique des actes du congrès et William Foix, en charge de l'édition. Nous remercions Rose-Marie Arbogast, Myriam Boudadi-Maligne, Noël Coye, Allowen Evin, Oscar Fuentes, Marie-Pierre Horard-Herbin, Véronique Laroulandie, Catherine Louboutin, Liliane Meignen, Claude Mordant, György Pálfi, Jean-François Piningre, Éric Robert, Catherine Theves pour leur relecture des différentes contributions.

\section{NOTES}

1. Cf. liste des communications et résumés des communications: http://www.cths.fr/co/ congres.php?id=163\# 


\section{AUTEURS}

\section{SANDRINE COSTAMAGNO}

Archéozoologue

Directrice de recherche au CNRS

CNRS - TRACES - UMR 5608, Université Toulouse 2 Jean Jaurès

Secrétaire de la Section de Pré-Protohistoire du CTHS

\section{LIONEL GOURICHON}

Archéozoologue

Chargé de recherche au CNRS

Université Côte d'Azur, CNRS, CEPAM (UMR 7264), Nice

\section{CATHERINE DUPONT}

Archéozoologue - Archéomalacologue

Chargé de recherche au CNRS

CNRS - CReAAH - UMR 6566, Université de Rennes

Membre de la Section de Pré-Protohistoire du CTHS

\section{OLIVIER DUTOUR}

Paléopathogiste - Bioanthropologue

Directeur d'Etudes EPHE, Université PSL

Chaire d'anthropologie biologique Paul Broca

PACEA-UMR 5199, CNRS-Université de Bordeaux

Président de la Section de Pré-Protohistoire du CTHS

\section{DENIS VIALOU}

Préhistorien, spécialiste de l'art

Professeur émérite au département de Préhistoire du Muséum national d'Histoire naturelle Membre émérite de la Section de Pré-Protohistoire du CTHS 


\title{
L'exploitation de l'Ours au Paléolithique : un point sur la question
}

\author{
Dominique Armand
}

\section{Introduction}

1 L'exploitation de l'Ours au Paléolithique a d'abord été envisagée sous le prisme du symbolisme. Au début du Xx siècle, E. Bächler (1920-1921) est l'un des premiers auteurs qui soutient la théorie d'un culte de l'Ours des Cavernes au Moustérien. Et pour lui, le culte de l'Ours accompagne une civilisation moustérienne alpine dont l'économie de subsistance aurait été largement dépendante de la chasse à l'Ours. Ces hypothèses seront battues en brèche par F.-Ed. Koby (1953) et J.-P. Jéquier (1975), qui montreront qu'il n'y a pas de chasse à l'ours dans ces sites alpins et que les artefacts ne sont pas d'origine anthropique, mais issus de phénomènes naturels. Pourtant, la théorie du culte de l'ours continuera à faire des adeptes, en évacuant souvent complètement la question de la chasse et de la consommation de l'animal. Plus récemment, ces questions d'exploitation des ours ont ressurgi. En 1992, P. Auguste, dans l'étude archéozoologique du gisement de Biache-saint-Vaast (France) mentionne des traces de découpe sur des restes d'ours. En 1994, M. Stiner observe des stries de boucherie sur des ossements d'ours de plusieurs sites italiens et soulève le problème des découvertes en contexte de grotte, où il est souvent difficile de déterminer si les ours sont morts en hivernation et ont été charognés ou s'ils ont été chassés.

2 En 1997, au colloque « l'homme et l'ours » à Auberives en Royans, L. Binford évoque des contraintes importantes liées à la taille des animaux, ainsi qu'au manque d'équipements des Préhistoriques (contraintes pour lui confirmées dans le domaine ethnographique) et qui auraient empêché les Hommes de Néandertal de chasser les ours des cavernes. Ils n'auraient été capables que d'exploiter les ours bruns mâles et femelles. L. Binford s'intéressait surtout au Paléolithique moyen et n'a pas exprimé d'opinion claire pour le Paléolithique supérieur. Pour M. Patou-Mathis (1998, p. 19) : 
"Jusqu'à présent pour des sites en grotte, aucune preuve ne permet de supposer une consommation de l'Ours des cavernes par les Préhistoriques. Il n'apparaît comme gibier occasionnel que dans quelques sites de plein air.»

3 L'exploitation des ours a donc été envisagée de façon négative dans les années 90, mais, depuis quelques années, les publications dans lesquelles des stries de découpe indiquent une utilisation de la chair ou de la peau des ours se multiplient. Toutefois, certains auteurs ont souligné que les cas de chasse étaient rares :

« Rare evidence of both Neanderthals and early modern humans hunting brown

and cave bears. » (Stiller et al., 2010, p. 976).

4 Jusqu'à présent, les données restent éparses et il n'existe pas de synthèse, exceptée pour des zones géographiques restreintes comme la Pologne (Wotjal, 2007) et le Jura souabe (Münzel et Conard, 2004).

5 Les prises de position concernant les questions de chasse versus charognage, les types humains les plus concernés par l'exploitation des ours, ou bien celles des espèces d'ours préférées par l'Homme reposent donc souvent sur des a priori ou du comparatisme ethnographique.

6 Ce travail a pour objectif de répondre à certaines de ces questions, notamment celles des taxons humains et animaux concernés, en se basant sur les données archéologiques. Il s'agit d'un point dans l'état actuel de nos connaissances. Il est possible qu'il soit biaisé par la difficulté d'accès à certains types de documentation (publications en russe ou dans les langues des pays de l'Est) et le bilan est susceptible d'évoluer en fonction de nouvelles découvertes.

\section{Méthode}

7 Les données à partir desquelles nous avons travaillé sont bibliographiques, excepté pour les gisements de Font-de-Gaume (Armand et al., 2003) Castanet (Armand, 2006) et Vidon (Campmas et al., 2011) pour lesquels nous avons participé à l'étude.

8 Les documents retenus sont ceux dans lesquels des analyses archéozoologiques ont démontré une exploitation des ours, grâce à la présence de traces de boucherie ou de blessures de chasse. Les sites pour lesquels la chasse était proposée, mais sans que ce ne soit basé sur des données archéozoologiques ont été écartés, par exemple, le site de Koudaro I en Ukraine, pour lequel une chasse à l'Ours des cavernes orientée vers l'acquisition des fourrures a été soupçonnée sur la base de l'abondance des os de pieds et de mains (Lioubin et Barychnikov, 1984), mais pour lequel aucune strie de découpe n'est signalée.

9 Les données sont celles fournies par les auteurs. Les dates sont exprimées en BP ou cal BP comme indiquées par les auteurs. Les taxons sont ceux mentionnés dans les publications. Pour le Jura souabe, nous avons retenu l'appellation Ursus spelaeus, utilisée dans les publications archéozoologiques, alors que dans des études paléontologiques et génétiques, pour certains sites, les restes d'ours sont parfois rapportés à Ursus ingressus (Münzel et al., 2014).

10 Pour les décomptes, chaque site et chaque niveau culturel différent d'un même site comptent pour une donnée. 


\section{Résultats et discussion}

11 Les sites dans lesquels une exploitation (dans le sens défini dans le paragraphe précédent) des ours a été mise en évidence sont au nombre de 44 et se répartissent dans une période chronologique allant de l'OIS 13 à l'OIS 2 et pour une extension géographique allant des Pyrénées à l'Italie, au sud et de l'Angleterre à la Pologne, au nord (fig. 1)

Dans l'état actuel des données, on peut noter certains manques dans cette répartition géographique (fig. 1 et tabl. 1). On n'observe que peu d'exemples dans les Pyrénées, où, pourtant, de nombreux gisements paléontologiques attestent de la présence des ours. Il n'existe pas de cas publiés pour l'Espagne. La même absence peut être remarquée dans plusieurs pays d'Europe centrale et d'Europe de l'est. Pour ces derniers, M. PatouMathis (2012, p. 286) pense que :

« Apparently, in Eastern Europe, Neanderthals have neither hunted the carnivores nor exploited their carcasses. On the other hand, in Crimea, the exploitation of carnivores appears slightly more intense in the levels with "transition industries" (as in Buran Kaya III) or with Proto-Aurignacian (as in Siuren I). »

Aucun exemple d'exploitation d'ours n'a été signalé au Portugal, mais seul l'Ours brun y était présent, l'Ours des cavernes n'y ayant jamais vécu. Les cas les plus nombreux se trouvent en France, en Allemagne et en Italie.

Figure 1 : carte de répartition des sites avec traces de découpe sur des restes d'ours.

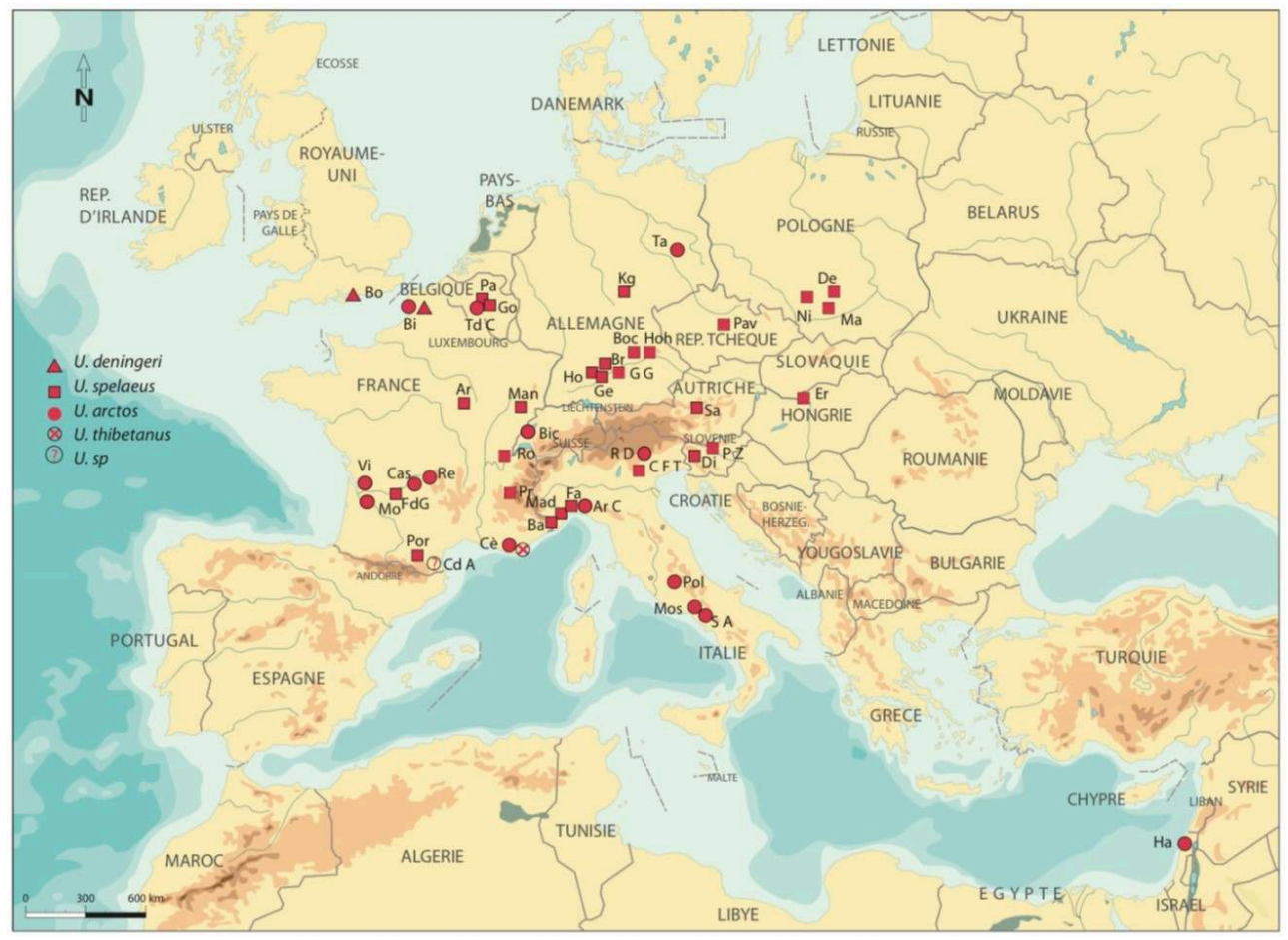

Ar: Arcy-sur-Cure ; Ba : Badalucco ; Bi : Biache-Saint-Vaast ; Bic : le Bichon ; Bo : Boxgrove ; Boc : Bockstein ; Br : Brillenhöhle ; Cas : Castanet ; C d A : Caune de l'Arago ; Cè : les Cèdres ; C F T : Covolo Fortificato di Trene ; De : Deszczowa cave ; Di : Divje Babe ; Er : Erd ; Fa : Fate ; Fo : Font-de-Gaume ; Ge : Geissenklösterle ; G G : Grosse Grotte ; Go : Goyet ; Ha : Hayonim ; Ho : Hohle Fels ; Hoh : Hohlenstein Stadel; Kg : Kogelstein ; Mad : Madonna dell'Arma ; Ma : Mamutowa cave ; Man : Mancenans; Mo : le Morin ; Mos : Moscerini ; Ni : Nietoperzowa cave ; Pa : grotte Pauline ; Pav : Pavlov ; Pol : Polesini ; Por : le Portel ; P Z : Potocka Zijalka ; Re : Régourdou ; R D : Riparo Dalmeri ; Ro : Rochedane ; S A : San'Agostino ; Sa : Salzofen ; Ta : Taubach ; Td C : Trou de Chaleux; Vi : Vidon. 
Tableau 1 : sites avec traces de découpe sur des restes d'ours.

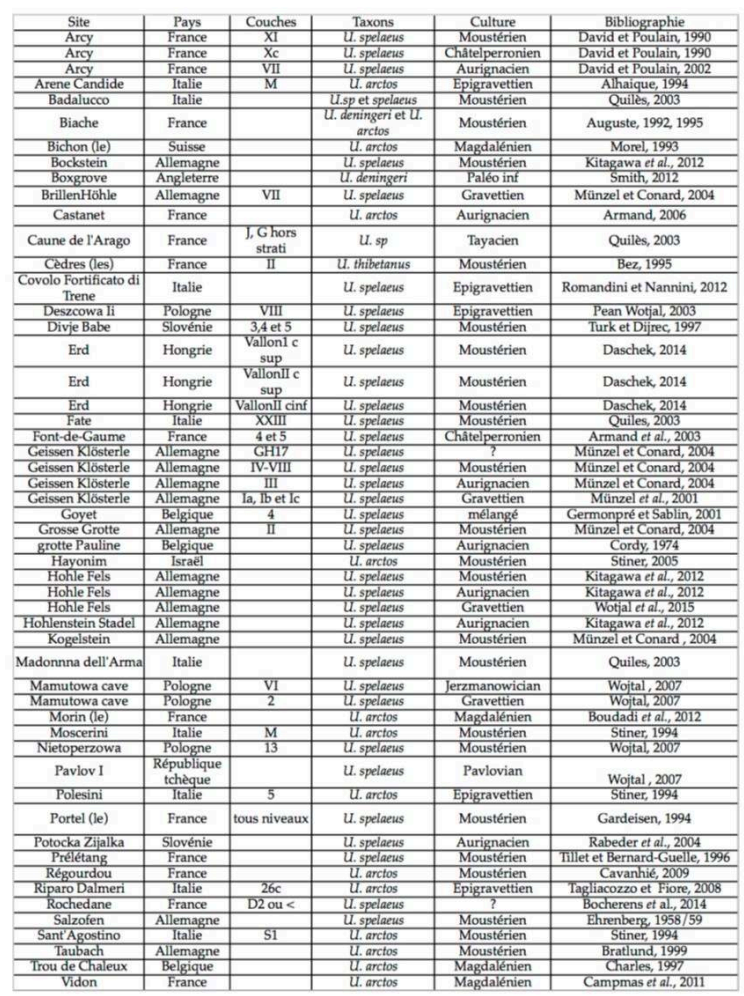

\section{Quels ours et quand?}

14 L'exemple le plus ancien concerne le site de la Caune de l'Arago en France (Quilès, 2003) et l'espèce n'est pas identifiée. Il s'agit, avec le site de Boxgrove en Angleterre (Smith, 2012) des deux seuls cas connus pour le Paléolithique inférieur.

15 Contrairement à ce qui a parfois été écrit, la majorité des exemples concerne l'Ours des cavernes (fig. 2) : 37 niveaux ont en effet livré des restes d'Ursus spelaeus avec des stries de découpe. Pour l'Ours brun (Ursus arctos), les exemples sont moins abondants : 14 cas ont été dénombrés. L'Ours de deninger (Ursus deningeri) et l'Ours du Tibet (Ursus thibetanus) ont également été exploités. Pour le premier, deux sites sont concernés : Boxgrove en Angleterre (Smith, 2012), dans un contexte acheuléen, et Biache-saintVaast en France (Auguste, 1992), attribué à du Moustérien. L'Ours du Tibet est uniquement signalé dans des niveaux moustériens de la fin du Pleistocène moyen de la grotte des Cèdres (France) (Bez, 1995). 
Figure 2 : proportion des taxons exploités.

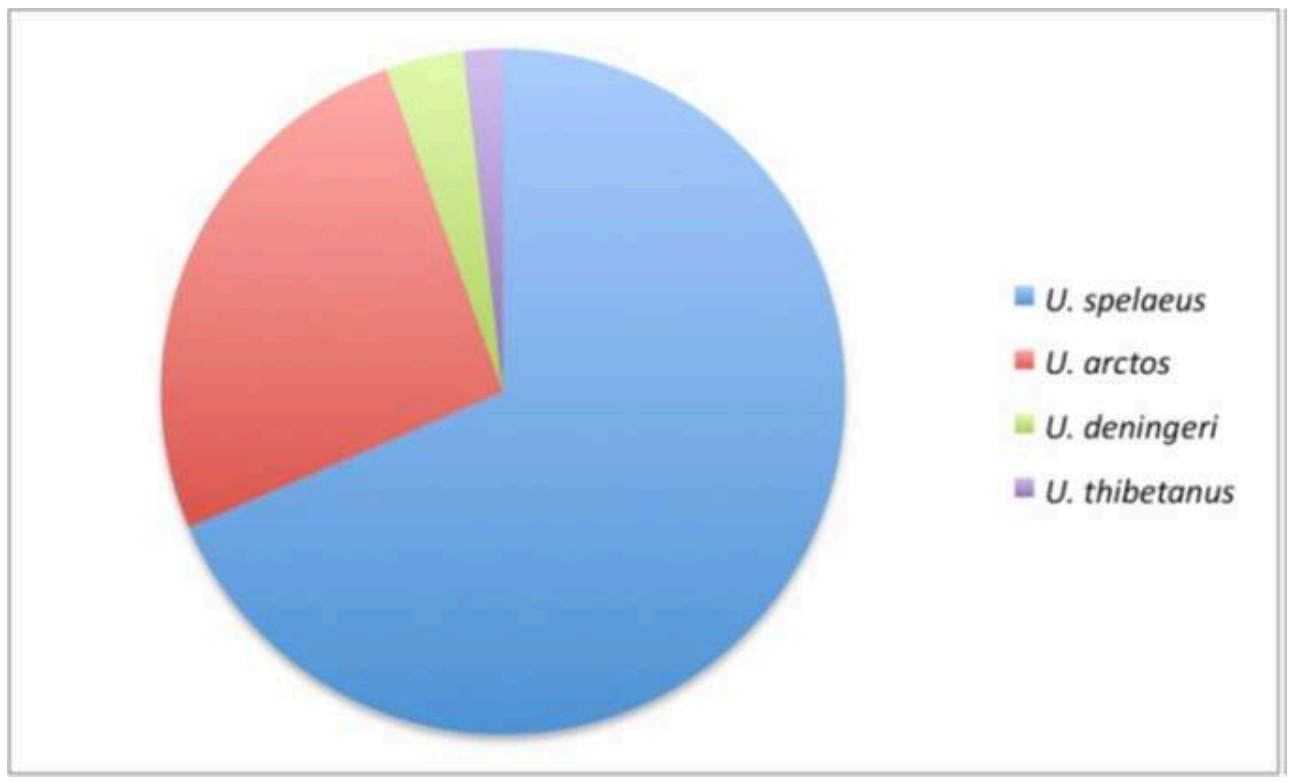

Les taxons exploités ne sont pas les mêmes au cours du temps et en fonction des cultures et de la géographie. L'exploitation des ours des cavernes est importante au Moustérien, en particulier postérieurement à l'Eemien (fig. 3). C'est donc l'Homme de Néandertal qui est l'acteur principal de l'utilisation des ours. Pour cette période, la répartition géographique des sites est large (Italie, Hongrie, Pologne, France, Allemagne, Slovénie, Belgique, République tchèque, Espagne) (fig.4). Il faut évidemment pondérer ce résultat relativement à la durée de la période considérée, plus longue que celle des cultures du Paléolithique supérieur.

Figure 3 : taxons en fonction des cultures.

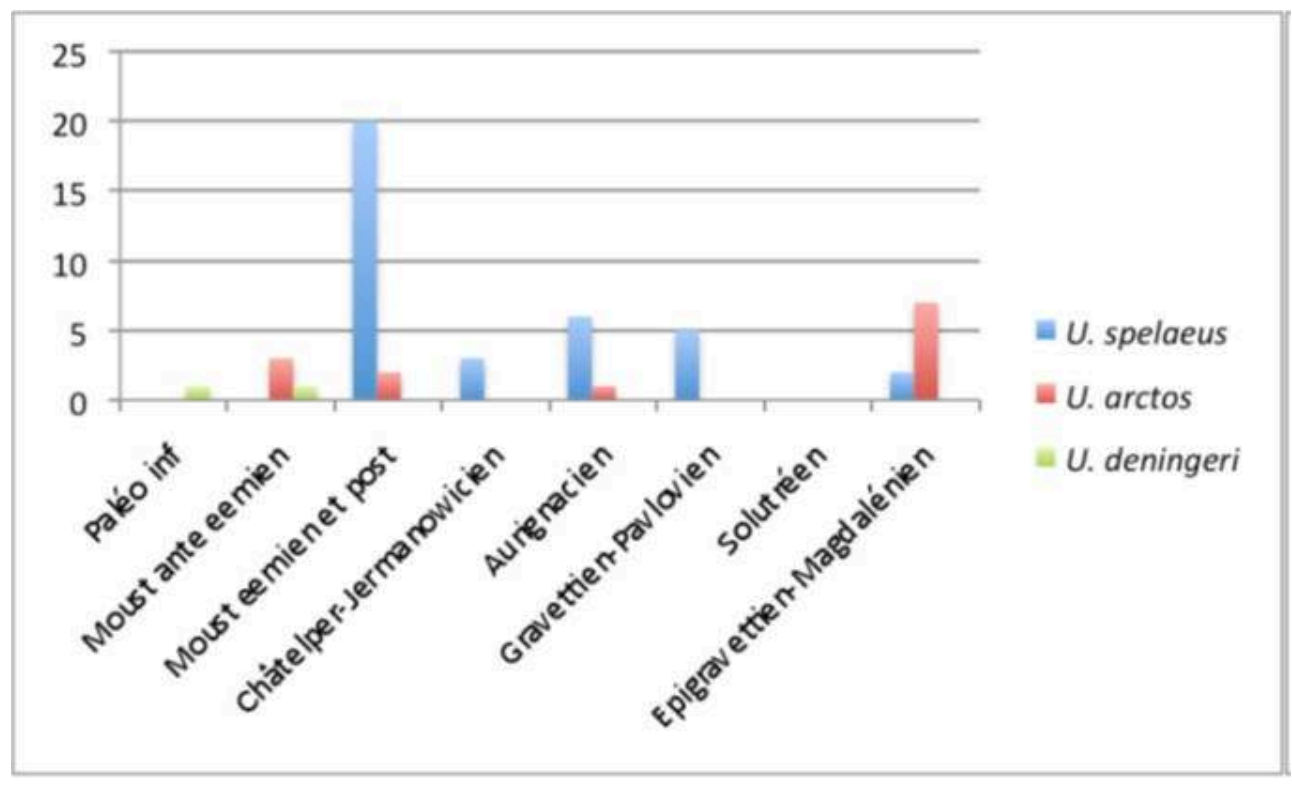


Figure 4 : carte de répartition des sites moustériens présentant des restes d'ours exploités.

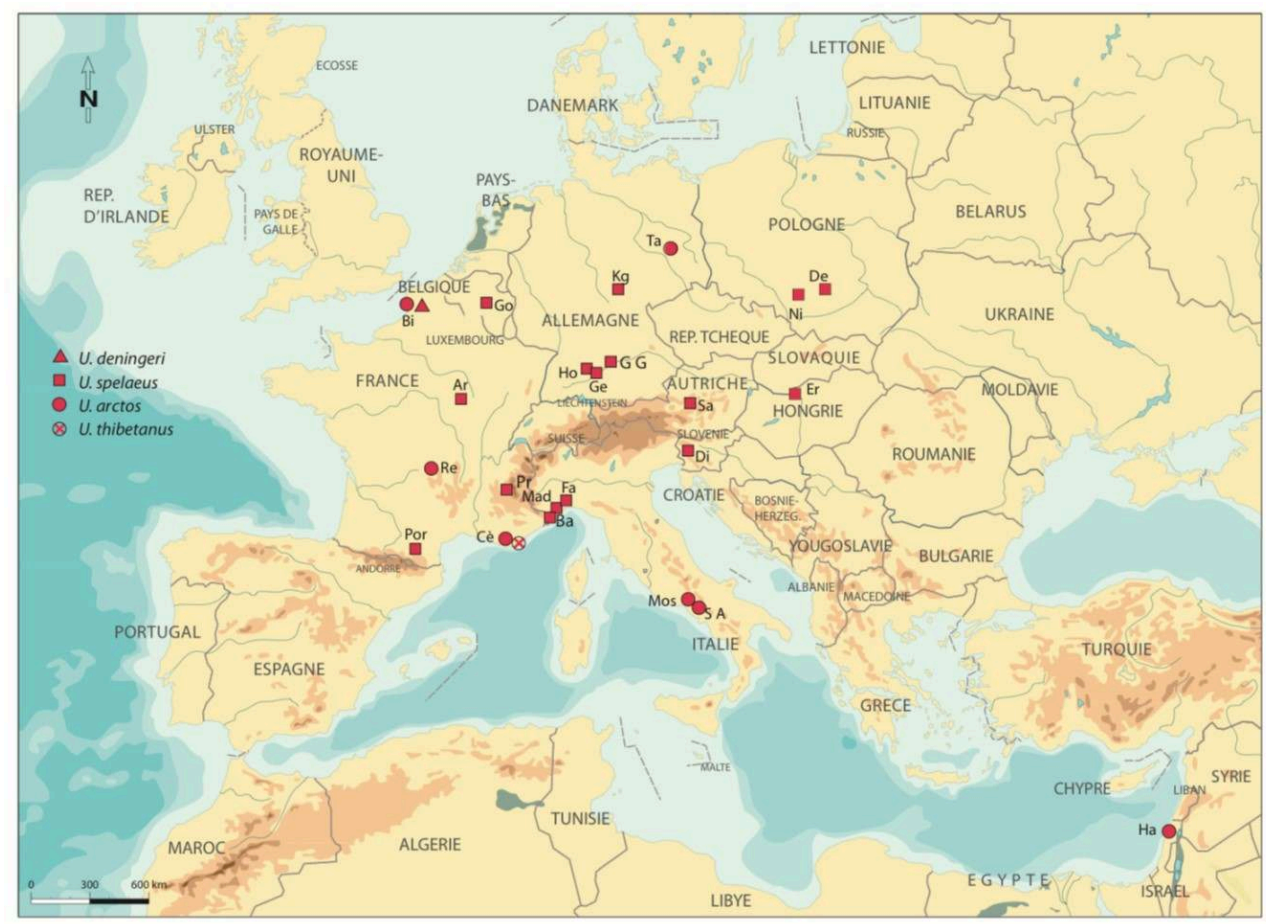

17 L'Ours des cavernes est moins exploité par la suite, mais il l'est tout de même au Châtelperronien, à l'Aurignacien, au Gravettien et à l'Epigravettien. Pour le Châtelperronien, il n'y a que 2 sites, en France, Arcy-sur-Cure (David et Poulain, 1990) et Font-de-Gaume (Armand et al., 2003). Pour l'Aurignacien (fig. 5), on trouve des exemples en France, en Allemagne, en Belgique; pour le Gravettien et le Pavlovien (fig. 6), en Allemagne (Jura souabe), en Pologne et en République tchèque et pour l'Epigravettien (fig. 7) les sites sont en Pologne et en Italie. 
Figure 5 : carte de répartition des sites aurignaciens présentant des restes d'ours exploités.

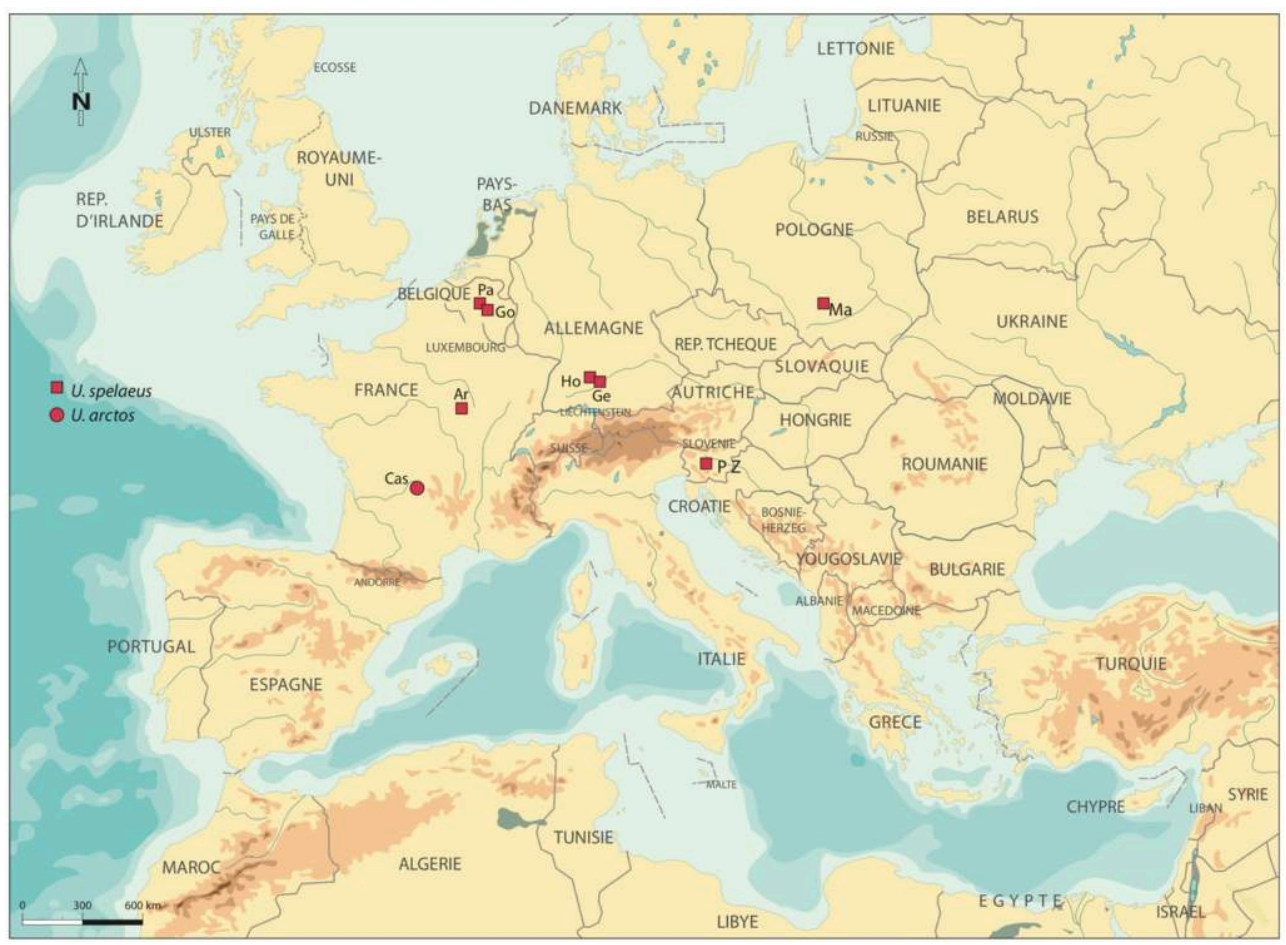

Figure 6 : carte de répartition des sites gravettiens présentant des restes d'ours exploités.

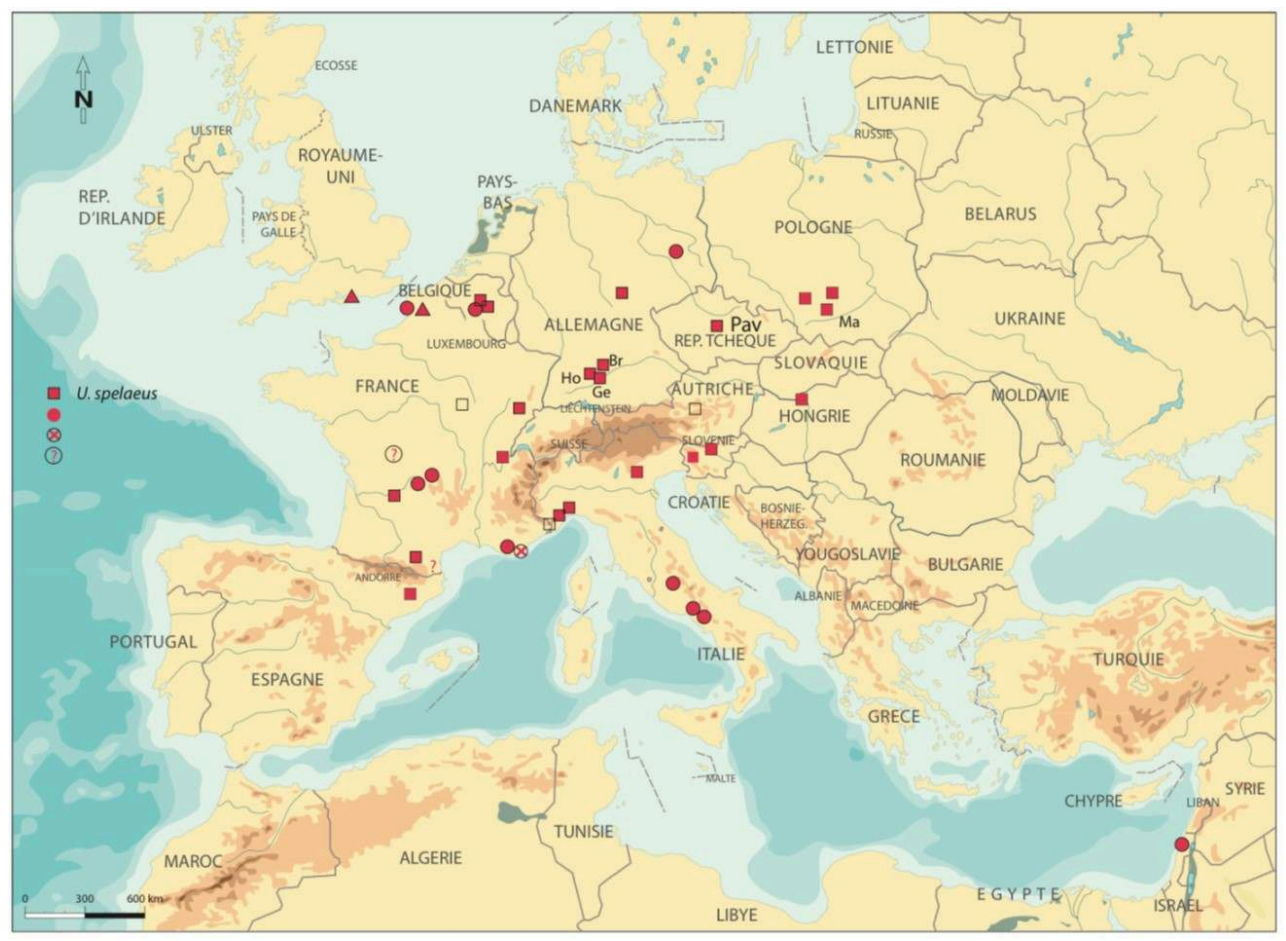


Figure 7 : carte de répartition des sites épigravettiens et madaléniens présentant des restes d'ours exploités.

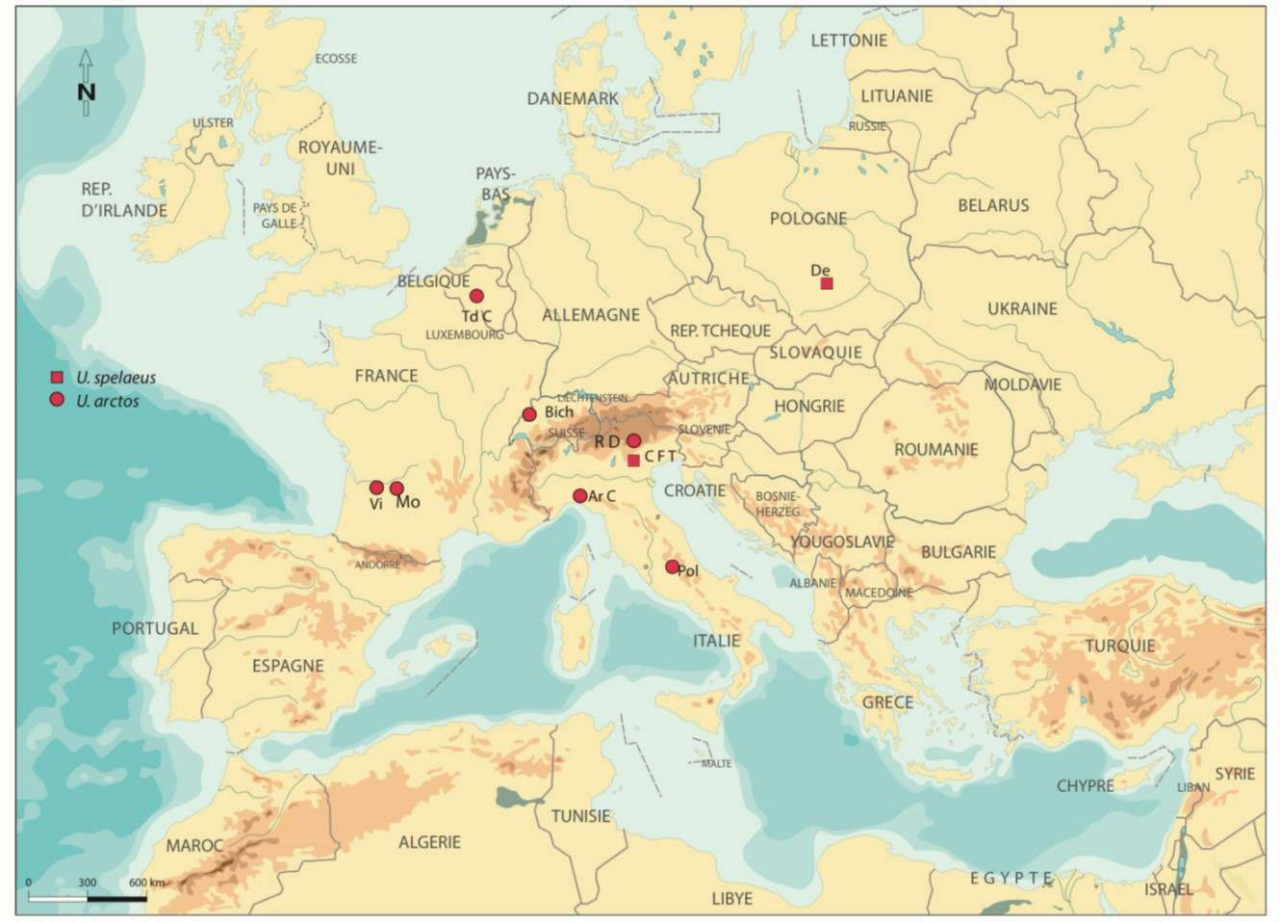

Les données actuellement disponibles indiquent que, dans le Jura souabe, le dernier ours des cavernes serait celui de Hohle Fels avec une date de $27440 \pm 140$ BP. H. Bocherens et collaborateurs (2014) ont obtenu une date plus tardive pour l'ours des cavernes de Rochedane (France) : $23900 \pm 110$ BP. Au Solutréen et au Magdalénien, l'Ours des cavernes avait déjà disparu en France (Bocherens et al., 2014). Mais, il semble avoir subsisté plus longtemps ailleurs: on le trouve encore, dans des niveaux épigravettiens postérieurs à 20000 ans BP, à Deszcowa I en Pologne (Pean et Wojtal, 2003) avec une date de $17640 \pm 140 \mathrm{AMS}{ }^{14} \mathrm{C}$ ans B.P. et à Covolo Fortificato di Trene en Italie (Romandini et Nannini, 2012) avec un âge de $18630 \pm 150$ AMS ${ }^{14} \mathrm{C}$ ans B.P.

Dans l'ensemble, les aires d'exploitation de l'ours des cavernes sont plus restreintes que celles de diffusion des cultures et des ours. On ne peut complètement exclure l'idée de biais ou de manques liés à l'état actuel des découvertes, ainsi qu'à des formes de réticence à envisager cette question d'exploitation des ours. Néanmoins il est possible d'envisager que cette activité n'ait pas été pratiquée dans certaines zones alors qu'elle l'était dans d'autres et qu'il ait pu exister des spécialisations régionales. Le Jura souabe semble être une manifestation de ce phénomène, plusieurs sites sont concernés et l'exploitation (ici la chasse est démontrée) s'est maintenue du Moustérien au Gravettien, pendant plus de 25000 ans (Münzel et Conard, 2004).

L'exploitation de l'Ours brun est plus importante au Moustérien, avant l'Eemien, puis est signalée à l'Aurignacien, au Magdalénien et à l'Epigravettien et absente, en l'état actuel des découvertes, au Solutréen, et au Gravettien (fig. 3). Certains biologistes évoquent une réduction de l'aire de répartition entre 25000 et $15000 \mathrm{BC}$ avec la présence de zones refuge en Italie, dans les Balkans, les Carpates et en Espagne (Sommer et Benecke, 2005), qui pourrait expliquer l'absence de site à ours brun exploité, pour cette période, en dehors des zones refuges. D'après certains auteurs, les populations d'ours bruns seraient, en revanche, restées à effectifs constants, en Europe 
à la fin du Pléistocène (Stiller et al., 2010). Quelle que soit l'hypothèse retenue, durant ce laps de temps, les ours bruns n'ont pas été exploités dans les zones refuge. Quoi qu'il en soit, il n'y a pas de corrélation entre les effectifs et l'intensité d'exploitation.

\section{Chasse ou charognage?}

21 La chasse est démontrée grâce à la présence de fragments de silex dans des ossements à Hohle Fels (Münzel et Conard, 2004) et Potocka Zijalka (Rabeder et al., 2004) pour l'Ours des cavernes et au Bichon (Morel, 1993) pour l'Ours brun.

Dans d'autres sites, les preuves sont indirectes. À Biache-saint-Vaast (Auguste, 1995) et Taubach (Bratlund, 1999), des sites de plein air, la saison n'est pas celle de l'hibernation et la courbe de mortalité n'est pas caractéristique d'une mort en hibernation, ce qui, joint à une certaine abondance de stries de découpe, conduit les auteurs à parler de chasse.

En définitive, les sites pour lesquels il n'y a pas de conclusion quant au mode d'acquisition sont les plus nombreux d'autant que les hypothèses formulées par certains auteurs sont sujettes à caution. Par exemple, à Covolo Fortificato di Trene (Italie), M. Romandidi et N. Nannini (2012) proposent une chasse à l'Ours, car les animaux exploités sont des jeunes, jeunes adultes et adultes, et parce qu'au sein de l'industrie lithique figurent des pointes à dos et à cran de grande dimension qui auraient donc été utilisées sur des proies de grande taille comme les ours. Pourtant, il s'agit d'un lieu d'hibernation et le pourcentage de stries sur les restes d'ours semble être faible puisque seulement 4 ossements portent des traces de boucherie pour 261 restes dans la couche B2, 1 reste pour 125 dans la couche B et 2 restes sans attribution de couche, avec des ratios dents/os pas connus pour ces différents niveaux.

\section{Différents types d'exploitation}

Les caractéristiques des sites, la quantité de restes d'ours et de stries de boucherie permettent de définir différents systèmes d'exploitation des ours :

- les tanières (lieux d'hibernation) avec un faible pourcentage de stries de découpe. La mort des Ours est plutôt d'origine naturelle et la faible intensité d'exploitation fait plutôt penser à du charognage. Le gisement moustérien du Régourdou (France) dans lequel les restes d'ours brun montrent un très faible pourcentage de stries (0,05\%) (Cavanhié, 2009) entre dans cette catégorie, ainsi que le site moustérien de Nietoperzowa (Pologne) où $0,7 \%$ des ossements d'Ours des cavernes portent des marques de boucherie (Wojtal, 2007).

- les tanières avec des pourcentages de stries de découpe plus élevés, pour plus d'individus, démontrant une stratégie plus organisée. Entre dans ce schéma le niveau châtelperronien de la grotte de Font-de-Gaume (France) où on observe $13 \%$ de stries sur les ossements d'ours des cavernes. La question de la chasse ou du charognage n'a pas été tranchée (Armand et al., 2003), mais même s'il s'agit de charognage, il était organisé et récurrent parce que plusieurs ours ont été exploités. Le niveau gravettien de Hohle Fels (Allemagne) était aussi une tanière exploitée de manière planifiée. $6 \%$ des ossements d'Ours des cavernes portent des stries de découpe (Kitagawa et al., 2012). La chasse est d'autre part démontrée grâce à la présence d'un fragment de pointe dans une vertèbre. 
- les sites de plein air, avec des quantités de restes d'ours importantes, des courbes de mortalité et une saisonnalité qui ne sont pas celles d'un site de mort naturelle. Ces éléments ont permis aux auteurs qui les ont étudiés de parler de chasse. À Biache-saint-Vaast (France) dans des niveaux moustériens, les ours bruns et les ours de deninger sont en majorité des adultes et, selon les segments anatomiques, le pourcentage de stries varie entre 0,3 et $11 \%$ (Auguste, 1992). À Taubach (Allemagne), ce sont des ours bruns, en majorité des adultes, qui ont été les proies des Néandertaliens (Bratlund, 1999). Le pourcentage de stries sur les ossements est de $26 \%$. Toutefois, d'après l'auteur, les donnés sur l'âge des individus et les traces anthropiques sont à prendre avec précaution: la collecte, ancienne, n'a pas été réalisée parfaitement.

- les sites avec seulement quelques restes d'ours, essentiellement de l'Ours brun, en grotte ou en plein air, et qui presque tous portent des marques anthropiques. Ces restes sont isolés relativement à leur contexte d'exploitation et leur origine ne peut être établie avec précision, sauf peut-être lorsqu'il s'agit de phalanges ou de métapodes, qui signalent un travail des peaux et donc plutôt une intervention rapide après la mort d'un animal (Romandini et Nannini, 2012). Sant'Agostino (Italie), où avec 3 éléments, l'ours représente 0,5 \% du nombre de restes dans le Moustérien (Stiner, 1994), entre dans ce schéma. Une de ces pièces (une première phalange) porte des stries. Dans l'Aurignacien (fouilles Peyrony) du gisement de Castanet (France), sur les quatre restes d'ours $(0,8 \%$ des restes fauniques identifiés) une phalange 1 porte des stries et une molaire est percée (Armand, 2006). À Polesini (Italie), dans de l'Epigravettien, trois restes d'ours sont présents parmi plus de 40000 restes (Stiner, 1994). Un fémur porte des stries. Dans le Magdalénien de l'abri Vidon (France), l'ours représente 0,4\% des restes, un os (une ulna) sur les deux présents est strié (Campmas et al., 2011).

Comme nous l'avons vu auparavant pour la question de la chasse et du charognage, les données disponibles ne permettent pas toujours de caractériser les sites. Il manque parfois le pourcentage de représentation des taxons ou la fréquence des stries, donc tous les sites n'ont pu être rangés dans la classification proposée.

\section{Conclusions et discussion}

L'Ours des cavernes est le taxon le plus exploité et l'a été majoritairement par l'Homme de Néandertal. Des ours des cavernes mâles ont été chassés, notamment à Hohle Fels ainsi que des ours bruns de grande taille dans le site moustérien de Taubach (Bratlund, 1999).

La chasse est démontrée, aussi bien pour Néandertal que pour l'Homme moderne, et concerne tant l'Ours brun que l'Ours des cavernes, remettant en cause les hypothèses de L. Binford (1997) sur l'incapacité des Néandertaliens à chasser des ours de grande taille.

Toutefois, les exemples où la chasse est avérée sont encore rares, parce que la démonstration est difficile à faire notamment dans les cas de grottes où les ours ont hiberné. De plus, la question n'a pas toujours été abordée dans les différentes publications et les données disponibles ne permettent pas d'aller plus loin dans les conclusions. Finalement, si les évidences pour la chasse des ours ne sont pas nombreuses, comme cela a déjà été souligné par Stiller et collaborateurs (2010), les exemples d'utilisation des ours le sont plus. Il est aussi évident que ce corpus n'est pas 
figé et qu'il est susceptible d'évoluer au gré de nouvelles découvertes ou de reprises de séries anciennes.

Dans la littérature, des tentatives ont été faites pour évaluer la période de déclin de l'Ours des cavernes et la relier à une activité humaine.

Dans le Jura souabe, une diminution du nombre de carnivores de moyenne et de grande taille, liée à une augmentation de la prédation des carnivores et de l'utilisation des grottes par les humains, a été observée dans 5 sites différents, du Moustérien à l'Aurignacien, mais surtout de l'Aurignacien au Gravettien (Kitagawa et al., 2012). Finalement, cette région est actuellement la seule pour laquelle une corrélation a été faite entre la diminution des effectifs des populations d'ours et une activité de chasse. Toutefois, cet exemple ne permet pas de parler de chasse intensive ou de surexploitation.

31 Dans leur travail sur la génétique de populations d'Ours des cavernes et d'Ours brun de la fin du Pleistocène, M. Stiller et collaborateurs (2010) écrivent que le déclin de l'Ours des cavernes aurait débuté il y a 50000 ans BP. Ils concluent que, ni les effets du climat, ni la chasse, ne peuvent être seuls responsables de la disparition de ce taxon, et que des facteurs multiples, parmi lesquels une concurrence entre hommes et ours pour les grottes serait en cause. D. Grayson et F. Delpech (2001) remarquent, qu'à la grotte XVI (France), le ratio Ours des cavernes/Ongulés diminue du Moustérien à l'Aurignacien. Ils relient ce phénomène à une augmentation des temps de résidence ou de la taille des groupes humains, donc à une compétition territoriale entre hommes et ours.

Dans notre corpus, on observe un pic d'exploitation de l'Ours des cavernes au cours du Paléolithique moyen, mais pour une période mal calée dans le temps. En revanche, aucune augmentation n'est observée à la charnière entre le Paléolithique moyen et le Paléolithique supérieur, ni ultérieurement au cours du Paléolithique supérieur.

33 Mais, il est envisageable qu'une globalisation des résultats concernant les interactions entre hommes et ours ne soit pas possible et qu'il y ait plutôt des phénomènes régionaux, c'est en tout cas l'impression que donne l'exemple de la chasse du Jura souabe ou celle de la compétition pour le territoire mis en évidence à partir de la grotte XVI.

34 Si les évidences pour la chasse des ours ne sont pas nombreuses, comme cela a déjà été souligné par Stiller et collaborateurs (2010), les exemples d'exploitation le sont plus. Dans certains cas, des analyses plus poussées permettraient de définir le mode d'acquisition des ressources.

Il est évident que ce corpus n'est pas figé et qu'il est susceptible d'évoluer au gré de nouvelles découvertes ou de reprises de séries anciennes.

\section{BIBLIOGRAPHIE}

ALHAIQUE F. 1994, «Taphonomic analysis of the faunal remains from the "P" and "M" layers of the Arene Candide (Savona, Italy)», Quaternaria Nova, vol. IV, p. 263-295. 
ARMAND D. 2006, « Abri Castanet (Dordogne, France): an aurignacian site with bear exploitation procurement. Bear exploitation in paleolithic time », dans E. S. TSOUKALA et G. RABEDER (dir.), actes $\mathrm{du} 12^{\mathrm{e}}$ international Cave Bear Symposium, Thessaloniki and Aridea, 2006, Scientific Annals, School of geologye, Aristotle University of Thessaloniki, Special vol. 98, p. 263-268.

ARMAND D., PLASSARD F. et PRAT F. 2003, «L'Ours des Cavernes de Font-de-Gaume III », Paléo, vol. 15, p. 241-244.

AUGUSTE P. 1992, «Étude archéozoologique des grands mammifères du site pléistocène moyen de Biache-saint-Vaast (Pas-de-Calais, France) », L’Anthropologie, vol. 96, n 1, p. 49-70.

AUGUSTE P. 1995, « Chasse ou charognage au Paléolithique moyen : l'apport du gisement de Biache-saint-Vaast (Pas-de-Calais). Bulletin de la Société préhistorique Française, vol. 92, nº 2 , p. 155-167.

BÄCHLER E., 1920-1921, « Das Drachenloch ob Vättis im Taminatale, 2445 m ü.M. und seine Bedeutung als paläontologische Fundstätte und prähistoriche Niederlassung aus der Altsteinzeit (Paläolithikum) im Schweizerland », Jahrbuch der St Gallischen Naturwissenschaftlichen Gesellschaft, vol. 59, p. 1-144.

BEZ J.-F. 1995, « Traces de boucherie sur les restes de grands mammifères », dans A. DEFLEUR A. et E. CREGUT-BONNOURE (dir.), Le gisement paléolithique moyen de la grotte des Cèdres (Var), Paris, D.A.F., vol. 49 , p. 43-47.

BINFORD L. R. 1997, « Linking Ethnographic Information on Man-Bear Interaction to European Cave Bear Deposits ", dans T. TILLET et L. R. BINFORD (dir.), L'Homme et l'Ours, colloque International, Auberives-en-Royans, 1997, p. 197-241.

BOCHERENS H., BRIDAULT A., DRUCKER D. G., HOFREITER M., MÜNZEL S. C., STILLER M. et VAN DER PLICHT J. 2014, « The last of its kind ? Radiocarbon, ancient DNA and stable isotope evidence from a late cave bear (Ursus spelaeus, Rosenmüller, 1794) from Rochedane (France) », Quaternary International, vol. 339-340, p. 179-188.

BOUDADI-MALIGNE M., MALLYE J.-B., LANGLAIS M. et BARSHAY-SZMIDT C. 2012, « Des restes de chiens magdaléniens à l'abri Morin (Gironde, France). Implications socio-économiques d'une innovation zootechnique ", Paléo, vol. 23, p. 117-136.

BRATLUND B. 1999, « Anthropogenic factors in the thanatocoenose of the last interglacial travertines at Taubach », dans The role of early humans in the accumulation of european lower and middle palaeolithic bone assemblages. Monographien des Römisch-germanischen Zentralmuseums 42 , p. 255-262.

CAMPMAS E., DAUJeARD C., LENOIR M., AJAS A., BAILlet M., BOURGEON L., DELVIGNe V., ROBERT B., TEYSSANDIER J., ARMAND D. et RIGAUD S. 2011, « Nouvelles données sur le Magdalénien de l'EntreDeux-Mers : la faune de l'Abri Vidon (Julliac, Gironde) », Préhistoire du Sud-Ouest, vol. 19, p. 3-18. CAVANHIÉ N. 2009, «L'Ours qui a vu l'Homme ? Étude archéozoologique et taphonomique du site paléolithique moyen de Régourdou (Montignac, Dordogne, France) », Paléo, vol. 21, p. 39-64.

CHARLES R. 1997, «The exploitation of carnivores and other fur-bearing mammals during the north-western european late upper Palaeolithic and Mesolithic ", Oxford journal of archaeology, vol. 16, $\mathrm{n}^{\circ}$ 3, p. 253-277.

CORDY J.-M. 1974, « La faune aurignacienne de la grotte Princesse Pauline à Marche-les-Dames ». Bulletin de la Société Royale Belge d'Anthropologie et de Préhistoire, vol. 85, p. 243-252 
DASCHEK E. 2014, Étude archéozoologique des grands mammifêres du gisement Paléolithique moyen d'Erd (Hongrie), BAR International Series 2694, Oxford, Archaeopress, 216 p.

DAVID F. et POULAIN T. 1990, «La faune de grands mammifères des niveaux XI et XC de la grotte du renne à Arcy-sur-Cure (Yonne) ", dans Paléolithique moyen récent et Paléolithique supérieur en Europe, colloque international de Nemours, 1988, p. 319-323.

DAVID F. et POULAIN T. 2002, Les mammifères, dans : l'Aurignacien de la grotte du Renne, XXXIV • supplément à Gallia Préhistoire, CNRS Ed., p. 51-82.

EHRENBERG K. 1958/59, « Vom dermaligen Forschungsstand in der Höhle am Salzofen », Quartär, vol. 10/11, p. 237-251.

GARDEISEN A. 1994, « Restes fauniques et stratégies de chasse dans le Pleistocène supérieur de la grotte ouest du Portel (Ariège, France) ». Thèse de Doctorat de l'Université Paul Valéry, Montpellier III, $484 \mathrm{p}$.

GERMOMPRÉ M. et SABLIN M. 2001, « The cave bear (Ursus spelaeus) from Goyet, Belgium. The bear den in Chamber B (bone horizon 4) », Bulletin de l'Institut royal des Sciences Naturelles de Belgique, Sciences de la terre, vol. 71, p. 209-233.

GRAYSON D. K. et DELPECH F. 2001, « The upper paleolithic at Grotte XVI (Dordogne, France): richness, evenness, and cave bears ", dans M. A. HAYS et P. T. THACKER (dir.), Questioning the answers: re-solving fundamental problems of the Early Upper Paleolithic. BAR International Series 1005, Oxford, Archaeopress, p. 187-197.

JÉQUIER J.-P. 1975, Le Moustérien Alpin. Révision critique, Eburodunum, vol. 2, Institut d'archéologie yverdonnoise, $128 \mathrm{p}$

KITAGAWA K., KRÖNNECK P., CONARD N. J. et MÜNZEL S. C., 2012, « Exploring cave use and exploitation among cave bears, carnivores and hominins in the Swabian Jura, Germany ", Journal of Taphonomy, vol. 10, $\mathrm{n}^{\circ}$ 3-4, p. 439-461.

КовY E.-Ed. 1953, « les Paléolithiques ont-ils chassé l'ours des cavernes ? ", Actes de la Société jurassienne d'Emulation, p. 1-48.

LIOUBIN V. P. et BARYSHNIKOV G. F. 1984, «L'activité de chasse des plus anciens habitants du Caucase (Acheuléen, Moustérien) », L'Anthropologie, vol. 88, n² 2, p. 221-229.

MOREL P. 1993, « Une chasse à l'ours brun il y a 12000 ans : nouvelle découverte à la grotte du Bichon (La Chaux-de-Fonds) », Archéologie suisse, p. 110-117.

MÜNZEL S. C., LANGGUTH K., CONARD N. J., UERPMANN H.-P. 2001, « Höhlenbärenjagd auf der Schwäbischen alb vor 30000 jahren », Archäologisches Korrespondenzblatt, vol. 31, p. 317-327.

MÜNZEL S. C. et CONARD N. 2004, "Cave bear hunting in Hohle Fels, a Cave Site in the Ach Valley of the Swabian Jura ", Revue de Paléobiologie, Genève, vol. 23, n² 2, p. 877-885.

MÜNZEL S. C., RIVALS F., PACHER M., DÖPPES D., RABEDER G., CONARD N. J. et BOCHERENS H., 2014, « Ecology of Late Pleistocene bears (Ursus spelaeus, Ursus ingressus) : Insight from stable isotopes (C, N, O) and tooth microwear », Quaternary International, vol. 339-340, p. 148-163.

PATOU-MATHIS M. 1998, «Consommation courante de l'Ours des Cavernes en Europe occidentale durant le paléolithique moyen : mythe et réalité ", Anthropozoologica, $2^{\circ}$ numéro spécial, p. 17-20. PATOU-MATHIS M., 2012, Interactions Between Neanderthals and Carnivores in Eastern Europe, Journal of Taphonomy, vol. 10, n 3-4, p. 277-290. 
PEAN S. et WOJTAL P. 2003, « Gravettian subsitence patterns related to pleniglacial palaeoenvironments in southern Poland », dans M. PATOU-MATHIS et H. BOCHERENS (dir.), Le rôle de l'environnement dans les comportements des chasseurs-cueilleurs préhistoriques Colloque/Symposium C3.1, actes du XIV Congrès UISPP, Liège, 2001 BAR International Series 1105, Oxford, Archaeopress, p. 23-37.

QUILÈs J. 2003, « Les Ursidae du Pleistocène moyen et supérieur en Midi méditerranéen : apports paléontologiques et archéozoologiques ", Thèse de doctorat, Museum National d'Histoire Naturelle, Paris, 2 t., 682 p.

RABEDER G., Withalm G., HOFReITER M., PACHER M. et KAVCiCK N. 2004, « Potocka Zijalka -

Paleontological and Archaeological results of the excavation campaigns 1997-2000 : a monograph ", PANGEO, p. 333.

ROMANDINI M. et NANNINI N. 2012, «Chasseurs épigravettiens dans le territoire de l'ours des cavernes : le cas du Covolo Fortificato di Trene (Vicenza, Italie) », L'Anthropologie, vol. 116, p. 39-56.

SMITH G. M. 2012, « Hominin-carnivore interaction at the Lower Palaeolithic site of Boxgrove, UK », Journal of Taphonomy, vol. 10, n 3-4, p. 373-394.

SOMMER R. S. et BENECKE N. 2005, « The recolonization of Europe by brown bears Ursus arctos Linnaeus, 1758 after the Last Glacial Maximum », Mammal Review, vol. 35, n² 2, p. 156-164.

STILLER M., BARYSHNIKOV G., BOCHERENS H., GRANDAL D’ANGLADE A., HILPERT B., MÜNZEL S. C., PINHASI R., RABEDER G., ROSENDHAL W., TRINKAUS E., HOFREITER M. et KNAPP M. 2010, « Withering Away - 25000 Years of Genetic Decline Preceded Cave bear Extinction », Molecular Biological Evolution, vol. 27, $\mathrm{n}^{\circ}$ 5, p. 975-978.

STINER M. C. 1994, Honor among Thieves. À Zooarchaeological Study of neandertal Ecology, Princeton University Press, $447 \mathrm{p}$.

STINER M. 2005, The Faunas of Hayonim Cave, Israël. À 200 000-year Record of Paleolithic Diet, Demography, and Society. American School of Prehistoric Research, Bull. 48, Peabody Musuem of Archaeology and Ethnology, Harvard University, 330 p.

TAGLIACOZZO A. et FIORE I. 2009, « Hunting strategies in a mountain environment during the Late Glacial in north eastern Italy », Preistoria alpina, vol. 44, p. 79-93.

TILLET T. et BERNARD-GUELLE S. 1996, « Behaviour patterns, strategies and seasonality in the mousterian site of Preletang (Vercors) : the mousterian in Alps », dans Middle Paaeolithic and Middle Stone Age settlement system, XIII ${ }^{\mathrm{e}}$ Congrès de l'UISPP, Forli, vol 6, T. 1, p. 319-326.

TURK I. et DIRJEC J. 1997, « Taxonomic and taphonomic survey of mammal macrofauna », dans TURK I. (dir.), Mousterian Bone Flute and other finds from Divje Babe I cave site in Slovenia, Znanstvenorazis kovalni center, Sozu, p. 99-113.

WOJTAL P. 2007, Zooarcheological studies of the late Pleistocene sites in Poland, Institute of Systematics and Evolution of Animals, Krakow, 189 p.

WOJTAL P., WILCZYNSKI J., NADACHOWSKI A. et MÜNZEL S. C. 2015, « Gravettian hunting and exploitation of bears in Central Europe », Quaternary International, vol. 359-360, p. 58-71. 


\section{RÉSUMÉS}

Alors que la question de l'exploitation des ours à des fins de subsistance a longtemps été éclipsée par celle d'une utilisation symbolique, de plus en plus de découvertes obligent à reconsidérer cette problématique. De nouveaux sites témoignant d'une utilisation des ours à des fins alimentaires ou pour la récupération de la peau sont en effet régulièrement publiés. Dans ce travail, nous essayons de faire un bilan de ces découvertes en nous intéressant surtout aux taxons exploités, en fonction des périodes et cultures. Les résultats obtenus montrent que c'est l'Ours des cavernes qui a été le taxon le plus abondamment exploité, et particulièrement à l'époque moustérienne.

\section{AUTEUR}

DOMINIQUE ARMAND

Ingénieure chargée de collections, UMR 5199, PACEA, Université de Bordeaux 


\title{
Quelle place pour le Mammouth dans l'économie des Gravettiens d'Arcy-sur-Cure (Yonne, France) il y a environ 27000 ans cal BP?
}

\author{
Nejma Goutas et Jessica Lacarrière
}

Cette étude a été financée dans le cadre du projet 2ARC - ARChives de fouilles ARCy-sur-Cure (coord. Goutas, Bodu et Mevel, UMR 7041) - programme Archives de fouilles des sites préhistoriques et antiques (resp. E. Bellon, USR 3225 et R. Vallet, UMR 7041) du Labex «Les passés dans le Présent » de l'université de Paris Ouest-la Défense (resp. G. Glasson-Deschaumes). Nous remercions les organisateurs du $141^{e}$ congrès du CTHS, «l'animal et l'homme » et en particulier ceux du colloque "Animal symbolisé - Animal exploité ", de nous avoir donné l'opportunité de présenter nos travaux. Nos remerciements vont au comité d'organisation et particulièrement à Sandrine Costamagno ainsi qu'au rapporteur anonyme pour leurs relectures des plus utiles. Nos remerciements les plus chaleureux aussi à l'ensemble de l'équipe du musée de l'Avallonais à Avallon pour leur accueil et leur aide précieuse sur les collections: Claude Renouard, Agnès Poulain, Karine Choisnard, Muriel Zimmermann, Adeline Descloux et Mathieu Dupont. Un merci tout particulier à Thérèse et Agnès Poulain pour nous avoir permis d'étudier les collections et les fonds d'archives inédits de Pierre Poulain sur la grotte du Trilobite. Nos remerciements s'adressent aussi à Jean-Jacques Cleyet-Merle, Michèle Julien, Stéphane Madelaine et Philippe Jugie pour les informations et clichés photographiques qu'ils nous ont communiqués sur la collection de la grotte du Renne conservée au MNP des Eyzies-de-Tayac. Nous remercions Aimé Besson, Quentin Roblin et Manal Merzouqui Mestour de l'université de Paris Ouest-La défense pour leur soutien logistique indispensable au projet 2ARC, ainsi que toute l'équipe du service Archives de la Maison Archéologie et Ethnologie (E. Bellon, A. MontagneBorras et $F$. Rimelin). Nos remerciements enfin à Erwan Le Gueut pour son travail très précieux sur les archives $d u$ Trilobite (fouilles Poulain et Parat) et toutes les informations qu'il nous a gentiment communiqué, ainsi qu'Élise Tartar pour son ultime et précieuse relecture du présent manuscrit. 


\section{Introduction}

1 Parler « d'économie du mammouth » pour les sociétés gravettiennes d'Europe centrale et orientale est une expression pleine de sens tant cet imposant mammifère est une ressource intensément exploitée par les groupes humains de ces régions (par exemple Péan et Wojtal, 2003 ; Brugère, 2000 ; Brugère et al., 2009 ; Goutas, 2013a ; Fladerer et al., 2014), conditionnant ainsi de nombreux aspects de ces sociétés : nourriture, objets utilitaires et symboliques (art et parure), habitation. En France, avant le dernier Maximum Glaciaire, l'acquisition et l'exploitation alimentaire des carcasses de ce mégaherbivore par les groupes gravettiens (entre 33500 - 24000 cal BP) restent peu documentées (Lacarrière, 2015), tandis que l'exploitation technique de l'ivoire et des ossements apparaît avoir fait intervenir des choix et des modalités de traitement bien distincts de ceux mis en œuvre en Europe centrale ou orientale (Goutas, 2013a).

Ces différences sont directement conditionnées par la disponibilité de cette ressource dans l'environnement : qu'il s'agisse d'une ressource vivante ou fossile. Il est délicat de mettre directement en relation le contexte chrono-climatique avec l'éthologie des animaux dont les restes ont été exhumés des gisements, et ceci pour plusieurs raisons. En premier lieu, car les cadres radiométriques disponibles pour les différents contextes régionaux du Gravettien ne sont pas d'égale qualité, et donc difficilement comparables (Rigaud, 2007-2008; Delpech et Texier, 2007 ; Klaric, 2008 ; Djindjian, 2011 ; Pesesse, 2013 ; Noiret, 2013). Si pour l'Europe centrale et orientale, les grandes archéoséquences et les nombreuses datations nous offrent un cadre cohérent et précis (Haesaerts et al., 2007 ; Noiret, 2013), il en est autrement pour d'autres régions. C'est le cas de la France, où l'ancienneté, l'imprécision des datations (écarts-types parfois très importants), la diversité des méthodes employées (méthode classique, AMS...), ou bien encore la nature des échantillons datés (quasi-absence de datations sur industrie osseuse), constituent autant de biais avec lesquels il nous faut composer (voir pour une synthèse récente Lacarrière, 2015). Quant au climat, il s'avère particulièrement instable à l'échelle de l'Europe dans la deuxième partie du MIS2, période qui marque l'émergence et le développement de ce qu'il est d'usage de nommer le "Gravettien ", durant laquelle les conditions du dernier Maximum glaciaire se mettent progressivement en place, entrecoupées de brèves phases de réchauffement (par exemple Fletcher et al., 2010 ; Helmens, 2014). Dès lors, articuler des questionnements environnementaux et éthologiques se révèle un exercice des plus complexes, surtout, quand l'espèce au centre de l'étude est le mammouth. Les principes de l'actualisme pour des espèces disparues, atteignent ici leurs limites. Ainsi, le mammouth est généralement associé à un environnement de steppe-toundra particulièrement froid et sec appelé également «steppe à Mammouth » (Guthrie, 1982, 1990). Ce type d'écosystème à pâturage aurait permis le développement d'une importante biomasse végétale (McNaughton, 1984; Zimov et al., 2012) favorable à la coexistence d'une mégafaune avec d'autres grands herbivores comme le bison et le cheval. Ce biome aurait eu une extension maximale à la fin du Pléistocène supérieur (Guthrie, 1990, 2001 ; Kahlke, 1999, 2014). Cependant, cette hypothèse de steppe dans laquelle évoluerait une grande diversité d'espèces n'a pas toujours fait l'unanimité, certains auteurs remettant en cause l'association stricte de ces faunes en synchronie (par exemple Colinvaux et West, 1984). Toutefois, d'après de récentes analyses $\mathrm{ADN}$ et l'étude des contenus stomacaux des différents animaux du cortège de la «steppe à Mammouth» en Sibérie et en Alaska, ceux-ci auraient 
consommé davantage de plantes non-graminoïdes que ce à quoi on se serait attendu en contexte de steppe-toundra. Ces plantes, plus riches en nutriments et facilement digérées, auraient permis la coexistence de ces grands herbivores (Willerslev et al., 2014). Les analyses isotopiques, quant à elles, tendent à démontrer une relative plasticité écologique pour le mammouth (Szpak et al., 2010). Quoi qu'il en soit, cette "steppe à Mammouth » est décrite comme particulièrement instable et se mettrait en place lors des phases de transition entre des périodes plus tempérées et des phases de refroidissement, impliquant des phases d'extinctions régionales et la perduration de populations à partir de zones-refuges (Mann et al, 2015). Ces discussions concernant la « steppe à Mammouth » en Béringie sont malheureusement difficilement transposables à l'Europe de l'Ouest où ce type d'association faunique est également observé, mais où les carcasses animales n'ont pas bénéficié des mêmes conditions de préservation que dans le permafrost (conservation de restes de végétaux consommés). Tout cela illustre la difficulté à déterminer le type de paysage dans lequel a pu évoluer ce proboscidien disparu et s'il a pu, effectivement, être contemporain des populations humaines étudiées.

3 Conscientes de ces limites inhérentes à la fois à l'état de la recherche pour le «Gravettien» et à l'objet de notre étude, nous essaierons de retracer certaines des intentions qui ont guidé les groupes gravettiens d'Arcy-sur-Cure (Yonne, Bourgogne) dans les choix et le traitement du mammouth. En décrivant les modalités d'exploitation alimentaire et artisanale de cet animal, c'est une part de l'organisation des systèmes sociaux et économiques impliqués dans son exploitation que nous voulons tenter d'approcher. Plus largement, l'exemple d'Arcy-sur-Cure sera l'occasion de discuter du statut de cet animal sur le reste du territoire français pendant son occupation au cours du Gravettien.

\section{Le mammouth au Gravettien, en France : état de la recherche}

4 En France, les données disponibles concernant l'exploitation du mammouth durant cette phase chrono-culturelle sont assez disparates. Pour commencer, l'identification au genre Mammuthus est souvent difficile tant les restes sont fragmentaires et peu nombreux. En effet, il est possible que ceux-ci, bien qu'associés aux niveaux gravettiens, proviennent de fossiles d'âges plus anciens et donc potentiellement à d'autres formes d'éléphantidés.

5 La plupart des fragments retrouvés sur les sites du Gravettien français correspondent à des dents jugales et des défenses. Un site de référence - Brassempouy (Landes) - est à ce titre célèbre pour son industrie "éburnéenne» (Piette, 1894). La zone située à l'entrée principale de la grotte du Pape évoque un atelier de fabrication de statuettes féminines (White, 2006), tandis que le secteur GG2, isolé et difficile d'accès, pourrait avoir servi pour un dépôt intentionnel de pointes en ivoire et de pointes à cran (Goutas et Simonet, 2009). À l'occasion d'un récent récolement des collections fauniques anciennes, d'autres éléments d'industrie sur ivoire ont été isolés (Lefèvre, 2014), ainsi qu'un fragment de coxal d'éléphantidé (Lacarrière, 2014).

6 Peu d'indices, en revanche, nous sont parvenus concernant une récupération alimentaire ou une exploitation des carcasses dans un objectif non strictement 
technique. Dans le Sud-Ouest de la France, deux autres gisements, tout aussi emblématiques du Gravettien français, peuvent être cités. Isturitz, dans les PyrénéesAtlantiques, a livré, dans un secteur isolé de la grande Salle et dans un contexte très probablement gravettien, une omoplate de mammouth en association avec de nombreuses pièces esquillées (Turq et al., 1998). On signalera également la Gravette en Dordogne qui livre une petite industrie sur os de très grand mammifère, rapportée à du mammouth par F. Lacorre (Lacorre, 1960 ; Goutas, 2004).

7 À notre connaissance, hormis ces gisements, seules les grottes du Renne et du Trilobite à Arcy-sur-Cure, où diverses modifications d'origine anthropique ont pu être clairement observées sur le matériel, peuvent être mobilisées dans la réflexion sur les liens alimentaires et techniques entre homme et mammouth.

\section{Préambule méthodologique}

8 Les restes retrouvés sur les sites préhistoriques ne permettent que difficilement de se prononcer sur les modalités d'acquisition des mammouths : chasse ou charognage, ou bien encore récupération par les hommes d'ossements ou de restes dentaires sur des carcasses fossiles (voir Péan, 2001; Brugère, 2009). En effet, l'une des particularités de cette ressource tient au fait que son exploitation technique par les hommes peut être totalement disjointe chronologiquement du moment où l'animal pourvoyeur a vécu. Ainsi, l'ivoire acquiert avec le temps, en s'asséchant, des propriétés très utiles à son exploitation : il se fissure et offre alors des lignes de faiblesse qui sont généralement mises à profit au cours du débitage (Christensen, 1999). De même, ses os, y compris à l'état fossile ou subfossile (si tant est bien sûr qu'ils aient bénéficié de conditions de conservation favorables), par leur masse et leur volume, constituent des matériaux encore exploitables pour l'aménagement, par exemple, de structures d'habitat ou encore comme supports passifs de type «billots ».

Dès lors, discuter des modalités d'acquisition de l'ivoire et des autres ressources potentielles d'un mammouth implique :

- de maîtriser le contexte de découverte, afin d'identifier les possibles biais taphonomiques ou les problèmes stratigraphiques ;

- d'analyser, quand cela est possible, le profil de mortalité à partir des restes dentaires, et ce, afin de déterminer si le type de mortalité se rapproche davantage d'une mortalité naturelle ou d'un autre type ;

- d'analyser la représentation squelettique. La présence des seuls restes dentaires évoque, par exemple, plutôt une récupération ponctuelle ;

- de discuter de l'état de fraîcheur des matières exploitées (os et ivoire) via la prise en compte de critères spécifiques (état des surfaces osseuses, nature des pans de fracture éventuellement associés, recoupement des surfaces de délitage et des stigmates techniques, etc.).

Enfin, une discussion autour des éventuelles traces anthropiques présentes sur les surfaces osseuses s'impose, car elles n'indiquent pas nécessairement un prélèvement de viande, et peuvent refléter une intention technique. En effet, même des traces de décharnement peuvent être consécutives à un nettoyage de la surface en amont d'une exploitation technique de l'os. Si la plupart des informations requises sont difficilement accessibles compte tenu du contexte sédimentaire et historiographique complexe des grottes d'Arcy, la présence de portions du squelette postcrânien préservées et de traces 
anthropiques observables sur les restes de ces proboscidiens représente un cas exceptionnel pour le Gravettien français.

11 Alors que les données relatives à l'exploitation technique de l'ivoire sont désormais assez nombreuses, et permettent d'en apprécier une certaine évolution au fil du temps, celles relatives à l'exploitation des os de mammouth sont, en revanche, très rares et l'exploitation de ce matériau est sans doute sous-estimée (difficulté de détermination taxinomique). Un retour aux collections archéologiques fondé sur une collaboration étroite entre archéozoologue et technologue est assurément une ambition méthodologique qu'il faut développer ${ }^{1}$, si l'on veut retracer les intentions qui ont guidé les groupes gravettiens dans le choix et le traitement de cette espèce animale. En ce sens, le travail ici proposé sur les séries d'Arcy-sur-Cure, constitue pour les sites gravettiens français, un premier essai de croisement concerté sur l'exploitation du mammouth.

\section{Remise en contexte historique des recherches sur Arcy}

Arcy-sur-Cure est de l'un des rares gisements du Bassin parisien ayant livré des occupations multistratifiées (fig. 1), couvrant une chronologie très vaste: du Paléolithique moyen au Paléolithique final (Leroi-Gourhan et Leroi-Gourhan, 1964 ; Mevel, 2013). Si les premières fouilles à Arcy-sur-Cure remontent à la fin du XIX siècle (fouilles De Vibraye, Ficatier, Parat), c'est véritablement avec l'arrivée en 1946 d'André Leroi-Gourhan et de son équipe que se structure un véritable programme de recherche sur le massif des grottes d'Arcy-sur-Cure/Saint-Moré (Bailloud, 1953; Leroi-Gourhan, 1961 ; Schmider, 1996 ; Schmider et al., 2004). Arcy-sur-Cure devient dès lors un terrain pionnier à la fois dans l'application de méthodes de fouilles et d'analyses modernes, d'autre part dans l'application d'une démarche des plus novatrices pour l'époque, celle d'une ethnologie des populations préhistoriques (Leroi-Gourhan, 1961; Leroi-Gourhan et Leroi-Gourhan, 1964). Avec la création, fin des années 1990, d'un $\mathrm{PCR}^{2}$ dédié aux problématiques archéologiques du Bassin parisien, devenu en 2005 l'un des thèmes de recherche de l'équipe Ethnologie préhistorique, les études sur les grottes d'Arcy-surCure/Saint-Moré ont connu un réel renouveau. De nouvelles opérations de terrain (David et al., 2001; Hardy et al., 2012), et de nouvelles datations ont été réalisées (Higham et al., 2010; Goutas et al., travaux en cours). En parallèle, une (re)lecture des séries anciennes et récentes est venue préciser le cadre chrono-culturel des occupations paléolithiques identifiées dans le massif de la Cure (Mevel, 2002, 2004 ; Bon et Bodu, 2002 ; Connet, 2002 ; Julien et al., 2002 ; Klaric, 2003 ; Bodu et Renard, 2013 ; Goutas, 2013b; Pétillon et Averbouh, 2013, Malgarini et al., sous presse). Dans la continuité de ces recherches, en 2014, un nouveau projet de l'équipe Ethnologie Préhistorique, a vu le jour sur les grottes d'Arcy-sur-Cure, et c'est dans ce cadre que prend place le travail que nous présentons aujourd'hui. Il s'agit du projet 2 ARC "ARChives de fouilles d'ARCy-sur-Cure " (coord. Goutas, Bodu et Mevel). Ce projet se structure autour de différents volets: 1 - archivistique; 2 - documentation et recherche: avec notamment, l'amorce de nouvelles études et analyses sur les collections anciennes, encore en grande partie inédites ; 3 - valorisation. 
Figure 1 : Localisation des grottes du Trilobite et du Renne à Arcy-sur-Cure.

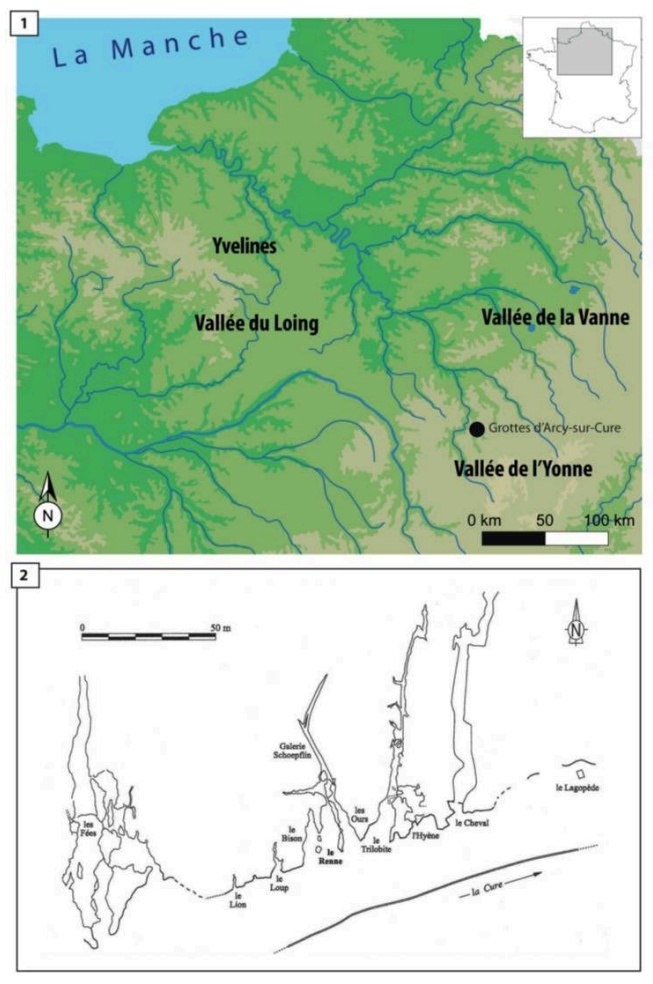

1 : à l'échelle de la France (d'après Mevel, 2013 - carte ( ) geoatlas ; 2 : au sein de la vallée de la Cure (Baffier et Girard, 1998, fig. 1).

\section{Présentation des grottes gravettiennes d'Arcy-sur-Cure : le Renne et le Trilobite}

Le Gravettien a été identifié dans quatre cavités (fig.1). À la Grande grotte et, potentiellement aussi, à la grotte du Cheval, c'est un art pariétal qui témoigne du passage des Gravettiens. On notera dès à présent, qu'un animal domine le bestiaire de l'art figuratif d'Arcy. Il s'agit précisément du mammouth.

Dans les grottes du Trilobite et du Renne, distantes de seulement quelques mètres, ce sont de véritables niveaux d'occupations qui ont été identifiés. Au sein de séquences stratigraphiques et sédimentaires complexes, et problématiques par certains aspects ce qui nécessairement biaise la représentativité des séries étudiées - des horizons ont été rapportés à une phase moyenne du Gravettien : le Rayssien. Ce dernier a été daté sur industrie osseuse à la grotte du Renne à $23180 \pm 210$ uncal BP (OxA- 21568 ) et $23070 \pm 210$ uncal BP (OxA- 21 567) (Higham et al., 2010), soit environ $27000 \mathrm{cal} \mathrm{BP}^{3}$.

\section{La grotte du Trilobite}

La grotte du Trilobite a été fouillée très anciennement, à la fin XIX $x^{e}$ siècle (collections Ficatier et Parat), puis par P. Poulain (conservateur du musée de l'Avallonnais) et le Spéléo-club d'Avallon de 1950 à 1953 (Le Gueut, Master en cours), donnant lieu à la constitution d'une petite collection inédite ${ }^{4}$, et dont les données sur le mammouth viendront nourrir ici notre propos. Ces séries ont connu une histoire complexe comme 
en atteste leur éclatement géographique au sein de différents musées de France (recensement en cours).

Les collections gravettiennes du Trilobite sont en grande majorité le résultat des fouilles de l'abbé Parat. Elles proviennent du niveau III, épais de 5 à $10 \mathrm{~cm}$, et fouillé sur $60 \mathrm{~m}^{2}$ environ. Ce niveau est probablement un palimpseste de plusieurs occupations successives. Décrit par l'abbé Parat comme riche, il se caractérise par son sédiment fortement rougeâtre et qui le distingue très nettement des autres niveaux, de teinte plutôt jaune (Parat, 1902).

16 L'existence de biais au sein de cette série est indiscutable (Goutas, 2013b) et est évoquée :

- par la faune collectée, où prédominent les os entiers et les gros fragments, parallèlement à une rareté des petits éléments osseux ;

- en industrie lithique par la découverte d'une centaine de pièces dans les déblais des fouilles Parat, à l'occasion de tamisages réalisés par R. Daniel (Mevel, 2004), mais aussi par la présence d'objets spécifiquement gravettiens dans le matériel recueilli au sein de la couche du Solutréen ancien (Bodu et Renard, 2013);

- en industrie osseuse, par la surreprésentation d'objets finis très investis, même après vérification des restes de faune, et par la présence de rares pièces clairement intrusives, dont une pointe à base fendue aurignacienne.

Sans négliger la conservation différentielle, les perturbations stratigraphiques ou bien encore les erreurs de lecture des niveaux archéologiques au cours de la fouille, certains éléments augurent incontestablement de l'existence de tris sélectifs opérés par les anciens fouilleurs. Ces tris, sans nul doute, participent aussi à expliquer la faible représentativité des déchets, supports et des outils osseux plus communs au profit de la collecte d'objets plus «esthétiques» (bâton percé, objets appointés massifs en ivoire, tibia de renne, etc., tous décorés de motifs non figuratifs); tous ces éléments accentuant sans doute artificiellement certains éléments de singularité de la série d'industrie osseuse du Trilobite.

\section{La grotte du Renne}

18 Dans cette cavité, trois couches gravettiennes furent identifiées (c. IV, V et VI) et fouillées par A. Leroi-Gourhan dans les années 1950-1960. Elles ont bénéficié de différentes études, les plus récentes étant celles conduites sur l'industrie osseuse (Goutas, 2013b) et la faune (Lacarrière, 2015). Plusieurs travaux ont montré que la séquence stratigraphique gravettienne avait subi diverses perturbations: bioturbations, érosion et remaniements par des coulées (Schmider et al., 2004), ayant entrainé, par endroits, des déplacements verticaux du mobilier comme en attestent quelques raccords lithiques intercouches (Mevel, 2002 ; Klaric, 2003).

D'après les travaux de B. Schmider, F. David, A. Roblin-Jouve et L. Klaric, la couche IV est la plus perturbée et ne correspondrait pas à un véritable niveau d'occupation (mélanges importants), tandis que la couche VI atteste de quelques contaminations avec l'Aurignacien sous-jacent (Mevel, 2002 ; Julien et al., 2002 ; Goutas, 2013b). Dans ce contexte, la couche $\mathrm{V}$ apparait la plus pertinente pour une étude des occupations gravettiennes, car elle correspondrait à un véritable sol d'habitat qui aurait moins souffert de perturbations. Pour autant, un outil sur une côte de taille mammouth issu 
de la couche IV sera aussi discuté, car il présente plusieurs points communs avec des outils de la grotte du Trilobite eux aussi potentiellement gravettiens.

\section{Des industries gravettiennes particulières...}

L'industrie lithique des deux cavités montre une association burins du Raysse/pointes de la Gravette (dont plusieurs micro-gravettes) (Schmider, 1995; Mevel, 2002, 2004 ; Klaric, 2003). Cette association, observable principalement dans les sites du Sud-Ouest, ne fait pas consensus. Elle est ainsi considérée comme problématique par L. Klaric (2003) qui l'interprète ici comme la conséquence d'un possible mélange entre une occupation majoritaire rayssienne, et un court épisode discret se rapportant à du Gravettien récent.

Une autre particularité de l'industrie lithique gravettienne d'Arcy tient à l'absence de "lamelles de la Picardie»- dont les supports seraient produits à partir des burins/ nucléus du Raysse (Klaric, 2003) - et à celle des burins de Noailles; ces derniers étant aussi souvent associés aux burins du Raysse dans les sites du Sud-Ouest.

$\mathrm{Du}$ point de vue de l'industrie osseuse, les séries d'Arcy révèlent aussi un certain nombre de traits originaux (Goutas, 2013b). On notera notamment :

- une multiplicité des «débitages baguettaires", jusqu'alors connus que pour les phases récente et finale du Gravettien (Laugerie-Haute, Pataud ; Roc de Combe) ;

- la présence de "pièces à aménagement de type Isturitz » classiques en bois de renne et d'autres plus originales, en ivoire. Longtemps considérées comme fossile directeur du Noaillien - ces objets très particuliers dont l'homogénéité typo-fonctionnelle a déjà été discutée - sont désormais attestés dans d'autres contextes du Gravettien français (Goutas, 2008). Leur présence dans le Gravettien d'Arcy confirme que ces objets ne sont pas exclusifs de la phase noaillienne.

Tous ces éléments de singularité sont-ils à mettre en relation avec l'occupation rayssienne du site? Ou faut-il y voir un indice supplémentaire en faveur d'une courte occupation gravettienne récente passée inaperçue à la fouille, selon l'hypothèse proposée par L. Klaric (2003) ? Il est en l'état difficile de statuer sur ces questions, mais un programme de datations est en cours sur l'industrie osseuse gravettienne du Trilobite et pourrait apporter de nouveaux éléments de discussion.

En définitive, on l'aura compris, les collections d'Arcy-sur-Cure posent un certain nombre de limites à notre étude. Toute tentative d'une approche palethnologique des comportements gravettiens quant à l'exploitation du mammouth à partir des séries de ces deux cavités ne peut donc être qu'un vœu pieux. Si une véritable approche globale de l'exploitation de cette ressource nous est impossible, nous pouvons néanmoins tenter de proposer des pistes de discussion quant à la place du mammouth dans l'économie gravettienne locale.

\section{Arcy : un potentiel inédit pour traiter de la relation Homme/ Proboscidien en France}

Au Trilobite, ce sont 22 restes qui ont été identifiés parmi les vestiges fauniques hors industrie (tabl. 1), et un total de 35 restes si l'on intègre les éléments d'industrie osseuse (tabl. 2). À la grotte du Renne, le mammouth est la seconde espèce représentée 
en termes de fréquence ( $\mathrm{NR}=97$ ou $\mathrm{NR}=125$ si l'on inclut l'industrie osseuse). Contrairement aux autres gisements français, ici, ce proboscidien n'est pas uniquement représenté par des restes dentaires mais également par des portions du squelette postcrânien. Cette proportion non négligeable dans le spectre faunique doit être considérée en regard de la présence de témoins variés de son exploitation technique. Les occupations d'Arcy livrent à cet égard l'une des plus importantes séries d'industrie sur ivoire du Gravettien français ( $\mathrm{N}=34)$, et l'un des rares exemples d'une industrie sur os pouvant se rapporter à cette espèce pour ces contextes $(\mathrm{N}=7)$. Cette originalité du site fait aussi écho à d'autres singularités observées au sein de la culture matérielle associée, sur lesquelles nous reviendrons brièvement par la suite (voir Goutas, 2013b).

Tableau 1 : Nombre de restes et parties anatomiques attribués au mammouth dans chacune des collections, hors industrie osseuse (Grotte du Renne, Grotte du Trilobite, collections Leroi-Gourhan, Parat et Poulain).

\begin{tabular}{|l|c|c|c|c|}
\cline { 2 - 5 } \multicolumn{1}{c|}{} & Grotte du Renne & \multicolumn{2}{c|}{ Grotte du Trilobite } & TOTAL \\
\hline Eléments anatomiques & collection Leroi-Gourhan & collection Parat & collection Poulain & \\
\hline Restes dentaires (défenses & 90 & 5 & 0 & 95 \\
\hline Mandibule & 1 & 1 & 0 & 2 \\
\hline Côte & 0 & 3 & 0 & 3 \\
\hline Scapula & 1 & 0 & 1 & 2 \\
\hline Humérus & 0 & 1 & 0 & 1 \\
\hline Radio-ulna & 1 & 0 & 0 & 1 \\
\hline Coxal & 1 & 3 & 2 & 6 \\
\hline Fémur & 2 & 0 & 0 & 2 \\
\hline Tibia & 1 & 0 & 0 & 1 \\
\hline Tarsiens & 0 & 1 & 0 & 1 \\
\hline Phalanges 1 & 0 & 3 & 0 & 3 \\
\hline phalanges 2 & 0 & 2 & 0 & 2 \\
\hline Total & $\mathbf{9 7}$ & $\mathbf{1 9}$ & 3 & $\mathbf{1 1 9}$ \\
\hline
\end{tabular}

Tableau 2 : Éléments d'industrie sur os de taille mammouth et sur ivoire (Grotte du Renne, Grotte du Trilobite, collections Leroi-Gourhan, Parat et Poulain).

\begin{tabular}{|c|c|c|c|}
\hline Grotte du Renne (Collection Leroi-Gourhan, couche $\mathrm{V}+1$ pièce couche IV) & IVOIRE & $\begin{array}{l}\text { OS } \\
\text { (très grand mammifère) }\end{array}$ & Total \\
\hline Fragments d'objets appointés & 8 & 0 & 8 \\
\hline Baguettes de statuts techniques variés (fragments d'objets finis, de supports cours de façonnage) & 11 & 0 & 11 \\
\hline Objet fini indéterminé (fragment) & 1 & 0 & 1 \\
\hline Matrices secondaires & 2 & 0 & 2 \\
\hline Déchets de réduction/réfection de baguettes ou de pointes & 4 & 0 & 4 \\
\hline Déchet ou support? & 1 & 0 & 1 \\
\hline Outil à partie active mousse "type brunissoir" (sur côte, couche IV) & 0 & 1 & 1 \\
\hline Total Grotte du Renne (Collection Leroi-Gourhan) & 27 & 1 & 28 \\
\hline \multicolumn{4}{|l|}{ Grotte du Trilobite (Collection Parat et Poulain, couche 3) } \\
\hline Outil à biseau unifacial de deuxième facture & 1 & 0 & 1 \\
\hline " Pièce à aménagements de type Isturitz" & 4 & 0 & 4 \\
\hline " Pièce à aménagements de type Isturitz" et à cannelure latérale guillochée & 1 & 0 & 1 \\
\hline Pointe massive à cannelure latérale guillochée & 1 & 0 & 1 \\
\hline Outils à partie active mousse et à biseau unifacial (os long indét. et os illiaque) & 0 & 2 & 2 \\
\hline Supports de découpe ( 3 sur coxaux et 1 sur scapula) & 0 & 4 & 4 \\
\hline Total Grotte du Trilobite (Collection Parat et Poulain) & 7 & 6 & 13 \\
\hline TOTAL DE LINDUSTRIE DES DEUX GROTIES & 34 & 7 & 41 \\
\hline
\end{tabular}




\section{Présentation du corpus osseux}

\section{Méthode et présentation générale des collections (faune et industrie)}

La plupart des vestiges osseux de proboscidiens non travaillés provenant de la grotte du Renne n'étaient pas accessibles lors de notre étude. Nous nous appuierons donc, pour évoquer cette cavité, sur les observations effectuées il y a quelques années par l'une d'entre nous (JL) et sur les données publiées de F. David (Schmider et al., 2004). Au sein d'un spectre faunique composé de 2028 restes osseux (industrie inclue), c'est le renne, taxon éponyme de la cavité, qui domine le spectre à $83,5 \%$, mais le mammouth représente la seconde espèce en termes de fréquence, suivi par le cheval et un boviné 5 .

La collection du Trilobite a livré quant à elle environ 460 vestiges osseux (industrie inclue), se rapportant majoritairement au renne et au cheval; 26 restes de proboscidiens ont été isolés au sein des collections de l'abbé Parat (tabl. 1 et tabl. 2). À cela s'ajoutent quatre fragments provenant de la collection Poulain.

Sur le plan archéozoologique, les restes de proboscidiens de la grotte du Trilobite ont fait l'objet de déterminations spécifiques puis ont systématiquement été observés à la loupe (grossissement $\mathrm{x} 20$ ). Les zones présentant des traces particulières ont ensuite été examinées sous microscope stéréoscopique ${ }^{6}$ (Nikon SMZ1500, grossissements 5x à 30x). Ainsi, nous avons pu distinguer différents types de traces, causées par des facteurs abiotiques (dissolution, fissures), par des carnivores (traces de manducation) ou des humains (incisions, entailles, stries ${ }^{7}$ ). L'estimation de l'âge des individus, que ce soit à partir des fusions épiphysaires ou selon des critères dentaires, a été réalisée à partir des travaux de G. Haynes (1991).

Si l'on considère seulement l'industrie osseuse, la grotte du Trilobite a livré 68 artefacts en os, bois de renne et ivoire. On signalera la présence d'épingles, de poinçons, de lissoirs, de retouchoirs, d'outils intermédiaires, de petites bipointes, de baguette demironde, et de pointes de projectiles. La série Parat, telle qu'elle nous est parvenue, est incomplète puisqu'une cinquantaine de pièces, essentiellement des objets appointés (outils et armatures), ont désormais disparu (Parat, 1902; Breuil, 1918). À la grotte du Renne, la couche $\mathrm{V}$ a livré 66 éléments d'industrie osseuse. L'équipement se compose presque exclusivement de poinçons en os et d'objets appointés en ivoire. Cette série est assez représentative des informations que l'on peut obtenir sur une série non triée (présence de déchets variés, d'objets finis et de supports). Les complémentarités anatomiques et techniques mises en évidence grâce à la méthode du remontage mental (sensu Averbouh, 2000) confirment qu'une partie de la production a eu lieu sur place (Goutas, 2013b).

Les pièces d'industrie sur os et ivoire de proboscidien ont bénéficié d'une étude technologique afin de rendre compte des activités de fabrication et d'utilisation qui ont eu lieu dans les deux cavités. Un examen à l'œil nu des artefacts a été systématiquement couplé à un examen sous microscope stéréoscopique (cf. supra) afin d'identifier les zones travaillées et/ou utilisées, de les localiser et de les caractériser à la fois en volume et en surface (grossissements 5x à 40x). 


\section{Caractérisation taphonomique des restes de mammouth}

31 Selon F. David (com. pers.), les os de mammouth de la grotte du Renne se présentaient sous la forme de fragments excessivement friables et fragiles. Un fémur dont la surface a été travaillée par l'homme offre, en revanche, un bon état de surface qui autorise une lecture précise des traces anthropiques (fig. 2).

Figure 2 : Fémur de mammouth portant de multiples stries anthropiques. Grotte du Renne.

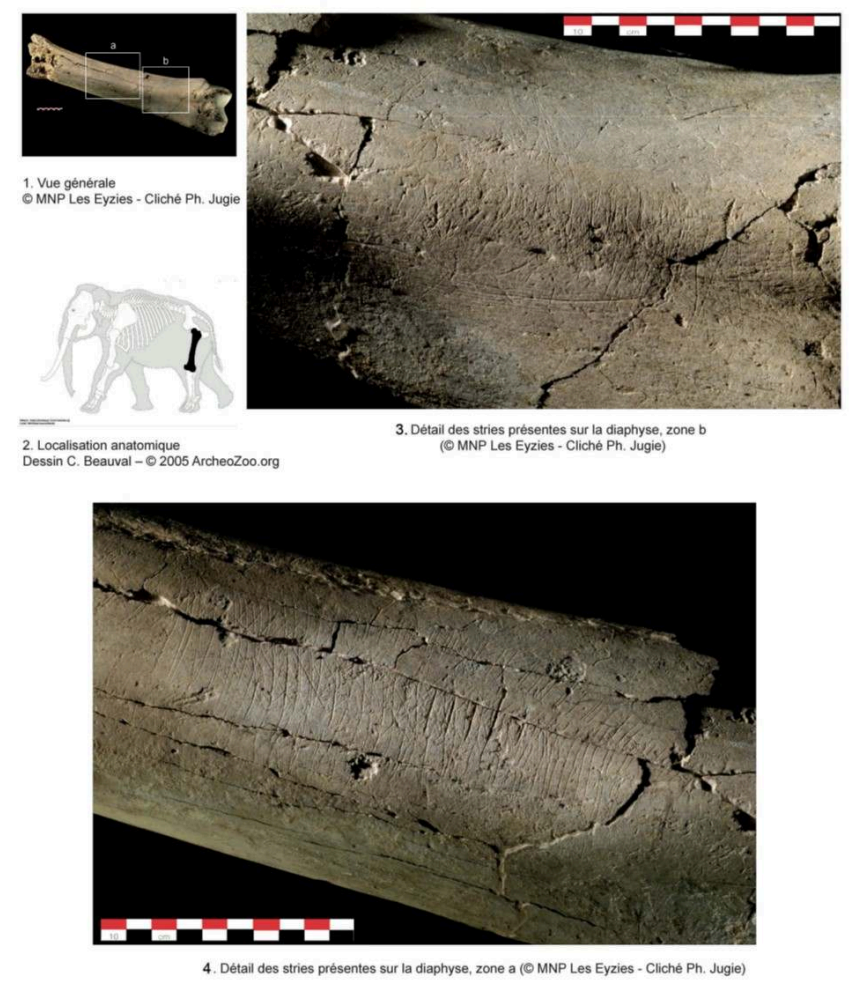

1 : vue générale ; 2 : localisation anatomique ; 3 et 4 : vues détaillées des zones portant des stries anthropiques organisées (clichés Ph. Jugie (c) MNP Les Eyzies; dessin de C. Beauval - (c) 2005 ArcheoZoo.org, d'après K. Schauer : http://www.archlsa.de) En définitive, les ossements de mammouth de la collection Parat et ceux de la collection Poulain ne présentent pas de différences majeures dans leurs états de surface, tandis que leur patine est assez homogène. Sans que nous puissions être affirmatives, ces éléments pourraient plaider en faveur d'une provenance stratigraphique et d'une histoire taphonomique commune de tous ces restes au sein de la grotte du Trilobite.

Les restes de mammouth du Trilobite révèlent aussi des états de surface variables. Ceux de la collection Parat sont principalement affectés par des cupules de dissolution et des fissures longitudinales probablement provoquées par une dessiccation consécutive à une exposition des ossements avant leur enfouissement. Ceux de la collection Poulain présentent un état légèrement plus médiocre (spongieux très friable par exemple), alors que les ossements des autres espèces associés (ongulés et carnivores) sont au contraire bien conservés.

Si les rares éléments d'industrie sur os de très grand mammifère présentent des états de surface équivalents aux restes de faune non travaillés, on remarquera cependant que les surfaces modifiées par l'homme offrent une conservation nettement meilleure. L'utilisation de ces os et les stigmates techniques ou fonctionnels qui les accompagnent (raclage, émoussé, lustré) auront entrainé une modification de la surface osseuse 
d'origine. En effet, pour qu'il y ait formation d'un émoussé ou d'un lustré, il est nécessaire qu'il y ait un frottement répété de deux matériaux, ce qui a pour corollaire une perte/ou un gain de matière plus ou moins important à l'endroit du contact (Semenov, 1964 ; Christensen, 1999; Maigrot, 1997; Legrand, 2005). Concernant le raclage, cette technique permet - au moyen d'une pression - d'éliminer de manière progressive de fines particules de matières (Averbouh, 2000). Dans ces différents cas de figure, les fibres osseuses sont tassées. Ce compactage des fibres ${ }^{8}$ pourrait avoir contribué à rendre la surface osseuse moins poreuse, et donc moins sensible à certaines altérations taphonomiques, comme la dissolution.

Dans les deux collections, les restes dentaires sont particulièrement mal conservés et se délitent suite à une fonte d'origine taphonomique du cément (fig. $3, \mathrm{n}^{\text {os }} 3$ et 4 ). Quatre os présentant des traces de carnivores (coll. Parat) sont également à noter : des traces de dents (punctures sensu Binford, 1981) sont présentes sur deux côtes. Des bords crénelés en partie proximale des os (crenulated edges, ibid.) et du mâchonnement (scooping out, ibid.) lisible sur l'extrémité distale de diaphyse d'un humérus ont également été relevés (fig. $3, n^{\circ}$ 5). Enfin, on signalera sur un fragment de scapula (coll. Poulain) utilisé comme outil, la présence de traces évoquant des empreintes de dents de rongeur (fig. $3, \mathrm{n}^{\text {os }} 7$ et 8 ).

Figure $3: 1$ et 2 : Représentation squelettique du mammouth dans les grottes du Trilobite et du Renne.

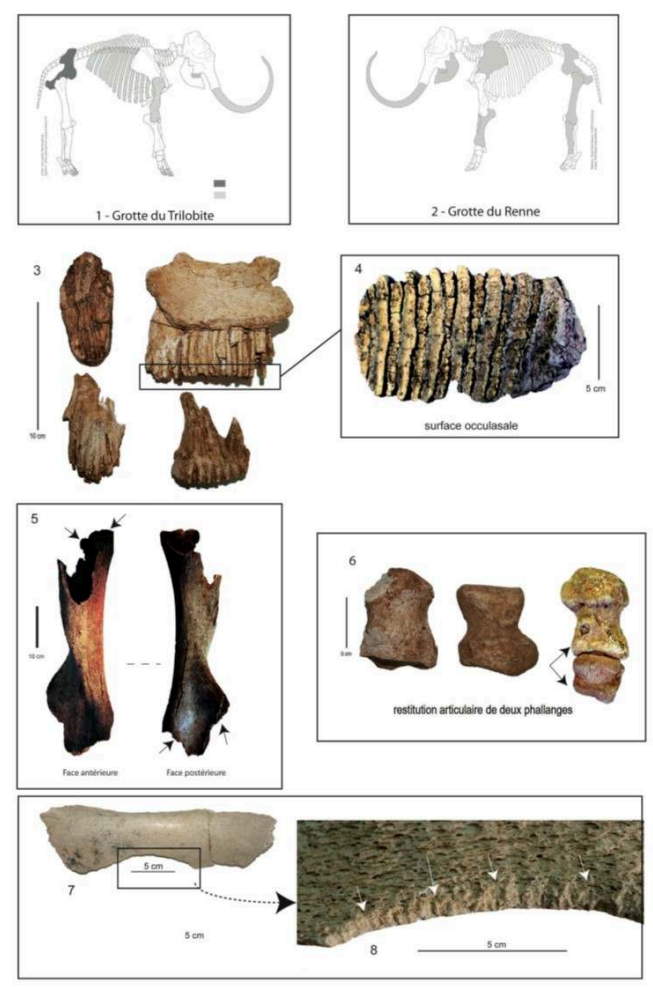

En gris clair : $\mathrm{NMI}=1$, en gris foncé $: \mathrm{NMI}=3$. Squelette d'Elephas modifié d'après un dessin de $\mathrm{C}$. Beauval - (c) 2005 ArcheoZoo.org (d'après K. Schauer : www.archlsa.de) ; 3 à 8 : restes osseux attribués au mammouth. Grotte du Trilobite : 3 et 4 : restes dentaires (clichés N. Goutas) ; 5 : humérus portant des traces de carnivores (clichés J. Lacarrière) ; $6:$ restitution articulaire de deux phalanges. Première et deuxième phalange, vue postérieure (clichés N. Goutas) ; 7 et 8 : scapula portant des traces de dents probablement de rongeur (clichés N. Goutas). 


\section{Représentation anatomique, âge et nombre des individus} fréquents (tabl. 1 et 2 et fig. 3). Trois fragments de côtes, trois de scapulas et six de coxaux ont été identifiés. Comme les scapulas, les coxaux sont présents dans les trois collections étudiées. Dans la catégorie des os longs, un reste d'humérus, un radioulnaire ainsi que deux fémurs sont conservés. Bien que ces os longs soient subcomplets, la plupart des épiphyses distales sont absentes à la grotte du Renne (Schmider et al., 2004). Au Trilobite, sur l'unique os long que nous avons pu observer directement (humérus de la collection Parat), nous avons également constaté l'absence des extrémités. Les bas de pattes sont représentés par quatre phalanges, dont deux qui ont pu être « réarticulées » (fig. 2, $n^{\circ}$ 6).

$\mathrm{Au}$ final, seule la catégorie des vertèbres n'est pas représentée au sein de ces deux grottes. Il est intéressant de remarquer qu'une certaine complémentarité apparaît dans la représentation anatomique des proboscidiens présents dans chacune des cavités. Si les restes dentaires restent majoritaires dans les deux cas, les côtes et le bas des pattes semblent plus fréquents dans la grotte du Trilobite alors que dans la grotte du Renne, au détriment de ces portions, c'est le squelette appendiculaire qui est mieux représenté (cf. fig. $3, n^{\circ} 1$ et 2 ).

D'après les restes dentaires et les fusions épiphysaires, de jeunes adultes et des adultes sont représentés dans l'assemblage. L'humérus appartient à un jeune adulte qui n'avait pas achevé son épiphysation et devait donc avoir entre 20 et 30 ans à sa mort (Haynes 1991).

38 À la grotte du Renne, F. David estimait que les os identifiés pouvaient appartenir à un seul individu, tandis qu'à la grotte du Trilobite, c'est un minimum de trois mammouths qui peut être ici décompté à partir des différents fragments de coxaux droits. Il est à noter que sur neuf éléments osseux latéralisés du Trilobite, huit proviennent du côté droit de l'animal (deux côtes, un humérus, quatre coxaux et une scapula). Nous ne sommes pas en mesure d'expliquer cette latéralisation préférentielle à droite.

\section{Modifications anthropiques des restes osseux de mammouth}

\section{Des stries de boucheries et des traces équivoques}

Des stries d'origine anthropique compatibles avec une activité de boucherie ont été enregistrées sur sept restes osseux. Elles concernent deux restes de côtes, trois phalanges, un fémur (mentionnés par F. David) et l'humérus (fig. 4). Si les stries sur les côtes et l'humérus peuvent se référer à du décharnement, celles sur les phalanges évoquent une activité de désarticulation ou de dépouillement. Une première et une deuxième phalange présentent des stries courtes en partie distale sur les faces médiales et latérales. Sur une autre deuxième phalange, l'emplacement, proche du bord proximal, et le fait que cette strie encercle une partie de la circonférence de l'os évoque également du dépouillement, déjà documenté dans les référentiels actuels sur des herbivores plus petits (par exemple Costamagno, 2012). Mais l'intention qui a guidé ces gestes est délicate à interpréter en raison de la rareté des référentiels expérimentaux sur les éléphantidés (Frison et Todd, 2001). 
Figure 4 : Stries de boucherie sur les restes osseux de proboscidiens.

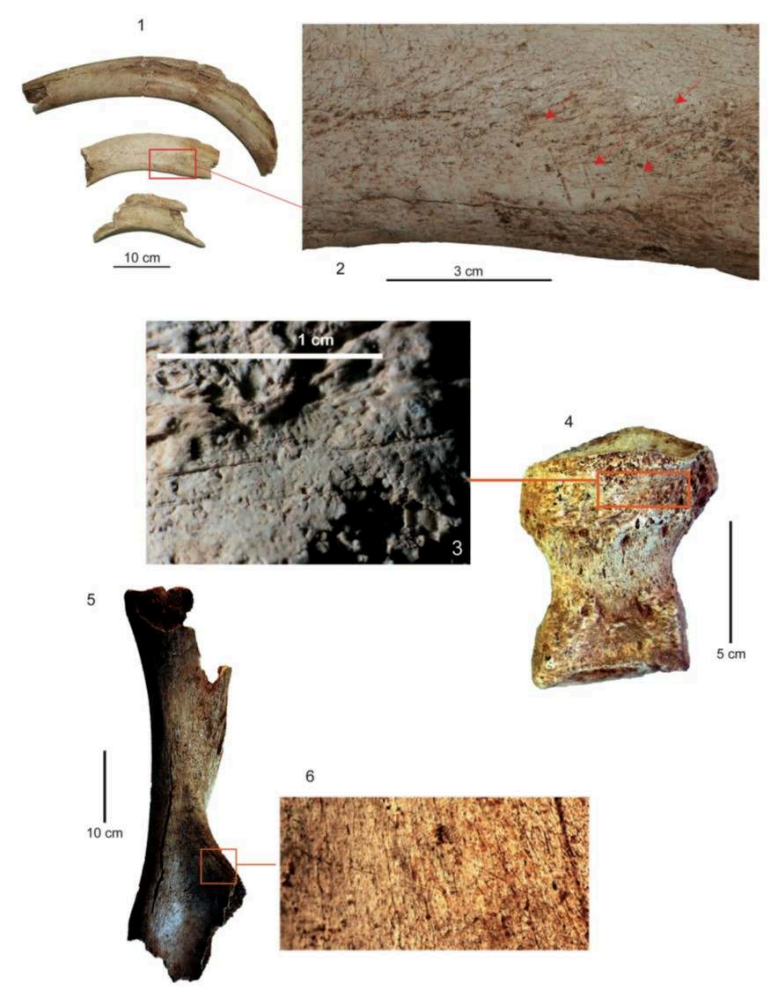

Grotte du Trilobite - 1 et 2 : côtes (clichés N. Goutas) ; 3 et 4 : phalange (clichés N. Goutas et J. Lacarrière) ; 5 et 6 : fémur (clichés J. Lacarrière).

En outre, trois des coxaux présentent des stigmates plus problématiques à interpréter : des incisions, pour certaines très profondes, des plages de raclage observables sur d'importantes surfaces, et des enfoncements, pour certains associés à des stries ( $c f$. infra). Certaines de ces traces ne semblent pas se rapporter à des activités de boucherie, tant par leur localisation, que par leur organisation et leur morphologie. Du fait de leur complexité et de leur imbrication apparente avec d'autres modifications anthropiques des surfaces, ces traces sont décrites plus en détail dans la partie suivante.

Enfin, à l'exception d'un outil sur fragment diaphysaire, discuté plus loin, nous n'avons observé aucune fracturation sur os frais pouvant évoquer une potentielle récupération de la moelle.

\section{Les modifications à des fins techniques}

$42 \mathrm{Au}$ Trilobite, sept pièces sont sur ivoire de mammouth et six sur os de très grand mammifère, théoriquement rapportables à cette même espèce (tabl. 2). Les critères objectifs de détermination spécifique au genre Mammuthus ne sont toutefois plus accessibles, les blocs anatomiques exploités ayant été débités et transformés. Pour cette raison, et bien que les portions d'os exploités soient trop grandes ou trop épaisses pour se rapporter au rhinocéros, nous préférons parler d'os de taille de très grand mammifère. À la grotte du Renne, la série étudiée est dominée par les objets en os $(\mathrm{N}=32)$, dont un potentiellement sur os de mammouth; toutefois, les artefacts sur ivoire de mammouth représentent $41 \%$ de l'assemblage $(\mathrm{N}=27)($ tabl. 2). 
Les industries osseuses de ces deux cavités, bien que différentes dans leur composition, partagent aussi des points communs, notamment dans l'exploitation technique des restes de mammouth.

\section{Une industrie sur os de très grand mammifère}

Il s'agit de 6 outils découverts dans la grotte du Trilobite. On signalera un premier groupe d'outils composé de trois fragments massifs de coxaux droits (collection Parat), et d'une hémi-scapula (collection Poulain) dont la latéralisation reste indéterminée (fig. 5 à 7). Les stigmates associés correspondent majoritairement à :

- des groupes de stries parallèles (de section en $\mathrm{V}$ symétrique), linéaires (parfois curvilignes), transversales ou obliques par rapport à l'axe du support et de profondeur variable (superficielle à profonde) ;

- et plus rarement à de courtes dépressions linéaires (entailles) de section dissymétrique.

Figure 5 : Coxal de mammouth portant diverses modifications anthropiques.

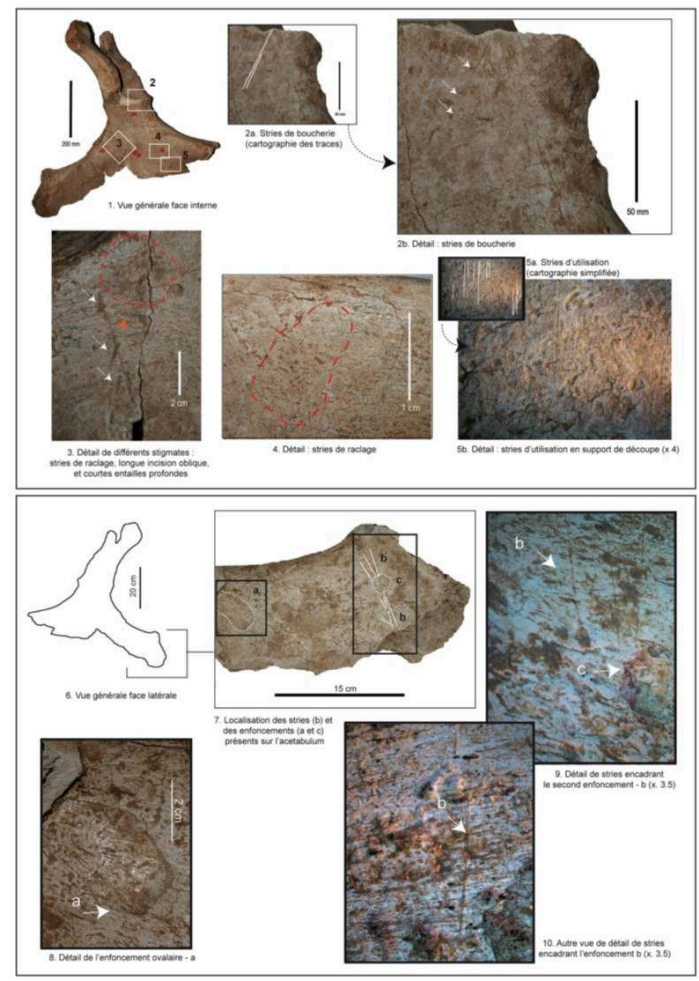

Grotte du Trilobite - traces de boucherie et d'utilisation : 1 à 5 (face interne) ; 6 à 10 (face latérale) (clichés N. Goutas). 
Figure 6 : Coxal de mammouth portant des traces d'utilisation variées.

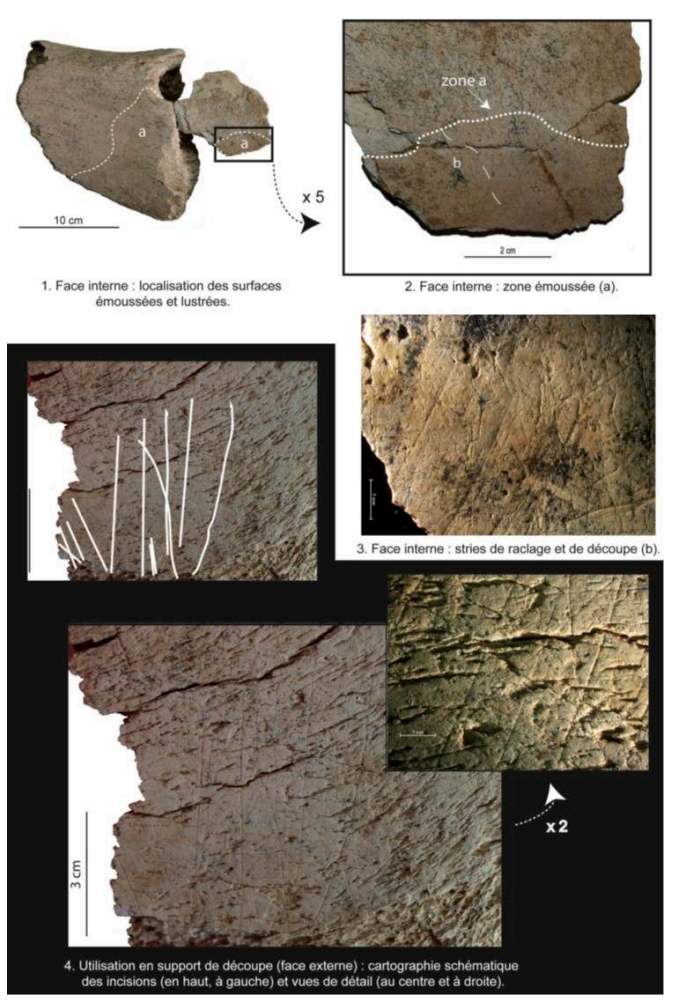

Grotte du Trilobite (clichés N. Goutas).

Figure 7 : Scapula de mammouth portant des traces d'utilisation.

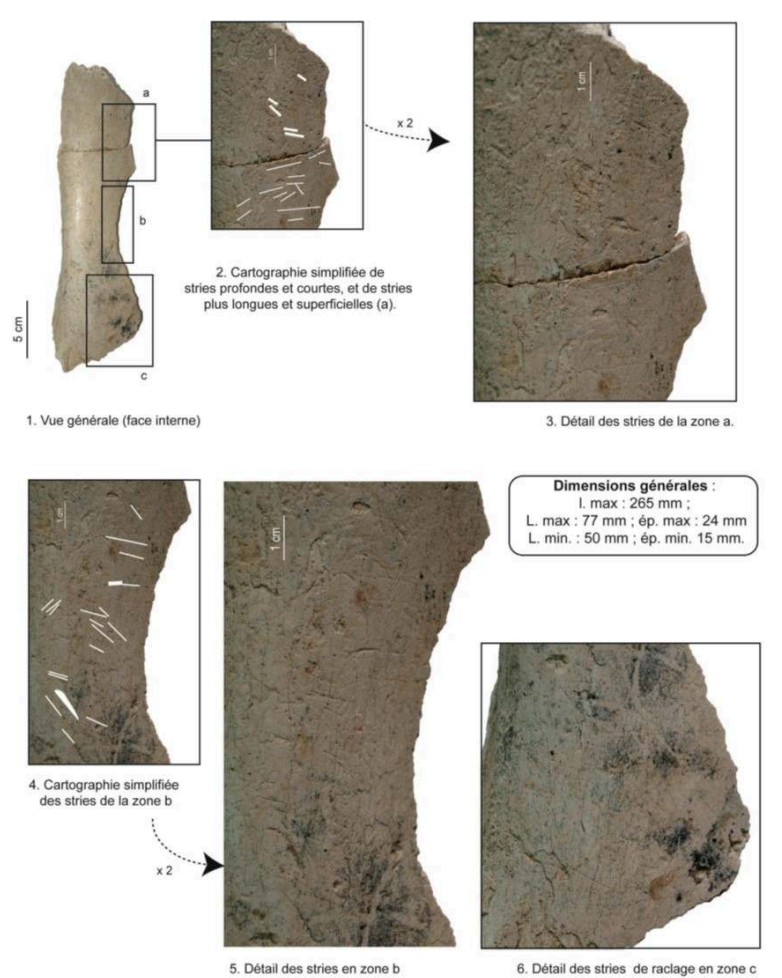

Grotte du Trilobite (clichés N. Goutas). 

massive, affectée d'un biseau unifacial plus ou moins marqué sur leur face inférieure. Le premier est aménagé sur un $\operatorname{coxal}^{9}$ (fig. $8, \mathrm{n}^{\text {os }} 1$ à 6). Une série de percussions diffuses, réalisées à intervalles relativement réguliers, aura permis de dégager un long éclat de contour subtriangulaire sur l'aile de l'os iliaque (face latérale). La partie mésiodistale de l'outil est longue de plus de $200 \mathrm{~mm}$ et relativement étroite en comparaison avec la massivité de la partie proximale, qui devait constituer la zone de préhension. Le volume de cette seconde extrémité devait offrir une importante inertie à l'outil et participer de son efficacité lors de son utilisation. Le biseau, bien que mal conservé, montre par endroits, un compactage des fibres osseuses, associé - sur son tranchant à des écrasements, et à un long arrachement de matière. Ces observations combinées à l'absence de stigmates fonctionnels sur l'extrémité opposée à la partie active, évoquent un mode d'action en percussion directe, suffisamment violent pour générer de tels endommagements distaux. Une utilisation par pression/compression est aussi envisageable. L'outil aura été mu à deux mains (compte tenu de son poids et sa taille), sur une matière semi-dure ou tendre, mais probablement pas souple, si l'on en juge par l'absence de polis d'usage, tout du moins à une échelle macroscopique.

Figure 8 : Outils à partie active mousse.

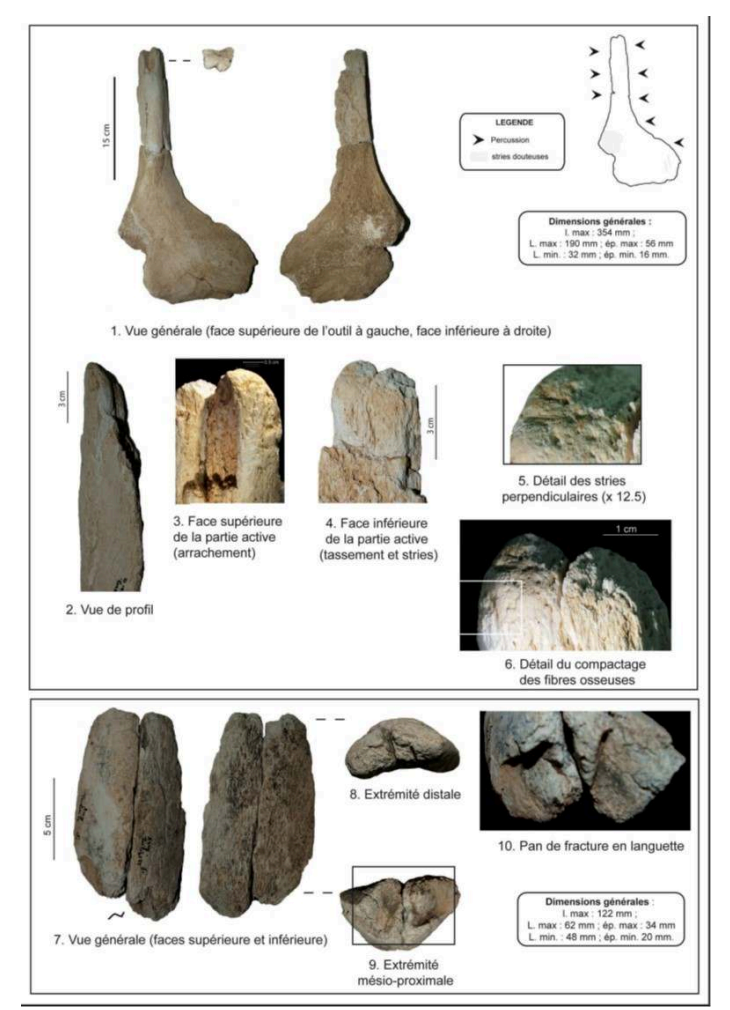

Grotte du Trilobite - 1 à 6 : sur coxal de mammouth. ; 7 à 10 : sur diaphyse d'os long de taille très grand mammifère (clichés N. Goutas). 

de section plan-convexe (fig. $8, \mathrm{n}^{\text {os }} 7$ à 10). Là encore, l'état de surface général est des plus contraignants, mais des plages résiduelles d'utilisation sont ici aussi conservées. La partie active est deux fois plus large que sur l'outil précédent. Cette fois encore, la face inférieure du biseau se caractérise par un comptage des fibres osseuses, mais son tranchant est trop altéré pour être analysé. En revanche, l'extrémité opposée porte elle aussi des écrasements recoupés par un important pan de fracture par flexion (en languette) évoquant une fracture sur os frais. Cet outil a été soumis à de fortes contraintes mécaniques. Une utilisation en percussion indirecte est envisageable (outil intermédiaire) et pourrait expliquer la localisation et l'amplitude de la fracture (possiblement) d'usage en partie mésio-proximale.

fut signalée par G. Bailloud:

«On ne peut enfin passer sous silence trois fémurs et un bassin de mammouth recouverts d'incisions, où dominent des séries de traits parallèles ou groupés par deux; il nous paraît s'agir là d'établis sur lesquels on aurait découpé des lanières de cuir» (Bailloud, 1953, p. 342).

Malheureusement, nous n'avons pu avoir accès à ces probables outils passifs non façonnés lors de notre étude. On peut cependant sans doute y rattacher une pièce des plus intéressantes conservée au Musée National de Préhistoire (collection LeroiGourhan) et dont l'existence nous a été signalée par M. Julien (com. pers.). Il s'agit d'un fémur de mammouth bien conservé et subcomplet (seul manque l'épiphyse distale). Sa diaphyse porte une série de longues incisions s'étalant sur une dizaine de centimètres de long (observation faite d'après photographie, voir fig. 2). Ces incisions, rectilignes ou curvilignes, fines et régulières, sont longues de plusieurs centimètres. Leur organisation varie au sein de cette série. Les incisions les plus proches de l'épiphyse distale sont parallèles entre elles et suivent une orientation strictement transversale; puis elles se retrouvent associées (dans une chronologie qu'il restera à préciser) à d'autres incisions, cette fois obliques, le tout formant un motif en croix. La nature de ces incisions parait en l'état peu compatible avec des pratiques bouchères et pourrait témoigner d'une utilisation passive de cet os ou d'un décor.

Nous avons aussi identifié un outil aménagé sur portion de côte de taille mammouth au sein de la couche IV. Bien conservé dans l'ensemble, il atteste d'une histoire complexe impliquant une étape de recyclage et une utilisation intense ou prolongée. La restitution chronologique de ces différentes actions techniques montre que l'outil a, selon toute vraisemblance, servi dans un premier temps comme support de découpe. Ceci est évoqué par la présence - sur une face et un bord de la côte - de dépressions linéaires (fig. $9, \mathrm{n}^{\circ} 2$ ), assez profondes, régulièrement espacées et de longueur modérée (entre 5 et $10 \mathrm{~mm}$ de long). Ces stigmates, par leur régularité, leur organisation et leur localisation ne renvoient pas à un schéma classique de traitement boucher des côtes, tandis qu'ils trouvent une explication des plus rationnelles dans une utilisation passive telle que celle évoquée plus haut. La profondeur de certaines entailles et à l'inverse le caractère superficiel de certaines incisions évoquent la découpe de matières relativement résistantes à souples. Dans un second temps, l'os aura été intentionnellement fracturé par une série de percussion diffuse, de manière à dégager un éclat régulier, étroit et épais sur l'un des deux bords naturels de la côte (fig. 9, $\mathrm{n}^{\circ} 1$ ). Une extrémité de l'éclat aura ensuite été façonnée pour aménager une partie active 
mousse trapue ${ }^{10}$, selon des modalités qui nous échappent, car les stigmates de façonnage sont ici totalement occultés par un intense poli d'usage. Ce dernier est homogène, très couvrant (y compris au niveau des interstices du tissu spongieux) et s'étend sur plusieurs centimètres sur toute la périphérie de la partie active (fig. $9, \mathrm{n}^{\circ} 3$ ). Il traduit un contact répété avec une matière relativement tendre ou souple. Cette pièce, par certains de ses stigmates fonctionnels, rappelle directement d'autres objets découverts à la grotte du Trilobite (cf. supra).

Figure 9 : Outil à partie active mousse sur côte de taille très grand mammifère.
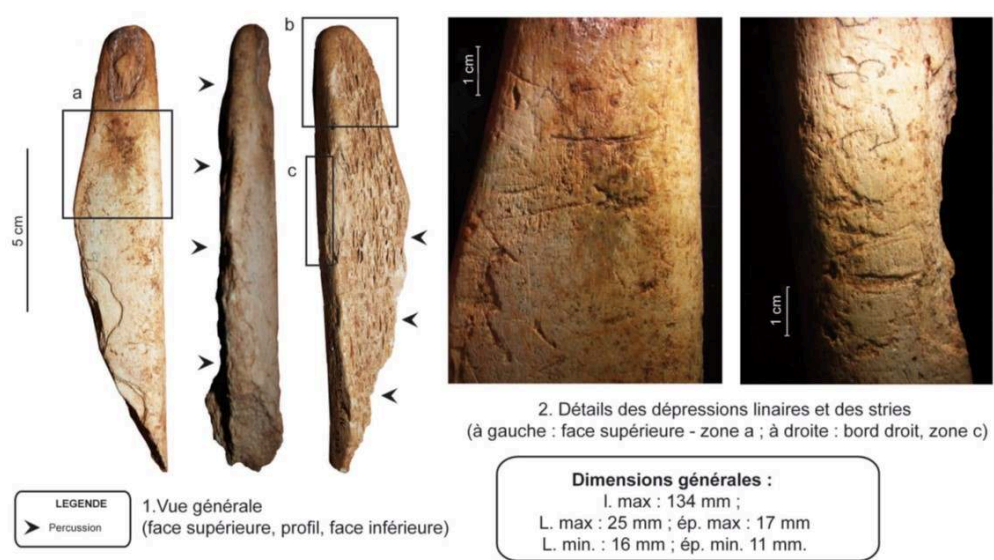

2. Détails des dépressions linaires et des stries (à gauche : face supérieure - zone $\mathrm{a}$; à droite : bord droit, zone $\mathrm{c}$ ) Dimensions générales : I. $\max : 134 \mathrm{~mm} ;$
$\max : 25 \mathrm{~mm} ;$ ép. $\max : 17 \mathrm{~mm}$ L. $\max : 25 \mathrm{~mm} ;$ ép. $\max : 17 \mathrm{~mm}$
L. $\min .: 16 \mathrm{~mm} ;$ ép. $\min .11 \mathrm{~mm}$.

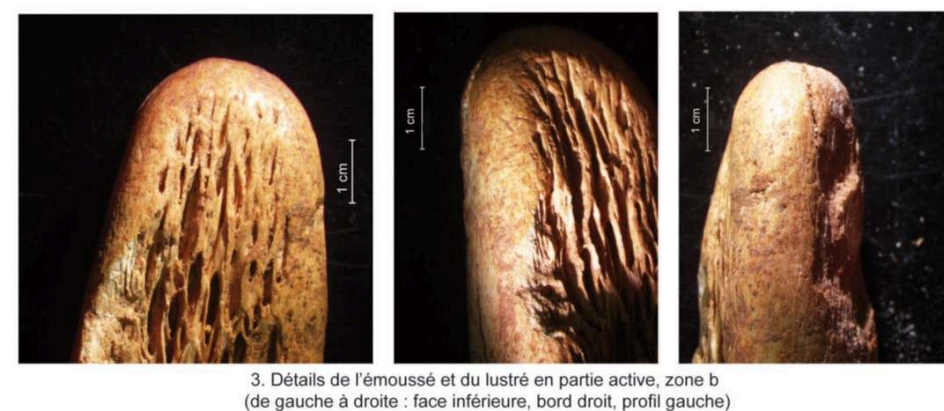

Grotte du Renne (couche IV) (clichés N. Goutas).

51 En définitive, l'exploitation des os de très grand mammifère dans les deux cavités apparaît très minimaliste. Le matériau os est soit directement utilisé sans aucune transformation - ses propriétés morphologiques, volumétriques et structurelles étant mises directement à profit - soit après une transformation limitée.

\section{L'exploitation technique des défenses de mammouth}

Parallèlement à cette exploitation technique d'os de très grand mammifère, les séries gravettiennes d'Arcy documentent une exploitation récurrente des défenses de mammouth, exclusivement tournée vers la production d'objets utilitaires. Aucun objet de parure n'a à ce jour été identifié, marquant en cela une différence majeure avec les niveaux aurignaciens et châtelperroniens d'Arcy (Baffier et Julien, 1990 ; Julien et al., 2002).

53 La Grotte du Trilobite livre ainsi 7 artefacts en ivoire (collection Parat exclusivement), exclusivement des objets finis, soit près de $11 \%$ de l'industrie osseuse que nous avons étudiée pour cette cavité (fig. 10, nos 1 à 3 ). Six pièces supplémentaires en ivoire avaient 
cependant été découvertes par l'abbé Parat (Breuil, 1918), et ont aujourd'hui disparu ${ }^{11}$. Même en prenant en compte ces objets disparus, sur les 115 pièces qui devaient originellement constituer la collection Parat, les artefacts en ivoire ne totaliseraient toujours que $6 \%$ de l'industrie. Ces derniers présentent des caractères morphotechniques (extrémité fusiforme, appointée mousse, massive et incisée) diagnostiques des "pièces à aménagements de type Isturitz ", dont on sait désormais qu'elles ne sont pas exclusives du Noaillien (Goutas, 2013b).

Figure 10 : Exemple de divers fragments d'objets appointés en ivoire découverts dans la grotte du Trilobite.
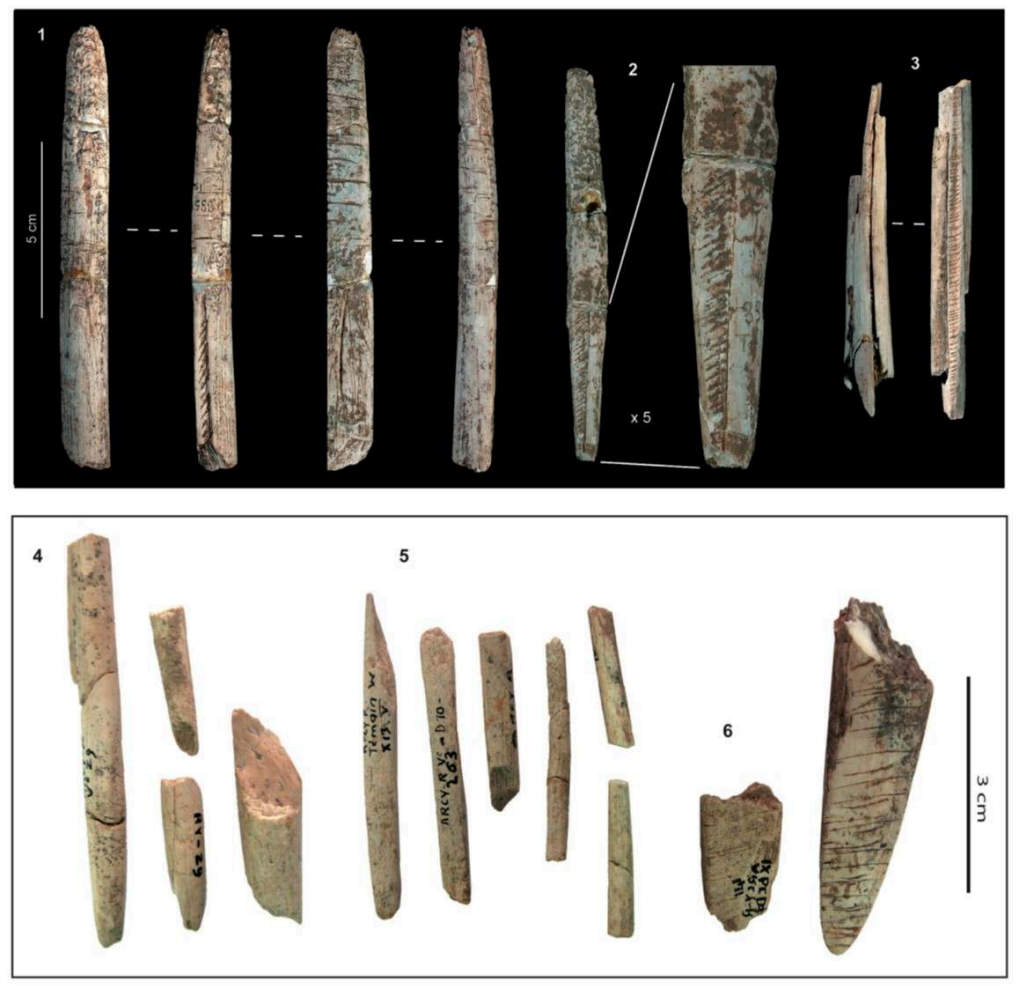

- 1 à 2 : « pièces à aménagement de type Isturitz »; 3 : pointe à cannelure latérale striée (clichés S. Oboukhoff) et dans la grotte du Renne - 4 et 5 : pointes sans attribut particulier ; 6 : « pièces à aménagement de type Isturitz » (clichés N. Goutas).

À la grotte du Renne, $41 \%$ des artefacts sont en ivoire $(N=27)$. L'équipement se rapporte cette fois encore à la catégorie des objets appointés (fig. 10, $\mathrm{n}^{\mathrm{os}} 4$ à 6 ) avec :

- d'une part, des pointes fines assez homogènes, d'une largeur et épaisseur inférieures ou égales à 5-6 mm ;

- d'autre part, des pointes plus hétérogènes d'un gabarit plus robuste avec des largeurs comprises entre 8 et $15 \mathrm{~mm}$ et des épaisseurs variant de 4 à $10 \mathrm{~mm}$. Le caractère non vulnérant et massif de plusieurs de ces fragments semble davantage cohérent avec des extrémités proximales de double-pointes qu'avec des extrémités distales. Là encore un fragment de pointe présente les «aménagements de type Isturitz » comme à la grotte du Trilobite.

Dans les deux cavités, l'exploitation de l'ivoire de mammouth est directement en lien avec des produits très investis se rapportant à la catégorie générique des objets appointés dont le statut fonctionnel n'est pas toujours évident à cerner (fragmentation importante et délitages naturels). Si certains de ces objets sont vraisemblablement des 
pointes de projectile, l'utilisation d'autres en outils de transformation ne peut être exclue. Ces objets ont bénéficié d'un façonnage très poussé (par raclage essentiellement), quasiment toujours suivi de l'aménagement d'un décor géométrique non figuratif. Sur certaines pièces, on notera la présence d'un méplat (à la grotte du Renne) ou d'une gouttière longitudinale (grotte du Trilobite) dont le fond est recouvert de courtes incisions obliques ou transversales, et dans un cas de croisillons (fig. 10, $\mathrm{n}^{\text {os }}$ 1-3). Cet aménagement particulier n'est pour l'heure, et à notre connaissance, documenté nulle part ailleurs dans le Gravettien français. Il était aussi présent sur plusieurs objets en bois de renne disparus de la collection (Parat 1902; Breuil 1918). Esthétique et/ou fonctionnel, cet aménagement semble, pour l'heure, refléter un marqueur technique et culturel spécifique des Gravettiens d'Arcy-sur-Cure.

À la grotte du Renne, la présence de déchets et de supports ${ }^{12}$, certes peu nombreux, nous renseigne sur la production in situ de baguettes. Les artefacts en ivoire sont façonnés à partir de baguettes extraites des couches internes de la défense, à distance de la cavité pulpaire dont nous n'avons retrouvé trace sur aucun d'entre eux. L'épaisseur de certains objets approchant les 15 ou les $20 \mathrm{~mm}$, après un façonnage important, indique une exploitation plus probable des troisième et deuxième tiers de la défense, à l'endroit où l'épaisseur de dentine est la plus épaisse. La longueur des baguettes recherchées est difficile à déterminer en raison d'un important taux de fragmentation, mais au moins quatre artefacts, bien qu'incomplets, indiquent une longueur non négligeable de 140 à $160 \mathrm{~mm}$ environ. Par ailleurs, les négatifs d'extraction (formés de sillons de rainurage convergents) présents sur deux matrices de seconde intention, ainsi que la forme de certaines baguettes indiquent une recherche de supports déjà préformés en pointe (fig. $11, \mathrm{n}^{\circ} 1$ ). On signalera à ce titre, le caractère particulier des matrices, ces dernières découlant d'un recyclage de pointes massives décorées (fig. 11, $\mathrm{n}^{\circ} 2$ ). 
Figure 11 : Déchet et supports attestant d'un débitage par double rainurage (grotte du Renne, couche V).

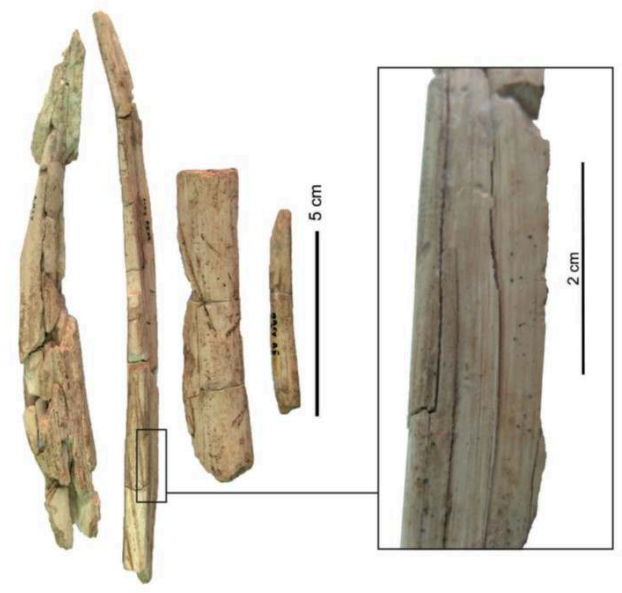

1. Baguettes portant des pans de sillons de rainurage sur leurs bords

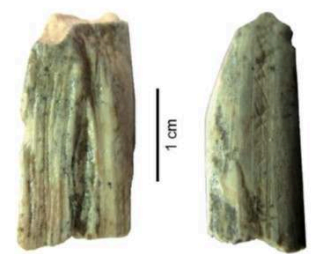
2. Matrice d'extraction de seconde intention (recyclage d'une ancienne pointe) :
à droite, vue sur le négatif d'extraction ; à gauche, vue du bord gauche de la matrice (avec stries de raclage et décors en croisillons).

1 : fragments de baguettes en ivoire avec vue de détail d'un pan de rainurage ; 2 : négatif d'extraction par double rainurage convergent sur matrice de seconde intention (clichés N. Goutas).

57 La compatibilité technique des déchets et des supports avec la dizaine de produits finis de la série (principalement des objets appointés) tend à corroborer une origine culturelle commune, et par là même une certaine intégrité de la série collectée; elle interroge en outre sur le lieu de production des objets finis et des supports. Le nombre limité de matrices retrouvées, en regard du nombre un peu plus important de baguettes et surtout d'objets finis associés, évoque un fractionnement dans le temps et l'espace de la chaîne opératoire (Goutas, 2013b). Ainsi, une partie des supports et des objets finis pourrait avoir été apportée par les Gravettiens à leur arrivée à Arcy (grotte du Renne). Les objets finis auraient été abandonnés sur place parce qu'endommagés. Ils auraient alors été remplacés par d'autres : certains intégralement fabriqués sur place, d'où la présence de matrices, et d'autres, façonnés à partir d'une réserve de baguettes apportée sur le site. Le façonnage générant la formation de déchets fragiles et discrets (poudre ou copeaux), ces derniers ne se seront pas conservés ou n'auront pu être collectés. Enfin, le nouvel équipement produit aura, partiellement ou majoritairement, été emporté au départ des Gravettiens. Cette hypothèse est cohérente avec les données morphométriques disponibles, puisque plusieurs objets finis présentent un gabarit inférieur ou équivalent à celui des baguettes retrouvées dans la cavité (fig. 12). Les pointes les plus fines de la série sont, en outre, compatibles avec le gabarit des baguettes prélevées sur les matrices, qui d'après les négatifs d'extraction devaient présenter une largeur comprise entre 5 et $10 \mathrm{~mm}$. 
Figure 12 : Rapport largeur/épaisseur des baguettes, des objets finis, des chutes de débitage et des matrices secondaires sur baguettes découverts dans le niveau gravettien de la grotte du Renne.

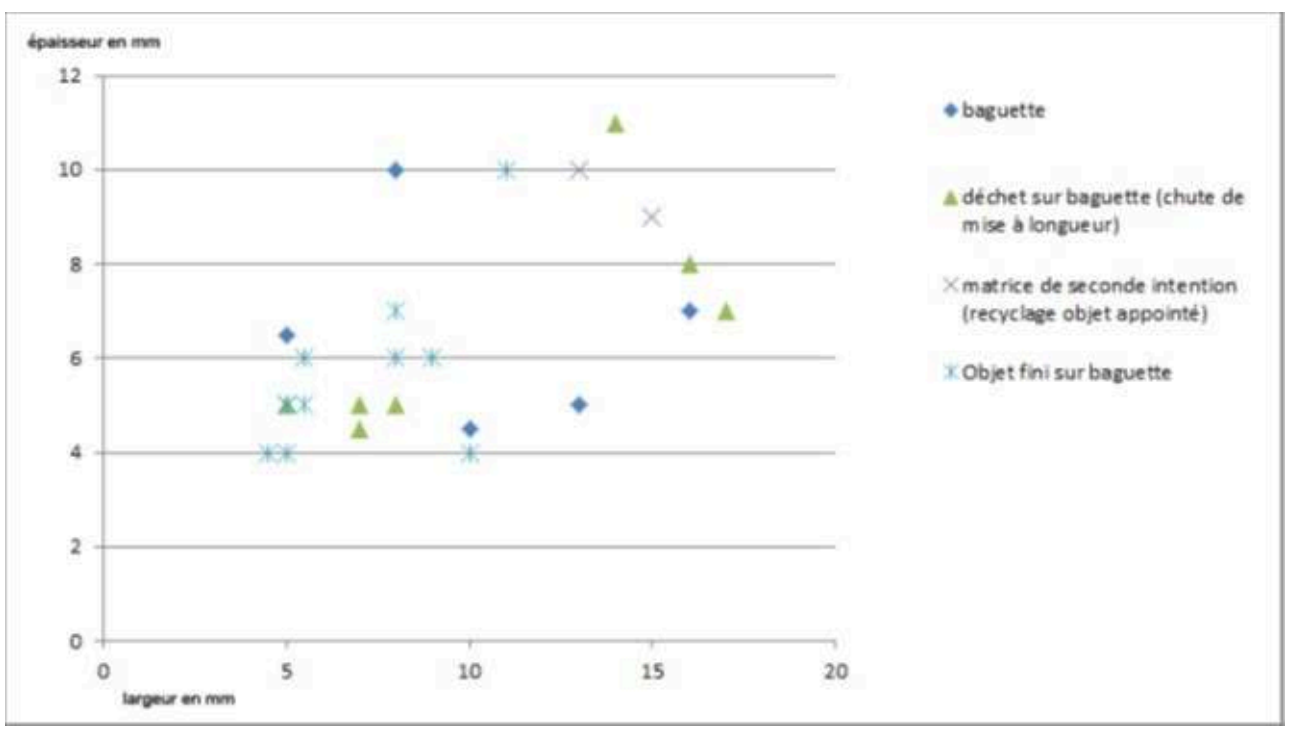

\section{Discussion sur l'origine des restes de mammouth exploités dans le Gravettien d'Arcy}

\section{Topographie du site et contexte climatique}

Rappelons en premier lieu que les os de mammouth sont omniprésents dans la région, notamment dans les grottes que l'abbé Parat a visitées à l'époque de ses fouilles du Trilobite. Les grottes de Saint-Moré (dont la «grotte du Mammouth» et la grotte de l'Homme), celles de l'Hyène, du Cheval et les niveaux châtelperroniens de la grotte du Renne à Arcy ont ainsi livré plusieurs fragments d'éléphantidés (Ficatier, 1886; Parat, 1900, 1902, 1903 ; Friant, 1959). Pas une couche ou presque sans que des restes de mammouths ne soient signalés, dans des proportions cependant le plus souvent très limitées. À l'occasion du creusement du tunnel de Saint-Moré en 1857, de nombreux restes de mammouth ont également été retrouvés. D'après la provenance stratigraphique de ces ossements au sein des différentes occupations paléolithiques d'Arcy, les restes de mammouth sont associés à différentes phases du Pléistocène. Toutefois, les publications mentionnant ces restes sont très anciennes et aucune datation sur os de mammouth des grottes d'Arcy et de St-Moré n'a, à ce jour, été réalisée.

Pour expliquer la présence du mammouth dans cette région bordant le Morvan, il nous faut évoquer la topographie des grottes d'Arcy. La vallée de la Cure a ainsi et de tout temps constitué un lieu attractif pour les hommes et les animaux, puisque les ravines et les versants de vallées offraient des accès à plusieurs points d'eau. D'autres conditions régionales spécifiques pourraient aussi avoir suscité l'intérêt des grands herbivores et en particulier des mammouths. Arcy est ainsi situé à environ $10 \mathrm{~km}$ d'une résurgence d'eau salée, intensément exploitée dès le Néolithique (Bernard et al., 2008). Or, sur le site Paléolithique supérieur russe de Shestakovo dans le Sud-Ouest sibérien, il a été démontré que la concentration de vestiges de mammouth était liée au sel naturel présent dans la région (Derevianko et al., 2000). Par ailleurs, certains auteurs proposent 
pour l'Arctique et la Sibérie que des changements climatiques aient abouti à une désalinisation des sols suite à des processus de lessivage défavorables à certains cations nutritifs (Leshchinskiy, 2009; Mann et al., 2015), et par voie de conséquence à l'alimentation des proboscidiens.

Sans transposer directement ces hypothèses à l'Europe de l'Ouest, il nous semble que la disponibilité en sel $^{13}$ et en eau dans le massif d'Arcy-sur-Cure a pu attirer les populations de mammouth localement. L'utilisation de cette région comme zone refuge à plusieurs moments du Paléolithique pourrait même être envisagée. Selon les conditions climatiques, des zones marécageuses ont pu ainsi exister à Arcy, favorisant les morts accidentelles et indirectement la formation d'accumulations naturelles, par la suite exploitées par les groupes humains de passage. Ceci est notamment envisageable à l'aune des études paléo-environnementales sur le Châtelperronien d'Arcy (David et al., 2001), qui montrent alors une évolution de la steppe froide à la steppe très froide «à Mammouths ». D'après ces données, nous pouvons déduire qu'au moment où les Gravettiens se sont installés à Arcy, le mammouth était présent localement au moins sous la forme de ressource fossile. En revanche, sans datation directe, il est impossible d'affirmer que des troupeaux évoluaient, même occasionnellement, dans la région lorsque les Gravettiens y sont venus. Nous pouvons juste souligner que le caractère instable du climat aux alentours de $27000 \mathrm{cal}$ BP, succédant à un bref épisode de réchauffement (Dansgaard/Oeschger 3), apparaît être un scénario compatible avec les conditions décrites en arctique pour le développement d'une steppe à Mammouth (voir supra Mann et al., 2015).

\section{Discussion sur l'origine des ossements : apport de la taphonomie et de l'archéozoologie}

60 Les ossements découverts dans la grotte du Trilobite témoignent d'états de surface assez homogènes et relativement corrects. La conservation un peu moins favorable des restes de mammouth issus de la collection Poulain, surtout en comparaison avec les ossements d'autres taxons, est vraisemblablement à mettre en relation avec une localisation particulière de ces restes dans la cavité (cf. supra). D'après les notes de fouilles associées, ces restes ont été découverts à l'occasion d'un sondage en bordure de parois (dans une zone probablement plus soumise au lessivage). La grande taille de ces os pourrait aussi expliquer cet état de fait, car elle implique une plus grande surface osseuse exposée et un enfouissement moins rapide que les ossements des autres espèces associées (Brugère 2009 ; Lyman et Fox, 1989 ; Mallye et Castel, com. pers.).

61 Nous pourrions aussi y voir un indice d'exploitation d'ossements subfossiles ou fossiles récupérés dans les environs et rapportés dans la cavité. Cette hypothèse peut être discutée au regard de la présence de traces anthropiques liées à l'enlèvement de la chair, sur ces ossements. Si ce sont les Gravettiens qui en sont les auteurs, il est dès lors logique d'envisager que l'acquisition des carcasses s'est effectuée relativement peu de temps après le décès de l'animal. L'utilisation d'ossements à l'état frais est aussi suggérée par un outil sur éclat diaphysaire portant une fracture par flexion (grotte du Trilobite, collection Poulain). Pour autant, et compte tenu du contexte régional, particulièrement riche en ossements de mammouths, nous ne pouvons totalement exclure l'hypothèse selon laquelle les os rapportés par les Gravettiens dans la cavité auraient été récupérés sur des sites d'habitat antérieurs aux fréquentations 
gravettiennes. On pense notamment aux occupations châtelperroniennes situées sur place (grotte du Renne) et ayant livré une quantité non négligeable de proboscidiens (David et al., 2001). En suivant ce raisonnement, les traces de boucherie et les altérations biologiques observées sur plusieurs os (traces de carnivores) seraient antérieures à leur apport par les Gravettiens dans la cavité. En effet, c'est sans doute la conservation, au moins partielle, de matière organique sur les os, qui aura alors suscité l'intérêt des hommes et des carnivores. Les traces possibles de rongeurs observées apparaissent en revanche plus récentes.

\section{Discussion sur l'origine de l'ivoire : apport de la taphonomie et de la technologie} en faveur d'un certain état de fraîcheur des défenses exploitées et, en ce sens, évoquer une acquisition proche dans le temps de la mort de l'animal. Or, d'autres paramètres doivent aussi être pris en compte, avant que de pouvoir établir un tel lien :

- en premier lieu, par leur petitesse, les artefacts en ivoire auront bénéficié d'un recouvrement plus rapide que les ossements de mammouth, et par là même d'un contexte de conservation plus avantageux ;

- deuxièmement, les propriétés intrinsèques de la dentine des proboscidiens ne sont pas à négliger. L'absence de canaux de havers, la fraction inorganique largement dominante autant que l'architecture tri-dimensionnelle complexe de l'ivoire en font un matériau résilient, dense, peu poreux (Christensen, 1999 ; Heckel, 2009 ; Heckel et Wolf, 2014), et donc potentiellement moins sensible au processus de lessivage que l'os ;

- troisièmement, cette conservation différentielle est en partie conditionnée par le taux de transformation important des objets en ivoire. Le raclage, principale technique de façonnage employée par les Gravettiens d'Arcy, par son action compactante des fibres osseuses, aura sans doute aussi favorisé cette meilleure préservation (cf. supra).

Les données technologiques montrent, en outre, que le débitage des défenses a été conduit par double rainurage. Ce point est des plus intéressants car ce choix technique pourrait être une réponse à l'état de fraîcheur de la matière. Rappelons que l'ivoire frais de mammouth possède une structure très contraignante nécessitant des choix 
techniques particuliers. La percussion sur ivoire frais, même violente, est peu efficace et le débitage incontrôlable (Christensen, 1999), sauf dans des conditions de taille très particulières impliquant une température environnante approchant les $20^{\circ}$ à $30^{\circ}$, et qui donnent lieu à la formation de déchets très particuliers ${ }^{14}$ (Giria et Khlopatchev, 2010), ici absents des séries étudiées. À ce stade, nous rappellerons que ce constat vaut quelle que soit la définition que l'on donne au terme "d'ivoire frais"; qu'il s'agisse d'un ivoire dont l'exploitation est contemporaine ou subcontemporaine de la mort de l'animal pourvoyeur (ivoire frais stricto sensu, Poplin, 1995 ; Christensen, 1999), ou d'un ivoire vieux de milliers d'années récupéré dans un bon état conservation (ivoire frais lato sensu), comme c'est le cas encore actuellement dans le pergélisol de l'Alaska et de Sibérie (White, 2004 ; Khlopatchev, 2006 ; Giria et Khlopatchev, 2010). Bien que de notre point de vue, ces différents types d'ivoire ne peuvent être mis sur un même plan d'égalité micro-structurelle, macroscopiquement ils se caractérisent par une absence de délamination et de fractionnement le long des plans naturels de faiblesse (Heckel et al., 2014). Or, à Arcy, nous disposons d'indices, certes discrets mais suggérant que c'est un ivoire bien conservé, mais ayant néanmoins partiellement amorcé un processus de dessiccation, qui a été travaillé. On notera la présence des facettes de délitage naturel façonnées ou recoupées des stigmates techniques et des fissures radiales qui ont été mises à profit lors du débitage par double rainurage pour favoriser le détachement des baguettes. Si le double rainurage a pu être utilisé pour répondre à une dureté encore contraignante de l'ivoire exploité, il apparaît qu'il vient surtout répondre à une volonté de contrôle du débitage ( $c f$. supra).

En définitive, sauf à envisager un hypothétique séchage artificiel et contrôlé de défenses fraîches ${ }^{15}$, tous les éléments que nous venons d'évoquer soutiennent l'hypothèse d'une exploitation d'ivoire subfossile, collecté vraisemblablement localement. Son acquisition ne peut donc intégrer les mêmes circuits d'acquisition que ceux envisagés pour les ossements de mammouth, si l'on retient l'hypothèse que les Gravettiens sont les auteurs des stries de boucherie associées ( $c f$. supra). En effet, la dessiccation, même partielle d'une défense ne se fait pas à une échelle de temps compatible avec une conservation des chairs sur les carcasses associées. La datation des os de mammouth et des fragments d'ivoire retrouvés dans les niveaux gravettiens d'Arcy, à l'image des travaux conduits sur les sites aurignaciens du Jura Souabe (Heckel, 2009 ; Heckel et Wolf 2014), serait assurément une autre source d'information précieuse pour statuer sur les modalités d'acquisition de ces ressources par les Gravettiens.

\section{Conclusion}

Au terme de cette étude, nous avons pu montrer qu'un certain nombre d'indices directs (traces de boucherie, un cas de fracture sur os frais) ou indirects (données taphonomiques et technologiques pour les artefacts en os et ivoire) permettent de renseigner l'état de fraîcheur du squelette post-crânien et des défenses des éléphantidés rapportés intentionnellement et exploités dans les niveaux gravettiens des grottes d'Arcy-sur-Cure et, par voie de conséquence, de discuter des modalités de leur acquisition.

L'identification de stries de boucherie, situées à proximité de stigmates techniques, tend à argumenter la présence sur les ossements de matières tendres animales (peaux, chair, périoste). Si nous ne pouvons prouver une consommation alimentaire, ni 
affirmer qu'il s'agit d'une récupération d'ossements (provenant d'autres cavités par exemple), il s'agit là d'indices inédits d'exploitation de carcasses d'éléphantidés dans un relatif état de fraîcheur associés à des horizons gravettiens. Comme le rappelle A. Brugère dans sa synthèse (2009), les stries de boucherie sur les carcasses de proboscidien sont rares en contexte archéologique (Gaudzinsky, et al. 2005). D'après les référentiels actuels, l'observation des ossements à l'issue de découpes de carcasses d'éléphant avec des outils métalliques n'a pas permis d'observer beaucoup de traces (Crader, 1983). Des expérimentations corroborent d'ailleurs ces constatations (Frison et Todd, 2001). Un élément d'explication réside dans la grande taille de ces os sur lesquels la masse de viande disponible permet à la fois un prélèvement plus aisé que sur les petits animaux, tout en favorisant l'absence ou la faible formation de traces de boucherie sur les os (Brugère, 2009, p. 145). Un périoste plus épais que sur les autres espèces est également une hypothèse avancée pour expliquer cette sous-représentation des stries de boucherie (Fladerer et al., 2004). Si l'on se base sur ces hypothèses, ce sont donc les actions de découpe particulièrement insistantes qui laisseront des traces sur les ossements.

Les ossements portant des traces de boucherie correspondent notamment à des coxaux, ces mêmes os qui, pour l'essentiel, ont servi d'outils passifs de type « billots ». Dès lors, si ces deux intentions (alimentaire et technique) ont pu converger, on ne peut exclure que les traces de boucherie observées soient justes la conséquence d'une première étape de nettoyage des os, en vue de leur seule exploitation technique. L'acquisition de ces ossements, compte tenu de leur poids et de leur volume, se sera nécessairement faite dans l'environnement proche du site. Environnement qui, on l'a vu, fut favorable à différentes périodes du Pléistocène, à l'implantation saisonnière de troupeaux de mammouths. Quant à statuer sur le mode d'acquisition de ces restes - chasse et/ou acquisition secondaire sur une carcasse encore fraîche - nous ne sommes pas en mesure de nous prononcer. Les données de l'archéozoologie atteignent ici leurs limites: les données populationnelles (âge et sexe), permettant d'établir des profils de mortalité et d'inférer sur les stratégies d'acquisition restant très limitées dans l'assemblage.

70 Les données de l'ivoire évoquent une stratégie d'acquisition potentiellement différente puisqu'il est clairement d'origine subfossile et aura donc nécessairement été collecté. D'ailleurs, et pour l'heure, seul ce type d'acquisition secondaire est documenté pour les sites gravettiens français. Plus largement, on soulignera une certaine constance dans l'exploitation de cette ressource tout au long du Gravettien. Si les sites livrant de riches séries comme celle d'Arcy ne sont pas nombreux en France, l'ivoire est utilisé à toutes les périodes, sur de nombreux gisements et il est exclusivement dévolu à la fabrication d'objets hautement investis (Goutas, 2013a). L'ivoire au Gravettien est employé pour des productions très diversifiées: de perles, de pendeloques, de diadèmes, ou de statuettes, mais aussi d'armatures de chasse, de bouchons d'outre, et parfois même d'outils, ou encore de possibles contenants comme un tronçon de défense évidé, long de $20 \mathrm{~cm}$ découvert dans le Gravettien final de Pataud (Bricker, 1995).

71 Ce statut particulier de l'ivoire de mammouth diffère radicalement du traitement technique de ses os : très rare, expédient et pour des usages strictement domestiques. En revanche, il fait écho à la place importante de ce mammifère dans l'art pariétal et mobilier des groupes gravettiens (Baffier et Girard, 2013; Jaubert et Feruglio, 2013; Petrognani, 2013). 
Pour conclure, notre appréciation de l'exploitation du mammouth dans le Gravettien d'Arcy, pour être complète, nécessitera un retour sur le matériel faunique de la grotte du Renne (fouilles A. Leroi-Gourhan). Ce matériel, non accessible quand nous conduisions cette étude croisée, avait été préalablement décrit par F. David ; il contient une défense subcomplète et des ossements dont certains portent des stries (Bailloud, 1953 ; Schmider et al., 2004). La mise en place d'une éventuelle campagne de datations permettrait de statuer plus clairement sur la ou les origines chronologiques des ossements de proboscidiens provenant des niveaux gravettiens d'Arcy. Ce très grand herbivore, au statut si particulier et dont les restes sont si rares en Europe de l'Ouest, représente une espèce clé d'un point de vue paléo-environnemental et culturel. C'est pourquoi, une meilleure caractérisation temporelle de la présence de cette espèce dans nos latitudes et notamment dans les grottes des massifs d'Arcy et de St-Moré constituerait un apport déterminant pour poursuivre la discussion sur les relations entre Homme et proboscidien.

\section{BIBLIOGRAPHIE}

AVERBOUH A. 2000, «Technologie de la matière osseuse travaillée et implications palethnologiques : l'exemple des chaînes d'exploitation du bois de cervidé chez les Magdaléniens des Pyrénées ", Paris, Thèse de doctorat de Préhistoire, Université de Paris 1, Paris, 2 vol.

BAFFIER D. et JULIEN M. 1990, «L'outillage en os des niveaux châtelperroniens d'Arcy-sur-Cure (Yonne) », Mémoires du Musée de Préhistoire d'Ile-de-France, vol. 3, p. 329-334.

BAFFIER D. et GIRARD M. 1998, « Les cavernes d'Arcy-sur-Cure », Paris, La Maison des roches, (collection Terres préhistoriques).

BAFFIER D. et GIRARD M. 2013, « L'art pariétal gravettien du nord de la France », dans OTTE M. (dir.), Les Gravettiens, Paris, Errance, p. 105-160.

BAILLOUD G. 1953, « Note préliminaire sur l'industrie des niveaux supérieurs de la Grotte du Renne, à Arcy-sur-Cure (Yonne) », Bulletin de la Société préhistorique de France, vol. 50 (5/6), p. 338-345.

BERNARD V., PÉTREQUIN P. et WELLER O. 2008, « Captages en bois à la fin du Néolithique : les Fontaines Salées à Saint-Père-sous-Vézelay (Yonne, France) » dans WELLER O., DUFRAISSE, A. et PÉTREQUIN P. (dir.), Sel, eau et forêt. D’hier à aujourd'hui. Presses Universitaires de Franche-Comté, 326-327.

BINFORD L. R. 1981, Bones : Ancient Men and Modern Myths, New York, Academic Press (Studies in Archaeology).

BODU P., DELOZE V., KRIER V., LOCHT J.-L, DEPAEPE P. et TEHEUX E. 1999, « Le Paléolithique supérieur de la vallée de la Vanne ", dans JULIEN M. et RIEU J.-L. (dir.), Occupations du Paléolithique supérieur dans le sud-est du Bassin parisien, Paris, Maison des sciences de l'homme, p. 162-195 (Documents d'archéologie française, 78). 
BON F. et BODU P. 2002, « Analyse technologique du débitage aurignacien », dans SCHMIDER B., (dir.), L'Aurignacien de la grotte du Renne. Les fouilles d'André Leroi-Gourhan à Arcy-sur-Cure (Yonne), Paris, CNRS Éditions, p. 115-133 (XXXIV Supplément à Gallia-Préhistoire).

BODU P. et RENARD C. 2013, « L'ancien Solutréen du Bassin parisien, quelques observations récentes ", dans BODU P., CHEHMANA L., KLARIC L., MEVEL L., SORIANO S. et TEYSSANDIER N. (dir.), Le Paléolithique supérieur ancien de l'Europe du Nord-Ouest, Paris, Société préhistorique Française, p. 117-141 (Mémoire 56).

BREUIL H. 1918, «Études de morphologie Paléolithique III. Les niveaux Présolutréens du Trilobite », Revue anthropologique, vol. 11-12, p. 309-333.

BRICKER H. M. 1995, Le Paléolithique supérieur de l'abri Pataud (Dordogne) : les fouilles de H. L. Movius Jr, Paris, Éd. Maison des sciences de l'homme (Documents d'archéologie française, 50).

BRUGÈrE A. 2009, «L'exploitation du Mammouth à Milovice et dans le Gravettien de Moravie (République Tchèque) », Paris, Thèse de doctorat, Université Paris 1 - Panthéon-Sorbonne.

BRUGÈRE A. 2014, « Not one but two mammoth hunting strategies in the Gravettian of the Pavlov Hills area (southern Moravia)», Quaternary international, vol. 337, p. 80-89.

BRUGÈRE A., FONTANA L. et OLIVA M. 2009, « Mammoth procurement and exploitation at Milovice (Czech Republic). New data for the Moravian Gravettian », dans FonTANA L., CHAUviÈre F.-X. et BRIDAULT A. (dir.), Search of total animal exploitation. Case studies from the Upper Palaeolithic and Mesolithic, actes du XV ème Congrès de l'IUSPP, Lisbonne 4-9 September 2006, Oxford, Archaeopress, p. 45-69 (BAR International Series 2040).

CHRISTENSEN M. 1999, Technologie de l'ivoire au Paléolithique supérieur. Caractérisation physico-chimique du matériau et analyse fonctionnelle des outils de transformation, Oxford, Archaeopress (BAR International Series, S751).

COLINVAUX P. A. et WEST F. H. 1984, « The Beringian ecosystem », Quarterny Review of Archaeology, vol. 5 (3), p. 10-16.

CONNET N. 2002, « Le Châtelperronien, réflexions sur l'unité et l'identité technoéconomique de l'industrie lithique. L'apport de l'analyse diachronique des industries lithiques des couches châtelperroniennes de la grotte du Renne à Arcy-sur-Cure (Yonne) », Villeneuve-d'Ascq, Thèse de doctorat, Université Lille I-Sciences et Technologies.

COSTAMAGNO S. 2012, « Des stries de boucherie aux sous-systèmes techniques de transformation et de consommation des ressources animales : apport de l'approche expérimentale », Bordeaux, Habilitation à diriger des thèses, Université Bordeaux.

CRADER D. C. 1983, «Recent single-carcass bone scatters and the problem of "butchery" sites in the archaeological record. » dans CLUTTON-BROCK, J. et GRIGSON, C. (dir.), Animals and Archaeology. Hunters and Their Prey, Oxford, Archaeopress, p. 107-141 (BAR International Series, 163).

DAVID F., CONNET N., GIRARD M., LHOMME V., MISKOWSKY J.-C. et ROBLIN-JOUVE A. 2001, « Le Châtelperronien de la grotte du Renne à Arcy-sur-Cure (Yonne). Données sédimentologiques et chronostratigraphiques », Bulletin de la société préhistorique française, vol. 98 (2), p. 207-230.

DEREVIANKO A.P., ZENIN, V.N., LESHCHINSKIY S.V. et MASHCHENKO E.N. 2000, « Peculiarities of mammoth accumulation at Shestakovo site in West Siberia », Archaeology, Ethnology \& Anthropology of Eurasia, vol. 3 (3), p. 42-55.

DJINDJIAN F. 2011, « Chronostratigraphie du Gravettien d'Europe occidentale : un modèle à réviser » dans GOUTAS N., KLARIC L., PESESSE D. et GUILLERMAIN P. (dir.), À la recherche des identités 
gravettiennes : actualités, questionnements et perspectives, actes de la table ronde sur le Gravettien en France et dans les pays limitrophes, Aix-en-Provence, 6 au 8 octobre 2008, Paris, Société préhistorique française, p. 185-196 (Mémoire $\mathrm{n}^{\circ}$ 52).

FICATIER A. 1886, « Étude paléoethnologique sur la Grotte magdalénienne du Trilobite à Arcy-sur-Cure (Yonne) », Imprimerie A. Gallot Auxerre.

FLADERER F. A., SALCHER-JEDRASIAK T. A. et HäNDEL M. 2014, « Hearth-side bone assemblages within the $27 \mathrm{kA}$ BP Krems-Wachtberg settlement : Fired ribs and the Mammoth bone-grease hypothesis ", Quaternary International, vol. 351, p. 115-133.

FLETCHER W. J., SANCHEZ GOÑI M. F., ALLEN J. R. M., CHEDDADI R., COMBOURIEU-NEBOUT N., HUNTLEY B., LAWSON I., LONDEIX L., MAGRI D., MARGARI V, MÜLLER U. C., NAUGHTON, F., NOVENKO, E., ROUCOUX, K. et TZEDAKIS, P. C. 2010, « Millennial-scale variability during the last glacial in vegetation records from Europe », Quaternary Science Reviews, vol. 29 (21-22), p. 2839-2864.

FRIANT M. 1959, «Les Proboscidiens Quaternaires de l'Europe occidentale » Vierteljahrsschrift der Naturforschenden Gesellschaft in Zürich, p. 158-173.

FRISON G. C. et TODD L. 2001, « The Colby mammoth kill site 48WA322 : hunting mammoths ; and experiments with Clovis tools and weaponry » Proceedings of the International Conference on Mammoth Site Studies, Lawrence, University of Kansas, p. 11-26 (Publications in Anthropology, 22).

GAUDZINSKI S., TURNER E., ANZIDEI A.P., ÀLVAREZ-FERNÁNDEZ E., ARROYO-CABRALES J., CINQ-MARS J., DOBOSI V.T., HANNUS A., JOHNSON E., MÜNZEL S.C., SCHEER P. et VILLA P. 2005, « The use of Proboscidean remains in every-day Palaeolithic life », Quaternary International, vol. 126, p. 179-194.

GIRIA E.Y. et KHLOPACHEV G.A., 2010, Secrets of ancient carvers of Eastern Europe and Siberia : Treatment techniques of ivory and reindeer antler in the Stone Age, Saint Petersburg, NAUKA.

GOUTAS N. 2004, «Caractérisation et évolution du Gravettien en France par l'approche technoéconomique des industries en matières dures animales (étude de six gisements du sud-ouest) », Paris, Thèse de doctorat, Université Paris 1-Panthéon Sorbonne.

GOUTAS N. 2008, « Les pointes d'Isturitz sont-elles toutes des pointes de projectile? », Gallia Préhistoire, vol. 50, p. 45-101.

GOUTAS N. 2013a, «De Brassempouy à Kostienki : l'exploitation technique des ressources animales dans l'Europe gravettienne », dans OTTE M. (dir.), Les Gravettiens, Paris, Errance, p. 105-160.

GOUTAS N. 2013b, « Nouvelles données sur l'industrie osseuse des grottes du Renne et du Trilobite à Arcy-Sur-Cure (Yonne, France) : vers l'identification de nouveaux marqueurs techniques et culturels du Gravettien moyen à burins du Raysse », dans BODU P., CHEHMANA L., KLARIC L., MEVEL L., SORIANO S. et TEYSSANDIER N. (dir.), Le Paléolithique supérieur ancien de l'Europe du Nord-Ouest, Paris, Société préhistorique française, p. 89-115 (Mémoire, 56).

GOUTAS N. 2015, «From stone flaking to grinding: Three original Pavlovian antler tools from Moravia (Pavlov I, Czech Republic) », Quaternary International, vol. 359-360, p. 240-260.

GoUtAS, N. et A. SIMONET. 2009, « Le Secteur GG2 de la Grotte du Pape à Brassempouy (Landes) : Un dépôt intentionnel d'armes gravettiennes ? ", Bulletin de la société préhistorique française, vol. 106 (2), p. 257-291.

GOUTAS N. et LACARRIÈRE J. 2013, « L'exploitation des cervidés dans le Gravettien d'Isturitz. Une approche archéozoologique et technologique des ressources animales : de leur acquisition à leur utilisation », dans de Las HERAS C., LASHERAS J.-A., ARRIZABALAGA Á., de la RASILLA M. (dir.), Colloque International : Pensando el Gravetiense : nuevos datos para la región cantábrica en su contexto peninsular 
y pirenaico, Santillana del Mar, Cantabrie, Espagne, du 20 au 22 octobre 2011, Musée d'Altamira et centre de recherches d'Altamira, p. 565-592 (vol. 23).

GUTHRIE D. R. 1982, « Mammals of the Mammoth Steppe as paleoenvironmental indicators », Paleoecology of Beringia, vol. 307, $326 \mathrm{p}$.

GUTHRIE D. R. 1990, Frozen Fauna of the Mammoth Steppe: The Story of Blue Babe, Chicago, the University of Chicago Press.

GUTHRIE D. R. 2001, « Origin and causes of the mammoth steppe : a story of cloud cover, woolly mammal tooth pits, buckles, and inside-out Beringia », Quaternary Science Reviews, vol. 20 (1), p. 549-574.

HAESAERTS P., BORZIAC I., CHIRICA V., DAMBLON F. et KOULAKOVSKA L. 2007, « Cadre stratigraphique et chronologique du Gravettien en Europe centrale », Paléo, vol. 19, p. 31-51.

HARDY M., DAVID F., D'IATCHENKO V., GIRARD M. et ROBLIN-JOUVE A. 2012, Arcy-sur-Cure (Yonne). Grotte du Bison, Comptes Rendus des travaux 2012, Service Régional de l'Archéologie de Bourgogne, Dijon. HAYNES G. 1991, Mammoths, mastodonts and elephants, Cambridge, Cambridge University Press.

HECKEL C. 2009, « Physical characteristics of mammoth ivory and their implications for ivory work in the Upper Paleolithic ", Mitteilungen der Gesellschaft für Urgeschichte, vol. 18, p. 71-91.

HECKEL C. et WOLF S. 2014, « Ivory debitage by fracture in the Aurignacian : experimental and archaeological examples », Journal of Archaeological Science, vol. 42, p. 1-14.

HECKEL C., MÜLLER K., WHITE R., FLOSS H., CONARD N., WOLF S. et REICHE I. 2014, « F-content variation in mammoth ivory from Aurignacian contexts : preservation, alteration, and implications for ivoryprocurement strategies », Quaternary International, vol. 404, p. 40-50.

HELMENS K. 2014, « The Last Interglacial-Glacial cycle (MIS 5-2) re-examined based on long proxy records from central and northern Europe », Quaternary Science Reviews, vol. 86 (15), p. 115-143.

HENRI-MARTIN L. 1906, « Maillets ou enclumes en os provenant de la couche moustérienne de la QUINA (Charente) », Bulletin de la Société Préhistorique Française, vol. 3, p. 155-162.

HIGHAM T., JACOBI R., JULIEN M., DAVID F., BASELL L., WOOD R., DAVIES W. et BRONK RAMSEY C. 2010, «Chronology of the Grotte du Renne (France) and Implications for the Context of Ornaments and Human Remains within the Châtelperronian ", Proceedings of the National Academy of Sciences of the United States of America, vol. 107 (47), p. 20234-20 239.

JAUBERT J. et FERUGLIO V. 2013, L'art pariétal gravettien en France, dans OTTE M. (Dir.), Les Gravettiens, Paris, Errance, p. 191-207.

JULIEN M., BAFFIER D. et LIOLIOS D. 2002, « L'outillage en matières dures animales ", dans Schmider B. (dir.), L'Aurignacien de la Grotte de Renne. Les fouilles d'André Leroi-Gourhan à Arcy-sur-Cure (Yonne), Paris, CNRS, p. 217-250 (Supplément à Gallia Préhistoire, 34).

KAHLKE R.-D. 1999, The History of the Origin, Evolution and Dispersal of the Late Pleistocene MammuthusCoelodonta Faunal Complex in Eurasia (Larges Mammals), Rapid City, Fenske Companies.

KAHLKE R.-D. 2014, « The Origin of Eurasian Mammoth Faunas (Mammuthus-Coelodonta Faunal Complex) », Quaternary Science Reviews, vol. 96, p. 32-49.

KLARIC L. 2003, «L'unité technique des industries à burins du Raysse dans leur contexte diachronique. Réflexions sur la diversité culturelle au Gravettien à partir des données de la Picardie, d'Arcy-sur-Cure, de Brassempouy et du Cirque de la Patrie ", Paris, Thèse de doctorat, Université de Paris 1. 
KLARIC L. 2008, « Anciennes et nouvelles hypothèses d'interprétation du Gravettien moyen en France : la question de la place des industries à burins du Raysse au sein de la mosaïque gravettienne ", dans RIGAUD J.-Ph. (dir.), Entités régionales d'une paléoculture européenne : le Gravettien, Actes de la table ronde des Eyzies-de-Tayac, juillet 2004, Les Eyzies de Tayac, SAMRA, p. 257-276 (Supplément Paléo, 20).

KHLOPACHEV G.A. 2006, Les industries des ivoires du Paléolithique supérieur de l'Europe orientale (en russe), Académie des sciences de Russie, Musée d'Anthropologie et d'Ethnographie de Pierre Le Grand (Kunstkamera, RAS), Saint-Pétersbourg, Nauka.

LACARRIÈRE, J. 2014, « Les restes fauniques de Brassempouy conservés au Musée Despiau-Wlérick », dans SIMONET A. (dir.), Brassempouy : les collections Dubalen et de Laporterie, Archéologie des Pyrénées occidentales et des Landes, p. 94-101 (hors-série $n^{\circ}$ 6).

LACARRIÈRE J. 2015, « Les ressources cynégétiques au Gravettien en France. Acquisition et modalités d'exploitation des animaux durant la phase d'instabilité précédant le maximum glaciaire ", Toulouse, Thèse de doctorat, Université Toulouse Jean Jaurès.

LACORRE F. 1960, La Gravette : Le Gravétien et le Bayacien, Laval, Imprimerie Barnéoud.

LEGRAND A. 2005, « Nouvelle approche méthodologique des assemblages osseux du Néolithique de Chypre. Entre technique, fonction et culture », Thèse de doctorat, Université de Paris X.

LEROI-GOURHAN A. 1961, « Les Fouilles d'Arcy-Sur-Cure (Yonne). (Hyène, R.G.S., Bison, Renne) », Gallia-Préhistoire, vol. 4, p. 3-16.

LEROI-GOURHAN Arl. et LEROI-GOURHAN A. 1964, «Chronologie des grottes d'Arcy-Sur-Cure (Yonne) », Gallia Préhistoire, vol. 7, p. 1-64.

LESHCHINSKIY S.V. 2009, « Mineral deficiency, enzootic diseases and extinction of mammoth in northern Eurasia », Doklady Biological Sciences, vol. 424, p. 72-74.

MCNAUGHTON S. J. 1984, « Grazing lawns : animal in herds, plant form, and coevolution », The American Naturalist, sec. 124, vol. 6, p. 863-886.

LYMAN R. L. et FOX G. L. 1989, « A critical evaluation of bone weathering as an indication of bone assemblage formation ", Journal of Archaeological Science, vol. 16 (3), p. 293-317.

MAIGROT Y. 1997, « Tracéologie des outils tranchants en os des V $V^{\mathrm{e}}$ et IV millénaires avant J-.C. dans le Bassin Parisien : essai méthodologique et application », Bulletin de la Société Préhistorique Française, vol. 94 (2), p. 198-216.

MALGARINI R., MEVEL L., BEREIZIAT G., BODU P., CUPILLARD C., DEBOUT G., CARQUIGNY N. sous presse, « Les faciès du Magdalénien moyen dans l'Est de la France : confrontation et discussion des industries osseuses et lithiques ", dans BOURDier C., CHEHMANA L., MALGARINI R., POLTOWics-BOBAK M. (dir.), L'essor du Magdalénien, aspects culturels, techniques et symboliques des faciès à navettes et à LussacAngles, Journées de la Société préhistorique française, Besançon, 17 et 18 octobre 2013.

MANN D. H., GROVES P., REANIER R. E., GAGLIOTI B. V., KUNZ M. L. et SHAPIRO B. 2015, « Life and extinction of megafauna in the ice-age Arctic », Proceedings of the National Academy of Sciences of the United States of America, vol. 112 (46), p. 14301-14306.

MEVEL L. 2002, « La couche VI de la grotte du Renne à Arcy-sur-Cure (Yonne) : Analyse de l'industrie lithique », Nanterre, Mémoire de Master 1, Université de Paris X-Nanterre. MEVEL L. 2004, «Les séries lithiques du Paléolithique supérieur ancien du Bassin parisien du Musée des antiquités nationales : état des connaissances », dans BODU P., CHEHMANA L. et 
TEYSSANDIER N. (dir.), Le Paléolithique supérieur au centre et au sud du Bassin parisien: des systèmes techniques aux comportements, Rapport de projet collectif de recherche, Saint-Denis, Service régional de l'Archéologie, p. 101-113.

MEVEL L. 2013, « Les débuts du Paléolithique supérieur dans le centre et le sud du Bassin parisien : nouveaux acquis, nouvelles problématiques et nouveaux terrains ", dans BODU P., CHEHMANA L., KLARIC L., MEVEL L., SORIANO S. et TEYSSANDIER N. (dir.), Le Paléolithique supérieur ancien de l'Europe du nord-ouest, Paris, Société préhistorique française, p. 173-193 (Mémoire 56).

NOIRET P. 2013, « De quoi Gravettien est-il le nom ? », dans OTTE M. (dir.), Les Gravettiens, Paris, Errance, p. 28-64.

PARAT A. 1900, «La Grotte de l'Ours, Le Trou de l'Hyène et la Grotte du Cheval », Bulletin de la Société des sciences historiques et naturelles de l'Yonne, vol. 54, p. 1-29.

PARAT A. 1902, « Les grottes de la Cure, côté d'Arcy. XXI : La Grotte du Trilobite, L'Égouttoir, Les Nomades, La Roche-aux-Chats ", Bulletin de la Société des sciences historiques et naturelles de l'Yonne, vol. 56, p. 49-90.

PARAT A. 1903, «Les grottes de la Cure, côté d'Arcy. La Grotte des Fées, le Gouffre des Fées, la Chambre Haute, le Petit Abri, le Grand Abri, la petite Niche, la Grande Niche, les Goulettes, la Niche d'En-Haut, la Fontaine de Saint-Moré », Bulletin de la Société des sciences historiques et naturelles de l'Yonne, vol. 57. p. 141-195.

patou-Mathis M. et SchWAB C. 2002, «Fiche générale », dans Patou-Mathis M. (dir.), Fiches typologiques de l'industrie osseuse préhistorique. Cahier $\mathrm{X}$ : retouchoirs, compresseurs, percuteurs os à impressions et éraillures, Commission de nomenclature sur l'industrie de l'os préhistorique, Aix-enProvence, Publications de l'Université de Provence, p. 11-20.

PÉAN S. 2001, «Comportements de subsistance au Gravettien en Europe Centrale ", Paris, Thèse de doctorat, Muséum national d'Histoire naturelle.

PÉAN S. et WOTJAL P. 2003, « Gravettian subsistence patterns related to Pleniglacial palaeoenvironments in Southern Poland ", dans PATOU-MATHIS M. H. et BOCHERENS H. (dir.), Le rôle de l'environnement dans les comportements des chasseurs-cueilleurs préhistoriques, Oxford, Archaeopress, p. 23-37 (BAR International Series, 1105).

PESESSE D. 2013, « Le Gravettien existe-t-il ? Le prisme du système technique lithique », dans OTTE M. (dir.), Les Gravettiens, Paris, Errance, p. 67-104.

PÉTILLON J.-P. et AVERBOUH A. 2013, « L'industrie osseuse du Solutréen au Magdalénien moyen dans le Bassin parisien », dans BODU P., CHEHMANA L., KLARIC L., MEVEL L., SORIANO S., et TEYSSANDIER N. (dir.), Le Paléolithique supérieur ancien de l'Europe du nord-ouest, Paris, Société préhistorique française, p. 143-158 (Mémoire 56).

PETROGNANI S. 2013, «L'art des Gravettiens, continuité et originalité », dans OTTE M. (dir.), Les Gravettiens, Paris, Errance, p. 209-214.

PIETTE E. 1894, L'époque éburnéenne et les races humaines de la période glyptique. Saint-Quentin : imprimerie Charles Poette.

POPLIN F. 1995, « Délitage et débitage dans le travail de l'ivoire vrai sur des exemples du Paléolithique supérieur ", dans HAHN J., MENU M., TABORIN Y., WALTER P. et Widemann F. (dir.), Le travail et l'usage de l'ivoire au Paléolithique supérieur, actes de la table ronde de Ravello, Rome, 29 au 31 mai 1992, p. 17-28. 
REIMER P. J., BARD E., BAYLISS A., BECK J. W., BLACKWELl P. G., BRONK RAMSEY C., BUCK C. E., CHENG H., EDWARDS, R. L., FRIEDRICH M., GROOTES P. M., GUILDERSON T. P, HAFLIDASON H., HAJDAS I., HATTÉ C., HEATON T. J, hOFFMANN D. L., HOgG A. G., HUGHEN K. A., KAISER K. F., KROMER B., MANNING S. W., NIU M., REIMER R. W, RICHARDS D. A., SCOTT E. M., SOUTHON J. R. STAFF R. A., TURNEY C. S. M. et van der PLICHT J. 2013, «Intcal 13 and Marine 13 radiocarbon age calibration curves 0-50,000 years Cal BP », Radiocarbon, vol. 55 (4) : 1869-1887.

RIGAUD J.-Ph. (dir.) 2007-2008, Le Gravettien : entités régionales d'une paléoculture européenne, actes de la table-ronde des Eyzies, juillet 2004, Les Eyzies de Tayac, SAMRA (Supplément Paleo, 19).

SCHMIDER B. 1995, «Le Protosolutréen d'Arcy-sur-Cure », Les Eyzies de Tayac, SAMRA, p. 179-183 (Supplément Paleo, 1).

SCHMIDER B. 1996, «L'origine du Gravettien dans le nord de la France », dans MONTET-WHITE A., PALMA di CESNOLA A. et VALOCH K. (dir.), The Upper Palaeolithic, Actes du $13^{\mathrm{e}}$ congrès de l'UISPP, Colloque XII : The Origin of the Gravettian, Forlí, 1996, Forlí, éd. ABACO (Colloquia 6), p. 249-255.

SCHMIDER B. 2001, L'Aurignacien de la grotte du Renne à Arcy-sur-Cure (Yonne). Les fouilles d'André LeroiGourhan, Paris, CNRS éditions (XXXIVe Supplément à Gallia-Préhistoire).

SCHMIDER B., David F., ROBLIN-JOUVE A. 2004, « Nouvelles données sur le Gravettien de la grotte du Renne à Arcy-sur-Cure (Yonne) ", dans DEWEZ M., NOIRET P. et TEHIEux E. (dir.), Le Paléolithique supérieur, actes du XIVe Congrès de l'UISPP, section VI, Liège, 2-8 sept. 2001, Sessions générales et posters, p. 13-21.

SEMENOV S.A. 1964, Prehistoric Technology : an experimental study of the oldest tools and artefacts from traces of manufacture and wear, London, Cory, Adams and Mackay.

SOULIER Ph. 2015, « André Leroi-Gourhan (1911-1986), un anthropologue encyclopédiste au Xx siècle ", dans SOULIER Ph. (dir.), André Leroi-Gourhan «l'homme, tout simplement », Nanterre, Maison Archéologie \& Ethnologie, Paris, de Boccard, p. 15-46 (Travaux, 20).

SOULIER M.-C., GOUTAS N., NORMAND Ch., LEGRAND A. et WHITE R. 2014, « Regards croisés de l'archéozoologue et du technologue sur l'exploitation des ressources animales à l'Aurignacien archaïque : l'exemple d'Isturitz (Pyrénées-Atlantiques, France) ", dans THIÉBAult C., costamagno S. et CLAUD E. (dir.), Exploitation des ressources organiques à la fin du Paléolithique moyen et au début du Paléolithique supérieur : interactions entre environnement et comportements techniques, $\mathrm{XXVII}{ }^{\mathrm{e}}$ Congrès Préhistorique de France Mémoire de la Société Préhistorique Française, p. 315-332 (vol. 2).

SZPAK P., GRÖCKE D.R., DEBRUYNE R., MACPHEE R.D. E., GUTHRIE R. D., FROESE D., ZAZULA G. D., PATTERSON W. P. et POINAR H. N. 2010, « Regional differences in bone collagen $\delta 13 \mathrm{C}$ and $\delta 15 \mathrm{~N}$ of Pleistocene mammoths : Implications for paleoecology of the mammoth steppe », Palaeogeography, Palaeoclimatology, Palaeoecology, vol. 286 (1-2), p. 88-96.

THIAULT M.-H. 2001, « L'exploitation et la transformation de l'ivoire de mammouth. Une étude technologique d'objets gravettiens de la grotte du Pape (Brassempouy, Landes) », Gallia Préhistoire, vol. 43, p. 153-174.

TURQ A., NORMAND C. et TEXIER J.-P. 1998, « Complexe archéologique de la colline de Gaztelu (Isturitz - Oxocelhaya - Erberua) », Rapport de fouille 1998, SRA Aquitaine, 52 p.

VINCENT A. 1993, «L'outillage osseux au Paléolithique moyen : une nouvelle approche », Thèse de doctorat, Université de Paris X- Nanterre, 2 vol. , 331 p. 
VORUZ J.-L. 1997, « L'outillage en os et en bois de cerf de Chalain 3 », dans PÉTREQUIN P. (dir.), Les sites littoraux néolithiques de Clairvaux-les-Lacs et de Chalain (Jura), III, Chalain station 3, 3200-2900 av. J.C., Paris, éd. de la Maison des Sciences de l'Homme, p. 467-510 (vol. 2).

WILLERSLEV E., DAVISON J., MOORA M., ZOBEL M., COISSAC E., EDWARDS M.E., LORENZEN E. D., VESTERGÅRD M., GUSSAROVA G., HAILE J. CRAINE J., GIELly L., BOESSENKOOL S., EPP L. S., PEARMAN P. B., CHEDDADI R., MURRAY D., BRÅTHEN K. A., YOCCOZ N., BINNEY H., CRUAUD C., WINCKER P., GOSLAR T., GREVE ALSOS I., BELLEMAIN E., KRAG BRYSTING A., R., J. H., MURTON J., SHER A., RASMUSSEN M., RøNN R., MOURIER T., COOPER A., AUSTIN J., MÖLLER P., FROESE D., ZAZULA G., POMPANON F., RIOUX D., NIDERKORN V., TIKHONOV A., SAVVINOV G., ROBERTS R. G., MACPHEE R. D. E., GILBERT M. T. P., KJÆR K. H., ORLANDO L., BROCHMANN C. et TABERLET P. 2014, « Fifty Thousand Years of Arctic Vegetation and Megafaunal Diet », Nature, vol. 506 (7486), p. 47-51.

WHITE R. 2004, « La parure en ivoire de Cro Magnon », Pour la science, vol. 43, p. 98-103. ZIMOV S.A., ZIMOV N.S., TIKHONOV A.N. et CHAPIN F.S. III. 2012, « Mammoth Steppe : A HighProductivity Phenomenon », Quaternary Science Reviews, vol. 57, p. 26-45.

\section{NOTES}

1. Pour un référencement des principales publications traitant de ces questions, nous renvoyons le lecteur à Goutas et Lacarrière, 2013, p. 568 et Soulier et al., 2014, p. 316.

2. Nom du PCR : «Le Paléolithique supérieur ancien au centre et au sud du Bassin parisien : des systèmes techniques aux comportements » (Bodu et al., 1999).

3. Calibration réalisée à l'aide de Intal 13 (Reimer et al., 2013).

4. Récemment redécouverte par sa fille Agnès Poulain, nous bénéficions des notes de fouilles associées. Pierre Poulain a notamment réalisé un sondage (S1) à l'intérieur de la cavité, en bordure de paroi est, à environ 30 mètres de l'entrée (au sud). Il a individualisé ses couches en suivant la même numérotation que l'abbé Parat ( 1 à 7 en coupe ouest et 1 à 5 en coupe sud). D'après ses notes de fouilles, les seules mentions aux restes de mammouth sont en lien avec la couche 3 (argileuse et à dalettes) qui, d'après son équivalent dans la séquence Parat, serait celle qui a livré le matériel gravettien. Pour la coupe sud, voici ce qu'il écrit: «à la base du 3 ou au sommet du 4, fragments de mammouth (plutôt dans le 3)»; pour la coupe ouest : C3 « Argileux, contenant 2 niveaux de dalettes. Outillage lithique abondant. Une côte avec incision, bois de renne dont 1 avec traces de décarnisation à la base, dont la première ramification de l'andouiller est à 25 centimètres de la base mammouth » (Archives P. Poulain, carnet SCA Trilobite, com. pers. Le Gueut, Master en cours).

5. Selon F. David, il s'agirait plutôt d'un aurochs (Schmider et al., 2004). Pour notre part (JL), nous n'avons pas réussi à trancher entre aurochs et bison.

6. Analyse réalisée au sein du Service d'Imagerie et de Microscopie Optique de la Maison Archéologie et Ethnologie, René-Ginouvès, de Nanterre (CNRS USR 3225).

7. Pour une définition de ces trois termes, voir Goutas 2015, p. 244.

8. Et les possibles modifications chimiques (non intentionnelles) qui pourraient en découler, du fait du contact répété de l'outil avec la matière travaillée, comme par exemple lors du travail d'une peau traitée.

9. Raccord de deux fragments affectés de fracture récente.

10. À l'image des outils classiquement dénommés « brunissoirs » dans la littérature.

11. Au même titre qu'une quarantaine d'autres pièces en os et bois de renne.

12. Bruts ou ayant subi une première étape de façonnage. 
13. Rappelons à cette occasion que deux autres gisements ayant livré des restes postcrâniens de mammouths, Isturitz et Brassempouy, sont équidistants de Salies-du-Béarn, ville fameuse pour ces sources salées.

14. À savoir des éclats (déchets de taille ou supports) découlant d'une fracturation de type conchoïdale et des blocs de débitage s'apparentant à des nucleus en pierre.

15. Cette hypothèse fut proposée par M.-H. Thiault (2001) pour les séries gravettiennes de Brassempouy et par R. White (2004) pour les parures aurignaciennes. Malheureusement, aucun référentiel expérimental ne permet, actuellement, de distinguer ces deux modes de « vieillissement » de l'ivoire (naturel ou d'origine anthropique).

\section{RÉSUMÉS}

La place du Mammuthus primigenius dans l'économie des groupes gravettiens d'Europe a considérablement varié suivant les régions considérées. En France, avant le dernier Maximum Glaciaire, son exploitation fait intervenir des choix et des modalités de traitement distincts de ceux mis en œuvre en Europe centrale ou orientale. Ces différences sont fortement conditionnées par sa disponibilité dans l'environnement. Les niveaux gravettiens des grottes du Renne et du Trilobite à Arcy-sur-Cure ont livré des témoins variés de l'exploitation de ce grand mammifère. En croisant les données de l'archéozoologie et de la technologie osseuse, nous essaierons de retracer les intentions qui ont guidé les groupes d'Arcy dans le choix et le traitement de cette espèce animale, ainsi que les activités engageant cette ressource. Plus largement, l'exemple d'Arcy-sur-Cure sera l'occasion de discuter du statut du mammouth sur le reste du territoire français au cours du Gravettien.

\section{AUTEURS}

\section{NEJMA GOUTAS}

Chargée de recherche,

Ethnologie préhistorique - UMR 7041, ArScan

MAE - Maison de l'Archéologie et de l'Ethnologie

\section{JESSICA LACARRIÈRE}

Chercheure associée,

TRACES - UMR 5608 - équipe SMP3C

Maison de la Recherche, Université Toulouse Jean Jaurès 


\title{
Le Renne (Rangifer tarandus), pilier de l'économie dans le Magdalénien supérieur de Peyrazet (Creysse, Lot)
}

\author{
Sandrine Costamagno, Jean-Marc Pétillon, Solange Rigaud, Delphine \\ Kuntz, Véronique Laroulandie et Mathieu Langlais
}

Les auteurs remercient la DRAC Occitanie, en particulier le Service Régional de l'Archéologie, le Conseil Départemental et l'association Archéologies du Lot pour l'aide financière apportée au projet. Nous remercions également P.-L. Lasfargues et Ph. Jardel pour nous avoir autorisé à fouiller ce gisement, ainsi que l'ensemble des bénévoles pour leur aide sur le terrain.

L'animal fournit de nombreuses ressources (peau, tendon, viande, cervelle, moelle, sang, matières dures comme le bois, l'os ou la dent...) répondant à des besoins variés, alimentaires, techniques, symboliques. Si certaines, comme la viande ou les abats, répondent à des besoins plus strictement nutritifs, d'autres ont un intérêt non alimentaire comme les dents, les étuis cornés, la peau, etc. D'autres encore servent, selon les besoins, à de multiples usages: c'est notamment le cas des substances graisseuses qui peuvent être consommées mais aussi utilisées pour le tannage des peaux ou comme combustible (e.g. Costamagno et Rigaud, 2014). Dans la majorité des sites archéologiques, à l'exception des matières osseuses qui ont une chance de se conserver, les autres matières disparaissent. Ainsi, ce sont principalement les traces d'exploitation présentes sur les ossements ou sur les outils ayant servi à l'extraction ou au travail de ces matières premières qui permettent de documenter les produits animaux recherchés par les groupes humains et plus largement les chaînes opératoires d'exploitation globale de l'animal mises en œuvre dans le passé (e.g. Castel et al., 1998 ; Fontana et al., 2009 ; Leduc, 2010 ; Soulier, 2013). L'intérêt d'intégrer, dans une même étude, les étapes de boucherie généralement reconnues par les archéozoologues et celles mises en évidence par les spécialistes des outillages et des parures en matières osseuses est majeur. C'est, en effet, la seule approche qui permet de s'interroger sur la segmentation dans le temps et dans l'espace de tout ou partie de la chaîne opératoire, apportant ainsi des données essentielles à la compréhension de la fonction des sites. Le 
niveau magdalénien de la grotte-abri de Peyrazet dominé par le renne (Rangifer tarandus) offre un terrain d'enquête idéal pour développer ce type d'approche.

\section{Présentation du gisement}

2 Sondée par P. Chalard au début des années 1990, la grotte-abri de Peyrazet est une ancienne galerie karstique qui surplombe d'une vingtaine de mètres le lit actuel de la Dordogne (fig. 1). Elle est située à une altitude NGF de $127 \mathrm{~m}$. Des fouilles programmées, coordonnées par deux d'entre nous, (ML et VL) y ont été conduites de 2008 à 2015 (Langlais et al., 2009; Langlais et Laroulandie, 2014). La cavité offre une séquence tardiglaciaire s'étendant du Magdalénien supérieur au Laborien récent (Langlais et al., 2015 ; Langlais et Laroulandie, 2016). Les couches 4 et 5 à la base de la séquence ont livré un matériel homogène qui, en particulier d'après les morphotypes d'armatures lithiques (lamelles à dos appointées et pointues) et la présence de fragments de pointes barbelées en bois de cervidé, a été rapporté au Magdalénien supérieur (Langlais, Pétillon dans Langlais et Laroulandie, 2014). Cet ensemble daté du Bölling (12 $180 \pm$ 60 BP Ly7827/SacA22774, $12580 \pm 80$ BP Ly6437/SacA17857, $12720 \pm 80$ BP Ly6436/ SacA1856) (Langlais et Laroulandie, 2014), a fourni un matériel osseux anthropogène largement dominé par le renne (Costamagno dans Langlais et Laroulandie, 2014). Ce dernier est associé à un outillage lithique représenté essentiellement par des burins, suivis de lames retouchées, grattoirs et microperçoirs (Langlais dans Langlais et Laroulandie, 2014) et un équipement osseux composé notamment d'aiguilles à chas (Pétillon dans Langlais et Laroulandie, 2014). Ces couches sont très riches en restes de microvertébrés (poissons, amphibiens, oiseaux, micromammifères et mésomammifères) issus pour la plupart de l'activité de prédateurs non-humains (Danger, Laroulandie, Mallye, Royer dans Langlais et Laroulandie, 2014).

Figure 1 : A. Peyrazet dans son contexte tardiglaciaire régional (fond de carte M. Jarry, INRAP ; DAO M. Langlais). B. plan de la cavité avec emprise des fouilles, projection horizontale des vestiges coordonnés dans l'ensemble supérieur et localisation des coupes (DAO Archéosphère).
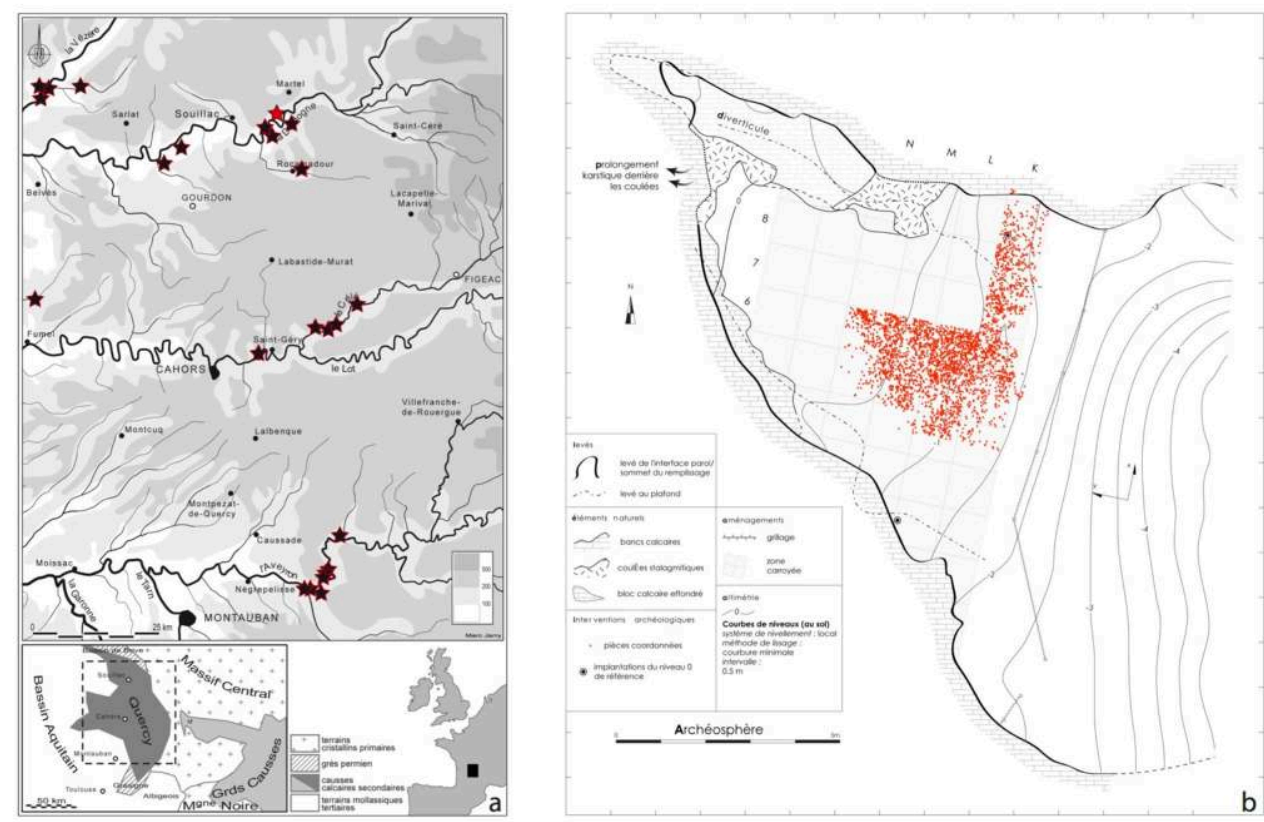


\section{Matériel et méthode d'étude}

Le matériel étudié est issu de l'ensemble magdalénien supérieur qui a été fouillé sur $12 \mathrm{~m}^{2}$ environ. Tous les restes osseux d'ongulés déterminés ont fait l'objet d'une étude archéozoologique visant à définir leur origine, leur état de conservation ainsi que les opérations de boucherie dont ils ont fait l'objet. Que ce soit pour le $\mathrm{NMI}^{1}$ ou le $\mathrm{NME}^{2}$, ce sont les nombres minimums de combinaison qui ont été calculés. Toutes les surfaces ont été observées avec une loupe manuelle (x 10) sous lumière rasante et les critères de reconnaissance classiquement utilisés pour l'identification des agents à l'origine des marques ont été retenus (White, 1992; Fisher, 1995; Blumenschine et al., 1996). Différents référentiels actualistes ont été retenus pour l'interprétation des traces de boucherie (Binford, 1981 ; Abe, 2005 ; Costamagno, 2012 ; Soulier et Costamagno, 2017). En complément, tous les éléments d'industrie osseuse ont fait l'objet d'observations typo-technologiques incluant la recherche de raccords entre fragments, la prise de mesures et l'observation systématique à la loupe binoculaire (grossissement $\times 10$ à $\times 30$ ). Un microscope Leica Z6 APO équipé d'une caméra numérique a été utilisé pour documenter les modifications d'origine anthropique observées sur les objets de parure. La localisation et le degré de développement des aménagements et des usures observés sur les objets ont été systématiquement enregistrés. Dans le cadre de cet article, seule l'exploitation du renne est discutée en détail.

\section{Résultats}

\section{Spectre faunique chassé}

4 Sept taxons d'ongulés ont été identifiés (fig. 2). Le renne (Rangifer tarandus), avec plus de $95 \%$ des restes, domine largement le spectre faunique tandis que le chamois (Rupicapra rupicapra), deuxième ongulé chassé, ne représente que $3 \%$ des restes déterminés. Les autres gibiers sont le bouquetin (Capra ibex), les bovinés et le cheval (Equus caballus). Les vestiges de chevreuil (Capreolus capreolus) proviennent majoritairement du sommet de la couche 4 et de l'interface couche 3/couche 4 . Un reste de chevreuil de la couche 4 est daté de l'Alleröd [11810 \pm 50 BP SacA22775/ Ly7826 ; 13 804-13 464 cal BP ; (Langlais et Laroulandie 2015)], témoignant de mélanges avec les niveaux sus-jacents. Sans datation directe des restes de cerf (Cervus elaphus) provenant également du sommet de la couche 4 -, il est difficile de savoir si les quelques vestiges identifiés sont contemporains du Magdalénien ou si, comme les restes de chevreuil, ils témoignent de mélanges stratigraphiques avec les couches susjacentes riches en cerf (Costamagno dans Langlais et al. 2015). 


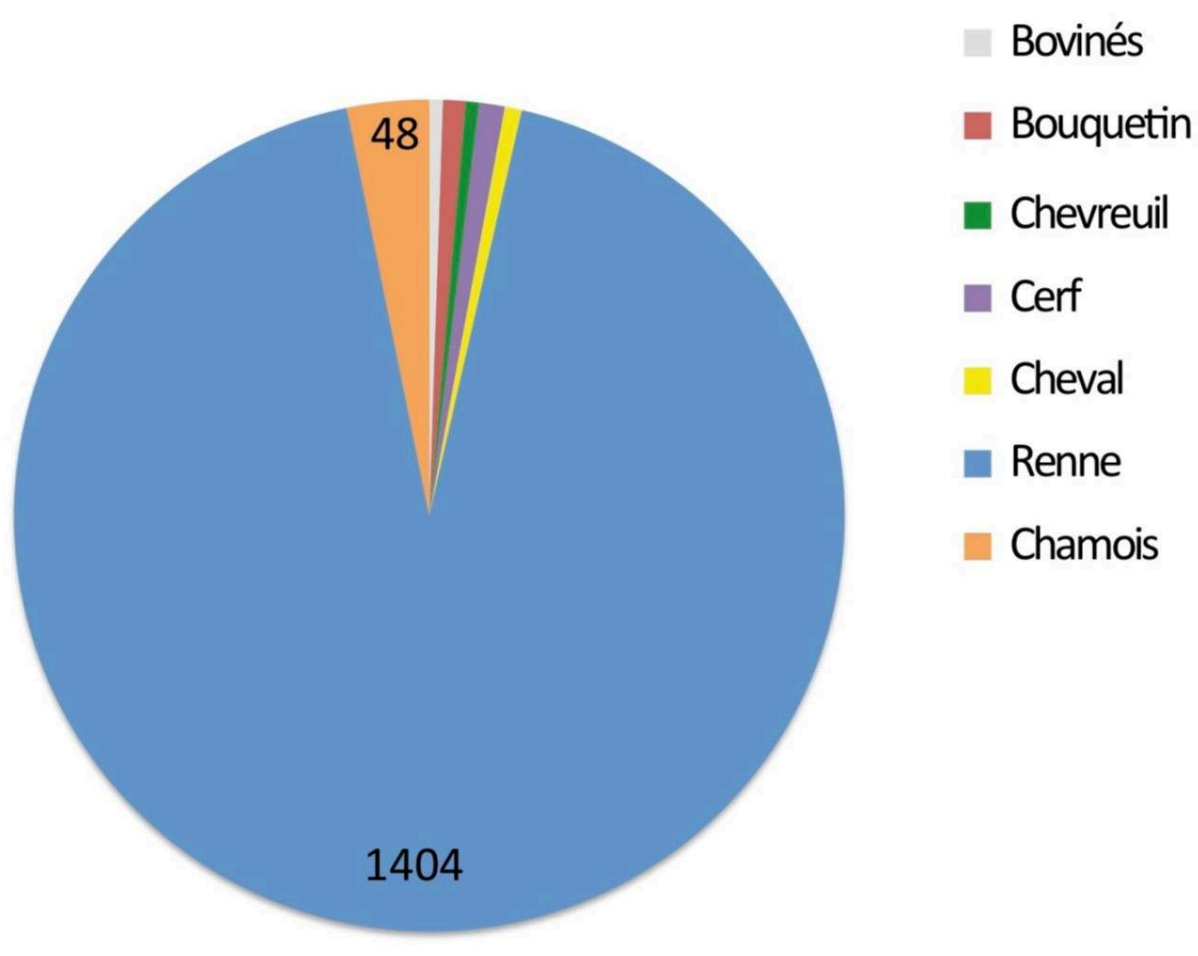

\section{État de conservation des ossements}

5 Les ossements présentent des états de surface assez contrastés: les surfaces sont parfaitement lisibles sur près de la moitié des pièces tandis qu'elles sont totalement détruites dans $15 \%$ des cas et partiellement conservées pour les autres. Parmi les différents processus taphonomiques ayant eu un impact sur les ossements, l'action des racines et, dans une moindre mesure, de la corrosion et du concrétionnement explique ces états de surface médiocres (tabl. 1). Il existe une corrélation statistiquement significative entre l'abondance relative des éléments squelettiques $\left(\mathrm{MAU}^{3}\right)$ et leur densité (Lam et al. 1999) au seuil de $1 \%\left(\mathrm{r}_{\mathrm{s}}=0,368 \mathrm{ddl}=43\right)$. Bien que significatif, ce coefficient très faible montre que la densité des ossements n'est pas le seul facteur responsable de la représentation différentielle des éléments squelettiques. En effet, si l'on ne prend en compte que les extrémités des os longs, le coefficient de corrélation devient non significatif $\left(r_{s}=0,298, d d l 11\right)$. De plus, relativement à leur densité moyenne $(0,47)$, les vertèbres sont nettement sous-représentées (MAU moyen $=6,6)$ par rapport à d'autres portions qui pourtant se caractérisent par des densités plus faibles, comme l'extrémité proximale de l'humérus (densité $=0,26 ; \% \mathrm{MAU}=23,8$ ) ou l'extrémité distale du fémur (densité $=0,32 ; \% \mathrm{MAU}=33,3$ ). La conservation différentielle semble donc avoir joué un rôle relativement minime dans l'histoire taphonomique de l'ensemble osseux, ce que confirme la présence de quelques restes de fœtus. Enfin, l'impact des carnivores est assez limité puisque moins de $4 \%$ des ossements portent des traces de dents et/ou de digestion. 
Tableau 1 : traces et processus taphonomiques enregistrés sur les ossements, à l'exclusion des traces anthropogéniques.

\begin{tabular}{|l|r|r|}
\hline & Nombre de restes & \% NR \\
\hline Traces de racines & 813 & 53,2 \\
\hline Traces de corrosion & 407 & 26,6 \\
\hline Concrétionnement & 194 & 12,7 \\
\hline Fissures longitudinales & 188 & 12,3 \\
\hline Desquamation & 168 & 11,0 \\
\hline Traces d'émoussés & 96 & 6,3 \\
\hline Traces de dents & 41 & 2,7 \\
\hline Délitement & 24 & 1,6 \\
\hline Cupules de dissolution & 23 & 1,5 \\
\hline Dépôts de manganèse & 7 & 0,5 \\
\hline Traces de digestion & 12 & 0,8 \\
\hline
\end{tabular}

\section{Nombre d'animaux exploités et saison d'acquisition}

6 En ne prenant en compte que les restes osseux, le bouquetin, le chamois, les bovinés et le cerf correspondent chacun à un seul individu et le cheval à deux. Le renne est, quant à lui, représenté, sur la base des premières phalanges, par 14 individus dont deux jeunes et deux foetus. Les restes dentaires, pourtant relativement peu nombreux, proviennent d'un minimum de 12 individus pour le renne, 4 pour le chamois et 1 pour les autres espèces. La présence de 8 restes de fotus de rennes témoigne de l'abattage de femelles. Certains, issus d'un individu presque à terme, semblent indiquer des chasses menées vers la fin du printemps alors que d'autres, de plus petite taille, renvoient à des épisodes de chasse plus précoces, probablement en début d'hiver.

\section{Mode de transport des carcasses}

7 Le profil squelettique du renne montre un déséquilibre des différentes parties anatomiques (tabl. 2 et fig. 3). Le squelette axial post-crânien est peu abondant. C'est tout particulièrement le cas des vertèbres dont le \% MAU moyen ne dépasse pas $7 \%$. Du fait de la présence de nombreux fragments de côtes attribués à des mammifères de taille moyenne, on peut s'interroger sur la signification de la sous-représentation des côtes de renne (MAU = 7,7\%). Néanmoins, ces fragments n'étant qu'au nombre de 122 , les côtes de renne, même potentiellement sous-estimées, devaient être initialement peu abondantes dans la zone fouillée. La rareté des vertèbres aux regards de l'abondance relative de certaines portions plus fragiles ( $c f$. supra) fait pencher en faveur d'un abandon de ces parties sur le site d'abattage ou de leur présence dans un autre secteur de la grotte.

Pour la tête, une nette différence existe entre le crâne $(\mathrm{NME}=4)$ et les hémi-mandibules $(\mathrm{NME}=20 ; \mathrm{NMI}=12)$, liée en particulier à l'abondance des incisives $(\mathrm{NMI}=12)$, 
surnuméraires relativement aux dents jugales $(\mathrm{NMI}=8)$. Les fragments de bois sont peu nombreux (bois de renne $: \mathrm{n}=37$; bois de cervidé indéterminé $: \mathrm{n}=19$ ) et seuls un bois de chute de gros module et un bois de petit module sont clairement attestés sur le site.

9 Le membre antérieur est mieux représenté que le membre postérieur. Jusqu'aux métapodes, les éléments squelettiques de chaque membre se caractérisent par des fréquences relativement proches, pouvant témoigner d'une introduction de pattes complètes sur le site. La sous-représentation des membres postérieurs pourrait être liée à une spatialisation des activités de boucherie qui est aussi perceptible à travers l'abondance des phalanges et des sésamoïdes. Comparé à ce qui est généralement perçu sur les sites magdaléniens du Sud-Ouest de la France (e.g. Costamagno 1999 ; Soulier et al. 2014 ; Kuntz et al. 2016), la surreprésentation de ces éléments squelettiques - \% MAU phalange $1=100 ; \%$ MAU phalange $2=78,4 ; \%$ MAU sésamoïde médial $=75$ - est remarquable. Au-delà d'une spatialisation des activités de boucherie, cette surreprésentation des incisives et des extrémités de pattes de renne et de chamois pourrait suggérer une disjonction dans l'introduction des quartiers de carcasses en lien avec l'exploitation de matières particulières.

Tableau 2 : nombre minimum d'éléments squelettiques (NME) de renne et pourcentage d'unités animales minimales (MAU).

\begin{tabular}{|c|r|r|}
\hline Elément squelettique & \multicolumn{1}{|c|}{ NME } & \multicolumn{1}{|c|}{$\%$ MAU } \\
\hline Atlas & 1 & 4,5 \\
\hline Axis & 1 & 9,1 \\
\hline Vertèbre cervicale & 3 & 5,5 \\
\hline Vertèbre thoracique & 5 & 3,5 \\
\hline Vertèbre lombaire & 9 & 11,7 \\
\hline Côte & 21 & 7,3 \\
\hline Scapula & 0 & 0,0 \\
\hline Humérus & 14 & 63,6 \\
\hline Radius & 10 & 45,5 \\
\hline Ulna & 9 & 40,9 \\
\hline Pisiforme & 14 & 63,6 \\
\hline Pyramidal & 5 & 22,7 \\
\hline Scaphoïde & 3 & 13,6 \\
\hline Semi-lunaire & 5 & 22,7 \\
\hline Capitato-trapézoïde & 2 & 9,1 \\
\hline Unciforme & 3 & 13,6 \\
\hline Métacarpien & 10 & 45,5 \\
\hline Fémur & 8 & 36,4 \\
\hline Patella & 10 & 45,5 \\
\hline Tibia & 8 & 36,4 \\
\hline Malléole & 3 & 13,6 \\
\hline Calcaneum & 9 & 40,9 \\
\hline Astragale & 4 & 18,2 \\
\hline Cubo-naviculaire & 8 & 36,4 \\
\hline Grand cunéiforme & 9 & 40,9 \\
\hline Petit cunéiforme & 1 & 4,5 \\
\hline Métatarsien & 8 & 36,4 \\
\hline Phalange 1 & 83 & 94,3 \\
\hline Phalange 2 & 69 & 78,4 \\
\hline Phalange 3 & 26 & 29,5 \\
\hline Sésamoïde med. & 66 & 75,0 \\
\hline Sésamoïde lat. & 42 & 47,7 \\
\hline Petit sésamoïde & 26 & 59,1 \\
\hline & & \\
\hline & & \\
\hline & 3 & \\
\hline & & \\
\hline & & \\
\hline
\end{tabular}


Figure 3 : abondance relative des éléments squelettiques de rennes (en \% MAU, pour les effectifs cf. tabl. 2).

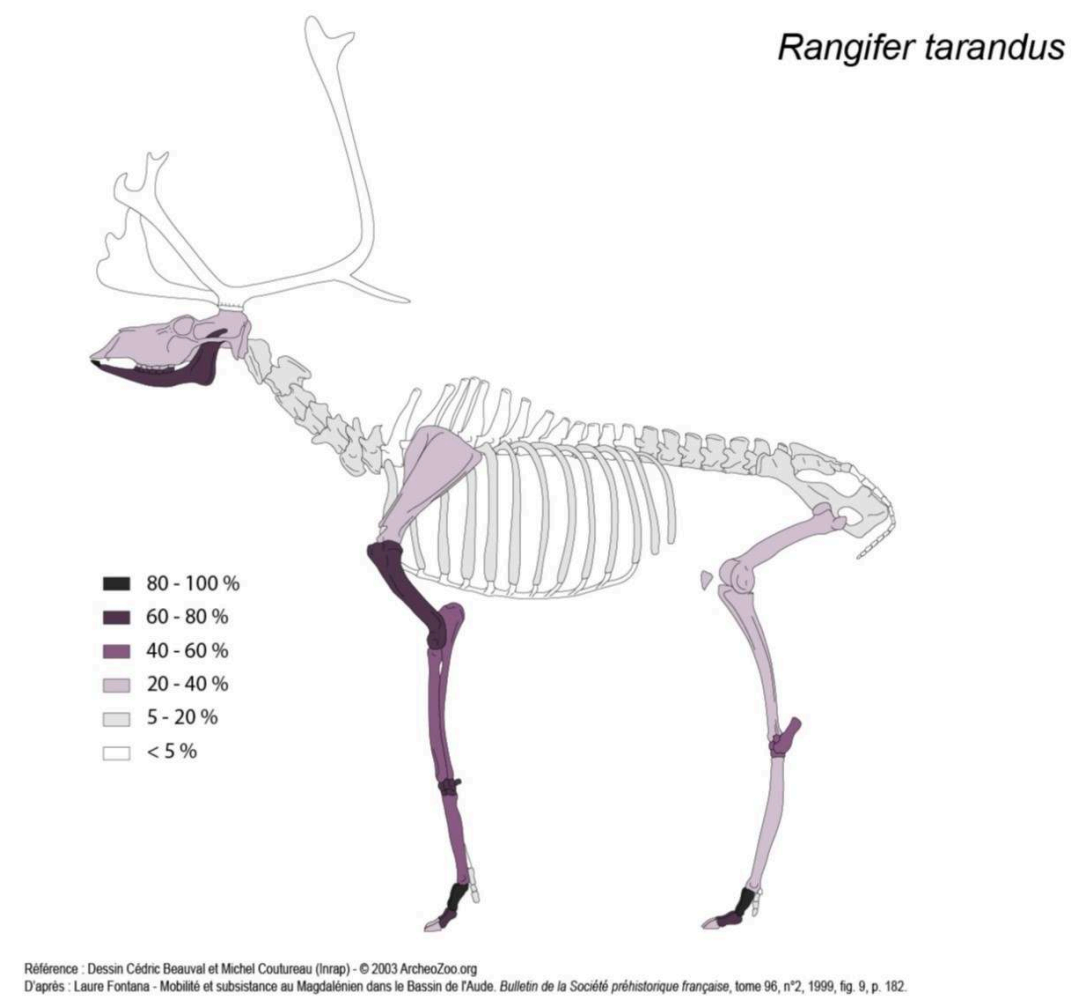

\section{Les produits animaux recherchés}

\section{La peau}

Plusieurs stries de boucherie correspondent à du dépouillement. C'est le cas des stries longitudinales relevées sur un fragment médial de métacarpien, trois de métatarsien, deux phalanges 1 et une phalange 2 de renne (fig. $4 \mathrm{n}^{\circ} 1$ ). Ces stries correspondent à l'incision longitudinale de la peau des pattes. Les nombreuses stries transverses ou obliques observées sur les métapodes résultent, quant à elles, du détachement de la peau. La présence de stries transversales sur la face antérieure des premières ou des deuxièmes phalanges indique que la peau a pu être incisée à ce niveau-là. Néanmoins, la relative rareté des stries liées à l'entame circulaire sur les phalanges - pourtant nombreuses - semble indiquer une incision de la peau au plus près des extrémités des pattes. Dans cette zone, les masses tendineuses empêchent en effet le plus souvent tout contact de l'outil avec l'os. 

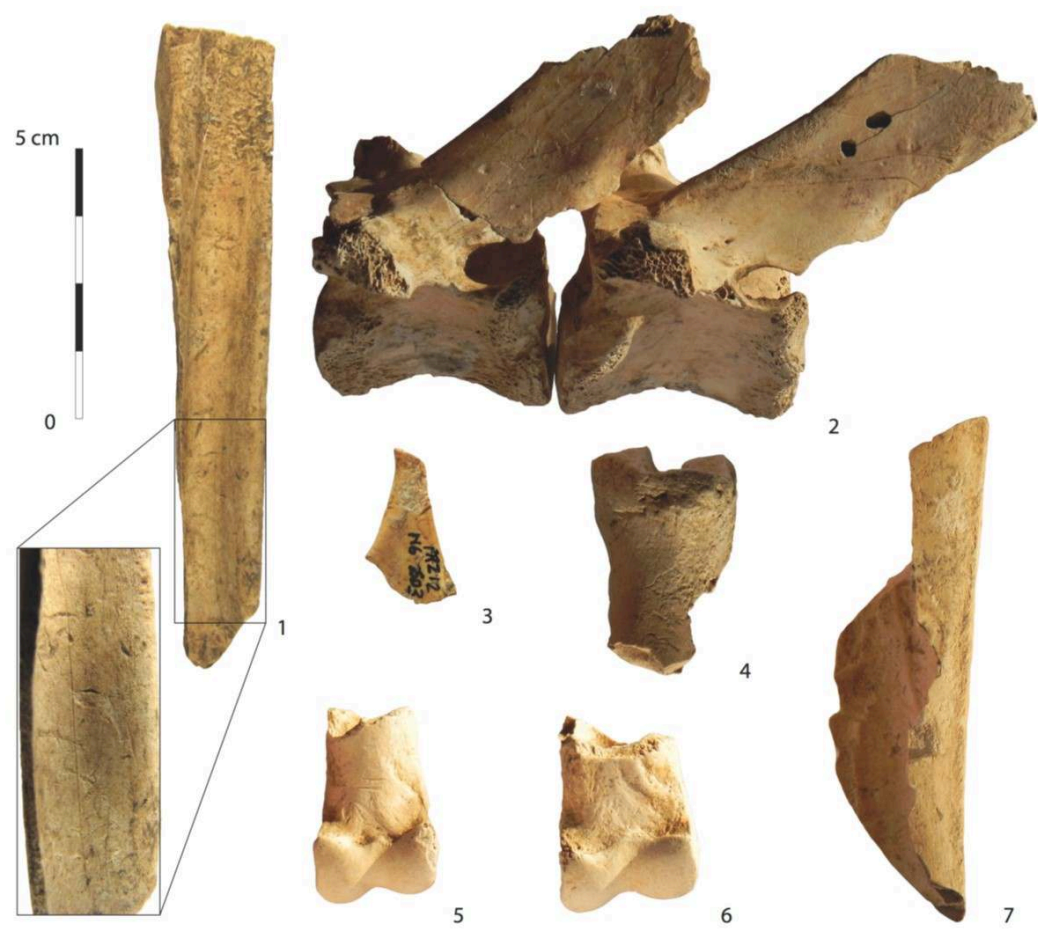

1 : stries longitudinales de dépouillement sur métatarsien. $2:$ stries de décharnement sur vertèbres thoraciques. 3 : stries en lien avec le prélèvement de la langue sur os hyoïde. 4 : encoche de percussion sur phalange 1 de renne. 5 et 6 : stries d'extraction des tendons sur phalanges 1. 7 : encoche de percussion sur fragment diaphysaire de fémur (photos : V. Laroulandie ; DAO : S. Costamagno).

L'abondance des phalanges précédemment évoquée pourrait indiquer un apport de peaux indépendamment de celles provenant des rennes chassés introduits dans la cavité sous la forme de segments de carcasses. Les phalanges pouvant rester attachées à la peau au moment du dépouillement de la carcasse, l'hypothèse d'un traitement de peaux de renne avec une extraction secondaire des phalanges est une hypothèse envisageable et ce, d'autant plus, qu'elles sont plus particulièrement concentrées dans un secteur particulier de l'abri (carrés K6 et L6) (fig. 5). 
Figure 5 : fréquence relative des phalanges de renne par carré (DAO Archeosphère modifié par $\mathrm{M}$. Langlais).

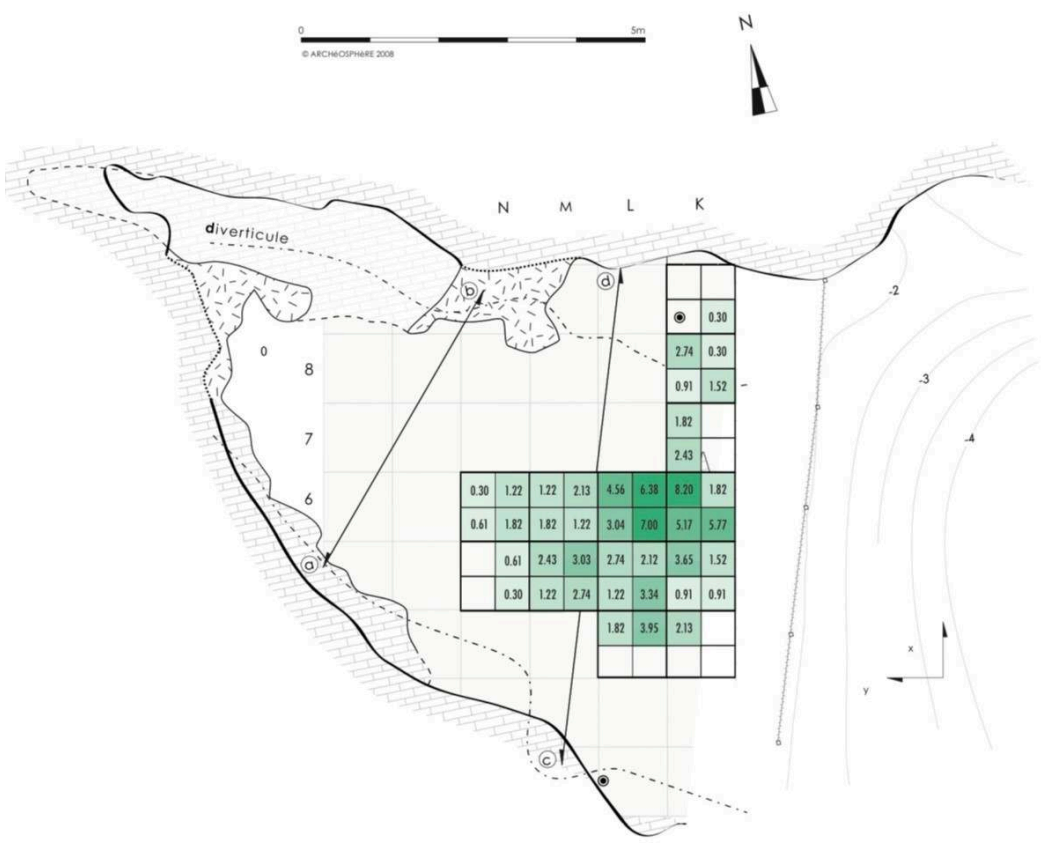

\section{La viande}

La majorité des stries relevées sur les ossements de renne correspond à des stries de décharnement. Présentes sur tous les os longs charnus et les ceintures, elles sont majoritairement longitudinales sur le fémur et plus diversifiées sur les autres éléments squelettiques (transversales, obliques, longitudinales). Des stries présentes sur l'épine des vertèbres thoraciques ou les processus transverses des lombaires attestent du prélèvement du filet sur place qui pouvait aussi être directement extrait sur le lieu de chasse sans transport du squelette axial (fig. $4 \mathrm{n}^{\circ}$ 2). Au niveau de la face linguale de la mandibule et sur l'os hyoïde, les stries observées témoignent de la récupération de la langue (fig. $4 \mathrm{n}^{\circ}$ 3). Sur le crâne et la face vestibulaire de la mandibule, les stries pourraient tout autant correspondre à du décharnement qu'à du dépouillement.

\section{La moelle et la graisse contenue dans le tissu spongieux}

13 À côté de la viande, la moelle a fait l'objet d'une exploitation intensive comme c'est fréquemment le cas sur les sites du Paléolithique supérieur (e.g. Mateos Cachorro 2005 ; Costamagno et Rigaud 2014; Soulier et al. 2014). Tous les os longs trouvés à la fouille sont fragmentés, à l'exception des os de foetus. Les phalanges ont également été intensément fracturées : moins de $10 \%$ sont complètes (tabl. 3). Comme pour les os longs, les bords de fracture des phalanges sont caractéristiques d'une fracturation sur os frais (Villa et Mahieu 1991) et nombre d'entre elles portent des impacts de percussion (tabl. 3 et fig. $4 \mathrm{n}^{\circ} 4$ et 7 ). 
Tableau 3 : Nombre minimum de premières et deuxièmes phalanges, nombre de phalanges entières et nombre de fragments portant des traces de percussion par taxon (NRD $=$ Nombre de restes déterminés).

\begin{tabular}{|l|r|r|}
\hline & Phalange 1 & Phalange 2 \\
\hline NRD & 160 & 129 \\
\hline NME & 83 & 69 \\
\hline NME complet & 7 & 7 \\
\hline NRD avec impact & 48 & 35 \\
\hline
\end{tabular}

Les restes brûlés (tamis + os coordonnés) comptent pour moins de $1 \%$ des restes osseux de mammifères. Au sein de l'échantillon étudié en détail (i. e. les fragments supérieurs à $3 \mathrm{~cm}$ ), près des deux tiers portent de petites plages de combustion brunes ou ne sont pas entièrement carbonisés. Sur la base de ces données, la graisse du tissu spongieux n'a, de toute évidence, pas ou peu été utilisée comme combustible à Peyrazet. Pour l'extraction de la graisse, il est plus délicat de conclure. Néanmoins, comparativement à des gisements où cette hypothèse est avancée (voir par exemple Costamagno et Rigaud, 2014), les portions et os spongieux sont relativement abondants.

\section{Les tendons et les sabots}

Malgré l'abondance des fragments de métapodes de renne, peu $(\mathrm{n}=3)$ portent des stries caractéristiques de l'extraction des tendons. Cette opération laissant habituellement des traces aisément identifiables, les tendons des pattes pourraient n'avoir été que rarement exploités à Peyrazet. Au niveau des phalanges, les stries situées en face postérieure, caractéristiques du retrait des tendons, ont été relevées sur 9 phalanges 1 et 6 phalanges 2 (fig. $4 \mathrm{n}^{\circ} 5$ et 6 ). Enfin, des stries observées sur une phalange 3 signalent une récupération des sabots.

\section{L'os}

Parmi les 62 pièces d'industrie en os, 11 sont attribuées au renne et 49 à des ongulés de la taille du renne ou à des mammifères indéterminés. Les pièces renvoyant sans conteste à l'exploitation d'autres espèces ne sont que deux : un déchet de débitage sur ulna d'oiseau et un autre sur os long de petit vertébré. On peut donc avancer que le renne a fourni l'essentiel de la matière première utilisée dans l'industrie en os.

17 Les trois quarts de cette industrie $(n=46)$ se rapportent à la fabrication et à l'utilisation des aiguilles à chas. Toutes les étapes de la chaîne opératoire de ces objets sont représentées: déchets de débitage ou de façonnage, supports, ébauches, objets finis. Parmi les 11 déchets de débitage de supports d'aiguilles, hormis les deux pièces mentionnées ci-dessus, deux sont indéterminés et les sept autres sont des métapodes, parmi lesquels six métatarsiens de renne. Tous portent des traces d'extraction de baguettes par double rainurage (fig. 6). Les fragments d'aiguilles sont nombreux, et la moitié montre des fractures par flexion évoquant des dommages survenus lors de l'utilisation ou par piétinement sur os frais (fig. 7). À ces objets s'ajoutent trois petites 
bipointes entièrement façonnées par raclage, renvoyant sans doute également à des activités de confection.

18 Le reste de l'industrie en os comprend: deux lissoirs sur côte; un probable support pour un objet du même type; un fragment diaphysaire de fémur de renne vraisemblablement utilisé en percussion lancée; et deux pièces gravées, dont un fragment de métacarpien gauche de renne portant un vestige de motif animalier.

Figure 6 : Industrie en os ; déchets de débitage de baguettes (supports d'aiguilles) par rainurage longitudinal.

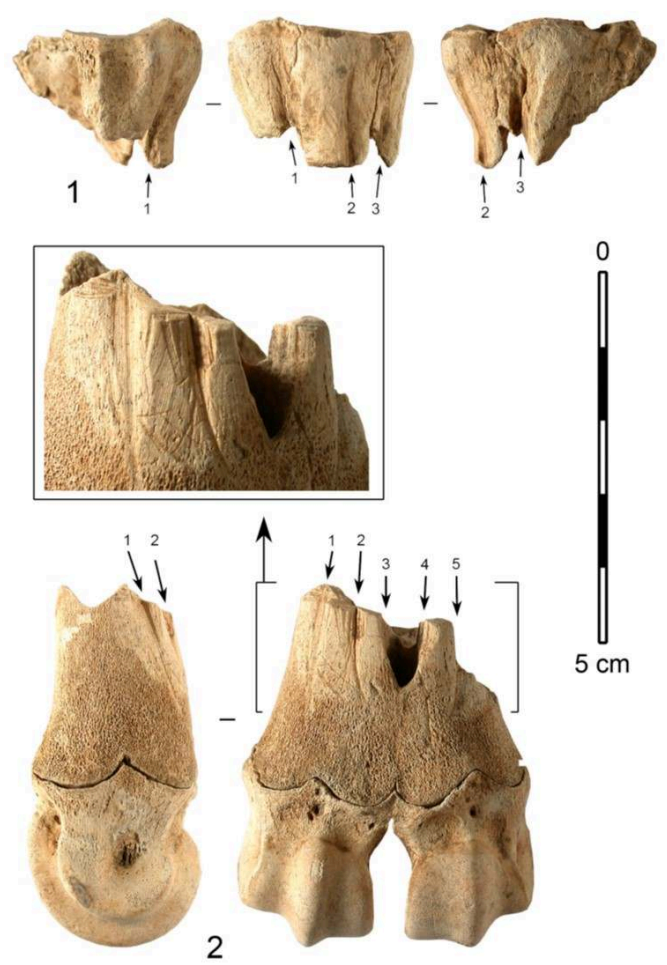

1 : extrémité proximale de métatarsien de renne, avec flèches indiquant l'emplacement des rainures. 2 : extrémité distale de métatarsien de renne, avec flèches indiquant l'emplacement des rainures et détail de la zone travaillée (photos et DAO : J.-M. Pétillon).

Figure 7 : Industrie en os ; produits sur baguette.
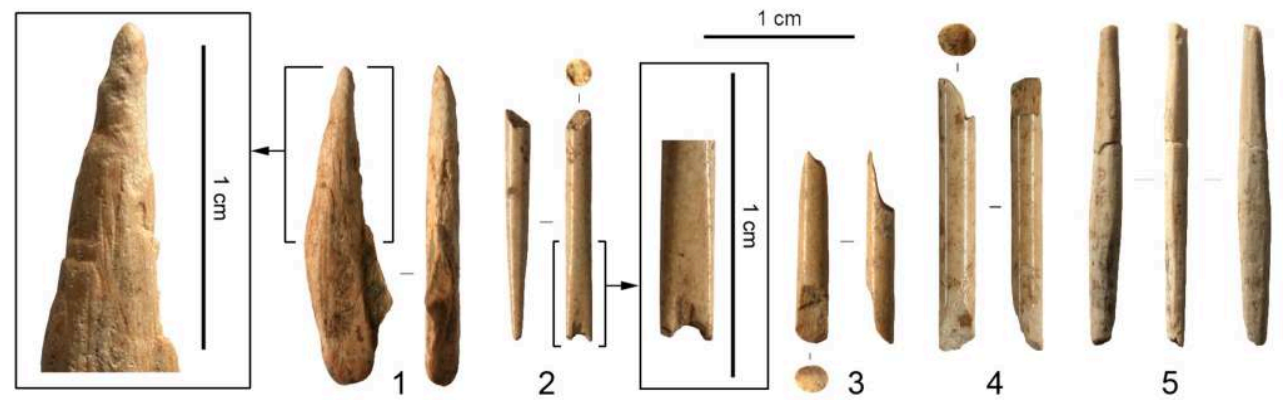

1 : déchet de façonnage d'aiguille, avec détail du sectionnement par raclage en diabolo. 2 : fragment mésial d'aiguille, avec détail du chas. 3-4 : fragments mésiaux d'aiguilles. 5 : déchet de réfection d'aiguille (photos et DAO : J.-M. Pétillon). 


\section{Le bois}

Parmi les 39 pièces travaillées en bois de cervidé, toutes celles dont l'espèce a pu être identifiée $(n=14)$ se rapportent au renne; l'usage du bois de cerf n'est pas attesté. C'est essentiellement la perche de bois de module moyen et gros qui a été utilisée. Une seule pièce documente les modalités d'acquisition de ces bois : un déchet de débitage sur base de bois de chute de gros module montre qu'une partie au moins de la matière première a été acquise par collecte (fig. 8).

Figure 8 : Industrie en bois de renne ; partie basilaire de bois de chute droit de renne, déchet d'extraction de baguettes par rainurage longitudinal multiple avec détail des extractions (photos et DAO : J.-M. Pétillon).

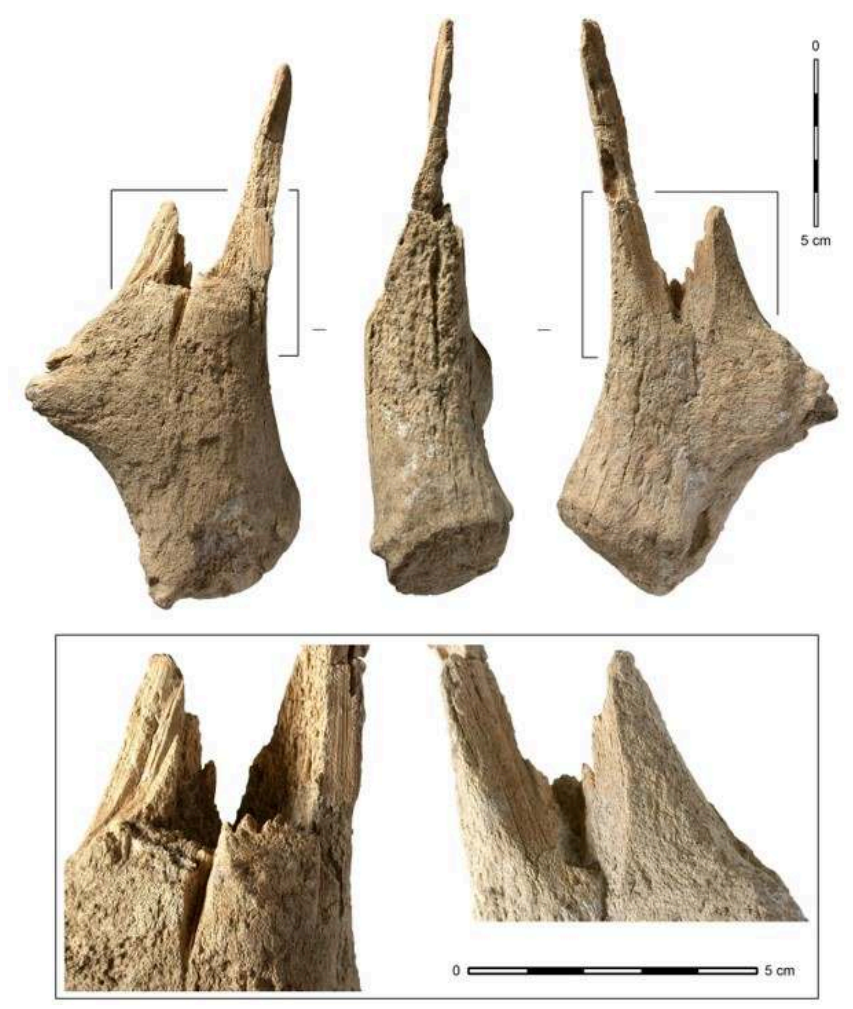

20 L'industrie en bois de cervidé se rapporte pour l'essentiel à la production d'objets sur baguette extraite par double rainurage (fig. 9): huit déchets de débitage et trois fragments de baguette témoignent de ce procédé. À l'exception d'un outil intermédiaire, les 10 objets finis sur baguette sont tous des armatures de projectile. Avec les aiguilles à chas, ce sont les seuls outils en matières osseuses dont la chaîne opératoire complète est documentée à Peyrazet. Parallèlement au double rainurage, la percussion a été utilisée pour le débitage du bois de renne, comme l'atteste la présence de neuf éclats dont six ont pu être remontés; l'objectif de ces débitages reste difficile à déterminer. 
Figure 9 : Industrie en bois de renne ; outil intermédiaire sur baguette extraite par double rainurage, brisé lors de son utilisation.

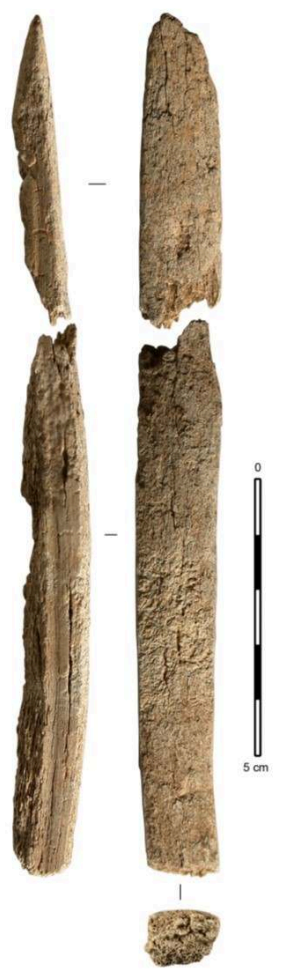

\section{Les dents}

Parmi les 69 dents labiales d'ongulés de petite taille, 27 dents ( 2 canines et 25 incisives) de renne portent des traces de sciage (fig. $10 \mathrm{~A}$ ). Elles ont d'abord été sciées mésiodistalement en face vestibulaire puis certaines d'entre elles ont été cassées par flexion (fig. 10 B). Aucune usure due à l'attache et au port de ces objets n'est identifiée sur le matériel de Peyrazet. L'identification de deux appariements (fig. $10 \mathrm{~A}$ ) suggère qu'au moins une partie des dents n'a pas été dispersée par un système d'échange avant leur introduction sur le site.

Figure 10 : A : Planche synthétique des dents labiales sciées de renne, les astérisques signalent les fragments d'une même dent, les accolades indiquent les dents provenant potentiellement d'un même individu (détermination S. Costamagno), B : exemple de traces de sciage mésio-distal observé sur la face vestibulaire des incisives de renne (photos et DAO : S. Rigaud).

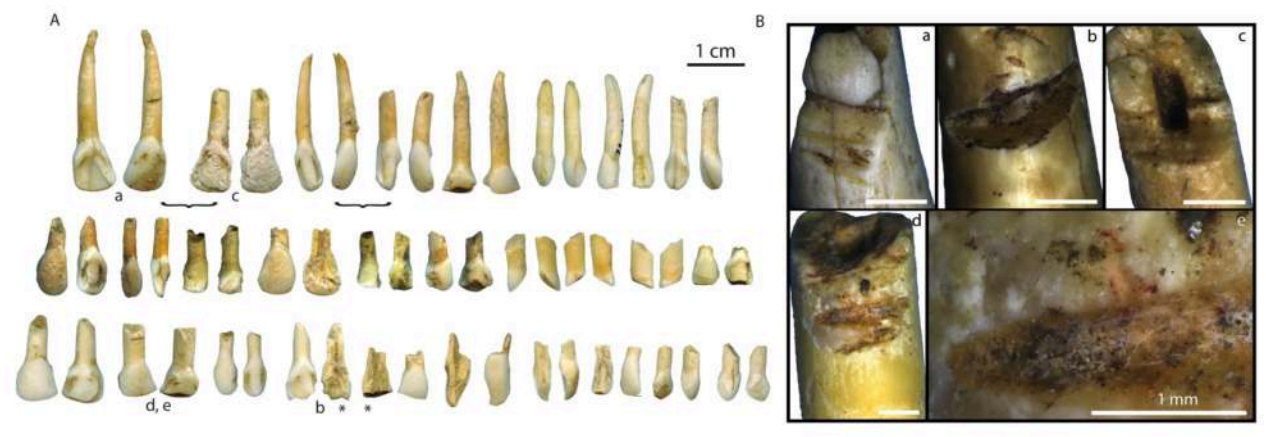


Fréquentes au Magdalénien (e.g. Poplin, 1983; Bullinger et Müller, 2005 ; Berganza et Arribas, 2010 ; Ducasse et al., 2011 ; Kuntz et al., 2015), les dents sciées d'ongulés sont souvent assimilées à de la parure en raison de l'absence de traces indiquant leur emploi à des fins techniques et de l'utilisation d'objets similaires par de nombreuses sociétés traditionnelles à des fins ornementales. Ni perforation, ni rainurage n'ayant été observé, un système d'attache par collage et sertissage au sein d'un support souple, semi-rigide à rigide peut être envisagé, mais aucune trace de résidu de substance adhésive n'a été identifiée sur les pièces de Peyrazet.

Le maintien des incisives dans les parties charnues des gencives tel que décrit dans les travaux ethnographiques (Meldgaard, 1980 ; Poplin, 1983 ; Gundestrup, 1991) aurait également pu permettre leur port après séchage. La présence d'appariements abonde en ce sens.

\section{Discussion et conclusion}

24 À Peyrazet, les matières premières fournies par le renne sont nombreuses (peau, viande, moelle, tendon, sabot, os, bois, dent) et reflètent la diversité des activités menées sur le site que l'on perçoit aussi à travers les premiers résultats de l'étude fonctionnelle de l'industrie lithique, actuellement menée par J. Jacquier. Pourvoyeur de ressources à destinations alimentaires, techniques et ornementales, le renne y occupe une place centrale comme c'est généralement le cas dans les gisements pénécontemporains de la zone Périgord/Quercy (Costamagno, 1999 ; Castel et al., 2013 ; Costamagno et al., 2016). L'analyse archéozoologique permet de documenter principalement l'exploitation alimentaire des rennes chassés durant l'occupation du site tandis que l'étude des matières osseuses enrichit le spectre des ressources utilisées ; mais c'est réellement le croisement des données issues de ces divers registres qui permet d'entrevoir toute la complexité de cette exploitation (fig. 11). 
Figure 11 : Chaîne opératoire d'exploitation globale du renne (DAO : S. Costamagno).

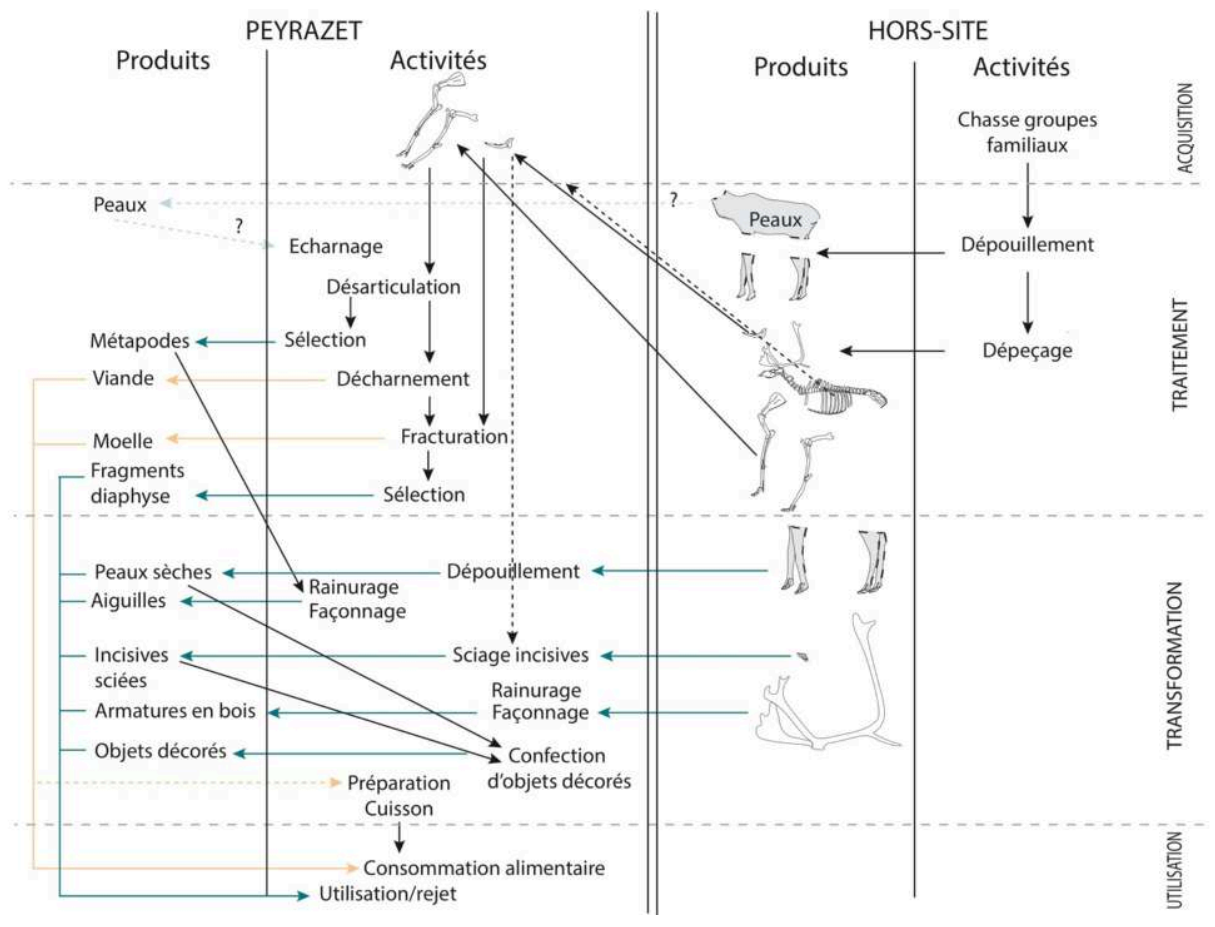

Les rennes, abattus durant la mauvaise saison, ont subi une première boucherie sur le site d'abattage (dépouillement et dépeçage) puis ont été introduits sous forme de segments de carcasses dans la grotte. Une partie de l'équipement de chasse a été confectionnée sur place à partir d'au moins un bois de chute de gros module récolté probablement au début de l'automne avant que le sol ne soit recouvert de neige tandis que les bois de plus petits calibres peuvent provenir des femelles chassées durant l'occupation. Les membres, parfois accompagnés du squelette axial post-crânien, ont été préférentiellement transportés dans l'abri. La viande et la moelle de renne, intensément recherchées, fournissaient l'alimentation de base des chasseurscollecteurs, tout au moins lors de leur séjour à Peyrazet.

La surabondance des extrémités de pattes de renne (phalanges et sésamoïdes) également perceptible chez le chamois (Costamagno dans Langlais et Laroulandie, 2014) signe un apport de peaux indépendamment de celles provenant des individus chassés. À partir du seul registre faunique, il est délicat de savoir si les peaux des animaux abattus durant l'occupation de la cavité ont été rapportées au camp. L'analyse tracéologique en cours devrait fournir des données complémentaires sur cet aspect (Jacquier, en cours).

Relativement aux sites magdaléniens du sud-ouest de la France, la chaîne opératoire de production des aiguilles à chas occupe une place prépondérante à Peyrazet. Le renne est à nouveau le principal, voire l'unique, animal fournissant des matrices pour la confection de baguettes osseuses servant à façonner sur place des aiguilles à chas. Intensément utilisées comme l'attestent les nombreuses fractures en languette, ces aiguilles signent des activités de confection d'objets ou de vêtements en peau. Là encore, l'analyse tracéologique de l'industrie lithique permettra sans doute de préciser la mise en œuvre de cette activité.

(Costamagno, Rigaud dans Langlais et Laroulandie, 2014) associée à d'autres éléments 
de parure réalisés sur coquillages (Rigaud dans Langlais et Laroulandie, 2014) vient conforter cette hypothèse. La surreprésentation des incisives par rapport aux autres restes dentaires est un argument en faveur d'une introduction préférentielle de ces supports dont une partie au moins n'était pas issue des rennes chassés. Si l'absence d'outils de sciage (Jacquier dans Langlais et Laroulandie, 2015) peut indiquer l'introduction d'incisives déjà sciées, la présence de racines isolées montre qu'une partie d'entre elles a pu être transformée durant l'occupation. L'hypothèse d'une fabrication de parures dans l'abri est confortée par l'identification de coquillages non usés, certains intacts, d'autres fracturés au percement (Rigaud dans Langlais et Laroulandie, 2014). Les incisives sciées qui ne portent aucune trace de suspension ou de résidu de substance adhésive sont donc probablement les restes d'un stock beaucoup plus conséquent de dents sciées, ou de portions labiales de gencives, intégrées à la sphère technique de fabrication d'objets ou de vêtements de peau.

À la grotte-abri de Peyrazet, le renne fournissait donc l'essentiel des ressources animales. Acquises durant l'occupation du site ou provenant de stocks antérieurs, cet exemple montre une partie au moins de la complexité de la gestion de ces ressources par les nomades du Magdalénien supérieur. Outre le bois de renne, nous avons pu mettre en évidence que d'autres matières utilisées dans la sphère technique faisaient l'objet d'une planification sur le long terme. Cela n'a rien d'étonnant en soi mais il est rare que le registre paléolithique dans un contexte de grotte permette d'atteindre ce degré de lecture.

\section{BIBLIOGRAPHIE}

ABE Y. 2005, « Hunting and butchering patterns of the evenki in the Northern Transbaikalia Russia », Ph. D., New-York, Stony Brook University.

BERGANZA E. et ARRIBAS J.-L. 2010, « Dientes de herbívoros serrados e incisos de la cueva de Santa Catalina (Lekeitio, Bizkaia)», Munibe, vol. 61, p. 57-70.

BINFORD L.R. 1981, Bones : Ancient Men and Modern Myths, New York, Academic Press.

BLUMENSCHINE R.J., MAREAN C.W. et CAPALDO S.D. 1996, « Blind tests of interanalyst correspondence and accuracy in the identification of cut-marks, percussion marks and carnivore tooth marks on bone surface ", Journal of Archaeological Science, vol. 23, p. 493-508.

BULLINGER J. et MÜLLER W. 2005, « Nouvelles découvertes d'incisives de marmotte sciées dans des sites magdaléniens de l'arc jurassien », dans DUJARDIN V. (dir.), Industries osseuses et parures du Solutréen au Magdalénien en Europe, Paris, Société préhistorique française, p. 347-351 (Mémoire XXXIX).

CASTEL J.-C., KUNTZ D., CHAUVIÈRE F.-X., GERBE M. et JUILlARD F. 2013, « L'exploitation du monde animal au Paléolithique supérieur en Quercy. Un état des connaissances », dans M. JARRY, J.-P. BRUGAL et C. FERRIER (dir.), Modalités d'occupation et exploitation des milieux au Paléolithique dans le sud- 
ouest de la France : l'exemple du Quercy, actes de la session C67 du XV eongrès de l'UISPP, Lisbonne, septembre 2006, p. 395-418 (Paléo, supplément 4).

CASTEL J.-C., Liolios D., CHADELle J.-P. et GENESTE J.-M. 1998, « De l'alimentaire et du technique : la consommation du renne dans le Solutréen de la grotte de Combe Saunière ", dans BRUGAL J.-P., MEIGNEN L. et PATOU-MATHIS M. (dir.), Économie préhistorique : les comportements de subsistance au Paléolithique, XVIII ${ }^{\mathrm{e}}$ Rencontres Internationales d'Archéologie et d'Histoire d'Antibes, Antibes, APCDA-CNRS, p. 433-450.

COSTAMAGNo S. 1999, «Stratégies de chasse et fonction des sites au Magdalénien dans le sud de la France », Bordeaux, Thèse de Doctorat, Université de Bordeaux I.

COSTAMAGno S. 2012, « Des stries de boucherie au sous-système technique d'exploitation de l'animal : apports de l'approche expérimentale », Habilitation à diriger des recherches, Bordeaux, Université Bordeaux 1.

COSTAMAGNO S., BARSHAY-SZMIDT C., KUNTZ D., LAROULANDIE V., PÉTILLON J.-M., BOUDADI-MALIGNE M., LANGLAIS M., MALLYE J.-B. et CHEVALLIER A. 2016, « Reexamining the timing of reindeer disappearance in southwestern France in the larger context of late Glacial faunal turnover », Quaternary International, vol. 414, p. 34-61.

COSTAMAgno S. et RIGAUd J.-P., 2014 « L'exploitation de la graisse au Paléolithique », dans S. COSTAMAGNO (dir.), Histoire de l'alimentation humaine : entre choix et contraintes, actes du $138^{\mathrm{e}}$ congrès du CTHS, Rennes avril 2013, Paris, CTHS, p. 134-152.

Ducasse S., CASTel J.-C., Chauvière F.-X., langlais M., CAMus H., Morala A. et TURQ. A. 2011, « Le Quercy au cœur du Dernier Maximum glaciaire. La couche 4 du Petit Cloup Barrat et la question de la transition badegoulo-magdalénienne ", Paléo, vol. 22, p. 101-154.

FISHER J.W. 1995, « Bone Surface Modifications in Zooarchaeology », Journal of Archaeological Method and Theory, vol. 2, p. 7-68.

FONTANA L., CHAUVIÈRE F.-X. et BRIDAULT A. (dir.) 2009, In Search of Total Animal Exploitation - Case Studies from the Upper Palaeolithic and Mesolithic, actes du XV ̀̀me Congrès de l'IUSPP, Lisbonne 4 au 9 septembre 2006, Oxford, Archaeopress (BAR International Series 2040).

GUNDESTRUP B. 1991, Det kongelige danske Kunstkammer 1737. The Royal Danish Kunstkammer 1737., København, Nationalmuseet, Nyt Nordisk Forlag Arnold Busck.

KUNTZ D., COSTAMAGNO S., FEYFANT L. et MARTIN F. 2016, « The exploitation of ungulates in the Magdalenian in the Entre-Deux-Mers (Gironde, France) », Quaternary International, vol. 414, p. 135-158.

KunTZ D., SÉcher A., COSTAMAgno S., MALlye J.-B., PÉTILlon J.-M., PEschauX C., PUBERT E., RENDU W., BOUDADI-MALIGNE M., LAROULANDIE V., BARSHAY-SZMIDT C. et LANGLAIS M. 2015, « Le Roc de Marcamps 2 (Prignac-et-Marcamps, Gironde) : nouvelles données sur la subsistance et les traditions techniques au début du Magdalénien moyen », Bulletin de la Société Préhistorique Française, vol. 112, p. 475-516.

LAM Y.M., CHEN X. et PEARSON O.M. 1999, «Intertaxonomic variability in patterns of bone density and the differential representation of Bovid, Cervid, and Equid elements in the archaeological record ", American Antiquity, vol. 64, p. 343-362.

LANGlais et laroulandie V. (coord.), BOUdADi-MALigne M., CHALARd P., COSTAMAGNo S., DANGER M., HENRI-GAMBIER D., LACRAMPE-CUYAUBÈRE F., MALLYE J.-B., PÉTILLON J. M., RIGAUD S., ROYER A., SITZIA L. 2014, La grotte-abri de Peyrazet (Creysse, Lot, France), une séquence tardiglaciaire pour le Haut-Quercy; 
Le Magdalénien supérieur, rapport de fouilles programmées, synthèse de la triennale (2012-2014), DRAC-SRA Midi-Pyrénées.

LANGLAis M. et LAROULANDiE V. (coord.), COSTAMAGNo S., DANGER M., JACQUIER J., KUNTZ D., LACRAMPECUYAUBÈre F., MALLYE J.-B., MUTH X., PÉTILLON J.-M., RIGAUD S., ROYER A., SITZIA L. 2015, La grotte-abri de Peyrazet (Creysse, Lot, France), une séquence tardiglaciaire pour le Quercy, rapport de fouilles programmées \& d'APP, DRAC-SRA Midi-Pyrénées.

LANGLAIS M. et LAROULANDIE V. 2016, « La grotte-abri de Peyrazet (Creysse, Lot, France) : une

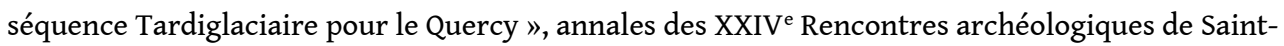
Céré (Lot), p. 63-67.

LANGlais M., LAROULANDie V., BRUXelles L., ChaLARD P., COCHARD D., COSTAMAGNo S., DELFOUR G., KUNTZ D., Le GALL O., PÉTILLON J.-M. et QUEFFELEC A. 2009, « Les fouilles de la grotte-abri de Peyrazet (Creysse, Lot) : nouvelles données pour le Tardiglaciaire quercinois », Bulletin de la Société Préhistorique Française, vol. 106, p. 150-152.

LANGlais M., LAROUlandie V., JACQUier J., COSTAMAgno S., Chalard P., MALlye J.-B., PÉTILlon J.-M., RIGAUD S., ROYER A., SITZIA L., COCHARD D., DAYET L., FAT-CHEUNG C., Le GALl O., QUEFFELEC A. et LACRAMPE-CUYAUBère F. 2015, « Le Laborien récent de la grotte-abri de Peyrazet (Creysse, Lot, France). Nouvelles données pour la fin du Tardiglaciaire en Quercy », Paléo, vol. 26, p. 79-116.

LEDUC C. 2010, « Acquisition et exploitation des ressources animales au Maglemosien : essai de reconstitution des chaînes opératoires globales d'exploitation d'après l'analyse des vestiges osseux des sites de Mellerup et Lundby Mose (Sjaeland - Danemark) », Thèse de doctorat, Paris, Université de Paris 1.

MATEOS CACHORRO A. 2005, « Meat and fat: intensive exploitation strategies in the Upper Palaeolithic approached from bone fracturing analysis », dans J. MULVILLE et A. OUTRAM (dir.), The Zooarchaeology of fats, oils, milk and dairying, actes du $9^{\mathrm{e}}$ Congrès de l'ICAZ, Durham, 23 au 28 août 2002, Oxford, Oxbow Books, p. 150-159.

MELDGAARD J. 1980, «Greenland », dans B. DAM-MIKKELSEN et T. LUNDBÆK (dir.), Ethnographic objects in the Royal Danish Kunstkammer 1650-1800, København, Nationalmuseet, p. 3-16.

POPLIN F. 1983, «Incives de Renne sciées du Magdalénien d'Europe occidentale », dans POPLIN F. (dir.), La faune et l'Homme préhistorique, Paris, Société préhistorique française, p. 55-66 (Mémoire XVI).

SOULIER M.-C. 2013, « Entre alimentaire et technique : l'exploitation animale aux débuts du Paléolithique supérieur. Stratégies de subsistance et chaînes opératoires du traitement du gibier à Isturitz, La Quina aval, Roc-de-Combe et Les Abeilles ", Thèse de doctorat, Toulouse, Université de Toulouse 2 - Le Mirail.

SOULIER M.-C., KUNTZ D., LACARRIÈRE J. et CASTEL J.-C. 2014, « Le Renne comme ressource alimentaire : discussion entre pratiques actuelles et paléolithiques » dans costamagno S. (dir.), Histoire de l'alimentation humaine : entre choix et contraintes, actes du $138^{\mathrm{e}}$ congrès du CTHS, Rennes avril 2013, CTHS, Paris, p. 153-169.

SOULIER M.C. et Costamagno S. 2017, « Let the cutmarks speak! Experimental butcheries to reconstruct carcass processing ", Journal of Archaeological Science Reports, vol. 11, p. 882-802.

VILLA P. et MAHIEU E. 1991, «Breakage patterns of human long bones », Journal of Human Evolution, vol. 21, p. 27-48. 
WHITE T.D. 1992, Prehistoric cannibalism at Mancos 5MTUMR-2346, Oxford, Princeton University

Press.

\section{NOTES}

1. $\mathrm{NMI}=$ Nombre minimum d'individus .

2. $\mathrm{NME}=$ Nombre minimum d'éléments squelettiques.

3. $\mathrm{MAU}=$ Minimal Animal Units.

\section{RÉSUMÉS}

Le renne, Rangifer tarandus, tout comme les autres gibiers des chasseurs-collecteurs paléolithiques, fournit potentiellement de multiples matières premières à usage alimentaire, technique ou symbolique. Par une étude pluridisciplinaire des restes fauniques issus de l'ensemble Magdalénien supérieur de la grotte-abri de Peyrazet, nous nous sommes attachés à reconstituer la chaîne opératoire d'exploitation globale de cette espèce, gibier de prédilection des chasseurs-collecteurs ayant occupé ce site il y a 15000 ans. Le profil squelettique dominé par les extrémités de pattes pourrait suggérer une introduction complémentaire de peaux - en plus des quartiers de carcasses - qui serait en lien avec certaines activités réalisées sur le site. Les traces anthropogènes, nombreuses et variées, indiquent une exploitation de viande, de moelle et de matières dures provenant du renne. La mise en évidence d'un schéma opératoire complet de production d'aiguilles sur os ainsi que la présence d'éléments de parure, principalement des incisives sciées, soutient l'hypothèse que, à côté d'un panel d'activités variées, des objets ou des vêtements ont été confectionnés voire décorés sur place.

\section{AUTEURS}

\section{SANDRINE COSTAMAGNO}

TRACES - UMR 5608 - CNRS,

Université Toulouse Jean-Jaurès

\section{JEAN-MARC PÉTILLON}

TRACES - UMR 5608 - CNRS,

Université Toulouse Jean-Jaurès

\section{SOLANGE RIGAUD}

PACEA - UMR 5199 - CNRS,

Université de Bordeaux 
DELPHINE KUNTZ

ArScAn - UMR 7041 - CNRS

Maison de l'Archéologie et de l'Ethnologie

VÉRONIQUE LAROULANDIE

PACEA - UMR5199 - CNRS,

Université de Bordeaux

MATHIEU LANGLAIS

PACEA - UMR5199 - CNRS,

Université de Bordeaux 


\title{
L'utilisation des petits gibiers au Tardiglaciaire : le cas de Rochereil (collection Jude, Dordogne)
}

\author{
Jean-Baptiste Mallye, Véronique Laroulandie, Peggy Bonnet-Jacquement, \\ Myriam Boudadi-Maligne, Mathieu Langlais, Elena Man-Estier, Carole \\ Vercoutère et Patrick Paillet
}

Les recherches menées sur la grotte de Rochereil ont été rendues possible par le financement du Projet Collectif de Recherche "Peuplement et cultures à la fin de du Tardiglaciaire dans le nord du Périgord, entre Dronne et Tardoire ». Nous tenons à remercier le Ministère de la Culture et de la Communication et le Service Régional d'Archéologie de la région Aquitaine pour leur soutien financier. Nous tenons à remercier également les descendants de la famille Jude qui ont mis à notre disposition une partie des collections de la grotte de Rochereil ainsi que la Mairie de Brantôme et le Musée National de Préhistoire pour nous avoir facilité l'accès à la collection Jude. Nous remercions également les deux rapporteurs de cet article, qui, par leurs conseils avisés, ont permis d'en améliorer le contenu. Les recherches menées au sein du laboratoire PACEA sont facilitées par le projet LABEX LaScArBX, projet bénéficiant d'une aide de l'État gérée par l'Agence Nationale de la Recherche au titre du programme Investissements d'avenir portant la référence ANR-10-LABX-52.

1 La fin des temps glaciaires est le théâtre d'importants changements climatiques, environnementaux et culturels. Globalement, dans le sud de la France, cette période voit la disparition des espèces continentales de milieu froid et ouvert, et leur remplacement par des communautés animales de milieu tempéré. Malgré de récentes avancées sur le sujet, notamment sur la disparition du renne (e.g. Bridault et al., 2000 ; Costamagno et al., 2016), le rythme de recomposition des biocénoses reste à préciser tant au niveau macro-régional que micro-régional, chaque espèce ayant une résilience qui lui est propre. Ces changements ont affecté la disponibilité des ressources potentiellement exploitables par les chasseurs-collecteurs. Leurs conséquences sur l'occupation du milieu, la subsistance, les dynamiques sociétales constituent un enjeu important des recherches systémiques conduites sur cette période (e.g. Pétillon et al., 2016 ; Laroulandie et al., 2017). 
2 Dans le sud-ouest de la France, la plupart des sites du Magdalénien supérieur montrent que la chasse est orientée vers les ongulés (e.g. Fontana 1998; Fontana 2000 ; Costamagno, 2003 ; Feyfant et al., 2015 ; Kuntz et al., 2016). Une intensification de la capture des petits gibiers à poils et à plumes ainsi que la pêche marque également cette période (Le Gall, 2003; Cochard 2004; Costamagno et al., 2008; Jones, 2009; Laroulandie, 2009 ; Langlais et al., 2012 ; Laroulandie, 2016). Notons néanmoins que ce caractère apparaît fortement variable d'un site à l'autre tant au niveau des espèces concernées que de leur importance relative. Dans cette région, l'exploitation du monde animal à l'Azilien comme au Laborien est moins bien connue; mais les données indiquent encore que les activités cynégétiques sont orientées vers les ongulés - cheval, cerf ou aurochs - et les petits gibiers - lapin, castor notamment - (Cochard, 2004 ; Jones, 2004, 2006, 2016 ; Fat Cheung et al., 2014 ; Langlais et al., 2014a, 2015a ; Chevallier, 2015).

De nombreux modèles ont été proposés dans différentes régions de l'ancien monde pour expliquer les raisons de l'incorporation de petits gibiers dans l'économie des sociétés préhistoriques. Ces modèles mettent en cause les conditions environnementales, l'augmentation de la pression démographique, une baisse de la mobilité des groupes humains, les innovations techniques ou encore des changements dans l'organisation sociale (e.g. Stiner et al., 1999 ; Stiner, 2001 ; Stiner et Munro, 2002 ; Hockett et Haws, 2003, 2005 ; Cochard, 2004 ; Cochard et Brugal, 2004 ; Costamagno et Laroulandie, 2004 ; Müller, 2004; Costamagno et al., 2008; Costamagno et al., 2009; Langlais et al., 2012 ; Rillardon et Brugal, 2014 ; Jones 2016). Ils ne sont pas exclusifs et force est de constater que le nombre croissant d'études montre que le phénomène est complexe et non linéaire au cours du temps. Dans cet article, nous proposons une documentation inédite qui participe à ce débat. Le cas d'étude présenté concerne la séquence tardiglaciaire de Rochereil, en Dordogne. Ce gisement, fouillé par Jude (1960), livre un abondant matériel qui a fait l'objet d'une récente révision pluridisciplinaire dans le cadre du PCR «Peuplements et cultures à la fin du Tardiglaciaire dans le nord du Périgord, entre Dronne et Tardoire » dirigé par l'un de nous (P. P.).

4 À la lumière des données contextuelles régionales, de nouvelles analyses technoéconomiques et de datations radiocarbones, cette séquence est à même d'apporter des éléments de réponse participant à la connaissance des changements environnementaux et culturels marquant la fin des temps glaciaires dans cette région du Périgord. L'attention est ici focalisée sur l'exploitation des petits gibiers. Nous adoptons une démarche inductive fondée sur une analyse taphonomique et archéozoologique détaillée du matériel. Cette approche est susceptible de renseigner les chaînes opératoires mises en œuvre et les produits qui étaient recherchés.

\section{Le site de Rochereil : contexte et nouveaux travaux}

5 Le gisement de Rochereil est situé sur la commune de Grand Brassac en bordure de la Dronne à une centaine de mètres du gisement de Pont d'Ambon. La grotte fut découverte au début du $\mathrm{xx}^{\mathrm{e}}$ siècle par Raoul de Ricard et a connu deux campagnes de fouille. La première a été menée par Maurice Féaux et le Marquis Gérard de Fayolle en 1912 et 1921, la seconde par Paul-Émile Jude de 1935 à 1939. Cette dernière a livré une riche collection de vestiges qui est présentée dans une monographie (Jude, 1960). L'auteur y décrit une stratigraphie formée de quatre couches horizontales. La couche la 
plus profonde et stérile est composée de sables fluviatiles. La deuxième a livré un ensemble attribué au Magdalénien. La troisième, découpée par endroits en trois sousensembles, livre de l'Azilien. Au sommet, la dernière couche contenait quelques vestiges du Néolithique et de périodes historiques (Jude, 1960, p. 10).

La grotte de Rochereil est connue pour la diversité et l'abondance de son art mobilier sur os et bois de cervidé (Man-Estier et Paillet, 2013 ; Paillet et Man-Estier, 2014 ; ManEstier et al., sous presse). Ce site a également livré une riche industrie osseuse magdalénienne récemment réévaluée (Rémy, 2013) ainsi que quelques éléments aziliens en cours d'étude. La révision du matériel lithique met en évidence une séquence "classique ", où se succèdent le Magdalénien supérieur, l'Azilien ancien, récent et le Laborien (Langlais et Bonnet-Jacquement, 2012). La majorité des morphotypes d'armatures diagnostiques de chaque technocomplexe, définie au niveau macro-régional, se retrouve dans les différentes couches reconnues par Jude. Néanmoins, si l'on se réfère aux données contextuelles régionales (e.g. Fat Cheung et al., 2014 ; Fat Cheung, 2015 ; Langlais et al., 2014 a et b, 2016), des erreurs de lecture lors de la fouille ou des processus post-dépositionnels ont vraisemblablement induit quelques mélanges. En l'absence de coordonnées tridimensionnelles une réévaluation archéostratigraphique s'avère impossible. De fait, lors des interprétations, il faut garder en mémoire qu'un certain degré d'hétérogénéité existe au sein des ensembles archéologiques définis par Jude.

\section{Datations ${ }^{14} \mathrm{C}$ AMS}

7 Avant la reprise du matériel par l'équipe pluridisciplinaire, seule une date était disponible pour le site de Rochereil (Mafard et al., 2007). Réalisée sur le crâne de l'enfant dit magdalénien, le résultat (OxA-16932: 11 255 \pm 50 ) indique pourtant un âge connu régionalement pour l'Azilien (Fat Cheung, 2015).

8 Dans le cadre du PCR, une série de 17 dates sur ossements identifiés taxinomiquement et de provenance stratigraphique connue (c'est-à-dire marqués selon les subdivisions de Jude) a été réalisée. Ces nouvelles dates (tabl. 1) nous ont permis de tester la stratigraphie de Jude et de documenter la recomposition des faunes de la région à la fin du Tardiglaciaire (Mallye et al., 2014). 
Tableau 1 : Rochereil : résumé des datations radiocarbone réalisées sur les différents taxons suivant les attributions stratigraphiques données par Jude.

\begin{tabular}{|l|l|l|l|r|r|}
\hline Référence & Marquage & Taxon & \multicolumn{1}{|c|}{ Code labo } & Âge 14C BP & $\begin{array}{c}\text { Âge calibré BP 99,7\% } \\
\text { (intCal13) }\end{array}$ \\
\hline ROC 5439 & Azilien & Cheval & Lyon-11466 (SacA37720) & $10390 \pm 50$ & $12539-11978$ cal BP \\
\hline ROC 4760 & Azilien & Lapin & Lyon-11468 (SacA37722) & $10465 \pm 50$ & $12634-12055$ cal BP \\
\hline ROC 5310 & Azilien & Cerf & Lyon-11467 (SacA37721) & $11170 \pm 50$ & $13181-12805$ cal BP \\
\hline ROC 10008 & Azilien & Sanglier & Lyon-10166 (SacA32833) & $11340 \pm 50$ & $13328-13059$ cal BP \\
\hline ROC 10006 & Azilien & Chevreuil & Lyon-10168 (SacA32835) & $11530 \pm 60$ & $13567-13179$ cal BP \\
\hline ROC 4909 & Azilien sup. & Lapin & Lyon-11469 (SacA37723) & $12070 \pm 60$ & $14170-13735$ cal BP \\
\hline ROC 5366 & Azilien & Aurochs & Lyon-11465 (SacA37719) & $12270 \pm 60$ & $14786-13923$ cal BP \\
\hline ROC 10001 & Azilien & Renne & Lyon-10164 (SacA32831) & $12290 \pm 60$ & $14827-13951$ cal BP \\
\hline ROC 10000 & Azilien & Renne & Lyon-10172 (SacA32839) & $12430 \pm 50$ & $15051-14131$ cal BP \\
\hline ROC 5219 & Magdalénien & Sanglier & Lyon-10165 (SacA32832) & $10125 \pm 45$ & $12087-11404$ cal BP \\
\hline ROC 5290 & Magdalénien & Cerf & Lyon-11464 (SacA37718) & $10780 \pm 50$ & $12797-12574$ cal BP \\
\hline ROC 5218 & Magdalénien & Renne & Lyon-10169 (SacA32836) & $12100 \pm 60$ & $14202-13744$ cal BP \\
\hline ROC 5220 & Magdalénien & Sanglier & Lyon-10171 (SacA32838) & $12180 \pm 60$ & $14455-13758$ cal BP \\
\hline ROC 5285 & Magdalénien & Cheval & Lyon-11463 (SacA37717) & $12240 \pm 60$ & $14703-13835$ cal BP \\
\hline ROC 5221 & Magdalénien & Chevreuil & Lyon-10167 (SacA32834) & $12270 \pm 60$ & $14786-13923$ cal BP \\
\hline ROC 5217 & Magdalénien & Renne & Lyon-10170 (SacA32837) & $12390 \pm 60$ & $15027-14081$ cal BP \\
\hline ROC 5282 & Magdalénien & Aurochs & Lyon-11462 (SacA37716) & $12430 \pm 60$ & $15074-14118$ cal BP \\
\hline
\end{tabular}

9 La plupart des vestiges provenant de l'ensemble magdalénien ont donné des dates situées entre 14000 et 15000 cal BP (fig. 1). Mais, deux dates, l'une sur cerf et l'autre sur sanglier, sont postérieures à $13000 \mathrm{cal} \mathrm{BP.} \mathrm{Ces} \mathrm{deux} \mathrm{dates} \mathrm{correspondent} \mathrm{davantage}$ à ce qui est connu régionalement pour l'Azilien (Fat Cheung et al., 2014; Fat Cheung 2015). Pour l'ensemble azilien défini par Jude, l'inverse s'observe: les dates se concentrent entre 14000 et 11500 cal BP alors que trois dates dont deux réalisées sur des restes de renne, sont antérieures à 14000 cal BP. Ces trois dates correspondent à ce qui est connu régionalement pour le Magdalénien supérieur (Langlais, 2010 ; BarshaySzmidt et al., 2016 ; Langlais et al., 2016). 
Figure 1 : Rochereil : ensemble des datations réalisées dans le cadre du PCR.

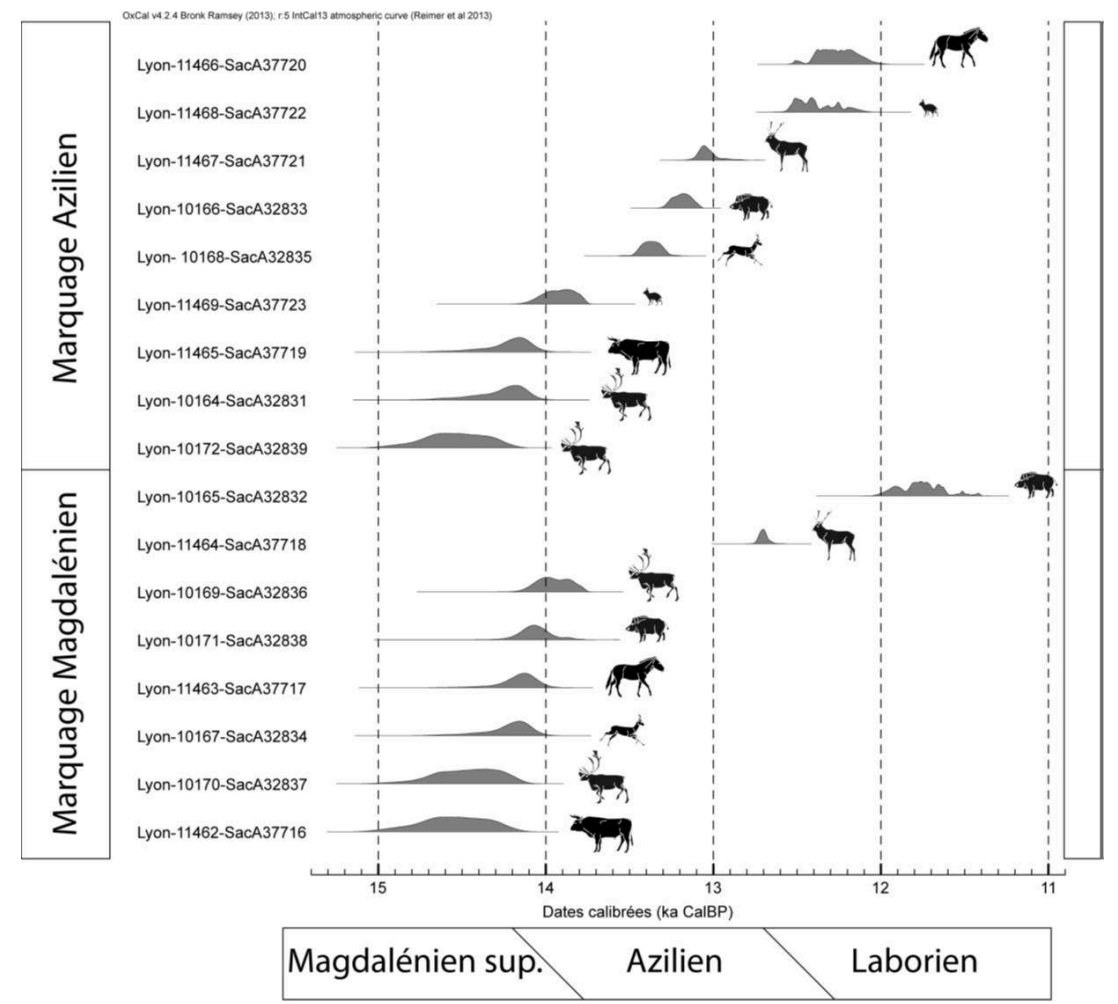

Les dates ont été ordonnées par ordre décroissant selon les attributions contextuelles portées par chacune des pièces. Le cadrage chronologique des différents technocomplexes est issu des données provenant de Langlais (2010), Langlais et al. (2012, 2014a et b, 2016), Barshay-Szmidt et al. (2016), Fat Cheung et al. (2014); Fat Cheung (2015).

Ainsi, comme pour les éléments lithiques, il est fort probable que ces mélanges soient le résultat d'erreurs de lecture à l'interface des deux ensembles. Cette hypothèse est renforcée par l'analyse des restes de macrofaune; en effet l'étude de la grande faune menée par l'une d'entre nous (C.V.) a montré que les restes de renne sont essentiellement contenus dans le Magdalénien tandis que le cerf, les Bovinés et le cheval sont essentiellement présents dans l'ensemble azilien. Enfin, les dates sur renne considérées comme fiables par le laboratoire ne dépassent pas le début de l'Allerød. Ce résultat va dans le sens de la récente synthèse sur la disparition régionale de cette espèce (Costamagno et al., 2016).

\section{La mésofaune de Rochereil}

\section{Matériel et méthode}

11 Au cours du PCR, une étude tapho-archéozoologique classique a été entreprise sur les restes de mésofaune. La reprise d'une collection ancienne pose cependant plusieurs difficultés lors de l'interprétation des données. Il reste en effet délicat d'interpréter précisément la représentation anatomique, une récolte partielle des vestiges étant clairement visible lors de l'analyse du matériel : les fragments de diaphyses sont sousreprésentés par rapport à ce qui caractérise les ensembles recueillis au tamisage et certains éléments de petite taille sont manquants. Néanmoins, le matériel étant extrêmement bien préservé, l'étude des traces permet, pour certaines espèces, 
d'aborder globalement les schémas d'exploitation et les produits animaux recherchés. Les traces de boucherie ont été comparées aux référentiels ethnoarchéologiques ainsi qu'aux résultats de différentes expérimentations publiés (Henshilwood, 1997; Laroulandie, 2001; Lloveras et al., 2009; Mallye, 2007, 2011 ; Val et Mallye, 2011 ; Pedergnana et Blasco, 2016 ; Romandini et al., 2016) dans le but d'identifier les produits recherchés.

La mésofaune de Rochereil est relativement abondante et variée : près de 1400 restes appartiennent à une vingtaine de taxons (Laroulandie, 2012; Mallye, 2013; Laroulandie, en préparation; Mallye, en préparation). Des traces anthropogènes variées ont été observées sur plusieurs d'entre elles. Parmi les oiseaux, ce type de marques s'observe sur des ossements de cygne, Cygnus sp., d'anatidés, d'aigle royal, Aquila chrysaetos, de Lagopèdes, Lagopus sp., de chouette harfang, Bubo scandiacus, et divers passériformes dont le grand corbeau, Corvus corax et une espèce de petite taille. Pour les mésomammifères, la liste compte plusieurs carnivores, parmi lesquels figurent le renard, Vulpes sp., le blaireau, Meles meles, le glouton, Gulo gulo, et le chat forestier, Felis silvestris, ainsi que des glires dont le castor, Castor fiber, le spermophile, Spermophilus citellus, les lièvres, Lepus sp. et le lapin de garenne, Oryctolagus cuniculus. Pour ce premier bilan archéozoologique, l'attention s'est focalisée sur le harfang, le lagopède, le spermophile et le lapin qui représentent à eux seuls $80 \%$ des petits animaux de Rochereil, toutes couches confondues (Tabl.2). Le marquage des indications stratigraphiques sur les pièces concerne près de la moitié de ces vestiges. Pour le spermophile, le harfang et les lagopèdes, les pièces marquées sont toutes ou majoritairement attribuées au Magdalénien supérieur (fig. 2). Pour le lapin de garenne, l'essentiel des pièces est marqué "Azilien». Compte tenu de l'identification de pollution des ensembles archéologiques (voir supra) et des données contextuelles régionales, nous postulons, dans cette étude, que les restes de spermophile, harfang et lagopèdes non marqués appartiennent plus probablement au niveau magdalénien. Quant au lapin, il est plus vraisemblablement azilien. Bien sûr, d'autres dates directes permettraient de valider cette hypothèse de travail.

Tableau 2 : Rochereil : Nombre de restes de harfang, lagopède, spermophile et lapin selon les attributions stratigraphiques notées par Jude.

\begin{tabular}{|c|c|c|c|c|}
\hline Taxons & Magdalénien & Azilien & Sans indication & Total \\
\hline Spermophile & 175 & 4 & 265 & $\mathbf{4 4 4}$ \\
\hline Lapin de garenne & 45 & 155 & 148 & $\mathbf{3 4 8}$ \\
\hline Harfang & 87 & 4 & 134 & $\mathbf{2 2 5}$ \\
\hline Lagopède & 33 & 1 & 26 & $\mathbf{6 0}$ \\
\hline Total & $\mathbf{3 4 0}$ & $\mathbf{1 6 4}$ & $\mathbf{5 7 3}$ & $\mathbf{1 0 7 7}$ \\
\hline
\end{tabular}


Figure 2 : Rochereil : Abondance des espèces considérées selon leur attribution culturelle.

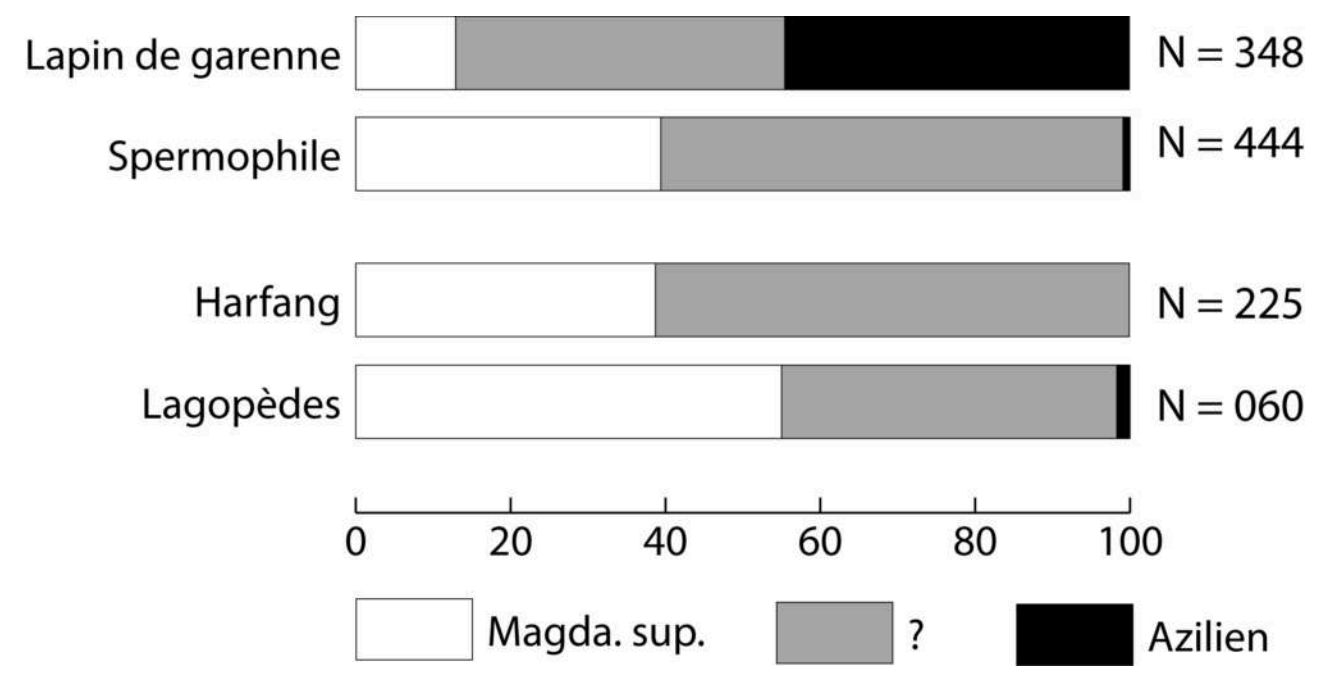

\section{Le lapin des niveaux « aziliens »}

Pour l'Azilien, près de 350 restes de lapins ont été identifiés. Ils renvoient à un minimum de 60 individus adultes. Près de $20 \%$ des os portent des stries, ce qui est élevé par rapport à ce qui est connu pour les ensembles osseux de lapins du même faciès culturel (e.g. Cochard, 2004). Ces chiffres doivent toutefois être pris avec précaution au regard des méthodes de récolte sélective des ossements lors des fouilles.

Les traces sur les os documentent diverses étapes de la chaîne opératoire de boucherie depuis le dépouillement des carcasses en passant par leur tronçonnement, le décharnement des os et la récupération de la moelle (fig. 3). Des traces de brûlures distales (sensu Vigne et al., 1981 ; Vigne et Marinval-Vigne 1983) ont pu être identifiées sur les extrémités proximales et distales des membres ainsi que l'extrémité du museau attestant de la cuisson de quartiers de carcasses au contact de la flamme. Enfin, si la peau a été retirée préalablement à la consommation de la chair, nous ne pouvons savoir si elle a été conservée par les chasseurs-collecteurs de l'Azilien. Ces observations sont assez similaires à celles qui ont été faites pour d'autres ensembles de la même période (Cochard, 2004). 
Figure 3 : Rochereil : Localisation et dénombrement des traces de boucherie et de cuisson sur les restes de lapin « azilien ».

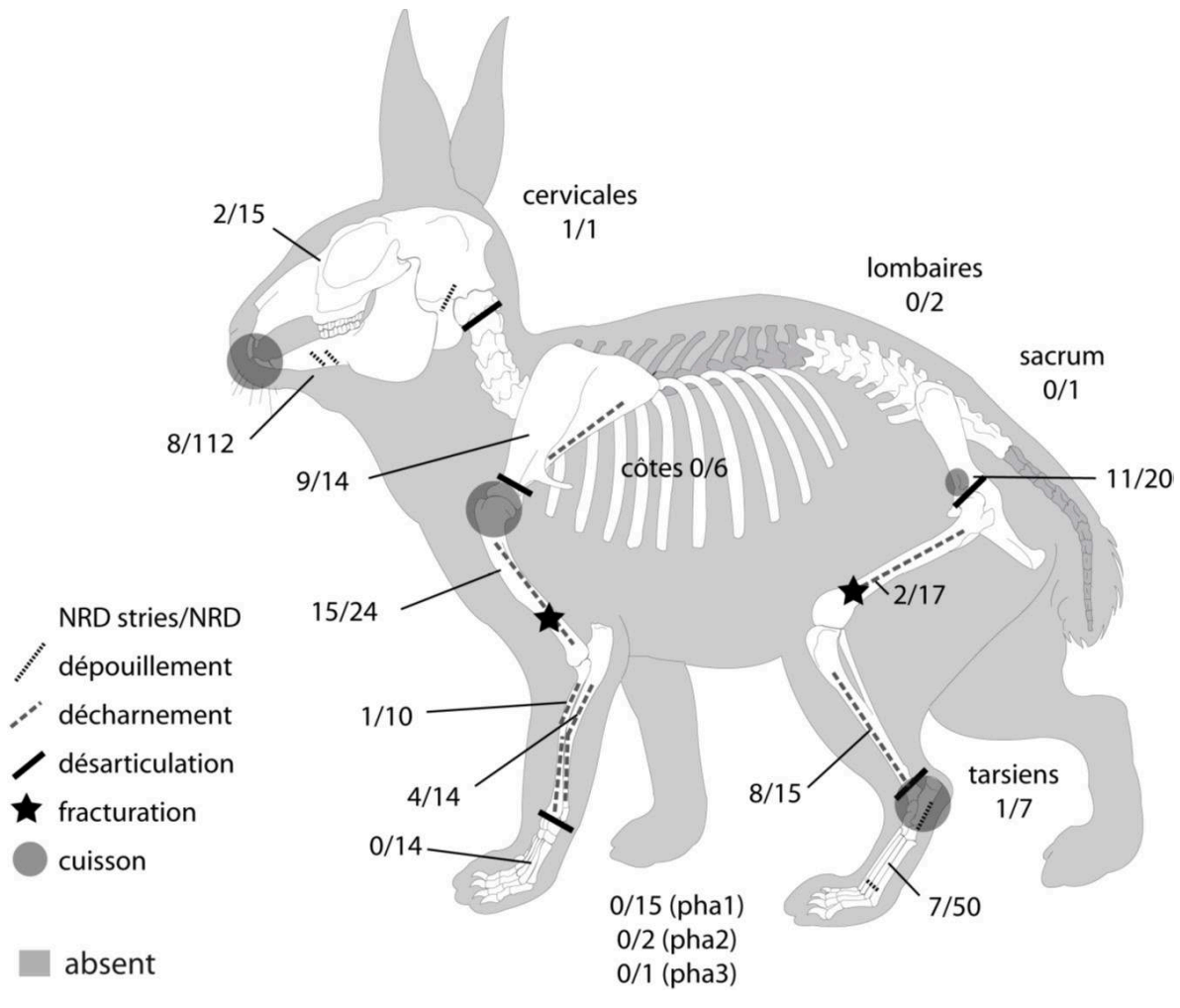

Modifié d'après le dessin de M. Coutureau et V. Forest (c) 1996 ArcheoZoo.org.

\section{Le spermophile du Magdalénien}

Dans le niveau magdalénien, l'abondance des restes osseux de spermophile est à noter. Ce petit écureuil terrestre avait déjà intrigué Jude qui rapporte en avoir trouvé en plus grande quantité que le renne dans la couche magdalénienne (Jude, 1960, p. 2512).

Ce rongeur de la même famille que la marmotte vit actuellement dans les régions de steppes à graminées d'Europe centrale. Mesurant une vingtaine de centimètres pour une masse de 200 à 400 grammes, il vit en colonie d'une dizaine d'individus, hiberne d'octobre à mars dans des terriers. La femelle met au monde chaque année de 5 à 8 petits (Macdonald et Barrett, 1993). Le décompte des restes récoltés permet d'individualiser 31 individus. Le fait remarquable de cette série réside dans l'observation de nombreuses traces anthropogéniques sur l'ensemble du squelette (fig. 4). Des manques évidents en ossements sont notés notamment au niveau des bas de pattes, des côtes et des vertèbres. Ils concernent des éléments de petite dimension et/ ou fragiles et sont plus probablement le résultat de la conservation et du ramassage différentiel que d'un transport sélectif par les chasseurs du Magdalénien supérieur. En dépit de ce constat, nous pouvons quand même établir une chaîne opératoire de préparation et de consommation des carcasses allant du dépouillement à la cuisson et au décharnement. 
Figure 4. Rochereil : Localisation et dénombrement des traces de boucherie sur les restes de spermophile.

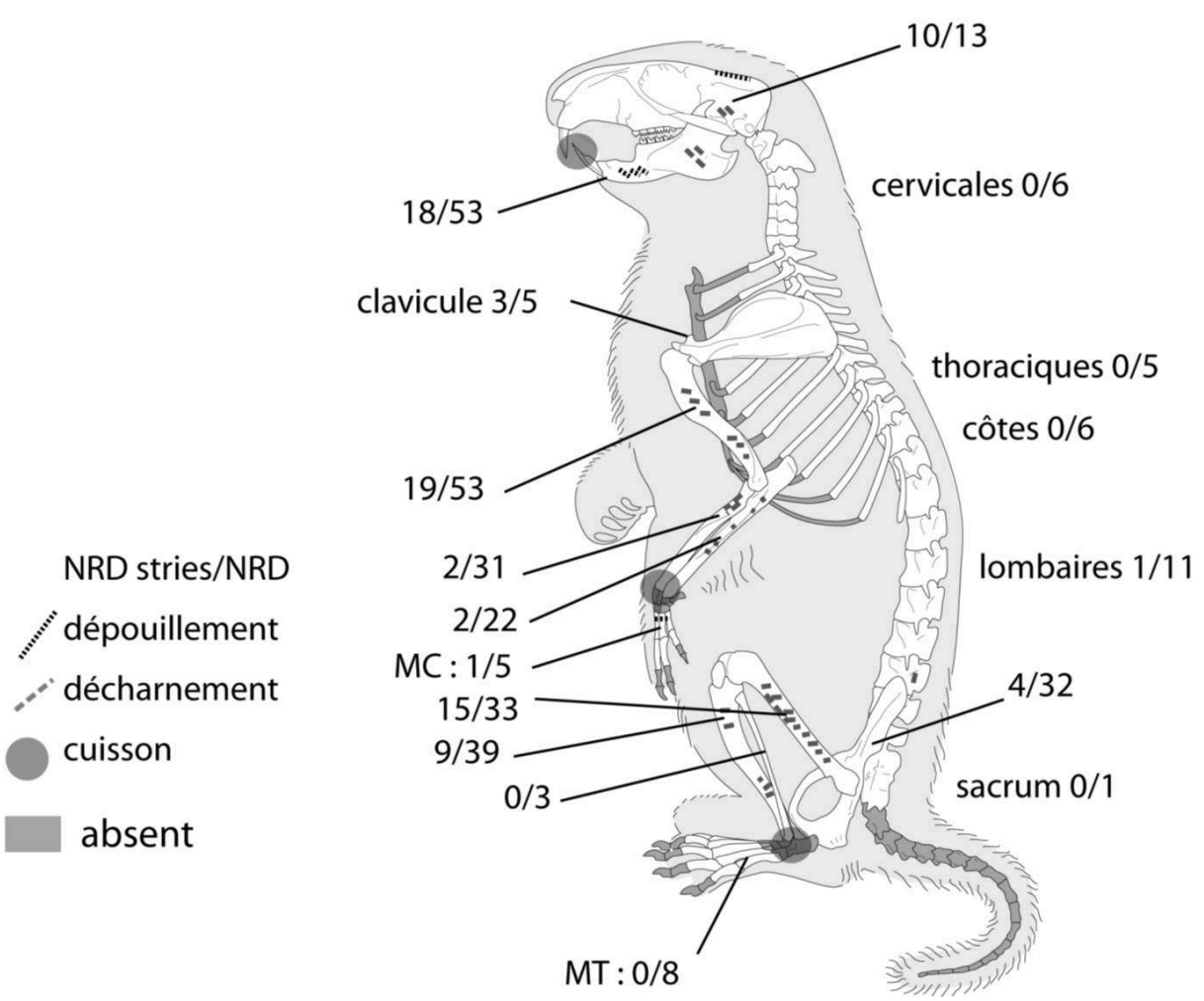

Squelette de Marmotte utilisé pour l'occasion modifié d'après le dessin de C. Beauval et C. Tomé Carpentier (c) 2015 ArcheoZoo.org.

Les traces de découpe localisées au sommet du crâne sur les pariétaux (fig. 5a) ainsi que celle situées sur le diastème de la mandibule (fig. $5 b$ ) ou encore sur les métapodes (fig. 5c) peuvent être interprétées comme relevant du dépouillement des carcasses. La minutie et donc le temps consacré à cette étape de préparation des carcasses peuvent constituer un indice fort quant à la récupération de la peau de ces rongeurs. Les témoignages ethnographiques ne manquent pas; de nombreuses populations d'Amérique du Nord confectionnent des manteaux en peau de spermophile (Honigmann, 1954 ; Mandelbaum, 1979 ; Gillespie, 1981 ; Burch, 1984 ; Wein et Freeman, 1995 ; Brunton, 1998; Ignace, 1998). À Rochereil, sachant qu'un minimum de 31 individus a été capturé et connaissant la surface de peau disponible sur chaque individu nous pouvons estimer à $1 / 2$ mètre carré environ la surface de fourrure potentiellement obtenue.

Le décharnement est assez bien marqué sur les os longs par la présence de stries transverses sur le corps des diaphyses tel que sur les fémurs, les humérus, les tibias (fig. $5 \mathrm{~d}-\mathrm{i})$. Ces traces sont moins fréquentes sur les ulnas ou les radius. D'autres stries sont visibles au niveau de la fosse massétérique de la mandibule, les pariétaux, sur les apophyses zygomatiques, sur les vertèbres ou encore sur l'os coxal. Ici encore elle dénote une attention particulière à détacher la chair des ossements.

Enfin, des traces de brûlures distales ont été observées à l'extrémité de la couronne des incisives (fig. $5 \mathrm{j}$ et $\mathrm{k}$ ) et des extrémités distales de certains os longs (fig. 5l). La récurrence dans la localisation de ces traces indique que les chasseurs du Magdalénien supérieur ont fait griller les carcasses à proximité d'une source de chaleur. Ici encore le 
registre ethnographique mentionne cette pratique chez les populations d'Indiens d'Amérique du Nord (Hungry Wolf, 1974, 1975 ; MacClellan, 1975, 1987 ; Albright, 1984).

Si le spermophile est reconnu dans de nombreux sites de Paléolithique moyen et supérieur son exploitation par l'Homme est beaucoup moins bien documentée. Elle est décrite dans les gisements de Verberie (Enloe, 2000, 2010), à Monruz (Müller, 2013), au Bois Ragot (couches 6 à 4, Marquet, 2005) et à l'abri du Morin (Langlais et al., 2012). Son exploitation est présumée dans les sites du Rond du Barry (Marquet, 1993) et du Rocaux-Sorciers (Marquet, 2010). Présents en nombre variable dans les sites du Magdalénien inférieur et moyen, les restes de spermophile ne portent pas de traces anthropogéniques et semblent avoir été apportés par des prédateurs non-humains (Castel, 1999 ; Kuntz et al., 2015 ; Langlais et al., 2015b). Ainsi l'exploitation par l'Homme de ce rongeur n'est actuellement documentée que pour le Magdalénien supérieur. Le cas de Rochereil est tout à fait exceptionnel, car il permet une restitution relativement fine de la chaîne opératoire.

Figure 5 : Rochereil : traces de boucherie et de cuisson sur les restes de spermophile.

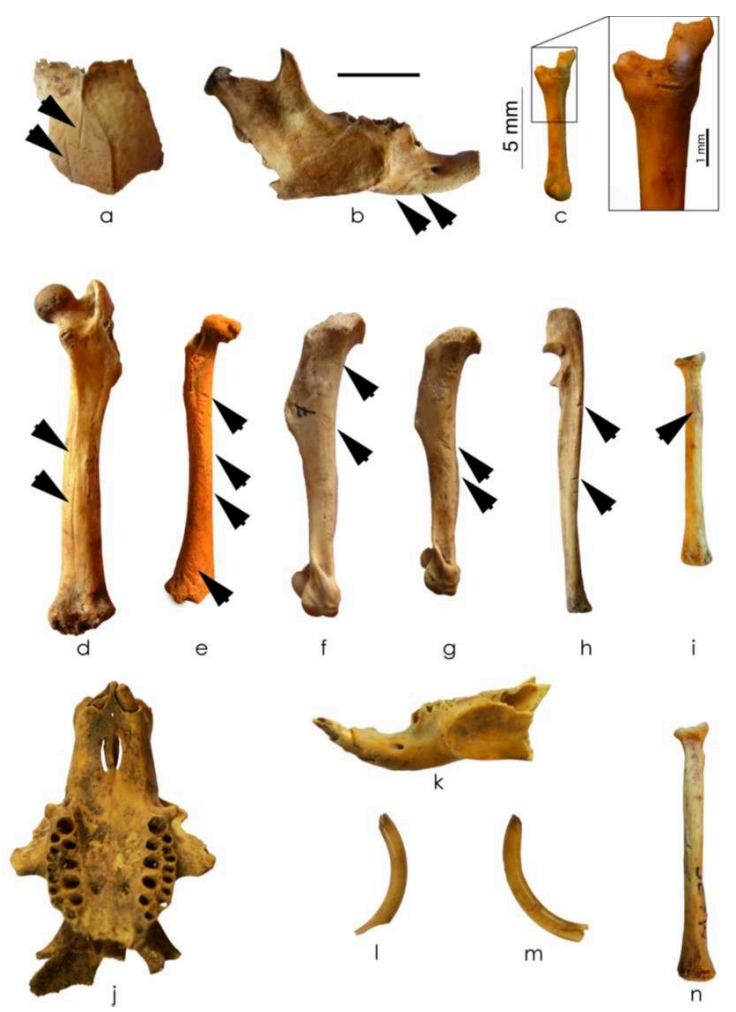

Dépouillement : a sur fragments de pariétaux, b sur mandibule et e sur métapode. Décharnement : d et e sur fémur, f et g sur humérus, h sur ulna, i sur radius. Cuisson : j sur les incisives supérieures, k sur l'incisive portée par la mandibule, I et M. sur des incisives inférieures, n sur l'extrémité distale d'un radius. Sauf mention contraire le trait représente $1 \mathrm{~cm}$.

\section{Les lagopèdes et le harfang du Magdalénien}

Une soixantaine d'ossements de lagopèdes appartenant à 7 individus adultes a été identifiée. Un tiers d'entre eux porte des stries de boucherie indiquant des gestes de désarticulation au niveau de l'aile et de décarnisation au niveau des parties les plus charnues des carcasses (fig. 6). Les produits recherchés semblent, a minima, être la 
viande. Aucun indice direct ne permet d'argumenter en faveur de l'utilisation des os ou des plumes de ce gallinacé.

Figure 6 : Rochereil : Localisation et décompte des traces de boucherie sur les os de lagopède.

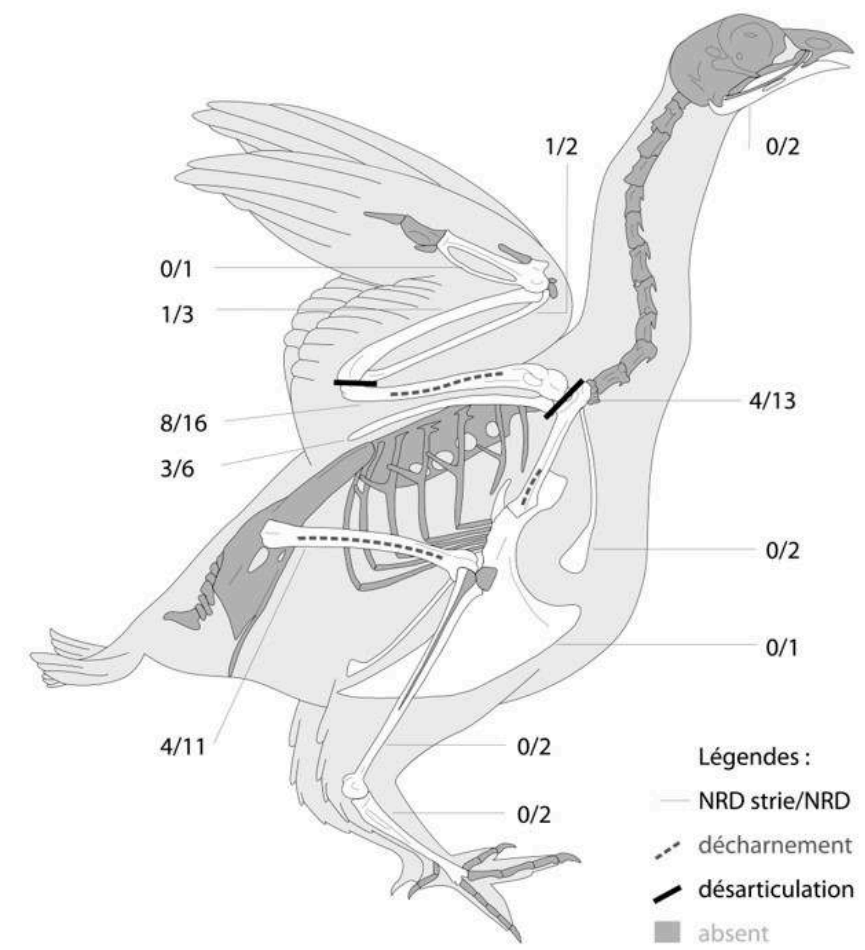

Modifié d'après le dessin de M. Coutureau et V. Laroulandie @ 2007 ArcheoZoo.org

23 La situation apparaît très différente pour la chouette harfang. Ce rapace de grande taille est représenté par plus de 200 restes osseux provenant de 17 individus adultes. Plus de la moitié présente des stries (au sens large) résultant de l'activité des chasseurs magdaléniens (fig. 7, Laroulandie 2016). Certaines correspondent au prélèvement des masses carnées, comme celles qui s'observent sur le coracoïde, l'extrémité proximale de l'humérus, le fémur ou le tibiotarse. 
Figure 7 : Rochereil : Localisation et décompte des traces de boucherie sur les os de chouette harfang.

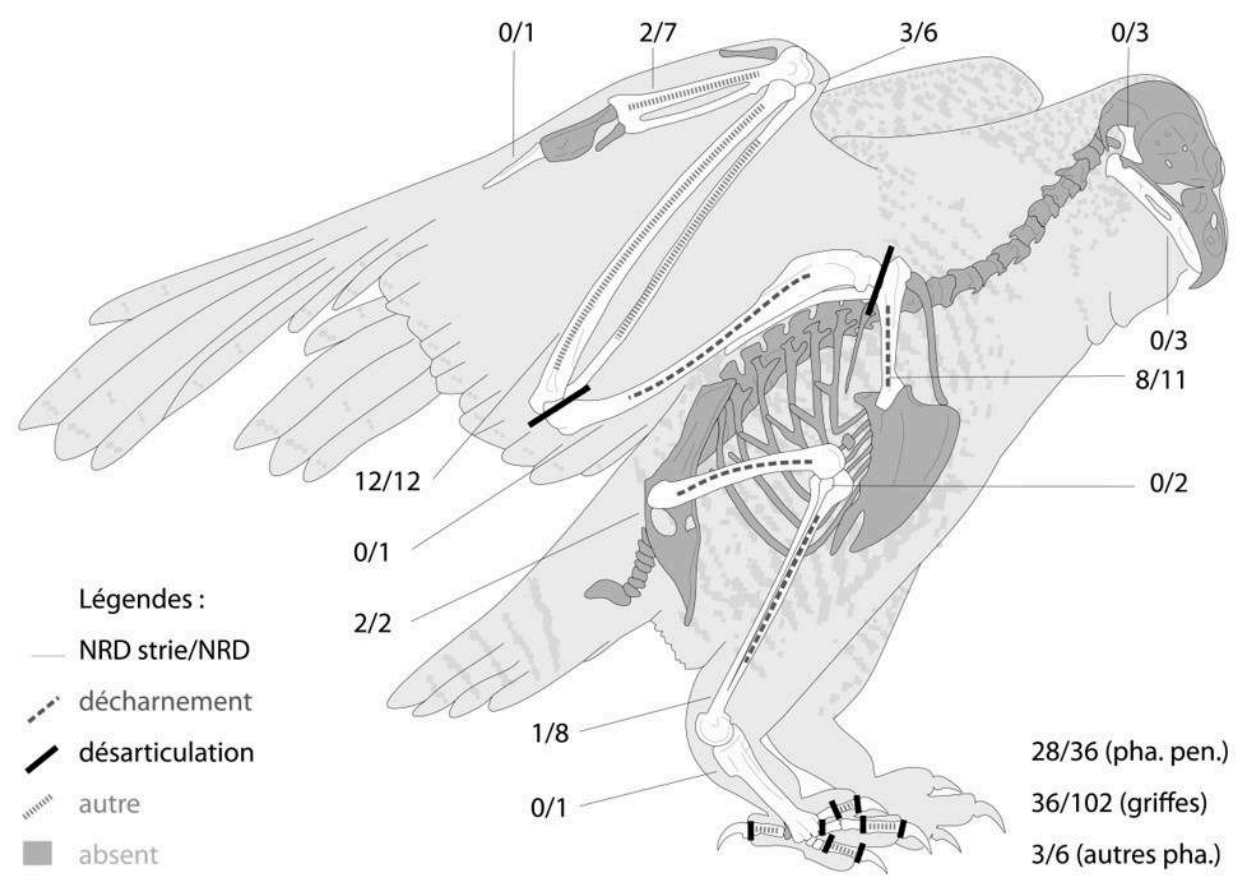

Modifié d'après le dessin de M. Coutureau et V. Laroulandie (c) 2007 ArcheoZoo.org. plusieurs traces techniques: préparation des surfaces par raclage intense, début de débitage par rainurage longitudinal (Laroulandie 2016, fig. 17, et 18). Des ulnas et des phalanges du pied ont également été décorées (Laroulandie 2016, fig. 13 et 15). Au terme de cette énumération, il apparaît que les chasseurscollecteurs qui ont fréquenté Rochereil ont recherché une large variété de produits provenant de la grande chouette des neiges.

\section{Conclusion}

Les données issues de la collection de Rochereil témoignent, entre le Magdalénien et l'Azilien, d'un changement dans les espèces de petits gibiers qui sont exploitées. Une 
évolution de la disponibilité des espèces liée aux changements environnementaux lors du passage du Bølling à l'Allerød vers $14000 \mathrm{cal} \mathrm{BP}$ en est sans doute la cause. Ce changement participe à d'autres modifications techno-économiques et artistiques.

À l'Azilien, le lapin est un classique des tableaux de chasse de la région. Cette exploitation est par ailleurs documentée dans les sites de Pont d'Ambon (Jones, 2004, 2006), de la Faurélie (Cochard, 2004), de l'abri Murat (Mallye, en préparation) ou de Pégourié (Séronie-Vivien, 1994, 1995), qui sont tous situés au Nord de la Garonne.

29 Au niveau régional pour le Magdalénien supérieur, la consommation du harfang et des lagopèdes est relativement bien connue (Laroulandie, 2009, 2016). L'exploitation alimentaire et technique du harfang et l'importance de ce rapace dans les systèmes de représentation des sociétés ont été soulignées dans une quinzaine de sites pénécontemporains du Bassin aquitain et de ses proches marges (voir synthèse Laroulandie, 2016).

L'exploitation du spermophile est plus originale et semble être propre aux groupes du Magdalénien supérieur qui l'ont chassé (ou piégé) pour sa fourrure et sa chair. La consommation de la viande est attestée au Morin (Langlais et al., 2012) et à Verberie (Enloe, 2000). À Monruz (Müller, 2013) le spermophile semble avoir été acquis à des fins esthétiques, les mandibules pouvant avoir servi d'éléments de parure ou de décors. La révision des autres séries ayant livré de nombreux restes de spermophile permettra de mieux connaître les modalités de sa consommation par les Hommes.

31 La motivation de ces acquisitions apparaît variée : matière carnée, matière première osseuse, griffes, fourrure, plumes. Elle ne répond donc pas à un besoin strictement alimentaire. À titre de discussion, à Rochereil, pour le Magdalénien, le poids de viande obtenu de l'exploitation de la cinquantaine d'individus équivaut à la moitié d'un renne. On peut donc se poser la question de la finalité d'une telle consommation. Était-elle réservée à une certaine catégorie de personne ? Était-elle consommée à une période particulière de la vie? Avait-elle un usage prophylactique?

32 Les données de Rochereil, bien que provenant de fouilles anciennes apportent ainsi de nouvelles informations sur l'exploitation des petits gibiers. Elles confirment certains traits vus dans d'autres séries contemporaines et parallèlement ajoute son lot d'originalité aux connaissances précédemment acquises.

\section{BIBLIOGRAPHIE}

ALBRIGHT S.L. 1984, Tahltan Ethnoarchaeology, Burnaby, B.C., Simon Fraser University, Departement of Archaeology.

BARSHAY-SZMIDT C., COSTAMAGNO S., HENRY-GAMBIER D., LAROULANDIE V., PÉTILLON J.-M., BOUDADI-MALIGNE M., KUNTZ D., LANGLAIS M. et MALLYE J.-B. 2016, « New extensive focused AMS14C dating of the Middle and Upper Magdalenian of the western Aquitaine/Pyrenean region of France (ca. 19-14 kA cal BP): Proposing a new model for its chronological phases and for the timing of occupation ", Quaternary International, vol. 414, p. 62-91. 
BRIDAUlt A., CHAIX L., PION G., OberLIN C., THIÉBAult S. et ARGANT J. 2000, « Position chronologique du Renne (Rangifer tarandus L.) à la fin du Tardiglaciaire dans les Alpes du Nord françaises et le Jura méridional ", dans PION G. (dir.), Le Paléolithique supérieur récent : nouvelles données sur le peuplement et l'environnement. Actes de la table ronde de Chambéry, 12 au 13 mars 1999, Paris, Société préhistorique française, p. 47-57.

BRUNTON B.B. 1998, « Kootenai », dans WALKER D.E. et STURTEVANT W.-C. (dir.), Handbook of North American Indians, Washington D.C., Smithsonian Institution, p. 223-228.

BURCH E.S., Jr 1984, « Kotzebue Sound Eskimo », dans WALKER D.E. et STURTEVANT W.-C. (dir.), Handbook of North American Indians, Washington D.C., Smithonian Institution, p. 303-311.

CASTEL J.-C. 1999, « Comportements de subsistance au Solutréen et au Badégoulien d'après les faunes de Combe Saunière (Dordogne) et du Cuzoul de Vers (Lot) », Thèse de doctorat, Talence, Université Bordeaux 1.

CHAUVIRÉ C. 1965, « Les oiseaux du gisement magdalénien du Morin (Gironde) », dans Actes du 89e congrès des Sociétés Savantes, Lyon, p. 255-266.

CHEVAlLIER A. 2015, « Chasse et traitement des mammifères durant le Magdalénien et l'Azilien dans le sud-ouest de la France. La place particulière du Cerf », Thèse de doctorat, Paris, Université de Paris 1.

COCHARD D. 2004, « Les léporidés dans la subsistance paléolithique du sud de la France », Thèse de doctorat, Talence, Université Bordeaux 1.

COCHARD D. et BRUGAL J.-P. 2004, « Importance des fonctions des sites dans les accumulations paléolithiques de léporidés ", dans BRUGAL J.-P. et DESSE J. (dir.), Petits animaux et sociétés humaines. Du complément alimentaire aux ressources utilitaires. XXIV ème rencontres internationales d'archéologie et d'histoire d'Antibes, Antibes, APDCA, p. 283-296.

COSTAMAGNO S. 2003, «Exploitation de la grande faune au Magdalénien dans le sud de la France », dans COSTAMAGNO S. et LAROULANDIE V. (dir.), Mode de vie au Magdalénien : les apports de l'archéozoologie. XIV ème Congrès UISPP, 2 au 8 septembre 2001, Liège, Oxford, Archaeopress, p. 73-88 (BAR International Series).

COSTAMAGNO S., BARSHAY-SZMIDT C., KUNTZ D., LAROULANDIE V., PÉTILLON J.-M., BOUDADI-MALIGNE M., LANGLAIS M., MALLYE J.-B. et CHEVALLIER A. 2016, « Reexamining the timing of reindeer disappearance in southwestern France in the larger context of late glacial faunal turnover », Quaternary International, vol. 414, p. 34-61.

COSTAMAGNo S., COCHARD D., LAROULANDiE V., CAZALS N., LANGlais M., VALDEYRon N., DACHARY M., BARBAZA M., GALOP D., MARTIN H. et PHILIBERT S. 2008, « Nouveaux milieux, nouveaux gibiers, nouveaux chasseurs ? Évolution des pratiques cynégétiques dans les Pyrénées du Tardiglaciaire au début du Postglaciaire ", Bulletin de la Société Préhistorique Française, vol. 105, p. 17-27.

COSTAMAGNO S. et LAROULANDIE V. 2004, «L'exploitation des petits vertébrés dans les Pyrénées françaises du Paléolithique au Mésolithique : un inventaire taphonomique et archéozoologique », dans BRUGAL J.-P. et DESSE J. (dir.), Petits animaux et sociétés humaines. Du complément alimentaire aux ressources utilitaires. XXIV ème rencontres internationales d'archéologie et d'histoire d'Antibes, Antibes, Éditions APDCA, p. 403-416.

COSTAMAGNO S., LAROULANDIE V., LANGLAIS M. et COCHARD D. 2009, « Exploitation du monde animal sur le versant nord des Pyrénées durant le Tardiglaciaire », dans FULLOLA J.-M., VALDEYRON N. et LANGLAIS M. (dir.), Els Pirineus i les àrees circumdants durant el Tardiglacial. Mutacions i filiacions 
tecnoculturals evolucion paleoambiental. Actes du XIVe Colloque international d'Archéologie de Puigcerdà, Hommage à G. Laplace, novembre 2006, Institut d'Estudis Ceretans, p. 185-209.

ENLOE J.-G. 2000, « Le Magdalénien du Bassin parisien au Tardiglaciaire : la chasse aux rennes comparée à celle d'autres espèces ", dans PION G. (dir.), Le Paléolithique supérieur récent : nouvelles données sur le peuplement et l'environnement. Table ronde de Chambéry 12 au 13 mars 1999, Paris, Société Préhistorique française, p. 39-45.

ENLOE J.-G. 2010, « Faunal and Site Structure at Verberie », dans ZUBRow E., AUDOUZE F. et ENLOE J.-G. (dir.), The Magdalenian Household, Unraveling Domesticity, Albany, State University of New York, p. 22-50.

FAT CHEUNG C. 2015, «L'Azilien pyrénéen parmi les sociétés du tardiglaciaire ouest-européen : apport de l'étude des industries lithiques », Thèse de doctorat, Université Toulouse 2 le Mirail.

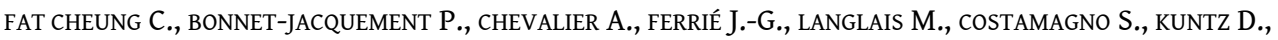
LAROULANDIE V., MALLYE J.-B., VALDEYRON N. et BALLISTA S., 2014 « L'azilien récent du sud-ouest français : mise en commun de données et premiers résultats, Les sociétés de l'Allerød et du Dryas récent entre Atlantique et Méditerranée ». Séance de la société Préhistorique Française 24 au 25 mai 2012, Bordeaux.

FEYFANT L., COCHARD D., MALLYE J.-B. 2015, « Exploitation du cheval au Magdalénien supérieur dans le Sud-Ouest de la France. Le cas de l'abri Faustin (Cessac, Gironde) », Bulletin de la Société Préhistorique Française, vol. 112, p. 693-716.

FONTANA L. 1998, « Subsistance et territoire au Magdalénien supérieur dans les Pyrénées : l'apport des données archéozoologiques de la grotte de Belvis (Aude) », Bulletin Préhistoire du Sud-Ouest, Nouvelles Études, vol. 5, p. 131-146.

FONTANA L. 2000, «La Chasse au renne au Paléolithique supérieur dans le Sud-Ouest de la France : nouvelles hypothèses de travail », Paleo, vol. 12, p. 141-164.

GILLESPIE B.C. 1981, « Mountain Indians », dans Helm J. et STURTEVANT W.-C. (dir.), Handbook of North American Indians, Washington D.C., Smithonian Institution, p. 326-337.

HENSHILWOOD C.S. 1997, «Identifying the collector: evidence for human processing of the Cape Dune Mole-Rat, Bathyergus suillus, from Blombos Cave, Southern Cape, South Africa ", Journal of Archaeological Science, vol. 24, p. 659-662.

HOCKETT B. et HAWS J.A. 2003, « Nutrional Ecology and Diachronic Trends in Palaeolithic Diet and Health », Evolutionary Anthropology, vol. 12, p. 211-216.

HOCKETT B. et HAWS J.A. 2005, « Nutrional ecology and the human demography of Neandertal extinction », Quaternary International, vol. 137, p. 21-34.

HONIGMANN J.-J. 1954, The Kaska Indians : An ethnographic reconstruction, New Haven, Yale University Press.

HUNGRY Wolf A. 1974, Charlo's People Say: The Flathead Tribe of Montana, Invermere, B.C., Good Medicine Books.

HUNGRY Wolf A. 1975, Blackfoot People, Invermere, B.C., Good Medicine Books.

IGNACE M.B. 1998, « Shuswap ", dans WALKER D.E. et STURTEVANT W.-C. (dir.), Handbook of North American Indians, Washington D.C., Smithsonian Institution, p. 203-208. 
JONES E.L. 2004, « Broad spectrum diets and the european rabbit (Oryctolagus cuniculus) : Dietary change during the Pleistocene-Holocene transition in the Dordogne, Southwestern France », Ph. D Thesis, University of Washington.

JONES E.L. 2006, « Prey choice, mass collecting, and the wild European rabbit (Oryctolagus cuniculus) », Journal of Anthropological Archaeology, vol. 25, p. 275-289.

JONES E.L. 2009, « Climate change, patch choice, and intensification at Pont d'Ambon (Dordogne, France) during the Younger Dryas ", Quaternary Research, vol. 72, p. 371-376.

JONES E.L. 2016, In search of the Broad Spectrum Revolution in Paleolithic Southwest Europe, New-York, Springer (Springer briefs in Archaeology).

JUDE P.-E. 1960, La grotte de Rochereil. Station magdalénienne et azilienne, Paris, Masson et Cie (Mémoire 30).

KUNTZ D., COSTAMAGNO S., FEYFANT L. et MARTIN F. 2016, « The exploitation of ungulates in the Magdalenian in the Entre-Deux-Mers (Gironde, France) », Quaternary International, vol. 414, p. 135-138.

Kuntz D., SÉcher A., COStamagno S., MAllye J.-B., PÉTIllon J.-M., PeschauX C., PUbert É., RENDU W. BOUDADI-MALIGNE M., LAROULANDIE V., BARSHAY-SZMIDT C. et LANGLAIS M. 2015, « Le Roc de Marcamps 2 (Prignac-et-Marcamps, Gironde) Nouvelles données sur la subsistance et les traditions techniques au début du Magdalénien moyen », Bulletin de la Société Préhistorique Française, vol. 112, p. 475-516.

LANGLAIS M. 2010, Les sociétés magdaléniennes de l'isthme pyrénéen, Paris, Comité des travaux historiques et scientifiques (Documents préhistoriques 26).

LANGLAIS M. et BONNET-JACQUEMENT P. 2012, « Rochereil, une séquence tardiglaciaire revisitée. Bilan sur les armatures lithiques (Collection Jude, Abbaye de Brantôme) », dans PAILLET P. (dir.), Rapport intermédiaire d'opération archéologique, PCR Peuplement et culture à la fin du Tardiglaciaire dans le Nord du Périgord, entre Dronne et Tardoire, Bordeaux, DRAC-SRA Aquitaine, p. 77-88.

LANGLAIS M., BONNET-JACQUEMENT P., DETRAIN L. et VALDEYRON N. 2014a, « Le Laborien : ultime sursaut technique du cycle évolutif paléolithique du sud-ouest de la France », dans JAUBERT J., FOURMENT N. et DEPAEPE P. (dir.), Transitions, ruptures et continuités durant la Préhistoire, 2. Paléolithique et Mésolithique. Actes du XXVIIe Congrès préhistorique de France (Bordeaux - Les Eyzies, juin 2010), Paris, Société préhistorique française, p. 567-582.

LANGLAIS M., COSTAMAGNo S., LAROUlANDIE V., PÉTILlON J.-M., DisCAMPS E., MALlYE J.-B., COCHARD D. et KUNTZ D. 2012, « The evolution of Magdalenian societies in South-West France between 18,000 and 14,000 calBP : Changing environments, changing tool kits », Quaternary International, vol. 272/273, p. $138-149$.

LANGLAIS M., DETRAin L., FeRRIÉ J.-G., MALLYe J.-B., MARQUebIELle B., RIGAUd S., TURQ A., BONNETJACQUEMENT P., BOUdADI-MALIGNE M., CAUX S., FAT CHEUNG C., NAUDINOT N., MORALA A., VALDEYRON N. et CHAUVIÈRE F.-X. 2014b, « Réévaluation des gisements de La Borie del Rey et de Port-de-Penne : nouvelles perspectives pour la transition Pléistocène-Holocène dans le Sud-Ouest de la France ", dans LANGLAIS M., NAUDINOT N. et PERESANI M. (dir.), Les groupes culturels de la transition PléistocèneHolocène entre Atlantique et Adriatique. Actes de la séance de la société préhistorique française de Bordeaux, 24 au 25 mai 2012, Paris, Séances de la Société préhistorique française, p. 83-128.

LANGLAIS M., LAROULANDiE V., COSTAMAgno S., PÉTILlon J.-M., MALlye J.-B., LACRAMPE-CUYAUbère F., BOUDADI-MALIGNE M., BARSHAY-SZMIDT C., MASSET C., PUBERT É., RENDU W. et LENOIR M. 2015a, 
« Premiers temps du Magdalénien en Gironde. Réévaluation des fouilles Trécolle à SaintGermain-la-Rivière (France) », Bulletin de la Société Préhistorique Française, vol. 112, p. 5-58.

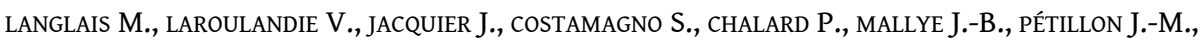
RIGAUD S., ROYER A., SITZIA L., COCHARD D., DAYET L., FAT CHEUNG C., Le GALl O., QUEFFELEC A. et LACRAMPECUYAUBÈRE F. 2015b, « Le Laborien récent de la grotte-abri de Peyrazet (Creysse, Lot, France). Nouvelles données pour la fin du Tardiglaciaire en Quercy », Paleo, vol. 26, p. 79-116.

LANGLAis M., SÉCHER A., CAUX S., DELVIGNE V., GOURC L., NORMAND C. et SÁNCHEZ de la Torre M. 2016, « Lithic tool kits: A Metronome of the evolution of the Magdalenian in southwest France (19,000-14,000 cal BP) », Quaternary International, vol. 414, p. 92-107.

LAROULANDIE V. 2001, « Les traces liées à la boucherie, à la cuisson et la consommation d'oiseaux. Apport de l'expérimentation », dans BOURGUIGNON L., ORTEGA I. et FRÈRE-SAUTOT M.-C. (dir.), Préhistoire et approche expérimentale, Monignac, Monique Mergoil, p. 97-108.

LAROULANDIE V., 2009, « De la plume à l'œuf : exploitation des ressources aviaires au Magdalénien dans le Sud de la France », dans FONTANA L., CHAUVIÈRE F.-X. et BRIDAULT A. (dir.), In search of Total Animal exploitation. Cases studies in Upper Palaeolithic and Mesolithic, actes du XVème Congrès de l'IUSPP, Lisbonne 4 au 9 septembre 2006, Oxford, Archaeopress, pp. 71-89. (BAR International Series 2040).

LAROULANDIE V. 2011, « Les restes aviaires de Rochereil (Dordogne) : bilan des travaux 2011 », dans PAILLET P. (dir.), Rapport de prospection thématique annuelle Peuplement et cultures de la fin du Tardiglaciaire dans le Nord du Périgord, DRAC-SRA Aquitaine, Bordeaux, p. 36-42.

LAROULANDIE V. 2016, « Hunting Fast-Moving, Low-Turnover Small Game : the Status of the Snowy Owl (Bubo scandiacus) in the Magdalenian », Quaternary International, vol. 414, p. 174-197.

LAROULANDie V., costamagno S., LANGLAis M. et PÉTILLON J.-M., 2017. L'œuf ou la poule ? Retour sur le projet Magdatis, « Le Magdalénien de la façade atlantique face aux changements environnementaux » in LANDAIS A., SANCHEZ-GOÑI M.-F. (coord.), un panorama de la recherche actuelle sur le quaternaire, Actes du colloque Q10, Paléoclimats et environnements quaternaires, Quoi de neuf sous le soleil ? Bordeaux, février 2016, Quaternaire 28(2)., pp. 277-283. https:// quaternaire-revue.org/8162

Le GALL 0. 2003, « Des Magdaléniens et... des poissons », dans Costamagno S. et LARoulandie V. (dir.), Mode de vie au Magdalénien : les apports de l'archéozoologie, actes du XIV ème Congrès UISPP, 2 au 8 septembre 2001, Liège, Oxford, Archaeopress, p. 119-128 (BAR International Series1144).

LLOVERAS L., MORENO GARCÍA M. et NADAL J. 2009, « Butchery, Cooking and Human Consumption Marks on Rabbit (Oryctolagus cuniculus) Bones : An experimental Study », Journal of Taphonomy, vol. 7, p. 179-201.

Macclellan C. 1975, My Old People Say : An Ethnographic Survey of Southern Yukon Territory - Part 1, Ottawa, Canadian Museum of Civilization.

MACCLELLAN C. 1987, A history of the Yukon Indians ; Part of the Land, Part of the Water, Vancouver, Douglas \& McIntyre.

MACDONALD D.W., BARETT P. 1993, Guide complet des Mammiferes de France et d'Europe, Lausanne, Delachaux et Niestlé.

MAFART B., GUIPERT G., ALLIEZ-PHILIP C. et BRAU J.-J. 2007, « Virtual reconstruction and new palaeopathological study of the Magdalenian child's skull of Rochereil », Palevol, vol. 6, p. 569-579. 
MALLYE J.-B. 2007, « Les restes de Blaireau en contexte archéologique : Taphonomie, Archéozoologie et éléments de discussion des séquences préhistoriques », Thèse de doctorat, Talence, Université Bordeaux 1.

MALLYE J.-B. 2011, « Réflexion sur le dépouillement des petits carnivores en contexte archéologique : Apport de l'expérimentation », Archaeofauna, vol. 20, p. 7-25.

MALLYE J.-B. 2013, « La mésofaune de Rochereil : suite et fin d'un inventaire », dans PAILLET P. (dir.), DRAC-SRA Aquitaine, Bordeaux, (Rapport Rapport intermédiaire d'opération archéologique, Projet Collectif de Recherche, Programme P11 No 2012-63 Peuplement et cultures de la fin du Tardiglaciaire dans le Nord du Périgord entre Dronne et Tardoire, DRAC-SRA Aquitaine, Bordeaux, p. 49-51.

MALLYE J.-B., BOUDADI-MALIGNE M., LANGLAIS M. et LAROULANDIE V. 2014, « Rochereil et son cadre radiochronologique, synthèse des datations radiocarbones obtenues », dans PAILLET P. (dir.), Peuplements et cultures à la fin du Tardiglaciaire dans le nord du Périgord, entre Dronne et Tardoire, Rapport PCR, DRAC-SRA Aquitaine, Bordeaux, p. 33-36.

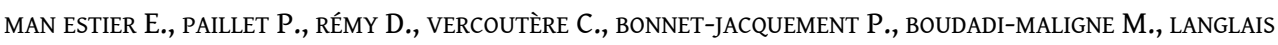
M., LAROULANDIE V., MALLYE J.-B., RIGAUD S. sous presse, « Supports et représentations dans l'art mobilier magdalénien de Rochereil (Grand-Brassac, Dordogne, France) », dans CLEYET-MERLE J.-J., GENESTE J.-M. et MAN-ESTIER E. (dir.), L'art au quotidien- objets ornés du Paléolithique supérieur, actes du colloque, Les Eyzies-de-Tayac, 16 au 20 juin 2014, Paleo.

MAN-ESTIER E., PAILLET P. 2013, « Rochereil et l'art magdalénien de la fin du Tardiglaciaire dans le nord du Périgord (Dordogne, France) », dans GROENEN M. (dir.), Expressions esthétiques et comportements techniques au Paléolithique, Oxford, Archaeopress, p. 7-36 (BAR International Series 2493).

MANDELBAum D.G. 1979, The plains Cree : An ethnographic, Historical, and comparative Study, Regina, University of Regina Press.

MARQUET J.-C. 1993, Paléoenvironnement et chronologie des sites du domaine atlantique français d'âge pléistocène moyen et supérieur d'après l'étude des rongeurs, Tours, Les Cahiers de la Claise (Suppl. $\left.\mathrm{n}^{\circ} 2\right)$.

MARQUET J.-C. 2005, « Reconstruction du climat et de l'environnement du site du Bois-Ragot à Gouex d'après l'étude des rongeurs ", dans CHOLLET A. et DUJARDIN V. (dir.), La grotte du bois-Ragot à Gouex (Vienne). Magdalénien et Azilien. Essais sur les hommes et leur environnement, Paris, Société préhistorique française, p. 373-384 (Mémoire 38).

MARQUET J.-C. 2010, « La microfaune : les rongeurs », http://www.catalogue-roc-aux-sorciers.fr/ html/12/collection/add_8.html

MOURER-CHAUVIRÉ C. 1975, Les oiseaux du Pléistocène moyen et supérieur de France, Villeurbanne, Document des laboratoires de Géologie de la Faculté de Lyon 64.

MÜLLER W. 2004, « One horse or a hundred hares ? Small game exploitation in an Upper Palaeolithic context », dans BRUGAL J.-P. et DESSE J. (dir.), Petits animaux et sociétés humaines. Du complément alimentaire aux ressources utilitaires, actes des $\mathrm{XXIV}^{\mathrm{e}}$ rencontres internationales d'archéologie et d'histoire d'Antibes, Antibes, APDCA, p. 489-498.

MÜLLER W. 2013, Le site magdalenien de Monruz, 3 Acquisition, traitement et consommation des ressources animales, Neuchâtel, Archéologie neuchâteloise 49.

PAILLET P. et MAN ESTIER E. 2014, « De nouvelles découvertes d'art mobilier laborien dans le nord du Périgord », dans LANGLAIS M., NAUDINOT N. et PERESANI M. (dir.), Les groupes culturels de la transition 
Pléistocène-Holocène entre Atlantique et Adriatique, actes de la séance de la Société préhistorique française de Bordeaux, 24 au 25 mai 2012, Paris, Société préhistorique française, p. 129-154.

PEDERGNANA A. et BLASCO R. 2016, « Characterising the exploitation of avian resources: An experimental combination of lithic use-wear, residue and taphonomic analyses ", Quaternary International, vol. 421, p. 255-269.

PÉTILLON J.-M., LAROULANDiE V., COSTAMAGNO S. et LANGLAIS M. 2016, « Testing environmental determinants in the cultural evolution of hunter-gatherers : A three-year multidisciplinary project on the occupation of the western Aquitaine basin during the Middle and Upper Magdalenian (19-14 kyr cal BP) », Quaternary International, vol. 414, p. 1-8.

REIMER P.J., BARD E., BAYLISS A., BECK J.W., BLACKWELl P.G., BRONK RAMSEY C., BUCK C.E., CHENG H., EDWARDS R.L., FRIEDRICH M., GROOTES P.M., GUILDERSON T.P., HAFLIDASON H., HAJDAS I., HATTÉ C., HEATON T.J., HOFFMANN D.L., HOGG A.G., HUGHEN K.A., KAISER K.F., KROMER B., MANNING S.W., NIU M., REIMER R.W., RICHARDS D.A., SCOTT E.M., SOUTHON J.-R., STAFF R.A., TURNEY C.S.M. et VAN DER PLICHT J. 2013, " IntCal13 and Marine13 radiocarbon age calibration curves 0-50,000 years cal BP », Radiocarbon, vol. 55, p. 1869-1887.

RÉMY D. 2013, « Caractérisation techno-économique d'industries en bois de cervidés du Badegoulien et du Magdalénien : le cas du Rond-du-Barry (Haute-Loire) et de Rochereil (Dordogne) », Thèse de doctorat, Université de Montpellier 3.

RILLARDON M. et BRUGAL J.-P. 2014, «What about the Broad Spectrum Revolution ? Subsistence strategy of hunter-gatherers in Southeast France... ", Quaternary International, vol. 337, p. 129-153.

ROMANDINI M., FIORE I., GALA M., CESTARI M., GUIDA G., TAGLIACOZZO A. et PERESANI M. 2016, «Neanderthal scraping and manual handling of raptors wing bones : Evidence from Fumane Cave. Experimental activities and comparison », Quaternary International, vol. 421, p. 154-172. SÉRONIE-VIVIEN M.-R. 1994, « Données sur le Lapin azilien. Le matériel du gisement de Pégourié, Caniac-du-Causse (Lot) », Bulletin de la Société Préhistorique Française, vol. 91, p. 378-384.

SÉRONIE-VIVIEN M.-R. 1995, La grotte de Pégourié, Caniac-du-Causse (Lot), Préhistoire Quercynoise 2. STINER M.C. 2001, « Thirty years on the « Broad Spectrum Revolution » and paleolithic demography », PNAS, vol. 98, p. 6993-6996.

STINER M.C. et MUNRO N.D. 2002, « Approaches to prehistoric diet breath, demography, and prey ranking systems in time and space », Journal of Archaeological Method and Theory, vol. 9, p. 181-214. STINER M.C., MUNRO N.D., SUROVELL T. A., TCHERNOV E. et BAR-YOSEV O. 1999, « Paleolithic population growth pulses evidenced by small animal exploitation », Science, vol. 283, p. 190-194.

VAL A. et MALLYE J.-B. 2011, « Small carnivore skinning by professionals : Skeletal modifications and implications for the European Upper Palaeolithic », Journal of Taphonomy, vol. 9, p. 221-243.

VIGNE J.-D. et MARINVAL-VIGNE M.-C. 1983, « Méthode pour la mise en évidence de la consommation du petit gibier ", dans CLUTTON-BROCK J. et GRIGSON C. (dir.), Animals and Archaeology. 1 : Hunters and their prey, Oxford, Archaeopress, p. 239-242 (BAR International Series 163).

VIGNE J.-D., MARINVAL-VIGNE M.-C., de LANFRANCHI F. et WeISS M.-C. 1981, « Consommation du « Lapinrat » (Prolagus sardus Wagner) au Néolithique ancien méditerranéen Abri d'Araguina-Sennola (Bonifacio, Corse) », Bulletin de la Société Préhistorique Française, vol. 78, p. 222-224.

WEIN E.E. et FREEMAN M.M.R. 1995, « Frequency of traditional food use by three Yukon First Nation living in Four communities », Arctic, vol. 48, p. 161-171. 


\section{NOTES}

1. «Il s'agit d'une faune de steppe classique, assez pauvre en espèces. Elle comprend, par ordre d'importance : le Spermophile, le Renne, le Cheval, le Bœuf, de nombreux Rapaces et Poissons. »

\section{RÉSUMÉS}

En Europe de l'Ouest, l'exploitation des petits gibiers par les chasseurs-collecteurs du Tardiglaciaire est une pratique connue. S'exerçant sur une variété de petites proies, elle n'est pas systématique, ce qui interroge sur sa place dans les sociétés du passé. Différentes espèces d'oiseaux et de petits mammifères sont concernées, avec des répartitions chrono-géographiques plus ou moins étendues reflétant en partie les paléo-biocénoces. Les études taphonomiques et archéozoologiques qui se développent permettent de préciser l'ampleur de cette pratique et les produits recherchés lors de l'exploitation des petits gibiers. Cet article présente les résultats récemment obtenus pour le site de Rochereil (Grand-Brassac, Dordogne) dans le cadre du PCR (Projet collectif de recherche) «Peuplements et cultures à la fin du Tardiglaciaire dans le nord du Périgord, entre Dronne et Tardoire » dirigé par P. Paillet. Près de 1400 restes de petits vertébrés ont été exhumés des fouilles anciennes conduites par Paul-Émile Jude. Si beaucoup d'entre eux ne possèdent pas d'attribution stratigraphique précise, les vestiges attribués à un niveau archéostratigraphique indiquent une évolution des pratiques entre le Magdalénien et l'Azilien. $\mathrm{Au}$ Magdalénien, des espèces plutôt de climat froid (spermophile, glouton, renard, harfang, lagopède) servent de ressource alimentaire et de matière première (os, dent, plume, peau) comme en témoignent de nombreuses traces d'activité sur les ossements. À l'Azilien ces espèces laissent la place au lapin qui est exploité pour sa viande, sa graisse et sa moelle et peut-être pour sa fourrure.

\section{AUTEURS}

\section{JEAN-BAPTISTE MALLYE}

PACEA UMR 5199 CNRS,

Université de Bordeaux

VÉRONIQUE LAROULANDIE

PACEA UMR 5199 CNRS,

Université de Bordeaux

\section{PEGGY BONNET-JACQUEMENT}

Musée National de Préhistoire, PACEA UMR 5199 CNRS,

Université de Bordeaux 


\section{MYRIAM BOUDADI-MALIGNE}

PACEA UMR 5199 CNRS,

Université de Bordeaux

MATHIEU LANGLAIS

PACEA UMR 5199 CNRS,

Université de Bordeaux

\section{ELENA MAN-ESTIER}

Ministère de la Culture et la Communication,

SRA Bretagne

\section{CAROLE VERCOUTÈRE}

HNHP, UMR7194, MNHN,

Musée de l'Homme

\section{PATRICK PAILLET}

HNHP, UMR7194, MNHN,

Musée de l'Homme 


\title{
Subsistance en zone côtière durant le Middle Stone Age en Afrique du Nord : étude préliminaire de l'unité stratigraphique 8 de la grotte d'El Mnasra (Témara, Maroc)
}

\author{
Émilie Campmas, Amel Chakroun, Driss Chahid, Arnaud Lenoble, Larbi \\ Boudad, Mohamed Abdeljalil El Hajraoui et Roland Nespoulet
}

\begin{abstract}
Nous tenons à remercier les organisateurs du CTHS pour leur invitation à présenter les résultats de nos recherches lors de la $141^{\text {ème }}$ édition du congrès à Rouen. Nous remercions vivement $A$. Akkerraz le directeur de l'Institut National des Sciences de l'Archéologie et du Patrimoine (INSAP) de Rabat pour avoir permis l'accès aux collections. Nous exprimons notre reconnaissance au Ministère des Affaires Étrangères et du Développement International (MAEDI), ainsi qu'au Ministère de la Culture du Maroc qui financent la mission Maroco-française «El Harhoura-Témara » (M.A. El Hajraoui et R. Nespoulet dir.). Nous remercions E. Stoetzel pour nous avoir fourni des résultats issus de l'analyse en cours de la microfaune. Nous exprimons notre gratitude à M. Cammas pour l'infographie de la figure 1. Nous remercions E. Lesvignes et M. Lebon pour les photographies des coquilles de mollusque de la figure 3. Nous tenons également à remercier les relecteurs, S. Costamagno et $C$. Dupont, pour leurs commentaires et conseils avisés.
\end{abstract}

L'exploitation préhistorique des ressources côtières a largement été discutée pour l'Holocène, du fait de la description de véritables amas coquilliers à cette période (e.g. Dupont, 2006 ; Dupont et al., 2009 ; Álvarez-Fernández, 2011, 2015 ; Colonese et al., 2011 ; Gutiérrez-Zugasti, 2011; Jerardino, 2016). Cependant, il existe des enregistrements témoignant de ce type d'exploitation pour les périodes antérieures, par exemple lors du réchauffement du stade isotopique 5 ( $130-80 \mathrm{ka})$ en Afrique, zone et période de développement du Middle Stone Age (e. g. Campmas et al., 2015, 2016 ; Will et al., 2015a, 2015b). 
Le Middle Stone Age (daté entre 31 et 30/20 ka environ) est une période importante pour l'évolution humaine. En effet, à cette période, de nombreuses innovations (pointes lithiques, industrie osseuse, parures et emmanchements) viennent enrichir le bagage culturel des Hommes anatomiquement modernes avant qu'ils ne se dispersent hors d'Afrique (e. g. Mcbrearty et Brooks, 2000 ; Henshilwood et al., 2001, 2009, 2011 ; Rots et Van Peer, 2006; Vanhaeren et al., 2006, 2013; d'Errico et al., 2005, 2009, 2012 ; Bouzouggar et al., 2007 ; d'Errico et Henshilwood, 2007 ; Villa et al., 2009 ; Rots et al., 2011 ; Bouzouggar et Barton, 2012 ; El Hajraoui et al., 2012a ; d'Errico et Backwell, 2016 ; Campmas, 2017 ; Hublin et al., 2017 ; Richter et al., 2017).

Pour les périodes anciennes, les zones côtières et l'exploitation des ressources littorales qui y sont associées ont pu jouer un rôle dans l'évolution humaine. En effet, des hypothèses proposent que : l'apport de nouveaux nutriments riches en chaînes d'acide gras poly-insaturé a pu être bénéfique pour la croissance cérébrale et la diminution de la mortalité infantile (e. g. Cunnane et Stewart, 2010; Parkington, 2010 ; Cunnane et Crawford, 2014); les zones côtières riches en nutriments ont pu être favorables à la dispersion des populations humaines (e. g., Mellars, 2006, Mellars et al., 2013 ; Erlandson et Braje, 2015); les ressources littorales ont pu compléter l'apport des ressources terrestres, pallier leur raréfaction et rendre plus durables les occupations (e.g. MarínArroyo, 2013). Les données ethnographiques suggèrent que l'adaptation au milieu côtier peut entraîner une augmentation de la taille des groupes et une complexification sociale (e. g., Yesner, 1980 ; Kelly, 1983, 1992), ce qui a peut-être joué un rôle dans l'émergence des marqueurs identitaires à cette période (Campmas et al., 2016).

4 Si les recherches sur l'occupation des zones côtières au Middle Stone Age se multiplient en Afrique du Sud (Marean et al., 2007 ; Marean, 2011, 2014 ; Jerardino et Marean, 2010 ; Langejans et al., 2012 ; Will et al., 2015a, 2015b), l'Afrique du Nord comprend également de nombreux sites côtiers Middle Stone Age qui ont livré de la malacofaune marine, en particulier la région de Rabat-Témara: grotte des Contrebandiers (Steele et ÁlvarezFernández, 2011, 2012), grotte d'El Mnasra (Campmas et al., 2016) ; grotte d'El Harhoura 1 (Aouraghe, 2001; Monchot et Aouraghe, 2009), grotte d'El Harhoura 2 (Campmas et al., 2015 ; Nouet et al., 2015) et grotte de Dar es Soltane 1 (Ruhlmann, 1951) (fig. 1).

5 Cet article s'attache donc à fournir les premiers éléments d'une vision systémique des stratégies de subsistance des populations Middle Stone Age d'Afrique du Nord en zone côtière, à partir des données issues de l'Unité Stratigraphique (US) 8 d'El Mnasra. Combinant l'étude des faunes terrestres et des faunes marines, il se concentre plus particulièrement sur les résultats préliminaires relatifs à l'exploitation des ressources marines. 
Figure 1 : Localisation des sites Middle Stone Age (en noir) et de la zone d'observation de la thanatocénose (Carrière 10, en gris) de la région de Témara-Rabat (en haut) et morphologie (en bas) de la côte (infographie : E. Campmas et M. Cammas).
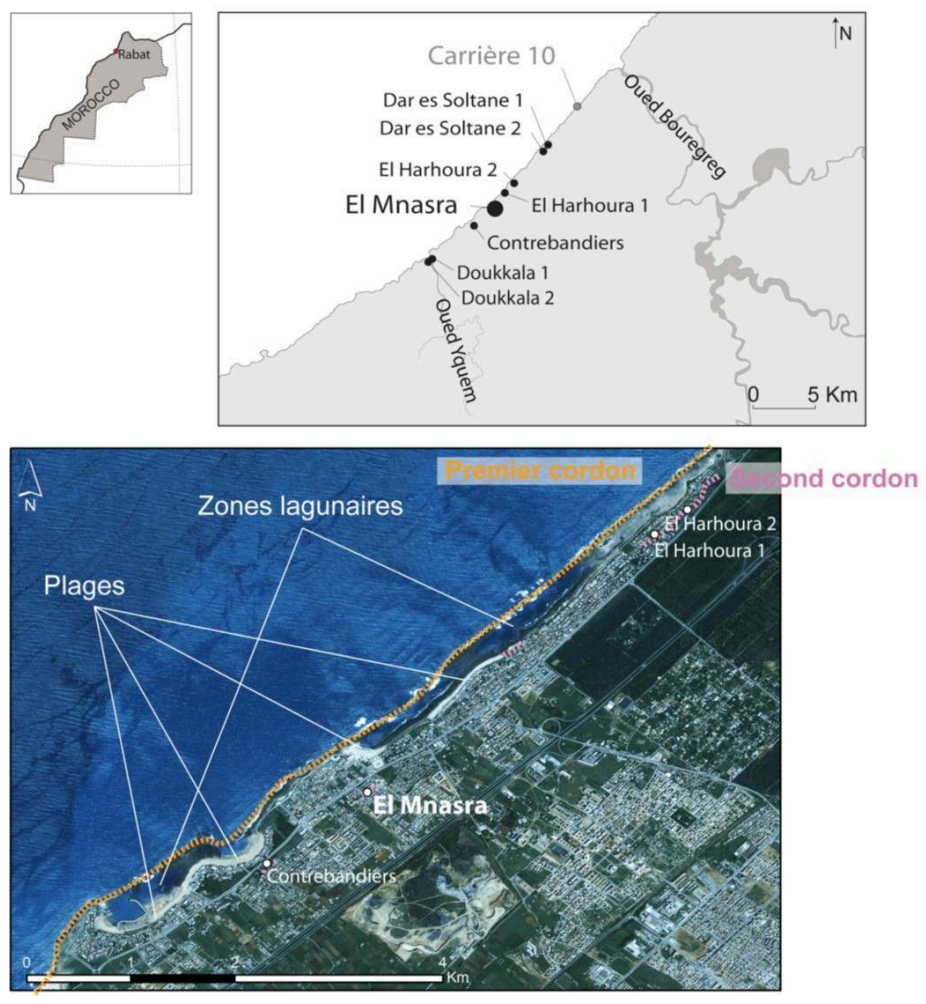

\section{Spécificité géomorphologique de la région de Témara}

6 La zone côtière de Rabat-Témara, située entre les oueds Yquem au sud-ouest et Bouregreg au nord-est (fig.1), est constituée d'une série de cordons consolidés subparallèles à la côte. Les grottes de Témara sont creusées dans le second cordon dunaire et s'ouvrent sur une plaine littorale, l'Oulja. Cette dernière s'étire le long de la côte pour former un sillon séparé du littoral par le premier cordon dunaire dans lequel est façonné le trait de côte actuel. Cette morphologie littorale a été acquise lors du dernier interglaciaire, d'abord par le façonnement de la falaise fossile entaillant le second cordon, lors du haut niveau marin du Stage Isotopique Marin (SIM) 5.5 (Weisrock, 2016), puis par la formation du premier cordon, il y a environ 100000 ans, au cours de l'intervalle du SIM 5.3 (Chahid et al., 2016). En contrebas de ce cordon se rencontre un trottoir littoral à vasques pouvant être émergé lors des marées basses (Texier et al., 1985 ; Mhammdi et al., 2008; Chahid et al., 2016) (fig. 2). En outre, ce premier cordon est entrecoupé de criques abritant de petites plages sableuses (fig. 1). Ces variations environnementales littorales, visibles actuellement à Témara, sont à l'origine d'une diversité importante d'habitats côtiers: zones à substrat induré ou meuble, zones soumises à l'activité des vagues et zones lagunaires plus abritées. Il en résulte une importante biodiversité littorale, à l'image de celle qu'ont pu connaître certaines phases du Pléistocène. 
Figure 2 : Coupe schématique de la morphologie de la zone côtière de Témara-Rabat dans la zone de Dar es Soltane (modifiée d'après Chahid et al., 2016).

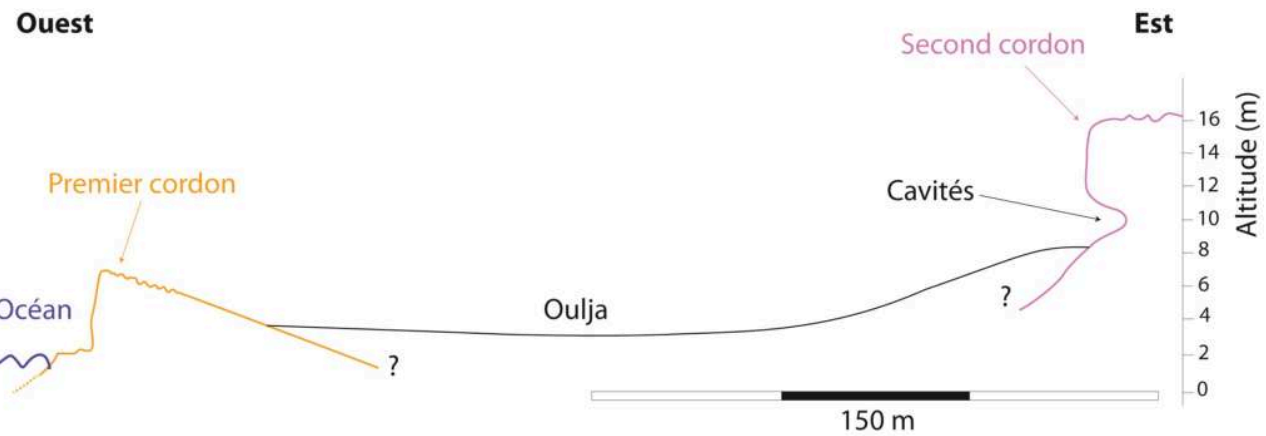

\section{Unité stratigraphique 8 de la grotte d'El Mnasra}

7 La grotte d'El Mnasra (fig. 1) est actuellement située à environ $300 \mathrm{~m}$ du rivage et à $14 \mathrm{~m}$ au-dessus niveau marin moyen exprimé dans le nivellement général du Maroc. Elle mesure environ $20 \mathrm{~m}$ de longueur maximale et $14 \mathrm{~m}$ de largeur maximale (El Hajraoui et al. 2012b). Comme les autres cavités de cette région, elle comprend des remplissages qui s'étalent sur tout le Pléistocène supérieur et l'Holocène (Nespoulet et al., 2008 ; El Hajraoui et al., 2012a,b). Le niveau présenté ici correspond à l'US 8, fouillée sur une large surface et datée du stade isotopique 5. Cette US de la lithostratigraphie d'A. Lenoble (Lenoble, 2010) correspond aux couches 7, 6 et 5 de l'archéostratigraphie de M.A. El Hajraoui et A. Debénath (2012a). Les dates OSL obtenues pour ces couches placent leur dépôt entre 110 et 100 ka environ (Schwenninger et al., 2010 ; Jacobs et al., 2012). Ces dates sont un peu plus anciennes que celles obtenues par ESR-U/Th sur des dents d'ongulés, qui situent ces niveaux entre 90 et 60 ka environ (Janati Idrissi et al., 2012). À l'heure actuelle la question sur ce décalage de dates entre les deux méthodes de datation utilisées, avec des dates ESR-E/Th plus jeunes que les dates OSL, qui se répète également à El Harhoura 2 (Jacobs et al., 2012 ; Janati Idrissi et al., 2012), n'est toujours pas résolue. Ici nous privilégions les dates OSL car pour de nombreux dépôts sédimentaires de sites archéologiques d'Afrique du Nord qui sont datés par cette méthode elles présentent une cohérence entre elles (Barton et al., 2009; Schwenninger et al., 2010 ; Jacobs et al., 2011) et sont en accord avec les dates obtenues par TL à la grotte des Contrebandiers (Dibble et al., 2012).

8 L'US 8, qui est marquée par une quantité significative de sédiments à dominante anthropique (charbons, cendres) (Lenoble, 2010), a livré différents types d'artefacts (industries lithiques, restes osseux, matières colorantes, coquilles de mollusques) et des foyers (El Hajraoui et al., 2012a).

L'analyse taphonomique et archéozoologique détaillée des macro et méso vertébrés terrestres provenant des fouilles 2002-2009 de cette US a fait l'objet de plusieurs publications (Campmas, 2012 ; Campmas et al., 2015, 2016). En revanche, en dehors des coquilles ayant pu servir d'ornements (El Hajraoui et al., 2012e), la malacofaune n'avait jusqu'à présent fait l'objet d'aucune étude. Ainsi, pour cette catégorie de matériel, nous fournissons dans cet article des données consécutives à des identifications préliminaires réalisées sur la malacofaune cotée durant la campagne de fouille 2014. Plusieurs critères ont été retenus pour coter cette malacofaune lors de la fouille: éléments $>2 \mathrm{~cm}$ comme tout autre type de vestige et/ou présence du crochet pour les 
bivalves, de l'apex pour les Trochidae et Patellidae ou de la columelle pour les Muricidae. Notons que les fragments ou coquilles entières de Nassariidae repérés à la fouille ont été systématiquement cotés. Les mollusques terrestres cotés sont les coquilles entières de grandes dimensions, principalement des Helix.

\section{Exploitation des ressources animales}

\section{Taxons consommés}

10 Les Hommes ont une alimentation diversifiée, comme en témoigne la coexistence de déchets alimentaires de vertébrés terrestres, de malacofaune marine et, peut-être, de malacofaune terrestre. La consommation des ressources littorales est attestée par la présence de coquilles de mollusques marins, principalement de Patellidae et Mytilidae, mais aussi Trochidae et Muricidae (fig. 3a-d) (Campmas et al., 2016). Ainsi, l'US 8 se serait déposée entre $\sim 110-100 \mathrm{ka}$ (Jacobs et al., 2012). Ces datations indiquent que cette unité s'est formée postérieurement au haut niveau marin du dernier interglaciaire (SIM 5.5, $125 \mathrm{ka}$ ), ce dernier correspondant à l'US 11 d'El Mnasra, un dépôt littoral surmontant l'encaissant et contenant de rares coquilles de gastéropodes et bivalves, située à environ $3 \mathrm{~m}$ sous l'US 8 (Lenoble, 2010). Sur la base de son âge, l'US 8 peut, en revanche, être mise en relation avec le haut niveau marin du SIM 5.3, au cours duquel l'océan se serait situé une vingtaine de mètres en deçà du haut niveau marin précédent (Shackleton, 2000, Waelbroeck et al., 2002). L'apport des coquilles de mollusques marins ne résulterait donc pas d'événements naturels (e. G. tempêtes), ce que corroborent les observations sédimentologiques qui concluent, tant sur la base de l'organisation des dépôts que des stocks sédimentaires mobilisés, à l'absence de contribution marine, même ponctuelle, dans l'édification de l'US 8 (Lenoble, 2010). Une première observation de la surface des coquilles à l'œil nu suggère également qu'elles ne présentent pas d'érosion liée au ressac des vagues signifiant que ces mollusques ont dû être collectés frais. Ces interprétations concordent avec le contexte géomorphologique régional, notamment avec la période d'édification du premier cordon littoral (cf. supra, Chahid et al., 2016). En effet, la ligne de rivage contemporaine de l'édification de l'unité US 8 se serait donc trouvée, à son plus haut niveau, éloignée comme à l'actuel d'environ $500 \mathrm{~m}$ de la grotte d'El Mnasra, c'est-à-dire à la fois suffisamment proche du site pour permettre un accès facile aux occupants de la cavité et, dans le même temps, suffisamment éloignée pour soustraire la grotte aux atteintes directes de l'océan.

11 Notons également la présence de rares vertèbres de poisson de petite taille, ainsi que des restes d'échinodermes. Aucun reste de mammifère marin n'a en revanche été identifié.

12 Les ressources terrestres comprennent de nombreux ongulés (gazelles, suidés, alcélaphinés, équidés, bovinés et peut-être même de l'éléphant, du rhinocéros ou de l'hippopotame), ainsi que des tortues, dont la présence de traces de chauffe préférentiellement localisées en face externe des carapaces témoigne de leur consommation ( $c f$. infra). En revanche, la question de l'origine des escargots terrestres n'est pas clairement tranchée (Campmas et al., 2016). Certaines espèces de mollusques continentaux, comme les Helix sp., sont comestibles, à ce titre, leur présence dans le site pourrait résulter d'une consommation humaine. Cependant, la présence de gastéropodes terrestres dans les remplissages sédimentaires de cavités peut être 
attribuée à différents facteurs, tels que le creusement de terriers dans les sédiments par certaines espèces fouisseuses à l'estive ou à l'hibernation, le comportement troglophile d'autres espèces, ou encore leur introduction par de petits prédateurs (carnivores, oiseaux) (Girod, 2011).

Les données de fouille 2014 montrent que les restes de vertébrés terrestres sont aussi bien représentés que ceux de la malacofaune marine (Tabl.1). Ces premières observations, qui devront être complétées, suggèrent que les enregistrements des occupations côtières pléistocènes ne correspondent pas à de véritables «amas coquilliers" au sein desquels les composants principaux sont les coquilles de mollusques. Ils sont caractérisés par de multiples composants, tels que des industries lithiques, des restes fauniques, des coquilles d'œufs d'autruche ou des pigments, au sein d'une matrice sédimentaire comme l'ont indiqué M. Will et al. (2015a, p. 67) pour les sites Middle Stone Age d'Afrique du Sud.

Tableau 1 : Nombre de restes cotés lors des fouilles 2014 (volume fouillé $<1 \mathrm{~m}^{3}$ ) par catégorie de vestiges (Campmas et al., 2016)

\begin{tabular}{|l|c|c|c|c|}
\hline & $\begin{array}{c}\text { Malacofaune } \\
\text { marine }\end{array}$ & $\begin{array}{c}\text { Malacofaune } \\
\text { terrestre } \\
\text { (principalement } \\
\text { cf. Helix sp.) }\end{array}$ & Vertébrés & Lithique \\
\hline $\begin{array}{l}\text { Nombre de } \\
\text { restes cotés }\end{array}$ & 201 & 101 & 237 & 158 \\
\hline
\end{tabular}

\section{Utilisation de l'animal dans les sphères technique et symbolique}

14 Les ressources animales n'ont pas été utilisées aux seules fins alimentaires. En effet, au total depuis 2004, il est probable que plus de 200 parures en coquilles de mollusques marins de petite taille, appartenant principalement à des Nassarius circumcinctus, ont été mises au jour (fig. 3e), ce qui en fait la plus grande série pour toute l'Afrique (El Hajraoui et al., 2012e ; analyse en cours). Concernant l'échantillon 2014, ces coquilles représentent environ $5 \%$ de la malacofaune marine. Néanmoins cette fréquence n'est qu'indicative, car les coquilles de ce taxon de faible dimension sont souvent retrouvées dans les refus de tamis qui n'ont pas été intégrés à cette étude préliminaire. 


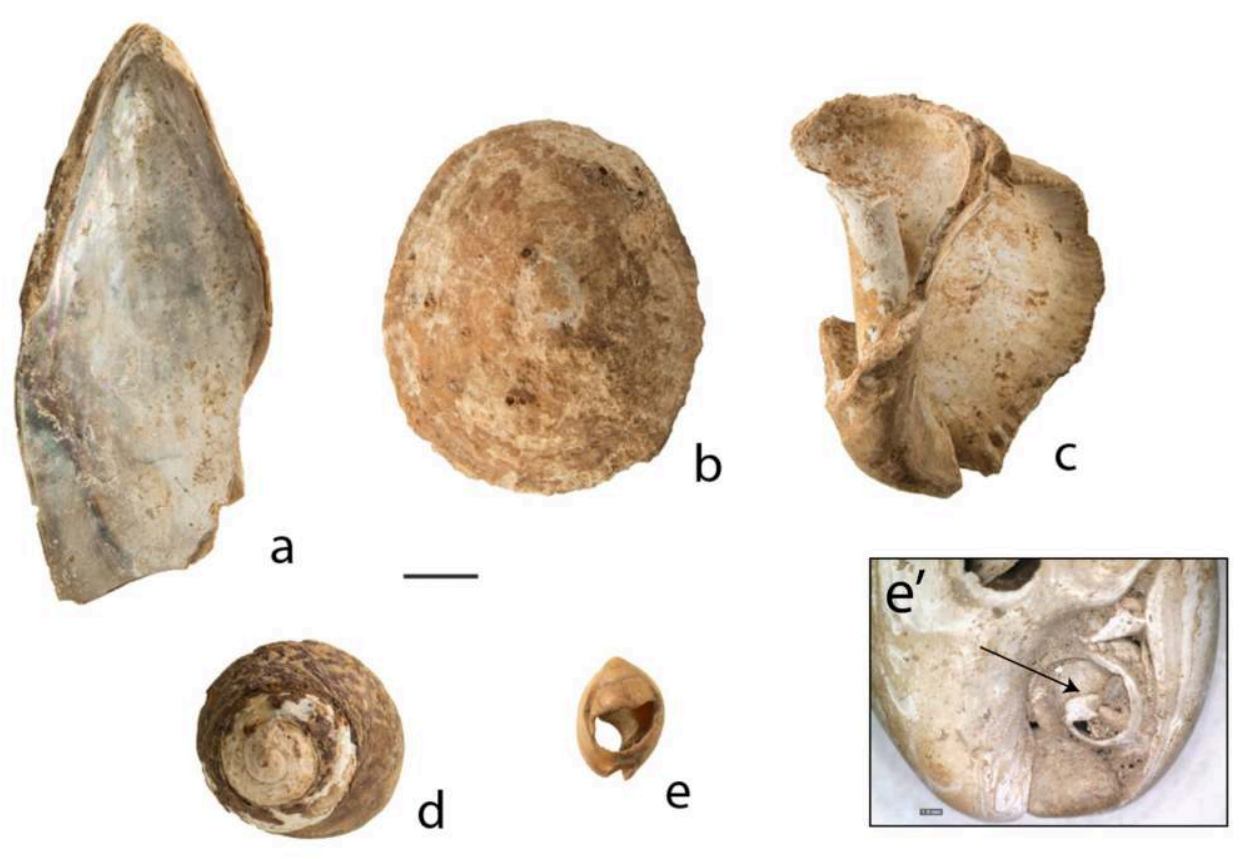

(a : Mytilidae, b : Patellidae, c : Muricidae ; d : Trochidae ; e : Nassariidae ; échelle : $1 \mathrm{~cm}$; Photographies : E. Lesvignes ; e' : coquille de Nassariidae contenant des fragments de coquilles et un gravier, photographie M. Lebon et E. Campmas) (adapté de Campmas et al., 2016).

Les restes de faune terrestre ont également été utilisés pour la production d'industrie osseuse sur différents supports tels que les côtes de grands mammifères et les os longs de gazelle (Campmas, 2012 ; El Hajraoui et Debénath, 2012b ; Campmas et al., 2016). Ils sont issus des espèces présentes dans le spectre des espèces consommées.

\section{Zones et modalités d'acquisition}

Les mollusques marins consommés sont, pour l'essentiel, des espèces intertidales de littoraux rocheux (Patellidae, Mytilidae, Trochidae et Muricidae). Elles étaient donc vraisemblablement accessibles lors des basses mers à proximité des cavités. Si les moules se décrochent par section du byssus, et peuvent se collecter en masse, les patelles sont plus délicates à décrocher et se collectent une par une (e.g. Fa, 2008 ; Jerardino, 2016). L'exploitation de ces deux taxons nécessite donc des modalités/ techniques différentes de collecte. Dans le site proche d'El Harhoura 2, des encoches sur les coquilles de patelle suggèrent leur collecte (Nouet et al., 2015). Cependant, si la collecte des patelles peut être réalisée avec un outil plat glissé entre la coquille et le rocher, elles peuvent également être aussi détachées sans outil, par exemple la nuit, lorsqu'elles se nourrissent, ou par percussion avec un simple galet (e.g. Russell et al., 1995).

Bien que les hommes aient pu traiter/consommer certains mollusques, tels que les Stramonita haemastoma, directement à proximité de la ligne de rivage, comme le font actuellement les pêcheurs côtiers de mulets à Rafraf (Nord de la Tunisie) (A. Chakroun, observation personnelle), nos discussions ne s'appuient que sur les espèces ramenées dans les sites. 

de la zone côtière de Témara-Rabat offre un point de comparaison intéressant pour déterminer les ressources disponibles dans l'environnement littoral préhistorique contemporain de l'US 8. Un de ces enregistrements géologiques est observable dans la carrière 10 de Rabat. Il est composé d'alternances de sables fins et de niveaux coquilliers riches en débris de gastéropodes et de lamellibranches formés par les laisses de tempêtes accumulés en haut de plage sableuse (fig. 4). L'assemblage malacologique qu'il recèle se caractérise notamment par l'espèce Stramonita haemastoma, représentée en abondance lorsque les laisses de tempêtes renseignent les coquilles des espèces les plus grosses, à l'image de la partie supérieure des dépôts (Chakroun et al., 2013, 2017 ; Chahid et al., 2016). Cette espèce généralement signalée dans les dépôts marins tunisiens est accompagnée par le marqueur de réchauffement climatique Persististrombus latus. La position stratigraphique des dépôts et la datation de ces derniers par U-series vers 125-120 ka ont permis à A. Chakroun et al. (2016) d'émettre l'hypothèse que leur abondance puisse correspondre au réchauffement du sous-stade isotopique 5.5. Cependant, dans la région d'Agadir, des Stramonita haemastoma issus de niveaux riches en cette espèce ont été datés par U/Th et ont fourni entre autres des âges aux alentours de 90-70 ka (Weisrock et al., 1999). D'une façon générale, la région d'Agadir étant plus méridionale, la présence d'espèces chaudes y est moins remarquable (Brebion et al., 1984). Mais, C.E. Stearns et D.L. Thurber (1965) avaient également obtenu un âge de $95 \pm 5 \mathrm{ka}$, pour certaines des formations marines de la région de Rabat, à savoir un dépôt rougeâtre présent occasionnellement sur le littoral, comprenant en association des coquilles d'espèces terrestres et marines dont Stramonita haemastoma (fig. 4). Une date OSL ( $99,9+-8,0$ ka) obtenue récemment sur ce sédiment rouge clair sablo-limoneux riche en coquilles de gastéropodes marins et terrestres dans la zone de Dar es Soltane confirme cet âge (Chahid 2017 ; Chahid et al., 2016, 2017). À la carrière 10, en l'attente de datation, l'interprétation chronologique peut se baser sur l'analyse stratigraphique de la coupe. Cette dernière suggère que les niveaux coquilliers à litage plan se sont formés en position de hautes mers, lors du plus haut niveau marin du dernier interglaciaire, soit au cours du SIM 5.5. La formation rougeâtre qui les surmonte, quant à elle, se serait formée à l'étage supralittoral lors d'une récurrence marine n'ayant pas atteint ce même niveau et qui, à ce titre, peut être rattachée au SIM 5.3. Ainsi, les dépôts de cette séquence pourraient s'être mis en place à différentes périodes du stade isotopique 5 (Chahid et al., 2017). Dans tous les cas, les taxons présents dans les différents ensembles de ce site témoigneraient donc des espèces disponibles pour les Hommes préhistoriques. 
Figure 4 : Dépôts naturels de la région de Rabat-Témara (Carrière 10) riches en coquillages marins.
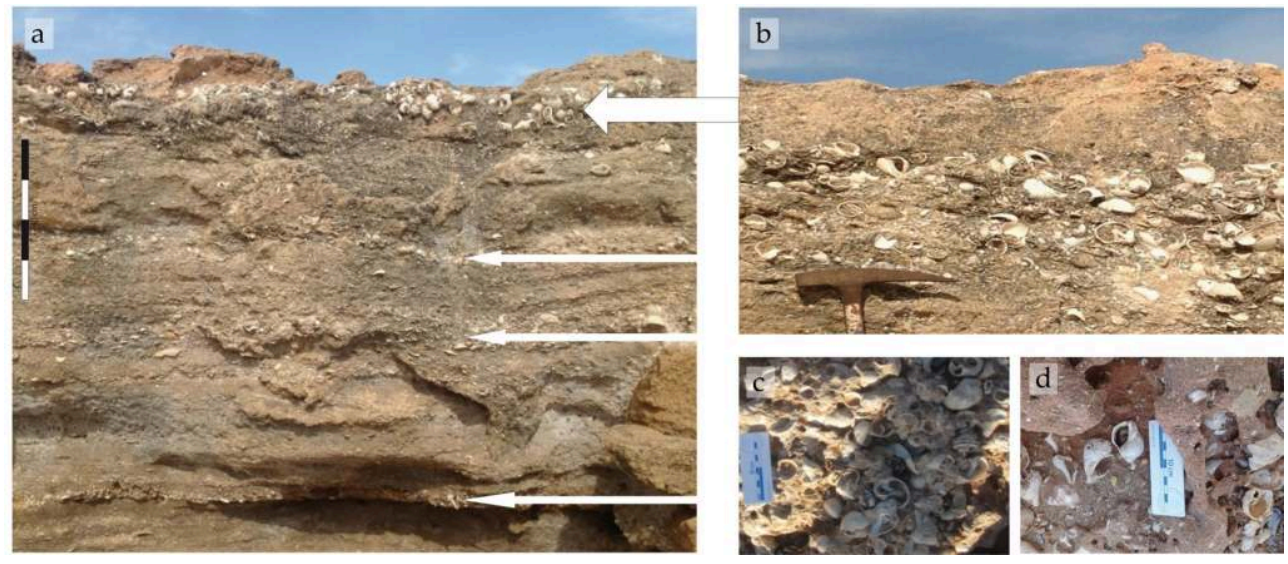

a) Vue générale du dépôt, les flèches indiquent les différents niveaux coquilliers marins alternant avec des dépôts de sables fins, b) Détail du niveau sommital riche en Stramonita haemastoma ; c) Détail du niveau sommital en vue zénithale ; d) Détail du dépôt rougeâtre tapissant les formations marines dans une zone riche en Stramonita haemastoma (Photographies A. Chakroun).

Les mollusques de cette thanatocénose naturelle proviennent aussi bien de la zone littorale intertidale qu'infratidale, de substrats rocheux et sableux, que de milieux lagunaires et de côtes rocheuses. Il en résulte une variété spécifique importante à l'image de la diversité malacologique du milieu naturel. De façon intéressante bien qu'attendue, toutes les familles de mollusques présentes à la carrière 10 ne sont pas retrouvées à El Mnasra, où seuls les Nassariidae, les Muricidae, les Trochidae, les Patellidae et les Mytilidae sont identifiés. Cette sélection s'accorde avec l'hypothèse d'une collecte anthropique.

Plus remarquable est la rareté des coquilles de Patellidae et de Mytilidae dans la thanatocénose de la carrière 10 alors que ces coquilles de mollusques sont observées en nombre à El Mnasra. Dans la mesure où ces animaux vivent souvent regroupés, ce biais entre le site préhistorique d'El Mnasra et l'accumulation naturelle de carrière 10 pose question sur : 1- la rareté de ces mollusques dans l'environnement local et la possibilité de leur collecte sélective par les Hommes ou de leur collecte dans d'autres zones géographiques, induisant donc de longues distances de transport ; 2- l'enregistrement fragmentaire du spectre malacologique local que représente la thanatocénose du locus étudié de la carrière $10 ; 3$ - la non contemporanéité de l'enregistrement naturel de la carrière 10 observé et du dépôt de l'US 8 et donc l'impossibilité d'utiliser cette séquence naturelle comme échantillon de comparaison. Cette dernière hypothèse ne semble toutefois pas à privilégier. En effet, actuellement, les coquilles de Mytilidae et de Patellidae sont rares dans les accumulations de coquilles mortes de haut de plages. Sur le littoral atlantique marocain actuel, ces coquillages se rencontrent en zone interdidale, dans un milieu directement exposé à la houle. Il en résulte alors une faible représentation dans les accumulations supratidales de milieu abrité. La sousreprésentativité de ces familles à la carrière 10 pourrait donc être normale, puisque cette thanatocénose ne représente qu'un type d'habitat côtier (hypothèse 2). Ce faisant, leur abondance à El Mnasra résulterait plutôt de choix humains. Néanmoins, la multiplication de l'observation des thanatocénoses naturelles pouvant s'être déposées durant le stade isotopique 5 dans cette région et la datation de ces dépôts permettront d'asseoir plus en avant cette question. 
21 Dans l'US 8 d'El Mnasra, parmi les espèces consommées la prépondérance de taxons vivant sur des substrats indurés, donc de côtes rocheuses, et l'absence de faune de substrat meuble, se rencontrant en zone lagunaire par exemple, pourraient résulter : 1de la non contemporanéité de l'enregistrement naturel de la carrière 10 observé et du dépôt de l'US 8, et donc encore une fois de l'impossibilité d'utiliser cette séquence naturelle comme échantillon de comparaison, mais cette hypothèse n'est pas la plus convaincante (cf. supra) ; 2- d'un traitement différentiel de ces ressources, avec seules les espèces de côtes rocheuses ramenées dans les sites; 3-d'une connaissance incomplète de l'environnement côtier, et notamment des espèces endobenthiques non visibles directement qui peuvent donc être plus difficiles d'accès; 4- d'un choix lié à une recherche de rentabilité ; 5- d'un tabou alimentaire ; 6- de la non représentativité pour les espèces rarement consommées de l'échantillon observé de l'US 8 d'El Mnasra (qui correspond seulement aux coquilles cotées à la fouille en 2014).

22 Concernant le troisième point, la présence des Nassariidae, mollusques détritivores et appréciant notamment les environnements lagunaires, pourrait suggérer que les Hommes avaient la capacité d'acquérir de la malacofaune en substrat meuble (Tabl. 2). Nassarius circumcinctus et Tritia gibbosula sont présents dans la thanatocénose naturelle de la carrière 10 (Lenoble et al., 2011 ; Chakroun et al., 2013, 2017 ; Chahid et al., 2016). Des Nassariidae sont également présents dans les affleurements de la plage de Guyville, située entre la grotte d'El Mnasra et le site de la Carrière 10, et contenus cette fois dans les formations rougeâtres qui pourraient être contemporaines du SIM 5.3 (Lenoble et al., 2011). Cela indique qu'ils auraient pu être collectés à proximité des sites, dans un environnement différent, mais proche de celui où ont été collectées les espèces consommées. Ils pouvaient peut-être se rencontrer notamment dans l'Oulja, située entre les grottes et le premier cordon dunaire littoral, où se brisent les vagues. Toutefois, l'aspect des coquilles présentant des usures liées au ressac des vagues et la présence d'un gravier et/ou des fragments de coquilles coincés à l'intérieur de leur coquille (fig. $3 \mathrm{e}$ ) suggèrent qu'elles ont été collectées en position secondaire après la mort du mollusque, en bord de plage et/ou au sein d'une thanatocénose fossile. 
Tableau 2 : Données écologiques par famille et liste faunique des espèces de la thanatocénose naturelle de la carrière 10 de Rabat.

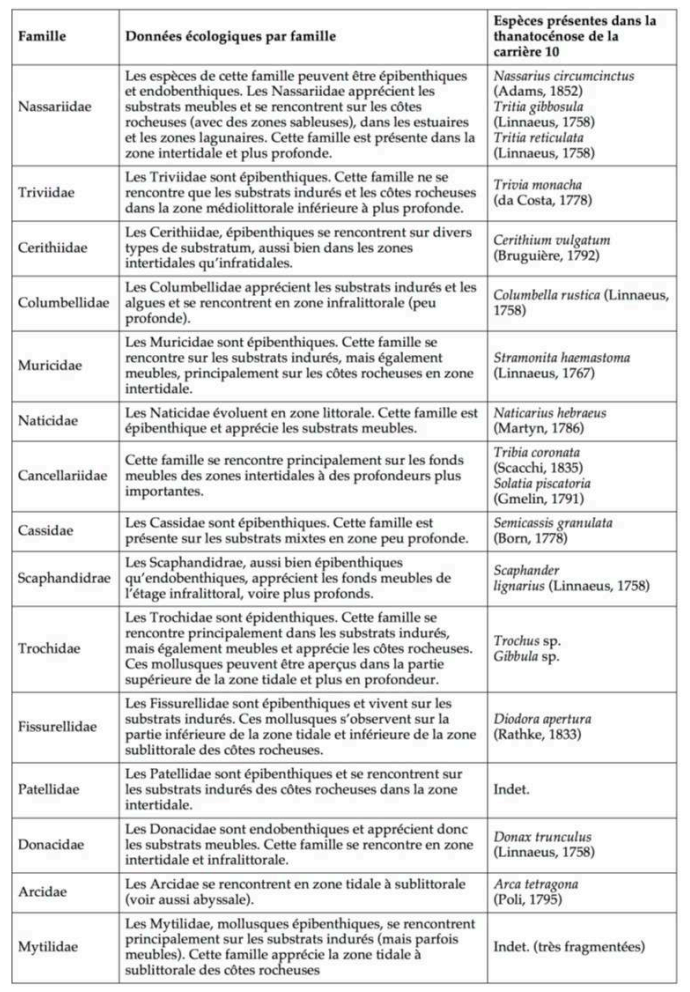

[La nomenclature des identifications taxinomiques est réalisée selon WoRMS, les données écologiques par famille sont issues de R. Perrier (1954), D.E. Bucquoy et al. (1982-1986, 1987-1998), C. Dupont (2006), S. Tlig-Zouari et F. Maamouri-Mokhtar (2008), M.V. Modica et al. (2011), G. Lindner (2015), Chakroun A. et D. Zaghbib-Turki (2017) et http://doris.ffessm.fr/].

Ainsi, concernant l'exploitation des ressources littorales et en particulier des mollusques, l'abondance des Patellidae et des Mytilidae à El Mnasra pourrait traduire des choix humains, vers ces mollusques de substrats rocheux présents dans la zone intertidale. En revanche, les coquille de taxons à valeur symbolique (e. G. Nassariidae) proviennent d'autres milieux, type carrière 10. Par conséquent, les mollusques selon leur usage ont été recherchés dans des environnements différents, mais pouvant être proches les uns des autres.

En revanche, les ongulés, pour lesquels la localisation est plus difficile à prédire, ont dû être chassés. Néanmoins, la présence de très jeunes individus (périnataux) soulève des questions sur leurs modalités d'acquisition: chasse de femelles gravides et/ou " collecte » des jeunes cachés dans les hautes herbes (Campmas et al., 2016). L'analyse en cours de la microfaune de l'US 8 indique un habitat de type steppes-savanes plutôt fermées et humides. Par exemple, le genre Arvicanthis est un rongeur qui ne se rencontre actuellement plus que le long de la vallée du Nil et dans les savanes subsahariennes à fort couvert végétal (plaines herbeuses avec des arbustes et arbres épars), et qui apprécie la proximité des sources d'eau (Stoetzel et al., 2014). Les insectivores (musaraignes) sont aussi bien représentés, et l'herpétofaune (amphibiens, squamates) bien diversifiée, indiquant également qu'il ne s'agissait pas d'une période très aride (Stoetzel, communication personnelle). Ces conclusions concordent avec les ongulés présents. En effet, ils ont des affinités pour les savanes arborées (gazelles, alcélaphinés, bovinés, équidés, phacochères, rhinocéros, éléphants), les points d'eau 
(hippopotame) ou les zones plus boisées (sanglier) (Amani et al., 2012 ; Campmas et al., 2016). Ainsi, l'acquisition des ongulés était probablement locale. Même si le nombre de restes déterminés par taxon est faible, toutes les régions anatomiques du squelette, en particulier pour les gazelles, sont décrites (Campmas et al., 2016). Cette représentation anatomique suggère qu'elles ont été ramenées complètes, ce qui pourrait aller également dans le sens d'une acquisition locale de ce taxon. Les tortues terrestres (Testudo graeca) et semi-aquatiques (Mauremys leprosa), animaux semi-sessiles encore actuellement présents dans la région, ont probablement aussi été acquises à proximité du site.

\section{Traitement des ressources et pratiques culinaires}

Pour les ongulés, toutes les phases de la chaîne opératoire du traitement des carcasses sont identifiées (dépouillement, désarticulation par découpe et hyper-extension, décarnisation, fracturation des os longs). Les ongulés ont donc fourni en plus de leur chair, d'autres ressources alimentaires, telles que la moelle (Campmas et al., 2016). En revanche, le traitement des mollusques nécessite moins d'étapes que les Ongulés. Par exemple, les patelles, une fois décrochées du rocher, sont directement consommables, alors que les bivalves, tels que les moules, nécessitent, à minima, leur ouverture.

Dans l'US 8, sont décrits de nombreux foyers de différents types: fermés (avec des bordures de dalles et/ou de galets), ouverts (avec des limites diffuses et sinueuses) et sur-creusés (creusés dans le sédiment argileux consolidé avec des bordures sinueuses). L'une des structures ouvertes contenait des coquilles, des fragments d'os brûlés et des éclats dans une lentille riche en cendre (El Hajraoui et al., 2012c). De plus, les restes de faune brûlés sont très nombreux dans cette US, mais il est difficile de rattacher ces traces de chauffe à de la cuisson et/ou utilisation de l'os comme combustible et/ou à des fins sanitaires (nettoyage de la zone d'occupation par exemple) et/ou accidentelle (installation d'un foyer dans une zone qui comportait des restes de faune) (Campmas et al., 2016). En revanche, la localisation des traces de chauffe sur les plaques osseuses de tortues nous permet de discuter de la cuisson des ressources animales. Même si de nombreuses plaques osseuses sont complètement brûlées, comme une large partie du matériel faunique, lorsqu'elles le sont sur une seule face, c'est la face externe qui est principalement atteinte (parmi les plaques osseuses brûlées $36 \%$ le sont seulement en face externe alors que seulement $3 \%$ le sont seulement en face interne). Cette atteinte préférentielle des faces externes pourrait traduire des phénomènes de cuisson. Ainsi, cette cuisson des aliments pratiquée par les groupes atériens soulève des questions quant à la cuisson des mollusques (notamment avec des coquilles décrites dans certains foyers), voire l'ouverture des moules qui est facilitée par la chauffe. Ainsi, si la chauffe des moules a été réalisée par cuisson directe sans contenant, sur ou sous la braise (e.G. Aldeias et al., 2016), une étude attentive de l'état des surfaces des coquilles et des analyses physico-chimiques (FTIR) des différents taxons permettront peut-être d'apporter des éléments de réponse à cette réflexion.

\section{Fonction du site et occupation du territoire côtier}

D'autres activités que l'exploitation de ressources animales ont également été pratiquées dans le site, comme la production d'industries lithiques (Debénath et $\mathrm{El}$ 
Hajraoui, 2012 ; Campmas et al., 2016) ou l'utilisation de pigments (El Hajraoui et al., 2012d). choppers ou des lames sont également décrits. Une grande diversité de matière première, principalement locale, de mauvaise qualité, a été utilisée. Les chaînes opératoires de débitage sont fractionnées et correspondent principalement aux phases finales, à l'exception de la matière première hyper-locale $(<5 \mathrm{~km})$. Les pièces pédonculées présentes dans la série lithique représentent différents types d'outils (laminaires à tranchants bruts, pointes, grattoirs etc.). Elles peuvent être réaffûtées et donc représenter des outils transportables. Les comportements techniques paraissent donc flexibles et traduisent la présence de groupes mobiles (Debénath et El Hajraoui, 2012 ; El Amrani El Hassani et Morala, 2012 ; Morala et al., 2012 ; Campmas et al., 2016).

De plus, la faible densité de matériel et le faible nombre de proies (NMI ongulés $=19$ ) vont également dans le sens d'occupations de courte durée. La présence de jeunes animaux, notamment de périnataux, témoigne, a minima, d'occupations durant le printemps. Les matières premières de qualité médiocre n'expliquent pas la venue des Hommes dans cette région. L'attractivité du milieu littoral pour ses ressources tant alimentaires que symboliques pourrait être un facteur explicatif (Campmas et al., 2016). Cependant, il semble que les Hommes n'aient pas exploité au maximum les ressources alimentaires du milieu côtier à leur disposition, puisqu'ils n'ont semble-t-il pas consommé les taxons endobenthiques.

il est également fait mention de la présence de coquilles de mollusques dans d'autres niveaux Middle Stone Age de la région de Témara-Rabat, à Dar es Soltane 1 (Rhulmann, 1951), El Harhoura 1 (Aouraghe, 2001), à El Harhoura 2 (Nouet et al., 2015) ou à la grotte des Contrebandiers (Steele et Álvarez-Fernández, 2011, 2012) (fig. 1). Pour la grotte des Contrebandiers, T.E. Steele et E. Álvarez-Fernández $(2011,2012)$ fournissent un spectre malacologique plus précis. Concernant les niveaux datés par OSL entre 110 et 100 ka qui ont aussi livré des pièces pédonculées (Jacobs et al., 2011), T.E. Steele et E. ÁlvarezFernández (2011) décrivent selon la nomenclature du site WoRMS une majorité de Patellidae (Patella caerulea, Cymbula safiana, Patella ulyssiponensis et surtout Patella vulgata) et de Mytilidae (Mytilus sp., Perna perna), mais aussi dans une moindre proportion des Trochidae (Phorcus lineatus), des Muricidae (Stramonita haemastoma) et des Arthropodes de la classe des Crustacés tels que les balanes (Steele et ÁlvarezFernández, 2011). Si le spectre malacologique de l'US 8 d'El Mnasra semble similaire à celui de la grotte des Contrebandiers (Steele et Álvarez-Fernández, 2011, 2012), la couche 8 d'El Harhoura 2, datant également de la même période selon l'OSL (Jacobs et al., 2012) n'a, en revanche, livré que des patelles (Nouet et al., 2015 ; Campmas et al., 2016) (fig. 5c). Même si une accessibilité différentielle aux biotopes est envisageable, cette variation de spectre intersites soulève également des questions sur la spécialisation de certains sites et leur éventuelle complémentarité.

En outre, l'US 6 d'El Mnasra, récemment refouillée, apparaît extrêmement riche en coquilles de mollusques marins (fig. 5b). Cette US de la lithostratigraphie d'A. Lenoble (2010), située au-dessus de l'US 8, pourrait correspondre au sommet de la couche 4 de l'archéostratigraphie de M.A. El Hajraoui et A. Debénath (2012a) d'après A. Lenoble (2012). Elle serait datée à 95,4 $\pm 9.3 \mathrm{ka}$ par OSL (Jacobs et al., 2012). Cette observation interroge sur la récurrence des occupations de la zone côtière, notamment en lien avec 
les hauts niveaux marins (Campmas et al., 2016), mais seule l'analyse du matériel issu de ce niveau et la multiplication des datations permettront d'aborder cette question.

Figure 5 : Niveaux d'occupations Pléistocènes en cours de fouille à Témara
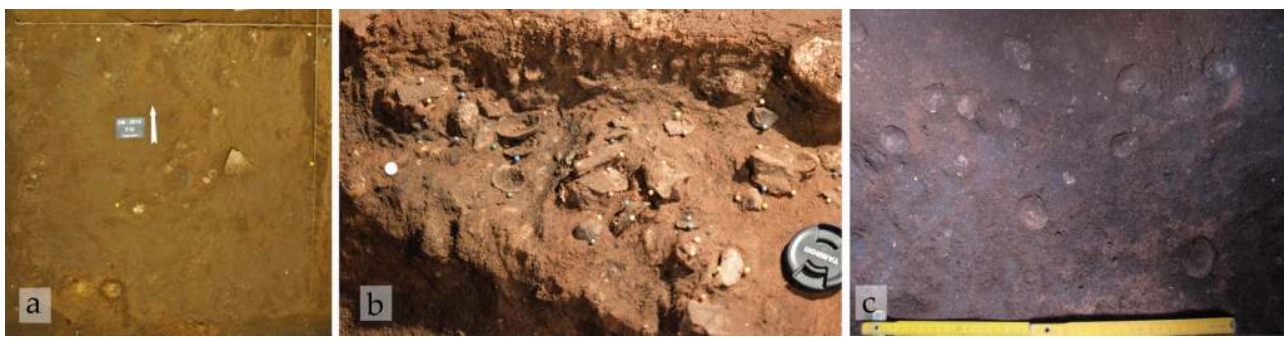

a) US 8 d'El Mnasra, Photographie R. Nespoulet ; b) US 6 d'El Mnasra, photographie E. Campmas ; c) couche 8 d'El Harhoura 2, photographie R. Nespoulet).

\section{Conclusion}

Ces premiers résultats s'insèrent dans une dynamique de recherche (mission El Harhoura-Témara) visant à mieux caractériser les comportements des populations Middle Stone Age qu'ils soient techniques, alimentaires ou symboliques en intégrant aux réflexions l'évolution des paléoenvironnements.

Les Hommes ont occupé la façade atlantique marocaine au stade isotopique 5 et ont exploité des ressources diversifiées. Ils ont tiré parti aussi bien des écosystèmes terrestres que littoraux. Au sein des ressources côtières disponibles, ils semblent avoir préféré les mollusques de côtes rocheuses (en particulier les Patellidae et les Mytilidae) qu'ils ont pu collecter lors des marées basses dans un environnement proche des cavités. Ces ressources animales, qui proviennent de biotopes différents, n'ont pas été exploitées seulement à des fins alimentaires, puisqu'ils ont utilisé des parures en coquilles de Nassariidae, ainsi que la faune terrestre pour l'industrie osseuse. Si ces données préliminaires montrent que les Hommes ont exploité des ressources marines et terrestres locales, il est cependant nécessaire de mieux cerner leur degré de complémentarité en identifiant la part occupée par chaque type de ressources dans l'alimentation des Hommes et la mobilité saisonnière de ces groupes.

Ainsi, la région de Témara apparaît être une région clef pour documenter les occupations côtières et préciser le degré d'adaptation de ces populations au milieu côtier pour ces périodes anciennes.

\section{BIBLIOGRAPHIE}

ALDEIAS V., GUR-ARIEH S., MARIA R., MONTEIRO P. et CURA P. 2016, « Shell we cook it ? An experimental approach to the microarchaeological record of shellfish roasting ». Archaeological Anthropological Science (en ligne). 
ÁLVAREZ-FERNÁNDEZ E. 2011, « Humans and marine resource interaction reappraised :

Archaeofauna remains during the late Pleistocene and Holocene in Cantabrian Spain », Journal of Anthropological Archaeology, n 30, p. 327 - 343.

ÁLVAREZ-FERNÁNDEZ E. 2015, « Continuity of human-marine fauna interaction during the Holocene in Cantabrian Spain », Quaternary International, n³ 364, p. 188 - 195.

AMANI F, BOUgARIANE B. et STOETZEL E. 2012, « partie III-Grotte d'El Mnasra : Chapitre XVI. Faunes et paléoenvironnements ", dans El haJRAOUI A.M., NESPOUlET R., DEBÉNATH A. et DibBle H.L. (dir.), La Préhistoire de La Région de Rabat-Témara. Rabat, Éd. INSAP, Ministère de la Culture (Villes et Sites Archéologiques du Maroc, vol. III), p. 110 - 117.

AOURAGHE H. 2001, «Contribution à la connaissance des faunes pléistocènes supérieures du Maroc : les vertébrés d'El Harhoura (Témara) comparés à ceux de plusieurs sites du Maghreb », thèse de Doctorat, Oujda, Université Mohamed I.

BARTON R.N.E., BOUZOUGGAR A., COLLCUTT N.C., SCHWENNINGER J.-L. et CLARK-BALZAN L. 2009, « OSL dating of the Aterian levels at Dar es-Soltan I (Rabat, Morocco) and implications for the dispersal of modern Homo sapiens ", Quaternary Science Reviews, n² 28, 1914 - 1931.

BOUZOUGGAR A. et BARTON N. 2012, "The Identity and Timing of the Aterian in Morocco », dans HUBLIN J. J et Mc PHERRON S.P. (dir.), Modern Origins : A North African Perspective, New York, Éd. Springer, p. $93-105$.

bouzouggar A., barton N., VANHAEREn M., D'errico F., COllcutt S., higham T., hodge E., PARFitT S., RHODES E., SCHWENNINGER J.-L., STRINGER C., TURNER E., WARD S., MOUTMIR A. et STAMBOULI A. 2007, « 82,000-year-old shell beads from North Africa and implications for the origins of modern human behavior ", Proceedings of the National Academy Sciences of the United State of America, $\mathrm{n}^{\circ} 104$, p. $9964-9969$.

BREBION P.H., HOANG C.T. et WEISROCK A. 1984, « Intérêt des coupes d'Agadir-Port pour l'étude du Pleistocene supérieur marin du Maroc », Bulletin du Muséum National d'Histoire Naturelle, Paris, $\mathrm{n}^{\circ}$ 6, p. $129-151$

BUCQUOY D.E., DAUTZENBERG P. et DOLLFUS G. 1982-1986, « Mollusques marins du Roussillon », Tome Ier, Gastéropodes, Paris, Éd. J.-B. Baillières \& Fils.

BUCQUOY D.E., DAUTZENBERG P. et DOLlFUS G.1987-1998, « Mollusques marins du Roussillon, Tome II, Pélécypodes ", Paris, Éd. J.-B. Baillières \& Fils.

CAMPMAS E. 2012, «Caractérisation de l'occupation des sites de la région de Témara (Maroc) au Pléistocène supérieur et nouvelles données sur la subsistance des hommes du Paléolithique moyen d'Afrique du Nord : Exemples des approches taphonomiques et archéozoologiques menées sur les faunes d'El Harhoura 2 et d'El Mnasra ", thèse de Doctorat, Talence, Université Bordeaux 1.

CAMPMAS E. 2017, « Integrating human-animal relationships into new data on Aterian complexity: a paradigm shift for the North African Middle Stone Age ", African Archaeological Review, $\mathrm{n}^{\circ} 34$, p. 469-491.

CAMPMAS E., AMANI F., MORALA A., DEBÉNATH A., El hajRAoui M.A. et NESPOUlET R. 2016, « Initial insights into Aterian hunter-gatherer settlements on coastal landscapes : The example of Unit 8 of El Mnasra Cave (Témara, Morocco) », Quaternary International, nº 413, p. 5-20.

CAMPMAS E., Michel P., COSTAMAgno S., AMANi F., STOETZEL E., NeSPOUlEt R. et El hajRAOUi M.A. 2015, «Were Upper Pleistocene human/non-human predator occupations at the Témara caves (El 
Harhoura 2 and El Mnasra, Morocco) influenced by cliate change? ", Journal of Human Evolution, $\mathrm{n}^{\circ} 78$, p. $122-143$.

CHAHID D., BOUdAD L., LENOBLE A., El HMAIDI A., CHAKRoun A. et JACOBS, Z. 2016, « Nouvelles données morpho-stratigraphiques et géochronologiques sur le cordon littoral externe (SIM 5-c) de Rabat Témara, Maroc », Geomorphologie, Relief, Processus, Environnement, n² 22, p. 253-264.

CHAHID D., BOUdAD L., LENOBLE A., LAMOTHE M., CHAKRoun A., FALGUères C. et NESPOULET R. 2017, « Les paléo-rivages des formations littorales atlantiques du Pléistocène Moyen - Supérieur de RabatTémara (Maroc) ", L'anthropologie, nº 121, p. 122-132.

CHAKROUN A., CHAHID D., BOUdAD L., CAMPMAS E., LENOBLE A., NESPOUlet R. et El HAJRAOUI M.A. 2017, « The Pleistocene of Rabat (Morocco) : Mollusks, Coastal Environments and Human Behavior », African Archaeological Review, $n^{\circ} 34$, p. 493-510.

CHAKRoun A., BOUDAD L., LENOBle A., CHAHID D., NESPOUlet R. et El HAJRAOUI M.A. 2013, « La malacofaune marine des dépôts littoraux du stade isotopique 5 (Temara-Maroc) : données paléontologiques et paléoécologiques ». Recueil de la Septième Rencontre des Quaternaristes Marocains (RQM7), p. 10-11.

CHAKROUN A. et ZAGHBIB-TURKI D. 2017, « Facies and fauna proxies used to reconstruct the MIS 5 and MIS 7 coastal environments in eastern Tunisia ». Geological Quarterly, n 61, p. 186-204.

CHAKRoun A., ZAGHBIB-TURKI D. et TURKI M.M. 2016, « The Upper Pleistocene deposits in Rafraf (Northeastern Tunisia) : New data on the Persististrombus latus level », Arabian Journal of Geosciences, $\mathrm{n}^{\circ}$ 9, p. 1-13.

COLONESE A.C., MANNINO M.A., BAR-YOSEF MAYER D.E., FA D.A., FINLAYSON J.-C., LUBELl D. et STINER M.C. 2011, « Marine mollusc exploitation in Mediterranean prehistory : An overview », Quaternary International, $\mathrm{n}^{\circ} 239$, p. $86-103$.

CUNNANE S.C. et CRAWFORD M.A. 2014, « Energetic and nutritional constraints on infant brain development : Implications for brain expansion during human evolution », Journal of Human Evolution, $\mathrm{n}^{\circ} 77$, p. $88-98$.

CUNNANE S.C. et STEWART C. 2010, Human Brain Evolution : The Influence of Fresh Water and Marine Food Resources, New Jersey, Éd. Wiley-Backwell.

DEBÉNATH A. et El haJRAoui M.A. 2012, « partie III-Grotte d'El Mnasra : Chapitre XXII. L'industrie lithique », dans El haJRAOUI A.M., NESPOULET R., DEBÉNATH A. et DIBBLE H.L. (dir.), La Préhistoire de La Région de Rabat-Témara. Rabat, Éd. INSAP, Ministère de la Culture (Villes et Sites Archéologiques du Maroc, vol. III), p. 165 - 173.

D'ERRICO F. et BACKWELL L. 2016, « Earliest evidence of personal ornaments associated with burial : The Conus shells from Border Cave », Journal of Human Evolution, n 93, p. 91- 108.

D'ERRICO F., GARCÍA MORENO R. et RIFKIN R.F. 2012, « Technological, elemental and colorimetric analysis of an engraved ochre fragment from the Middle Stone Age levels of Klasies River Cave 1, South Africa ", Journal of Archaeological Science, $\mathrm{n}^{\circ}$ 39, p. 942-952.

D'ERRICO F. et HENSHILWOOD C.S. 2007, « Additional evidence for bone technology in the southern African Middle Stone Age », Journal of Human Evolution, n 52, p. 142 - 163.

D'ERRICO F., HENSHILWOOD C., VANHAEREN M. et van NIEKERK K. 2005, « Nassarius kraussianus shell beads from Blombos Cave : evidence for symbolic behaviour in the Middle Stone Age ", Journal of Human Evolution, $\mathrm{n}^{\circ} 48$, p. 3 - 24 . 
D’ERRICO F., VANHAEREN M., BARTON N., BOUZOUGGAR A., MIENIS H., RICHTER D., HUBLIN J.-J., MCPHERRON S. et LOZOUET P. 2009, «Additional evidence on the use of personal ornaments in the Middle Paleolithic of North Africa ", Proceedings of the National Academy of Sciences of the Unites States of America, $\mathrm{n}^{\circ}$ 106, p. 16051 - 16056.

Dibble H., Aldeias V., Alvarez-Fernandez E., Blackwell B.A.B., Hallett-Desguez E., Jacobs Z., Goldberg P., Lin C.S., Morala A., Meyer M.C., Olszewski D.I., Reed K., Reed D., Rezek Z., Richter D., Roberts R.G., Sandgathe D., Schurmans U., Skinner A.R., Steele T. et El Hajraoui A.M., 2012 - New excavations at the site of Contrebandiers Cave, Morocco. PaleoAnthropology p. 145-201.

DUPONT C. 2006, « La malacofaune de sites mésolithiques et néolithiques de la façade atlantique de la France : Contribution à l'économie et à l'identité culturelle des groupes concernés », Oxford, Éd. Archaeopress (BAR International Series, vol. 1571).

DUPONT C., TRESSET A., DESSE-BERSET N., GRUET Y., MARCHAND G. et SCHULTING R. 2009, « Harvesting the Seashores in the Late Mesolithic of Northwestern Europe : A View From Brittany ", Journal of World Prehistory, n 22, p. 93 - 111.

El AMRANI El HASSANI I.-E. et MORALA A. 2012, « Réflexions méthodologiques sur la lithologie des assemblages paléolithiques de la région de Rabat-Témara (Maroc) », Bulletin de l'Institut Scientifique de Rabat, Section Science de la Terre, $\mathrm{n}^{\circ}$ 34, p. 1 - 14.

El hajRaoui M. A. et DEBÉNATH A. 2012a, « partie III-Grotte d'El Mnasra : Chapitre XV. Contexte géologique et remplissage sédimentaire », dans El HAJRAOUI A.M., NESPOULET R., DEBÉNATH A. et DIBBLE H.L. (dir.), La Préhistoire de La Région de Rabat-Témara. Rabat, Éd. INSAP, Ministère de la Culture (Villes et Sites Archéologiques du Maroc, vol. III), p. 108 - 109.

El hajRAoui M. A. et DEBÉNATH A. 2012b, « partie III-Grotte d'El Mnasra : Chapitre XXIV. L'industrie osseuse », dans El hajRAoui A.M., NESPOUlet R., DEBÉNATH A. et DibBle H.L. (dir.), La Préhistoire de La Région de Rabat-Témara. Rabat, Éd. INSAP, Ministère de la Culture (Villes et Sites Archéologiques du Maroc, vol. III), p. $179-188$.

El hajRaOUi M. A., DEBÉNATH A. et NESPOUlet R. 2012b, « partie III-Grotte d'El Mnasra : Chapitre XIV. Présentation du site et archéostratigraphie », dans El Hajraoui A.M., NESPOULET R., DEBÉNATH A. et DIBBLE H.L. (dir.), La Préhistoire de La Région de Rabat-Témara. Rabat, Éd. INSAP, Ministère de la Culture (Villes et Sites Archéologiques du Maroc, vol. III), p. 105-109.

El hajRAOUI M. A., DEBÉNATH A. et NESPOULET R. 2012c, « partie III-Grotte d'El Mnasra : Chapitre XXIII. Foyers et structure anthropique », dans El HAJRAOUI A.M., NESPOULET R., DEBÉNATH A. et DIBBLE H.L. (dir.), La Préhistoire de La Région de Rabat-Témara. Rabat, Éd. INSAP, Ministère de la Culture (Villes et Sites Archéologiques du Maroc, vol. III), p. 174 - 178.

El hajRAoui M. A., DEBÉNATH A. et NESPOULET R. 2012d, « partie III-Grotte d'El Mnasra : Chapitre XXV. L'hématite ", dans El haJRAOUI A.M., NESPOULET R., DEBÉNATH A. et DIBBLE H.L. (dir.), La Préhistoire de La Région de Rabat-Témara. Rabat, Éd. INSAP, Ministère de la Culture (Villes et Sites Archéologiques du Maroc, vol. III), p. 189 - 190.

El hajRAOUi M. A., NESPOULET R., DEBÉNATH A. et DiBBle H.L. 2012a, La Préhistoire de la région de RabatTémara, Villes et Sites Archéologiques du Maroc, Rabat, Éd. INSAP, Ministère de la Culture (Villes et Sites Archeologiques du Maroc, vol. III).

El hajRaoui M. A., oudouche, H., NESPoulet R. 2012e, « partie III-Grotte d'El Mnasra. Chapitre XXVI. Étude des coquilles perforées découvertes à Témara ", dans El HAJRAOUI A.M., NESPOULET R., DEBÉNATH A. et DIBBLE H.L. (dir.), La Préhistoire de La Région de Rabat-Témara. Rabat, Éd. INSAP, Ministère de la Culture (Villes et Sites Archéologiques du Maroc, vol. III), p. 191 - 199. 
ERLANDSON J.-M. et BRAJE T.J. 2015, « Coasting out of Africa : The potential of mangrove forests and marine habitats to facilitate human coastal expansion via the Southern Dispersal Route », Quaternary International, $\mathrm{n}^{\circ} 382$, p. $31-41$.

FA D.A. 2008, « Effects of tidal amplitude on intertidal resource availability and dispersal pressure in prehistoric human coastal populations : The Mediterranean - Atlantic transition ", Quaternary Science Review, n² 27, p. $2194-2209$.

GIROD A. 2011, « Land snails from Late Glacial and Early Holocene Italian sites ». Quaternary International, $\mathrm{n}^{\circ} 244$, p. 105-116.

GUTIÉRREZ-ZUGASTI I. 2011, « Coastal resource intensification across the Pleistocene - Holocene transition in Northern Spain : Evidence from shell size and age distributions of marine gastropods ", Quaternary International, n² 244, p. $54-66$.

HENSHILWOOD C.S., D’ERRICO F., MAREAN C.W., MILO R.G. et YATES R. 2001, « An early bone tool industry from the Middle Stone Age at Blombos Cave, South Africa : Implications for the origins of modern human behaviour, symbolism and language ", Journal of Human Evolution, n 41, p. 631 - 678.

HENSHILWOOD C.S., D’ERRICO F., van NIEKERK K.L., COQUINOT Y., JACOBS Z., LAURITZEN S.-E., MENU M. et GARCÍA-MORENO R. 2011, «A 100,000-Year-Old Ochre-Processing Workshop at Blombos Cave, South Africa ", Science, $\mathrm{n}^{\circ} 334$, p. $219-222$.

HENSHILWOOD C.S., D'ERRICO F. et WATTS I. 2009, « Engraved ochres from the Middle Stone Age levels at Blombos Cave, South Africa », Journal of Human Evolution, n 57, p. 27 - 47.

HUBLIN J.-J., BEN-NCER A., BAILEY S.E., FREIDLINE S.E., NEUBAUER S., SKINNER M.M., BERGMANN I., LE CABEC A., BENAZZI S., HARVATI K. et GUNZ P. 2017, « New fossils from Jebel Irhoud, Morocco and the panAfrican origin of Homo sapiens », Nature, n 546, p. 289 - 292.

JACOBS Z., MEYER M.C., ROBERTS R.G., ALDEIAS V., DIBBLE H. et El HAJRAOUI M.A. 2011, « Single-grain OSL dating at La Grotte des Contrebandiers (Smugglers Cave"), Morocco : improved age constraints for the Middle Paleolithic levels ", Journal of Archaeological Science, n 38, p. 3631 - 3643.

JACOBS Z., ROBERTS R.G., NESPOULET R., El hAJRAOUI M.A. et DEBÉNATH A. 2012, « Single-grain OSL chronologies for Middle Palaeolithic deposits at El Mnasra and El Harhoura 2, Morocco : Implications for Late Pleistocene human - environment interactions along the Atlantic coast of northwest Africa », Journal of Human Evolution, n 62, p. 377 - 394.

JANATI IDRISSI N., FALGUÈRES C., HADDAD M., NESPOULET R., El HAJRAOUI M.A., DEBÉNATH A., BEJJIT L., BAHAIN J.-J., MICHEL P., GARCIA T., BOUDAD L., El HAMMOUTI K. et OUJAA A. 2012, « Datation par ESR-U/ Th combinées de dents fossiles des grottes d'EL Mnasra et d'El Harhoura 2, région de RabatTemara. Implications chronologiques sur le peuplement du Maroc atlantique au Pléistocène supérieur et son environnement ", Quaternaire, n²3, p. 25 - 35.

JERARDINO A. 2016, « On the origins and significance of Pleistocene coastal resource use in southern Africa with particular reference to shellfish gathering ", Journal of Anthropological Archaeology, n 41, p. $213-230$.

JERARDINO A. et MAREAN C.W. 2010, «Shellfish gathering, marine paleoecology and modern human behavior : perspectives from cave PP13B, Pinnacle Point, South Africa ». Journal of Human Evolution, $\mathrm{n}^{\circ} 59$, p. $412-424$.

KELLY R.L. 1983, « Hunter-Gatherer Mobility Strategies », Journal of Anthropological Research, $n^{\circ}$ 39, p. $277-306$. 
KELLY R.L. 1992, « Mobility/Sedentism : Concepts, Archaeological Measures, and Effects », Annual Review of Anthropology, n 21, p. $43-66$.

LANGEJANS G.H.J., van NIEKERK K.L., DUSSELDORP G.L. et THACKERAY J.-F. 2012, « Middle Stone Age shellfish exploitation : Potential indications for mass collecting and resource intensification at Blombos Cave and Klasies River, South Africa ", Quaternary International, vol. 270, p. 80 - 94.

LENOBLE A. 2010, « Lithostratigraphie de la grotte d'El Mnasra. Description et hypothèses proposées », dans El HAJRAOUI, M.A. et NESPOULET, R. (dir.), Mission archéologique El Harhoura-Témara, Rapport d'activité 2010, pp. $14-15$.

LENOBLE A. 2012, «Chronostratigraphie du site d'El Mnasra », dans El Hajraoui, M.A. et Nespoulet, R. (dir.), Mission archéologique El Harhoura-Témara, Rapport d'activité 2012, pp. 32 - 34.

LENOBLE A., BOUDAD L. et JACOBS Z. 2011, « Paléoenvironnements contemporains des sites préhistoriques ", dans El HAJRAOUI, M.A. et NESPOULET, R. (dir.), Mission archéologique El HarhouraTémara, Rapport d'activité 2011, pp. 13 - 22.

LINDNER G. 2015, « Coquillages marins : Plus de 1000 espèces des mers du monde ». Paris, Ed. Delachaux et Niestlé.

MAREAN C.W. 2011, «Coastal South Africa and the co-evolution of the modern human lineage and the coastal adaptation », dans BICHO N.F., HAWs J.A. et DAVIS L.A. (dir.), Trekking the Shore : Changing Coastlines and the Antiquity of Coastal Settlement. New York, Éd. Springer, p. 421 - 439.

MAREAN C.W. 2014, " The origins and significance of coastal resource use in Africa and Western Eurasia ", Journal of Human Evolution, $n^{\circ} 77$, p. $17-40$.

MAREAN C.W., BAR-MATTHEWS M., BERNATCHEZ J., FISHER E., GOLDBERG P., HERRIES A.I.R., JACOBS Z., JERARDINO A., KARKANAS P., MINICHILLO T., NILSSEN P.J., THOMPSON E., WATTS I. et WILLIAMS H.M. 2007, «Early human use of marine resources and pigment in South Africa during the Middle Pleistocene ", Nature, n 449, p. $905-908$.

MARÍN-ARROYO, A.B. 2013, « Human response to Holocene warming on the Cantabrian Coast (northern Spain) : An unexpected outcome », Quaternary Science Review, n 81, p. 1 - 11. MCBREARTY, S. et BROOKS, A.S. 2000, « The revolution that wasn't : A new interpretation of the origin of modern human behavior ", Journal of Human Evolution, n 39, p. 453 - 563.

MELLARS P. 2006, « Why did modern human populations disperse from Africa ca. 60,000 years ago ? A new model », Proceedings of the National Academy of Sciences of United States of America, $\mathrm{n}^{\circ} 203$, p. $9381-9386$.

MELLARS P., GORI K.C., CARR M., SOARES P.A. et RICHARDS M.B. 2013, « Genetic and archaeological perspectives on the initial modern human colonization of southern Asia », Proceedings of the National Academy of Sciences of United States of America, $n^{\circ}$ 110, p. $10699-10704$.

MHAMMDI N., MEDINA F., KELLETAT D., AHMAMOU M. et ALOUSSI L. 2008, « Large boulders along the Rabat coast (Morocco) : Possible emplacement by the November $1^{\text {st }} 1755$ A.D. tsunami $"$, Science of Tsunami Hazards, $\mathrm{n}^{\circ}$ 27, p. 17-32.

MOdiCA M.V., BOUCHET P., CRUAUd C., UTGE J. et Oliverio M. 2011, « Molecular phylogeny of the nutmeg shells (Neogastropoda, Cancellariidae) », Molecular Phylogenetics and Evolution, $\mathrm{n}^{\circ} 59$, p. 685-697.

MONCHOT H. et AOURAGHE H. 2009, « Deciphering the taphonomic history of an Upper Paleolithic faunal assemblage from Zouhrah Cave/El Harhoura 1, Morocco », Quaternaire, n 20, p. 239 - 253. 
MORALA A., El AMRANI El hASSANI I.E. et DEBÉNATH A. 2012, « partie III-Grotte d'El Mnasra : Chapitre XXI. Lithologie : données générales », dans El HAJRAOUI, A.M., NESPOULET, R., DEBÉNATH, A. et DIBBLE, H.L. (dir.), La Préhistoire de La Région de Rabat-Témara. Rabat, Éd. INSAP, Ministère de la Culture (Villes et Sites Archéologiques du Maroc, vol. III), p. 154 - 614.

NESPOUlet R., DebÉNATH A., El hajRAOUi M.A., Michel P., CAMPMAS E., OUJAA A., BEN-NCER A., LACOMBE J.P., STOETZEL E. et BOUdAD L. 2008, « Le contexte archéologique des restes humains atériens de la région de Rabat-Témara (Maroc) : Apport des fouilles des grottes d'El Mnasra et d'El Harhoura 2 », dans AOURAGHE H., HADDOUMI H., El HAMMOUTI K. et OUjDA A. (dir.), Le Quaternaire Marocain Dans Son Contexte Méditerranéen. Actes des quatrièmes rencontres des Quaternaristes marocaines (RQM4). Oujda, Éd. facultés des Sciences d'Oujda, novembre 2007, p. 356 - 375.

NOUET J., CHEVAlLARd C., FARRE B., NEHRKE G., CAMPMAs E., STOETZEL E., El HAJRAoui M.A. et NeSPOUlet R. 2015, « Limpet shells of the Aterian level 8 of El Harhoura 2 Cave (Témara, Morocco) :

Preservation state of crossed-foliated layers », PlosONE, $n^{\circ}$ 10, e0137162.

PARKINGTON J. 2010, « Coastal diet, Encephalization, and Innovative Behaviors in the Late Middle Stone Age of Southern Africa ", dans CUNNANE S.C. et STEWART K.M. (dir.), Human Brain Evolutionthe Influence of Freshwater and Marine Food Resources. New Jersey, Éd. Wiley Blackwell, p. 189 - 203.

PERRIER R. 1954, « La faune de France, IX : Vertébrés, Bryozoaires, Brachiopodes, Mollusques, Protocordés (Amphioxus - Tuniciers) », Paris, Éd. Delagrave.

RICHTER D., GRÜN R., JOANNES-BOYAU R., STEELE T.E., AMANI F., RUÉ M., FERNADES P., RAYNAL J.-P., GERRADS D., BEN-NCER A., HUBLIN J.-J. et MCPHERRON S. 2017, « The age of the hominin fossils from Jebel Irhoud, Morocco, and the origins of the Middle Stone Age ", Nature, n 546, p. 293-296.

ROTS V. et Van PEER P. 2006, « Early evidence of complexity in lithic economy : Core-axe production, hafting and use at Late Middle Pleistocene site 8-B-11, Sai Island (Sudan) », Journal of Archaeological Sciences, $\mathrm{n}^{\circ}$ 33, p. $360-371$.

ROTS V., Van PEER P. et VERMEERSCH P.M. 2011, « Aspects of tool production, use, and hafting in Palaeolithic assemblages from Northeast Africa », Journal of Human Evolution, n 60, p. 637 - 664 .

RUHLMANN A. 1951, La grotte Préhistorique de Dar es-Sotlan, Paris, Éd. Larose.

RUSSELL N., BONSALL C. et SUTHERLAND D., 1995, « The exploitation of marine molluscs in the Mesolithic of western Scotland : evidence from Ulva Cave, Inner Hebrides », dans FISCHER A. (dir.), Man and Sea in The Mesolithic. Oxford: Oxbow Book, p. 273-288.

SCHWENNINGER J.-L., COLLCUTT S., BARTON N., BOUZOUgGAR A., El HAJRAOUI M.A., NESPOULET R., DEBÉNATH, A. et CLARK-BALZAN, L. 2010, «A new luminescence chronology for Aterian cave sites on the Atlantic coast of Morocco », dans GARCEA E.E.A. (dir.), South-Eastern Mediterranean Peoples between 130,000 and 10,000 Years Ago, Oxford, Éd. Oxbow books, p. 18-36.

SHACKLETON N.J. 2000, « The 100,000-Year Ice-Age Cycle Identified and Found to lag Temperature, Carbon Dioxide, and Orbital Eccentricity ». Science, n 289, p. $1897-1902$.

STEARNS C.E. et THURBER D. 1965, «Th230-U234 dates of Late Pleistocene marine fossils from the Mediterranean and Moroccan littorals », Quaternaria, $\mathrm{n}^{\circ}$ 7, p. $29-42$.

STEELE T., E. et ÁlVAREZ-FERNÁNDEZ E. 2011, « Initial Investigations into the Exploitation of Coastal Resources in North Africa During the Late Pleistocene at Grotte des Contrebandiers, Morocco, dans BICHO N.F., HAWS J.A. et DAVIS L.A. (dir.), Trekking the Shore: Changing Coastlines and the Antiquity of Coastal Settlement. New York, Éd. Springer, p. 383 - 403. 
STEELE T.E., ÁLVAREZ-FERNÁNDEZ E. 2012, « partie IV-La grotte des Contrebandiers : Chapitre XXX. Restes de Mollusques marins ", dans El haJRAoui A.M., NESPOUlet R., DEBÉNATH A. et DIBBLE H.L. (dir.), La Préhistoire de La Région de Rabat-Témara. Rabat, Éd. INSAP, Ministère de la Culture (Villes et Sites Archéologiques du Maroc, vol. III), p. 223 - 227.

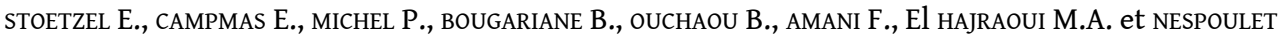
R. 2014, «Context of modern human occupations in North Africa : Contribution of the Témara caves data ", Quaternary International, n 320, p. 143 - 161.

TEXIER J.-P., RAYNAL J.-P., LEFÈVRE D. 1985, « Essai de chronologie du Quaternaire marocain », Bulletin d'Archéologie Marocaine, $\mathrm{n}^{\circ}$ 26, p. 11-26.

TLIG-ZOUARI S. et MAAMOURI-MOKHTAR, F. 2008, « Macrobenthic species composition and distribution in the Northern Lagoon of Tunis », Transitional waters bulletin, $\mathrm{n}^{\circ} 2, \mathrm{p} .1-11$.

VANHAEREN M., D'ERRICO F., STRINGER C., JAMES S., L., TODD J. et Mienis H. 2006, « Middle Paleolithic Shell Beads in Israel and Algeria », Science, $\mathrm{n}^{\circ}$ 312, p. 1785 - 1788.

VANHAEREN M., D'ERRICO F., van NIEKERK K.L., HENSHILWOOD C.S. et ERASMUS R.M. 2013, « Thinking strings : Additional evidence for personal ornament use in the Middle Stone Age at Blombos Cave, South Africa ", Journal of Human Evolution, n 64, p. 500 - 517.

VILLA P., SORESSI M., HENSHILWOOd C. et MOURRE V. 2009, « The Still Bay points of Blombos Cave (South Africa) », Journal of Archaeological Science, n 36, p. $441-460$.

WAELBROECK C., LABEYRIE L., MICHEL E., DUPLESSY J.-C., MCMANUS J.-F., LAMBECK K., BALBON E. et LABRACHERIE M. 2002, « Sea-level and deep water temperature changes derived from benthic foraminifera isotopic records », Quaternary Science Reviews, n² 21, p. 295 - 305.

WEISROCK A. 2016, « Niveaux marins du Maroc atlantique durant le dernier Interglaciaire (SIM 5.5, SIM 5.3 et SIM 5.1) ». Geomorphologie, Relief, Processus, Environnement, nº 22, p. 245-251.

WEISROCK A., OCCHIETTI S., HOANG C.-T., LAURIAT-RAGE Agnès, BREBion P. et PICHET P. 1999, « Les séquences littorales pléistocènes de l'Atlas atlantique entre Cap Rhir et Agadir, Maroc ", Quaternaire, $\mathrm{n}^{\circ} 10$, p. $227-244$.

WILL M., KANDEL A., W. et CONARD, N.J. 2015a, « Coastal Adaptations and Settlement Systems on the Cape and Horn of Africa during the Middle Stone Age », dans CONARD N.J. et DELAGNES A. (dir.), Settlement Dynamics of the Middle Paleolithic and Middle Stone Age. Tubingen, Éd. Kerns Verlag, p. 47 $-75$.

WILL M., KANDEL A.W., KYRIACOU K. et CONARD N.J. 2015b, « An evolutionary perspective on coastal adaptations by modern humans during the Middle Stone Age of Africa », Quaternary International, $n^{\circ} 404$, p. $68-86$.

YESNER D.R. 1980, « Maritime Hunter-Gatherers : Ecology and Prehistory ». Current Anthropology, $\mathrm{n}^{\circ} 21$, p. $727-750$.

\section{RÉSUMÉS}

L'occupation Middle Stone Age de l'unité stratigraphique 8 de la grotte d'El Mnasra, située sur la côte atlantique marocaine, a livré des coquilles de mollusques marins, associées à des restes de faune terrestre, des industries lithiques et des pigments. Les Hommes anatomiquement modernes qui ont occupé cette cavité ont exploité des ressources diversifiées, marines et terrestres. Au sein des ressources côtières disponibles, ils semblent avoir préféré les mollusques 
de côte rocheuse (en particulier les Patellidae et les Mytilidae, mollusques qui ne s'enfouissent pas) qu'ils ont pu collecter lors des marées basses dans un environnement littoral proche de la cavité. Les ressources animales en plus d'avoir été exploitées à des fins alimentaires ont été utilisées à des fins symboliques (ornements en coquilles de Nassariidae) ou techniques (industrie osseuse).

\section{AUTEURS}

\section{ÉMILIE CAMPMAS}

TRACES, CNRS-UMR 5608,

Université Toulouse Jean Jaurès, France

\section{AMEL CHAKROUN}

Département de géologie, Faculté des Sciences de Tunis,

Université de Tunis El Manar, Tunisie

\section{DRISS CHAHID}

Université Moulay-Ismaïl, Meknès, Maroc, HNHP, CNRS-UMR 7194, Muséum National d'Histoire Naturelle, Université de Perpignan Via Domitia, Sorbonne Universités, France

\section{ARNAUD LENOBLE}

PACEA, CNRS-UMR 5199,

Université de Bordeaux, France

\section{LARBI BOUDAD}

Université Moulay-Ismaill, Faculté des Sciences,

Meknès, Maroc

MOHAMED ABDELJALIL EL HAJRAOUI

INSAP, Rabat, Maroc

\section{ROLAND NESPOULET}

HNHP, CNRS-UMR 7194, Muséum National d'Histoire Naturelle, Université de Perpignan Via Domitia, Sorbonne Universités, France 


\title{
Perles discoïdes en coquille marine et en roche de l'âge du Bronze dans le Centre-Ouest de la France : l'exemple du Mas de Champ Redon à Luxé
}

\author{
Caroline Mougne, Catherine Dupont, Querré Guirec, Patricia Semelier et \\ Valérie Audé
}

\begin{abstract}
Nous souhaitons remercier José Gomez de Soto et Isabelle Kerouanton pour leurs relectures attentives de ce manuscrit. Nous tenons également à remercier Luc Laporte pour ses précieux conseils lors de l'étude des perles discoïdes.
\end{abstract}

1 Les coquilles de mollusques marins sont utilisées comme matière première pour la confection de parure depuis le Paléolithique. Tout d'abord à l'état brut simplement percées, les coquilles vont, dès le début du Néolithique en France, être façonnées pour obtenir des parures plus élaborées comme des perles discoïdes (Bonnardin, 2009 ; Prost et al., 2012). Les bivalves de la famille des Cardiidés, et plus particulièrement le genre Cerastoderma appelé plus couramment coque, sont souvent utilisés pour la fabrication de perles discoïdes. Ce type de perle a été découvert sur plusieurs sites du Néolithique et de l'âge du Bronze en France (Taborin, 1974 ; Laporte, 1994, Pauc, 1997 ; Bocquenet, 1998 ; Bonnardin, 2009 ; Dupont et Laporte, 2009; Gruet et Laporte, 2009; Laporte, 2009 ; Pauc, 2011 ; Prost et al. 2012) et du Néolithique récent en Grèce (Miller, 1996). Leur étude a permis de reconstituer certaines chaînes opératoires de fabrication de ces perles. Quelques expérimentations viennent aussi compléter ces observations sur le territoire français (Pauc, 1997 ; Ricou et Esnard, 2000 ; Bonnardin, 2009; Ricou et al., 2009 ; Pauc, 2011).

2 Trente-neuf perles discoïdes en coquille marine, majoritairement du genre Cerastoderma, ont été découvertes dans deux sépultures individuelles de l'âge du Bronze ancien sur la commune de Luxé, dans le Centre-Ouest de la France. Ce type de perles est 
attesté majoritairement dans des sépultures collectives, dont la couverture chronologique est assez large, voire incertaine, mais rarement en sépulture individuelle, ce qui constitue un des intérêts majeurs de cette étude. Cette collection est en effet un exemple rare en France, et encore unique en Centre-Ouest pour l'âge du Bronze.

\section{Présentation du site}

Le site archéologique du Mas de Champ Redon est localisé à Luxé, en Charente, dans le Centre-Ouest de la France, à une centaine de kilomètres du littoral actuel (fig. 1). Il a fait l'objet d'une fouille en 2011 par l'Institut national de recherches archéologiques préventives (Inrap) sous la direction de V. Audé (Audé, 2013). Cette opération a permis, entre autres, de mettre en évidence un petit ensemble sépulcral d'une superficie d'environ $4 \mathrm{~m}^{2}$, composé de trois sépultures individuelles déposées dans des fosses architecturées en blocs de calcaire non équarris. Les datations radiocarbones effectuées pour chacun des squelettes donnent des résultats relativement homogènes situés vers la seconde moitié de l'âge du Bronze ancien, soit entre 1900 et 1600 av. J.-C. environ, sans que l'on puisse toutefois déterminer l'ordre d'installation des tombes.

Figure 1 : Localisation, plan et illustrations du site du Mas de Champ Redon à Luxé.

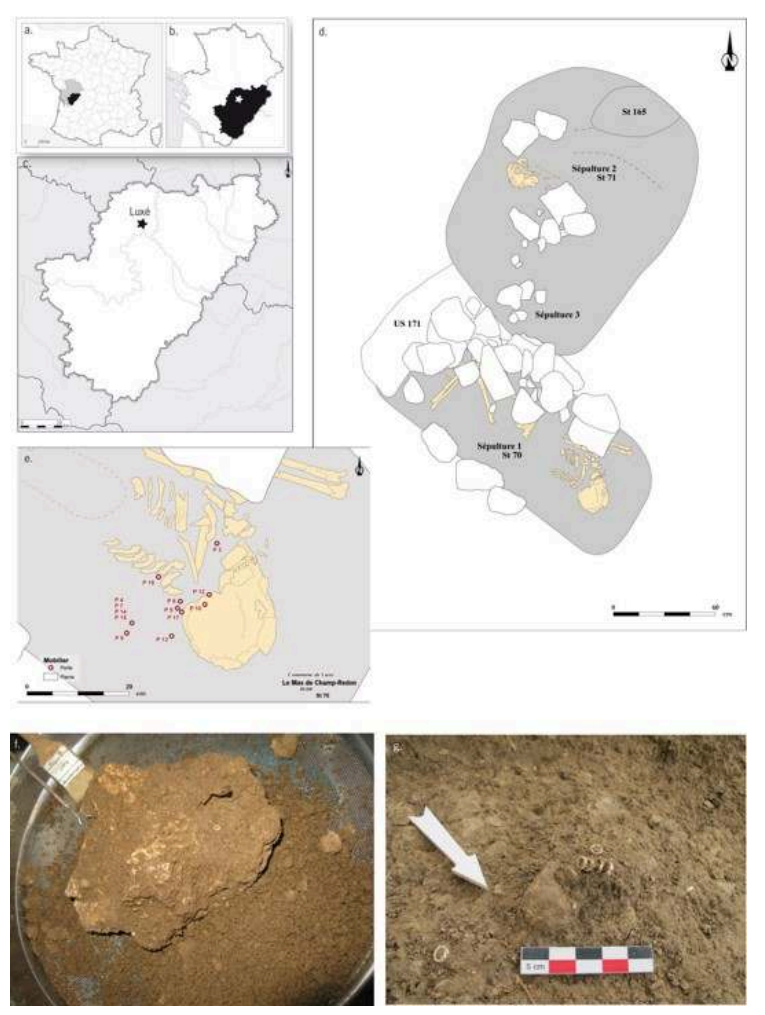

a, b, c : Localisation du site, d: Plan des trois sépultures du Mas de Champ Redon (Audé 2013, p. 45). e : Plan de détail de la sépulture 1 du Mas de Champ Redon avec emplacement des perles trouvées in situ ( $n^{\circ}$ des perles attribuées pour l'étude) (Audé 2013, p. 53). f: Perles trouvées lors du tamisage en laboratoire dont certaines localisées contre la partie postérieure de la joue droite de la sépulture 1 du Mas de Champ Redon (Audé 2013, p. 65). g : Perles (dont quatre accolées) trouvées in situ dans la sépulture 1 du Mas de Champ Redon (nº d'étude : 4, 7, 14, 15) (Audé 2013, p. 54). 
Deux des trois sépultures étaient associées à quarante perles discoïdes soit trente-neuf en test coquillier marin étudiées par C. Mougne et C. Dupont et une perle en roche analysée par G. Querré (fig. 2 et 3).

Figure 2 : Perles discoïdes en coquillage marin de la sépulture 1 du Mas de Champ Redon à Luxé avec le numéro de chaque perle en haut à gauche (pour les mesures des perles se référer au tableau 1) (cl. C. Mougne).

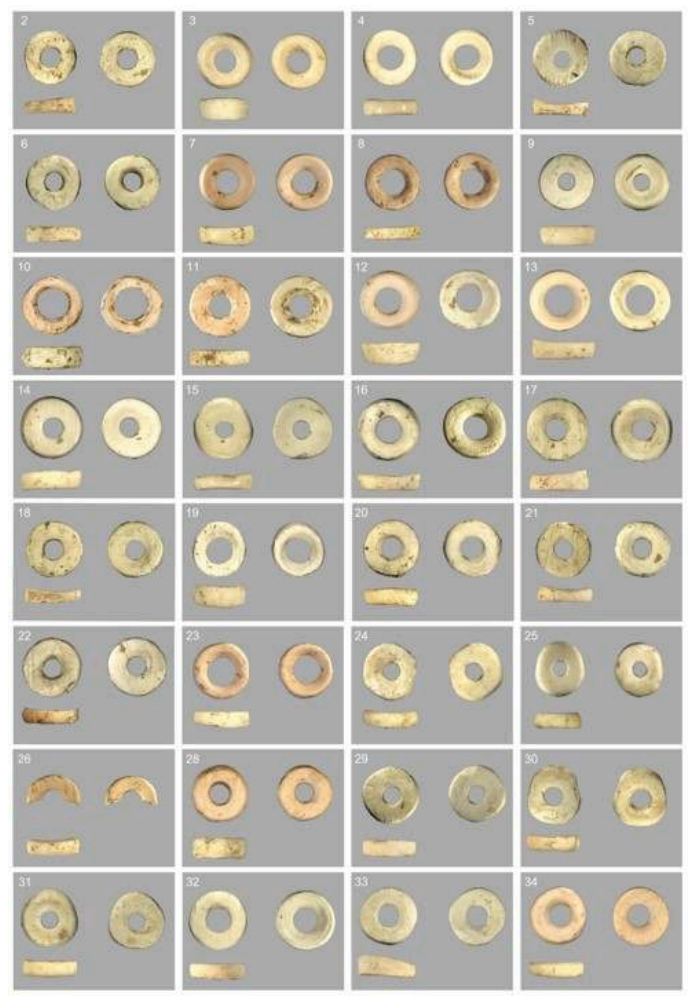

Figure 3 : Perles discoïdes en coquillage marin et en roche (perle $\left.n^{\circ} 40\right)$ de la sépulture 2 du Mas de Champ Redon à Luxé avec le numéro de chaque perle en haut à gauche (pour les mesures des perles se référer au tableau 1) (cl. C. Mougne).
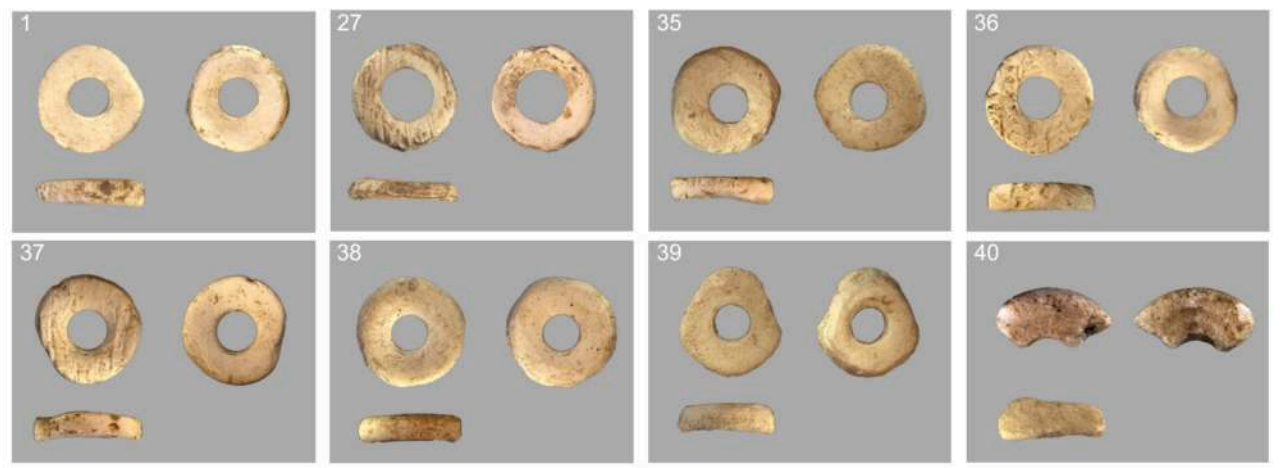

\section{Matériel et méthode}

Les informations et les résultats présentés ont pu être établis à partir du ramassage à vue et des prélèvements sédimentaires (318 litres) effectués sur le terrain, mais également au cours de la fouille fine réalisée en laboratoire sous la responsabilité de V. 
Audé (fig. 1). Sur les quarante perles découvertes, trente-deux étaient situées dans la tombe du jeune adulte (sépulture 1 , structure $\mathrm{n}^{\circ} 70$ ) et huit dans celle de l'enfant âgé de 7 ans environ (sépulture 2, structure $n^{\circ} 71$ ). Aucun élément de parure n'a été découvert dans la tombe du plus jeune enfant âgé d'environ 4 ans. Toutes ces perles, découvertes soit in situ durant la fouille soit au cours du tamisage des sédiments, étaient positionnées entre le crâne et l'épaule des deux individus. Le mobilier funéraire de cet ensemble sépulcral est constitué quasi exclusivement de ces quarante perles discoïdes (Mougne, 2015). Des éclats de silex et nodules de céramique, découverts durant le tamisage, ne semblent pas avoir été déposés volontairement dans les tombes, mais ont plus vraisemblablement été apportés, de façon résiduelle, avec les terres de comblement (Audé, 2013).

6 Toutes les perles discoïdes ont été observées, puis photographiées, à la loupe binoculaire. Cette méthode est indispensable pour l'observation des stigmates de façonnage et d'usure mais également pour l'identification de la matière première et des processus taphonomiques. Les perles et certains détails de celles-ci ont ensuite été photographiés sous loupe binoculaire (grossissement jusqu'au 80X) afin d'illustrer au mieux les hypothèses avancées. Quatre séries de mesures ont été prises au pied à coulisse digital au centième de millimètre : la longueur correspond à la dimension prise dans le sens des côtes ornant la coquille; la largeur est la mesure qui lui est perpendiculaire; seule l'épaisseur maximale de la perle a été retenue, car sujette à variation d'un bout à l'autre de la perle; enfin le diamètre de la lumière de la perforation correspond au diamètre du percement.

\section{Résultats}

\section{Choix des espèces}

7 Sur les quarante perles, trente-neuf ont été fabriquées à partir de coquillage marin (fig. 4). Vingt-neuf au moins proviennent du genre Cerastoderma, appelé couramment coque ou Cardium. Cette détermination a pu être réalisée grâce au dessin des côtes observables sur la coquille, à leurs dimensions mais également à l'épaisseur des perles ainsi qu'à leur courbure (fig. 5-b et fig. 6) La coque commune Cerastoderma edule, de son ancien nom latin Cardium edule, peut être confondue facilement avec la coque des marais Cerastoderma glaucum, de son ancien nom latin Cardium glaucum, présente à la fois sur les côtes atlantiques et méditerranéennes. La différenciation de ces deux espèces n'a pas été possible pour les perles de Luxé. Pour les dix autres, l'identification n'a pas été possible, mais il est assuré qu'elles ont été façonnées à partir de coquilles marines du fait de la structure du matériau employé (fig. 5-a).

8 Une perle en roche a également été identifiée. Les analyses chimiques montrent qu'elle a été réalisée probablement à partir d'un calcaire cristallin particulièrement pur ou bien d'un fragment de marbre.

9 Le choix des tests de Cerastoderma sp. pour confectionner des parures n'est pas anodin. En effet, cette coquille est parfaitement adaptée à la confection de perles discoïdes, car sa texture est moins dure que celle d'autres bivalves et coquillages marins (Ricou et Esnard, 2000). De plus, la forme discoïde demande une matière première dont l'épaisseur est suffisante et peu convexe, ce qu'offrent les coques, coquillages les plus communs pour la fabrication de ce type de perles (Taborin, 1974, p. 141). 
Figure 4 : Matière première et forme des perles.
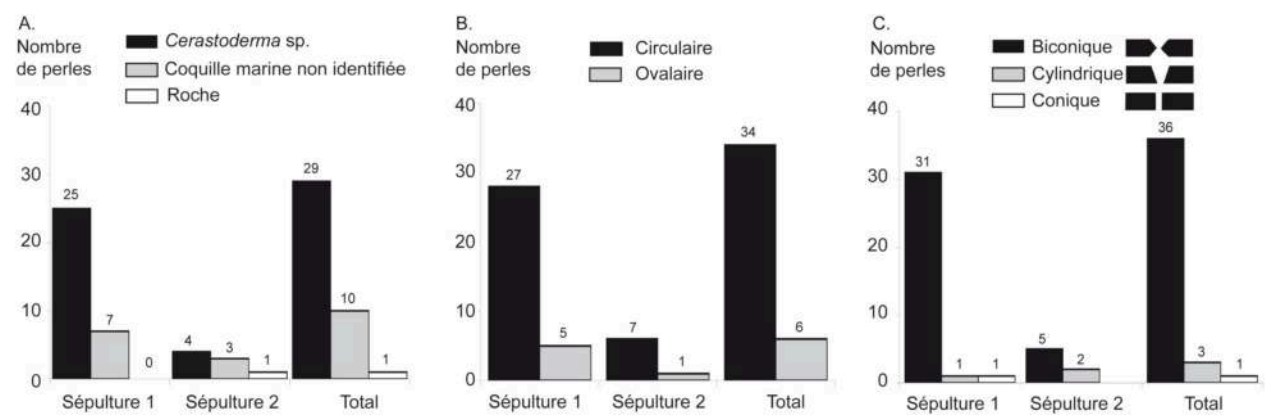

a : matière première des perles. b : forme générale des perles. c : section des perforations.

Figure 5 : Détail de la structure des perles témoignant de l'utilisation de test coquillier au Mas de Champ Redon (cl. C. Mougne).

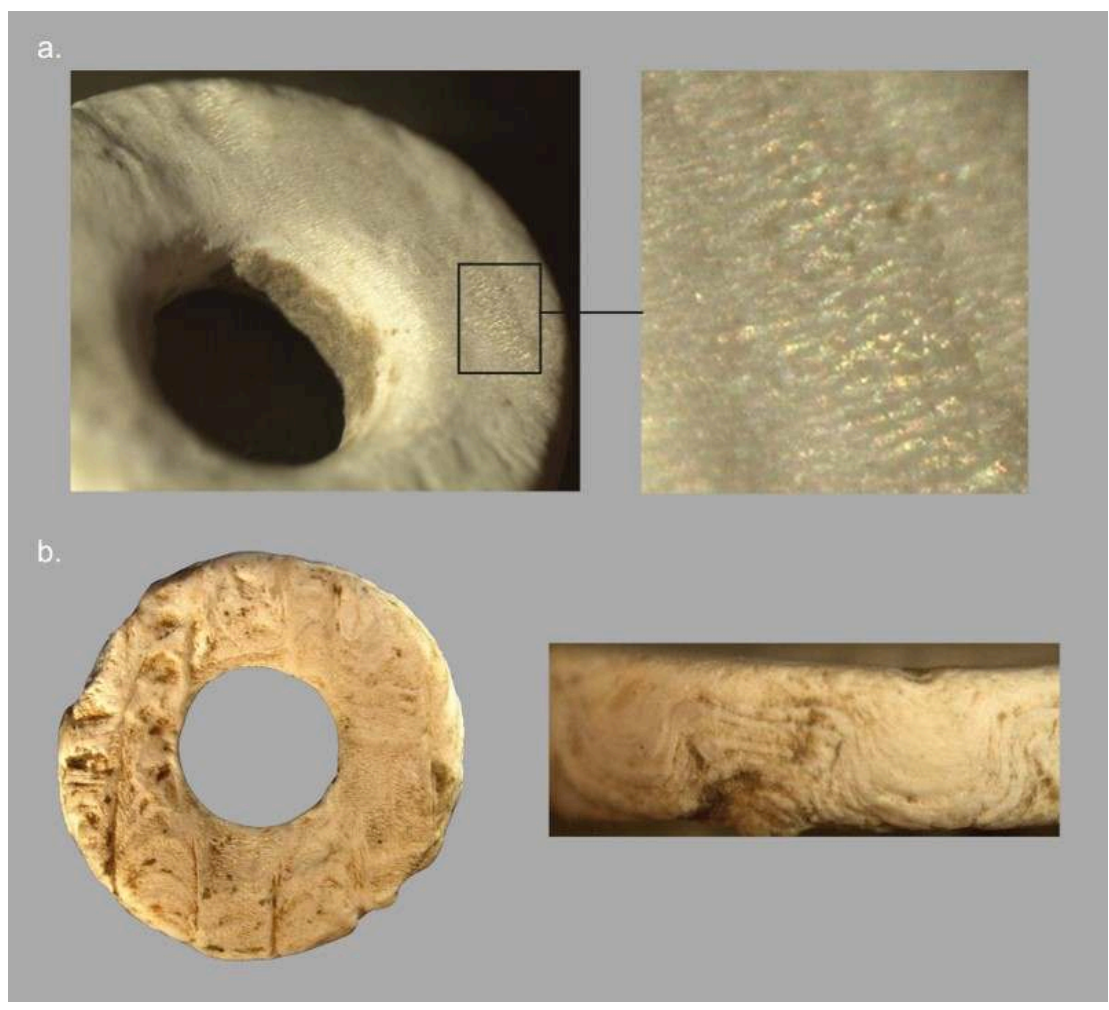

a : perle $n^{\circ} 6, L=5,2 \mathrm{~mm}$ : structure du coquillage marin, $b$ : perle $n^{\circ} 36, L=6,15 \mathrm{~mm}$ : présence de côtes, ornementations des coquillages marins appartenant à la famille des Cardiidés ( $L=$ longueur maximale). 
Figure 6 : a : Cerastoderma glaucum $(L=30 \mathrm{~mm}), \mathrm{b}$ : Cerastoderma edule $(\mathrm{L}=26 \mathrm{~mm})(\mathrm{L}=$ longueur maximale) (cl. C. Mougne).

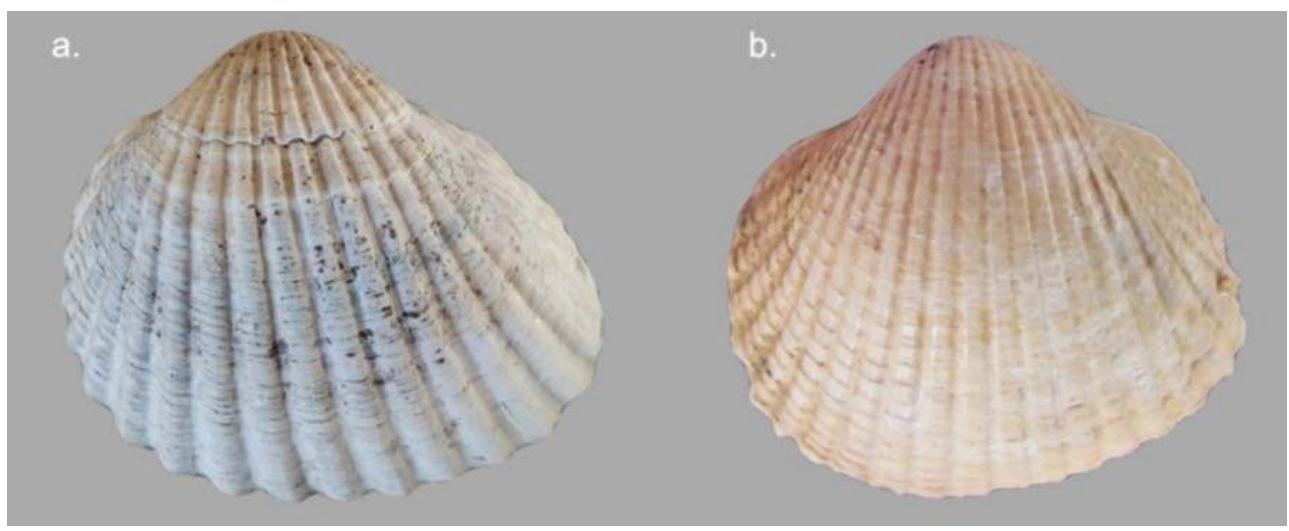

\section{Taphonomie}

Cette analyse préalable permet d'estimer le niveau de conservation des artefacts. Sur les quarante perles discoïdes, deux sont fragmentées. La première, en test coquillier a été brisée lors de la post-fouille (fig. $2 \mathrm{n}^{\circ}$ 26). Quant à la deuxième, en roche, sa cassure semble ancienne (fig. $3 \mathrm{n}^{\circ} 40$ ). Globalement, la surface des perles est assez altérée, la surface d'origine a disparu. Cette altération est due à la fois à la nature du terrain, aux racines, mais également aux émanations chimiques qui ont eu lieu lors de la décomposition des corps. Le poli peut partiellement ou totalement avoir disparu (fig. 7b), faisant parfois apparaître la structure de la coquille. Celle-ci est composée, entre autres, de plusieurs accrétions de carbonate de calcium qui se matérialisent par des lignes parallèles longitudinales dans le sens horizontal et vertical (fig. 5-a, fig. 7-h). Des petits cratères de dissolution, dus aux phénomènes physico-chimiques, sont aussi présents sur plusieurs perles (fig. 7-g). De plus, des petits enlèvements sont parfois situés entre l'extrémité des faces et le contour. Leur forme et leur localisation sur la perle indiquent que ces stigmates ne sont pas dus à l'usure (fig. 7-a, b, c, d). Il est néanmoins difficile de connaître leur origine. Ils peuvent être dus à la phase de façonnage ou refléter le heurt des perles les unes contre les autres. Enfin, des stries irrégulières et sans orientation préférentielle sont observables sur la perle $\mathrm{n}^{\circ} 25$ (fig. 7f). Ces dernières pourraient provenir de facteurs naturels, du façonnage ou de l'utilisation. Des traces de l'action de vers marins de la famille des annélides, pouvant faire penser au genre Polydora, sont visibles sur plusieurs perles (fig. 7-e). Ces vers creusent des galeries en forme de virgule, reconnaissables par deux perforations associées au niveau du percement de la surface des coquilles. Certaines de ces galeries ont percé toute l'épaisseur du test. Cette observation indique que ces coquilles ont été ramassées mortes échouées sur la plage ou dans un gisement fossile. 
Figure 7 : Modifications taphonomiques sur les perles discoïdes du site du Mas de Champ Redon (cl. C. Mougne).

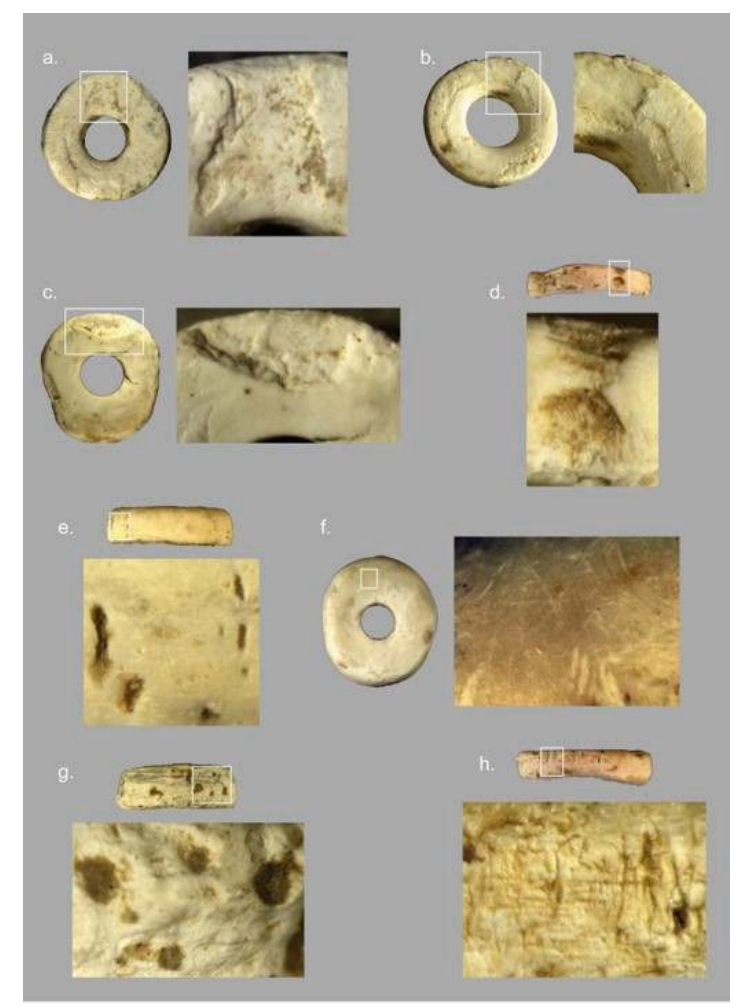

- Petits enlèvements situés entre l'extrémité des faces et le contour. a : perle $n^{\circ} 6, L=5,2 \mathrm{~mm}, b$ : perle $n^{\circ} 16, L=5,24 \mathrm{~mm}, c$ : perle $n^{\circ} 30, L=5,1 \mathrm{~mm}$, $d$ : perle $n^{\circ} 37, L=5,37 \mathrm{~mm}$,

- Traces de l'action de vers marins de la famille des annélides, potentiellement du genre Polydora

e : perle $n^{\circ} 31, L=4,66 \mathrm{~mm}$,

- Stries irrégulières et sans orientation préférentielle

$f$ : perle $n^{\circ} 25, L=5,68 \mathrm{~mm}$,

- Petits cratères de dissolution, dus aux phénomènes physico-chimiques

$\mathrm{g}$ : perle $\mathrm{n}^{\circ} 10, \mathrm{~L}=7,51 \mathrm{~mm}$,

- Accrétions de carbonate de calcium matérialisées par des lignes parallèles longitudinales dans le

sens

horizontal et vertical

$\mathrm{h}$ : perle $\mathrm{n}^{\circ} 35, \mathrm{~L}=6,09 \mathrm{~mm}$ ( $\mathrm{L}=$ longueur maximale).

\section{Morphométrie}

11 La morphologie des perles est majoritairement circulaire pour trente-quatre d'entre elles, tandis que six sont légèrement ovalaires (fig. 4). Cette forme ovalaire pourrait avoir été souhaitée, mais elle peut également être due à un façonnage préparatoire trop trapézoïdal (Ricou et al., 2009, p. 517).

La longueur des perles se situe entre 4,68 et 7,25 mm pour une moyenne de 5,52 $\mathrm{mm}$, avec vingt-trois perles entre 5 et $5,5 \mathrm{~mm}$ (tabl. 1 et fig. 8 ). La largeur se situe, quant à elle, entre 4,33 et 7,57 $\mathrm{mm}$ pour une moyenne de $5,47 \mathrm{~mm}$ avec vingt et une perles entre 5 et 5,5 mm (tabl. 1 et fig. 8). Quant à l'épaisseur maximale, elle mesure entre 1,28 et $2,67 \mathrm{~mm}$ pour une moyenne de $1,75 \mathrm{~mm}$ avec vingt-quatre perles entre 1,5 et $2 \mathrm{~mm}$ (tabl. 1 et fig. 8). L'épaisseur des valves d'un bivalve telle la Cerastoderma est régulière, sauf dans des zones précises comme les bords ventral et dorsal ${ }^{1}$. L'observation d'épaisseurs non constantes sur tout le profil de la perle pourrait montrer que celles-ci ont été fabriquées à partir de certaines parties de la périphérie ou de l'umbo de la 
valve de la Cerastoderma. Le poids moyen d'une perle discoïde en test coquillier est de $0,06 \mathrm{~g}$.

13 Le fragment de perle en roche mesure $5,2 \mathrm{~mm}$ maximum de longueur et pèse $0,06 \mathrm{~g}$. Il s'agit du quart d'une perle circulaire à percement central. Les dimensions d'origine de la perle sont un diamètre reconstitué de 7,8 $\mathrm{mm}$ et une épaisseur de 2,3 $\mathrm{mm}$.

Tableau 1 : Mesures des perles discoïdes du Mas de Champ Redon.

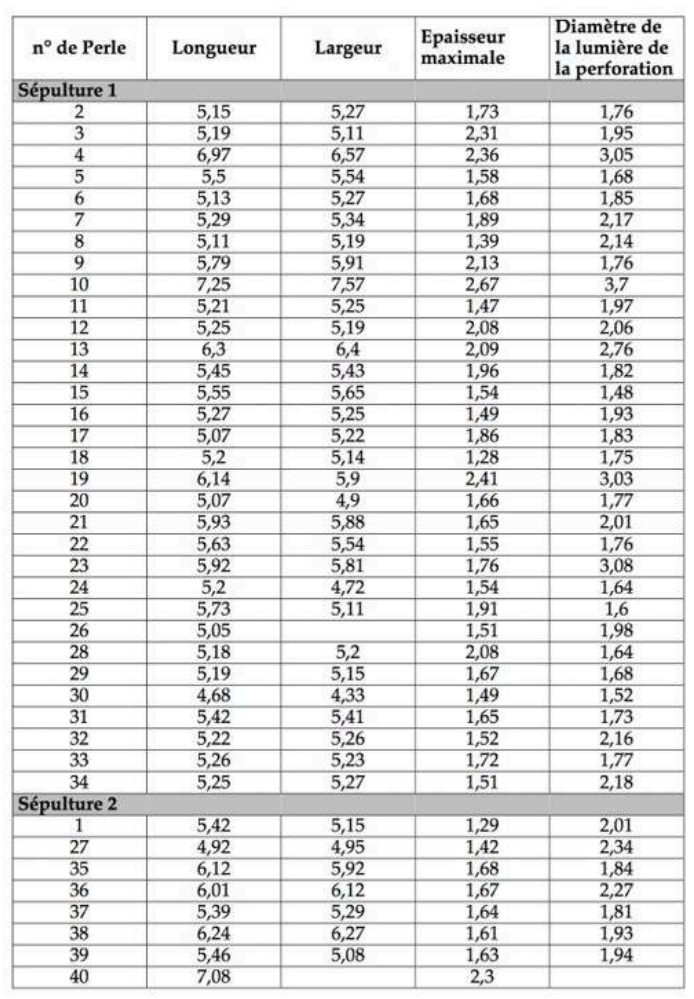

Figure 8 : Distribution des longueurs, largeurs, épaisseurs et dimensions des perforations des perles en coquille marine.
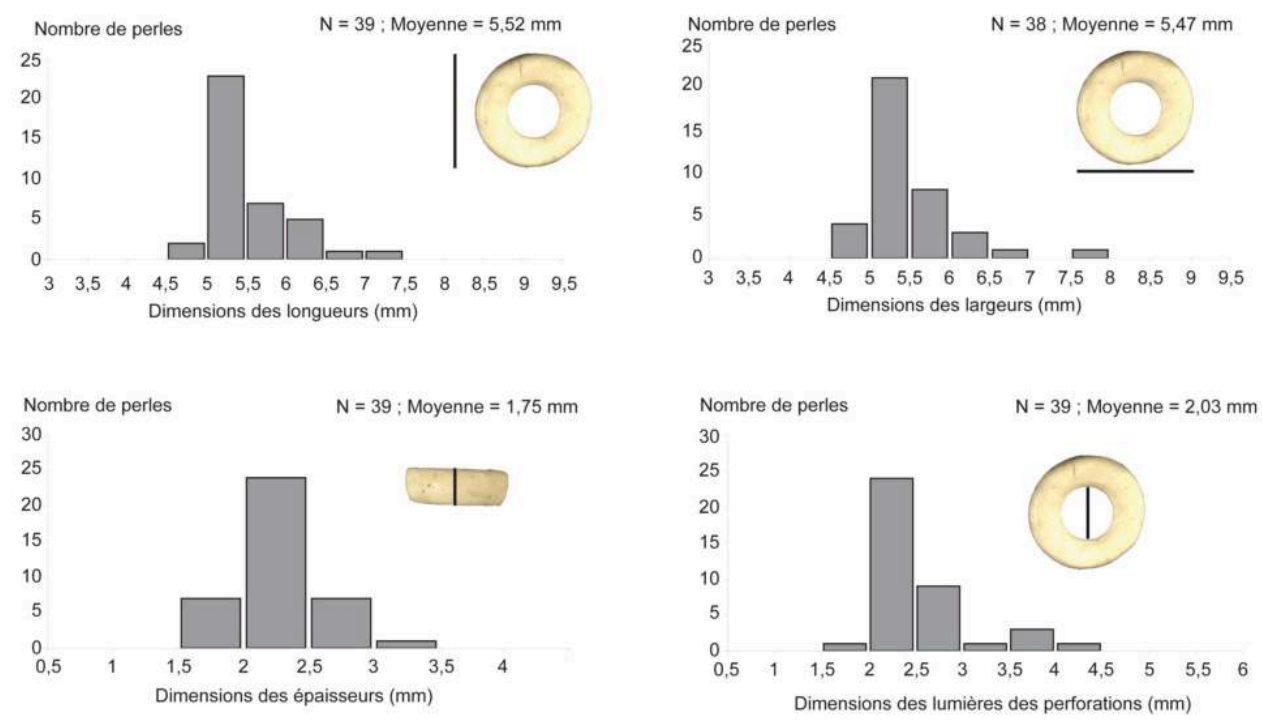


\section{Techniques de façonnage}

14 Au moins vingt-neuf perles du Mas de Champ Redon ont été fabriquées à partir de coquilles de Cerastoderma sp. Aucune ébauche n'a été trouvée sur le site, ce qui est logique du fait de la nature du dépôt, en contexte funéraire. Il est ainsi difficile d'émettre des hypothèses sur leur technique de façonnage. Néanmoins, parmi les perles discoïdes en coquillage marin, celles réalisées en cardiidés, et plus particulièrement en Cerastoderma, sont les plus étudiées (Laporte, 1994; Miller, 1996; Pauc, 1997; Bocquenet, 1998 ; Ricou et Esnard, 2000 ; Bonnardin, 2009 ; Laporte, 2009 ; Ricou et al., 2009 ; Pauc, 2011 ; Prost et al., 2012) Les différentes méthodes utilisées seront décrites au fur et à mesure de l'étude technique.

Quatre phases interviennent systématiquement lors de la fabrication d'une perle discoïde :

- l'extraction d'une partie de la matière première correspondant au débitage d'une préforme ;

- la mise en forme de l'objet par le façonnage ;

- l'obtention d'une lumière au centre de la rondelle par la perforation ;

- et enfin le polissage d'une partie au moins de la pièce. L'ordre dans lequel ces différentes phases interviennent, les outils et les savoir-faire sont culturels et difficiles à déterminer à partir uniquement de produits finis.

\section{Débitage}

Le débitage est la première étape dans la confection d'une parure discoïde. Il consiste à extraire une ébauche de l'objet désiré à partir d'un bloc de matière première par sciage ou percussion. Deux méthodes de débitage pour la confection de perles discoïdes en Cerastoderma ont été mises en évidence. La première consiste à débiter la valve par percussion directe de la face externe du test avec un galet ouvragé (Ricou et Esnard, 2000 ; Gruet et Laporte, 2009; Ricou et al., 2009), méthode qui permet d'obtenir plusieurs préformes. La seconde est la percussion indirecte sur la face interne du test à l'aide d'un poinçon en matière dure végétale ou animale (Pauc, 1997), méthode qui ne fournit qu'une seule préforme (Bonnardin, 2009, p. 92).

Nous ne possédons évidemment aucune information sur les techniques employées lors de cette étape initiale pour les perles du Mas de Champ Redon.

\section{Façonnage}

18 Cette seconde étape consiste à donner au fragment débité sa forme générale. D'après plusieurs études et expérimentations, le façonnage commence par une sélection des préformes. Ensuite, un dégrossissage par percussion directe avec un petit galet est réalisé sur tout le contour afin que la pièce ait une forme polygonale (Bonnardin, 2009, p. 92-93). Enfin, une égalisation des faces par abrasion est effectuée pour aplanir particulièrement la face externe, toujours convexe et ornée de côtes (Ricou et Esnard, 2000 ; Ricou et al., 2009).

Ce travail occasionne des stigmates particuliers du genre stries, ébréchures ou facettes, mini-rayures, aplats et arrondis. La strie visible sur la perle $n^{\circ} 28$ pourrait ainsi avoir été causée par le façonnage (fig. 9). Différents degrés d'abrasion peuvent être aussi reconnus sur les perles $\mathrm{n}^{\text {os }} 5,17,20,36$ et 37 grâce à l'effacement plus ou moins marqué du relief des côtes sur la face externe. De plus certaines perles du Mas de Champ Redon 
comportent, entre le contour et l'extrémité des faces, plusieurs petits enlèvements résultant possiblement du façonnage par percussion (fig. 7-a, c, d).

Figure 9 : Strie de façonnage visible sur la perle $\mathrm{n}^{\circ} 28$ du site du Mas de Champ Redon (Longueur = 5,18 mm) (cl. C. Mougne).

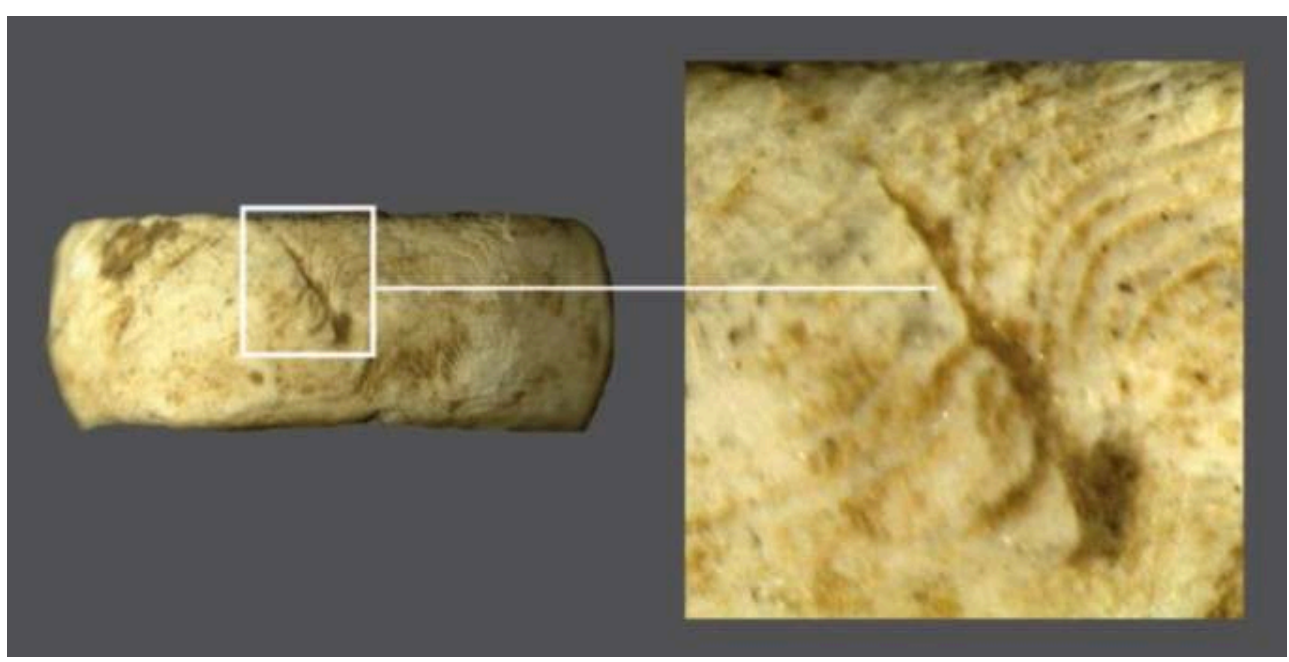

\section{Perforation}

La perforation est généralement effectuée lorsque la pièce est à l'état d'ébauche, afin sans doute de prévenir une potentielle cassure sur un objet fini et de centrer plus facilement l'orifice par un polissage final (Barge-Mahieu et Taborin, 1991). Les expérimentations ont montré que l'incision ou le grattage au centre étaient préférentiellement réalisés sur la face interne de la valve qui est parfois légèrement concave. Une minute suffirait à percer entièrement la face interne de la préforme avec un foret (Ricou et Esnard, 2000). L'ajout d'eau est essentiel, car il accroît l'adhérence de l'objet au support, active le forage, et empêche la mèche de chauffer. Quant à la face externe, elle peut être perforée dans un second temps, si la perle est épaisse (Bonnardin, 2009, p. 94).

21 Cinq techniques de perforation peuvent être utilisées et se combiner entre elles: l'abrasion d'une zone convexe, le sciage, la percussion directe, la pression et la rotation circulaire (Taborin, 1974, p. 124-127 ; Barge-Mahieu et Taborin, 1991).

Parmi ces techniques de perforation, celle réalisée par rotation circulaire à l'aide d'un foret est la plus probable pour les perles du Mas de Champ Redon. En effet, des stries transversales et concentriques, régulièrement espacées et laissées sur les parois des orifices sont visibles sur quinze perles en test coquillier (fig. 10-a et -b). Il est à noter que les accrétions de carbonate de calcium du coquillage sont parfois représentées par de fines lignes. Il faut être vigilant afin de ne pas les confondre. 
Figure 10 : Techniques de percement et formes des parois des perforations des perles discoïdes du site du Mas de Champ Redon.

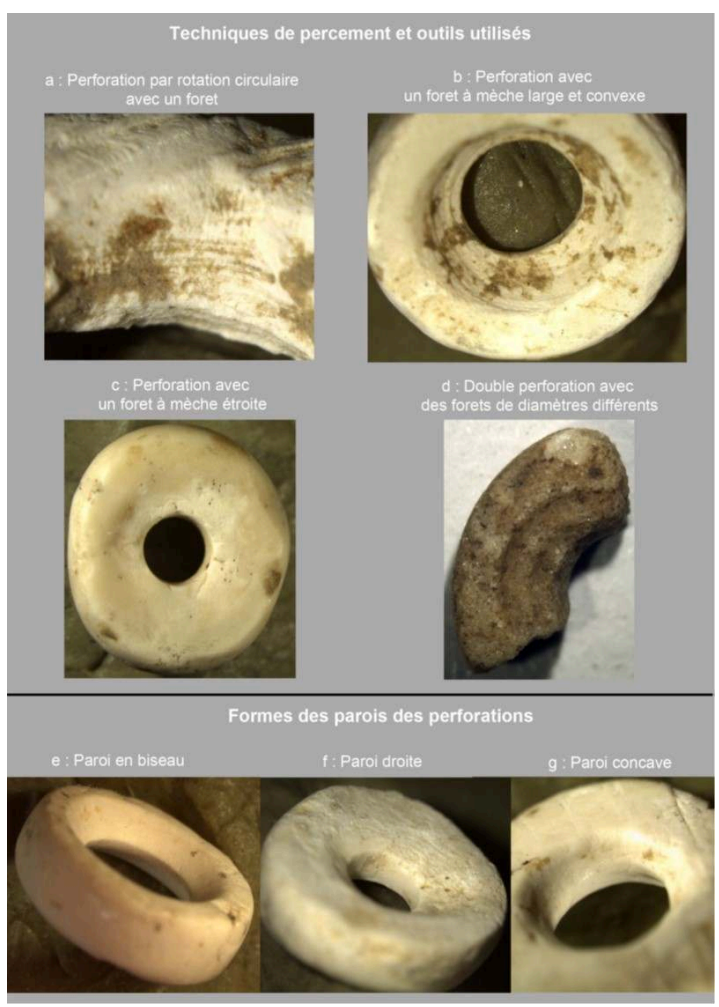

a : perle $n^{\circ} 10, L=7,25 \mathrm{~mm}, b$ : perle $n^{\circ} 11, L=5,21 \mathrm{~mm}, c$ : perle $n^{\circ} 25, L=5,73 \mathrm{~mm}, d$ : perle $n^{\circ} 40$, $L=5,58 \mathrm{~mm}$, e : perle $n^{\circ} 13, L=6,30 \mathrm{~mm}$, $f$ : perle $n^{\circ} 31, L=5,42 \mathrm{~mm}, \mathrm{~g}$ : perle $n^{\circ} 20, L=5,07 \mathrm{~mm}$ $(\mathrm{L}=$ longueur) (cl. C. Mougne).

Les perforations ont été réalisées par rotation circulaire avec un foret à mèche large le plus souvent (fig. 10-b) et avec un outil plus étroit plus rarement (fig. 10-c). La perle en roche possède une perforation en entonnoir "pallier", indice probable d'un changement de foret ou de la cassure d'un perçoir.

Trente-six perles en test coquillier présentent une perforation de profil biconique (fig. 4-c; fig. 10-e). Le travail a commencé sur une face jusqu'à la moitié, ou plus, de l'épaisseur, puis sur la face opposée dans le même axe jusqu'à la jonction des deux amorces. Sur les perforations biconiques, les deux cônes ne sont ni de même profondeur ni de même diamètre. L'un des deux cônes est souvent nettement plus large, plus profond et l'inclinaison de ses parois est plus accentuée. Deux perles du Mas de Champ Redon portent des perforations coniques, amorcées à partir d'une seule face (fig. 4-c). Enfin, une dernière perle en test coquillier possède un percement cylindrique (fig. 4-c). Quant à la perle en roche, elle a une section conique.

Le diamètre de la lumière pour toutes les perles en test coquillier se situe entre 1,48 et $3,7 \mathrm{~mm}$ pour une moyenne de 2,03 $\mathrm{mm}$ et pour trente-trois de ces perles entre 1,5 et $2,5 \mathrm{~mm}$ (tabl. 1 et fig. 8). La dimension d'origine de la perle en roche est, quant à elle, de $2,6 \mathrm{~mm}$.

\section{Polissage}

Le polissage constitue en général la phase finale de la fabrication. Il consiste à achever la forme de l'objet et à éliminer les traces de façonnage à l'aide de surfaces abrasives à 
grains fins comme le schiste ou le grès. Il unifie l'aspect de l'objet et lui donne souvent aussi sa brillance. Le polissage peut être caractérisé par des stries longitudinales et transversales de va-et-vient générateur des arrondis et de la brillance. Malheureusement, les perles de Luxé ont subi des modifications taphonomiques qui ont généralement entraîné la disparition d'une partie de leur surface externe d'origine et de leur poli (fig. 7-b).

Un poli est présent sur la face externe de trente-cinq perles. Il est absent sur deux perles et n'a pas pu être observé sur les deux derniers exemplaires en raison de leur trop forte altération. Le poli a provoqué la quasi voire la totale disparition du relief des côtes sur certaines des parures (fig. 11-g). Les faces internes sont, quant à elles, également polies sur trente perles mais avec un degré moins prononcé et sur une surface plus réduite. Il est à noter qu'aucun poli recouvrant $100 \%$ de la surface n'a été observé sur les perles de la sépulture 2 contrairement à onze perles de la sépulture 1 . Ceci est-il dû à une conservation différentielle ou à une finition différente des pièces ?

Figure 11 : Usure de surface et de volume, et échancrures, sur les perles du site du Mas de Champ Redon.

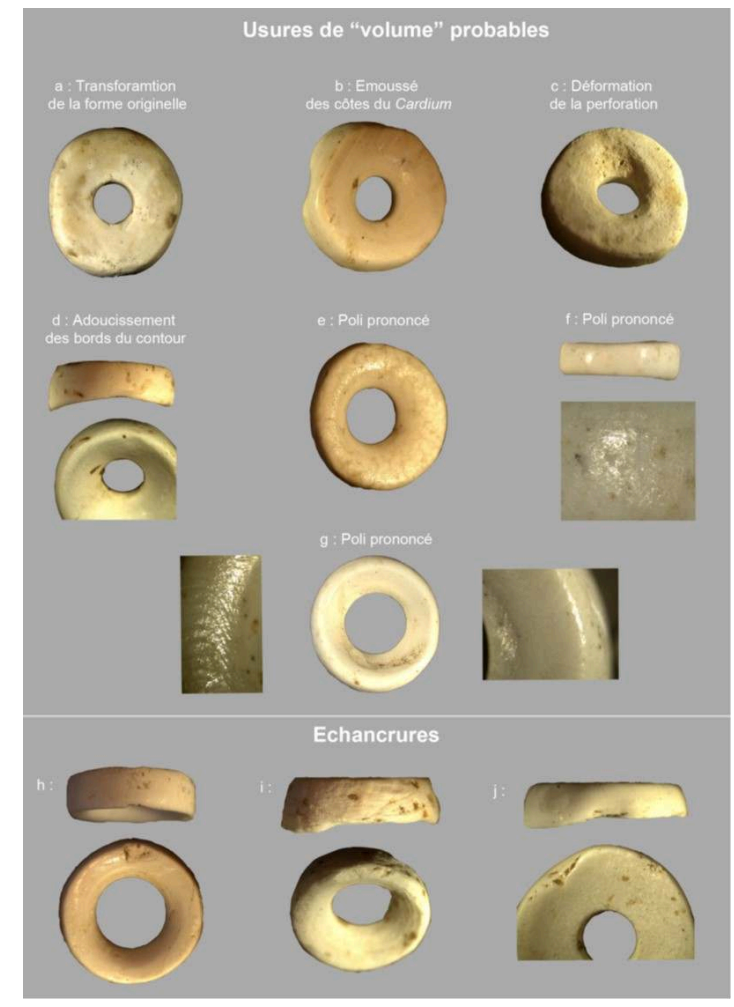

a : perle $n^{\circ} 25, L=5,73 m m, b$ : perle $n^{\circ} 15, L=5,55 m m, c$ : perle $n^{\circ} 31, L=5,42 m m, d$ : perle $n^{\circ} 14$, $L=5,45 \mathrm{~mm}$, e : perle $n^{\circ} 34, L=5,25 \mathrm{~mm}$, f et $\mathrm{g}$ : perle $n^{\circ} 4, L=6,97 \mathrm{~mm}, \mathrm{~h}$ : perle $n^{\circ} 13, L=6,30 \mathrm{~mm}, i$ : perle $n^{\circ} 12, L=5,25 \mathrm{~mm}, j$ : perle $n^{\circ} 15, L=5,55 \mathrm{~mm}(L=$ longueur) (cl. C. Mougne).

Le lustrage, dernière étape de la finition, n'est pas toujours effectué. Il se réalise en frottant l'objet sur une peau sèche ou mouillée enduite le plus souvent de sable. Cette étape reste cependant difficile à distinguer car elle peut être confondue avec l'usure. 


\section{Stigmates d'usure} des indices d'usures. Les parures ont pu être déposées dans les tombes après leur utilisation par les vivants ou être seulement destinées aux morts. Si ces perles ont été portées par les vivants des traces d'usure pourraient être observées. Selon S. Bonnardin, les facteurs de l'usure sont la durée et la fréquence du port, la méthode d'assujettissement des objets sur un support, les systèmes d'attache, l'agencement des objets dans une parure et le ou les effleurements avec le ou les supports en contact avec la parure (Bonnardin, 2009, p. 116). Néanmoins, il est difficile de distinguer les stigmates d'usure des traces liées à l'altération naturelle de la coquille antérieurement à la fabrication de l'objet de celles dues à la fabrication. Un objet peut de surcroît cumuler plusieurs traces d'origines différentes. Tout d'abord, les coquilles utilisées pour la fabrication des parures peuvent avoir été ramassées à l'état d'épaves puis utilisées comme matière première. L'érosion marine, altération naturelle, laisse des stigmates parfois assez proches des traces d'usage, mais possède des formes particulières donnant un aspect roulé et uniforme à l'ensemble de la coquille (Taborin, 1993, p. 171). Il ne semble pas y avoir ce type d'usure sur les perles du Mas de Champ Redon. De plus, il est ardu de distinguer certaines traces de façonnage, dues à la finition, des stigmates d'usure (fig. 11-e, -f et -g). En effet, un lustrage analogue à celui produit par la dernière phase du façonnage a pu être également effectué durant le port par le frottement des perles sur la peau, sur un vêtement ou sur une autre perle. Cette question peut également être posée pour des pièces très polies (fig. 11-g). Le seul moyen de différencier l'origine du poli est de réaliser une étude microscopique et d'effectuer une comparaison entre pièces archéologique et expérimentale comme cela a été réalisé par F. d'Errico et ses collaborateurs (d'Errico et al., 1993, p. 186). Ces chercheurs ont en effet pu différencier l'origine de certains polis par l'étude de leur forme, de leur disposition, de leur orientation et de leur largeur. Cette étude n'a pu être réalisée dans le cadre de cet article.

Les traces d'usures ont été renseignées par plusieurs auteurs. Y. Taborin (1993) a décrit plusieurs types de stigmates et déformations qui pourraient correspondre à des traces d'usure: les lustrages, les émoussés, les échancrures des perforations ou les agrandissements du forage. I. Sidéra (1993) a également identifié et décrit deux types d'usure pour l'industrie osseuse différenciant l'usure des volumes de l'usure de surface. Ces données ont ensuite été reprises par S. Bonnardin (2009).

31 L'usure des volumes correspond aux émoussés qui transforment la forme originelle de l'objet, particulièrement visible sur la perle 25 (fig. 11-a). Les stades de déformation avancés de l'usure se caractérisent par des émoussés, définis comme un adoucissement des volumes, plus ou moins déformant (Bonnardin, 2009, p. 112). Il aboutit à des transformations locales d'une ou plusieurs parties de la perle. Cet émoussé est visible sur plusieurs perles du Mas de Champ Redon: disparition petit à petit des côtes naturelles de la coquille (fig. 11-b) et des traces de fabrication (fig. 11-g), déformation de la perforation (fig. 11-c), adoucissement ou arrondissement des arêtes et des bords des contours (fig. 11-d), et disparition des stries de forage (Bonnardin, 2009, p. 112-115).

L'usure de surface est, quant à elle, définie par des polis lisses, brillants et visibles à l'œil nu (Sidéra, 1993, p. 202) et par des stries. Ces usures de surface peuvent être dues à plusieurs facteurs d'origine naturelle ou anthropique. 

du point de vue des matières premières, mais variés par les formes, les dimensions, les techniques de façonnage, de finition, ou les stigmates d'usure identifiés. Dans la sépulture de l'adulte, la présence de pièces neuves est probable, contrairement à celle de l'enfant. Les caractéristiques des perles discoïdes de Luxé ne respectent pas un standard particulier mais constituent des groupes divers. Cette diversité d'objet de parure a déjà été observée dans des sépultures plus anciennes (Taborin, 1993 ; Sidéra, 2002 ; Bonnardin, 2006, 2009, p. 188 ; Rigaud, 2011) et plusieurs hypothèses peuvent être émises. S. Bonnardin suppose que la parure constituée de perles en coquillage neuves et anciennes, et de formes diverses, pourrait avoir été composée au moment du décès de l'individu (Bonnardin, 2006, 2009, p. 188). Cette parure serait donc dédiée au monde des morts et non à celui des vivants. Nous n'aurions donc plus affaire à une parure auparavant portée par les vivants, mais à une parure mortuaire, faite à l'intention exclusive du défunt. I. Sidéra, quant à elle, estime d'après son étude sur les craches de cerf, que ce mélange d'objets neufs, ou presque neufs, et d'objets fortement usés, pourrait indiquer que les parures étaient complétées au fur et à mesure de leur usure (Sidéra, 2002). Ainsi, lorsqu'une perle se brise ou se perd, elle serait remplacée par une neuve ou une ancienne. S. Rigaud reprend cette dernière hypothèse en envisageant que l'intensité des traces de port signifierait que ces objets sont portés sur de nombreuses années, voire par plusieurs générations (Rigaud, 2011). Selon, l'hypothèse émise par I. Sidéra (2002), les parures du Mas de Champ Redon, composées d'éléments anciens et récents, pas ou peu usées, auraient pu être réassorties peu avant le décès.

Pour les treize perles trouvées in situ dans la sépulture de l'adulte plusieurs associations sont possibles. Quatre perles ont été découvertes accolées et reposant sur leur tranche (perles $\mathrm{n}^{\circ \mathrm{s}} 4,7,14$ et 15) (fig. 1-e et - g). Elles mesurent 5,29 à 6,97 mm de longueur, présentent un diamètre de lumière de 1,48 à $3,05 \mathrm{~mm}$, et sont de finition plus ou moins identique (tabl. 1). Leur position dans la sépulture suggère qu'elles étaient enfilées sur un lien. Les perles $\mathrm{n}^{\circ} 10$ et $\mathrm{n}^{\circ} 12$ se trouvaient également l'une à côté de l'autre, face contre face (fig. 1-e), et de même orientation. Mais leurs longueurs diffèrent, mesurant $5,25 \mathrm{~mm}$ pour l'une et 7,25 $\mathrm{mm}$ pour l'autre. Il en est de même pour les diamètres de leurs lumières, de 2,06 et 3,7 mm (tabl. 1). Enfin, les perles $n^{\circ 5} 5$ et 6 , contigües, et quasi 
identiques par leurs dimensions et leur façonnage, possèdent une perforation plus étroite, et leur technique de percement fut différente de celle de la perle $\mathrm{n}^{\circ} 17$ trouvée à côté (tabl. 1). Ces quelques associations viennent confirmer la diversité des gabarits de perles au sein de la même parure.

Au Mas de Champ Redon, les perles discoïdes trouvées dans les tombes de l'adulte et de l'enfant étaient situées entre le crâne et l'épaule, et certaines étaient positionnées derrière la tête. La partie supérieure des inhumations était peu perturbée, mais il ne peut être exclu que des animaux fouisseurs aient pu les déplacer; plus petit que des ossements, les perles peuvent facilement rouler. Quoi qu'il en soit, ces perles pourraient donc correspondre à une parure de tête ou à une parure de cheveux, vu leur localisation. Cinq perles ont également été trouvées sous la joue droite de l'adulte, ce qui laisse également envisageable une ornementation des oreilles. Enfin, la présence d'un collier, plus ou moins disloqué, est tout autant possible. Dans la littérature archéologique française, les parures de tête sont rarement signalées. Lorsqu'elles le sont, elles se situent sur le devant du crâne, comme si elles avaient constitué un bandeau ou avaient été cousues sur une pièce de vêtement de type capuche (Rolland et $\mathrm{Hu}, 1935$; Bonnardin, 2009), ce qui ne semble pas être le cas au Mas de Champ Redon. Une étude ethnographique des peuples des îles Salomon a néanmoins montré que des peignes et des pendants d'oreille en matières périssables (bois, végétaux, etc.) étaient ornés avec de petites perles discoïdes en coquillage marin (Burt, 2009). Si de telles parures avaient été déposées dans les tombes du Mas de Champ Redon, il n'en resterait donc plus que les perles en coquillage, les matières végétales ayant disparu.

Certaines perles discoïdes sont façonnées dans le but d'être suspendues par enfilage sur un lien, le long duquel elles peuvent pendre librement. Elles peuvent aussi être fixées par des nœuds ou des entrelacs et avoir un mouvement plus limité, ou être totalement immobilisées sur un lien. Notons que quelques perles du Mas de Champ Redon paraissent avoir été enfilées sur un lien (perles $\mathrm{n}^{\circ \mathrm{s}} 4,7,14$ et 15) (fig. 1-g).

\section{Indication du statut social ?}

Des différences de traitement sont-elles visibles en fonction de l'âge, du sexe, et du statut social des défunts?

Au Mas de Champ Redon, des disparités en termes de nombre, de composition et de finition des perles sont perceptibles selon les différences d'âge des défunts des sépultures du Mas de Champ Redon. Tout d'abord, la quantité de perles découvertes se distingue d'une sépulture à l'autre. L'adulte a été trouvé avec un assemblage de trentedeux perles, alors que l'enfant âgé d'environ 7-8 ans n'en possédait que huit. Quant à la sépulture du plus juvénile, aucune perle n'y a été trouvée. Cette absence pourrait être justement due à son jeune âge. Néanmoins, les biais taphonomiques pourraient également expliquer ce manque, les variations des facteurs pouvant parfois être fortes au sein d'un même ensemble. Quoi qu'il en soit, une différence numérique importante existe entre ces trois sépultures et pourrait être liée à l'âge des défunts. Les matières premières utilisées pour la confection des perles diffèrent également entre la sépulture $\left(n^{\circ} 1\right)$ de l'adulte et celle de l'enfant $\left(n^{\circ} 2\right)(f i g .4)$. L'intégralité de la parure de l'adulte a été façonnée à partir de coquillages marins. La parure de l'enfant est, quant à elle, composée de sept perles en coquillages marins et d'une perle en roche. Enfin, la finition des objets semble également différer. En effet, le degré du poli des perles est beaucoup 
moins accentué et moins étendu pour la sépulture de l'enfant que pour celle de l'adulte, caractérisée par un façonnage plus soigné (fig. 2 et 3). Cette dernière différence pourrait être liée au degré et à la durée du port des parures, sans doute plus importantes chez l'adulte que chez l'enfant. En effet, un port prolongé peut atténuer les irrégularités avec un poli d'usure plus intense.

41 Pour ce qui est d'un traitement différent selon les sexes des inhumés, les références font encore défaut sur la façade atlantique française. Au Mas de Champ Redon, les ossements sont très mal conservés pour que la diagnose sexuelle puisse être effectuée. Néanmoins, il pourrait être intéressant d'effectuer une étude ADN sur ces ossements dans l'optique de préciser le sexe des sujets et observer leur éventuelle parenté. La parure en perles discoïdes en coquillage n'est pas réservée au sexe féminin. De nombreux exemples ethnographiques montrent le contraire ; aussi leur présence dans une tombe d'adulte ne peut, à elle seule, être un argument suffisant pour caractériser le sexe féminin de l'individu (Burt, 2009).

Il est toutefois difficile d'aller plus avant dans l'examen du caractère «social » des perles en coquillage marin, en raison du nombre limité d'individus étudiés.

\section{Réflexion générale sur les perles discoïdes en Cerastoderma sur le territoire national}

L'amorce d'une comparaison régionale et nationale a paru appropriée afin de replacer les perles discoïdes du Mas de Champ Redon dans un contexte plus large et de discerner de possibles aires d'influence ou de circulation. Cette mise en perspective étendue au territoire national n'est, à ce jour, qu'une amorce, qui devra dans le futur être largement complétée. Au cours de l'inventaire, des limites sont rapidement survenues. Tout d'abord, les ensembles clos sont rares en contexte de sépultures collectives, cellesci placées dans des dolmens réutilisés et des grottes, étant souvent attribuées, mais sans certitude, à la période Campaniforme/Bronze ancien. De plus, dans la littérature, la description des pièces reste souvent sommaire, ne précisant pas toujours la matière première utilisée ni les dimensions exactes, ce qui peut, par exemple, rendre difficile la discrimination entre certaines perles en calcaire et perles en test coquillier, qui se ressemblent fortement à l'œil nu. Malgré ces inconvénients, une première approche comparative a pu être réalisée à l'échelle du territoire français. Seules les perles discoïdes en test coquillier trouvées dans des contextes Campaniforme/âge du Bronze ont été inventoriées.

\section{Centre-Ouest}

Les perles discoïdes en Cerastoderma du Mas de Champ Redon s'intègrent dans une tradition perceptible en Charente (fig. 12) (Laporte, 2009, p. 535), où deux sites funéraires à sépultures collectives ont livré des perles discoïdes en coquille marine : l'abri des Renardières aux Pins (Gomez de Soto et Boulestin, 2003), et la grotte des Perrats à Agris (Gomez de Soto et Boulestin, 1996, p. 50, 2007). L'analyse des perles de ces deux sites par L. Laporte est en cours. La première collection est composée de quatre perles dont l'espèce n'est pas connue ; et la seconde de cinq éléments discoïdes en Cerastoderma. Dans ce dernier site, quatre perles présentent des dimensions comprises entre 4 et $6 \mathrm{~mm}$ de diamètre pour une épaisseur allant de 0,5 à $1,5 \mathrm{~mm}$ et un diamètre de lumière de $1,5 \mathrm{~mm}$. La cinquième, quant à elle, se distingue du lot par un 
diamètre de $12 \mathrm{~mm}$, une épaisseur de $3 \mathrm{~mm}$ et un diamètre de lumière de $3 \mathrm{~mm}$ (Laporte, 2009, p. 526). Les quatre premières perles sont assez proches morphologiquement de celles de Luxé, même si le diamètre de la lumière (de 2,09 mm) est légèrement plus élevé chez ces dernières.

Figure 12 : Sites archéologiques datés de l'âge du Bronze ancien et moyen en France ayant livré des perles discoïdes en test coquillier marin, et plus particulièrement en Cardiidés (DAO C. Mougne ; fond de carte L. Quesnel).

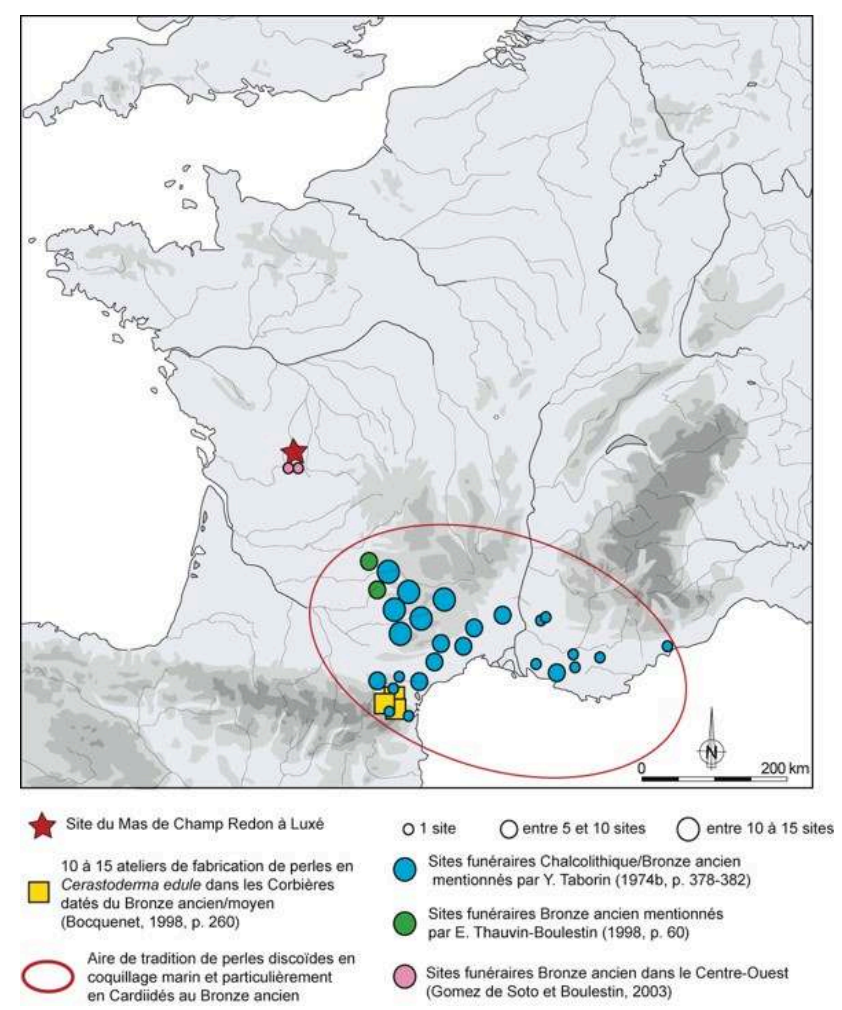

Façade méditerranéenne

En dehors du Centre-Ouest, au niveau national, les perles discoïdes en coquillage marin ne sont connues, au Campaniforme et à l'âge du Bronze ancien, que sur la façade méditerranéenne, dans les régions des Grands Causses et du Quercy, du Languedoc et de la Provence (fig. 12).

\section{Quercy et Grands Causses}

Dans les Grands Causses et le Quercy, les perles discoïdales sont très présentes au Chalcolithique-Bronze ancien, et il est rare qu'un site archéologique n'en fournisse pas au moins quelques-unes (Taborin, 1974, p. 378-382 ; Barge, 1982; Thauvin-Boulestin, 1998, p. 60 ; Laporte, 2009). La matière première la plus fréquemment utilisée pour la confection de parure est la coquille marine, le plus souvent du genre Cerastoderma (Thauvin-Boulestin, 1998, p. 60).

Pour exemple dans les Grands Causses, le dolmen des Quartoux à Montricoux (Tarn-etGaronne) abritait plusieurs inhumés superposés, dont un paré d'un collier de perles formé de 221 perles en test de coques Cerastoderma sp. et accompagné d'un vase attribué à l'âge du Bronze ancien (Pajot, 1983; Laporte, 2009, p.531). Le diamètre 
moyen de ces perles est de $10 \mathrm{~mm}$, la plus grosse mesurant $11 \mathrm{~mm}$ et la plus petite $9 \mathrm{~mm}$, avec une épaisseur variant de 1,5 à $3 \mathrm{~mm}$ (valeur moyenne de 2,3 $\mathrm{mm}$ ) et un diamètre moyen de la lumière de $2,9 \mathrm{~mm}$. Dix perles discoïdes en Cerastoderma identiques à celles du site de Quartoux ont été découvertes dans la chambre secondaire du tumulus du Pech, à Saint-Antonin-Noble-Val, dans le Tarn-et-Garonne (Laporte, 2009, p. 531).

Les perles discoïdes en test coquillier sont également connues dans les dolmens du Quercy, aux mobiliers datés du Campaniforme ou de l'âge du Bronze ancien. Pour exemple, le dolmen de la Devèze à Marcilhac (Lot) renfermait dix-huit perles discoïdes en coquillage marin d'un diamètre de 10 à $12 \mathrm{~mm}$, d'une épaisseur de $2 \mathrm{~mm}$ et d'un diamètre de lumière de 3 à $4 \mathrm{~mm}$ (Clottes, 1964). La chambre principale du dolmen du Pech de Grammont à Gramat (Lot) présentait 600 perles discoïdes en Cardiidés d'un diamètre moyen de $11,6 \mathrm{~mm}$, d'une épaisseur moyenne de $2,9 \mathrm{~mm}$ et d'un diamètre de lumière de 2,6 mm (Clottes et Carrière, 1969). Les techniques de façonnage étaient semblables à celles des perles de Quartoux. Néanmoins, dans la chambre secondaire de ce même dolmen, de nombreuses perles en test ont été découvertes, de taille bien différente de celles de la chambre principale, mesurant entre 7 et $8 \mathrm{~mm}$ de diamètre (Clottes, 1977 ; Laporte, 2009, p. 533). Cent une perles en test coquillier ont également été trouvées dans le dolmen du Pech $\mathrm{n}^{\circ} 1$ à Alvignac (Lot). Trente-deux avaient un diamètre de 8 à $10 \mathrm{~mm}$ et 69 un de 3 à 6 mm (Carrière et Clottes, 1970 ; Laporte, 2009, p. 531).

\section{Languedoc et Roussillon}

En Languedoc-Roussillon, H. Barge fait référence à la découverte de perles discoïdes en test coquillier mais l'identification de l'espèce, les mesures et les techniques de façonnage ne sont pas indiquées (Barge, 1982, p. 197-198). D’après Y. Taborin, (Taborin, 1974, p. 375) :

«Les disques en test sont très répandus dans la région Aude-Roussillon. Presque tous les sites de cette région en ont fourni à cette époque [...] Les disques sont en test de Cardium, rarement en Pectunculus.»

Dans le département de l'Aude, le dolmen de Saint-Eugène à Laure a donné plus de 1800 perles discoïdes et celui de Jappeloup à Trausse plus de 500 (Sicard, 1930; Taborin, 1974, p. 375). L'atelier de perles du Moulin à Durban-Corbières (Aude), attribué à l'âge du Bronze ancien, a été identifié comme un site de production de perles discoïdes en coque Cerastoderma (Bocquenet, 1998) (fig. 12). Il semblerait donc que les fabricants de perles discoïdes en Cerastoderma étaient itinérants. Ils fabriquaient leurs perles à l'intérieur du massif des Corbières et diffusaient les perles finies à l'ensemble du massif et dans les régions avoisinantes, participant ainsi à une économie à longue distance (Bocquenet, 1998). Ces perles possèdent une forme régulière dont les deux faces sont abrasées, et une perforation biconique dont le premier percement a été réalisé à partir de la face interne. La publication de la série de Durban-Corbières n'indique pas les mesures des perles, rendant impossible la comparaison avec celles du Mas de Champ Redon sans retour aux collections. 


\section{Provence}

51 En Provence, vingt sites datés du Chalcolithique et de l'âge du Bronze, possédant des perles discoïdes en test coquillier, ont été inventoriés pour la Provence par Y. Taborin (1974, p. 375). Cet inventaire n'est pas exhaustif, mais il donne une idée de l'importance de ce type d'élément de parure dans la région. Il existe des perles discoïdes taillées en test de Cardiidés dans de nombreux gisements, et en particulier dans les dolmens où elles sont parfois découvertes en nombre élevé (Taborin, 1974). Ainsi, le dolmen de Duffends III à Saint-Vallier (Drôme) en a livré 200 (Taborin, 1974). Il est à préciser que pour cette région, le nombre de disques en coquillage reste bien inférieur à celui des disques en pierre, dont le nombre dépasse parfois plusieurs milliers sur le même site.

Les perles discoïdes en Cerastoderma de Champ Redon s'intègrent, comme nous l'avons $\mathrm{vu}$, dans une tradition perceptible en Centre-Ouest, au Campaniforme/âge du Bronze. Sur la façade méditerranéenne, 23937 perles discoïdes en test ont été répertoriées par H. Barge-Mahieu et Y. Taborin (1991), dont 521 ont été mesurées. Elles possèdent un diamètre compris entre 3 et $23 \mathrm{~mm}$ pour une valeur moyenne de $8,2 \mathrm{~mm}$. Les perles du Mas de Champ Redon, avec un diamètre moyen de $5,54 \mathrm{~mm}$, ne s'inscrivent pas dans cette moyenne. Enfin, les perles du site de l'âge du Bronze ancien des Moulins, dans les Corbières, ressemblent à celles du Mas de Champ Redon par les techniques de fabrication mises en œuvre, mais leurs dimensions ne sont pas connues.

53 Sur le site du Mas de Champ Redon à Luxé, trois sépultures individuelles de l'âge du Bronze ancien ont été découvertes. Deux des inhumations possédaient un total de trente-neuf perles discoïdes en test coquillier marin en grande majorité du Cerastoderma, appelé plus couramment coque ou Cardium. Trente-deux étaient situées dans la tombe de l'adulte et sept dans celle de l'enfant de 7-8 ans. Dans cette dernière, une perle discoïde, probablement en calcaire cristallin particulièrement pur, ou en marbre, a également été découverte. Toutes ces perles mesurent en moyenne 5,52 $\mathrm{mm}$ de longueur, 5,47 de largeur, 1,75 $\mathrm{mm}$ d'épaisseur et 2,03 $\mathrm{mm}$ de diamètre de la lumière. Leur forme est majoritairement circulaire et les deux faces sont polies. La perforation est généralement biconique avec une face d'attaque interne. Ce percement a été réalisé par rotation circulaire avec un foret à mèche large et conique, ou mais plus rarement avec un outil plus étroit. Les perles possèdent des usures plus ou moins importantes attribuables à leur port. Plusieurs groupes de perles, du point de vue des formes, des techniques de façonnage et de l'usage, sont perceptibles au sein de cette collection. Cette diversité pourrait démontrer soit que les parures étaient remplacées au fur et à mesure de leur usure (Sidéra, 2002 ; Rigaud, 2011), soit qu'une partie des perles était confectionnée au dernier moment pour le défunt (Bonnardin, 2009). Ces perles pourraient également provenir soit de plusieurs ateliers, soit avoir été confectionnées par différents artisans, ou voire produits par des « amateurs ».

Les perles étaient positionnées entre le crâne et l'épaule des deux défunts. Elles pourraient donc s'apparenter à des parures de cheveux et d'oreille et leur association avec des matières périssables n'est pas à écarter. Quatre perles dans la tombe de l'adulte semblent, par leur position, avoir été enfilées sur un lien. L'éventualité de la présence d'un collier disloqué ou encore de perles cousues sur un support est aussi possible. L'hypothèse d'attribuer ces perles à des monnaies peut également être évoquée. 
la parure permet d'observer des différenciations entre les trois sépultures du Mas de Champ Redon. En effet, la tombe du plus jeune ne détient aucune perle, quant à celle de l'enfant de 7-8 ans, elle possède huit perles, dont une en roche, et de finition grossière comparée aux trente-deux perles découvertes dans la tombe de l'adulte.

Les perles discoïdes en Cerastoderma du Mas de Champ Redon s'intègrent dans une tradition perceptible en Centre-Ouest et sur la façade méditerranéenne. Des études supplémentaires seront nécessaires afin de relier les perles du Mas de Champ Redon à un réseau de production et d'échange venant de sites atlantiques ou/et méditerranéens.

\section{BIBLIOGRAPHIE}

AUDÉ V. (dir.) 2013, Le Mas de Champ Redon à Luxé. Un ensemble sépulcral de l'âge du Bronze ancien et un habitat rural du premier âge du Fer, rapport de fouille préventive, Inrap, LGV-SEA L'Isle d'Espagnac, Inrap Poitou-Charentes, Poitiers, Service régional de l'archéologie, $270 \mathrm{p}$.

BARGE H. 1982, Les parures du Néolithique ancien au début des Âges des métaux en Languedoc, Paris, Centre national de la Recherche scientifique, 396 p.

BARGE-MAHIEU H., TABORIN Y. 1991, « Fiche générale des objets de parure » dans H. CAMPS-FABRER (dir.), Objets de parure (Fiches typologiques de l'industrie osseuse préhistorique. Cahier IV), Aix-enProvence, Université de Provence, p. 1-19.

BOCQUENET J.-P. 1998, «Les ateliers de perles en coquillages marins des Pyrénées méditerranéennes. L'exemple de l'atelier de perles du « moulin » à Durban-Corbières (Aude) », dans G. CAMPS (dir.), L'homme préhistorique et la mer, Actes du $120^{\mathrm{e}}$ Congrès national des Sociétés historiques et scientifiques, Aix-en-Provence, 1995, Paris, Comité des travaux historiques et scientifiques, p. 259-272.

BONNARDIN S. 2006, «Production pour les vivants, production pour les morts », dans L. ASTRUC, F. BON, V. LEA, P.-Y. MILCENT, S. PHILIBERT (dir.), Normes techniques et pratiques sociales. De la simplicité des outillages pré- et protohistoriques, $\mathrm{XXVI}^{\mathrm{e}}$ Rencontres internationales d'Archéologie et d'Histoire d'Antibes, Antibes, 2005, Antibes, Association pour la Promotion et la Diffusion des Connaissances archéologiques, p. 207-212.

BONNARDIN S. 2009, «La parure funéraire au Néolithique ancien dans les Bassins parisien et rhénan. Rubané, Hinkelstsein et Villeneuve-Saint-Germain », Paris, Société préhistorique française (Mémoire de la Société préhistorique française 49), 322 p.

BURT B. 2009, Body Ornaments of Malaita, Solomon Islands, London, The British Museum press, $168 \mathrm{p}$. CARRIÈRE M., CLOTTES J. 1970, « Le dolmen du Pech n 1, à Alvignac (Lot) », Gallia Préhistoire, vol 13, p. 109-149.

CLOTTES J. 1964, « Le dolmen de la Devèze (Marcilhac - Lot) », Bulletin de la Société préhistorique française, Études et travaux, vol 61, hors série, p. 323-336. 
CLOTTES J. 1977, Inventaires des mégalithes de la France, 5, Lot, Paris, Centre national de la Recherche scientifique, $552 \mathrm{p}$.

CLOTTES J., CARRIÈRE M. 1969, « Le dolmen double du Pech-de-Grammont (Gramat, Lot) », Bulletin de la Société préhistorique française, vol 66, p. 432-447.

D’ERRICO F., JARDÓN-GINER P., SOLER-MAYOR B. 1993, « Identification des traces de manipulation, suspension, polissage sur l'art, mobilier en bois, bois de cervidés, Ivoire », dans P.-C. ANDERSON, S. BEYRIES, M. OTTE, PLISSON H. (dir.), Traces et fonctions : les gestes retrouvés, actes du colloque international de Liège, Liège, 1990, Liège, Université de Liège (Études et Recherches archéologiques de l'Université de Liège 50), p. 177-188.

DUPONT C., LAPORTE L. 2009, « Objets de parure recueillis sur le site artenacien de La Perroche », dans L. LAPORTE (dir.), Des premiers paysans aux premiers sur la façade atlantique de la France (3500-2000 av. J.-C.), Chauvigny, Association des Publications chauvinoises (Mémoire XXXIII), p. 505.

GOMEZ de soto J. avec la collaboration de Boulestin B. 1996, Grotte des Perrats à Agris (Charente). 1981-1994. Étude préliminaire, Chauvigny, Association des Publications chauvinoises, 139 p. GOMEZ de soto J., Boulestin B. 2003, Le complexe funéraire des Renardières (Les Pins, Charente) : regards sur la mort et la société au Bronze ancien, Bulletin de la Société préhistorique française, vol 100, n 4, p. 757-790.

GRUET Y., LAPORTE L. 2009, Objets de parure recueillis sur le site artenacien de Ponthezières, dans L. LAPORTE (dir.), Des premiers paysans aux premiers métallurgistes sur la façade atlantique de la France (3500-2000 av. J.-C.), Chauvigny, Association des Publications chauvinoises (Mémoire XXXIII), p. $470-504$.

LAPORTE L. 1994, « Parures et centres de production dans le Centre Ouest de la France au Néolithique final », thèse de doctorat, Université de Paris I, 231 p.

LAPORTE L. 2009, « La parure néolithique dans le Centre-Ouest de la France » dans LAPORTE L., Des premiers paysans aux premiers métallurgistes sur la façade atlantique de la France (3500-2000 av. J.-C.), Chauvigny, Association des Publications chauvinoises (Mémoire XXXIII), pp. 455-469.

MILLER M.A. 1996, «The manufacture of cockle shell beads at Early Neolithic Franchti Cave, Greece: a case of craft specialization? ", Journal of mediterranean Archaeology, vol 9, n 1, p. 7-37.

MOUGNE C. 2015, « Exploitation et utilisation des invertébrés marins durant la Protohistoire sur le territoire continental et littoral Manche-Atlantique français ", thèse de doctorat ArchéologieArchéométrie, Université de Rennes 1, 707 p.

РАјот В. 1983, «Fouilles de sauvetage des Quartous, à Montricoux », Travaux de l'institut d'art et de Préhistoire de l'Université de Toulouse-Mirail, vol 25, p. 219-234

PAUC P. 1997, « Reproduction de perles circulaires réalisées en test de Cerastoderma edule », dans C. CHEVILLOT (dir.), Journées d'archéologie expérimentale, bilan des années 1996-1997, Parc archéologique de Beynac (Dordogne, France), Beynac-et-Cazenac, Association des Musées du Sarladais, pp. 9-66. PAUC P. 2011, « Complément d'expérimentation de fabrication d'éléments de parure en coquillages marins d'après les sites-ateliers et les sources de matières premières dans l'Aude, sud de la France », dans A. MORGADO A., J. BAENA PREYSLER, D. GARCíA GONZÁLEZ (dir.), La investigacíon experimental aplicada a la arqueología, Granada, Universidad de Granada, p. 255-262.

PROST D., BEDAUlT L., BIARD M., DUPONT C., FROMONT N., HAMON C., LEPINAY D., Le MAHO S. 2012, « Le site du Néolithique ancien de Saint-Pierre-d'Autils (Haute-Normandie - Eure) : présentation liminaire », Internéo 9, Actes de la Journée d'information du 17 novembre 2012, Paris, p. 49-60. 
RICOU C., ESNARD T. 2000, «Étude expérimentale concernant la fabrication de perles en coquillage de deux sites artenaciens oléronais ", Bulletin de la Société préhistorique française, vol 97, n 1 , p. 83-93.

RICOU C., ESNARD T., LAPORTE L. 2009, « Archéologie expérimentale. Éléments de comparaison ethnographiques et archéologiques ", dans LAPORTE L., Des premiers paysans aux premiers métallurgistes sur la façade atlantique de la France (3500-2000 av. J.-C.), Chauvigny, Association des Publications chauvinoises (Mémoire XXXIII), p. 506-520.

RIGAUD S. 2011, « La parure : traceur de la géographie culturelle et des dynamiques de peuplement au passage Mésolithique - Néolithique en Europe ", thèse de doctorat, université de Bordeaux, $476 \mathrm{p}$.

ROLLAND H., HU P. 1935, « Fouilles d'une grotte néolithique effondrée à Villevenard », Bulletin de la Société archéologique champenoise, vol 3-4, p. 81-85.

SICARD G. 1930, « Ossuaire de l'allée couverte de Saint-Eugène (Aude) », Bulletin de la Société préhistorique française, vol 27, p. 536-544.

SIDÉRA I. 1993 « Les assemblages osseux en Bassin parisien et rhénan au VI ${ }^{\mathrm{e}}$ au $\mathrm{IV}^{\mathrm{e}}$ millénaires BC. Histoire, techno-économie et culture », thèse de doctorat, Université de Paris I, 636 p.

SIDÉRA I. 2002, « D'après l'exemple du Val-de-Reuil : outils, armes et parures en os à la fin du Néolithique dans le Bassin parisien, représentations individuelles et pratiques collectives », Gallia Préhistoire, vol 44, p. 215-230.

TABORIN Y. 1974, La parure en coquillage de l'Épipaléolithique au Bronze ancien en France, Gallia Préhistoire, vol 17, n 1, p. 101-179; vol 17, n², p. 307-417.

TABORIN Y. 1993, Traces de façonnage et d'usage sur les coquilles perforées, dans P.C. ANDERSON, S. BEYRIES, M. OTTE, H. PLISSON (dir.), Traces et fonctions : gestes retrouvés, actes du colloque international de Liège, Liège, 1990, Liège, Université de Liège (Études et Recherches archéologiques de l'Université de Liège 50), p. 255-267.

THAUVIN-BOULESTIN E. 1998 « Le Bronze ancien et moyen des Grands Causses et des causses du Quercy », Paris, Comité des Travaux historiques et scientifiques (Documents préhistoriques 11), 506 p.

\section{NOTES}

1. Le crochet ou la charnière, où les valves sont jointes, est la partie dorsale de l'animal. La partie opposée est dite ventrale.

2. L'umbo est l'extrémité saillante des valves d'un mollusque bivalve de forme arrondie.

\section{RÉSUMÉS}

Un petit ensemble sépulcral de l'âge du Bronze ancien composé de trois tombes individuelles a été découvert sur le site du Mas de Champ Redon à Luxé dans le Centre-Ouest de la France, fouillé par l'Institut national de recherches archéologiques préventives (Inrap) en 2011 sous la direction 
de V. Audé. Deux des trois sépultures ont livré quarante perles discoïdes ; trente-neuf en test coquillier marin et une perle en roche. Bien que souvent découvertes dans des sépultures collectives, ces formes de parure sont en revanche rarement associées aux tombes individuelles. Cette caractéristique fait du site de Luxé un cas rare en France et unique dans le Centre-Ouest pour l'âge du Bronze ancien. Parmi les perles fabriquées à partir de coquilles marines, vingt-neuf au moins proviennent du genre Cerastoderma, appelé couramment coque. L'identification n'a pas été possible pour les dix autres, mais la structure du matériau employé assure qu'elles ont été façonnées à partir de coquilles marines. Les éléments de parure, du point de vue des formes, des techniques de façonnage et du degré d'usure, sont différents selon les défunts, et sur un même individu. Les perles étaient positionnées entre le crâne et l'épaule, évoquant plusieurs utilisations possibles. Il est à souligner qu'une différenciation des trois sépultures, du point de vue de l'âge des individus, semble perceptible à partir de l'étude de ces parures. Les perles du Mas de Champ Redon ne semblent pas trouver d'équivalent, tant d'un point de vue morphologique que technique sur le territoire national. Des recherches et des études supplémentaires restent donc à poursuivre pour relier les perles de ce site à un réseau de production et d'échange en provenance de sites atlantiques ou méditerranéens.

\section{AUTEURS}

\section{CAROLINE MOUGNE}

Ingénieur de recherche contractuel,

UMR 6566 CReAAH

CATHERINE DUPONT

Chargée de recherche au CNRS,

UMR 6566 CReAAH

\section{QUERRÉ GUIREC}

Ingénieur de recherche au ministère de la Culture,

UMR 6566 CReAAH

\section{PATRICIA SEMELIER}

Anthropologue

\section{VALÉRIE AUDÉ}

Responsable d'opération, Inrap 


\title{
Polyvalence de l'élevage au IV
} millénaire avant notre ère sur l'habitat ceinturé de Wallendorf « Hutberg » (Saxe-Anhalt, Allemagne)

\author{
Svenja Höltkemeier
}

Toute ma gratitude s'adresse au Landesamt für Denkmalpflege und Archäologie Sachsen-Anhalt qui a mis à ma disposition les ossements animaux de Wallendorf. Je remercie chaleureusement Hans-Jürgen Döhle pour l'accueil et les discussions stimulantes que ce corpus faunique a soulevé. Cette étude a été menée dans le cadre d'un doctorat à l'Université Paris 1 Panthéon-Sorbonne et je suis très reconnaissante envers mon directeur Jean-Paul Demoule et ma tutrice Lamys Hachem. Le présent article a bénéficié de nombreuses suggestions et corrections et je remercie vivement les relecteurs pour leur soutien scientifique.

1 L'analyse archéozoologique de l'enceinte fossoyée néolithique de Wallendorf «Hutberg» (ca.3700-2930 cal. BC) est importante à plus d'un titre. Tout d'abord, l'occupation de ce site s'inscrit dans un contexte de changement, à la fois au niveau social avec la cohabitation de différents groupes culturels dans l'aire d'étude, au niveau environnemental avec le changement climatique de l'Atlantique au Subboréal et au niveau économique avec l'apparition de nouvelles activités spécialisées. L'enjeu est donc de voir si ces modifications se reflètent dans la composition de la faune de ce site et comment elles peuvent être identifiées.

2 Ainsi, un des objectifs est de caractériser le sous-système technique de l'exploitation des ressources animales de l'habitat ceinturé de Wallendorf (fig. 1). Ceci permet de savoir quelles espèces ont été chassées ou élevées, dans quel but et plus précisément, comment et où les différentes activités se sont déroulées. L'ensemble des données obtenues apporte des connaissances sur les relations qu'entretenaient les hommes avec les animaux, inédites pour le groupe culturel Hutberg. 
Plus largement, cette étude s'inscrit dans la problématique des produits du vivant et des produits finaux animaux utilisés au $\mathrm{IV}^{\mathrm{e}}$ millénaire av. N. è. en Allemagne centrale. De ce fait, elle permet de combler une lacune sur l'exploitation animale durant ce millénaire dans une région particulièrement propice aux pratiques agropastorales.

Figure 1 : schéma du sous-système technique de l'exploitation des ressources animales (modifié d'après Tresset, 1996, fig. 3 ; Vigne, 1998, fig. 1). Intégration des comportements (Sigaut, 1980), de la notion de l'entretien et du recyclage. DAO : S. Höltkemeier.

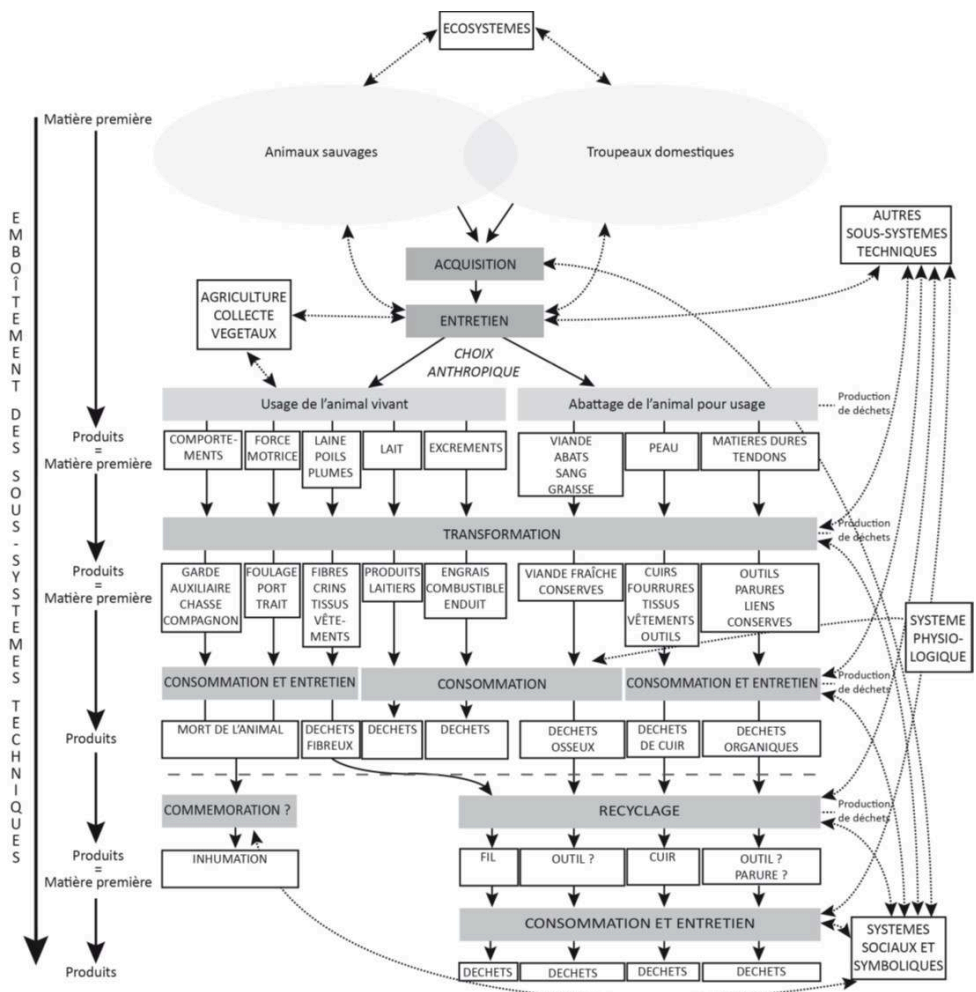

\section{Cadre général}

\section{Le IV ${ }^{e}$ millénaire av. N. è. en Allemagne centrale}

$4 \quad \mathrm{Au} \mathrm{IV}^{\mathrm{e}}$ millénaire, l'Allemagne centrale est entièrement néolithisée, suite au courant danubien (Lichardus et al., 1985). Ce millénaire voit des changements climatiques notables, qui marquent vers 3700 cal. BC la transition de l'Atlantique au Subboréal (Dreibrodt et al., 2012). Certaines fluctuations qui rythment cette période sont des péjorations climatiques, comme les cold events (CE) et les North Atlantic ice-rafting debris events (IRD). Ces évènements ont pu altérer les conditions de vie et l'économie des sociétés, tout en les incitant à des adaptations et restructurations (Gronenborn, 2009, 2010).

Durant le $\mathrm{IV}^{\mathrm{e}}$ millénaire, des transformations fondamentales d'ordre technique, économique, social et idéologique débouchent sur l'émergence de nouvelles sociétés inégalitaires. La production alimentaire se perfectionne, avec un meilleur rendement et l'extension des réseaux d'échange. Dans la seconde moitié de ce millénaire, le cheval domestique, originaire des steppes pontiques, apparaît (Lichardus et al., 1985). De nouvelles technologies sont introduites et conduisent à l'émergence de nouveaux 
artisans, dont l'existence se voit dans le mobilier funéraire des défunts (ibidem). Parmi ces inventions figurent celles en lien avec le transport, comme le travois, le double joug et la roue; ou encore l'araire pour le travail des champs (Lichardus et al., 1985, p. 490-495 ; Pétrequin et al., 2006).

6 Ces changements marquent les hommes de la fin du Néolithique et se reflètent dans leur symbolique, où les animaux y jouent un grand rôle. Par exemple, l'importance symbolique attribuée au bélier traduit probablement la production textile à l'aide de cet animal, qui fournit plus de laine que le castrat ou la brebis (Higham, 1969). Le bélier est utilisé comme décor sur les céramiques ou est modelé en terre cuite, comme la figurine issue d'une tombe à Jordanów en Pologne (Behrens, 1973, fig. 29 ; Midgley, 1992, p. 384 ; Müller, 1998, p. 86-87). Quant à l'utilisation de la force bovine, elle se traduit par exemple par les "symboles fourchus ", gravés sur les pierres des allées couvertes de Warburg (3370-2925 cal. BC) et de Züschen ( $32^{e}$ siècle av. N. è.), en Allemagne centrale (Günther, 1990). Ces symboles sont aussi présents sur des céramiques, comme à Salzmünde « Schiepzig » (Grimm, 1938, fig. 16).

\section{Les usages des animaux par les hommes}

7 Grâce aux données archéozoologiques, il est possible de caractériser les relations entre l'animal et l'homme. Inspiré de travaux de deux archéozoologues (Tresset, 1996, fig. 3 ; Vigne, 1998, fig. 1), le sous-système technique de l'exploitation des ressources animales est illustré ici en insistant sur la différenciation de l'état de l'animal : vivant ou mort (fig. 1). Y ont été intégrés les comportements des animaux (Sigaut, 1980), la notion d'entretien et de recyclage.

8 La transformation d'un élément naturel en un produit fini se fait par une succession d'opérations, en commençant par l'acquisition et l'entretien. Puis, l'homme est face à un choix primordial : laisser l'animal en vie et l'utiliser vivant ou alors le tuer pour tirer profit de son cadavre. C'est un choix économique basé sur le rendement, qui dépend du stock des matières premières et répond aux besoins des hommes. Une fois ce choix effectué, l'homme peut utiliser et transformer ces matières, afin d'obtenir des produits plus sophistiqués, qui sont ensuite distribués et consommés. Les produits destinés à une utilisation sur le long terme peuvent bénéficier d'un entretien régulier. Après consommation, ils sont soit absorbés entièrement, soit produisent des déchets, qui peuvent être jetés ou recyclés. Enfin, les matériaux deviennent des déchets finaux quand ils ne peuvent plus être réutilisés. Un cas particulier existe, il s'agit de la mort d'un animal ayant eu un statut privilégié par rapport aux autres animaux. Cet animal peut être inhumé, dans une sépulture propre ou accompagnant un ou plusieurs défunts, ce qui les distingue des autres animaux "ordinaires » (voir Ghesquière et Hachem, ce volume).

\section{Matériel et méthodes}

\section{Présentation du site}

9 Wallendorf est le site éponyme d'un groupe culturel local, le Hutberg, qui fait partie de la culture de Michelsberg (Müller, 2001, p. 243 ; Klassen, 2004, p. 276-277). Il est localisé en Allemagne centrale, dans la région de Mittelelbe-Saale, environ $25 \mathrm{~km}$ à l'ouest de 
Leipzig. Le site est implanté sur un éperon situé sur la rive gauche de la rivière Luppe, un des affluents de la Saale (fig. 2). L'éperon domine d'une hauteur de $16 \mathrm{~m}$ les plaines alluviales au nord, à l'est et à l'ouest. Au sud, il est protégé par une cuvette marécageuse. Le substrat se compose de différents cailloutis alluviaux, surmontés d'un terrain argileux (Benesch, 1941).

Les premières fouilles de sauvetage ont eu lieu à la fin des années 1930 sous la direction de F. Benesch. Elles ont livré plusieurs types de structures, dont 76 fosses d'un diamètre de 1 à 2,3 $\mathrm{m}$ et d'une profondeur de 0,7 à 1,6 $\mathrm{m}$ (Benesch, 1941, planche I et VII). Certains ensembles ont été interprétés comme des maisons rectangulaires en se basant sur des remontages céramiques entre fosses et sur la présence de trous de poteaux, de sablières basses et de torchis. Cinq fosses contenaient des squelettes ou des parties de squelettes humains démunis de tout mobilier funéraire. De plus, l'éperon était bordé de talus qui étaient encore conservés sur une hauteur variant entre $40 \mathrm{~cm}$ et $1,5 \mathrm{~m}$. Trois tumulus se trouvaient à l'intérieur de ce système taluté. L'attribution culturelle de l'habitat a été compliquée, en raison de la présence d'éléments Baalberge $(29 \%)$, Michelsberg (25\%), Salzmünde (21 \%) et Jordansmühl (1 \% - Benesch, 1941, p. 20).

Figure 2 : localisation du site étudié (point rouge) et des autres sites mentionnés dans le texte.

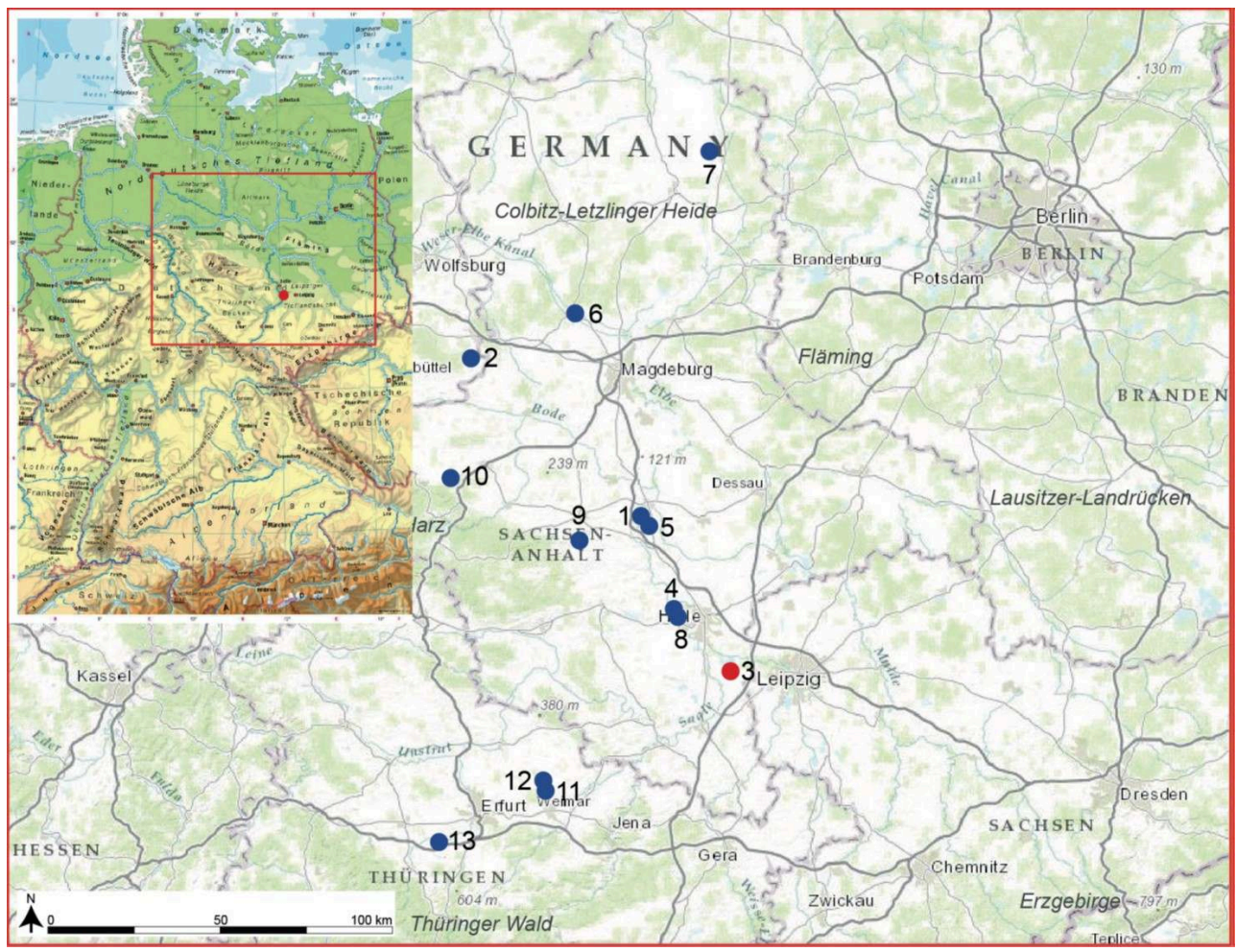

1 : Gröna ; 2 : Runstedt ; 3 : Wallendorf « Hutberg » ; 4 : Salzmünde «Schiepzig » ; 5 : Peißen « Mühlberg »; 6 : Haldensleben ; 7 : Niedergörne ; 8 : Halle Dölauer Heide « Langer Berg » ; 9 : Quenstedt « Schalkenburg »; 10 : Derenburg «Steinkuhlenberg »; 11 : Großobringen « Sportplatz »; 12 : Krautheim «Allstedter Mühlberg »; 13 : Wandersleben.

11 Depuis ces premières analyses, la présence des groupes culturels Michelsberg et Salzmünde a été confirmée (Lüning, 1967, p. 293). La présence d'éléments Jordansmühl et Baalberge a été en revanche rejetée par plusieurs archéologues (dont Mildenberger et Preuß, voir dans Schunke, 1994). Selon H. Behrens, c'est un habitat du Salzmünde (Behrens, 1973, p. 199), alors que J. Beran trouve beaucoup d'éléments Baalberge et 
Michelsberg, mais pas d'indice Salzmünde (Beran, 1993). Afin de préciser cette attribution culturelle, plusieurs campagnes conduites par le Landesamt für Denkmalpflege und Archäologie (service régional de l'archéologie du Land) Saxe-Anhalt ont eu lieu sur différents secteurs. Des prospections géomagnétiques ont révélé une enceinte à triple fossé préservée sur 9,2 ha, englobant une surface d'environ 20,5 ha (fig. 3). Le matériel mis au jour lors des sondages a été attribué en grande partie au Néolithique. On y trouve des outils en pierre et en os, une bague en cuivre, des fragments de récipients, des fusaïoles en céramique et des ossements animaux. Les fosses contenaient des tessons attribués soit au groupe culturel Hutberg, soit au groupe culturel Salzmünde, soit aux deux groupes (Schlenker, inédit; Schlenker et al., 2016). Les datations au ${ }^{14} \mathrm{C}$ font aussi apparaître deux phases d'occupation : une de 3700 à 3500 cal. BC et une autre qui commence vers 3350 cal. BC (Müller, 1999, p. 53, 88 et fig. 6). La présence de trois tumulus attribués à la Culture de la céramique cordée et de plusieurs sépultures datant des âges de métaux indique la réoccupation du site. Dans cet article, l'analyse se base sur le matériel des fouilles anciennes et seules les données fauniques attribuées au groupe culturel Hutberg sont prises en compte, pour écarter tout risque de mélange avec les occupations plus récentes (fig. 4).

Figure 3 : plan des structures archéologiques mises au jour lors des fouilles anciennes et récentes de Wallendorf « Hutberg ».

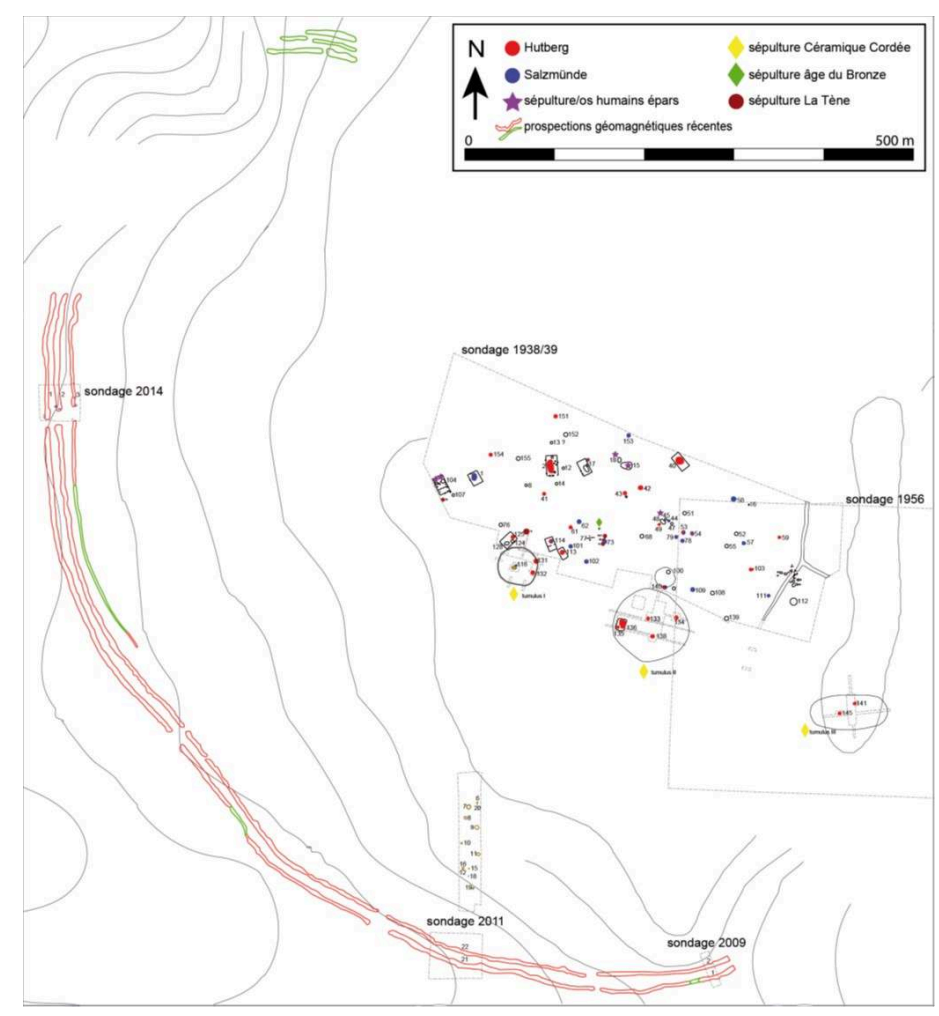

DAO : LDA Saxe-Anhalt, modifié. 
Figure 4 : chronologie de 4200 à 2600 cal. BC des groupes culturels et périodisation de I à V du complexe culturel des Gobelets en Entonnoir (TRBK) en région Mittelelbe-Saale (MES).

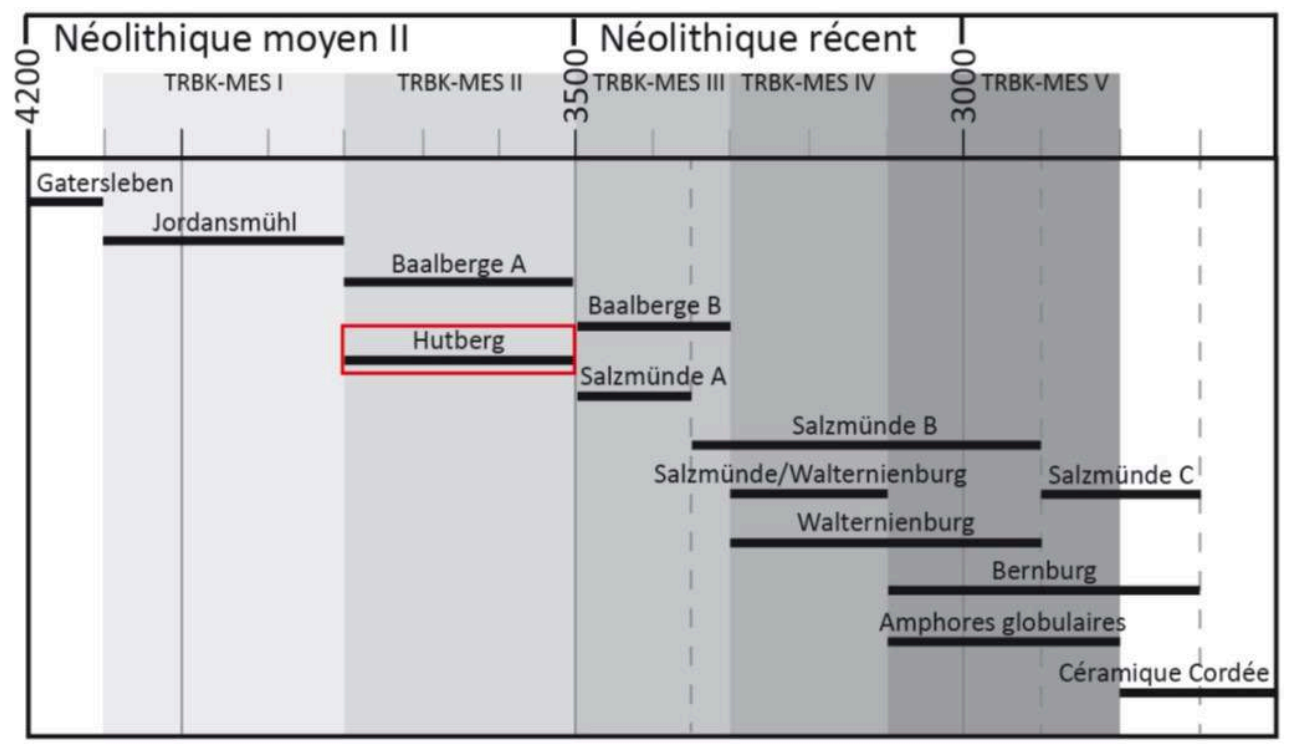

Dates issues de Müller, 2001 ; DAO : S. Höltkemeier.

\section{Méthodes}

Différentes méthodes archéozoologiques sont appliquées pour appréhender le soussystème technique de l'exploitation des ressources animales du site. Les restes animaux sont déterminés selon le principe de l'anatomie comparée avec des collections de comparaison et des référentiels ostéologiques. Les atlas utilisés rassemblent plusieurs espèces (Schmid, 1972; Barone, 1976; Prummel, 1987 ; Hillson, 2005) ou sont dédiés à une famille, comme les bovins (Boessneck et al., 1963), les caprinés (Boessneck et al., 1964 ; Payne, 1985) et les suinés (Helmer, 1987 ; Payne et Bull, 1988). La nomenclature spécifique usitée se réfère au système universel (Gentry et al., 2004). Les données sont enregistrées dans une base FileMaker Pro, avec latéralisation et pesée au dixième de gramme. Le pourcentage de représentation par partie squelettique (PRi - Dodson et Wexlar, 1979) est calculé pour connaître l'état général du matériel et la part des sélections anthropiques. Les traces de boucherie sont relevées à l'œil nu sous lumière rasante et le code de Binford est noté (Binford, 1981). L'indice pathologique (PI) est calculé pour les phalanges affectées de lésions ostéologiques (Bartosiewicz et al., 1997, p. 20).

Plusieurs «nombre minimal» d'individus complémentaires sont utilisés : le NMI de fréquence pour le décompte du nombre minimal de parties de squelette (NMPS), le NMI de combinaison (NMIc) pour les séries dentaires et le NMI par individualisation (NMIi) pour la liste d'espèces (Poplin, 1976; Tresset, 1996). L'évaluation quantitative de la viande et d'abats potentiellement consommés se base sur la méthode Meat and Offal Weight (Vigne, 1991). Les mesures sont prises avec un pied à coulisse selon un référentiel ostéométrique (Von den Driesch, 1976) et celles des bovins peuvent être consultées en tableau 4. Ces données métriques permettent d'évaluer la hauteur au garrot des animaux grâce aux coefficients établis pour les bovins (Matolcsi, 1970) et les moutons (Teichert, 1975a). L'indice logarithmique de taille (LSI) est calculé, il est adapté aux petits corpus (Simpson et Roe, 1939; Höltkemeier, 2016, p. 91-94). Une 
femelle aurochs est utilisée comme individu standard de référence pour les bovins (Steppan, 2001), un bélier pour les moutons (Steppan, 2003, tabl. 77) et un sanglier mâle pour les porcs (Deschler-Erb et Marti-Grädel, 2004, p. 182). Les âges d'abattage des animaux sont estimés sur les os et les dents. Le moment d'épiphysation des os du squelette postcrânien varie entre le bovin (Barone, 1976, p. 53), les caprinés (Zeder, 2006) et le porc (Bridault et al., 2000). L'estimation des âges dentaires se base sur un référentiel pour le bovin (Jones et Sadler, 2012), les caprinés (Payne, 1973) et le porc (Lemoine et al., 2014). La distinction sexuelle se fait pour les bovidés sur la cheville osseuse et le coxal, celle des suinés sur les canines.

\section{Composition et répartition de la faune}

14 Le corpus est constitué de 890 restes osseux dont 530 ont été déterminés (tabl. 1). Ce sont des rejets détritiques issus de fosses; aucun reste ne provient des fosses qui ont contenu des ossements humains. Le spectre faunique se compose presque essentiellement d'animaux domestiques. Les bovins sont la première ressource alimentaire, tant en nombre de restes déterminés qu'en nombre minimal d'individus, suivis des caprinés et des porcs. La faune sauvage n'est représentée que par un oiseau aquatique et un rapace. Une autre espèce est indirectement attestée, car 2,5\% des restes déterminés ont été rongés par un carnivore. En effet, certaines extrémités articulaires d'animaux domestiques ont des enfoncements de la surface osseuse, dont la taille et la forme suggèrent qu'il s'agit de marques dentaires de chien (fig. 5a).

Tableau 1 : liste et spectre de faune de Wallendorf.

\begin{tabular}{lccccc} 
Wallendorf « Hutberg » & NR & \% NR & PR (g) & \% PR & NMIi \\
\hline Bovin domestique (Bos taurus) & 467 & 88,1 & 15311,6 & 94,0 & 11 \\
Mouton (Ovis aries) & 15 & 2,8 & 174,2 & 1,1 & 2 \\
Chèvre (Capra hircus) & 1 & 0,2 & 16,1 & 0,1 & 1 \\
Caprinés (Ovis aries/Capra hircus) & 23 & 4,3 & 205 & 1,3 & \\
Porc (Sus domesticus) & 21 & 4,0 & 436,2 & 2,7 & 5 \\
Suinés (Sus sp.) & 1 & 0,2 & 146,1 & 0,9 & 1 \\
Canard/sarcelle (Anas sp.) & 1 & 0,2 & 0,4 & 0,002 & 1 \\
Buse variable (Buteo buteo) & 1 & 0,2 & 1,8 & 0,01 & 1 \\
\hline déterminés & $\mathbf{5 3 0}$ & $\mathbf{5 9 , 6}$ & $\mathbf{1 6 2 9 1 , 4}$ & $\mathbf{8 6 , 9}$ & $\mathbf{2 2}$ \\
indéterminés & 360 & 40,4 & 2451,2 & 13,1 & \\
\hline TOTAL & $\mathbf{8 9 0}$ & & $\mathbf{1 8 7 4 2 , 6}$ & & \\
\hline animaux domestiques & 527 & 99,4 & 16143,1 & 99,1 & 19 \\
animaux sauvages & 2 & 0,4 & 2,2 & 0,0 & 2 \\
animaux domestiques ou sauvages & 1 & 0,2 & 146,1 & 0,9 & 1 \\
\hline
\end{tabular}

Données en nombre de restes (NR), masse des restes en grammes (PR) et nombre minimal d'individus par individualisation (NMli). 
Figure 5 : particularités des restes animaux de Wallendorf.

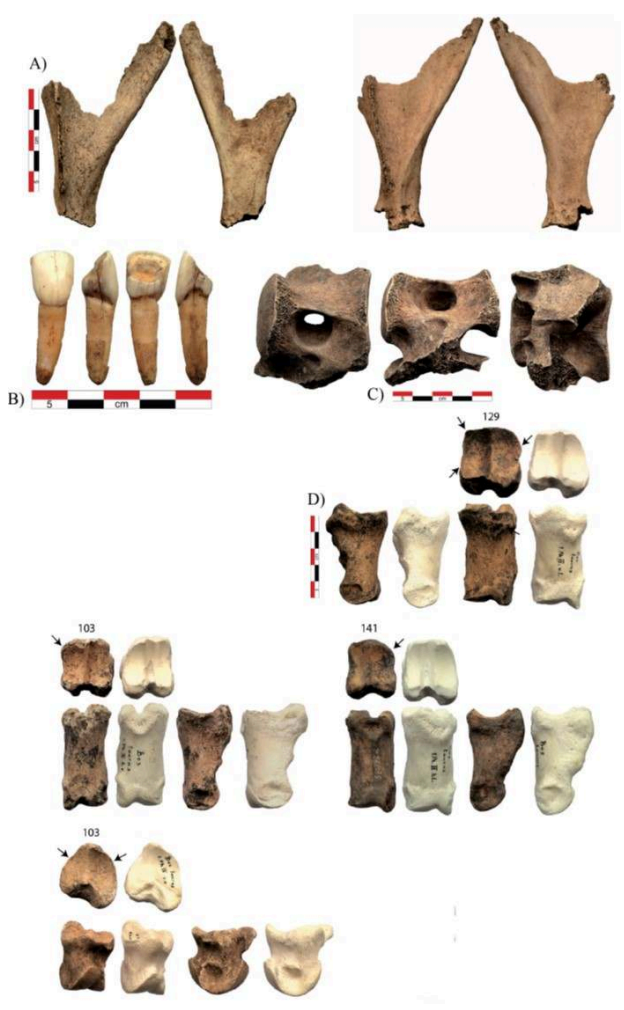

A) Deux omoplates gauches de caprinés (Ovis aries/Capra hircus) de la fosse 103. Les enfoncements ont été provoqués par un carnivore. Vues latérales ( $7^{\text {ère }}$ et $3^{\mathrm{e}}$ ) et vues médiales ( $2^{\mathrm{e}}$ et $4^{\mathrm{e}}$ ). $\mathrm{B}$ ) Incisive droite de bovin (Bos taurus) de la fosse 141. Un défaut en forme de coin est visible au niveau du collet. De gauche à droite : vue buccale; vue vestibulaire ; vue linguale; vue mésiale. C) Vertèbre lombaire de bovin (Bos taurus) de la fosse 155. Elle est affectée par une anomalie de croissance. De gauche à droite : vue ventrale; vue latérale droite; vue dorsale. D) Premières et deuxièmes phalanges de bovin (Bos taurus) avec des anomalies (élargissement de la surface articulaire proximale et exostoses). À leur droite ont été placées pour comparaison des phalanges de bovin actuel provenant de l'ostéothèque du LDA Saxe-Anhalt.

La répartition spatiale est inégale, car seule une partie des fosses contenait des restes animaux, dont presque le tiers est issu de la fosse 49 (fig. 6). Une autre zone de concentration se situe au niveau de la fosse 133. Les ossements ont passé un temps variable à l'air libre, car les stades d'altération 1 à 4 ont été remarqués (Behrensmeyer, 1978). Le stade 1, à savoir une exposition à l'air libre de moins de 3 ans est le plus fréquent, suivi du stade 2. Les os significativement altérés sont rares, ceux du stade 4 proviennent des fosses 49 et 134 . Un mélange de stades d'altération différents au sein de la même structure est rare, mais existe pour les fosses 49 (stade 1 à 4), 103 et 133 (stade 1 à 3). Ces structures ont été utilisées plus longtemps que les autres. Le fait que ces deux dernières structures aient livré des os rongés est intéressant, car la fosse 49 en est dépourvue. 
Figure 6 : distribution spatiale des restes animaux de Wallendorf.

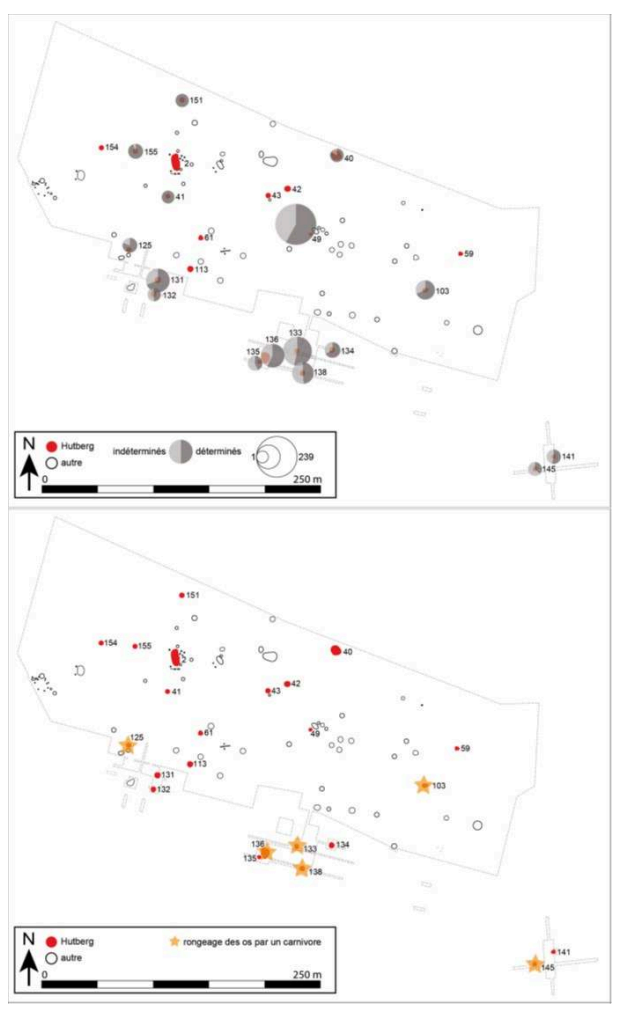

Nombre de restes déterminés et indéterminés (en haut) ; restes rongés par un carnivore, présents dans les structures marquées par une étoile (en bas).

\section{Résultats par espèce}

\section{Les bovins (Bos taurus)}

Les bovins sont représentés par toutes les régions anatomiques et la distribution par latéralisation ne montre pas de dominance d'un côté sur l'autre (tabl.2). Le pourcentage de représentation par partie squelettique fait ressortir la sousreprésentation du rachis, peut-être liée à sa forte fragmentation, et une bonne représentation des membres et de leurs extrémités (fig. 7). Les dents, moins fragiles que les ossements, sont également nombreuses. Ces herbivores ont pu fournir 1,3 tonne de viande et d'abats, qui proviennent surtout d'individus âgés de plus de 2 ans. 
Tableau 2 : distribution des restes de bovins (Bos taurus), de moutons (Ovis aries), de chèvre (Capra hircus), de caprinés $(O / C)$, de porcs (Sus domesticus), de suiné indéterminé (Sus sp.), de canard/ sarcelle (Anas sp.) et de buse variable (Buteo buteo) de Wallendorf.

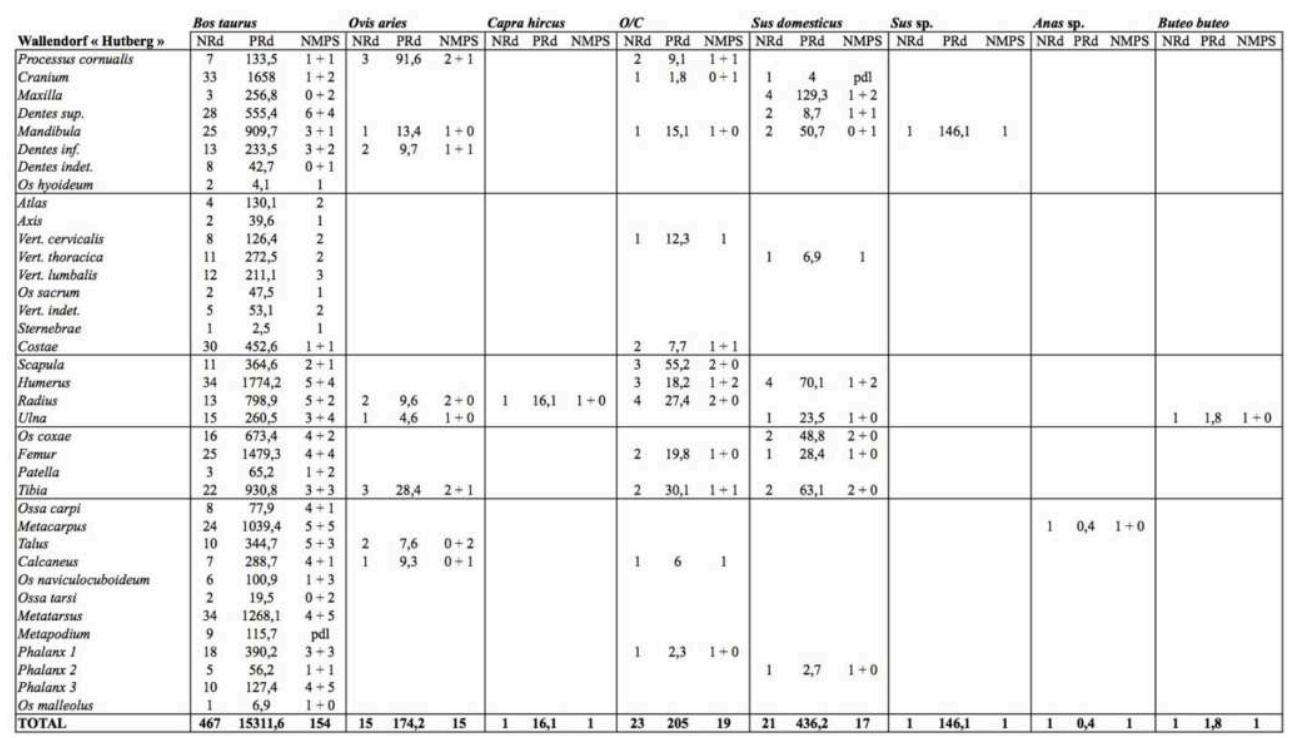

Abréviation : $p d l=$ pas de latéralisation

Figure 7 : pourcentage de représentation par partie squelettique (PRi) des bovins (Bos taurus), des caprinés (Ovis aries/Capra hircus) et des porcs (Sus domesticus) de Wallendorf.

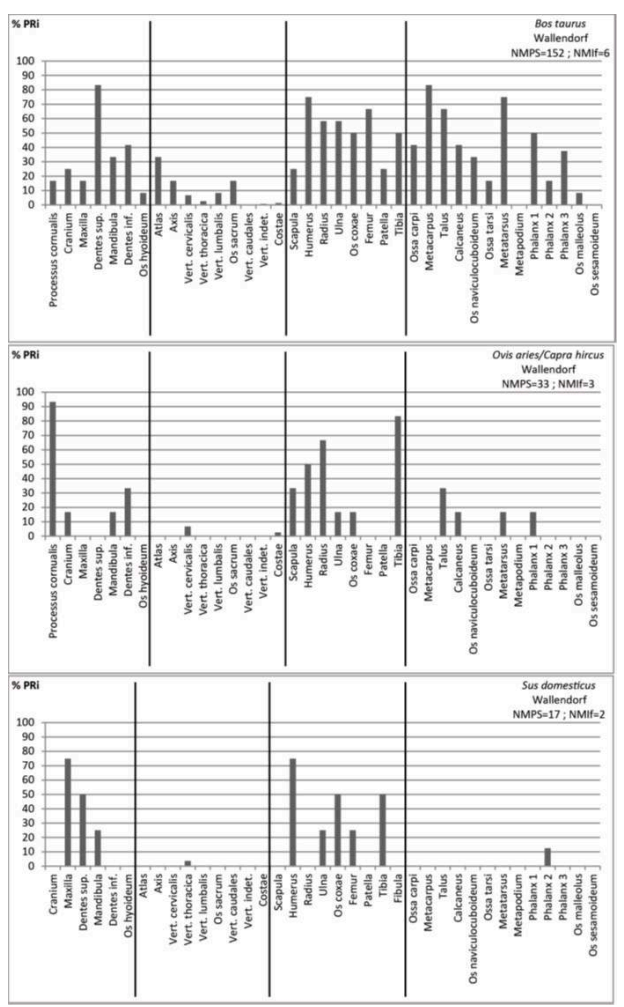

17 Des traces de dépouillage sont présentes sur l'os nasal et le métatarse (fig. 8 ; MTd-2 selon Binford, 1981). Lors de cette activité, les phalanges ont été jetées entières (63,6 \%) ou plus rarement à l'état fragmentaire, car peu ont des traces de fracture intentionnelle $(9,1 \%)$. Dans plusieurs cas, l'atlas et l'axis ont été fracturés par percussion, indiquant 
que la tête a pu être séparée du tronc. La tête a été désossée et la mâchoire inférieure désarticulée par le sectionnement du muscle masséter et par la désarticulation du processus condylaire (M-2 et M-5 selon Binford, 1981). Les stries transversales sur l'os hyoïde indiquent que la langue a pu être prélevée à cru. Le crâne a été fracturé, probablement afin d'en extraire la cervelle, car des stries de découpe au silex ont été remarquées sur un fragment de la cavité cérébrale. La levée des filets à cru est suggérée grâce aux stries longues et fines sur les épines des vertèbres thoraciques et par les stries transversales sur les côtes, proche de leur tête articulaire (TV-2 et RS-1 selon Binford, 1981). Le dépeçage des membres antérieurs a été fait au niveau humérus/ radius-ulna, et de l'extrémité proximale du métacarpe (Hd-2, Hd-3, RCp-3, RCp-5, MCp-1 selon Binford, 1981). Le désossage de ces morceaux est perceptible sur la scapula, l'humérus et le radius (S-3, S-4 et Hd-6 selon Binford, 1981; Rs-a selon Soulier et Costamagno, 2017). La désarticulation des membres postérieurs a été faite entre le coxal et le fémur, et les extrémités ont été démembrées au niveau du tarse ( $\mathrm{Fp}-1$ et TA-1 selon Binford, 1981). Des traces de désossage existent sur le coxal, le fémur et le tibia (Fp-4 et Tp-3 selon Binford, 1981). Le prélèvement des tendons est attesté par des stries courtes présentes sur la face caudale des diaphyses de métacarpes (Costamagno, 2012, p. 30 et fig. 13-14; Mcs-f selon Soulier et Costamagno, 2017). Les côtes ont été sectionnées par fracturation et décarnisées sur leur face externe. Cet enlèvement du gril costal se voit aussi par des stries fines sur la face interne des côtes, proche de l'articulation (RS-3 selon Binford, 1981). Il est impossible de préciser la façon dont la colonne vertébrale a été débitée, en raison d'une trop forte fragmentation des vertèbres. Presque tous les éléments squelettiques ont été fracturés et particulièrement les os longs, ce qui renvoie à la récupération de la moelle osseuse. 
Figure 8 : localisation des traces de dépouillage, de désarticulation, de décarnisation, de fracturation et de cuisson relevées sur les os des bovins, des caprinés et des porcs de Wallendorf.

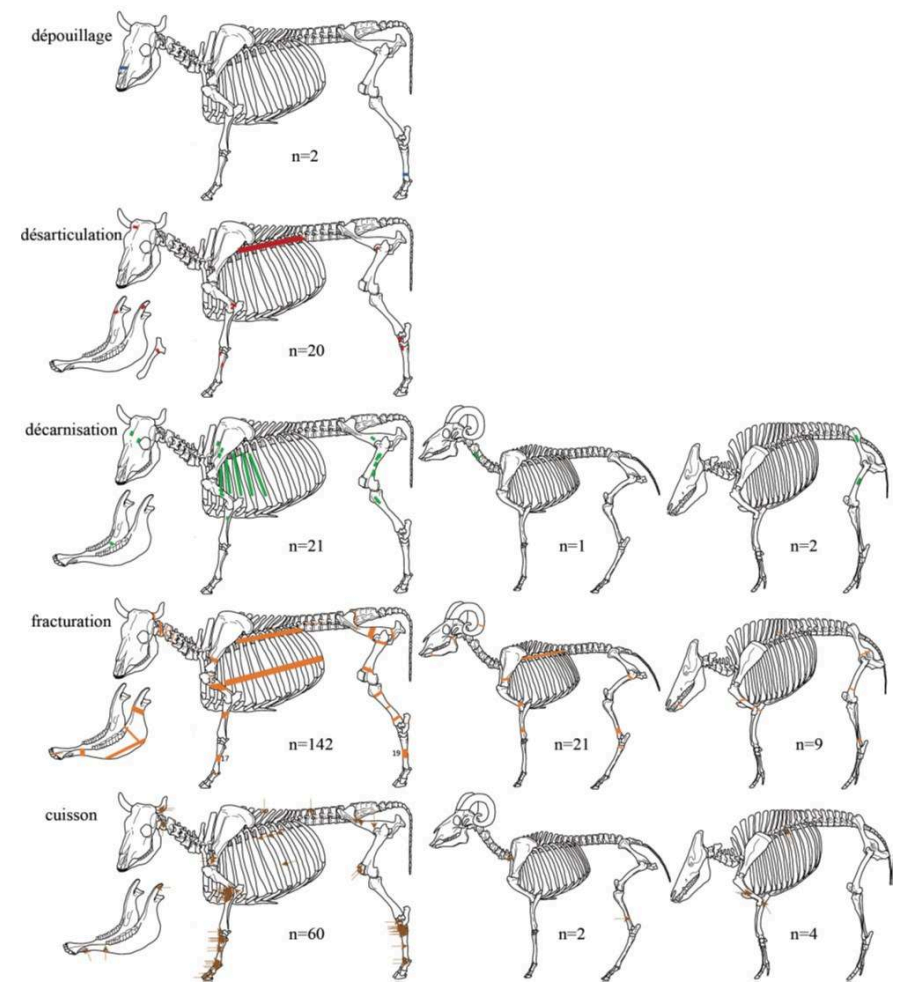

Dessins de M. Coutureau, INRAP.

Les habitudes culinaires semblent être variées. La combustion des os aux endroits peu charnus ou dépourvus de viande après la boucherie suggère le rôtissage. L'ébullition de la viande et la récupération de la moelle peuvent se refléter par la forte récurrence d'os fracturés. Le désossage de parties charnues peut refléter soit la consommation directe de morceaux dépourvus d'os, soit la conservation de la viande (salaison, fumage ou séchage). Nous avons essayé de reconstituer le patron de découpe des bovins de Wallendorf en nous basant sur l'ensemble de ces traces : une exploitation maximale de tous les produits peut être proposée (fig. 9). Les morceaux carnés sont variés, car les pièces charnues tout comme celles moins prisées ont été prélevées (Fleischwertklassen A, B, C selon Uerpmann, 1972).

Les bovins de ce site sont tous de taille inférieure à la femelle de référence (fig. 10). La hauteur au garrot d'une vache, estimée sur un métatarse (tabl. 3), est de $105,8 \mathrm{~cm}$. Les valeurs LSI sont distribuées de manière assez étalée, allant de $-0,34$ à $-0,01$. Néanmoins, deux pics (autour de $-0,11$ et $-0,06$ ) reflètent vraisemblablement le dimorphisme sexuel de cette population. Les valeurs très basses se basent sur des mesures prises sur des os qui s'épiphysent assez tôt (métatarse et tibia distaux). Toutefois, le moment de soudure des os n'est peut-être pas l'unique cause de ces valeurs basses, car d'autres éléments du squelette qui s'épiphysent aussi relativement tôt (radius proximal, phalanges) ont des valeurs plus élevées. De ce fait, il pourrait s'agir d'un changement proportionnel du bovin, changement potentiellement causé par sa domestication et par les pratiques agropastorales subies. En se basant sur les critères morphologiques, on décompte un mâle pour trois femelles. Il est difficile de dire si des individus castrés sont présents, mais cela pourrait être le cas pour le plus grand bovin (valeur LSI de -0,01). 
Tableau 3 : Phalanges bovines (Bos taurus) de Wallendorf avec anomalies liées à l'usure et à la surcharge du squelette.

\begin{tabular}{ccccc} 
structure & partie anatomique & sexe & âge & PI \\
\hline 129 & Phalanx I ant. dext. & $\delta /$ castré ? & $>20-24$ mois & 0,36 \\
103 & Phalanx I post. sin. & $\delta /$ castré ? & $>20-24$ mois & 0,27 \\
141 & Phalanx I post. dext. & $\delta ? ~$ & $>20-24$ mois & 0,18 \\
103 & Phalanx II ant. dext. & $\delta /$ castré ? & $>15-18$ mois & 0,09 \\
\hline
\end{tabular}

Abréviations : $\mathrm{PI}$ = indice pathologique, ant. = antérieur, post. = postérieur, sin. = gauche, dext. = droit.

Figure 9 : essai de reconstitution du patron de découpe des bovins (Bos taurus) de Wallendorf en se basant sur les traces observées à la surface des os.

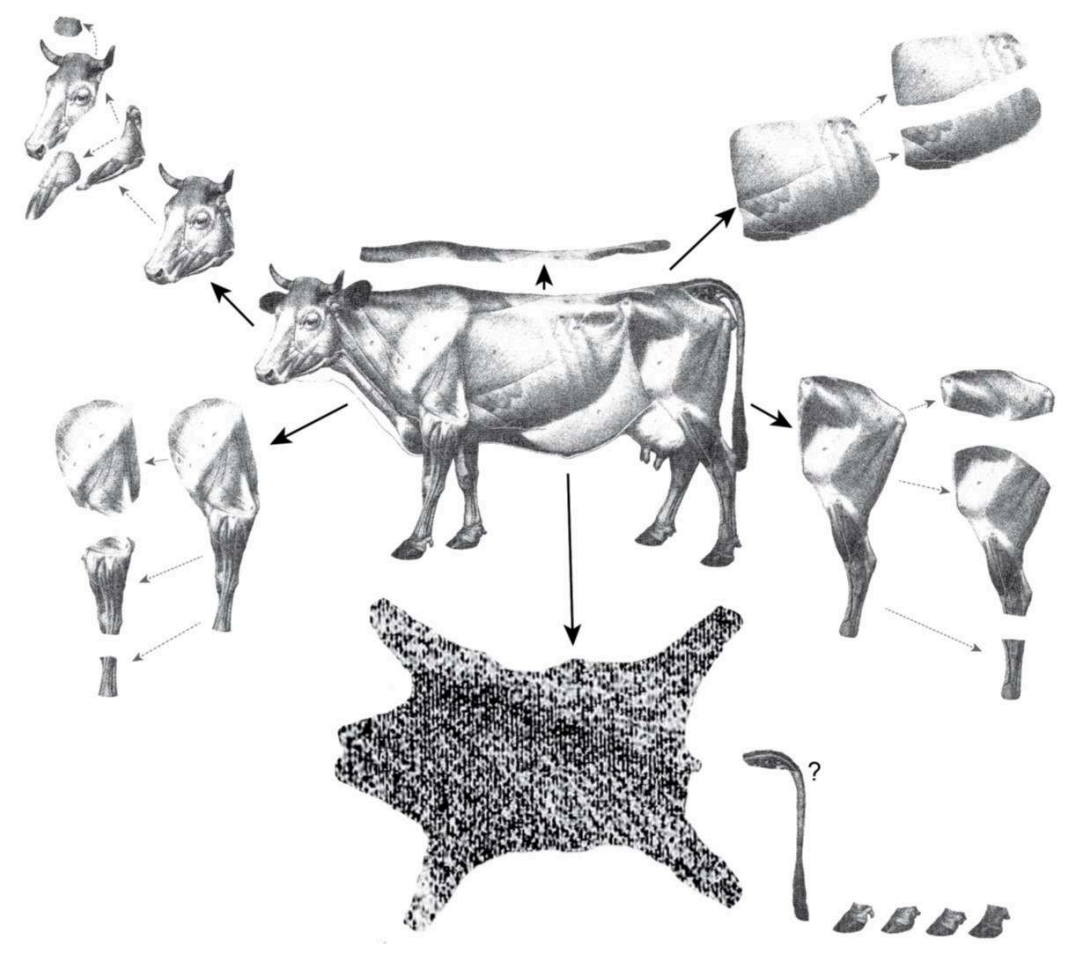

Découpe primaire (flèches noires) et secondaire (flèches grises).

Estampe de la vache issue d'Ellenberger et al., 1956, fig. 2. 
Figure 10 : indices logarithmiques de taille (LSI) des bovins (Bos taurus) de Wallendorf.

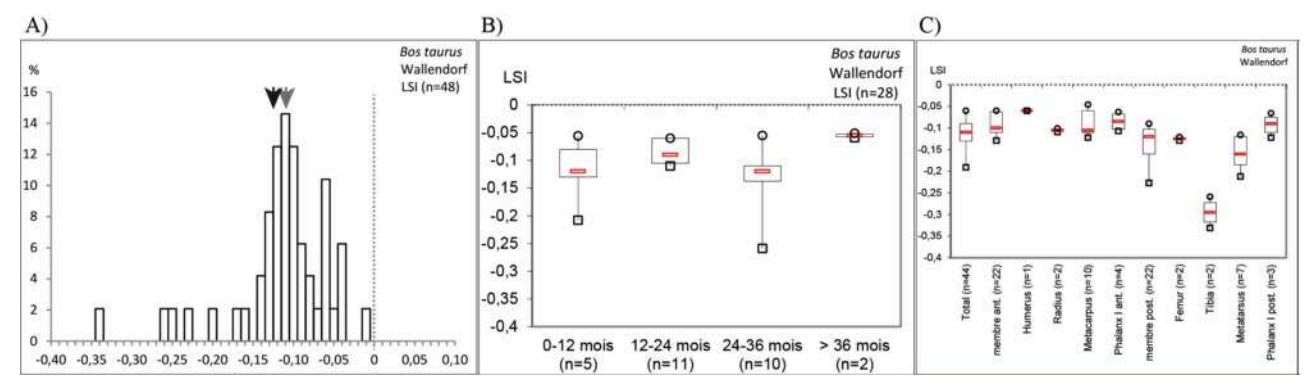

A) Variabilité de la taille avec indication de la moyenne (flèche noire) et de la médiane (flèche grise). B) Distribution par tranche d'âge. C) Distribution par élément de squelette. Les données sont basées sur la médiane (rectangle rouge) et représentées en déciles.

Les bovins ont été abattus à des âges variables (fig. 11). Le profil basé sur les dents fait ressortir un premier pic d'abattage pour les veaux âgés de 0 à 6 mois. Entre 20 et $30 \%$ (en Nd et NMI) du troupeau bovin a été abattu avant d'atteindre l'âge de maturité sexuelle des vaches, vers 2 ans. Les classes d'âge $E F$ et $G$ sont les mieux représentées et cet abattage d'individus âgés entre 2 et 6,5 ans se reflète dans la courbe de survie du troupeau (fig. 11). Les vieux bovins sont peu représentés et tous sont abattus avant que les vaches ne deviennent stériles, vers 10 ans. Ce profil suggère une exploitation mixte. L'abattage de veaux et d'adultes âgés entre 4 et 6,5 ans plaide en faveur d'une exploitation laitière (Vigne et Helmer, 2007), dont l'abattage post-lactation, c'est-à-dire l'abattage des veaux au moment de leur sevrage, est une caractéristique (Tresset, 1996, 1997 ; Balasse et al., 1997, 2000). Cette hypothèse est renforcée d'une part par la dominance de femelles adultes au sein du troupeau et d'autre part par le faible taux de nouveau-nés abattus (classe A), car les éleveurs ont besoin d'eux pour obtenir du lait lors de la traite (Balasse et al., 2000 ; Balasse, 2003).

La mise à mort de veaux sevrés témoigne également d'une recherche de viande tendre et celle des individus âgés entre 4 et 6 ans indique l'élimination de vaches dont la production laitière diminue, on parle aussi de vaches de réforme (Helmer, 1992; Tresset, 1996, 1997 ; Balasse et al., 2000 ; Bréhard et al., 2010). L'exploitation bouchère est visible par le fort abattage des bovins âgés entre 2 et 4 ans, moment de leur meilleur rendement en qualité et en quantité de viande. D'après des données recueillies sur des sites de la France méditerranéenne, cette pratique semble apparaître au IV millénaire (Blaise et al., 2010). La présence de quelques bovins plus âgés soulève la question de l'utilisation de leur force. L'estimation des âges d'abattage basée sur l'état d'épiphysation des os fournit les mêmes tendances et soutient l'hypothèse d'une exploitation mixte (fig. 11). 
Figure 11 : abattage des bovins (Bos taurus) de Wallendorf.

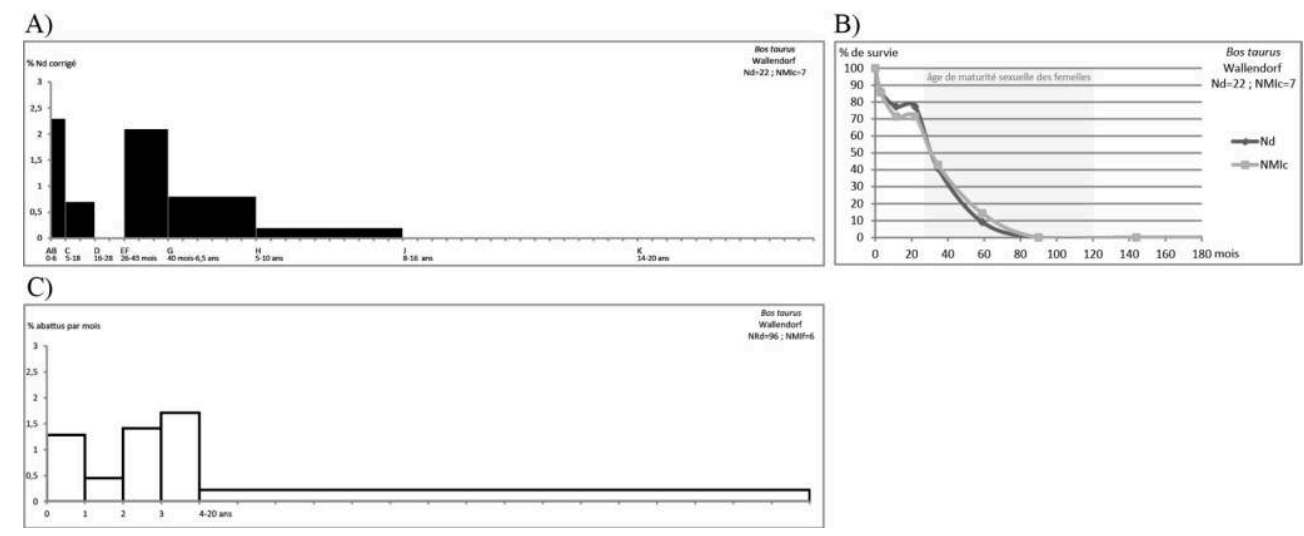

A) Profil basé sur les dents. B) Courbe de survie. C) Profil basé sur les os longs. Abréviations :

$\mathrm{Nd}=$ nombre de restes dentaires, $\mathrm{NMIC}=$ nombre minimal $\mathrm{d}^{\prime}$ individus de combinaison, $\mathrm{NRd}=$ nombre de restes déterminés, NMIf = nombre minimal d'individus de fréquence.

22 Peu d'anomalies ont été remarquées. Une incisive a un défaut en forme de coin au niveau du collet (fig. 5b), conséquence de l'abrasion dentaire lors de l'ingestion alimentaire (Müller, 1990). Une vertèbre lombaire a une anomalie de croissance, se traduisant par un foramen vasculaire surdimensionné (fig. 5c). Quatre phalanges présentent des déformations à différents stades, ce qui représente $17,4 \%$ de ces éléments squelettiques (fig. $5 \mathrm{~d}$ ). Elles ont toutes un élargissement de la surface articulaire proximale, mais leur indice pathologique est plutôt faible (tabl.4). Il pourrait s'agir de pathologies résultant d'une utilisation de ces individus pour leur force. Toutefois, le pâturage des bovins dans une zone marécageuse peut aussi produire ce type de déformations osseuses (Chaix, com. pers.). La détermination du sexe de ces individus est délicate, notamment en raison de la déformation des os et de leur épiphysation relativement précoce. 
Tableau 4 : Données ostéométriques en $\mathrm{mm}$ du bovin (Bos taurus) de Wallendorf.

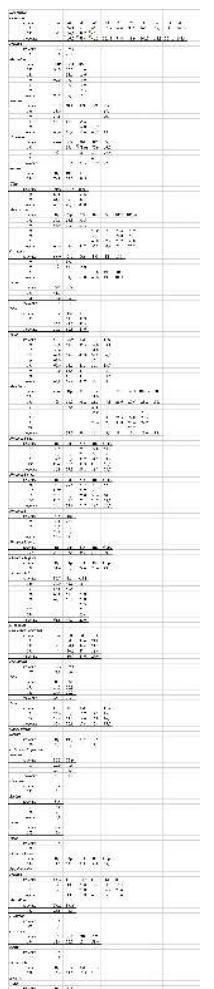

Précisions : () mesure estimée, * reste affecté d'une anomalie.

\section{Les caprinés (Ovis aries/Capra hircus)} nombreux éléments du squelette sont absents et le rachis est fortement sousreprésenté (fig. 7). Cette composition peut indiquer un import de viande, un lieu de boucherie primaire localisé hors de la zone de fouille ou alors un biais taphonomique. $\mathrm{Au}$ moins $43 \mathrm{~kg}$ de viande et d'abats ont pu être acquis, provenant surtout d'individus âgés de plus de 2 ans.

La décarnisation du squelette se voit au niveau du cou (fig. 8). Comme pour le bovin, les côtes ont été sectionnées par fracturation en dessous de la tubérosité du muscle iliocostal et la fracturation d'os longs illustre la récupération de la moelle et vraisemblablement le dépeçage. Des traces relevant de la cuisson à la flamme ont été constatées au niveau de l'épaule et du gigot. Ces données sont trop limitées pour proposer un patron de découpe.

Très peu de valeurs LSI existent pour les caprinés. Elles sont toutes inférieures à celles de l'individu utilisé comme référence standard. Seuls deux talus permettent de calculer la hauteur au garrot des moutons, elle est en moyenne de $62,6 \mathrm{~cm}$. Ceci est à considérer avec précaution, car cet os se prête mal à l'approche. Le sex-ratio, obtenu sur les chevilles osseuses, est de 1/1.

Peu de données sont disponibles pour déterminer les modes de gestion et d'exploitation du troupeau ovin. Les âges obtenus sur les os longs permettent dans le meilleur des cas d'indiquer les tendances $(\mathrm{n}=12$; NMIf $=3)$. On note l'abattage continu d'individus dès leur première année. L'abattage d'un agneau de 6 à 12 mois est attesté par les dents. 


\section{Les porcs (Sus domesticus)}

Les porcs sont représentés majoritairement par des fragments de crâne et de membres (fig. 7). Aucun côté n'est surreprésenté par rapport à l'autre (tabl. 2). Ces animaux ont pu fournir au moins $256 \mathrm{~kg}$ de viande et d'abats, à condition qu'ils aient été abattus et consommés sur place.

enté décharnés (fig. 8). Les os longs ont été fracturés pour leur moelle et certaines parties ont été probablement débitées au percuteur. Les côtelettes et l'épaule ont été cuites au-dessus d'un feu.

9 Les deux valeurs LSI obtenues sur la scapula et sur l'ulna sont négatives et ces porcs étaient donc de plus petite taille que l'individu standard.

Les porcs ont été abattus à des âges variables, mais aucun animal n'a atteint sa quatrième année, ce qui renvoie à un rendement maximal (fig. 12). Le troupeau a été réduit de $40 \%$ avant que les femelles n'atteignent la maturité sexuelle vers 9 mois, ce qui indique une recherche de viande tendre. Cette hypothèse est soutenue par un sexratio de deux mâles pour une femelle, décompté sur les mâchoires.

Figure 12 : abattage des porcs (Sus domesticus) de Wallendorf.

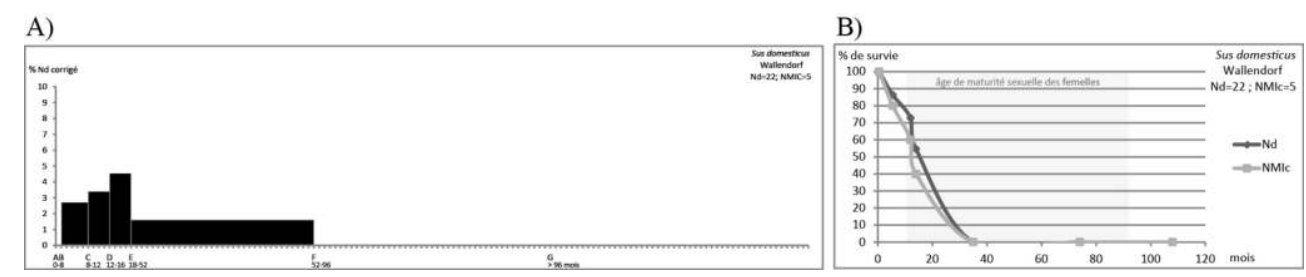

A) Profil basé sur les dents. B) Courbe de survie. Abréviations : $\mathrm{Nd}=$ nombre de restes dentaires, $\mathrm{NMIc}=$ nombre minimal d'individus de combinaison.

\section{Discussion}

31 L'analyse archéozoologique de Wallendorf a été effectuée dans le cadre d'un doctorat et s'intègre dans une recherche régionale (Höltkemeier, 2016). À la suite d'une première synthèse (Döhle, 1997), de nouvelles données ont permis de mener une étude approfondie de certaines problématiques et d'apporter des résultats documentés. Il s'agit d'abord du type d'approvisionnement carné, car le taux des animaux chassés et élevés varie d'un site et d'un groupe culturel à l'autre. À Wallendorf, l'élevage apporte la majorité des produits d'origine animale et les bovins sont la première ressource de ces matières. C'est aussi le cas pour la majorité des sites localisés en région MittelelbeSaale qui datent entre 4200 et 2800 av. N. è. (Höltkemeier, 2016, p. 260-266). Néanmoins, certains sites se démarquent de ce schéma, comme une fosse d'habitat à Gröna (Lengyel tardif ; Teichert, 1975b) et d'autres fosses à Niedergörne (Céramique aux impressions profondes; Stolle et al., 1988). Sur ces deux sites, la chasse, la collecte de bivalves et la pêche sont des activités importantes.

Le sous-système technique de l'exploitation des ressources animales (fig.1) de Wallendorf est marqué par une exploitation mixte des bovins, alors que d'autres sites régionaux peuvent être plus dédiés à un produit en particulier. C'est par exemple le cas 
de l'enceinte fossoyée de Quenstedt "Schalkenburg» (Bernburg; Müller, 1985) où l'exploitation bouchère de la triade domestique est importante, ou encore de l'habitat fossoyé de Krautheim "Allstedter Mühlberg" (Bernburg; Benecke, inédit) où l'exploitation laitière des bovidés est prépondérante. Ainsi, la gestion des troupeaux et les pratiques pastorales ne sont pas toujours les mêmes. Pour les enceintes fossoyées de Wallendorf et Salzmünde « Schiepzig » (Salzmünde), on note un sex-ratio des bovins de $1 / 3$, alors qu'il est de $1 / 1$ à Quenstedt et de $1 / 10$ à Krautheim. La castration des bovins est probable à Wallendorf et elle est même sûre pour les autres sites.

La question de l'usage des bovins pour leur force motrice a été soulevée pour Wallendorf. À Salzmünde, elle est confirmée par un profil d'abattage caractéristique de cette pratique et par la présence de nombreux os portant des déformations pathologiques (Höltkemeier, 2016). Ces altérations du squelette liées à sa surcharge existent pour les bovins de différents sites de l'aire chronoculturelle considérée, mais il semble bien que ceux de Wallendorf soient les plus anciens (ibidem). Une datation au ${ }^{14} \mathrm{C}$ de ces os et l'acquisition de données semblables lors des fouilles récentes pourraient confirmer cette hypothèse et contribuer à dater l'apparition de l'usage de la force bovine dans l'aire d'étude.

Les caprinés, principalement représentés par des moutons sur l'ensemble des sites, et les porcs sont une autre ressource de produits du vivant et finaux, mais leur importance relative fluctue d'un site à l'autre. En règle générale, les caprinés sont en termes de nombre de restes plus abondants que les porcs. Seul quatre cas contraires sont connus: dans la fosse d'habitat de Runstedt (Baalberge ?; Enderle, 1977) aucun reste de capriné n'a été recensé, dans l'habitat fortifié de Derenburg "Steinkuhlenberg " (Müller, 1964) les porcs sont légèrement plus abondants, dans les fosses d'habitat de Haldensleben (Céramique aux impressions profondes ; Prilloff, 1982) les caprinés et les porcs sont représentés de manière équivalente et dans la maison mortuaire de Wandersleben (Culture des Amphores globulaires; Barthel, 1983) les porcs sont beaucoup plus représentés que les caprinés. Les moutons ont été élevés pour différents besoins. À Salzmünde par exemple, l'exploitation bouchère et laitière sont couplées, et celle du textile est également bien représentée (Höltkemeier, 2016, p. 270). Sur l'enceinte de Großobringen « Sportplatz » (Bernburg; Barthel, 1985), l'élevage ovin semble être orienté vers une exploitation mixte de toison et de viande. La castration des béliers n'a pas pu être démontrée à Wallendorf, mais elle est une pratique courante à Krautheim, Quenstedt et Großobringen. Le sex-ratio des caprinés de Wallendorf est de $1 / 1$, comme à Quenstedt. Sur les autres sites, ce sont soit les mâles qui dominent, comme à Salzmünde (3/1), soit les femelles, comme à Krautheim (1/2) et Großobringen (1/5). À Wallendorf, les porcs ont été abattus pour leur viande tendre, et c'est aussi le cas sur les autres sites. Le sex-ratio du troupeau porcin est de 2/1 à Wallendorf, de $1 / 1$ à Salzmünde et Quenstedt et de $1 / 2$ à Krautheim.

Les ossements animaux mis au jour lors des fouilles anciennes à Wallendorf proviennent essentiellement de fosses. Plusieurs zones de concentration existent (fig. 6) et ces restes ont passé un temps variable à l'air libre. À Salzmünde, presque toutes les structures ont livré des ossements animaux, mais en quantité très variable (Höltkemeier, 2016, p. 248-255). Souvent, ce sont des rejets détritiques, mais certains dépôts animaux existent également (ibidem, p. 241-246). L'analyse spatiale détaillée des ossements animaux d'autres sites régionaux de la période chronoculturelle considérée 
n'a pas été effectuée. On sait juste qu'à Wandersleben, les ossements animaux brûlés se concentrent plus à l'entrée qu'au fond de la maison mortuaire (Barthel, 1983).

La gestion des animaux abattus et la préparation de la viande par les hommes néolithiques sont rarement abordées dans les études. Sur l'enceinte de Peißen "Mühlberg", attribuée au groupe culturel Salzmünde, il semble que la découpe a eu lieu à proximité ou sur les zones fouillées. Les parties riches en viande sont transformées et certains morceaux semblent avoir été rôtis, d'autres ont été bouillis et la moelle osseuse a été récupérée (Becker, 1999). Les traces de découpe au silex ont été détaillées pour les ossements animaux issus de l'enceinte fossoyée du groupe culturel Bernburg de Halle Dölauer Heide "Langer Berg ». Leur analyse révèle que la découpe bouchère a été faite sur place (Müller, 1978). En se basant sur la représentation des parties anatomiques, H.-J. Barthel propose que la viande d'animaux domestiques consommée dans l'enceinte de Großobringen a été découpée ailleurs, alors que les cervidés ont été apportés entiers et débités sur le site (Barthel, 1985). Le traitement des carcasses et les pratiques culinaires carnées sont détaillés pour Salzmünde (Höltkemeier, 2016, p. 227-231). Leur analyse montre que la chaîne opératoire de découpe bouchère est assez classique, mais qu'elle peut varier d'une espèce à l'autre. Les pratiques culinaires semblent être variées, mais le rôtissage est toujours bien représenté. Ceci concorde avec les résultats obtenus pour Wallendorf (cf. supra).

Après ce tour d'horizon des sites chronoculturellement comparables à Wallendorf "Hutberg», ce dernier présente les caractéristiques du sous-système technique régional de l'exploitation animale. Les sites considérés montrent différents cas de figure, certains étant spécialisés, comme Krautheim. Dans ce contexte, Wallendorf apparaît polyvalent, mettant à profit le maximum du potentiel des animaux. Ce site pourrait donc être plus autonome que d'autres qui se complètent par leur spécialisation. Ces derniers étant plus récents, il pourrait s'agir là d'une conséquence des changements majeurs qui s'opèrent lors du passage du Néolithique moyen II au Néolithique récent (pour plus de précision, voir Höltkemeier, 2016).

\section{BIBLIOGRAPHIE}

BALASSE M. 2003, « Keeping the young alive to stimulate milk production ? Differences between cattle and small stock », Anthropozoologica, vol. 37, p. 3-10.

BALASSE M., BOCHERENS H., TRESSET A., MARIOTTI A. et VIGNE J.-D. 1997, «Émergence de la production laitière au Nonlithium? Contribution de l'analyse isotopique d'ossements de bovins archéologiques ", Comptes rendus de l'Académie des Sciences, Séries IIA, Sciences de la terre et des planètes, vol. 325, p. 1005-1010.

BALASSE M., TRESSET A., BOCHERENS H., MARIOTTI A. et VIGNE J.-D. 2000, « Un abattage « post-lactation » sur des bovins domestiques néolithiques. Étude isotopique des restes osseux du site de Bercy (Paris, France) », Ibex, vol. 5/ Anthropozoologica, vol. 31, p. 39-48. 
BARONE R. 1976, Anatomie comparée des mammifères domestiques. Tome I. Ostéologie, Paris, Vigot Frères.

BARTHEL H.-J. 1983, « Tierknochen », dans W. GALL, A. BACH, H.-J. BARTEL et P. LANG (dir.), Neolithische Totenhütte bei Wandersleben, Alt-Thüringen, vol. 18, p. 18-27.

BARTHEL H.-J. 1985, « Die Tierreste aus einer “Grabenanlage“der neolithischen Bernburger Kultur », dans H.-J. BARTHEL et M. TEICHERT (dir.), Beiträge zur Archäozoologie 3, Weimar, Museum für Ur- und Frühgeschichte Thüringens, p. 59-101 (Weimarer Monographien zur Ur- und Frühgeschichte, 13).

BARTOSIEWICZ L., VAN NEER W. et LENTACKER A. 1997, Draught cattle : their osteological identification and history, Tervuren, Musée royal de l'Afrique centrale (Annales sciences zoologiques, 281).

BECKER C. 1999, « Neue Tierknochenanalysen zum Spätneolithikum des Mittelelbe-SaaleGebietes ", Bericht der Römisch-Germanischen Kommission, vol. 80, p. 91-121.

BEHRENS H. 1973, Die Jungsteinzeit im Mittelelbe-Saale-Gebiet, Berlin, Deutscher Verlag der Wissenschaften (Veröffentlichungen des Landesmuseums für Vorgeschichte in Halle, 27).

BEHRENSMEYER A. K. 1978, « Taphonomic and ecologic information from bone weathering », Paleobiology, vol. 4, p. 150-162.

BENECKE N. inédit, «Tabellen mit Daten zur Auswertung des Krautheimer Fundkomplexes, unpublizierte Daten », Berlin, DAI.

BENESCH F. 1941, Die Festung Hutberg : eine jungnordische Mischsiedlung bei Wallendorf, Kr. Merseburg, Halle a. d. Saale, Gebauer-Schwetschke (Veröffentlichungen der Landesanstalt für Volksheilkunde zu Halle, 12).

BERAN J. 1993, Untersuchungen zur Stellung der Salzmünder Kultur im Jungneolithikum des Saalegebietes, Wilkau-Haßlau, Beier \& Beran (Beiträge zur Ur- und Frühgeschichte Mitteleuropas, 2).

BINFORD L. R. 1981, Bones : Ancient men and modern myths, New York, London, Toronto, Academic press (Studies in archaeology).

BLAISE E., BRÉHARD S., CARRÈre I., FAVRIE T., GOURICHON L., HELMER D., RIVIÈRE J., TRESSET A. et VIGNE J.-D. 2010, « L'élevage du Néolithique moyen 2 au Néolithique final dans le Midi méditerranéen de la France : État des données archéozoologiques ", dans O. LEMERCIER, R. FURESTIER et E. BLAISE (dir.), IV millénaire. La transition du Néolithique moyen au Néolithique final dans le sud-est de la France et les régions voisines, Lattes, Association pour le développement de l'archéologie en LanguedocRoussillon, p. 261-284 (Monographies d'archéologie méditerranéenne, 27).

BOESSNECK J., JÉQUIER J.-P. et STAMPFLI H. R. 1963, Seeberg Bürgäschisee-Süd - Die Tierreste, Bern, Stampfli Verlag (Acta Bernensia, 2, 3).

BOESSNECK J., MÜLLER H.-H. et TEICHERT M. 1964, « Osteologische Unterscheidungsmerkmale zwischen Schaf (Ovis aries Linné) und Ziege (Capra hircus Linné) », Kühn-Archiv, vol. 78, p. 1-129.

BRIDAULT A., HORARD-HERBIN M.-P., PELLÉ E., FIQUET P., MASHKOUR M. et VIGNE J.-D. 2000, « Wild boarage at death estimates : the relevance of new modern data for archaeological skeletal material. 1. Presentation on the corpus. Dental and epiphyseal fusion ages », Anthropozoologica, vol. 31, p. 11-18.

BRÉHARD S., BEECHING A. et VIGNE J.-D. 2010, « Shepherds, cowherds and site function on middle Neolithic sites of the Rhône valley : An archaeozoological approach to the organization of territories and societies ", Journal of Anthropological Archaeology, vol. 29, p. 179-188. 
COSTAMAGNO S. 2012, «Des stries de boucherie aux sous-systèmes techniques de transformation et de consommation des ressources animales : apport de l'approche expérimentale », thèse d'habilitation à diriger des recherches, Bordeaux, Université de Bordeaux I - Sciences et Technologies.

DESCHLER-ERB S. et MARTI-GRÄDEL E. 2004, « Viehhaltung und Jagd. Ergebnisse der Untersuchungen der handaufgelesenen Tierknochen », dans S. JACOMET, U. LEUZINGER et J. SCHIBLER (dir.), Die jungsteinzeitliche Seeufersiedlung Arbon - Bleiche 3 : Umwelt und Wirtschaft, Frauenfeld, Kanton Thurgau, p. 158-252 (Archäologie im Thurgau, 12).

DODSON P. et WEXLAR D. 1979, « Taphonomic investigations of owl pellets », Paleobiology, vol. 5, 3, p. 275-284.

DÖHLE H.-J. 1997, « Zum Stand der Untersuchungen an neolithischen Tierknochen aus Mitteldeutschland », Jahresschrift für mitteldeutsche Vorgeschichte, vol. 79, p. 111-147.

DREIBRODT S., ZAHRER J., BORK H.-R. et BRAUER A. 2012, « Witterungs- und Umweltgeschichte während der norddeutschen Trichterbecherkultur - rekonstruiert auf Basis mikrofazieller Untersuchungen an jahresgeschichteten Seesedimenten ». dans M. HINZ et J. MÜLLER (dir.), Siedlung Grabenwerk Großsteingrab. Studien zu Gesellschaft, Wirtschaft und Umwelt der Trichterbechergruppen im nördlichen Mitteleuropa, Bonn, Habelt, p. 145-158 (Frühe Monumentalität und soziale Differenzierung, 2).

ELLENBERGER W., BAUM H. et DITTRICH H. 1956, An atlas of animal anatomy for artists, New York, Dover Publications.

ENDERLE K. 1977, « Die Tierknochen der neolithischen Siedlung der Trichterbecherkultur Runstedt bei Helmstedt », Neue Ausgrabungen und Forschungen in Niedersachsen, vol. 11, p. 161-165.

GENTRY A., CLUTTON-BROCK J. et GROVES C. P. 2004, « The naming of wild animal species and their domestic derivatives », Journal of Archaeological Science, vol. 31, p. 645-651.

GRIMM P. 1938, « Die Salzmünder Kultur in Mitteldeutschland », Jahresschrift für die Vorgeschichte der sächsisch-thüringischen Länder, vol. 29, p. 1-104.

GRONENBORN D. 2009, «Climate fluctuations and trajectories to complexity in the Neolithic: towards a theory », Documenta Praehistoria, vol. 36, p. 97-110.

GRONENBORN D. 2010, «Climate, crises, and the "neolithisation" of central Europe between IRDevents 6 and 4 ", dans D. GRONENBORN et J. PETRASCH (dir.), Die Neolithisierung Mitteleuropas. The spread of the Neolithic to central Europe, Mainz, Römisch-Germanisches Zentralmuseum, p. 61-80 (RGZM-Tagungen, 4).

GÜNTHER K. 1990, « Neolithische Bildzeichen an einem ehemaligen Megalithgrab bei Warburg, Kreis Höxter (Westfalen)», Germania, vol. 68, p. 39-65.

HELMER D. 1987, « Les Suidés du Cardial : sangliers ou cochons? », dans J. GUILAINE, J. COURTIN, J.-L. ROUDIL et J.-L. VERNET (dir.), Premières communautés paysannes en Méditerranée occidentale, Paris, CNRS, p. 215-220.

HELMER D. 1992, La domestication des animaux par les hommes préhistoriques, Paris, Masson.

HIGHAM C. F. W. 1969, « The economic basis of the Danish Funnel-Necked Beaker (TRB) culture », Acta Archaeologica, vol. 40, p. 200-209.

HILLSON S. 2005, Teeth, Cambridge, University Press. 
HÖLTKEMEIER S. 2016, « L'exploitation animale au IVe millénaire avant notre ère en Allemagne centrale : les sites de Wallendorf et Salzmünde dans leur contexte régional », thèse de doctorat, Paris, Université Paris 1 - Panthéon-Sorbonne, 2 vol.

JONES G. G. et SADLER P. 2012, « Age at death in cattle : methods, older cattle and known-age reference material », Environmental Archaeology, vol. 17, 1, p. 11-28.

KLASSEN L. 2004, Jade und Kupfer. Untersuchungen zum Neolithisierungsprozess im westlichen Ostseeraum unter besonderer Berücksichtigung der Kulturentwicklung Europas 5500-3500 BC, Aarhus, University Press (Jutland Archaeological Society Publications, 47).

LEMOINE X., ZEDER M. A., BISHOP K. J. et RUFOLO S. J. 2014, « A new system for computing dentitionbased age profiles in Sus scrofa », Journal of Archaeological Science, vol. 47, p. 179-193.

LICHARDUS J., LICHARDUS-ITTEN M. avec la collaboration de BAILLOUD G. et CAUVIN C. 1985, La Protohistoire de l'Europe : Le Néolithique et le Chalcolithique entre la Méditerranée et la mer Baltique, Paris, Presses universitaires de France (Nouvelle Clio, 1 bis).

LÜNING J. 1967, « Die Michelsberger Kultur. Ihre Funde in zeitlicher und räumlicher Gliederung », Bericht der Römisch-Germanischen Kommission, vol. 48, p. 1-350.

MATOLCSI J. 1970, « Historische Erforschung der Körpergröße des Rindes auf Grund von ungarischem Knochenmaterial », Zeitschrift für Tierzüchtung und Züchtungsbiologie, vol. 87, p. 89-137.

MIDGLEY M. S. 1992, TRB Culture. The First Farmers of the North European Plain, Edinburgh, University Press.

MÜLLER H.-H. 1964, « Vorläufiger Bericht über die Untersuchung des Knochenmaterials von Derenburg-Steinkuhlenberg, unpubliziertes Manuskript », Halle (Saale), LDA Sachsen-Anhalt. MÜLLER H.-H. 1978, « Tierreste aus einer Siedlung der Bernburger Gruppe bei Halle (Saale) », Jahresschrift für mitteldeutsche Vorgeschichte, vol. 62, p. 203-220.

MÜLLER H.-H. 1985, « Tierreste aus Siedlungsgruben der Bernburger Kultur von der Schalkenburg bei Quenstedt, Kr. Hettstedt », Jahresschrift für mitteldeutsche Vorgeschichte, vol. 68, p. 179-220.

MÜLLER H.-H. 1990, « Keilförmige Defekte an fossilen und subfossilen Tierzähnen und ihre Bedeutung für die archäologische Forschung », dans J. SCHIBLER, J. SEDLMEIER et H. SPYCHER (dir.), Festschrift für Hans R. Stampfli. Beiträge zur Archäozoologie, Archäologie, Anthropologie, Geologie und Paläontologie, Basel, Helbing \& Lichtenhahn, p. 147-152.

MÜLLER H.-H. 1998, « Haustierhaltung, Jagd und Fischfang », dans J. PREUSS (dir.), Das Neolithikum in Mitteleuropa. Kulturen-Wirtschaft- Umwelt vom 6. bis 3. Jahrtausend v.u.Z. : Übersichten zum Stand der Forschung, Band 1/1, Teil A : Das Neolithikum in Mitteleuropa, Weissbach, Beier \& Beran, p. 79-90 (Archäologische Fachliteratur).

MÜLLER J. 1999, « Radiokarbonchronologie-Keramiktechnologie-Osteologie-AnthropologieRaumanalysen. Beiträge zum Neolithikum und zur Frühbronzezeit im Mittelelbe-Saale-Gebiet », Bericht der Römisch-Germanischen Kommission, vol. 80, p. 25-211.

MÜLLER J. 2001, Soziochronologische Studien zum Jung- und Spätneolithikum im Mittelelbe-Saale-Gebiet (4100-2700 v. Chr.). Eine sozialhistorische Interpretation prähistorischer Quellen, Rahden, Marie Leidorf (Vorgeschichtliche Forschungen, 21).

PAYNE S. 1973, « Kill-off patterns in sheep and goats : the mandibles from Aşvan Kale », Anatolian Studies, vol. 23, p. 281-303. 
PAYNE S. 1985, « Morphological distinctions between the mandibular teeth of young sheep, Ovis, and goats, Capra », Journal of Archaeological Science, vol. 12, p. 139-147.

PAYNE S. et BULL G. 1988, «Components of variation in measurements of pig bones and teeth, and the use of measurements to distinguish wild from domestic pig remains ", Archaeozoologia, vol. 2, p. 27-66.

PÉTREQUin P., ARBOGAST R.-M., PÉTREQUIN A.-M., Van WILligEN S. et BAILly M. 2006, Premiers chariots, premiers araires : La diffusion de la traction animale en Europe pendant les $I^{e}$ et III millénaires avant notre ère, Paris, CNRS (CRA Monographies, 29).

POPLIN F. 1976, «À propos du nombre de restes et du nombre d'individus dans les échantillons d'ossements », Cahiers du Centre de Recherches Préhistoriques de l'Université Paris 1, vol. 5, p. 61-74. PRILLOFF R.-J. 1982, « Tierreste aus einer tiefstichkeramischen Siedlung von Haldensleben, Kr. Haldensleben », Jahresschrift für mitteldeutsche Vorgeschichte, vol. 65, p. 73-82.

PRUMMEL W. 1987, « Atlas for identification of foetal skeletal elements of cattle, horse, sheep and pig. Part 2 », Archaeozoologia, vol. 1, 2, p. 11-41.

SCHLENKER B. inédit, « Durchsicht Altmaterial Hutberg Wallendorf (Grabung Benesch) durch B. Schlenker 14-16. Mai 2014. Keramiktypologische Datierung der Befunde, unpubliziertes Manuskript », Halle (Saale), LDA Sachsen-Anhalt.

SCHLENKER B., WOLLENWEBER R., SCHROETER-BEHRENS J. et FRIEDERICH S. 2016, « Die Michelsberger Kultur-Westeinflüsse in der älteren Trichterbecherkultur Mitteldeutschlands », Archäologie in Sachsen-Anhalt, vol. 8, p. 11-18.

SCHMID E. 1972, Atlas of animal bones : For prehistorians, archaeologists and Quaternary geologists, Amsterdam, Elsevier.

SCHUNKE T. 1994, « Michelsberger Kultur (MK) », dans H.-J. BEIER et R. EINICKE (dir.), Das Neolithikum im Mittelelbe-Saale-Gebiet und in der Altmark. Eine Übersicht und ein Abriss zum Stand der Forschung, Wilkau-Haßlau, Beier \& Beran, p. 129-143 (Beiträge zur Ur- und Frühgeschichte Mitteleuropas, 4). SIMPSON G. G. et ROE A. 1939, Quantitative zoology : Numerical concepts and methods in the study of recent and fossil animals, New York, London, McGraw-Hill Book Company (McGraw-Hill publications in the zoological sciences).

SIGAUT F. 1980, « Un tableau des produits animaux et deux hypothèses qui en découlent », Production pastorale et société, vol. 7, p. 20-36.

SOULIER M.-C. et COSTAMAGNO S. 2017, « Let the cutmarks speak! Experimental butchery to reconstruct carcass processing ", Journal of Archaeological Science : Reports, vol. 11, p. 782-802.

STEPPAN K. 2001, « Ur oder Hausrind ? Die Variabilität der Wildtieranteile in linearbandkeramischen Tierknochenkomplexen », dans R.-M. ARBOGAST, C. JEUNESSE et J. SCHIBLER (dir.), Rôle et statut de la chasse dans le Néolithique ancien danubien (5500-4900 av. J.-C.), Rahden, Marie Leidorf, p. 171-186 (Internationale Archäologie, 1).

STEPPAN K. 2003, Taphonomie, Zoologie, Technologie, Ökonomie : die Säugetierreste aus den jungsteinzeitlichen Grabenwerken in Bruchsal, Landkreis Karlsruhe, Stuttgart, Theiss (Materialhefte zur Archäologie in Baden-Württemberg, 66).

STOLLE T., BENECKE N. et BERAN J. 1988, « Zwei Siedlungsgruben der altmärkischen Gruppe der Tiefstichkeramik mit zahlreichen Tierresten von Niedergörne, Kr. Stendal », Jahresschrift für mitteldeutsche Vorgeschichte, vol. 71, p. 37-55. 
TEICHERT M. 1975a, «Osteometrische Untersuchungen zur Berechnung der Widerristhöhe bei Schafen », dans CLASON A. T. (dir.), Archaeozoological studies, Amsterdam, Oxford, North Holland, Elsevier, p. 51-69.

TEICHERT M. 1975b, « Tierreste aus einer neolithischen Siedlungsgrube bei Gröna, Kreis Bernburg ", Jahresschrift für mitteldeutsche Vorgeschichte, vol. 59, p. 21-23.

TRESSET A. 1996, « Le rôle des relations homme/animal dans l'évolution économique et culturelle des sociétés des $\mathrm{V}^{\mathrm{e}}$ et $\mathrm{IV}^{\mathrm{e}}$ millénaires en Bassin parisien : approche ethno-zootechnique fondée sur les ossements animaux ", thèse de doctorat, Paris, Université Paris 1 - Panthéon-Sorbonne, 3 vol.

TRESSET A. 1997, « L'approvisionnement carné Cerny dans le contexte néolithique du Bassin Parisien », dans C. CONSTANTIN, D. MORDANT et D. SIMONIN (dir.), La culture de Cerny : Nouvelle économie, nouvelle société au Néolithique, Nemours, Association pour la promotion de la recherche archéologique en Île-de-France, p. 299-314 (Mémoires du Musée de Préhistoire d'Ile-de-France, 6).

UERPMANN H.-P. 1972, « Tierknochenfunde und Wirtschaftsarchäologie. Eine kritische Studie der Methoden der Osteo-Archäologie », Archäologische Informationen, vol. 1, p. 9-27.

VIGNE J.-D. 1991, « The meat and offal weight (MOW) method and the relative proportion of ovicaprines in some ancient meat diets of the north-western Mediterranean », Rivista di Studi Liguri, vol. 57, 2, p. 21-47.

VIGNE J.-D. 1998, « Faciès culturels et sous-systèmes techniques de l'acquisition des ressources animales. Application au Néolithique ancien méditerranéen », dans A. D’ANNA et D. BINDER (dir.), Production et identité culturelle : actualité de la recherche, Antibes, Association pour la promotion et la diffusion des connaissances archéologiques, p. 27-45.

VIGNE J.-D. et HELMER D. 2007, « Was milk a "secondary product" in the Old World Neolithisation process? Its role in the domestication of cattle, sheep and goats ", Anthropozoologica, vol. 42, 2, p. 9-40.

VON DEN DRIESCH A. 1976, A guide to the measurement of animal bones from archaeological sites, Cambridge, Harvard University (Peabody Museum Bulletin, 1).

ZEDER M. A. 2006, « Reconciling rates of long bone fusion and tooth eruption and wear in sheep (Ovis) and goat (Capra)», dans D. RUSCILLo (dir.), Recent advances in ageing and sexing animal bones, Oxford, Oxbow Books, p. 87-118.

\section{RÉSUMÉS}

Le $\mathrm{IV}^{\mathrm{e}}$ millénaire av. N. è. est marqué par le passage de l'Atlantique au Subboréal et constitue un tournant majeur du Néolithique européen avec des transformations techniques, économiques, sociales et idéologiques notables. L'analyse de la faune de l'enceinte fossoyée du Néolithique récent de Wallendorf "Hutberg», localisée en région Mittelelbe-Saale (Allemagne), fait apparaître des pratiques nouvelles dans ce contexte de changements. Sur ce site, le sous-système technique de l'exploitation des ressources animales est caractérisé par différentes activités. Le troupeau bovin fournit la majorité des produits du vivant et finaux grâce à l'exploitation laitière et bouchère. L'utilisation de la force motrice bovine est suggérée par l'observation d'anomalies sur les phalanges. Les caprinés semblent aussi être élevés en vue d'une exploitation mixte et les porcs le sont pour l'apport en viande. Les techniques d'élevage sont maîtrisées et adaptées à 
chaque espèce, pour atteindre un rendement optimal. Enfin, les activités cynégétiques ont un rôle d'apport ponctuel et complémentaire du cheptel domestique.

\section{AUTEUR}

\section{SVENJA HÖLTKEMEIER}

Université Paris 1 Panthéon-Sorbonne

UMR 8215 Trajectoires

Maison de l'Archéologie et de l'Ethnologie 


\title{
Animal, homme et pathogènes. Préhistoire d'une relation complexe
}

\author{
Olivier Dutour
}

\section{Introduction}

1 Les relations entre les hommes et les animaux sont aussi anciennes que les origines de l'humanité. Ces relations ont connu un développement parallèle à celui de l'espèce humaine, en suivant diverses modalités : charognage, chasse, domestication, élevage, compagnie, commensalité, lesquelles correspondent à différentes étapes de l'évolution biologique et culturelle de l'homme et de ses modes de vie.

2 Les maladies infectieuses ont évolué dans le cadre de cette interface homme/animal, dans la mesure où la majorité des pathogènes humains provient de pathogènes animaux ayant franchi la barrière d'espèce à un moment donné de l'évolution humaine. Certains pathogènes humains "ancestraux» ont été acquis au Paléolithique avant l'émergence du genre Homo, d'autres avant l'apparition de l'espèce sapiens, d'autres encore sont contemporains de la domestication au Néolithique ou du développement des premières grandes cités protohistoriques.

3 La compréhension globale des phénomènes actuels d'émergence de nouvelles maladies humaines d'origine animale passe donc par celle des phénomènes évolutifs dans le temps long, et notamment dans celui de la Préhistoire.

\section{L'Homme, l'Animal et les Pathogènes, une question d'actualité}

4 Des épidémies récentes (grippe aviaire, grippe H1N1, syndrome respiratoire aigu sévère, chikungunya, fièvre Zika) ont souligné l'importance de l'interface hommeanimal-écosystèmes dans l'évolution et l'émergence des pathogènes.

5 Les pathogènes sont des espèces vivantes de complexité biologique variable, allant de simples molécules comme les virus à des organismes multicellulaires complexes comme 
les parasites. Ces espèces ont en commun la capacité de créer une maladie chez d'autres organismes en les infectant. Cette capacité, nommée pathogénicité ou virulence dépend de 3 «pouvoirs ", dont l'expression varie selon les espèces : le pouvoir invasif, qui est la capacité de se répandre dans les différents tissus de l'organisme infecté, par diffusion de proximité ou à distance ; le pouvoir infectieux qui est la capacité à établir un foyer d'infection, c'est-à-dire la possibilité de se fixer dans un endroit de l'organisme et de s'y développer et enfin le pouvoir pathogène, qui est responsable de l'intensité de l'expression de la maladie, allant de troubles bénins et/ou passagers jusqu'à la mort rapide.

6 La pathogénicité n'est pas une règle dans le monde microbien, c'est au contraire un phénomène minoritaire: à titre d'exemple on peut remarquer que l'ensemble des pathogènes humains représente seulement moins de $1 \%$ de la biodiversité microbienne totale (Editorial Nature, 2011). À l'origine de cette transformation pathogène, Lewis Thomas a mis en avant des relations symbiotiques mal négociées, des dépassements accidentels de barrières biologiques ou des franchissements opportunistes de frontières d'espèces (Thomas, 1974).

7 La classification des pathogènes différencie les agents conventionnels et les agents non conventionnels, ces derniers étant de reconnaissance plus récente. En effet, ce n'est qu'en 1982 que l'on a découvert la possibilité pour de simples molécules, des protéines, d'acquérir par modification de leur structure, des propriétés de type infectieux, à savoir la propriété de se transmettre d'un organisme à un autre et de provoquer une maladie. Ces agents infectieux non conventionnels ont été nommés "prions », pour protéines infectieuses (Prusiner, 1982). Les agents pathogènes conventionnels sont connus depuis plus longtemps, progressivement identifiés depuis les premiers travaux de Pasteur dès 1862, qui ont ouvert une nouvelle ère, celle de la microbiologie clinique. Ces pathogènes sont actuellement classés en 5 groupes principaux (Taylor et al, 2001) : les virus (incluant les prions), les bactéries, les champignons (incluant les moisissures), les protozoaires et les helminthes (vers parasites plats ou ronds). Les ectoparasites représentent un autre groupe à part.

8 La complexité biologique de ces agents biologiques infectieux est variable. Les virus sont constitués d'une seule molécule d'acide nucléique (ADN ou ARN) infectant une cellule hôte par pénétration et réplication. Les bactéries sont des procaryotes (organismes unicellulaires dont le génome n'est pas inclus dans un noyau). Les pathogènes eucaryotes (formés de cellules dotées de noyaux contenant leur génome) sont soit des organismes à une seule cellule (des protozoaires - comme l'agent de l'amibiase ou du paludisme - et des levures comme l'agent des candidoses), soit des organismes pluricellulaires, lesquels appartiennent à des groupes divers: des moisissures (comme l'agent de l'aspergillose), des champignons (par exemple celui de l'histoplasmose), des vers parasites qu'ils soient ronds (par exemple l'ascaris) ou plats (comme le ténia). Les ectoparasites comme les arthropodes (par exemple les poux de tête et de corps, les puces ou les tiques) sont indirectement pathogènes par leur rôle de vecteur d'infection (transmission d'agents biologiques pathogènes viraux, bactériens ou protozoaires).

9 Pour l'espèce humaine, on reconnaît actuellement 1415 espèces de pathogènes appartenant à 472 genres différents : $38 \%$ sont des bactéries, $22 \%$ des champignons et moisissures, $20 \%$ des vers parasites, $15 \%$ des virus et $5 \%$ de ces espèces sont des protozoaires (Taylor et al, 2001). 
10 Le plus gros contingent de ces pathogènes humains est clairement d'origine animale : près de $60 \%$ des pathogènes humains sont d'origine zoonotique, parmi lesquels les vers parasites, les bactéries et les virus sont les taxons les plus représentés (Woolhouse et Gowtage-Sequeria 2005). Les espèces animales qui servent ainsi de "réservoirs" de pathogènes pour l'homme appartiennent à divers taxons, aussi bien sauvages que domestiques (Cleaveland et al, 2001). Parmi les plus gros réservoirs animaux de pathogènes pour l'Homme figurent les Ongulés et les Carnivores, suivis par les Rongeurs puis par les Oiseaux et les Reptiles, les Primates, les Mammifères marins et enfin les Chiroptères.

11 Le passage d'un pathogène d'un hôte habituel (animal) à un hôte accidentel (autre animal ou homme) définit le franchissement de la barrière d'espèce (Vabret, 2006), processus responsable des phénomènes d'émergence de nouvelles maladies infectieuses chez l'homme. Ces phénomènes d'émergence sont en croissance exponentielle depuis une cinquantaine d'années: le rythme d'apparition de nouvelles maladies infectieuses serait actuellement d'une tous les 8 mois (Collectif, 2011).

12 Le cadre binaire de la classique relation hôte-pathogène, faisant intervenir un pathogène et son hôte, est maintenant conceptuellement dépassé : un même pathogène peut avoir plusieurs hôtes, plusieurs pathogènes peuvent se partager le même hôte. La multiplicité des hôtes et des pathogènes rend la relation biologique entre espèces infectantes et espèces infectées particulièrement complexe. Cette relation est devenue actuellement une biologie intégrative, étudiant les interactions multihôtesmultipathogènes (Woolhouse et al. 2001). Ces interactions conduisent à des réponses adaptatives des hôtes et des pathogènes, décrites dans le cadre de la co-évolution des espèces (Erlich et Raven, 1964) sous le nom de la course aux armements (Dawkins et Krebs, 1979) ou à la stratégie de la Reine Rouge (Van Valen, 1973).

13 Différents facteurs sociaux et environnementaux sont responsables de l'émergence de maladies infectieuses chez l'homme (McMichael, 2004) : l'expansion démographique, la mondialisation, les migrations, les guerres et les conflits, les perturbations des écosystèmes naturels par anthropisation des milieux, les changements climatiques. À cette liste l'auteur ajoute plusieurs facettes de la relation homme-animal facilitant le saut d'espèce : domestication, intensification de l'élevage, réduction de la biodiversité, intensification du contact inter-espèces, développement des nouveaux animaux de compagnie...

14 L'interface homme-animal est clairement identifiée en santé publique comme une clé de compréhension des maladies infectieuses. Ainsi, le Centre de Contrôle et de Prévention des Maladies (CDC, Atlanta, USA) a ouvert en 2009 un bureau One Health, chargé de la diffusion du concept du même nom, qui reconnaît que la santé humaine est connectée à la santé animale et à l'environnement. Cette approche de la santé humaine, prenant en compte l'interface homme-animal avait été commencée en 2004 lors d'un colloque de la Wildlife Conservation Society (WCS) à Manhattan, relayée en 2007 par l'American Medical Association, recommandant le partenariat entre médecine humaine et vétérinaire.

En 2010, les trois organisations internationales concernées, l'Organisation Mondiale de la Santé (WHO), l'Organisation Mondiale de la Santé Animale (OIE) et l'Organisation des Nations Unies pour l'Agriculture et l'Alimentation (FAO) réunies à Hanoi, rédigent une note tripartite visant au partage des responsabilités et à la coordination des activités pour lutter contre les risques de santé aux interfaces homme-animal-écosystèmes 
(Gibbs, 2014). On y retrouve notamment les notions d'évolution des pathogènes (Collectif, 2010) :

« Pathogens - viruses, bacteria or parasites - have evolved and perfected their life cycles in an environment that is more and more favorable to them and ensures their continuity through time by replicating and moving from diseased host to a susceptible new host » et d'interface homme/animal «Pathogens circulating in animal populations can threaten both animal and human health, and thus both the animal and human heath sectors have a stake in, and responsibility for, their control.»

Ce concept « One Health » est l'objet d'un document de travail stratégique du Ministère des Affaires Étrangères et Européennes du Gouvernement Français établi en 2011 (Collectif, 2011) et intitulé «Position française sur le concept «One Health/Une seule santé »: pour une approche intégrée de la santé face à la mondialisation des risques sanitaires ». On peut y noter (p. 14) la nécessité réaffirmée "d'une approche globale et d'une coopération renforcée entre les sciences du vivant, humaine, animale et environnementale, ainsi qu'avec l'ensemble des sciences humaines ». On relève également que parmi les thématiques prioritaires de recherche figurent «la modélisation des profils spatio-temporels des processus infectieux et leurs déterminants écologiques, épidémiologiques et socioéconomiques ».

Dès lors, l'établissement d'un cadre chronologique des processus d'émergence des pathogènes humains dans l'interface homme-animal-environnement, prenant en compte les événements infectieux survenus depuis les origines de l'Homme, prend ici tout son sens.

\section{Préhistoire des pathogènes humains et de l'interface homme-animal-environnement}

18 La reconstruction des scénarios de l'origine des pathogènes humains pendant la Préhistoire repose sur une approche pluridisciplinaire associant la paléopathologie humaine et animale associée aux nouveaux outils de diagnostic rétrospectif et à la dimension historique des maladies (Baker et al, 2015 ; Coqueugniot et al, 2015 ; Dutour et al, 1998; Dutour et al, 2003; Dutour, 2011), associant également la paléomicrobiologie (Zink et al, 2002; Drancourt et Raoult, 2005; 2008), la paléogénomique (Wagner et $\mathrm{al}, 2014$; Rasmussen et al, 2015) et la phylogénèse microbienne (Wirth et al, 2005, 2008).

Les pathogènes humains peuvent se répartir en fonction de leur ancienneté en 4 catégories (Reperant et Osterhaus, 2013). Les pathogènes humains anciennement hérités ont été acquis il y a plusieurs millions d'années, avant - ou au moment de l'émergence du genre Homo. Le bacille tuberculeux (Gagneux, 2012), les virus du groupe Herpès (Van Blerkom, 2003), le paludisme (Ollomo et al, 2009) feraient partie de ce groupe le plus ancien. Les pathogènes humains d'héritage plus récent ont été acquis il y a plusieurs centaines de milliers d'années, précédant - ou contemporain de l'émergence de l'espèce sapiens et antérieur ou postérieur au second Out of Africa. Parmi ceux-ci figurent certains virus, notamment hépatitique (Van Blerkom, 2003), la bactérie Helicobacter pylori (Linz et al, 2007) ou des vers parasites comme le Ténia (Hoberg et al, 2001). Ces deux premières catégories sont des pathogènes humains stricts, à transmission interhumaine, de pathogénicité modérée, faisant partie d'un « héritage 
pathogénique " de l'espèce humaine. La phylogénie et la phylogéographie de ces pathogènes se calquent en effet sur la génétique évolutive de l'espèce humaine, signant la longue co-évolution des deux espèces (Wirth et al, 2005).

Les deux autres catégories sont d'une part les pathogènes d'origine animale d'acquisition plus récente par l'homme mais qui se sont adaptés à une transmission interhumaine (virus HIV, SARS ou virus grippal aviaire), d'autre part des zoonoses infectant l'homme mais non adaptées à une transmission inter-humaine, imposant des sauts d'espèces itératifs (maladie des griffes du chat, pasteurellose, maladie de Lyme, rage, trypanosomiase).

On peut proposer 5 différentes interfaces homme/animal déterminant l'acquisition de pathogènes humains par saut d'espèces au cours de l'évolution humaine: l'interface naturelle, l'interface ressource, l'interface prédateur augmenté, l'interface de production, l'interface diffusée.

\section{L'interface « naturelle » des premiers Hominines (7 à 4 millions d'années)}

22 Cette période correspond à l'émergence d'Hominines bipèdes, aux aptitudes arboricoles conservées, probablement plus omnivores (plantes, fruits, petits animaux) et moins agressifs que les grands singes actuels, correspondant à des genres nommés Ardipithecus, Sahelantropus, Orrorin. Le cadre environnemental est celui de savanes arborescentes, coupées d'étendues d'eau. L'interface est de type naturelle, ces espèces d'Hominines ancestraux partagent leur environnement avec les autres espèces animales, sans le modifier. Les pathogènes ancestraux datant de cette période sont différents pathogènes viraux (Herpès virus; Papillomavirus; Polyomavirus ; Parvovirus ; Adénovirus ; Rétrovirus) (Van Blerkom, 2003) et des protozoaires transmis par des insectes vecteurs: Plasmodium (Ollomo et al, 2009) et Trypanosomes (Stevens et Gibson, 1999), les grands bovidés africains pliocènes constituant un important réservoir pour ces derniers.

\section{L'interface « ressource » des premiers Hominidés (4-2 millions d'années)}

Ces Hominidés (Australopithecus, Paranthropus et peut-être Homo habilis) ont une bipédie plus exclusive, vivent dans des milieux plus ouverts, bénéficient d'un régime alimentaire plus flexible et utilisent des outils rudimentaires pour découper des carcasses, décarniser et extraire la moelle osseuse. Ces pratiques d'utilisation de produits animaux vont augmenter le risque de contamination par des zoonoses. Cette période est celle de l'infection par des Mycobactéries ancestrales qui aboutiront à la tuberculose humaine (Gagneux, 2012) et l'émergence des poux humains dont les ancêtres sont des ectoparasites d'oiseaux et de mammifères (Weiss, 2009) qui ont changé d'hôte, quittant la dépouille de la proie ou de la charogne fraîche pour parasiter le prédateur ou le charognard opportuniste la découpant. 


\section{L'interface " prédateur augmenté » du genre Homo (2,5 millions d'années - 12000 ans)} période paléolithique, la première vers 1,8 millio 70000 ans. Pour la première, il est possible que la réduction de la charge parasitaire exerçant une pression démographique continue dans les climats tropicaux (paludisme, trypanosomiases) en raison de l'absence de vecteurs correspondants dans les climats tempérés à froid, aie contribué à l'expansion territoriale et démographique des Homo erectus en Europe, qui ont pu également rencontrer de nouveaux pathogènes des faunes européennes pléistocènes. Pour la seconde migration ayant amené les populations d'hommes modernes en Europe vers 50 - 40000 ans, certains auteurs font l'hypothèse que les pathogènes africains de ces derniers aient pu contribuer à hâter la disparition des Néandertaliens, immunitairement naïs face à des pathogènes africains (Wolff et Greenwood, 2010 ; Houldcroft et Underdown, 2016).

\section{L'interface de production de l'Homo sapiens au Néolithique (12 à 5000 ans)}

$\mathrm{Au}$ tournant de l'Holocène, lors de la déglaciation libérant plus de terres habitables, Homo sapiens reste la seule espèce d'Hominidés. Dès 12000 ans dans le Croissant Fertile, il transforme progressivement son mode de vie: construction d'habitats, premiers essais de cultures puis premières tentatives de domestication animale, commençant par l'Aurochs. Cette période va considérablement modifier l'interface paléolithique homme-animal-environnement (Diamond, 2002). Les contacts étroits et répétés avec les 
espèces animales domestiquées et l'expansion démographique permettent l'émergence massive de pathogènes dépendant de la démographie comme ceux de la variole, de la diphtérie, de la coqueluche, des oreillons (Wolfe et al, 2007), maladies humaines qui sont à l'origine toutes des zoonoses, sans qu'il soit encore possible de préciser les espèces nouvellement domestiquées ou commensales responsables de ces sauts d'espèce. La variole humaine pourrait provenir d'un virus de petits rongeurs commensaux (Van Blerkom, 2003).

À cette période néolithique, les échanges de pathogènes dans l'interface homme-animal fonctionnent dans les deux sens: ainsi le Ténia des bovidés domestiques est probablement d'origine humaine, et contracté au Néolithique : il descend de celui ayant contaminé les Homo erectus africains 1,7 millions d'années auparavant à partir de la viande des bovidés sauvages qu'ils chassaient (Hoberg et al, 2001). De même la tuberculose bovine viendrait de la tuberculose ancestrale contractée par les Hominidés 3 millions d'années plus tôt (Comas et Gagneux, 2009) à partir d'un réservoir animal non précisé. Ce fait est soutenu par l'existence vers 11000 ans dans le Croissant Fertile d'une infection tuberculeuse humaine précédant la domestication des bovidés (Baker et al, 2015).

\section{L'interface diffusée de la protohistoire à nos jours}

29 La poursuite de l'accroissement démographique va conduire au développement des agglomérations, constituant dans la protohistoire de véritables villes de plusieurs milliers d'habitants, conservant le caractère « villageois » de l'interface homme-animal défini par le contact étroit avec les espèces animales domestiques et commensales, ici à une échelle démographique bien supérieure. Ces concentrations de peuplement permettent le développement et le maintien de certains pathogènes à affinité démographique (rougeole, variole, peste, typhus, typhoïde), nécessitant en fonction de leur pouvoir immunogène, comme pour la rougeole, très immunisante, des communautés de plus de 200000 individus pour se maintenir (Bartlett, 1957). La protohistoire voit également se développer, parallèlement à ces expansions démographiques, les échanges commerciaux et les conflits armés, facteurs qui, associés aux concentrations de populations, font le lit des grandes épidémies. Un travail récent de paléogénomique (Rassmussen et al, 2015) fait remonter l'émergence du bacille de la peste à la période protohistorique en Europe, vers 6000 ans BP, date à partir de laquelle les adaptations nécessaires au franchissement de la barrière d'espèces entre rongeurs commensaux et populations humaines ont commencé à se mettre en place. Ce bacille émergent Yersinia pestis ne deviendra que 3000 ans plus tard, en acquérant sur ce laps de temps quelques mutations génétiques supplémentaires, lui donnant sa virulence et sa double transmission par les puces (forme bubonique) et par les hommes (forme pulmonaire), l'un des pathogènes les plus meurtriers de l'histoire de l'humanité.

30 L'interface homme-animal-environnement a évolué avec l'homme depuis ses origines les plus lointaines, chaque période de l'évolution humaine modifiant les équilibres de cette interface a apporté à l'homme son lot de nouveaux pathogènes, principalement en provenance du monde animal. La période actuelle se caractérise par une 
accélération considérable des phénomènes d'émergence. Seule une approche pluridisciplinaire et intégrative permettra de mieux comprendre les mécanismes et d'évaluer les enjeux, à la lumière de l'évolution. Dans ce cas, comme dans bien d'autres, la connaissance du passé éclaire le présent et permet d'anticiper l'avenir, dans le but de mieux contrôler l'apparition de nouveaux pathogènes.

\section{BIBLIOGRAPHIE}

BAKER O., LEE O. Y-C, WU H. H-T., BESRA G.S., MINNIKIN D.E., LLEWELLYN G., WILLIAMS C.M., MAIXNER F., O' SULLIVAN N., ZINK A., CHAMEl B., KHAWAM R., COQUEUGNIOT E., HELMER D., LE MORT F., GOURICHON L., DUTAILly B., PÁlFi G., COQUEUGNIOT H. et DUTOUR O. 2015, « Human tuberculosis predates domestication in ancient Syria. » Tuberculosis, vol 95, p. S4-S12.

BARTLETT MJ. 1957, « Measles periodicity and community size. », Journal of Royal Statistical Society A, vol 120 , p. $48-70$.

CLEAVELAND S., LAURENSON M.K. et TAYLOR LH. 2001, « Diseases of humans and their domestic mammals: pathogens characteristics, host range and the risk of emergence. » Phil Trans R Soc Lond B, vol 356, p 991-999.

COLLECTIF. 2010, « FAO-OIE-WHO Tripartite Concept Note. »

COLLECTIF. 2011, «Position française sur le concept « One Health/Une seule santé ». Document de travail stratégique. Ministère des Affaires Étrangères et Européennes. » http://

www.diplomatie.gouv.fr/fr/photos-videos-publications-infographies/publications/enjeuxplanetaires-cooperation-internationale/documents-de-strategie-sectorielle/article/positionfrancaise-sur-le-concept

COMAS I. et GAGNEUX S. 2009, « The past and future of tuberculosis research. » PLoS Pathogen 5, e1000600.

COQUEUGNIOT H., DUTAILly B., DESBARATS P., BOULESTIN B., PAP I., SZIKOSSY I., BAKER O., MONTAUDON M., PANUEL M., KARLINGER K., KOVÁCS B., KRISTÓF L.A., PÁLFI G. et DUTOUR O. 2015, « Three-dimensional imaging of past skeletal TB: from lesion to process. » Tuberculosis, vol 95, p. S73-S79.

DAWKINS R. et KREBS J.-R. 1979, « Arms races between and within species. » Proceedings of the Royal Society of London B, vol 205, p. 489-511.

DIAMOND J. 2002, « Evolution, consequences and future of plant and animal domestication. » Nature, vol 418, p. $700-707$.

DRANCOURT M. et RAOULT D. 2005, « Palaeomicrobiology: current issues and perspectives. », Review Microbiology, vol 3, p. 23-35.

DRANCOURT M. et RAOULT D. 2008, « Molecular Detection of Past Pathogens. » dans RAOUlT D, DRANCOURT M. (dir.) Paleomicrobiology : Past Human Infections. Springer, Berlin - Heidelberg, pp $55-68$.

DUTOUR O. 2011, « La paléopathologie. », Collection Préhistoire en Questions, éditions CTHS, Paris. 
DUTOUR O., ARDAGNA Y., MACZEL M. et SIGNOLI M. 2003, « Epidemiology of infectious diseases in the past. Yersin, Koch and the skeletons » dans GREENBLATT C, SPIEGELMAN M. (dir.) Emerging Pathogens, Archaeology, Ecology \& Evolution of infectious disease. Oxford University Press, Oxford, pp 151-166 DUTOUR O., SIGNOLI M. et PÁLFI G. 1998, « How can we reconstruct the epidemiology of infectious diseases in the past? » dans GREENBLATT C. (dir.) Digging for Pathogens: Ancient Emerging Diseases Their Evolutionary, Anthropological and Archaeological Context. Balaban, Rehovot, Israel, p. 241-263. EDITOR NATURE. 2011, « Editorial: Microbiology by numbers. » Nature Review Microbiology vol 9 , p. 628-628.

EHRLICH PR. et RAVEN PH. 1964, « Butterflies and plants: a study in coevolution. » Evolution, vol 18, p. 586-608.

GAGNEUX S., 2012, « Host-pathogen coevolution in human tuberculosis. », Philos Trans R Soc Lond B Biol Sci, vol 367, p. $850-859$.

GIBBS E.P.J., 2014, « The evolution of One Health: a decade of progress and challenges for the future. » Veterinary Record, vol 174 (4), p. 85-91.

HOBERG EP, ALKIRE NL, DE QUEIROZ A. et JONES A. 2001, Out of Africa: origins of the Taenia tapeworms in humans. Proc Biol Sci, vol 268, p. $781-787$.

HOULDCROFT CJ. et UNDERDOWN SJ. 2016, « Neanderthal genomics suggests a pleistocene time frame for the first epidemiologic transition. ", American Journal of Physical Anthropology, vol 160, 3, p. 379 -388 .

LINZ B, BALLOUX F, MOODLEY Y, MANICA A, LIU H, ROUMAGNAC P, FALUSH D, STAMER C, PRUGNOLLE F, VAN DER MERWE SW, YAMAOKA Y, GRAHAM DY, PEREZ-TRALLERO E, WADSTROM T, SUERBAUM S et ACHTMAN M. 2007, "An African origin for the intimate association between humans and Helicobacter pylori. ", Nature, vol 445, p 915 - 918.

OLLOMO B, DURAND P, PRUGNOLLE F, DOUZERY E, ARNATHAU C, NKOGHE D, LEROY E et RENAUD F. 2009, « A new malaria agent in African Hominids. ", PLoS Pathogen 5, e1000446.

PRUSINER SB. 1982, « Novel proteinaceous infectious particles cause scrapie. » Science ; vol 216 (4542), p. 136-44.

RASMUSSEN S, ALLENTOFT ME, NIELSEN K, ORLANDO L, SIKORA M, SJÖGREN KG, PEDERSEN AG, SCHUBERT M, VAN DAM A, KAPEL CM, NIELSEN HB, BRUNAK S, AVETISYAN P, EPIMAKHOV A, KHALYAPIN MV GNUNI A, KRIISKA A, LASAK I, METSPALU M, MOISEYEV V, GROMOV A, POKUTTA D, SAAG L, VARUL L, YEPISKOPOSYAN L, SICHERITZ-PONTÉN T, FOLEY RA, LAHR MM, NIELSEN R, KRISTIANSEN K et WILLERSLEV E. 2015, « Early divergent strains of Yersinia pestis in Eurasia 5,000 years ago. » Cell.; vol 163 (3), p. 571-582. STEVENS JR et GIBSON W., 1999, « The molecular evolution of trypanosomes. » Parasitologyl Today, vol 15 , p. $432-437$.

TAYLOR LH, LATHAM SM et WOOLHOUSE ME. 2001, « Risk factors for human disease emergence. », Philos Trans R Soc Lond B Biol Sci, vol 356, p. 983-989.

THOMAS L., 1974, « The Lives of a Cell: Notes of a Biology Watcher », New York, Viking Press. VABRET A., 2006, «Émergence et franchissement de barrières d'espèces : effet papillon? » Virologie, vol 10, p. 329-32.

VAN BLERKOM LM., 2003, « Role of viruses in human evolution. » Am J Phys Anthropol vol 122 (Suppl $37)$, p. $14-46$. 
VAN VALEN L., 1973, «A new evolutionary law », Evolutionary Theory, vol 1, p. 1-30.

WAGNER DM, KLUNK J, HARBECK M, DEVAULT A, WAGLECHNER N, SAHL JW, ENK J, BIRDSELL DN, KUCH M, LUMIBAO C, POINAR D, PEARSON T, FOURMENT M, GOLDING B, RIEHM JM, EARN DJD, DEWITTE S, ROUILLARD JM, GRUPE G, WIECHMANN I, BLISKA JB, KEIM PS, SCHOLZ HC, HOLMES EC et POINAR H 2014, « Yersinia pestis and the Plague of Justinian 541 - 543 AD: a genomic analysis. » Lancet Infectious Diseases, vol 14, p. 319-326.

WEISS RA., 2009, « Apes, lice and prehistory. » J Biol vol 8, p. 20.

WIRTH T, HILDEBRAND F, ALLIX-BÉGUEC C, WÖLBELING F, KUBICA T, KREMER K, VAN SOOLINGEN D, RÜSCHGERDES S, LOCHT C, BRISSE S, MEYER A, SUPPLY P et NIEMANN S 2008, « Origin, Spread and Demography of the Mycobacterium tuberculosis Complex. » PLoS Pathogen 4, e1000160.

WIRTH T, MEYER A. et ACHTMAN M., 2005, « Deciphering host migrations and origins by means of their microbes. » Molecular Ecology, vol 14, 11, p. 3289-3306.

WOLFE ND, DUNAVAN CP et DIAMOND J. 2007, « Origins of major human infectious diseases. » Nature, vol 447, p. $279-283$.

WOLFF H et GREENWOOD AD., 2010, « Did viral disease of humans wipe out the Neandertals? » Medical Hypotheses, vol 75 (1), p. 99-105.

WOOLHOUSE MEJ. et GOWTAGE-SEQUERIA S. 2005, « Host Range and Emerging and Reemerging Pathogens. » Emerging Infectious Diseases vol 11, p. 1842-1847.

WOolhouse MEJ, TAYLOR LH, HAYdon DT. 2001, « Population Biology of Multihost Pathogens. » Science, vol 292, p. 1109-1112.

ZINK AR, REISCHL U, WOLF H et NERLICH AG 2002, « Molecular analysis of ancient microbial infections. » FEMS Microbiology Letter vol 213, p. 141-147.

\section{RÉSUMÉS}

Plus de la moitié des pathogènes humains sont d'origine animale. La transmission d'agents infectieux (bactéries, virus, champignons, parasites) de l'animal à l'homme (anthropozoonoses) s'est faite depuis les périodes préhistoriques, pendant lesquelles les relations homme-animal ont connu différentes modalités, allant de la prédation à la domestication. Différents facteurs environnementaux, culturels et sociaux ont pu intervenir dans ce "saut d'espèce ", mécanisme ancien mais de plus en plus d'actualité dans les infections émergentes. Les considérables avancées méthodologiques et techniques réalisées par la biologie moléculaire dans les vingt dernières années ont révolutionné certains concepts en microbiologie, tant pour l'époque actuelle que pour le passé, permettant de retracer l'histoire évolutive de certains pathogènes dans l'interface animal - homme et dans le temps long.

\section{AUTEUR}

\section{OLIVIER DUTOUR}

Paléopathogiste - Bioanthropologue

Directeur d'Études EPHE, Université PSL

Chaire d'anthropologie biologique Paul Broca 
PACEA-UMR 5199, CNRS-Université de Bordeaux

Président de la Section de Pré-Protohistoire du CTHS 


\title{
Loups, chiens et sociétés du Paléolithique supérieur
}

\author{
Myriam Boudadi-Maligne, Jean-Baptiste Mallye, Jean-Christophe Castel, \\ Jean-Georges Ferrié, Laurent Crépin, Delphine Kuntz, Carole Vercoutère, \\ Marie-Cécile Soulier et Sandrine Costamagno
}

Nous tenons à remercier Roland Nespoulet, Laurent Chiotti, Michel Barbaza, Patrick Paillet, l'équipe du Musée National de Préhistoire pour l'accès à certaines séries archéologiques mentionnées dans le texte et pour les informations contextuelles capitales qu'ils nous ont communiquées. Ces recherches ont été en partie financées par l'ANR Magdatis (J.-M. Pétillon et V. Laroulandie, dir.), le PCR « Peuplements entre Dronne et Tardoire » (P. Paillet, dir.) et le Labex LaScArBx ANR-10-LABX-52 dans le cadre du projet TeHoTeCa (J.-B. Mallye et M. BoudadiMaligne, dir.). Enfin, nous remercions Lionel Gourichon pour l'organisation de la session " Entre chien et loup » et pour avoir accepté notre communication.

1 Du fait de son caractère innovant, la domestication du loup fait l'objet de très nombreux travaux. La question de l'apparition de chiens au sein de groupes humains du Paléolithique reste extrêmement débattue, en raison notamment du désaccord qui persiste concernant l'attribution taxinomique de certains restes de Canidés. C'est notamment le cas pour ceux de Goyet (Belgique, Germonpré et al., 2009), Predmostí (république Tchèque, Germonpré et al., 2009), Kostenki, Elisseevichi ou Razboinychia cave (Russie, Sablin et Khlopachev, 2002 ; Ovodov et al., 2011 ; Germonpré et al., 2012). Considérés par ces derniers auteurs comme se rapportant au chien (Canis familiaris) ils sont pour d'autres chercheurs, tout à fait comparables, d'un point de vue métrique et morphologique, à la forme sauvage : le loup (Canis lupus) (Boudadi-Maligne et Escarguel, 2014 ; Drake et al., 2015). Sur la base de considérations plus générales, leur attribution taxinomique est aussi jugée discutable (Morey, 2014).

2 Ainsi, selon que l'on considère ou non les Canidés issus de ces sites, comme se rapportant à la forme sauvage ou à la forme domestique, la domestication est considérée comme une innovation relevant du fait soit des Hommes du début du Paléolithique supérieur européen (i.e. Aurignaciens/Gravettiens), soit des populations du Tardiglaciaire. Cette divergence constitue le point de départ de notre travail car s'il est difficile de s'accorder sur des critères biométriques, le contexte dans lequel sont 
découverts les restes de grands Canidés peut apporter de nouveaux arguments pour discuter d'un rapprochement entre les Hommes et les grands Canidés. Ainsi, la découverte d'individus en contexte sépulcral (Ain Mallaha; Davis et Valla, 1978), l'identification de traces de consommation des ossements (e.g. Morey et Klippel, 1991), et/ou la présence conjointe de coprolithes et/ou de restes digérés sont des éléments contextuels pouvant signer la présence de Canidés au contact plus étroit des groupes humains.

\section{Méthode et corpus d'étude}

Pour interroger l'évolution de cette relation Hommes-Canidés et pour tenter d'aller audelà du débat basé quasi exclusivement sur des critères morphométriques sur lesquels aucun consensus n'est pour le moment retenu, nous avons choisi de croiser différents types de données.

4 Nous avons concentré notre travail sur les niveaux du Paléolithique supérieur du grand Sud-Ouest de la France bénéficiant d'une attribution chrono-culturelle précise. Les restes se rapportant à de grands Canidés étant omniprésents dans les gisements et niveaux archéologiques de cet espace géographique (plus de 200 occurrences répertoriées pour le Paléolithique supérieur), cette première approche, qui ne vise pas à l'exhaustivité, s'est attachée à l'étude de plusieurs gisements clés couvrants différents techno-complexes afin d'illustrer au mieux les différents cas de figure qui peuvent être rencontrés dans le domaine fossile. Dans cet objectif, nous avons compilé les données concernant les ensembles pour lesquels nous disposions à la fois de suffisamment d'éléments pour discuter de l'attribution taxinomique des restes de grands Canidés et de données taphonomiques et archéozoologiques précises.

5 Pour les 24 ensembles archéologiques considérés (tabl. 1), les données bibliographiques ont été compilées et 10 séries ont été réévaluées pour discuter de la question de l'émergence et de la diffusion du processus de domestication (fig. 1). 
Tableau 1 : Niveaux archéologiques des sites du grand Sud-Ouest de la France renfermant des restes de grands Canidés attribués au genre Canis et utilisés pour ce travail.

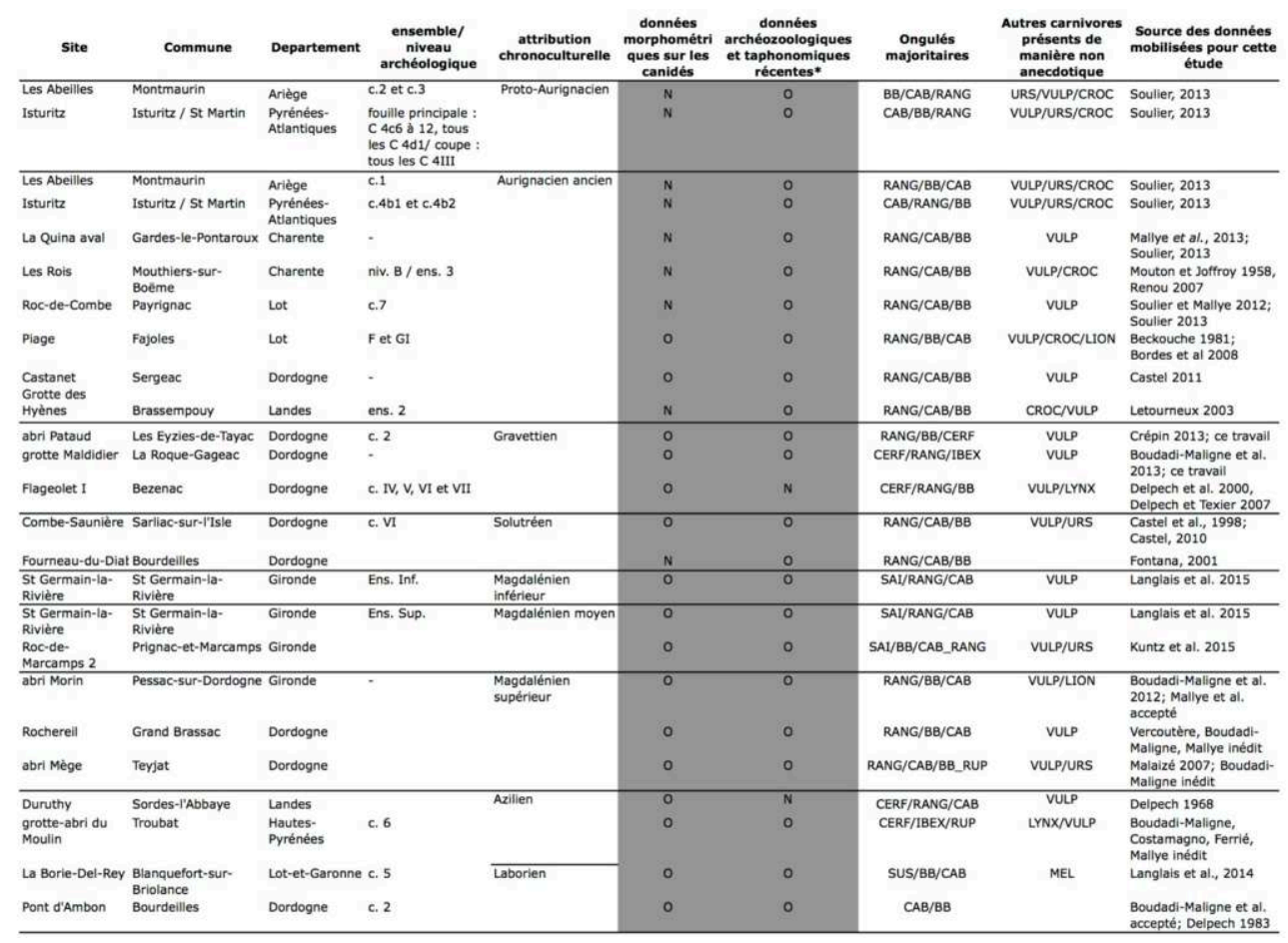

Pour les colonnes 6 et $7 \mathrm{~N}$ : non ; 0 : oui. * Sont qualifiées de récentes, les données issues des réévaluations menées ces 15 dernières années permettant de s'assurer de l'intégrité des niveaux considérés et de bénéficier de décompte faunique mis à jour. Les abréviations taxinomiques utilisées sont les suivantes : BB : Bos/Bison; CAB : Equus caballus; RANG : Rangifer tarandus ; CERF : Cervus elaphus ; RUP : genre Rupicapra ; IBEX : genre Capra ; SAI : Saiga tatarica ; SUS : Sus scrofa ; URS: Ursidés; VULP : Vulpinés (genre Vulpes) ; CROC : Crocuta crocuta spelaea ; Lion : Panthera leo ; LYNX: Lynx lynx; MEL : Meles meles. 
Figure 1 : Gisements cités dans le texte.

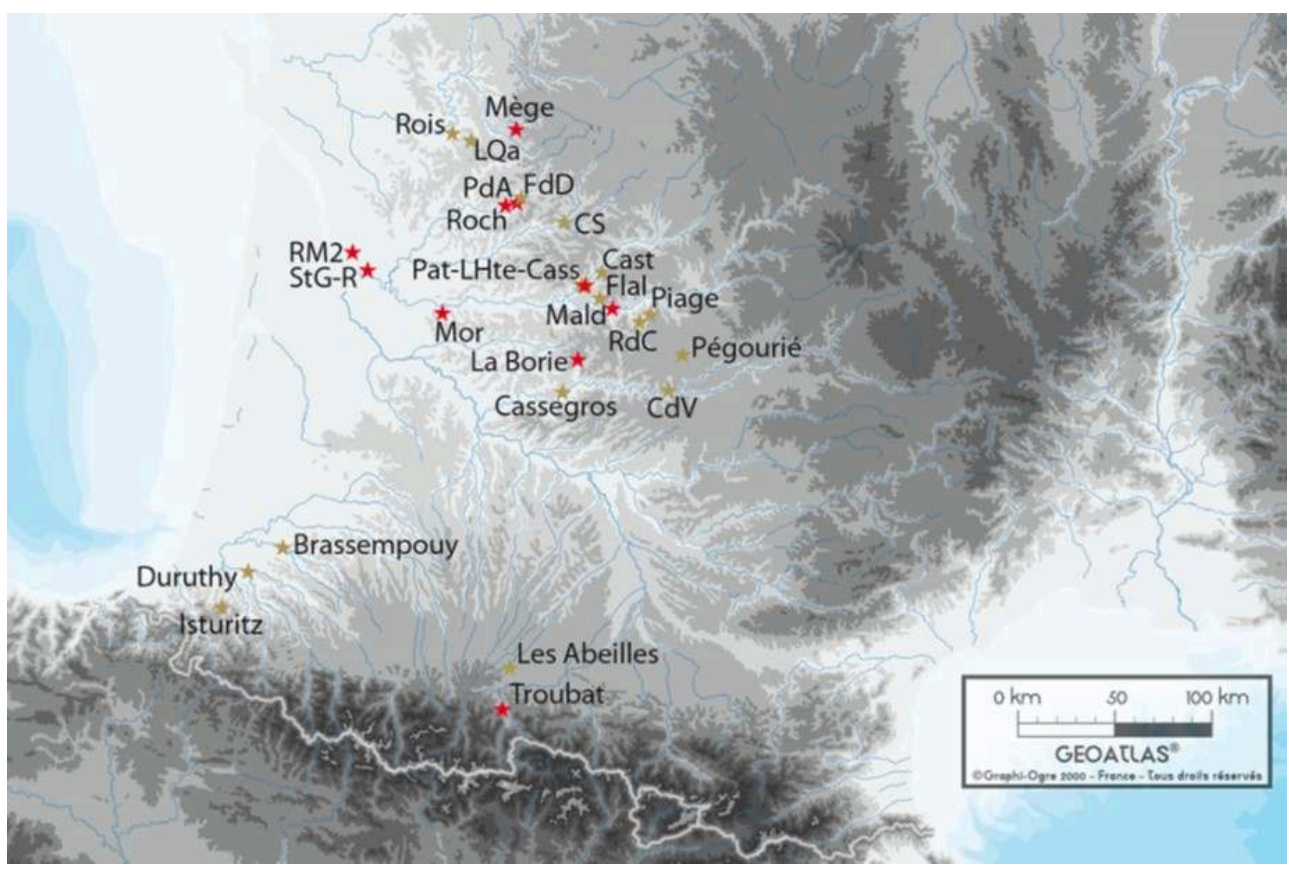

En rouge sont figurés les sites faisant l'objet d'une réévaluation ou en cours d'étude. Les abréviations utilisées sont les suivantes : RM2 : Roc-de-Marcamps 2 ; StG-R : Saint-Germain-la-Rivière ; Mor : abri du Morin ; PdA : Pont d'Ambon ; Roch : Rochereil ; LQa : La Quina aval ; FdD : Fourneau du Diable ; CS : Combe Saunière ; La Borie : La Borie-del-Rey ; Pat : Pataud ; LHte : Laugerie-Haute ; Cass : Casserole ; Flal : Le Flageolet I; Mald : Maldidier; Cast : Castanet; RdC : Roc-de-Combe ; CdV : Cuzoul de Vers.

$6 \quad$ Les dimensions collectées sur les restes de grands Canidés ont été comparées (via des analyses bivariées ou des tests statistiques en fonction des données disponibles) à des référentiels loups fossiles et actuels et chiens fossiles (Boudadi-Maligne et Escarguel, 2014) en vue de leur détermination taxinomique. Les résultats de ces analyses ont été confrontés aux données issues de l'archéozoologie afin de discuter des espèces associées aux restes de Canidés et de déterminer si elles portent des traces de consommation par les carnivores. Le cas échéant, notre approche vise à déterminer si ces traces sont compatibles avec celles qui sont décrites sur les restes consommés par les grands Canidés (i.e. chiens ou loups ; e.g. Haynes, 1983 ; Stiner, 2004).

7 Nous avons également choisi d'intégrer à notre réflexion les informations d'ordre taphonomique en procédant à une recherche systématique des restes digérés et/ou des coprolithes dans les niveaux analysés. Une fois exclus, sur des critères de taille, de forme et d'intensité de la digestion, ceux résultant de l'activité d'autres grands carnivores telle que l'hyène des cavernes, ou de petits carnivores tel que le renard, ces éléments constituent une piste d'interprétation de l'occupation du gisement. Nous partons en effet du principe que si des grands Canidés ont vécu durablement au contact de groupes humains, il est fort probable que les reliefs de leurs repas soient mêlés aux déchets culinaires et techniques générés par l'activité humaine. De la même manière, la présence de dents déciduales de chutes appartenant à un grand Canidé, indicateurs d'une fréquentation durable du site, est également systématiquement renseignée pour notre étude.

8 L'identification en fort pourcentage de restes digérés, de coprolithes et/ou de dents lactéales de grands Canidés, sans que nous puissions toutefois différencier le loup du 
chien, constitue de fait un bon indice d'un rapprochement entre les Hommes et les représentants du genre Canis.

\section{Résultats}

\section{L'Aurignacien}

Dans les niveaux attribués au Proto-Aurignacien, les restes de Canidés sont relativement rares et fragmentaires. À Isturitz (C $4 \mathrm{c} 6$ à 12 , tous les $\mathrm{C} 4 \mathrm{~d} 1$ et tous les $\mathrm{C}$ 4III) et aux Abeilles (c.2 et c.3), parmi les quelques vestiges attribués au genre Canis (respectivement 4 et 5 restes), un seul porte les traces d'une action anthropique. Il s'agit en l'occurrence de traces de dépouillement observées sur la couronne d'une canine de loup provenant des Abeilles (Soulier, 2013). L'intervention de carnivores est documentée dans ces deux ensembles par des traces de manducation, la présence de restes digérés, de coprolithes et de dents déciduales de hyénons. Ces vestiges sont à mettre en lien avec une fréquentation de la cavité par l'hyène des cavernes (Soulier, 2013) et ne préfigurent donc pas d'une présence de Canidés vivants au contact des Hommes.

Pour l'Aurignacien ancien, les séries de la Quina aval (Mallye et al., 2013), des Rois (niv. B/ens. 3 : Renou, 2007), du Roc de Combe (couche 7 : Soulier et Mallye, 2012), du Piage (couches F et GI : Beckouche, 1981), du Castanet (Castel, 2011), de la grotte des Hyènes (ensemble 2 : Letourneux, 2003), des Abeilles (c. 1 : Soulier, 2013) ou d'Isturitz (c.4b1 et c. 4b2 : Soulier, 2013), livrent peu de restes attribuables au genre Canis. Bien que souvent fragmentés, ils se rapportent à des individus de fort gabarit (i.e. dont les dimensions sont supérieures ou égales à celles obtenues sur les restes de loups sauvages actuels, voir Boudadi-Maligne, 2010) et sont donc tous rapprochés du loup. Ces restes présentent fréquemment des traces d'origine anthropiques et/ou proviennent de niveaux très anthropisés comme au Castanet où une partie du matériel provient d'un foyer (Castel, 2011 et inédit). Dans ces niveaux, exception faite d'Isturitz où le cheval est dominant, le taxon principalement exploité par l'Homme est le renne (tabl. 1). La présence de restes digérés ou manduqués est anecdotique. Notons toutefois, le caractère encore une fois particulier d'Isturitz où la présence de carnivores est attestée par l'identification des dents déciduales de hyénons, de coprolithes et d'os digérés/ manduqués imputables à l'activité de l'hyène des cavernes. Leur fréquence reste cependant relativement faible ( 1 dent déciduale de hyénon et 2,8 \% du matériel osseux portant des traces de carnivores) et semble, dans le cas d'Isturitz, relever de processus post-dépositionnel (Soulier, 2013)

\section{Le Gravettien}

11 À la grotte Maldidier (Boudadi-Maligne et al., 2012) et à l'abri Pataud (Crépin, 2013) ainsi que le cas du Flageolet I (Delpech et al., 2000), les restes se rapportant aux Canidés sont le plus souvent sub-complets.

12 Les données morphométriques concernant ces individus ne laissent aucun doute quant à leur attribution spécifique. Le fort gabarit de ces derniers, marqué notamment par des carnassières dont le diamètre mésio-distal dépasse les $29 \mathrm{~mm}$ (fig. 2) ainsi que par 
la robustesse des ossements, indique qu'il s'agit de loups entrant dans la variabilité de la sous-espèce $C$. lupus maximus (Boudadi-Maligne, 2012a).

Figure 2 : Diamètre mésio-distal (abscisses en $\mathrm{mm}$ ) en fonction du diamètre vestibulo-lingual (ordonnées en $\mathrm{mm}$ ) des carnassières inférieures de loup.

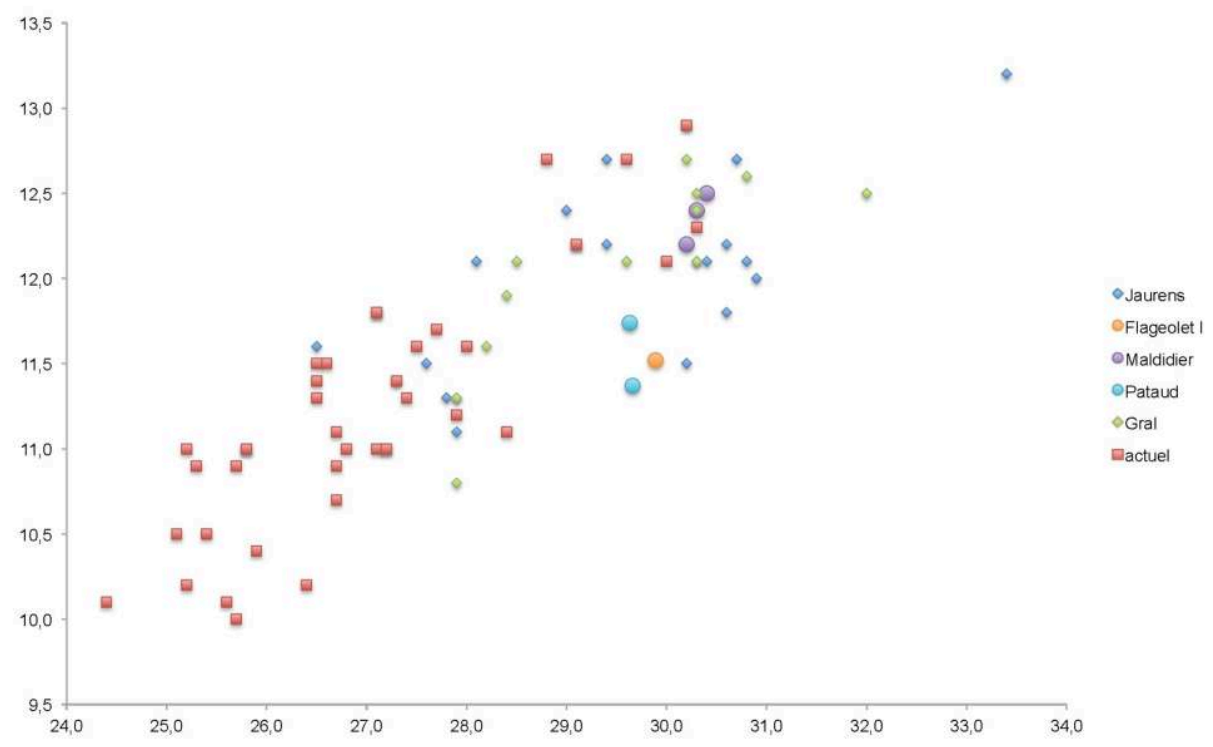

Les loups provenant des sites naturels de Jaurens et de l'Igue du Gral sont utilisés à titre de comparaison et illustrent la variabilité connue de la sous-espèce Canis lupus maximus (BoudadiMaligne, 2010 et 2012a)

13 Toutefois, dans la grotte Maldidier et à l'abri Pataud, le statut de ce carnivore semble assez particulier. À Maldidier on note en effet sur un fémur de loup, la présence de stries de découpes transversales en partie proximale de la diaphyse, ainsi que des traces de raclage en milieu de diaphyse (fig. 3). Ces traces, qu'elles soient d'ordre utilitaire et/ou symbolique, témoignent d'une manipulation de ces vestiges par les groupes humains ayant fréquenté la grotte Maldidier. 
Figure 3 : Fémur de loup (Canis lupus maximus) provenant de la grotte Maldidier.

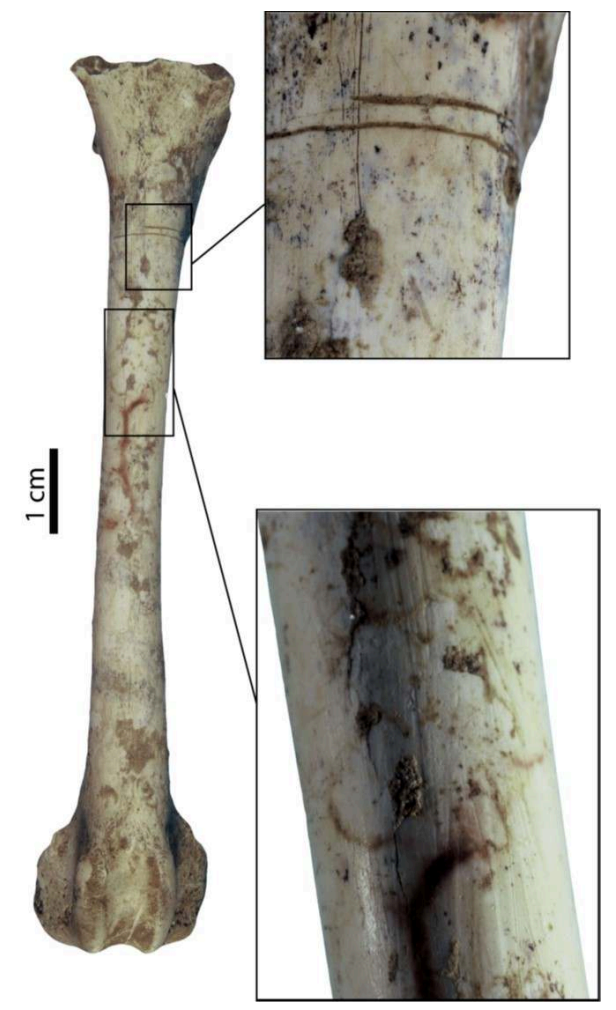

Zooms effectués sur les parties portant des traces d'origine anthropique, clichés J.-C. Castel.

14 À l'abri Pataud, les restes de Canidés sont, avec les restes humains, les seuls à ne pas avoir fait l'objet d'une exploitation aboutie. En effet, une seule pièce (tibia d'un adulte découvert lors des fouilles 2005-2015, Nespoulet, Chiotti dir.), présente, en partie proximale de diaphyse, des traces d'origine anthropique. Les autres restes de loup provenant de la couche $2(\mathrm{NR}=52)$ ne portent aucune trace liée à une exploitation par l'Homme et proviennent d'une zone assez restreinte de l'abri, à proximité des restes humains (Crépin, 2013).

15 L'état de surface et de conservation des ossements et leur positionnement à proximité des restes humains pourraient être interprétés comme le témoin d'une place particulière de cette espèce au sein des sociétés gravettiennes. Il est bien sûr impossible d'exclure l'hypothèse d'une mort sur place de ces bêtes, mais il est remarquable que ce cas de figure ne se rencontre qu'en contexte gravettien.

Malgré cette place ou ce statut particulier qui semble être donné aux grands Canidés, la présence de restes portant des traces de manducation ou de restes digérés demeure peu importante. Sur les restes d'ongulés principalement consommés (renne, cerf et bovidés : tabl. 1), le pourcentage d'os rongés, inférieur à $3 \%$, est considéré comme peu significatif. À l'abri Pataud ces traces sont mises en relation avec l'activité du renard (Crépin, 2013), tandis que les fragments de coprolithes découverts dans la grotte de Maldidier seraient le fait de l'hyène des cavernes, considérée ainsi comme la première occupante de la grotte (Boudadi-Maligne, 2013 ; Elalouf et al., 2016). 


\section{Le Solutréen}

17 Au Solutréen, le schéma semble à nouveau plus « classique » en ce sens que les restes de Canidés sont relativement fragmentaires. Cependant aucune trace d'origine anthropique n'est documentée sur les 52 restes de Canidés dénombrés à Combe Saunière (Castel et al., 1998) et les 17 restes du Fourneau du Diable (Fontana, 2001). Les dimensions des restes de Canidés de Combe Saunière et notamment des dents supérieures, indiquent que nous sommes en présence de loups d'un gabarit moyen pour cette période du Paléolithique supérieur

Quelques rares traces de morsure sont mises en évidence sur les ossements, mais leur fréquence demeure tout à fait anecdotique relativement à la totalité du matériel faunique analysé. Ces traces, de faible intensité et de petite dimension à Combe Saunière, semblent en lien avec l'activité d'un autre Canidé très bien représenté, le renard (Castel et al., 1998).

\section{Le Badegoulien}

Dans les niveaux badegouliens de la région, le genre Canis est quasi systématiquement mentionné dans les listes fauniques. C'est le cas dans le niveau badegoulien de Laugerie-Haute Est (Delpech, 1983), à Pégourié (Séronie-Vivien, 1995), à Casserole (Guadelli, 1993) ou à Cassegros (Ducasse et al., 2014, 2016). Dans ces niveaux, les quelques restes attribuables au genre Canis sont peu nombreux. Il s'agit principalement de dents le plus souvent perforées ou en cours d'aménagement comme dans le cas du Cuzoul de Vers (Clottes et al., 2012). Aucun indice d'un contact prolongé entre les Hommes et les Canidés n'est mis en évidence dans la région considérée.

\section{Le Magdalénien}

Pour le Magdalénien inférieur, l'analyse morphométrique menée sur les quelques restes de grand Canidé de l'ensemble inférieur du gisement de Saint-Germain-laRivière, indique qu'il n'y a aucun changement particulier de forme ou de taille des Canidés (Langlais et al., 2015) relativement aux périodes précédentes. Certains restes de Canidés sont utilisés à des fins techniques. Bien que la diète soit toujours majoritairement orientée sur les ongulés disponibles dans l'environnement (tabl. 1), elle intègre pour la première fois et de manière intensive des petits gibiers en l'occurrence la chouette harfang (Bubo scandiacus) (Langlais et al., 2015). La question de l'utilisation d'un auxiliaire de chasse tel que le chien pour l'acquisition de ces petites espèces, se pose. Néanmoins à Saint-Germain-la-Rivière, l'abondance des restes de harfang n'est pas corrélée avec une augmentation des témoignages indirects de la présence de Canidés à proximité des groupes humains. En effet, la présence d'ossements digérés ou rognés demeure dans ce gisement, anecdotique (i.e. inférieure à 1 \%) (Langlais et al., 2015).

21 Pour le Magdalénien moyen, les données morphométriques recueillies sur les quelques restes de Canidés de Saint-Germain-la-Rivière et du Roc-de-Marcamps 2 indiquent que les spécimens entrent une nouvelle fois parfaitement dans la variabilité des loups pléistocènes (Kuntz et al., 2015 ; Langlais et al., 2015). 
22 Au Roc-de-Marcamps 2, le caractère complet des ossements de loups et l'absence de traces sur ces derniers soulèvent la question de leur origine. Dans ce gisement la présence d'ossements rongés ou digérés concerne près de $3 \%$ des restes de faune (Kuntz et al., 2015). La taille des traces de dents et le gabarit des os semi-digérés excluent le renard et semblent plus compatibles avec l'activité d'un Canidé de taille moyenne.

23 Au Magdalénien supérieur, le rapprochement entre Hommes et grands Canidés est attesté par la mise en évidence de restes de chiens à l'abri Morin (Boudadi-Maligne et al., 2012) et à Mège (Boudadi-Maligne, inédit). Dans ces deux gisements, les restes attribués, sur la base d'analyses biométriques, au chien, ne sont pas les seuls restes se référant aux grands Canidés puisque plusieurs vestiges se rapportent également au loup. Les deux Canidés semblent cependant bénéficier du même type de traitement par les groupes magdaléniens, les deux portant des traces liées au prélèvement de la peau et de la viande (Boudadi-Maligne et al., 2012 et inédit).

$24 \mathrm{Au}$ Morin et à Mège, le faible nombre de traces de manducation et d'éléments digérés doit être mis en relation avec l'ancienneté des fouilles de ces deux gisements et l'absence de tamisage systématique des sédiments conduisant à une moins bonne représentativité du matériel et l'absence de coprolithes ou d'os semi-digérés. Il faut toutefois noter, parmi les vestiges provenant de l'abri Mège, la présence d'un coprolithe attribuable à un Canidé (collections Musée de l'Homme, Paris) et d'hémimandibules de jeunes Canidés (Museum de Bordeaux, collection Harlé) (BoudadiMaligne, inédit).

25 Cette présence de chiens dans les niveaux attribués au Magdalénien supérieur, n'est toutefois pas systématique. À Rochereil par exemple, l'ensemble des restes de Canis étudiés se rapporte exclusivement au loup (Boudadi-Maligne, 2012b). Toutefois, comme dans les ensembles précédemment mentionnés, plusieurs de ces restes portent des traces d'origine anthropique attestant de l'utilisation de ce Canidé à des fins alimentaires et utilitaires.

26 Pour ces trois gisements, il est difficile de discuter précisément des espèces associées aux Canidés et principalement exploitées par les groupes de chasseurs-cueilleurs en raison des problèmes taphonomiques et/ou des modalités de prélèvement (absence de coordonnées et tamisage non systématique) et de marquage des vestiges. Toutefois, dans ces sites, parmi les ongulés, ce sont classiquement le renne, les bovinés et le cheval qui dominent le spectre (tabl. 1), mais l'exploitation des petits gibiers (oiseaux, léporidés et petits carnivores) apparaît nettement plus importante. Quelques restes osseux portent des traces de manducation par les carnivores mais la fréquence de ces dernières est difficilement quantifiable pour les raisons indiquées ci-dessus.

\section{L'Azilien}

27 Les niveaux aziliens de Duruthy et Troubat livrent des données extrêmement différentes. Peu nombreux et fragmentaires à Duruthy, les restes de Canidés sont nettement mieux représentés à Troubat.

28 À Duruthy, la découverte d'une partie proximale d'un troisième métatarsien se rapportant à un Canis de petite taille, indique la présence de chiens dans le gisement (Boudadi-Maligne, inédit). La datation directe tentée dans le cadre de l'ANR Magdatis sur ce reste n'a, hélas, pas donné de résultat. L'attribution de cet élément au contexte 
azilien demeure donc incertaine. De plus nous ne bénéficions d'aucune information taphonomique permettant de documenter la présence de restes digérés ou consommés par des carnivores.

La série de Troubat est en cours de réévaluation par plusieurs d'entre nous. Les premiers résultats indiquent également la présence de petits Canis dans les niveaux archéologiques (c. 5 et c. 6). Ces restes, complets et ne portant aucune trace anthropogénique, sont accompagnés d'une part importante de restes digérés de petits ongulés, en l'occurrence de bouquetin (Capra pyrenaica) et de chamois (Rupicapra pyrenaica) (Ferrié, inédit).

\section{Le Laborien}

Deux séries livrant des restes attribués au genre Canis (La Borie-Del-Rey et Pont d'Ambon) viennent documenter ce techno-complexe. Pour la première, les restes sont peu nombreux et sont tous attribuables au loup (Langlais et al., 2014). Cependant, eu égard à l'ancienneté des fouilles, nous ne disposons que de peu d'éléments pour discuter des relations Hommes-Canidés.

31 À l'inverse, le Pont d'Ambon livre une série conséquente de restes de Canis. Sa réévaluation a permis de préciser le contexte chrono-culturel des restes de chiens décrits dès la fin des années 70 par G. Célérier et F. Delpech (1978). Cette attribution alors très controversée, apparaît aujourd'hui indiscutable au vu du très faible gabarit des individus découverts dans le gisement (Pionnier-Capitan et al., 2011) et de la date directe récemment obtenue (Boudadi-Maligne et al., à paraître). Les données d'ordre technologique, chronologique, biométrique et spatial, nous ont en effet permis de conclure que les restes de chiens sont contemporains de l'occupation laborienne et non azilienne (Boudadi-Maligne et al., à paraître). En outre, la découverte de restes inédits dans le matériel indéterminé confirme l'utilisation de cet animal domestique à des fins alimentaires.

\section{Discussion et conclusions}

À l'échelle du Paléolithique supérieur, et considérant les ensembles archéologiques retenus, un premier bilan diachronique peut être proposé pour le grand Sud-Ouest de la France. Pour faciliter cette modélisation, nous proposons d'établir une grille de critères permettant de mettre en évidence la présence de Canidés aux côtés des groupes paléolithiques (tabl. 2).

Tableau 2 : Éléments considérés comme diagnostiques pour discuter de la présence durable de grands Canidés au contact de groupes humains au cours du Paléolithique.

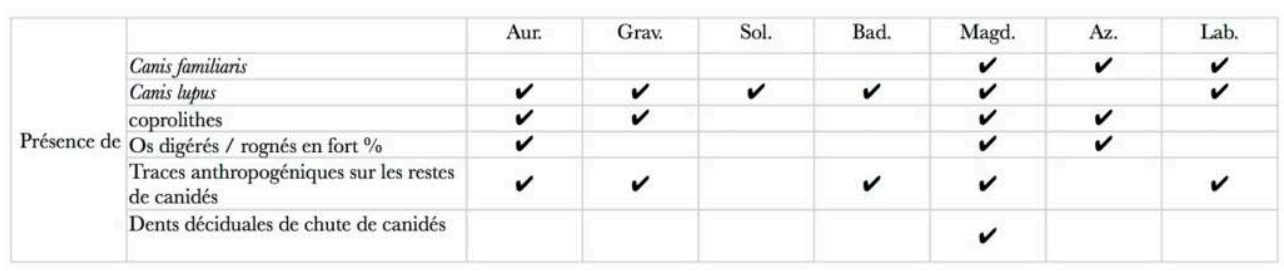

Les abréviations utilisées pour les différents techno-complexes : Aur. : Aurignacien ; Grav. : Gravettien ; Sol. : Solutréen; Bad. : Badegoulien; Magd. : Magdalénien ; Az. : Azilien ; Lab. : Laborien. 
(1)

mmes-Canidés. Néanmoins, les données dont nous disposons ne nous permettent pas de parler d'une première expérience de domestication. D'un point de vue morphologique, les Canidés en présence se réfèrent uniquement à du loup et aucune diminution de taille et/ou changement de forme n'est constaté. Nous pourrions proposer l'hypothèse d'expérience(s) d'apprivoisement mais face aux rares preuves archéologiques qui pourraient la valider, cette hypothèse doit être retenue avec circonspection. Il apparaît à ce stade de la discussion important d'insister sur la différence entre ces deux phénomènes que sont la domestication et l'apprivoisement en rappelant que le dernier n'implique pas de changements morphologiques et ne laisse par conséquent pas de traces interprétables d'un point de vue strictement paléontologique (e.g. Vigne et al., 2004). La domestication sous-entend une sélection des individus les plus dociles. Ainsi au fur et à mesure des générations d'importantes modifications phénotypiques (couleur du pelage, taille...), physiologiques (cycle de reproduction...) et comportementales (aboiement du chien adulte...) apparaissent (e.g. Gautier, 1990 ; Morey, 1992, 2010 ; Clutton-Brock, 1995 ; Trut, 1999; Miklósi, 2007). Certains de ces changements morphologiques impactent donc l'anatomie des individus et constituent des marqueurs de la domestication. Pour le Gravettien, il apparaît par ailleurs nécessaire de rappeler que l'hypothèse d'une mort sur place d'individus solitaires ne peut pas être exclue et que les indices qui pourraient être tentant d'interpréter comme un rapprochement entre le loup et l'Homme pourraient simplement relever de processus d'agrégation.

$36 \mathrm{Au}$ sein des techno-complexes suivants et plus précisément entre le Solutréen et le Magdalénien moyen, nous ne disposons pour l'heure d'aucun indice d'une perduration ou d'une intensification de ce possible rapprochement.

Au Magdalénien supérieur par contre, si l'ensemble des preuves attestant d'une vie des Canidés au contact des groupes humains n'est pas réuni (pas ou peu de traces de prédation par les Canidés et de coprolithes), les données morphométriques obtenues sur plusieurs restes ne laissent aucun doute quant à la présence de chiens dès cette phase du Paléolithique supérieur. Rappelons néanmoins que les séries sur lesquelles est basée notre réflexion ont été fouillées anciennement. Il est donc probable que certains de ces éléments (os digérés, coprolithes) s'ils étaient présents, n'ont pas été collectés et/ou conservés.

38 Le registre archéologique actuel, nous permet, en nous basant sur les données morphométriques et radiométriques, de mettre en évidence, à partir de la phase supérieure du Magdalénien et au cours de l'Azilien, plusieurs cas de domestication 
avérés traduisant d'un phénomène non isolé, perceptible en France via l'exemple du Closeau, au nord-est de notre zone d'étude, mais également dans le reste de l'Europe occidentale (fig. 4). Et s'il s'agit du premier animal sauvage à pénétrer la sphère domestique, il est intéressant de noter, à travers les exemples de l'abri du Morin et du Pont d'Ambon, qu'il semble traité comme les autres espèces chassées par les Hommes du Paléolithique et leurs successeurs.

Figure 4 : Zoom sur les sites du Paléolithique supérieur de France et des pays limitrophes ayant livré des restes de Canidés attribués au chien (Canis familiaris).

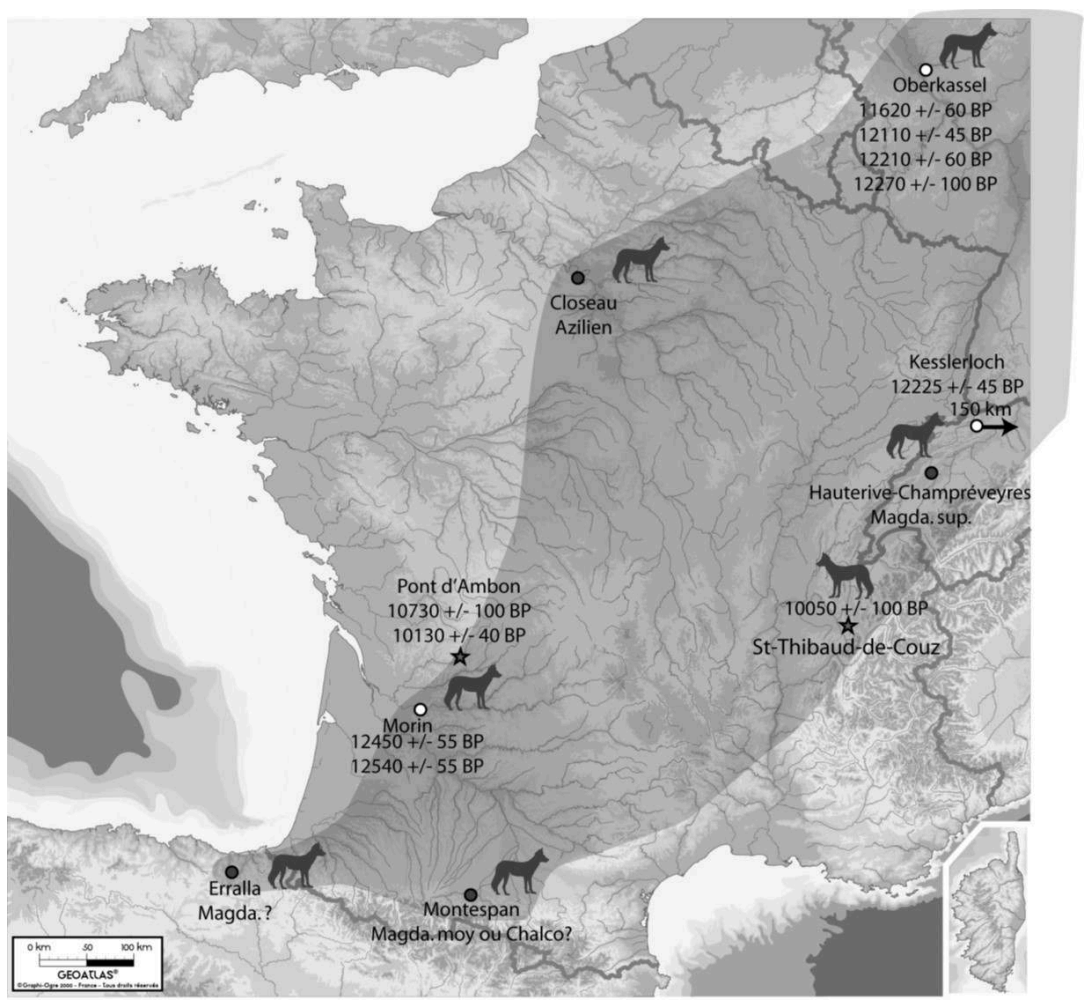

Les dates figurées correspondent aux datations directes effectuées sur ces restes. Les ronds gris correspondent aux sites pour lesquels nous ne bénéficions pas de dates directes sur chien, les ronds blancs aux sites pour lesquels les dates directes confirment l'attribution des chiens aux occupations du Magdalénien supérieur et les étoiles grises, aux sites dont les dates sur chiens rapprochent ces derniers des occupations laboriennes.

\section{BIBLIOGRAPHIE}

BECKOUCHE S. 1981, « Les grands mammifères du Paléolithique supérieur du Piage (Lot) », dans CHAMPAGne F. et ESPITALIÉ R. (Eds.), Le Piage. Site Préhistorique du Lot, Paris, Éditions du CNRS, p. 165-192.

BORDES J.-G., LEBRUN-RICALENS F., CASTEL J.-C., DUCASSE S., FAIVRE J.-P., FERUGLIO V., HENRY-GAMBIER D., LACRAMPE-CUYAUBÈRE F., LAROULANDIE V., LENOBLE A., MARTIN H., MAUREILLE B., MORALA A., RENARD C., 
RENDU W., RIGAUd S., ROUGIER H., TARTAR E., TEXIER J.-P., TEYSSANDIER N. 2008, « Les débuts du Paléolithique supérieur dans le Sud-Ouest de la France : fouilles 2004-2006 au Piage (Fajoles, Lot). Problématique et premiers résultats ", dans JAUBERT J., BORDES J.-G., ORTEGA I. (Eds.), Les sociétés du Paléolithique dans un grand Sud-Ouest de la France : nouveaux gisements, nouveaux résultats, nouvelles méthodes, Journées SPF, Université Bordeaux 1, Talence, 24 au 25 novembre 2006, p. 261-288. BOUDADI-MALIGNE M. 2012a, « Une nouvelle sous-espèce de loup (Canis lupus maximus nov. subsp.) dans le Pléistocène supérieur d'Europe occidentale ", Comptes Rendus Palevol, 11, p. 475-484. BOUDADI-MALIGNE M. 2012b, « 1.a.2-Chiens et loups entre Dronne et Tardoire - les cas de Rochereil et du Pont d'Ambon ", dans PAILLET P. (dir.), Rapport intermédiaire d'opération archéologique, PCR 2012-63, Peuplements et cultures à la fin du Tardiglaciaire dans le Nord du Périgord, entre Dronne et Tardoire, p. 16-18.

BOUDADI-MALIGNE M. 2013, « la grotte Maldidier », dans Bilan Scientifique Régional DRAC Aquitaine, p. 55-56.

BOUDADI-MALIGNE M., ESCARGUEL G. 2014, « A biometric re-evaluation of recent claims for Early Upper Paleolithic wolf domestication in Eurasia », Journal of Archaeological Science, 45, p. 80-89. BOUDADI-MALIGNE M., MALLYE J.-B., LANGLAIS M., BARSHAY-SZMIDT C. 2012, « Des restes de chiens magdaléniens à l'abri du Morin (Gironde, France). Implications socioéconomiques d'une innovation zootechnique », Paléo, 23, p. 39-53.

BOUDADI-MALIGNE M., BONNET-JACQUEMENT P., LANGLAIS M., FERRIÉ J.-G., MALLYE J.-B. à paraître, « Les chiens de Pont d'Ambon : statut, contexte et implications sociétales ", dans AVERBOUH A., CLEYETMERLE J.-J. et BONNET-JACQUEMENT P. (dir.), L'Aquitaine à la fin des temps glaciaires. Les sociétés de la transition du Paléolithique final au début du Mésolithique dans l'espace nord aquitain. Les Eyzies 24 au 26 juin 2015, Hommage à Guy Célérier, Paléo.

CASTEL J.-C. 2010, Comportements de subsistance au Solutréen et au Badegoulien d'après les faunes de Combe Saunière (Dordogne) et du Cuzoul de Vers (Lot), thèse de doctorat, Université de Bordeaux I, Éditions universitaires Européennes, Sarrebrück, 635 p.

CASTEL J.-C. 2011, «Archéozoologie de l'Aurignacien de l'Abri Castanet (Sergeac, Dordogne, France) : les fouilles 1994-1998 », Revue de Paléobiologie, 30(2), p. 783-815.

CASTEL J.-C., LIOlIOS D., CHADELle J.-P., GENESTE J.-M. 1998, « De l'alimentaire et du technique : la consommation du renne dans le Solutréen de la grotte de Combe Saunière » dans BRUGAL J.-P., MEIGNEN L. et PATOU-MATHIS M. (Eds.), Économie préhistorique : les comportements de subsistance au Paléolithique. APCDA-CNRS, XVIIIe Rencontres Internationales d'Archéologie et d'Histoire d'Antibes, Antibes, p. 433-450.

CÉLÈRIER G., DELPECH F. 1978, « Un chien dans l'Azilien de "Pont d'Ambon” (Dordogne) ? », Bulletin de la Société préhistorique française, p. 212-215.

CLOTTES J., GIRAUD J. P., CHALARD P. (Eds.) 2012, Solutréen et badegoulien au Cuzoul de Vers : des chasseurs de rennes en Quercy, ERAUL, Université de Liège, 488 p.

CLUTTON-BROCK J. 1995, « Origins of the dog : domestication and early history », dans : SERPELL J. (Éd.), The Domestic Dog. Its Evolution, Behaviour and Interactions with People. Cambridge University Press, Cambridge, p. 7-20.

CRÉPIN L. 2013, « Données archéozoologiques des grands mammifères » dans NESPOULET R., CHIOTTI L. et HENRY-GAMBIER D. (dir.), Le Gravettien Final de l'abri Pataud (Dordogne, France). Résultats des Fouilles et des Études 2005-2009. BAR International Series, 2458, Oxford, p. 63-88. 
DAVIS S., VALLA F. R. 1978, « Evidence for domestication of the dog 12,000 years ago in the Natufian of Israel », Nature, 276, p. 608-610

DELPECH F. 1968, « Faunes du Magdalénien IV et de l'Azilien du gisement de Duruthy commune de Sorde-l'Abbaye (Landes) », Actes de la Société linnéenne de Bordeaux, 105 (6), p. 3-25.

DELPECH F. 1983, Les faunes du Paléolithique supérieur dans le Sud-Ouest de la France, Bordeaux, Cahiers du Quaternaire, 6.

DELPECH F., GRAYSON D. K., RIGAUD J. P. 2000, « Biostratigraphie et paléoenvironnements du début du Würm récent d'après les grands mammifères de l'Abri du Flageolet I (Dordogne, France) », Paléo, 12(1), p. 97-126.

DRAKE A. G., COQUERELle M., COLOMBEAU G. 2015, « 3D morphometric analysis of fossil canid skulls contradicts the suggested domestication of dogs during the late Paleolithic », Scientific Reports, 5.

DUCASSE S., RENARD C. (dir.) 2014, PCR SAM “du Solutréen au Magdalénien" : changements dans

l'organisation socio-économique des groupes humains entre 24 et $19 \mathrm{ka}$ cal. BP. Rapport annuel de PCR, Service Régional de l'Archéologie Midi-Pyrénées, Toulouse, 129 p.

DUCASSE S., Le TENSORER J.-M. (dir.) 2016, La séquence solutréo-badegoulienne de la grotte de Cassegros : réévaluation collective et interdisciplinaire d'une séquence de référence pour le Dernier Maximum Glaciaire dans le sud-ouest français. Rapport annuel de PCR, Service Régional de l'Archéologie Aquitaine, Bordeaux, $112 \mathrm{p}$.

ELALOUf J.-M., FLAENDER M., Plaire D., LAMBOURDIÈRE J., VentOSA J., DEN DULK R., BOURDAT A.G., MALlye J.-B., BOUDADI-MALIGNE M. 2016, « Real-time molecular archeology », 4 th ICAZ Taphonomy Working Group, 7 au 10 septembre 2016, Paris.

FONTANA L. 2001, «Étude archéozoologique des collections du Fourneau du diable (Bourdeilles, Dordogne) : un exemple du potentiel des faunes paléolithiques issues des fouilles anciennes », Paléo, 13, p. 159-182.

GAUTIER A. 1990, La Domestication. Et l'homme créa l'animal. Paris, Errance Éd.

GERMONPRÉ M., SABLIN M.V., STEVENS R.E., HEDGES R.E.M., HOFREITER M., STILLER M., DESPRES V.R. 2009, « Fossil dogs and wolves from Paleolithic sites in Belgium, the Ukraine and Russia : osteometry, ancient DNA and stable isotopes ", Journal of Archaeological Science, 36(2), p. 473-490.

GERMONPRÉ M., LAZNICKOVA-GALETOVA M., SABLIN M.V. 2012, « Paleolithic dog skulls at the Gravettian Predmostí site, the Czech Republic », Journal of Archaeological Science, 39, p. 184-202.

GUADELLI J.-L. 1993, « La Faune », dans DETRAIN L. (Dir.), Fouilles préliminaires à l'agrandissement du Musée National de Préhistoire des Eyzies, 1991-1992, AFAN, p. 74-76.

HAYNES G. 1983, «A guide for differentiating mammalian carnivore taxa responsible for gnaw damage to herbivore limb bones ». Paleobiology, 9(2), p. 164-172.

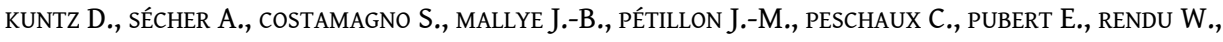
BOUDADI-MALIGNE M., LAROULANDIE V., BARSHAY-SZMIDT C., LANGLAIS M. 2015, « Le Roc de Marcamps 2 (Prignac-et-Marcamps, Gironde) : nouvelles données sur la subsistance et les traditions techniques au début du Magdalénien moyen », Bulletin de la Société préhistorique française, 112(3), p. 475-516.

LACARRIÈRE J. 2015, Les ressources cynégétiques au Gravettien en France. Acquisition et modalités d'exploitation des animaux durant la phase d'instabilité précédant le Maximum Glaciaire, thèse de doctorat, Université Toulouse-Jean-Jaurès. 
LANGLAIS M., DETRAIN L., FERRIÉ J.-G., MALlyE J.-B., MARQUEBIELlE B., RIGAUD S., TURQ A., BONNETJACQUEMENT P., BOUdADI-MALIGNE M., CAUX S., FAT CHEUNG C., NAUDINOT N., MORALA A., VALDEYRON N., CHAUVIÈRE F.-X. 2014, « Réévaluation des gisements de La Borie del Rey et de Port-de-Penne : nouvelles perspectives pour la transition Pléistocène - Holocène dans le sud-ouest de la France ", dans LANGLAIS M., NAUDINOT N., PERESANI M. (dir.), Les groupes culturels de la transition Pléistocène Holocène entre Atlantique et Adriatique, Table-ronde de Bordeaux, mai 2012, Séances de la SPF, vol. 3, p. 83-128.

LANGlais M., LAROUlandie V., COSTAMAGNo S., PÉTILlON J.-M., MALlye J.-B., LACRAMPE-CUYAUBÈRE F., BOUDADI-MALIGNE M., BARSHAY-SZMIDT C., MASSET C., PUBERT E., RENDU W., LENOIR M. 2015, « Premiers temps du Magdalénien en Gironde : réévaluation des fouilles Trécolle à Saint-Germain-la-Rivière (France) », Bulletin de la Société préhistorique française, 112(1), p. 5-58.

LETOURNEUX C. 2003, Devine qui est venu diner à Brassempouy? Approche taphonomique pour une interprétation archéozoologique des vestiges osseux de l'Aurignacien ancien de la grotte des Hyènes (Brassempouy, Landes), thèse de doctorat, Université Panthéon - Sorbonne, Paris, 319 p.

MALAIZÉ R. 2006, Étude archéozoologique de l'assemblage magdalénien supérieur de l'abri Mège (Teyjat, Dordogne), Mémoire de Master 2, Muséum National d'Histoire Naturelle.

MALLYE J.-B., SOULIER M.-C., LAROULANDIE V. 2013, « Grands carnivores et mésofaune de l'Aurignacien ancien à La Quina aval (Charente, France) (fouilles V. Dujardin) », Paléo, 24, p. 235-248.

MALLYE J.-B., KUNTZ D., LANGLAIS M., BOUDADI-MALIGNE M., BARSHAY-SZMIDT C., COSTAMAGNO S., PÉTILLON J.-M., GOURICHON L., LAROULANDIE V. à paraître, « Trente ans après, que reste-t-il du modèle d'azilianisation proposé au Morin par F. Bordes et D. de SONNEVILLE-BORDES ? » dans AVERBOUH A., CLEYET-MERLE J.-J. et BONNET-JACQUEMENT P. (dir.), L'Aquitaine à la fin des temps glaciaires. Les sociétés de la transition du Paléolithique final au début du Mésolithique dans l'espace nord aquitain. Les Eyzies 24 au 26 juin 2015, Hommage à Guy CÉLÉRIER, Paléo.

MIKLósı Á. 2007, Dog Behaviour, Evolution, and Cognition. Oxford University Press, Oxford.

MOREY D.F. 1992, « Size, shape and development in the evolution of the domestic dog », Journal of Archaeological Science, 19, p. 181-204.

MOREY D.F. 2010, Dogs. Domestication and the Development of a Social Bond. Cambridge University Press, Cambridge.

MOREY D. F. 2014, «In search of Paleolithic dogs : a quest with mixed results », Journal of Archaeological Science, 52, p. 300-307.

MOREY D.F., KLIPPEL W.E. 1991, « Canid scavenging and deer bone survivorship at an Archaic period site in Tenessee », Archaeozoologia, IV/1, p. 11-28.

MOUTON P., JOFFROY R. 1958, Le gisement aurignacien des Rois à Mouthiers (Charente), Supplément à Gallia N 9, Paris, Éditions du CNRS, 140 p.

OVODOV N.D., CROCKFORD S.J., KUZMIN Y.V., HIGHAM T.F.G., HODGINS G.W.I., VAN DER PLICHT J. 2011, « A 33,000 year-old incipient dog from the Altai Mountains of Siberia : evidence of the earliest domestication disrupted by the Last Glacial Maximum », PLoS ONE, 6(7).

PIONNIER-CAPITAN M., BÉMILLI C., BODU P., CÉLÉRIER G., FERRIÉ J.-G., FOSSE P., GARCIA M., VIGNE J.-D. 2011, « New evidence for Upper Palaeolithic small domestic dogs in South-Western Europe », Journal of Archaeological Science, 38, p. 2123-2140. 
RENOU S. 2007, Les comportements de subsistance dans le Sud-Ouest de la France à l'Aurignacien : Bilan bibliographique et analyse archéozoologique d'un gisement aurignacien, Les Rois (Mouthiers-sur-Boëme, Charente), mémoire de Master 2 Sciences et Technologies, Université de Bordeaux I, 79 p.

SABLIN M.V., KHLOPACHEV G.A. 2002, « The earliest Ice Age Dogs : evidence from Eli- seevichi I », Current Anthropology, 43, p. 795-799.

SÉRONIE-VIVIEN M.-R. (Dir.) 1995, La grotte de Pégourié, Caniac-du-Causse, Lot : Périgordien, Badegoulien, Azilien, Age du Bronze. Préhistoire quercinoise, supplément n², 334 p.

SOULIER M.-C. 2013, Entre alimentaire et technique : l'exploitation animale aux débuts du paléolithique supérieur : stratégies de subsistance et chaînes opératoires de traitement du gibier à Isturitz, La Quina aval, Roc-de-Combe et Les Abeilles, thèse de doctorat, Université Toulouse le Mirail - Toulouse II, 535 p., 196 p. annexes.

SOULIER M.-C., MALLYE J.-B. 2012, « Hominid subsistence strategies in the South-West of France : a new look at the early Upper Palaeolithic faunal material from Roc-de-Combe (Lot, France) », Quaternary International, 252, p. 99-108.

STINER M.C. 2004, "Comparative ecology and taphonomy of spotted hyenas, humans and wolves in Pleistocene Italy”, Revue de Paléobiologie, 23(2), p. 771-785.

TRUT L.N. 1999, «Early Canid domestication : the Farm-Fox Experiment », American Scientist, 87(2), p. $160-169$.

VIGNE J. D., GUILAINE J., DEBUE K., HAYE L., GÉRARD P. 2004, « Early taming of the cat in Cyprus », Science, 304(5668), p. 259-259.

\section{RÉSUMÉS}

Le processus de domestication du loup vraisemblablement initié au cours du Paléolithique supérieur, pose aujourd'hui encore de nombreuses questions en termes notamment d'ancienneté du phénomène et de sa diffusion au sein des différents groupes de chasseurs-cueilleurs se succédant au cours de cette période. Pour tenter d'apporter de nouveaux éléments de discussion, de nouvelles analyses pluridisciplinaires ont récemment été entreprises sur la Grotte Maldidier, l'Abri Pataud, l'Abri du Morin, l'Abri Mège, Rochereil, la Grotte-Abri du Moulin à Troubat et le Pont d'Ambon. Ce travail, à visée diachronique, permet de lancer une discussion concernant le statut sauvage ou domestique des grands Canidés dans ces contextes et plus généralement dans les séries du Paléolithique supérieur du Sud-Ouest de la France. Pour cette analyse, nous avons notamment croisé biométrie et archéozoologie. Les données biométriques obtenues à partir des restes de Canidés participent à la diagnose taxinomique. Les études archéozoologique et taphonomique de l'ensemble des vestiges fauniques associés à ces restes permettent quant à elle de documenter la prédation humaine et animale. L'ensemble de ces données nous permet donc de contextualiser la mise en place de cette innovation zootechnique majeure qu'est la domestication; et plus globalement, de questionner l'évolution des relations Hommes-Canidés à travers les différents techno-complexes du Paléolithique supérieur. 
AUTEURS

MYRIAM BOUDADI-MALIGNE

PACEA, UMR 5199,

Université de Bordeaux

JEAN-BAPTISTE MALLYE

PACEA, UMR 5199,

Université de Bordeaux

JEAN-CHRISTOPHE CASTEL

Muséum de Genève, département de la culture et du sport,

PACEA, UMR 5199, Université de Bordeaux

JEAN-GEORGES FERRIÉ

INRAP, route de Dolé,

F-97113 Gourbeyre, Guadeloupe

LAURENT CRÉPIN

HNHP, UMR 7194,

MNHN, Musée de l'Homme

DELPHINE KUNTZ

ArScAn, UMR 7041, Équipe Ethnologie préhistorique,

Maison de l'Archéologie et de l'Ethnologie

\section{CAROLE VERCOUTÈRE}

HNHP, UMR 7194, MNHN,

Musée de l'Homme

MARIE-CÉCILE SOULIER

TRACES, UMR 5608, Université Toulouse Jean Jaurès,

Maison de la Recherche

\section{SANDRINE COSTAMAGNO}

TRACES, UMR 5608, Université Toulouse Jean Jaurès,

Maison de la Recherche 


\title{
Loups et chiens au Néolithique et au Moyen Âge en France méditerranéenne
}

\author{
Vianney Forest et Isabelle Rodet-Belarbi
}

L'identification archéozoologique du loup à partir des os longs a longtemps reposé sur un principe simple, pour ne pas dire simpliste : « si c'est grand, c'est du loup ", à l'instar des couples de formes domestique et sauvage que sont le cochon et le sanglier ou le bœuf et l'aurochs. En effet, à ce jour, aucun travail n'a mis en évidence, sur les os longs, des critères morphoscopiques discriminants satisfaisants entre les deux espèces pour les périodes protohistoriques et historiques, immédiatement utilisables par l'archéozoologue travaillant en archéologie préventive (Pluskowski, 2006). Dans ce cadre, deux problèmes se posent immédiatement lors de la détermination spécifique des os longs de grands canins. D'une part, un certain nombre d'entre eux présentent des proportions intermédiaires entre les individus supposés domestiques ou sauvages, et de ce fait ne peuvent être attribués à l'une des espèces. Pour illustration, un humérus venant du site archéologique de Saint-Contest (Calvados, fin $\mathrm{VI}^{\mathrm{e}}$-VII ${ }^{\mathrm{e}}$ siècle; RodetBelarbi, 2013), placé entre deux humérus de chiens et l'humérus d'un loup de lignée italienne provenant du Parc du Mercantour (Alpes-Maritimes) ${ }^{1}$ (fig. 1), ne peut être rapporté à l'une des deux formes qui elles-mêmes sont très proches, et être attribué avec certitude à l'une ou l'autre des espèces ${ }^{2}$. D'autre part, le loup est souvent beaucoup moins grand que dans l'imaginaire collectif qui en a fait un animal redoutable, donc puissant, en raison de ses attaques parmi les populations paysannes (Moriceau, 2007, 2014). Ainsi, les plus petites louves de la lignée italienne, qui en France fréquentent actuellement les Alpes, le Sud-Est et le département des Pyrénées-Orientales, sont à peine plus grandes qu'un grand épagneul breton par exemple. Elles ont une hauteur au garrot de $50 \mathrm{~cm}^{3}$ tandis que les plus grands mâles approchent $70 \mathrm{~cm}^{4}$ (Vivianni et al., 2006, p. 34). 
Figure 1 : Comparaison entre deux humérus de chien médiévaux (à gauche), un humérus de loup du Parc du Mercantour (Alpes-Maritimes, à droite) et un humérus mis au jour sur le site archéologique de Saint-Contest (Calvados, fin $\mathrm{VI}^{\mathrm{e}}$ siècle - VII siècle, au centre) (Cliché I. Rodet-Belarbi).

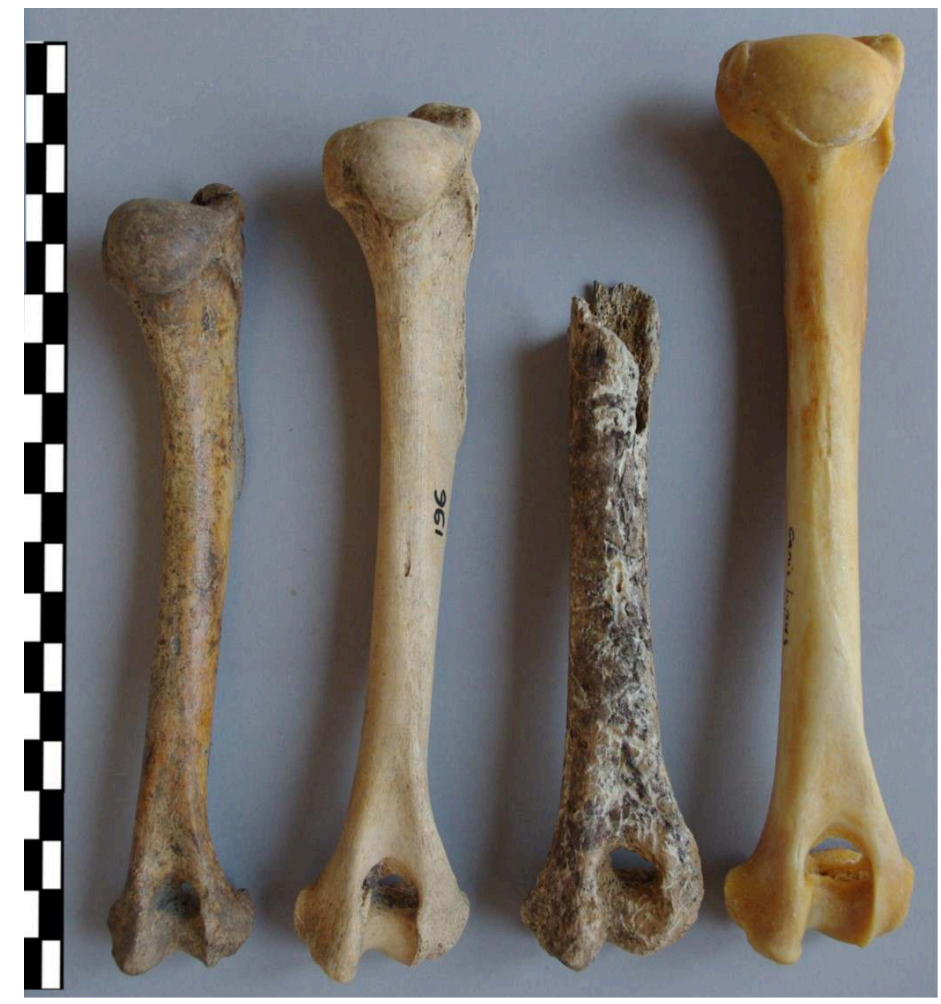

2 Cette sous-population italienne est une des trois qui vivent en Europe. Le loup eurasien que l'on retrouve aujourd'hui dans le nord et l'est de la France est plus grand. Sa taille varie de 60 à $80 \mathrm{~cm}$, voire $90 \mathrm{~cm}$ pour les grands mâles. Le loup ibérique, cantonné dans le quart nord-ouest de la péninsule, est à peine moins grand avec une hauteur au garrot de 60 à $80 \mathrm{~cm}$ au maximum. Ces données d'animaux contemporains constituent nos références puisque rien ne nous renseigne sur le format des loups des périodes protoet historiques, au moins dans le sud de la France.

3 Munis de ces deux constats, nous avions mené une première étude sur les os longs dits de loup qui nous avait conduits à conclure que les plus grands os attribués dans un premier temps au loup pouvaient tout aussi bien être ceux de grands chiens (RodetBelarbi et Forest, 2014). En conséquence, il nous avait semblé plus juste de parler alors d'os canins, c'est-à-dire appartenant au groupe des os de morphologie proche du chien et du loup, voire du renard pour de plus petits.

4 Nous étendons ici notre enquête aux périodes néolithique en Languedoc, médiévale et moderne en France méridionale, à l'aide des données issues des sites de notre zone d'étude usuelle, afin de voir si les modalités de distribution des valeurs mesurées sur les os longs peuvent permettre d'isoler le loup parmi les ossements.

5 Notre approche, de nature ostéométrique, concerne trois os longs qui sont les plus solides, et donc les mieux conservés sur les sites archéologiques. Deux appartiennent au membre thoracique, l'humérus, support du bras, et le radius, un des rayons de l'avantbras avec l'ulna/cubitus. Le troisième vient du membre pelvien, le tibia, axe de la jambe. Nous avons choisi de croiser la grande longueur de l'os avec la largeur minimale de la diaphyse. Toutefois comme nous disposons pour les loups actuels essentiellement 
des hauteurs au garrot limites toisées sur le vivant, et non de corpus de mesures osseuses ${ }^{5}$, nous avons repris le procédé de comparaison graphique qui croise la hauteur au garrot déduite des mesures d'ossements selon des formules établies par F. Koudelka (1885) et ajustées par R. A. Harcourt (1974) ${ }^{6}$, et l'indice de robustesse qui est le rapport de la largeur minimale de la diaphyse à la grande longueur?

\section{Au Moyen Âge}

6 Vingt-quatre sites répartis entre seize villes de France méridionale ont livré des os de canins entiers mesurables (fig. 2). Mais les données métriques recueillies sont éparses. Aussi, avons-nous ajouté un site qui est une exception géographique à notre entreprise. Il s'agit du village Wy-dit-Joly-Village dans le Val d'Oise où un puits dont le comblement daté du XIII ${ }^{e}$ siècle contenait une très grande quantité d'ossements, notamment de canins. L'étude archéozoologique, réalisée par Laurent Falières (1994), a restitué un minimum de 44 animaux ${ }^{8}$. La plupart d'entre eux ont été reconnus comme des jeunes chiens de type doligo-mésocéphale et de constitution assez gracile d'après les morphologies crâniennes, et pour quatre autres individus, comme des chiens de type brachymèle (Ibid., p. 260, 268) qui est la forme « basset » à l'exemple des teckels actuels. Ce lot fournit ainsi une première image des diverses morphologies de canins, dans une unité d'espace et de temps étroite.

Figure 2 : Liste des sites en France méridionale ayant livré des os entiers de canins mesurables, classés par période chronologique.

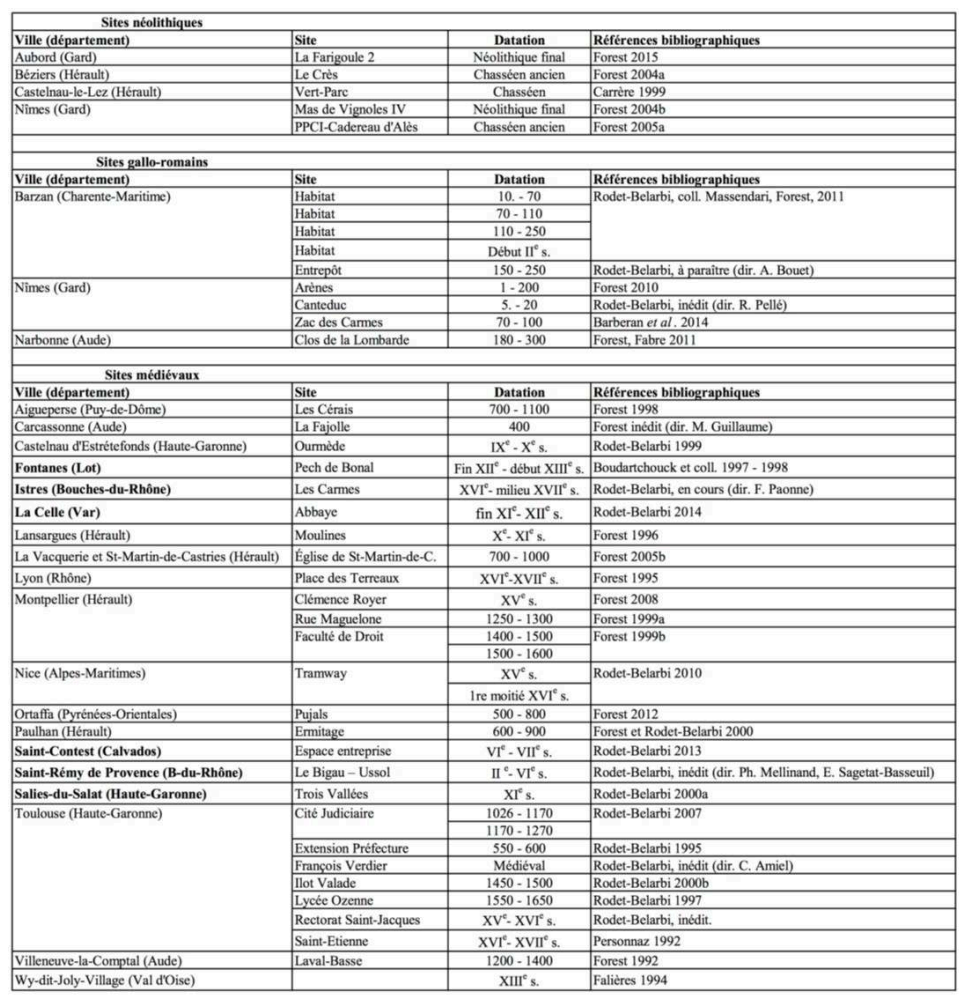

En gras, les communes et les sites ayant livré des os de grands canins.

7 La série de 22 humérus entiers présente un indice de robustesse d'environ 7 (fig. 3), qui définit des animaux eumétriques. Leurs hauteurs au garrot estimées varient de 40 à 
$65 \mathrm{~cm}$. Des os courts nettement plus robustes, dont l'indice se situe entre 11 et 12 , appartiennent à la forme "basset». Les mesures des ossements issus des sites méridionaux amplifient un peu la variabilité de la robustesse des formes eumétriques avec la présence d'individus plus petits dont la taille avoisine $32 \mathrm{~cm}$ au garrot. D'autres petits canins à pattes robustes apparaissent également.

8 Nous avons apposé les limites de variation des hauteurs au garrot des loups actuels ainsi que les mesures de deux humérus issus l'un, du squelette de loup italien actuel précédemment cité, et l'autre, d'un loup mâle actuel de Bulgarie ${ }^{9}$. Les humérus canins médiévaux de la France méridionale empiètent à peine la variabilité du loup eurasien, alors qu'ils recouvrent un peu plus de la moitié de celle du loup italien. Il apparaît ainsi très nettement que les conclusions établies lors de l'identification spécifique des humérus archéologiques vont dépendre du choix de la population lupine de référence ${ }^{10}$.

Figure 3 : Humérus de canins provenant de sites médiévaux et hauteurs au garrot de divers loups actuels.

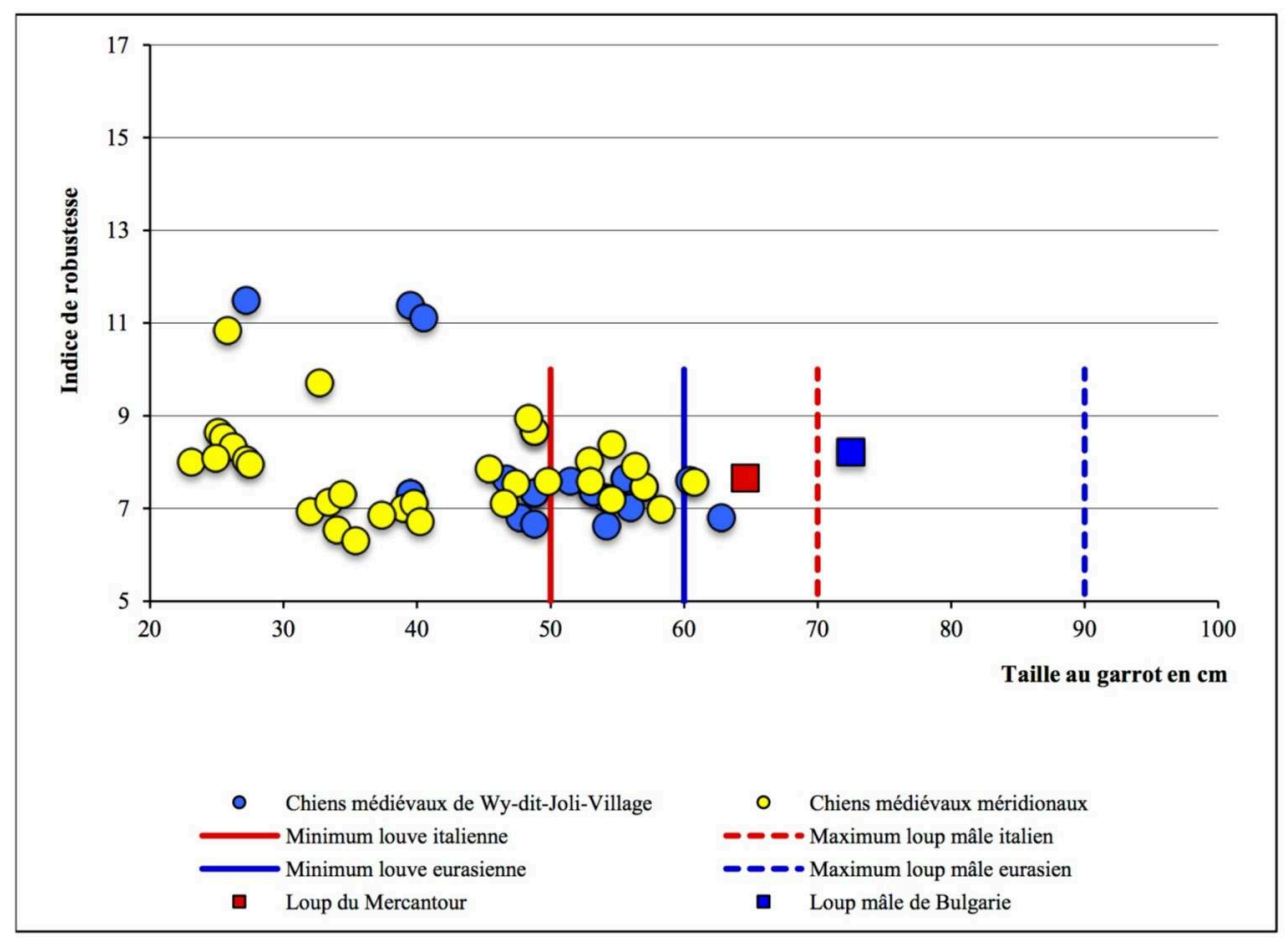

9 Les tibias canins archéologiques dessinent la même image que les humérus (fig. 4). La robustesse des formes «basset » est un peu plus étendue tandis que la confrontation avec les hauteurs au garrot du loup augmente très légèrement l'amplitude des chevauchements, notamment celle avec le loup italien. 
Figure 4 : Tibias de canins provenant de sites médiévaux et hauteurs au garrot de divers loups actuels.

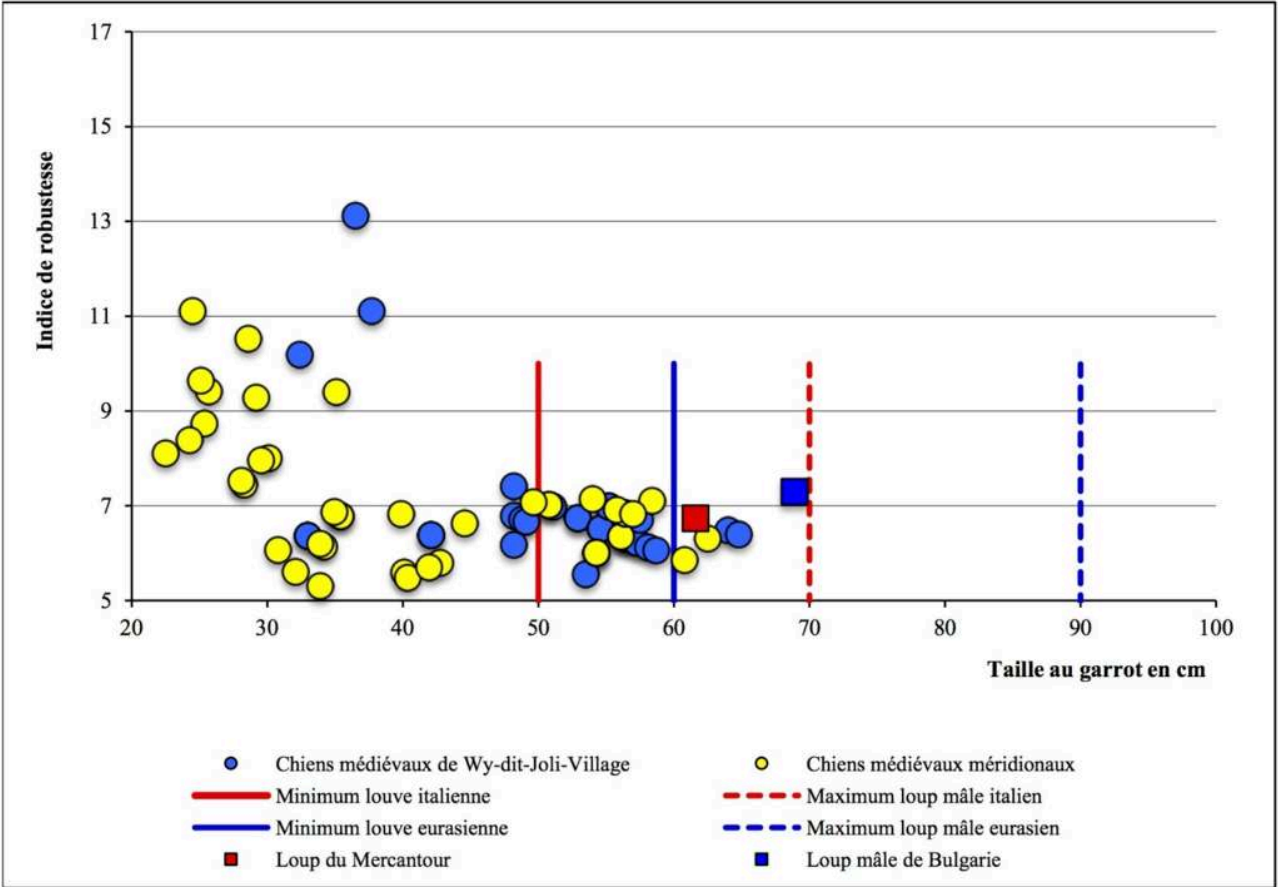

Enfin, le radius offre une distribution similaire à celles des deux premiers os longs (fig. 5). Lors de travaux précédents relatifs à la période romaine en Gaule, nous avions réuni les mesures de radius de chiens mis au jour dans le comblement de puits et de fosses à Nîmes (Gard ; Barberan et al., 2014), à Narbonne (Aude ; Forest et Fabre, 2011) et à Barzan (Charente-Maritime ; Rodet-Belarbi et coll., 2011), corpus augmenté par les données métriques regroupées par J. Peters (1998) sur les chiens romains de Germanie. Ces mesures complètent les vides de la répartition constituée à partir de notre échantillon médiéval, sans déplacer pour autant les principales limites établies à partir des distributions méridionales. Dans la zone de confluence avec les loups actuels, ils augmentent de $3 \mathrm{~cm}$ la hauteur au garrot maximale de l'échantillon. 
Figure 5 : Radius de canins provenant de sites romains et médiévaux, et hauteurs au garrot de divers loups actuels.

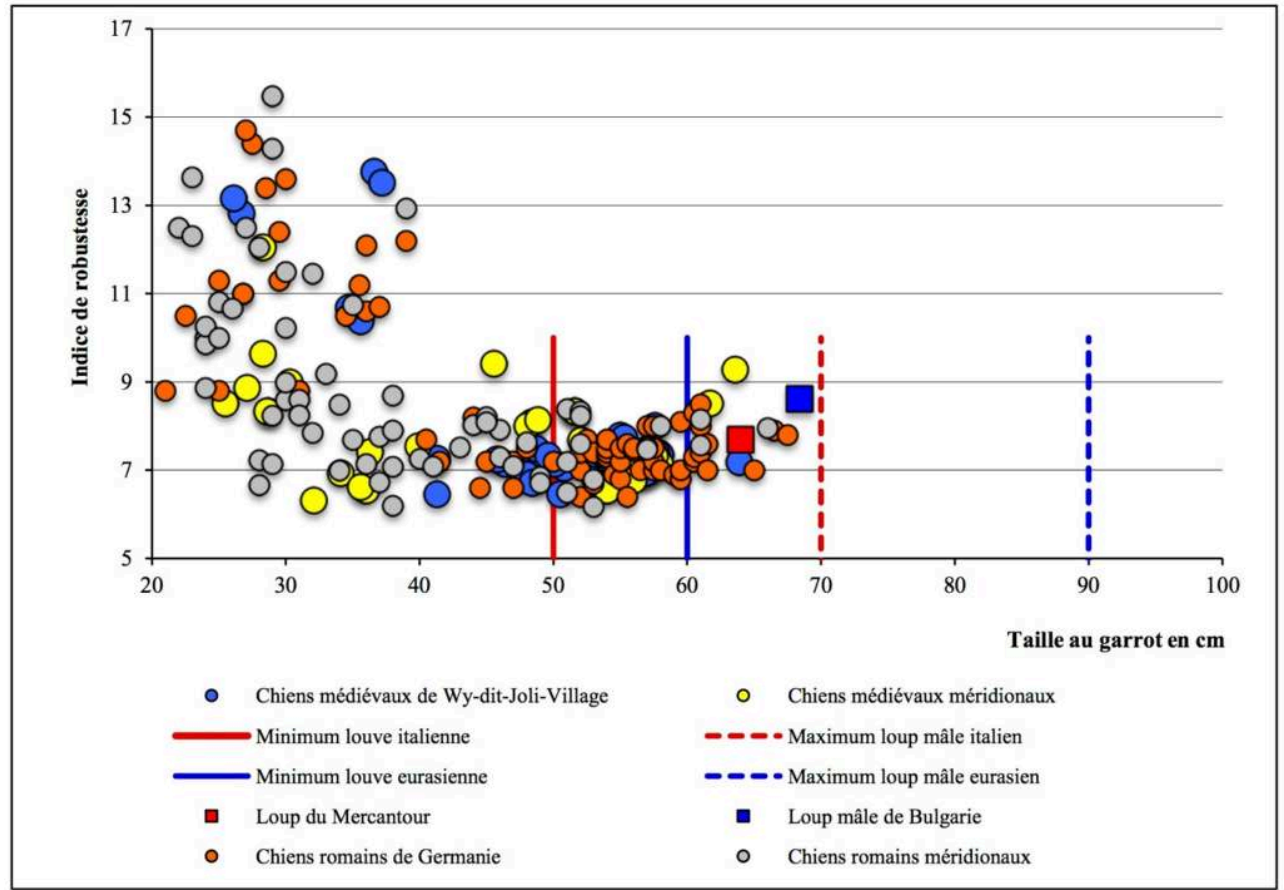

11 Mais alors, où est donc le loup médiéval ? Prenons l'exemple du site de Pech de Bonal à Fontanes, habitat rural isolé dans le Lot, occupé de la fin du XII siècle à la première moitié du XIII ${ }^{e}$ siècle. Nous avions identifié un humérus et un tibia comme provenant d'un loup, en raison des grandes longueurs et largeurs diaphysaires (Boudartchouck et coll., 1997-1998, p. 83). L'humérus a été replacé parmi les exemplaires mis au jour à Wydit-Joli-Village et dans les divers sites médiévaux méridionaux (fig.6). Que nous prenions le loup italien actuel ou le loup eurasien comme référence de la population lupine médiévale, il est impossible de dire si ces grands os sont ceux d'un chien ou d'un loup. Donc nous sommes obligés de parler de "grands canins " pour eux comme pour tout os issu d'un site du Moyen Âge entrant dans cette zone de recouvrement des mesures. Néanmoins, l'hypothèse d'une population médiévale de loup de même taille que le loup eurasien actuel permet d'élaborer un raisonnement plus positif. Si des spécimens de loup figurent parmi les grands os canins, il faudrait conclure qu'ils proviennent uniquement de petites femelles puisque ces grands os canins, dont celui de Fontanes, ne couvrent qu'un modeste tiers inférieur de la variabilité du loup eurasien. Les occupants des sites auraient ainsi procédé à un même tri parmi les loups, malgré la diversité chronologique et géographique des lieux de découverte. Une telle uniformité de comportement humain serait surprenante, bien que non exclue. En conséquence, nous aurions tendance à conclure que, dans le cas où la population locale de loups médiévaux est de taille similaire à celle de loups eurasiens actuels, les grands os canins sont essentiellement ceux de chiens. Les os de grands canins de Fontanes illustrent l'importance $d u$ choix des populations référentielles lupines utilisées par l'archéozoologue dans la perception du loup et l'identification des os archéologiques des grands canins. Le résultat peut en effet totalement changer selon le référentiel utilisé. 
Figure 6 : Humérus de canins provenant de sites médiévaux et du site de Fontanes (Lot), et hauteurs au garrot de divers loups actuels.

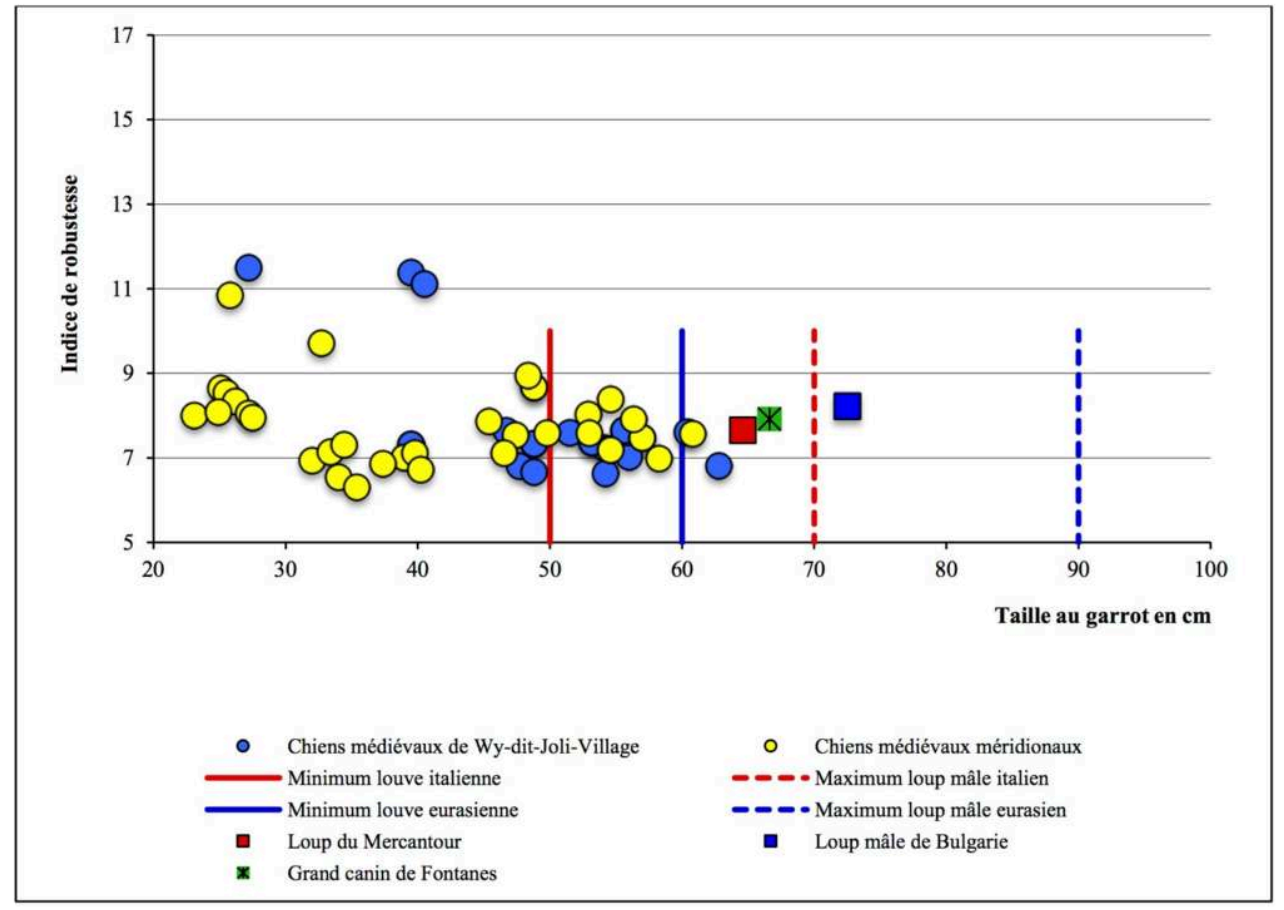

Très récemment, les squelettes de six loups dont un individu italien, conservés dans les collections du Laboratoire d'Anatomie Comparée du Muséum national d'Histoire naturelle de Paris, ont pu être opportunément mesurés. Les données métriques des humérus ont été placées parmi les précédentes et se répartissent autour de la valeur de hauteur au garrot « $60 \mathrm{~cm}$ » (fig. 7). La robustesse accentuée de trois d'entre eux, entre 8 et 9 , est à souligner. Elle est également mise en évidence par le radius (fig. 8). Nous nous sommes donc demandé si ce caractère pouvait être utilisé comme critère de différentiation avec le chien. Il n'en est rien. Car un grand canin ${ }^{11}$ d'une hauteur au garrot comprise entre 72 et $77 \mathrm{~cm}$ et identifié par Christian Küchelmann (2009) comme « chien » d'après divers indices, notamment crâniens, est aussi robuste que le loup de Bulgarie, notre valeur maximale (fig. 8). En conséquence, l'élargissement de la diaphyse pourrait simplement résulter du poids élevé de l'animal lorsqu'il est grand, qu'il soit chien ou loup. Il est par ailleurs intéressant de noter, à ce jour, qu'aucun des chiens romains dont les restes osseux ont été mis au jour sur divers sites de Germanie ne dépasse la limite des $70 \mathrm{~cm}$ au garrot. On ne remarque, en effet, aucune continuité entre ce groupe et le chien de Frise. Ce petit hiatus montre que ce dernier est exceptionnel au sein de cette population canine ${ }^{12}$. 
Figure 7 : Humérus de canins provenant de sites médiévaux, et hauteurs au garrot de divers loups actuels et de loups actuels du Muséum national d'Histoire naturelle de Paris.

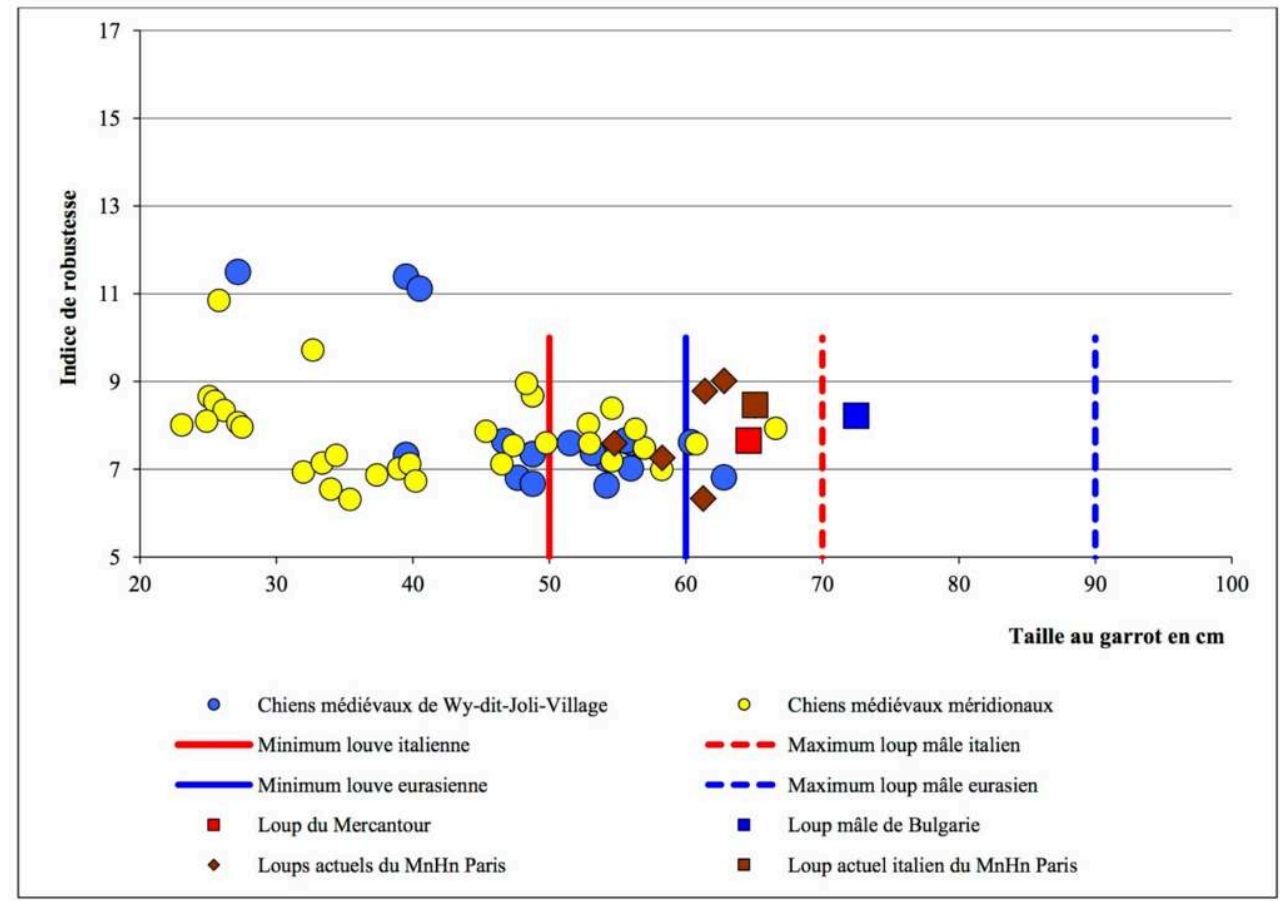

Figure 8 : Radius de canins provenant de sites romains et médiévaux, et hauteurs au garrot de divers loups actuels, de loups actuels du Muséum national d'Histoire naturelle de Paris, et d'un chien romain de Frise allemande.

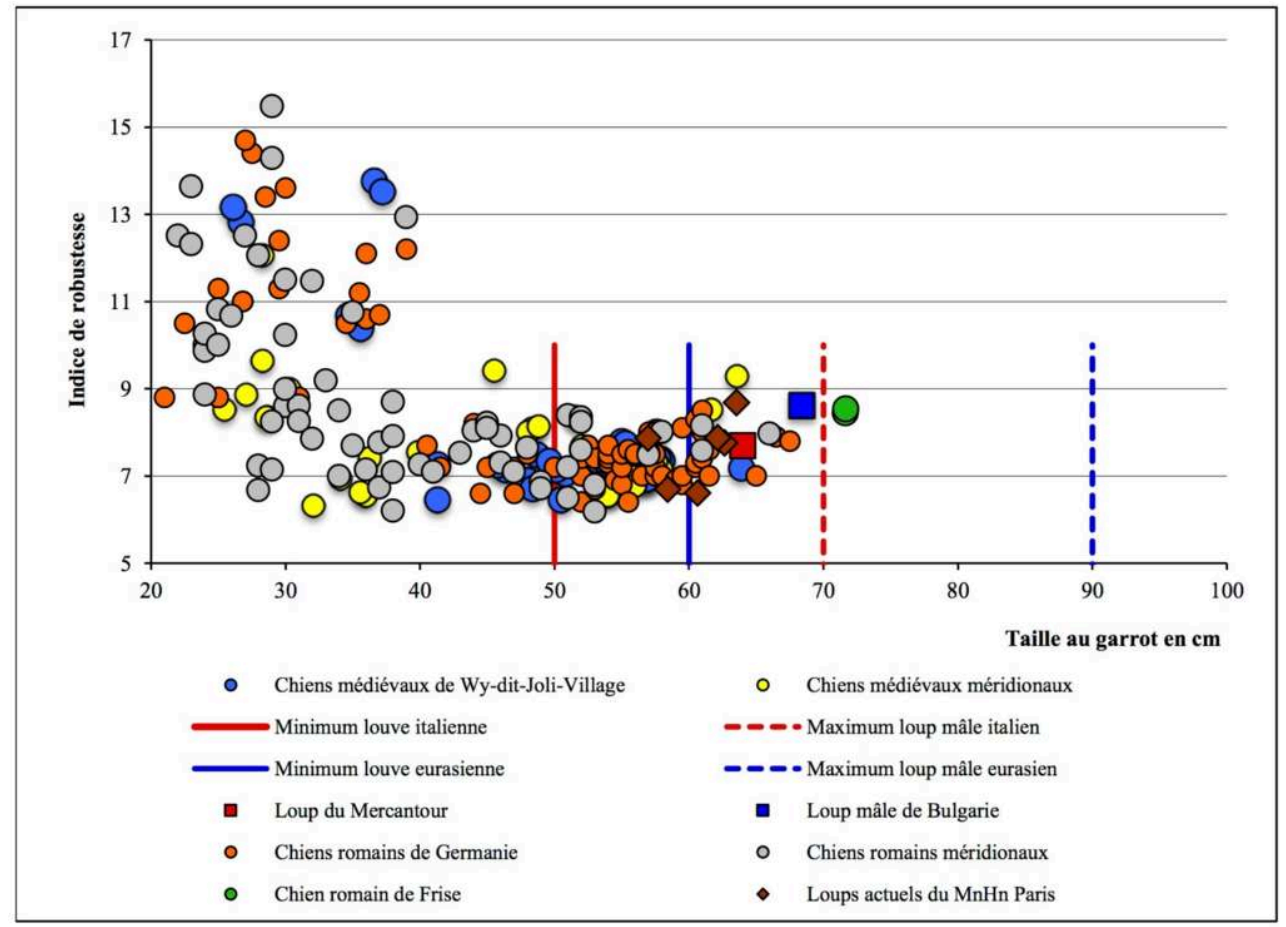




\section{Au Néolithique}

néolithiciens, du fait de la concomitance spectaculaire de squelettes canins et humains sur certains sites (Carrère et Forest, 2003 ; Forest, 2004a, à paraitre). Pourtant le bilan de la consultation de nos études sur la fin du Néolithique ancien, le Néolithique moyen chasséen et le Néolithique final en Languedoc méditerranéen nous a surpris. Les os canins entiers et mesurables sont finalement assez rares, partiellement à cause du mauvais état de conservation des vestiges osseux. Nos études qui ont porté sur une soixantaine de sites fouillés et une trentaine de diagnostics archéologiques, en ont relevé dans cinq sites localisés dans quatre communes, deux d'entre eux étant à Nîmes (Gard). Cette réalité reflète finalement une certaine rareté générale de ce taxon qui tranche avec les découvertes funéraires plus remarquables.

Ainsi, seuls quatre humérus entiers peuvent être pris en compte (fig. 9). Ils sont eumétriques et correspondent à des animaux de 37 à $50 \mathrm{~cm}$ de hauteur au garrot. Ils n'entrent donc pas dans l'intervalle des tailles au garrot des loups actuels. Les neuf tibias s'inscrivent dans un intervalle un peu plus large, avec deux individus dont les hauteurs au garrot estimées sont de $51 \mathrm{~cm}$ (fig. 10). Enfin, les onze radius ${ }^{13}$ confirment l'homogénéité des os canins néolithiques - la valeur maximale étant de $52 \mathrm{~cm}$ au garrot - et, en conséquence, celle de la morphologie des animaux originels (fig.11). Ces résultats concordent avec ceux issus de la synthèse réalisée par Ralph A. Harcourt sur les chiens néolithiques de Grande-Bretagne où l'intervalle de variation des hauteurs au garrot déduites des 25 humérus, radius et tibias s'étend de 37 à $47 \mathrm{~cm}$, à l'exception de deux os qui illustrent la présence de deux canins de 61 et $62 \mathrm{~cm}$ (Harcourt, 1974, p. 157). Le recouvrement entre les canins néolithiques languedociens et le loup italien est minime, et il est nul vis-à-vis du loup eurasien. Nous pouvons donc conclure qu'aucun os de loup n'a été rapporté sur les sites néolithiques du Languedoc. Pourtant, il serait étonnant que ce dernier n'eût pas rôdé autour des troupeaux dans cette région. Force est de constater qu'il n'est pas, à ce jour, restitué par l'archéologie, contrairement au lynx pardelle (Lynx pardinus) dont quelques ossements ont été mis au jour dans des contextes néolithiques ${ }^{14}$. Ces derniers prouvent bien qu'un contact existait avec les grands carnivores prédateurs d'animaux domestiques (Rodet-Belarbi et Forest, 2014, p. 21). 
Figure 9 : Humérus de canins provenant de sites néolithiques et médiévaux, et hauteurs au garrot de divers loups actuels.

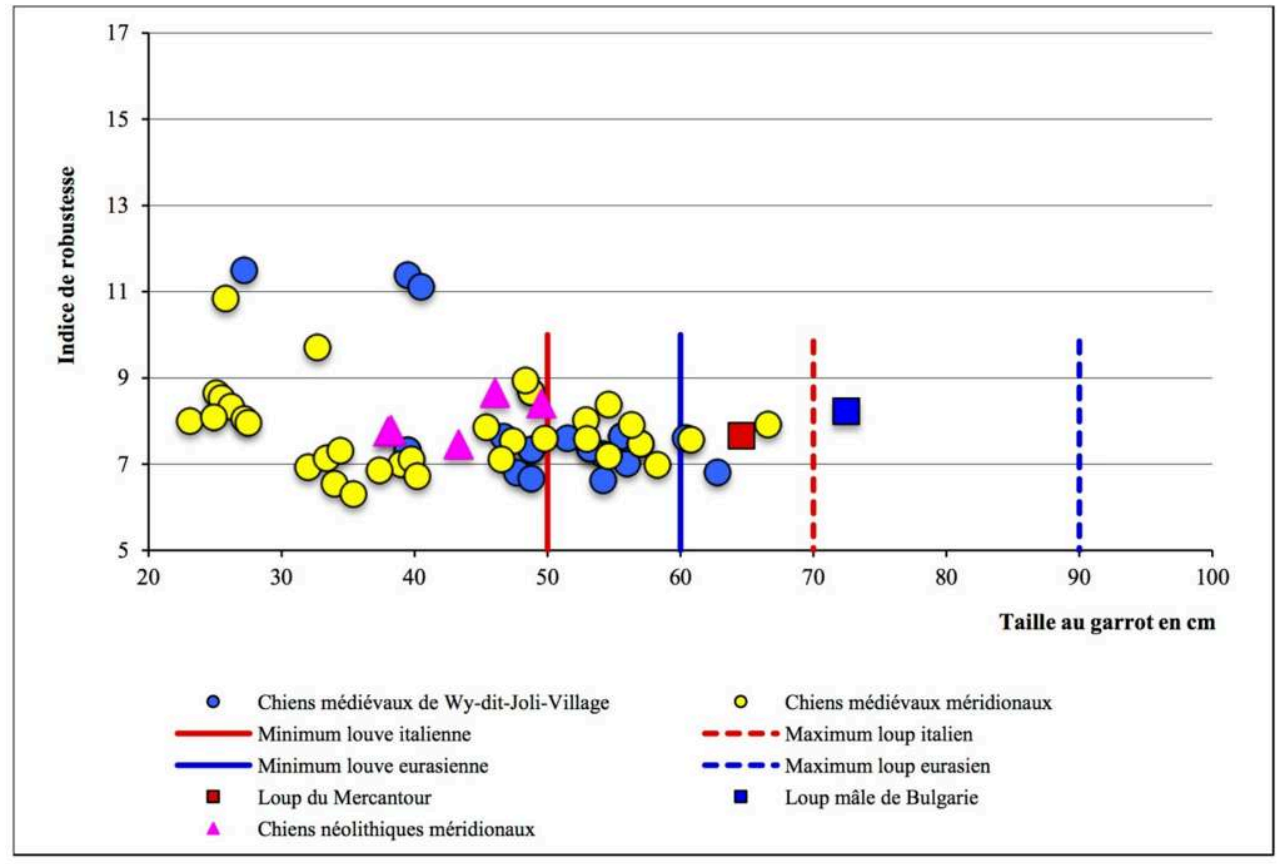

Figure 10 : Tibias de canins provenant de sites néolithiques et médiévaux, et hauteurs au garrot de divers loups actuels.

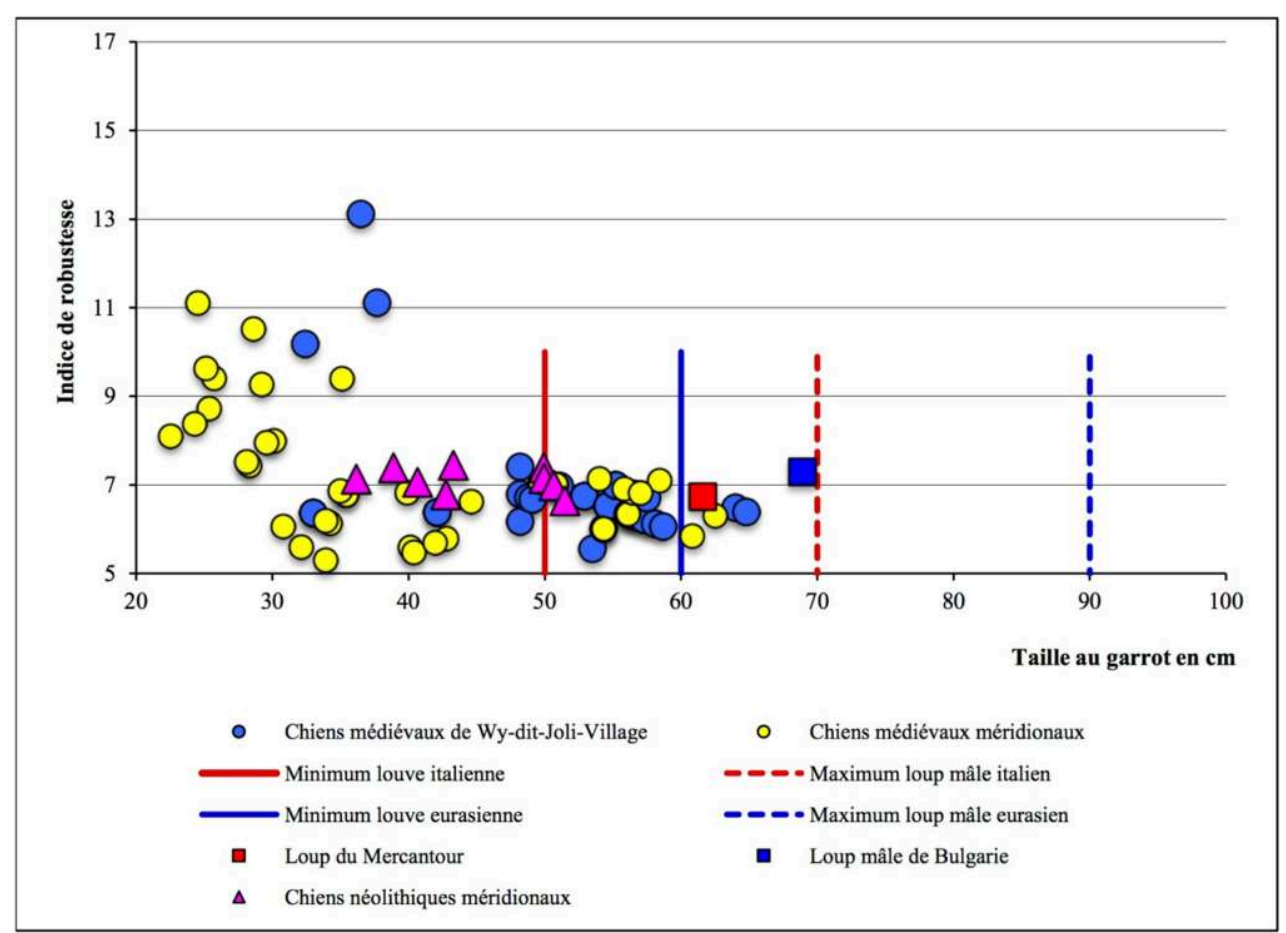


Figure 11 : Radius de canins provenant de sites néolithiques, romains et médiévaux, et hauteurs au garrot de divers loups actuels.

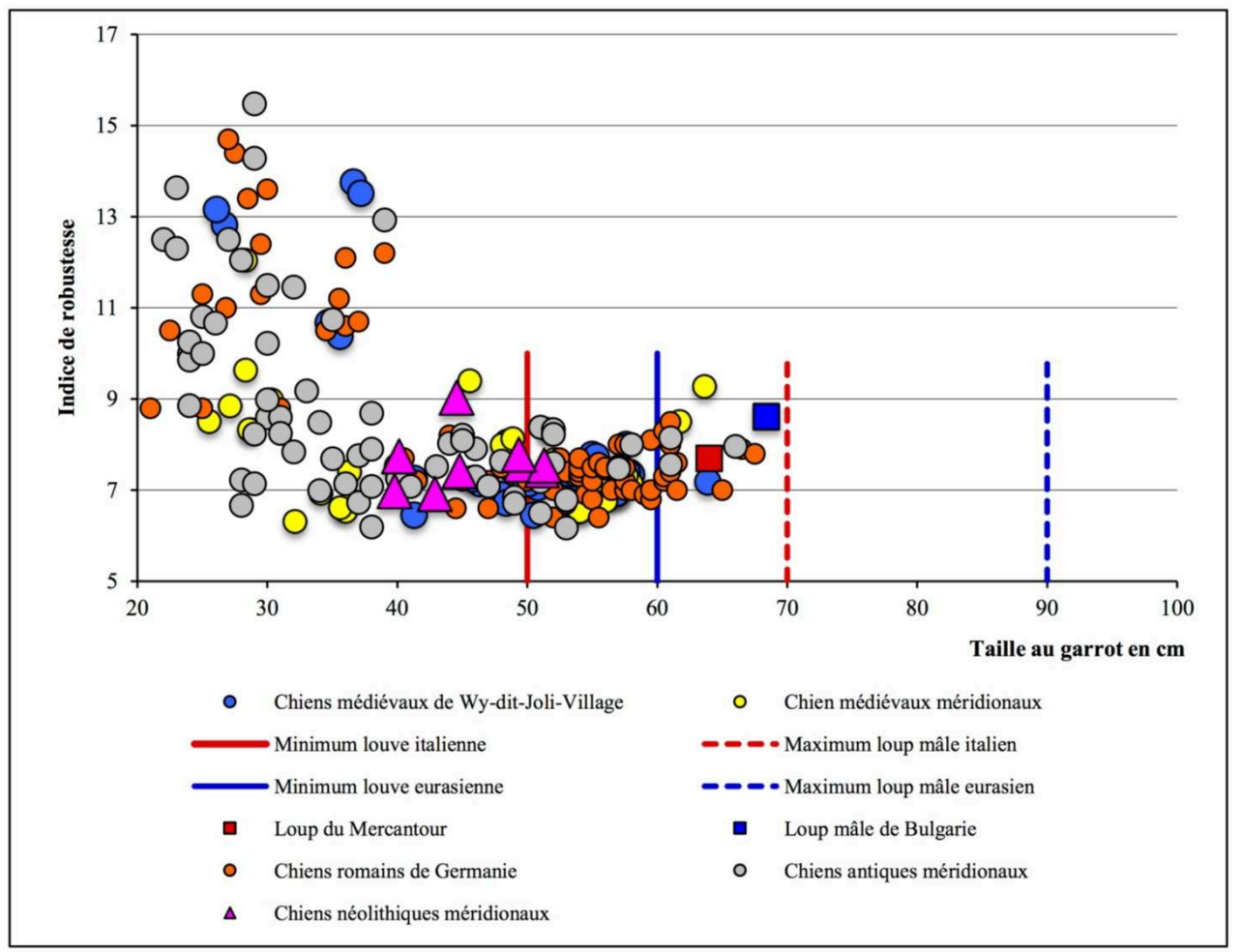

15 Accessoirement, notre recherche sur la distinction entre chien et loup nous a incités à regarder du côté du renard (Vulpes vulpes), autre canidé qui côtoie le chien. Ici aussi, nous ne connaissons pas de travaux qui mettent à notre disposition des critères morphoscopiques distinctifs à partir des os longs. De plus, nos propres observations récentes qui rejoignent une première expérience ancienne (Forest, 1994) nous conduisent à une grande prudence dans l'identification. L'approche ostéométrique montre que la question des grands canins se pose de la même manière pour des canins de taille moyenne, entre environ 30 et $40 \mathrm{~cm}$ de hauteur au garrot (fig. 12) ${ }^{15}$. Les chiens néolithiques languedociens, ne sont pas des loups, certes, mais les plus petits pourraient être des renards au vu de la dimension de leurs os ${ }^{16}$ ! 
Figure 12 : Radius de canins provenant de sites romains et médiévaux, et hauteurs au garrot de divers loups actuels, de loups et de renards actuels du Muséum national d'Histoire naturelle de Paris, et d'un chien romain de Frise allemande.

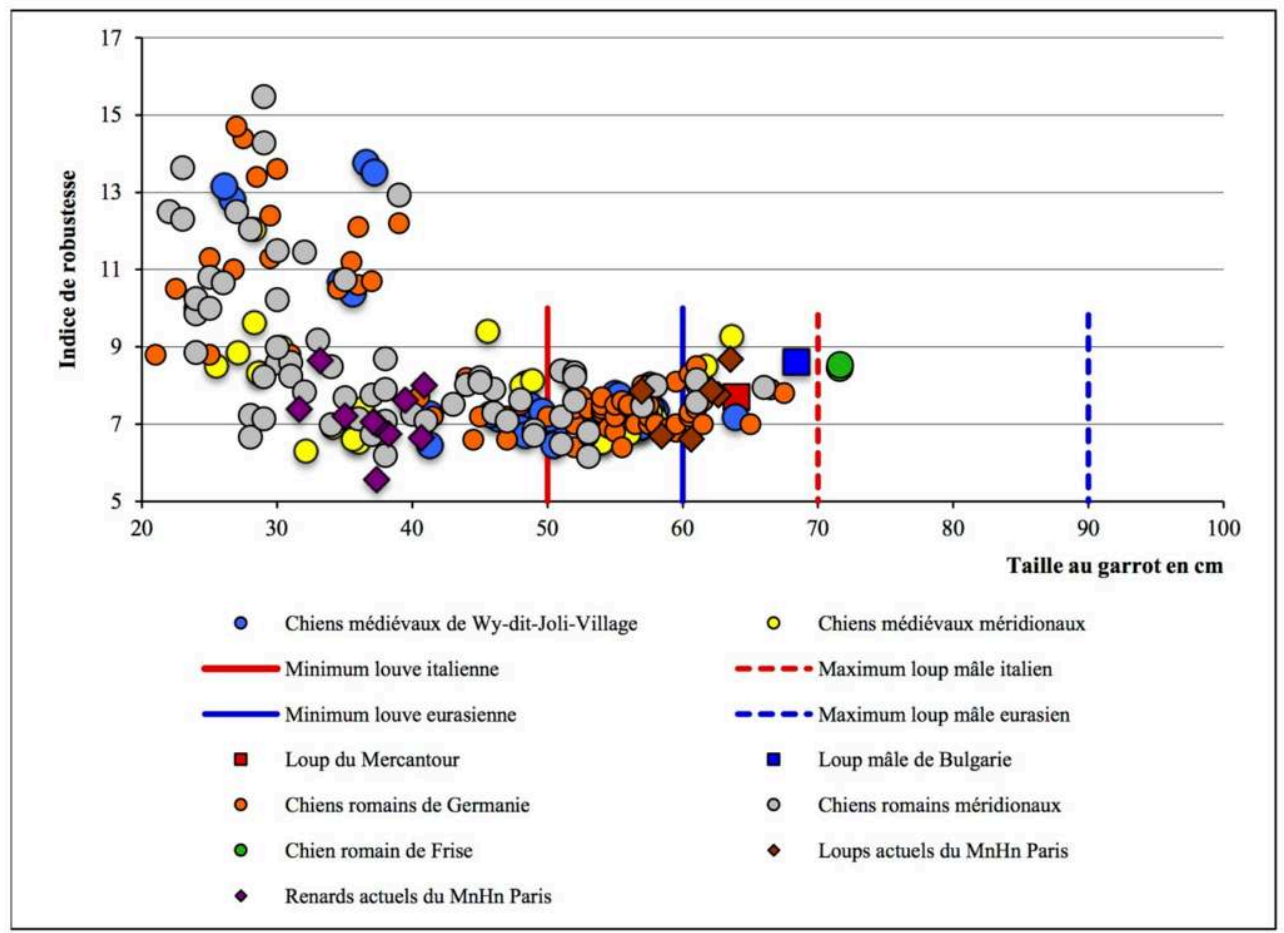

16 En France méridionale, nous sommes dépourvus en archéozoologie classique face aux os longs de canins dont la grande longueur donne une hauteur estimée au garrot égale ou supérieure à $50 \mathrm{~cm}$, c'est-à-dire concrètement ceux issus des niveaux archéologiques datés des périodes romaines et médiévales ${ }^{17}$. Ils peuvent être de chien ou de loup. Au contraire, ceux des canins néolithiques appartiendraient tous au chien à défaut d'être suffisamment grands pour se placer nettement dans l'intervalle de variation du loup, sans écarter pour certains l'hypothèse du renard. Les programmes de recherches en cours en morphométrie géométrique ou une systématisation des analyses ADN viendront peut-être suppléer notre carence pour les animaux des périodes historiques, voire de l'âge du Fer. Il faut par ailleurs remarquer que les tailles des plus grands chiens romains et médiévaux ne dépassent pas $70 \mathrm{~cm}$ au garrot, à l'exception d'un chien romain de Frise, et ne couvrent donc pas la distribution totale du loup eurasien. Il faut attendre les acquis zootechniques et l'établissement des races telles que le dogue allemand ou le Saint-Bernard pour trouver des chiens actuels possédant des hauteurs au garrot similaires à celle des plus grands loups (Rodet-Belarbi et Forest, 2014, p. 28). L'association des os longs isolés à un crâne complet permettrait de reconnaître éventuellement le loup, mais nous n'avons jamais été confrontés à ce cas de figure. Pourtant, afin de toucher les primes récompensant l'abattage d'un loup (Moriceau, 2010, p. 55), il fallait rapporter le cadavre « entier et couvert de sa peau » (Maccagnan, 2014, p. 103), ou seulement montrer la tête de l'animal à laquelle on coupait les oreilles pour qu'elle ne soit pas présentée plusieurs fois, ou la patte droite dans le cas des mâles (Beck et Fabre, 2014, p. 35). Ces pratiques auraient pu être un facteur favorisant la présence de ces restes dans les lieux habités et leur exhumation lors de fouilles archéologiques. Est-ce ainsi qu'il faut interpréter les ${ }^{18}{ }^{18}$, tous de grand format, d'une main droite d'adulte, découverts dans l'abbaye de La Celle (Var, fin $\mathrm{XI}^{\mathrm{e}}$-XII ${ }^{\mathrm{e}}$ siècle ; 
Rodet-Belarbi, 2014; fig. 13) ? À moins qu'ils ne soient les derniers témoins de la présence d'une peau même si aucune trace de découpe n'a été observée sur les diaphyses des métacarpes ${ }^{19}$. En effet, certains indices, plus anthropologiques, suggèrent parfois l'identification du loup. Ainsi la découverte de cinq phalanges d'un grand canin dans le château de Cabaret à Lastours (Aude; forge ; fig. 14), associée à une extrémité distale de métapode isolée par section avec une lame lourde et tranchante (fig. 15), nous a permis d'émettre l'hypothèse de pendants d'une peau préparée en fourrure (Forest et Rodet-Belarbi, 2001). L'exceptionnalité de ce type d'observation et les grandes dimensions des os nous ont conduits à parler d'une peau de loup. La responsable du chantier, Marie-Élise Gardel (1999), a été ravie : une célèbre châtelaine de Cabaret fut surnommée «la Louve », loba en occitan.

Figure 13 : Métacarpes II, III, et IV, et phalanges d'un grand canin mis au jour à l'abbaye de La Celle (Var, fin $\mathrm{XI}^{\mathrm{e}}-\mathrm{XII}$ siècle) (cliché I. Rodet-Belarbi).

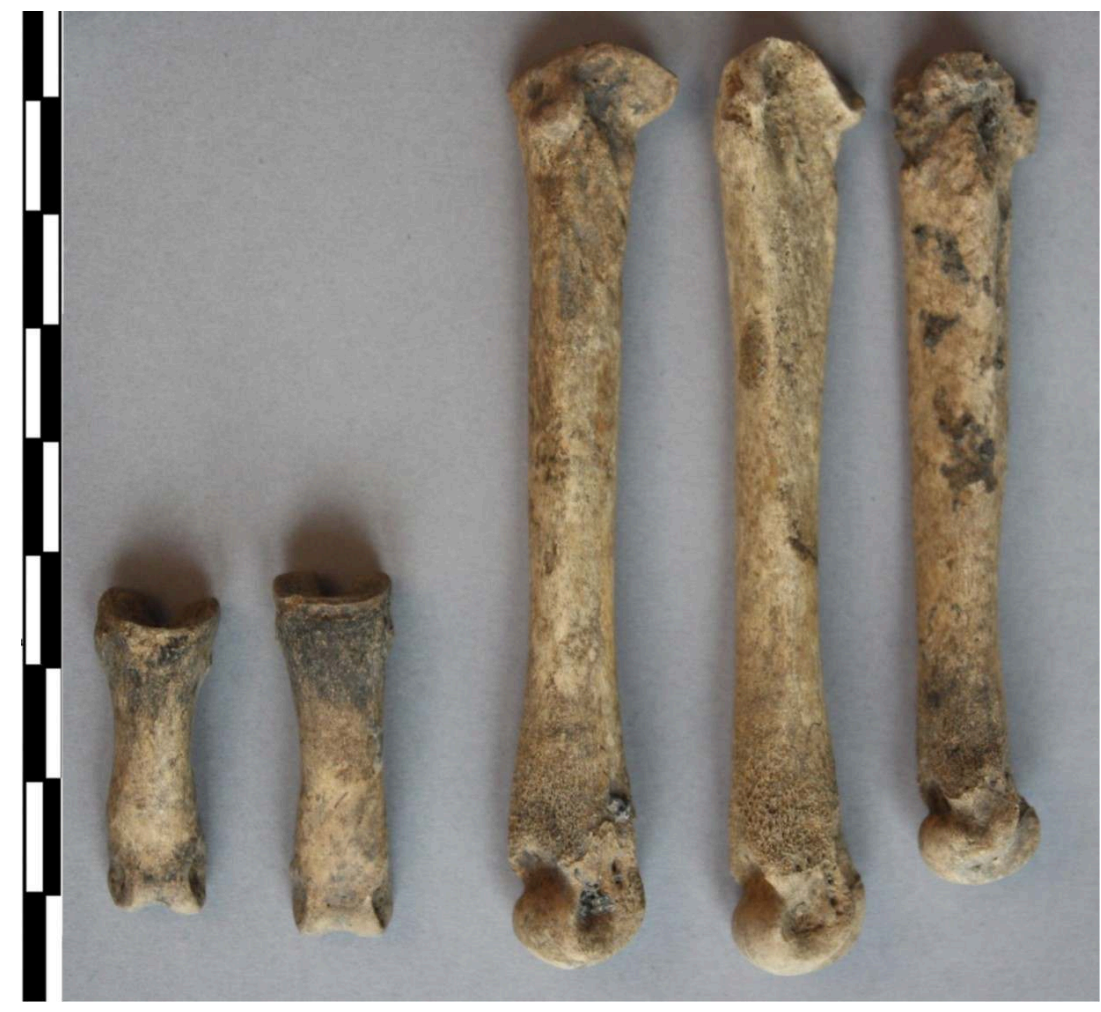


Figure 14 : Comparaison entre des phalanges de chien et celles d'un grand canin découvert sur le site médiéval de Cabaret à Lastours (Aude, 1 ère moitié XIII' siècle) (cliché I. Rodet-Belarbi).

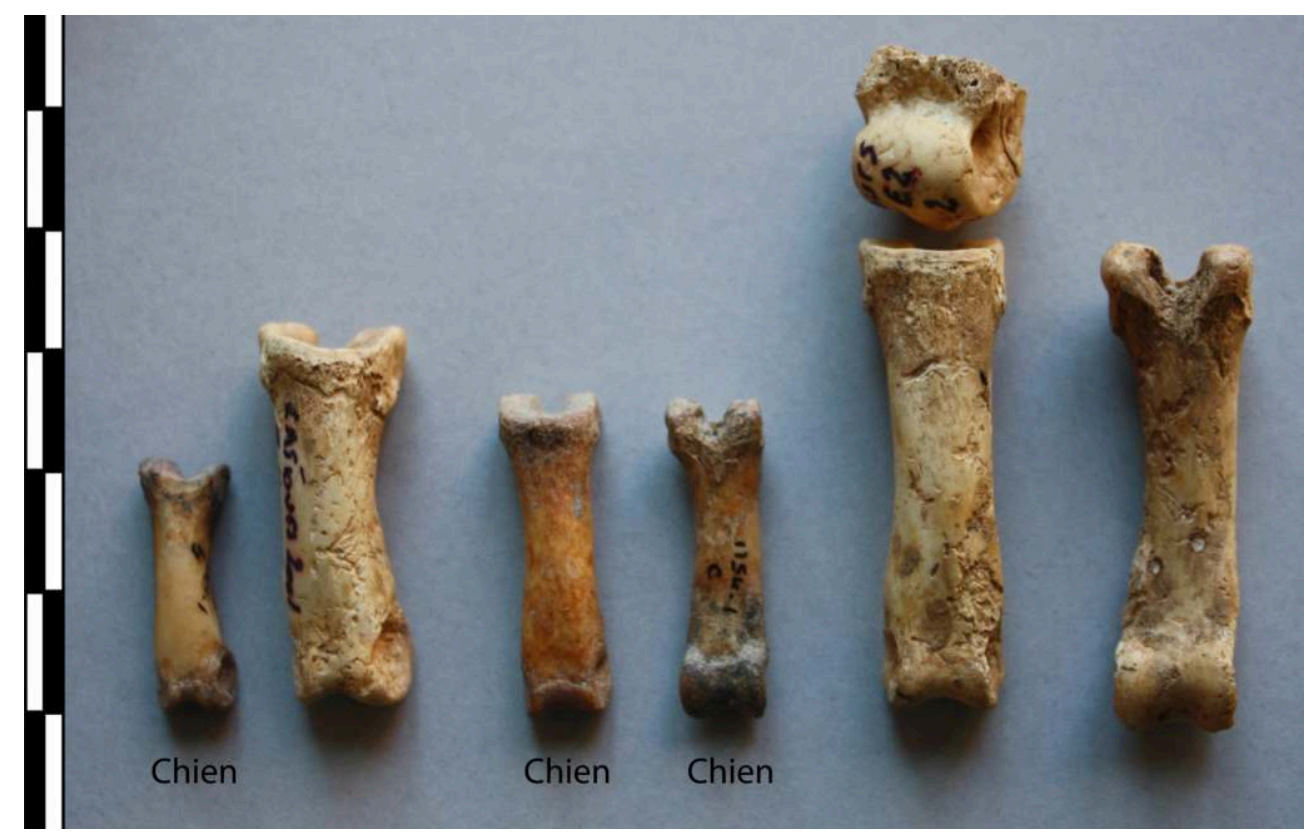

Figure 15 : Découpe sur un métapode de grand canin découvert sur le site médiéval de Cabaret à Lastours (Aude, $1^{\text {ère }}$ moitié XIII ${ }^{e}$ siècle) (cliché I. Rodet-Belarbi).

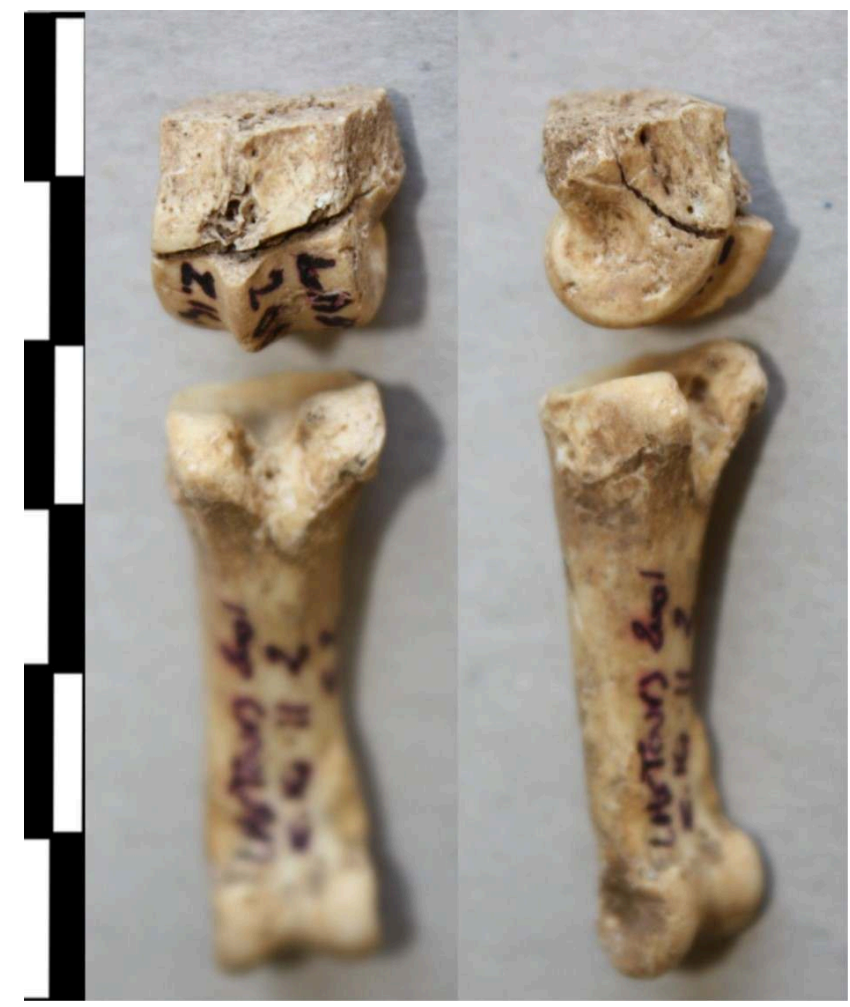

18 Quand la légende des hommes rejoint l'énigme archéozoologique du loup en France méridionale... 


\section{BIBLIOGRAPHIE}

BARBERAN Sébastien, CONVERTINI Fabien, DELAGE Richard, GAFÀ Raffaella, MAUFRAS Odile, PELLÉ Richard, RAUX Stéphanie et RODET-BELARBI Isabelle, « Un dépotoir des années soixante-dix-110 de n.è. aux portes de Nemausus et au bord de la voie Domitia », Revue Archéologique de la Narbonnaise, 47, 2014, p. 155-239.

BECK Corinne et FABRE Éric, « La destruction du loup en Bourgogne au Moyen Âge (1350-1440). Approche quantitative » dans MORICEAU Jean-Marc (dir.), Vivre avec le loup ? Trois mille ans de conflit, éd. Tallandier, 2014, p. 34-44.

BOUDARTCHOUCK Jean-Luc et coll. SALGUES Thierry, VEYSSIÈRE Frédéric, RODET-BELARBI Isabelle, GAROTIN Barnard, DIEULAFAIT Francis, BARRÈrE Michel, « L'habitat rural et le souterrain médiéval de Pech de Bonal (Fontanes, Lot) », Archéologie du Midi Médiéval, tome XV et XVI, 1997-1998, p. 67- 105.

CARRÈRE Isabelle, «Étude des chiens » dans VIGNAUD Alain (dir.), Les jardins de Vert parc, à Castelnaule-Lez, 34. Un habitat néolithique moyen de culture chasséenne. Document Final de Synthèse, fouille de sauvetage, AFAN Méditerranée, SRA Languedoc-Roussillon, 1999, 95 P., 43 fig.

CARRÈRE Isabelle et FOREST Vianney, « Archéozoologie du Néolithique final au Bronze ancien en Languedoc oriental », dans GUILAINE Jean, ESCALLON Gilles (dir.), Les Vautes (Saint-Gély-du-Fesc, Hérault) et la fin du Néolithique final en Languedoc oriental, Archives d'Écologie Préhistorique (Eds), Toulouse, 2003, p. 307-333.

CONVERTINI Fabien, FURESTIER Robin, ASTRUC Laurence, FOREST Vianney, JALLOT Luc, « Le Mas de Vignoles IV à Nîmes (Gard) : résultats préliminaires des fouilles d'un fossé à occupation campaniforme » dans DARTEVELLE Hélène (dir.), Auvergne, Midi - Actualités de la recherche : actes de la $5^{e}$ session, Clermont-Ferrand (Puy-de-Dôme), 8 et 9 nov. 2002, Préhistoire du Sud-Ouest, Cressensac, 2004, p. 493-507.

DELORT Robert, Le commerce des fourrures en Occident à la fin du Moyen Âge (vers 1300-vers 1450). Rome, École française de Rome, 1978, 2 vol. (Bibliothèque des Écoles françaises d'Athènes et de Rome, 236).

FALIÈRES Laurent, Étude archéozoologique du puits à chiens médiéval de Wy-dit-Joly-Village (Val d'oise), Thèse de doctorat vétérinaire, École nationale Vétérinaire de Toulouse, 94-TOU3 - 4041, 1994.

FOREST Vianney, «Archéozoologie des sites de Lastours, Durfort et Villeneuve-la-Comptal », dans Formes et fonctions de l'habitat castral en France méridionale. Les apports de la bordure méridionale du Massif Central. Rapport triennal de synthèse, Projet collectif 01 du programme H18 du CSRA «Villages et terroirs médiévaux et post-médiévaux », 1992, p. 128-150.

FOREST Vianney, « Approche du chien médiéval par l'archéozoologie », dans Histoire et évolution du chien, séminaire 25 et 26 mars 1994, Société française de cynotechnie, 1994, 14 p.

FOREST Vianney, «Étude ostéologique », dans ARLAUD Catherine et al., Place des Terreaux. Lyon 1991-1994, Document final de synthèse, Service Régional de l'Archéologie Rhône-Alpes, 1995, p. 423-447.

FOREST Vianney, «Étude de la faune », dans MARTIN Lucas (dir.), Moulines. Lansargues (Hérault). Habitat et cimetière du Moyen Âge (VIII $\left./ \mathrm{XIV}^{e}\right)$, Document Final de Synthèse, Service Régional de l'Archéologie Languedoc-Roussillon, Montpellier, 1996. 
FOREST Vianney, «Étude archéozoologique », dans ALFONSo Guy (dir.), Aigueperse (Puy-de-Dôme). Les Cérais. Habitat rural du Haut Moyen Âge. Nécropole de l'Âge du Fer, Document Final de Synthèse, AFAN, Service Régional de l'Archéologie Auvergne, 1998, 3 vol.

FOREST Vianney, «Étude archéozoologique », dans BERGERET Agnès et al., Rue Maguelone. Montpellier - Hérault (34). Archéologie et tramway, Document Final de Synthèse, Service Régional de l'Archéologie Languedoc-Roussillon, Afan, Montpellier, 1999a, p. 102-117

FOREST Vianney, « Les données archéozoologiques », dans GINOUVEz Olivier (dir.), Montpellier. La Faculté de Droit. Regard sur un îlot urbain d'origine médiévale (XIII ${ }^{e}-\mathrm{XVIII}{ }^{e}$ siècles), Document Final de Synthèse, Service Régional de l'Archéologie Languedoc-Roussillon, Montpellier, 1999b, p. 57-75. FOREST Vianney, «Étude archéozoologique », dans LOISON Gilles, FABRE Véronique, VILLEMEUR Isabelle (dir.), Rocade Nord de Béziers (34). Le Crès. Habitats préhistoriques en bordure de l'Orb. Structures domestiques et sépultures du Chasséen ancien, Document Final de Synthèse - fouille archéologique, INRAP, Service Régional de l'Archéologie Languedoc-Roussillon, Montpellier, 2004a, p. 55-63.

FOREST Vianney, «Premiers éléments sur la faune néolithique », dans JALlOT Luc (dir.), Mas de Vignoles IV à Nîmes (Gard). Volume I - Le Néolithique : synthèses et bilan scientifiques, Document Final de Synthèse - Fouille archéologique, INRAP, Service Régional de l'Archéologie LanguedocRoussillon, Montpellier, 2004b, p. 126-130

FOREST Vianney, « Étude archéozoologique partielle », dans HASLER Anne (dir.), Fossé aval du Cadereau d'Alès à Nîmes (Gard). Du Paléolithique supérieur à l'Antiquité sur le tracé du Cadereau d'Alès à Nîmes (Gard) : occupation paléolithique, habitats et sépultures néolithiques, traces agraires antiques, Document Final de Synthèse, INRAP, Service Régional de l'Archéologie Languedoc-Roussillon, Montpellier, 2005a, p. 201-213.

FOREST Vianney, «Étude archéozoologique (période médiévale et moderne) », dans BERGERET Agnès (dir.), L'Église Saint-Martin-de-Castries (Hérault, 34). D'un habitat rural carolingien à un prieuré cure dépendant de l'abbaye Saint-Guilhem-le-Désert, Rapport final d'opération, Service Régional de l'Archéologie Languedoc-Roussillon, Montpellier, 2005b, p. 94-115.

FOREST Vianney, «Étude archéozoologique : Ostéologie, conchyliologie », dans GINOUVEz Olivier, Collège Clémence Royer - Montpellier (Hérault) (à partir du XIII siècle), Rapport final d'opération de fouille archéologique en cours, Inrap, Service Régional de l'Archéologie Languedoc-Roussillon, Montpellier, 2008.

FOREST Vianney, «Étude archéozoologique : ostéologie et conchyliologie des ensembles d'époque romaine ", dans MANNIEZ Yves (dir.), Nouvelles données sur les abords de l'amphithéâtre de Nîmes (Gard). Fouille et surveillance de travaux préalables au projet Arènes-Esplanade-Feuchères (AEF). Trottoirs nord et ouest et place des Arènes, Rapport final d'opération de fouille archéologique, Inrap, Service Régional de l'Archéologie Languedoc-Roussillon, Montpellier, 2010, tome II, p. 109-149.

FOREST Vianney, «Étude archéozoologique », dans VIGNAUD Alain, RAUX André (dir.), PyrénéesOrientales, Trouillas, mas Domenech 464, passage de la ligne LGV. Un habitat du Néolithique ancien et du Néolithique moyen, Rapport Final d'Opération, Inrap, SRA Languedoc-Roussillon, Montpellier, 2011, p. 70-90.

FOREST Vianney, «Étude archéozoologique diagnostique. Ortaffa - Pujals (Pyrénées-Orientales) », dans котARBA Jérome, DOMinguez Cécile (dir.), Pyrénées-Orientales, Ortaffa, projets de parcs photovoltaïques «Colomina del Prat 1,2 et 3 ». Approche diachronique d'un terroir en bordure de la dépression de Bages, Rapport final d'opération-Diagnostic archéologique, Inrap, Service Régional de l'Archéologie Languedoc-Roussillon, Montpellier, 2012, vol. 2, p. 154-155 
FOREST Vianney, «Étude archéozoologique : ostéologie », dans RAUX André (dir.), ZAC de la Farigoule 2 - Aubord (Gard) (Néolithique final), Rapport final d'opération, Fouille archéologique en cours, Inrap, Service Régional de l'Archéologie Languedoc-Roussillon, Montpellier, 2015.

FOREST Vianney et FABRE Véronique, « Les vestiges anthropologiques et archéozoologiques ", dans SABRIÉ Maryse et SABRIÉ Raymond (dir.), La maison au grand triclinium du clos de la Lombarde à Narbonne, Archéologie et Histoire romaine, 19, éd. Monique Mergoil, 2011, p. 295-310.

FOREST Vianney et RODET-BELARBI Isabelle, « Étude archéozoologique », dans GINOUVEz Olivier (dir.), A75/Ermitage - Paulhan (Hérault). ( $v^{e}-\mathrm{XIII}{ }^{e}$ siècles), Document Final de Synthèse en cours, Afan, Service Régional de l'Archéologie Languedoc-Roussillon, Montpellier, 2000.

FOREST Vianney et RODET-BELARBI Isabelle, «Étude archéozoologique. Présentation des zones 14 et 16 de Cabaret, Lastours (Aude) », dans GARDEL Marie-Élise (dir.), Cabaret, Lastours (Aude), Document Final de Synthèse, SRA Languedoc-Roussillon, Montpellier, 2001.

FOREST Vianney (à paraître), « Ostéologie et Conchyliologie des Néolithique moyen/Chasséen et final/Vérazien en Languedoc méditerranéen », dans CONVERTINI Fabien (dir.), Le site du Champ du Poste (Carcassonne, Aude) : occupations et sépultures néolithiques.

GARDEL Marie-Élise (dir.), Cabaret. Histoire et archéologie d'un castrum. Les fouilles du site médiéval de Cabaret à Lastours (Aude), C.V.P.M., Maison des Mémoires, Carcassonne, 1999, 965 p.

HARCOURT Ralph A., « The dog in prehistoric and early historic Britain », Journal of Archaeological Science, 1, 1974, p. 151-175.

HERBIN-HORARD Marie-Pierre, « La viande de chien à l'âge du Fer : quels individus pour quelles consommations? », Gallia, 71-2, 2014, p. 69-87.

KOUDELKA F., « Das Verhältnis der Ossa longa zur Skeletthöhe bei den Säugetieren », Verhandl. Den Naturforsch. Ver. Brünn, 1885, 24, p. 127-153.

KÜCHELMANN, HANS Christian, «Ein Canidenskelett (5. - 8. Jh.) aus der Wurt Jemgumkloster (Gemarkung Holtgaste, Gde. Jemgum, Ldkr. Leer/Ostfriesland) », Nachrichten aus Niedersachsens Urgeschichte, 78, 2009, p. 57-78.

MACCAGNAN Stéphanie, « La gestion de la présence des loups dans les Alpes-Maritimes au XIX siècle ", dans MORICEAU Jean-Marc (dir.), Vivre avec le loup ? Trois mille ans de conflit, éd. Tallandier, 2014, p. 89-104.

MORICEAU Jean-Marc, Histoire du méchant loup. 3000 attaques sur l'homme en France, $\mathrm{XV}^{e}-\mathrm{XX}{ }^{e}$ siècle, Paris, Fayard, 2007, 627 p. ; $2^{\mathrm{e}}$ éd. augmentée, 2008, VI-634 p.

MORICEAU Jean-Marc, « La dangerosité du loup sur l'homme. Une enquête à l'échelle de la France ( $\mathrm{XVI}^{\mathrm{e}}-\mathrm{XX}^{\mathrm{e}}$ siècle) ", dans MORICEAU Jean-Marc et MADELINE Philippe (dir.), Repenser le sauvage grâce au retour du loup, Bibliothèque du pôle rural, $\mathrm{n}^{\circ}$ 2, Presses Universitaires de Caen, 2010, p. 41-74.

MORICEAU Jean-Marc (dir.), Vivre avec le loup ? Trois mille ans de conflit, éd. Tallandier, 2014, 619 p.

PERSONNAZ Benoit, Les ossements animaux du site de la place Saint-Etienne à Toulouse, le puits public (XVI$\mathrm{XVII}^{e}$ siècles), Thèse de doctorat vétérinaire, École nationale vétérinaire de Toulouse, 92-TOU3 4093, 1992.

PETERS Joris, Römische Tierhaltung und Tierzucht. Eine Synthese aus archäozoologischer Unterschung und scriftlich-bildicher Uberlieferung. Passauer Universitätsschriften zur Archäologie, Band 5, Verlag Marie Leidorf GmbH \& Co. Rahden, 1998, 444 p. 
PLUSKOWSKI Aleksander, Where are the wolves? Investigating the scarcity of European grey wolf (Canis lupus lupus) remains in medieval archaeological contexts and its implications, International Journal of Osteoarchaeology, 16, 2006, p. 279-295.

RODET-BELARBI Isabelle, «Étude des ossements animaux », dans CATALO Jean (dir.), ExtensionPréfecture, Toulouse. Document Final de Synthèse. Association pour les Fouilles Archéologiques Nationales, Service Régional de l'Archéologie Midi-Pyrénées, Toulouse, 1995.

RODET-BELARBI Isabelle, «Étude des ossements animaux », dans ARRAMOND Jean-Charles (dir.), Site du Lycée Ozenne à Toulouse (Haute-Garonne). Document Final de Synthèse. Association pour les Fouilles Archéologiques Nationales, Service Régional de l'Archéologie Midi-Pyrénées, Toulouse, 1997, 2 vol.

RODET-BELARBI Isabelle, «Étude des ossements animaux », dans REQUI Christophe (dir.), Site de l'Ourmède, Castelnau d'Estretefonds (Haute-Garonne). Document Final de Synthèse. Association pour les Fouilles Archéologiques Nationales, Service Régional de l'Archéologie Midi-Pyrénées, Toulouse, 1999.

RODET-BELARBI Isabelle, «Étude des ossements animaux », dans CHOPIN et al. (dir.), Salies-du Salat, site des trois vallées (Haute-Garonne). Document Final de Synthèse. Association pour les Fouilles Archéologiques Nationales, Service Régional de l'Archéologie Midi-Pyrénées, Toulouse, 2000a. RODET-BELARBI Isabelle, « Étude des ossements animaux », dans PONS (dir.), Toulouse, îlot Valade (Haute-Garonne). Document Final de Synthèse. Association pour les Fouilles Archéologiques Nationales, Service Régional de l'Archéologie Midi-Pyrénées, Toulouse, $2000 \mathrm{~b}$.

RODET-BELARBI Isabelle, «Étude des ossements animaux », dans CATALO Jean (dir.), Toulouse « Cité Judiciaire » (Haute-Garonne, Midi-Pyrénées), Rapport final d'opération, INRAP, 2007, 3 vol.

RODET-BELARBI Isabelle, « Étude des ossements animaux », dans BouIRON Marc, MONTEIL Karine, VACASSY Grégory (dir.), Alpes-Maritimes, Nice. Fortifier la ville médiévale et moderne : les fouilles du tramway. Rapport de fouille, Inrap, 2010, 5 tomes.

RODET-BELARBI Isabelle, « Étude des ossements animaux », dans Le GAILLARD Ludovic (dir.), SaintContest, Espace d'Entreprises II : enclos laténo-augustéen, carrières antiques et hameau médiéval au Clos de Bitot. Basse Normandie, Calvados, Rapport Final d'opération, 2013.

RODET-BELARBI Isabelle, La Celle, Var, Étude archéozoologique. Rapport d'étude sous la direction de Marc BORÉANI, Service département d'archéologie, Var, 2014.

RODET-BELARBI Isabelle et FOREST Vianney, « Le loup dans le " paysage » archéozoologique de France, du Néolithique aux Temps Modernes », dans MORICEAU Jean-Marc (dir.), Vivre avec le loup? Trois mille ans de conflit, éd. Tallandier, 2014, p. 19-33.

RODET-BELARBI Isabelle, coll. MASSENDARI Julie et FOREST Vianney, « Les mammifères et les oiseaux », dans BOUET Alain (dir.), Barzan III : un secteur d'habitat dans le quartier du sanctuaire du moulin du Fâ à Barzan, Ausionus, Mémoires 26/supplément 27, vol. 2, 2011, p. 763-843.

STUDER Jacqueline, «Études ostéologiques en relation avec la présence du loup en Valais », Bulletin de la Murithienne, 118, 2000, p. 25-26.

VIVIANI Alessia, GAZZOLA Andrea et SCANDURA Massimo, « Il Lupo : Un predatore sociale ed adattabile », dans APOLLONIO Marco et MATTIOLI Luca (dir.), Il Lupo in provincia di Arezzo, Editrice Le Balze, Montepulciano, 2006, p. 29-43. 


\section{NOTES}

1. Collection de comparaison de l'UMR 7264, CEPAM, Nice. Le sexe de cet animal n'est malheureusement pas connu.

2. D'autres exemples d'os de grands canins dont l'identification spécifique est délicate sont signalés dans la figure 2 .

3. La borne inférieure de l'intervalle de variation de la hauteur au garrot du loup italien dépend des sources de vulgarisation consultées. Certaines indiquent qu'elle se situe à $60 \mathrm{~cm}$ mais sans mentionner l'origine de cette valeur. Aussi, nous nous référons à l'article publié par A. Vivianni et al. (2006).

4. Deux mâles récemment tués à Simplon et à Reckingen (Suisse) avaient $64 \mathrm{~cm}$ de hauteur au garrot (Studer, 2000). L'auteur ne précise pas l'origine des loups mais d'après notre enquête (voir par exemple, http://www.pronatura.ch/grands-predateurs), il est fort probable que ces loups soient italiens. Cette valeur indique donc qu'une petite femelle peut avoir moins de $60 \mathrm{~cm}$ de haut, puisque l'on compte environ $10 \%$ de différence entre les deux sexes. Nous remercions Magali Fabre de nous avoir signalé cet article.

5. Il nous était matériellement impossible de constituer ce corpus à partir des collections muséales dispersées.

6. Notre présentation repose sur le postulat que les formules d'estimation des hauteurs au garrot s'appliquent indifféremment au chien domestique et au loup.

7. Cette présentation est critiquable car elle fait figurer deux valeurs liées entre elles. En effet, la hauteur au garrot (HG) est estimée chez les canins archéologiques à partir de la longueur (GL) à l'aide d'une formule de type $H G=a^{*} G L+b$. Outre la possibilité d'intégrer les bornes de variations des populations actuelles de loups, elle a l'avantage de simplifier la perception visuelle d'un lecteur peu familiarisé avec les nuages de points.

8. Cette estimation du Nombre Minimum d'Individus, calculée à l'échelle du puits, repose sur les atlas.

9. Collection de comparaison de l'UMR 8215, Trajectoires, Nanterre. Tous nos remerciements vont à Lamys Hachem (Inrap, UMR 8215) pour la communication des mesures de cet individu.

10. Notons que si la limite inférieure du loup italien retenue est celle de $60 \mathrm{~cm}$, cette alternative disparaît pour les plus petits individus litigieux.

11. Le cadavre de l'animal a été inhumé durant le $\mathrm{I}^{\mathrm{er}}$ siècle après $\mathrm{J}$.-C., sur le site de Jemgumkloster en Frise allemande. Nous remercions Christian Küchelmann de ces informations, en particulier de la mise à jour de la datation par rapport à la publication originale $\left(\mathrm{V}^{\mathrm{e}}-\mathrm{VIII} \mathrm{e}^{\mathrm{e}}\right.$ siècle ap. J.-C.).

12. Rappelons ici que des représentants de certaines races canines actuelles atteignent ou dépassent le mètre au garrot.

13. Les mesures similaires de plusieurs d'entre eux ne font apparaître que neufs triangles sur la figure.

14. Citons par exemple, une mandibule fragmentaire dans le comblement d'une fosse du Néolithique ancien final à Trouillas/Mas Domenech (Pyrénées-Orientales ; Forest, 2011), deux métatarses dans le comblement d'un fossé du Néolithique campaniforme à Nîmes/Mas de Vignoles XI (Gard ; Convertini et al., 2004).

15. Nous avons appliqué les formules d'estimation de la hauteur au garrot des chiens à des os de renards de la collection du Muséum national d'Histoire naturelle (Paris) comme s'ils avaient été attribués au chien lors d'une étude archéozoologique. Mais il est très probable que ces formules ne soient pas valables pour le renard.

16. Cependant, contrairement au loup, la tête du renard est assez nettement différente de celle du chien. La difficulté d'identification ne concerne donc que les os longs isolés. 
17. Pour mémoire, la morphologie des chiens se diversifie et leur taille augmente dès la fin de l'âge du Fer (Herbin-Horard, 2014). Néanmoins, des restes identifiés comme ceux de chiens de grande taille ont été découverts sur des sites plus anciens comme par exemple, à HauteriveChampréveyres (Suisse), daté de l'âge du Bronze, où les plus grands individus atteignent $63 \mathrm{~cm}$ au garrot (moyenne $=58 \mathrm{~cm}$, minimum $=53 \mathrm{~cm}$, maximum $=63 \mathrm{~cm}$, voire $70 \mathrm{~cm}$ d'après un fémur ; Studer, 2000).

18. Il a été retrouvé les métacarpes II, III et IV ainsi que deux phalanges proximales et une phalange intermédiaire.

19. R. Delort a relevé dans Le Traité de chasse de G. Phœbus la mention de moufles ou de pelisses confectionnées dans des peaux de loup (Delort 1978, p. 181).

\section{RÉSUMÉS}

Une synthèse exploratoire sur les os de grands canins de l'époque romaine a montré qu'ils pouvaient tout aussi bien appartenir à un chien de grande taille qu'à un loup (Canis lupus). Ce travail a été étendu au Néolithique en Languedoc, et au Moyen Âge en France méridionale afin de cerner la variabilité morphologique du chien et d'essayer de retrouver le loup par des raisonnements indirects. La période néolithique nous a paru intéressante car d'après le travail synthétique de R. Harcourt (1974) en Grande-Bretagne et nos observations recueillies au fil des études, la taille seule semblait suffire à séparer les deux espèces. Les données issues des sites archéologiques languedociens permettent de tester cette impression. Au contraire, l'approche appliquée au Moyen Âge confirme les résultats obtenus pour la période romaine, et montre que leur différentiation via l'analyse ostéométrique des os longs est irréalisable à défaut de critères ostéologiques morphoscopiques satisfaisants.

\section{AUTEURS}

\section{VIANNEY FOREST}

Docteur vétérinaire biologiste, archéozoologue Inrap, Traces UMR 5608, Toulouse

\section{ISABELLE RODET-BELARBI}

Archéozoologue Inrap, Université Nice Sophia Antipolis, CNRS, CEPAM, UMR 7264, Nice 


\title{
Une vie de chien auprès des premiers éleveurs agriculteurs du Néolithique ancien en Europe occidentale
}

\author{
Rose-Marie Arbogast
}

\section{Introduction}

1 Seul animal domestique auprès des chasseurs-cueilleurs du Mésolithique en Europe, le chien accompagne la diffusion des animaux domestiques en Europe occidentale au cours du VI ${ }^{\mathrm{e}}$ millénaire avant Jésus-Christ. Sur les sites de cette période, la découverte régulière de restes osseux attribuables à cette espèce parmi ceux des animaux domestiques de boucherie permet d'établir sa présence dans l'ensemble de l'aire d'extension des premières communautés agropastorales (Arbogast et al., 2005 ; HorardHerbin et al., 2014). La question n'est donc pas tant de savoir si cet animal joue un rôle auprès des premiers éleveurs, mais bien plutôt de préciser et de comprendre ce rôle. C'est l'objectif de cette contribution qui s'appuie sur les données inédites du site du Néolithique ancien de Herxheim (Rhénanie-Palatinat). Leur étude apporte un éclairage original sur la place qu'occupe cet animal et sur les traitements dont il fait l'objet. Elle permet aussi d'envisager une approche plus détaillée de la relation particulière instaurée entre l'homme et le chien qui demeure généralement hors de portée des reconstitutions archéologiques du fait de la relative discrétion de sa représentation au sein des assemblages archéologiques.

\section{Le chien sur les sites du Néolithique ancien danubien}

2 Les ensembles de faune associés aux habitats du Néolithique ancien danubien représentent une des documentations les plus importantes pour approcher la question du rôle des animaux au sein des premières communautés agro-pastorales en Europe 
occidentale. Les nombreuses analyses menées depuis une cinquantaine d'années soulignent la place prééminente des animaux de boucherie et laissent entrevoir une activité bien établie d'élevage, marquée par le développement d'un important pastoralisme bovin et dans une moindre mesure de celui des petits ruminants et de l'élevage du porc (Arbogast, 1994, 2005 ; Tresset et Vigne, 2001; Arbogast et Jeunesse, 2013). La représentation du chien au sein de ces assemblages est très discrète et contrairement à celle des animaux de boucherie, elle est loin d'être systématique. Sur l'ensemble des sites répertoriés, soit environ 160 habitats répartis entre la Pologne et le Bassin parisien, seuls 250 restes osseux attribués au chien (soit moins de 2 ossements par site, pour des occupations qui ont pu s'étirer sur plusieurs siècles) peuvent être répertoriés (Arbogast, 2005 ; Arbogast et al., 2005). La rareté des ossements de chien ne semble pas due à un défaut de représentativité statistique des lots de faune, car même les plus riches d'entre eux, comme ceux provenant des sites de Cuiry-les-Chaudardes (Hachem, 2011), de Vaihingen-an-der Enz (Schäfer, 2010a, 2010b) ou encore Eilsleben (Döhle, 1994), ne recèlent généralement qu'un faible nombre de restes épars totalisant le plus souvent moins de $1 \%$ des restes déterminés (Arbogast et al., 2005). Cette faible visibilité du chien semble très directement liée à la nature de la documentation disponible pour cette période, presque exclusivement formée des restes osseux associés aux dépotoirs d'habitat au sein desquels le chien fait figure de grand absent. À l'évidence, la place du chien ne peut être appréhendée dans ces ensembles principalement constitués de déchets issus de l'exploitation bouchère des animaux et de leur consommation. Cette réalité est en soi significative de la position particulière qui lui revient par rapport aux autres animaux domestiques. Il s'en distingue par le fait qu'il n'est pas consommé et que de ce fait la perception de son rôle se situe hors des possibilités de recouvrement des sources les plus abondantes. Il convient dès lors de changer d'angle de visée et de se tourner vers d'autres types de données.

Pour s'en convaincre, une première découverte, issue du domaine funéraire peut être mobilisée. Il s'agit d'une sépulture d'un homme et d'un chien, découverte dans la nécropole de Mitterndorf (Autriche) (fig. 1) datée du Rubané, dotée d'un riche mobilier funéraire comprenant une herminette, une valve de spondyle, une meule (Blesl, 2005 ; Bickle et Whittle, 2005). Le squelette complet d'un animal adulte (âge estimé à 3-4 ans), était disposé dans la partie inférieure de la fosse sépulcrale, en position étendue sur son flanc droit, au contact direct des pieds du squelette de l'homme. Cette position et le fait que l'animal a probablement été tué pour accompagner le défunt ne laissent guère de doute au sujet de l'intentionnalité de la communauté de traitement funéraire appliqué au chien et à l'homme. Cette découverte n'est pas sans évoquer celles d'inhumations de chiens attestées dans les nécropoles de chasseurs-cueilleurs de Vedbaeck et de Skateholm au Danemark (Larsson, 1990). Elle traduit un statut privilégié que les données de sites d'habitat ne laissent pas soupçonner. Elle est l'un des rares indices directs de l'existence d'une relation symbolique tellement forte entre le chien et les premiers éleveurs, que le besoin de sa perpétuation dans l'au-delà s'est fait ressentir. 
Figure 1 : Vue de la sépulture 481 de la nécropole de Mitterndorf (Autriche) datée du Rubané.

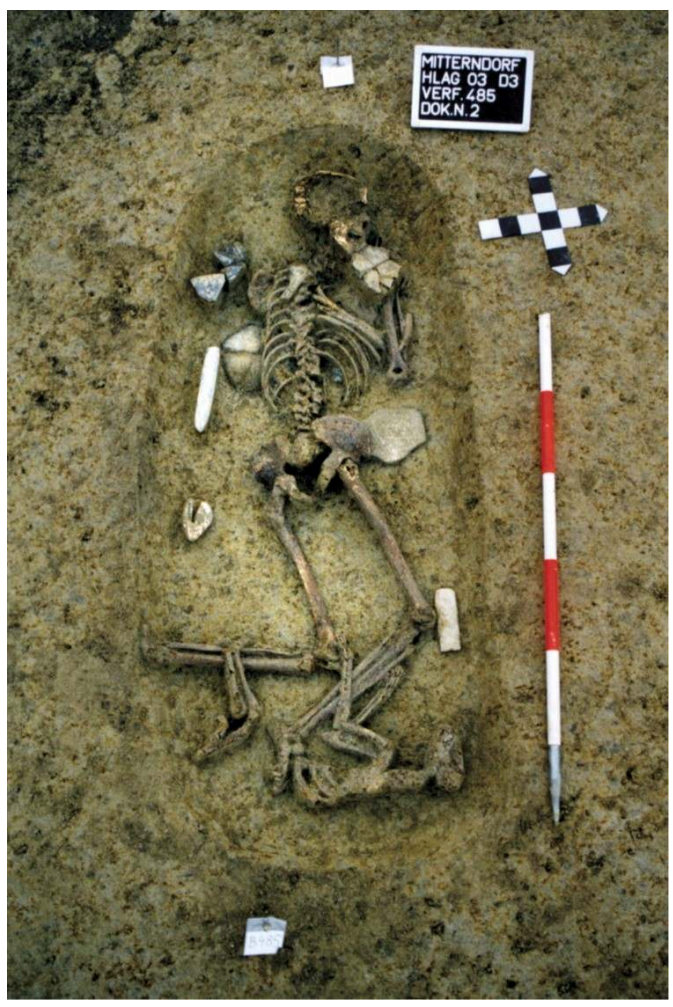

Cliché Abteilung für Archäologie Bundesdenkmalamt Österreich.

\section{Les restes de chien du site de Herxheim}

D'autres indices du statut particulier du chien auprès des éleveurs agriculteurs du Néolithique ancien sont livrés par l'étude de l'important site de Herxheim (Allemagne, Rhénanie-Palatinat) (fig. 2) qui a fait l'objet de plusieurs campagnes de fouilles menées par le Landesdenkmalamt de Speyer et un programme de recherches de la Deutsche Forschungs Gemeinschaft (DFG) auquel étaient associés des chercheurs français (archéologues, archéozoologues et anthropologues). Les travaux sur le terrain se sont échelonnés entre 1996 et 2010. Ils ont révélé une occupation du Néolithique ancien, datée entre 5300 et 4950 avant notre ère, avec un habitat qui se déploie à l'intérieur d'un espace délimité par une structure fossoyée, qui se présente comme une double enceinte reconnue sur plusieurs centaines de mètres et partiellement fouillée (fig. 2) (Zeeb-Lanz, 2009 ; Zeeb-Lanz et al., 2008, 2016). Cette double enceinte correspond en fait à un aménagement d'un type particulier pour lequel l'appellation "enceinte de type Rosheim » s'est généralisée, à la suite des travaux de Ch. Jeunesse (1996). Il s'agit en fait d'un pseudo-fossé constitué de fosses juxtaposées sur un tracé préétabli. Bien séparées les unes des autres au début de l'utilisation du site, les fosses finissent par occuper toute la circonférence de l'enceinte au fur et à mesure de l'utilisation du site et de l'aménagement de nouvelles fosses. Du fait de nombreux chevauchements et recoupements, les espaces entre les fosses finissent par disparaître, donnant l'impression d'une continuité qui n'a en fait jamais existé. L'installation peut se compléter par l'aménagement de plusieurs lignes parallèles de fosses. Il faut donc se représenter un ensemble de fosses alignées, certaines comblées, d'autres fraîchement 
creusées, se juxtaposant ou se recoupant. La variabilité des dimensions des fosses et de leur morphologie suggère le creusement de fosses par des groupes différents (Jeunesse, 1996). La rareté du mobilier associé à ce type de structures ne permet généralement pas de détailler l'historique des aménagements qui peuvent s'étendre sur une durée assez longue, ce qui permet d'écarter l'hypothèse d'une fonction défensive ou économique au profit d'une vocation cérémonielle. L'enceinte de Herxheim se distingue par un très abondant mobilier associant des vestiges de céramiques, d'outillage lithique, de très nombreux ossements humains ainsi que des restes de faune (Arbogast, 2009). D'après les caractéristiques stylistiques des très nombreux tessons décorés, la formation des assemblages associés aux deux rangées de fosses de l'enceinte peut être datée de l'étape finale du Rubané, aux alentours de 5000 BC. Elle marque la fin de l'occupation du site attestée dès l'étape ancienne et signe l'étape ultime du fonctionnement de l'enceinte (Boulestin et al., 2009, Zeeb-Lanz et al., 2016). C'est à cette période déterminante de l'histoire du site que se rapportent les assemblages de restes de faune les plus importants. Ceux associés aux fossés sont riches de plus d'un millier de restes pour ceux issus du fossé externe tandis que pour le fossé interne près de 4000 restes sont disponibles. Moins importants, ceux provenant de la zone d'habitat datés de la même période mobilisent néanmoins des ensembles assez conséquents (2650 restes) (tab. 1). Les restes de faune des fossés sont associés à de riches ensembles de vestiges mobiliers (céramique, lithique) ainsi qu'à de nombreux restes humains dont l'état de fragmentation et les nombreux stigmates de découpe et de prélèvement des masses musculaires et d'exposition au feu renvoient à des pratiques d'anthropophagie (Boulestin et al., 2009 ; Boulestin et Coupey, 2015).

Figure 2 : Localisation géographique et plan du site de Herxheim (Allemagne, land de RhénaniePalatinat).

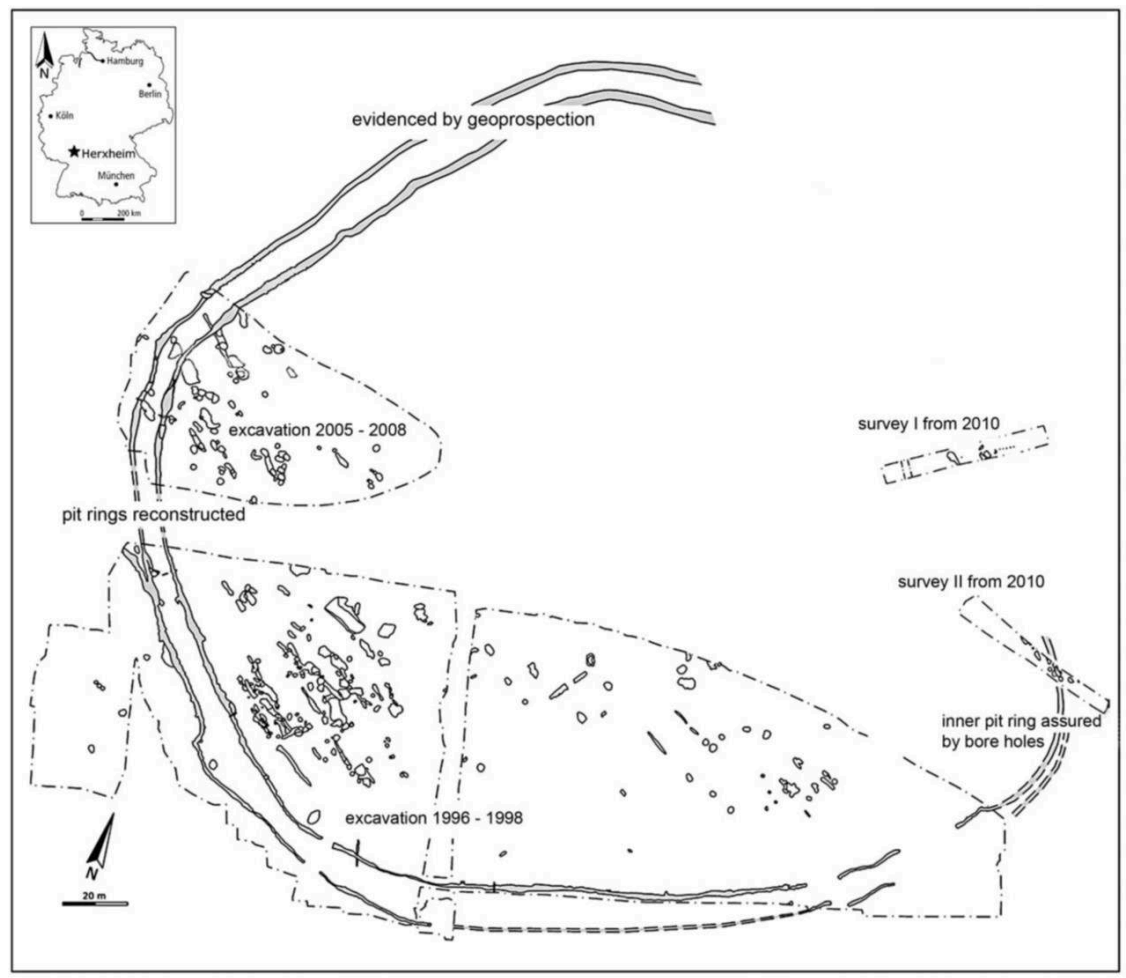


5 La composition des différents lots de faune reflète le rôle prépondérant accordé aux animaux domestiques et plus particulièrement aux bovins (Arbogast, 2009) (tab. 1). L'exploitation de la faune sauvage n'est pas délaissée comme le suggère la chasse privilégiée des grands ongulés sauvages (aurochs, cerf, sanglier) mais sa faible contribution ne permet pas de lui conférer un rôle important comme ressource de l'approvisionnement carné. Le rôle de l'élevage bovin est le plus marqué durant l'étape ancienne. Dès l'étape moyenne sa prépondérance tend à marquer le pas en faveur d'un recours plus équilibré aux animaux domestiques de plus petit gabarit. Plus favorable aux petits ruminants au Rubané moyen et récent, cette réorientation consacre le porc comme principal animal d'élevage au Rubané final qui se constate tant pour les assemblages de faune associés aux structures d'habitat que ceux issus des deux fossés. La différence la plus importante qui distingue les assemblages issus des différents contextes a trait à la représentation des restes de chien qui se retrouvent plus particulièrement dans le fossé interne alors qu'ils ne sont presque pas attestés ailleurs sur le site à l'exception d'un petit nombre d'entre eux $(n=17)$ issus de structures de la zone d'habitat contemporaines de la dernière phase d'utilisation de l'enceinte (fig. 3). Au total, 279 restes de chien, dont 256 issus du fossé interne, se rapportant à un nombre minimum de 13 individus ont pu être identifiés. Cet assemblage concentre plus de restes de chien que ceux disponibles dans l'ensemble des sites de la culture rubanée et représente la seule série conséquente d'ossements de chien disponibles datée du Néolithique ancien.

Tableau 1 : Décomptes (en nombre de restes) des ossements de faune, par étapes chronologiques et types de structures.

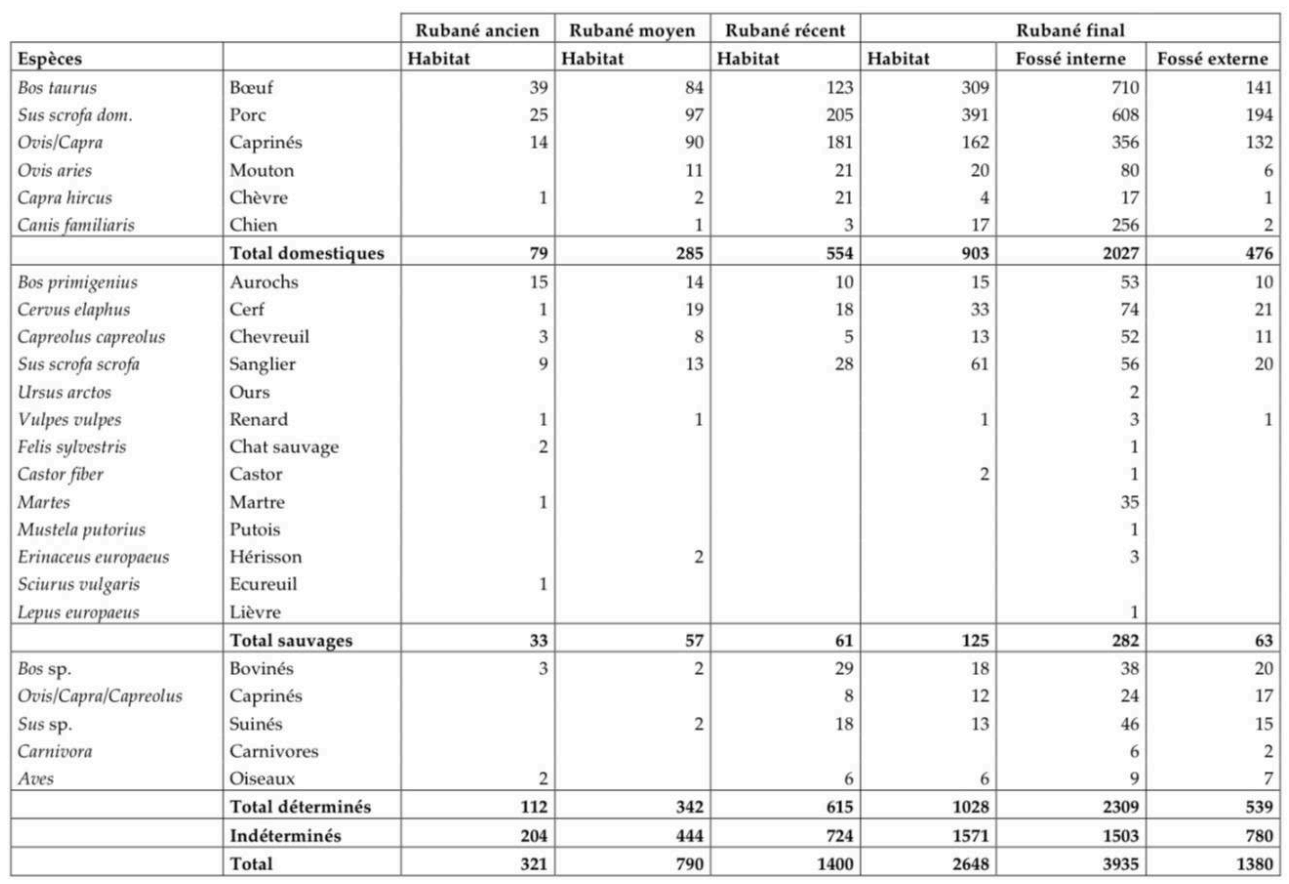


Figure 3 : Variation de la représentation des restes des animaux domestiques dans les différentes structures du site de Herxheim (en pourcentages sur le nombre de restes).

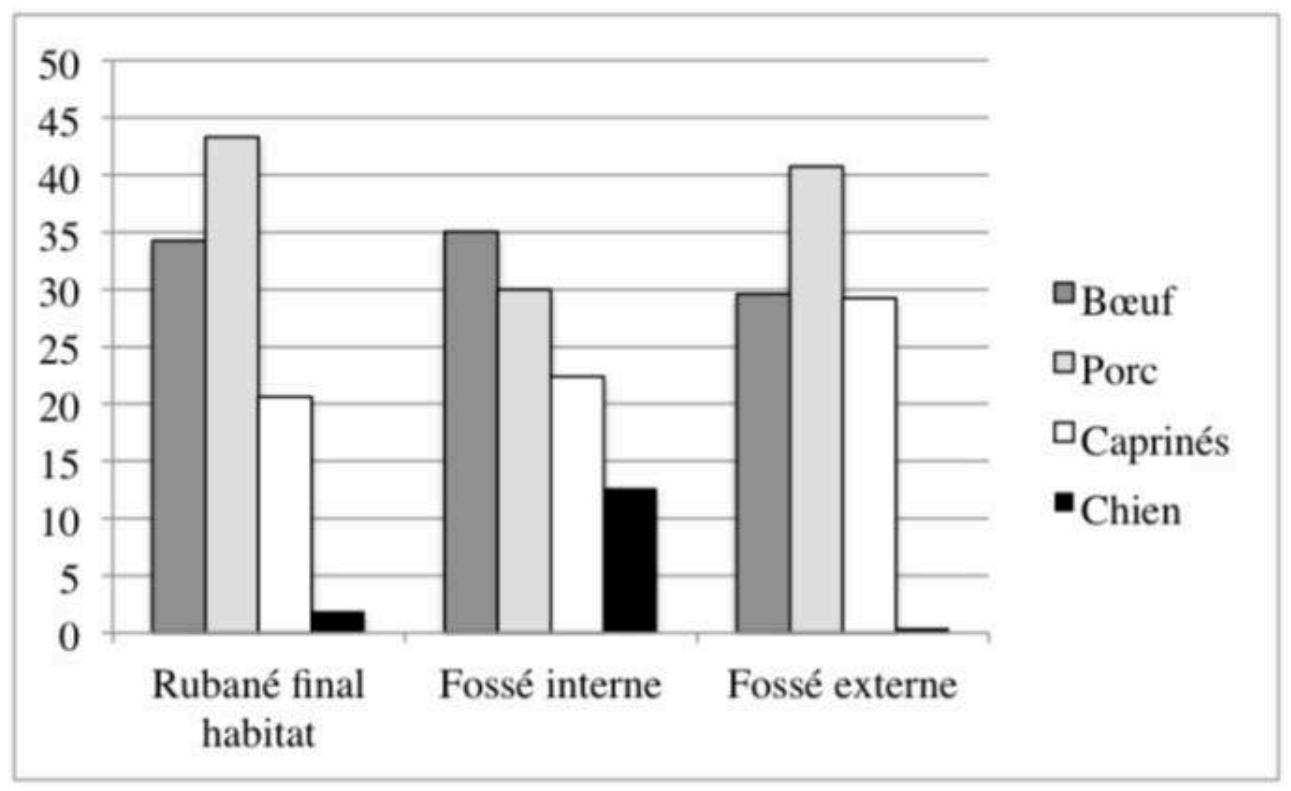

La représentation de cet animal au sein de rejets de consommation est une caractéristique très originale qui ne se retrouve dans aucune autre structure du site ni sur aucun autre site contemporain sur lesquels les chiens ne font généralement pas partie des animaux consommés (Arbogast, 2005). Elle renvoie à une pratique particulière qui semble aussi se traduire par des modalités de traitement des carcasses singulières manifestes tant au niveau de la fragmentation, de la mise en portion des carcasses, de la sélection des parties que du mode de préparation.

7 Ces ossements de chien sont assez bien conservés, souvent complets et indemnes de fracturation, contrairement aux ossements des ongulés sauvages et domestiques avec lesquels ils ont été rejetés et dont l'état de fragmentation systématique (fig. 4), traduit une exploitation détaillée et intensive des carcasses des animaux dont tous les éléments sont systématiquement désarticulés, isolés et fracturés. Les carcasses de chien ne semblent pas non plus avoir fait l'objet d'une découpe très détaillée dans la mesure où la plupart de ces ossements proviennent de petites concentrations de pièces anatomiquement proches. Ces éléments ne sont plus en connexion anatomique mais n'ont pour autant pas été dispersés dans le fossé, comme si chacun de ces petits ensembles de restes de chien résultait de rejets de quartiers d'animaux. Dans le détail, certaines de ces concentrations au sein du fossé interne, semblent correspondre à des segments anatomiques et permettent de reconstituer des parties de carcasses plus ou moins conséquentes : rachis, tronçons de colonne vertébrale, membres antérieurs et postérieurs, grills costaux... (fig. 5). Les traces de découpe observées ne sont pas très abondantes malgré un examen soigneux de l'ensemble des restes osseux sous binoculaire. Les plus nombreuses concernent les vertèbres et la zone sacrum, coxal et fémur (fig. 6, fig. 7A et fig. 7B). Par leur localisation, ces traces semblent plus relever de l'écorchement et de la désarticulation et témoignent plutôt de la préparation et du partage des carcasses que du prélèvement de la viande.

Des marques de l'action du feu sous forme de larges zones brunies et desquamées ont été observées sur les mandibules ainsi que sur les maxillaires (fig. $7 \mathrm{C}$ ), tandis que bon nombre de dents, à l'émail noirci et fissuré, arborent les stigmates d'une exposition 
directe aux flammes qui peuvent être mises en relation avec un mode de cuisson par rôtissage.

Figure 4 : Variation du taux de préservation, qui représente la part conservée, des ossements animaux dans les différentes structures du site de Herxheim.

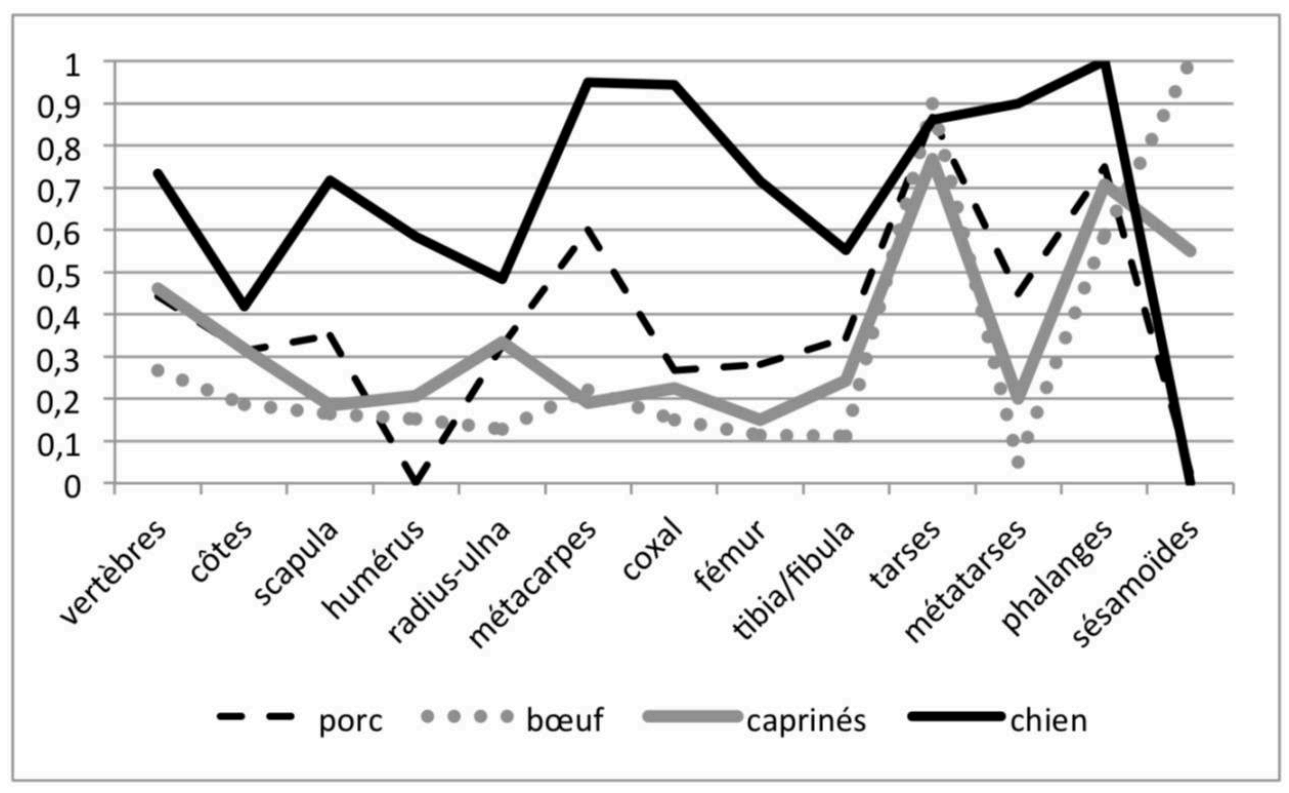

Figure 5 : Origine anatomique des restes de chien de différents lots issus du fossé interne du site de Herxheim.
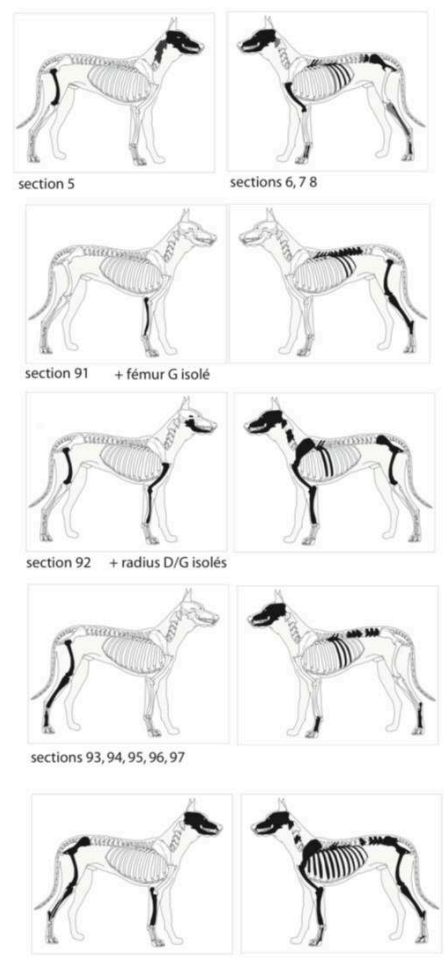
Figure 6 : Localisation des traces de découpe (traits noirs) et de brûlures (zones grisées) relevées sur les restes de chien du site de Herxheim (représentation de toutes les traces compilées sur une seule face).

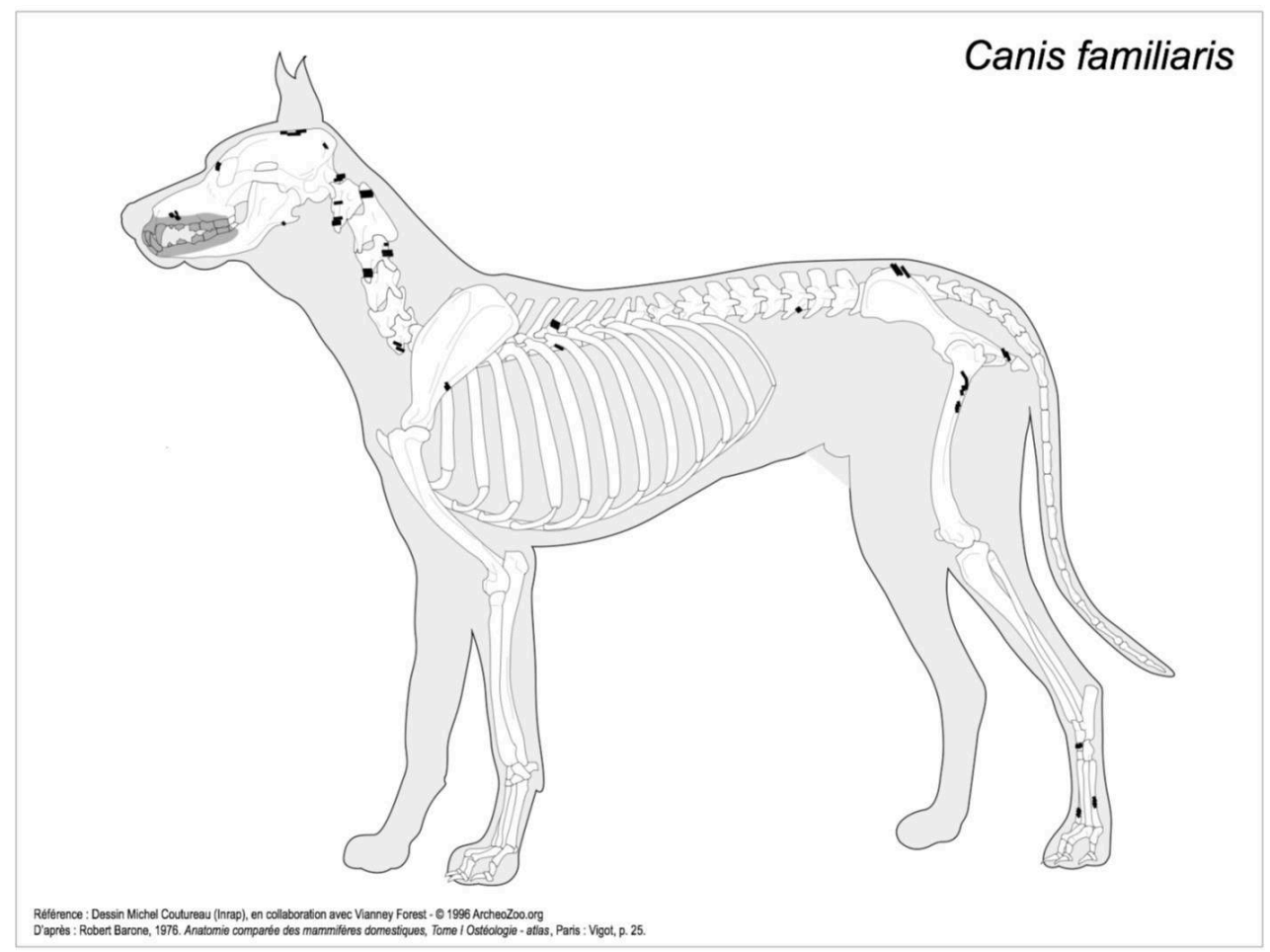

Figure 7 (A) : Vues de différents types de marques relevées sur les restes osseux de chien du site de Herxheim. Traces de désarticulation sur la branche montante de mandibules.

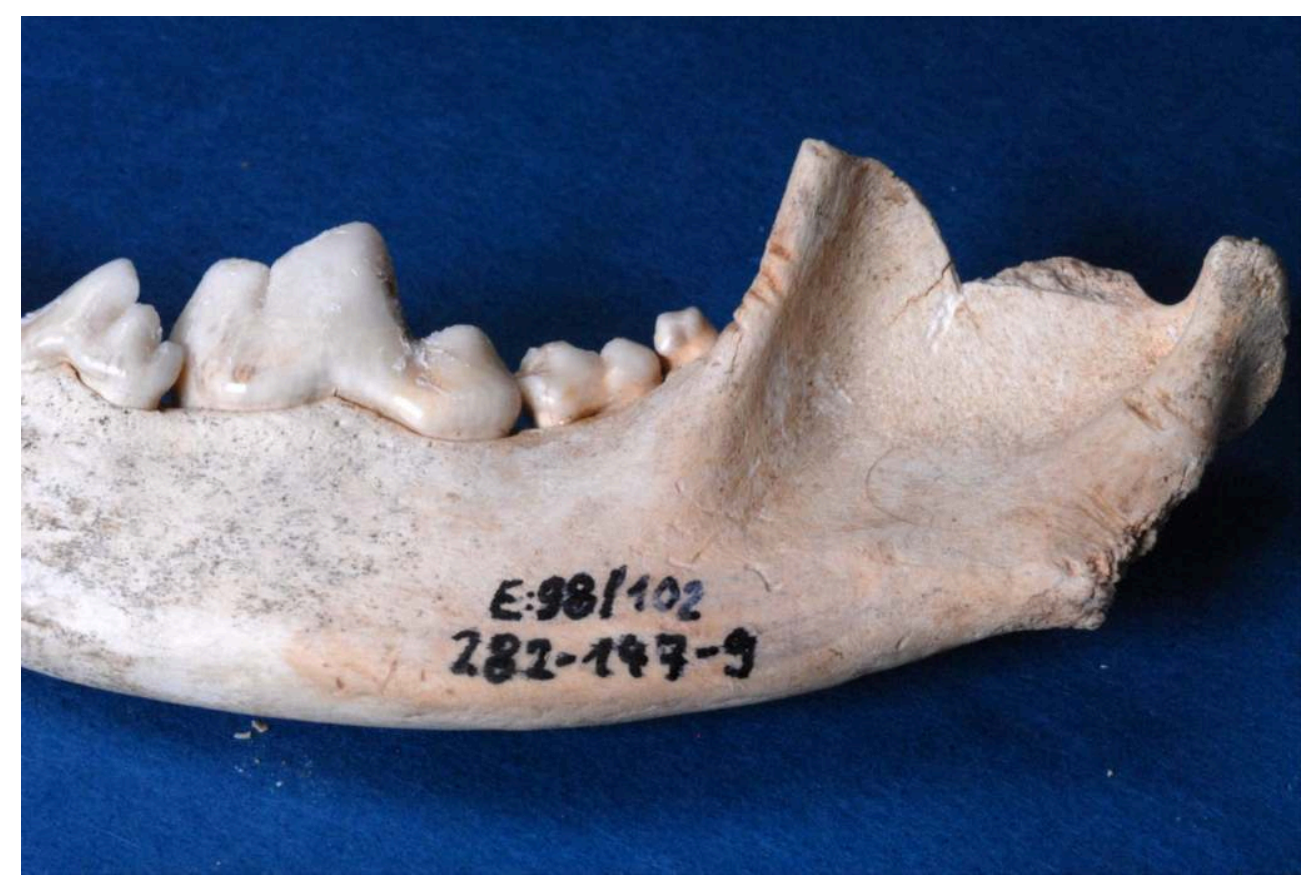

Clichés R.-M. Arbogast. 
Figure 7 (B) : Vues de différents types de marques relevées sur les restes osseux de chien du site de Herxheim. Traces de désarticulation sur les condyles articulaires de l'atlas.

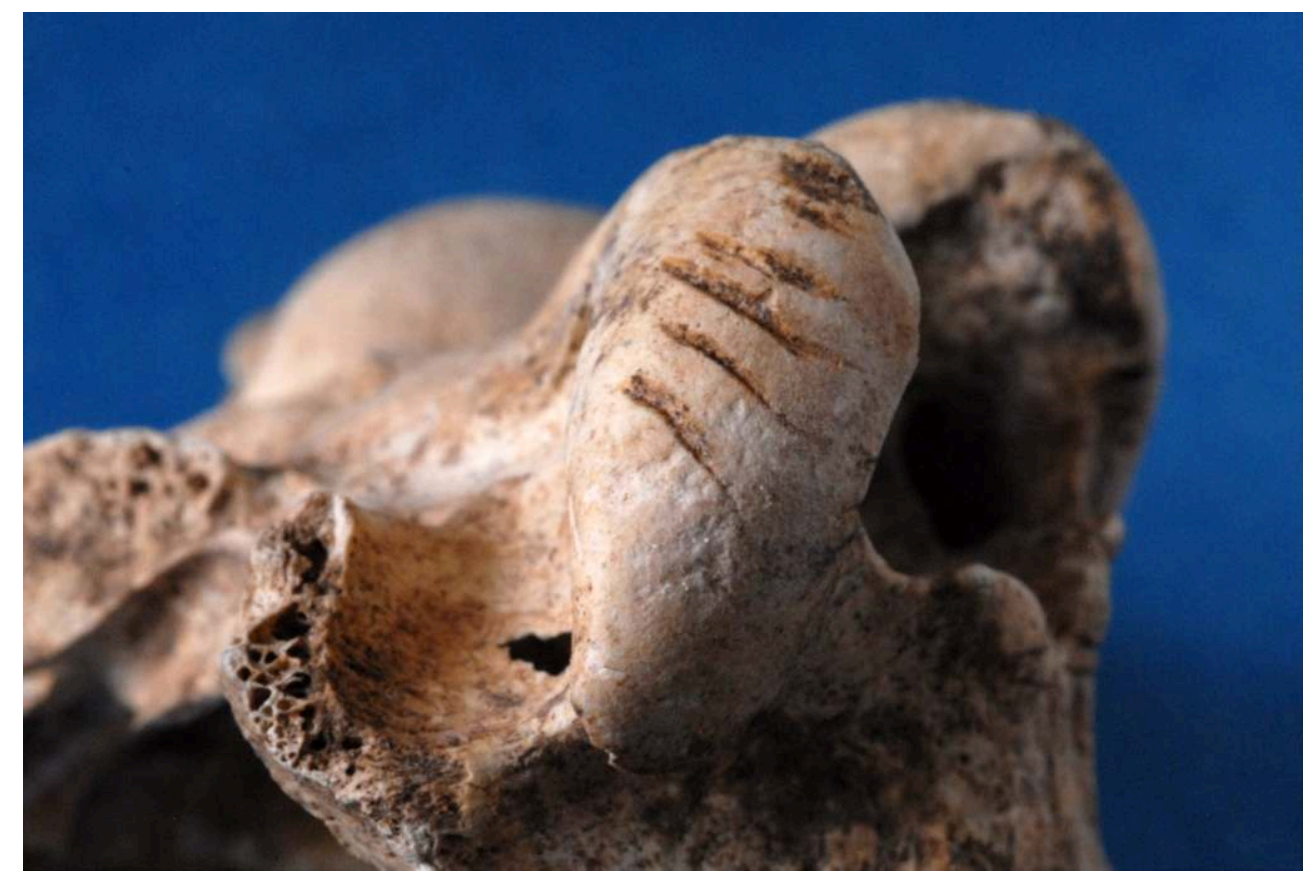

Clichés R.-M. Arbogast.

Figure 7 (C) : Vues de différents types de marques relevées sur les restes osseux de chien du site de Herxheim. Traces de brûlures sur les dents et l'os maxillaire.

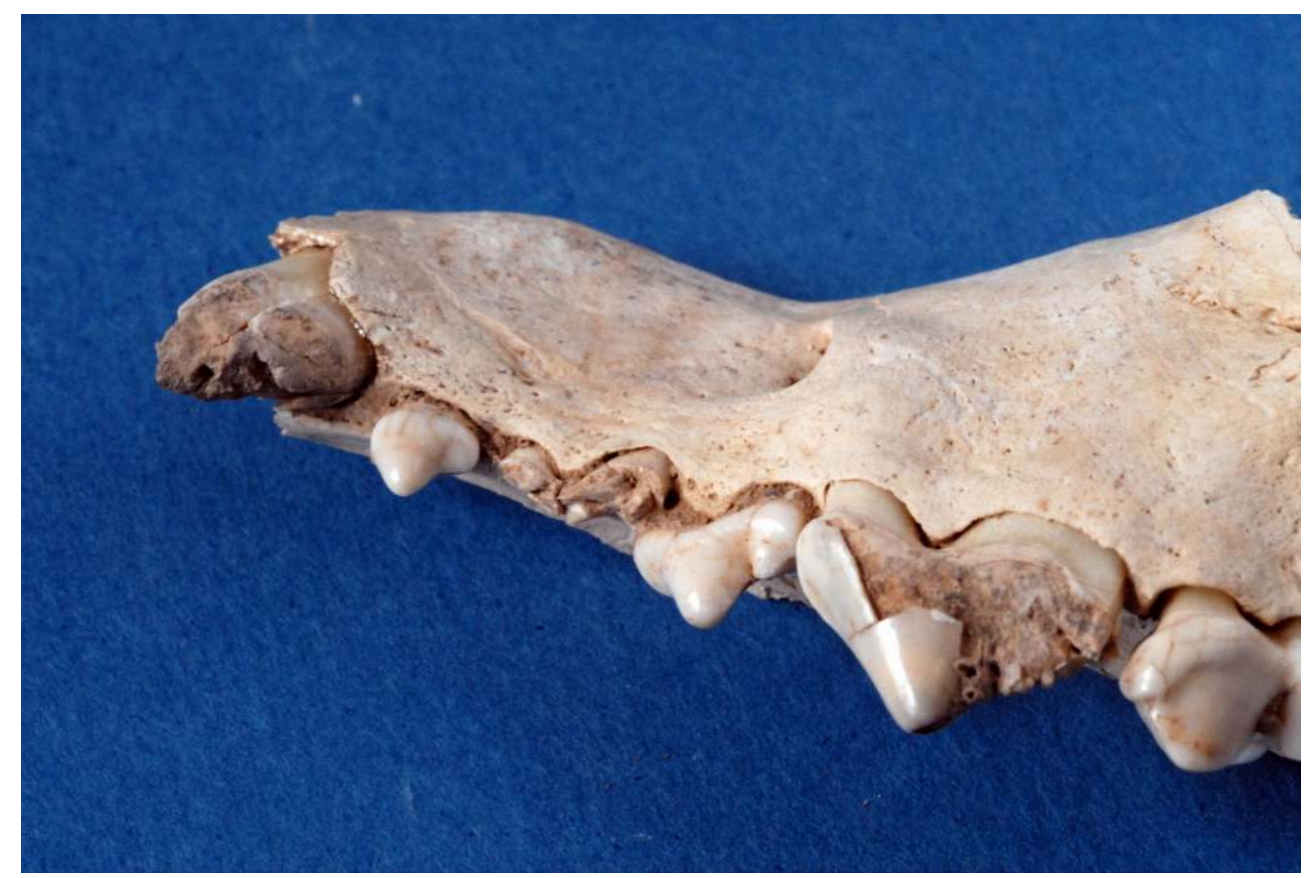

Clichés R.-M. Arbogast.

9 Ces restes de chien se répartissent sur l'ensemble du squelette avec néanmoins une surreprésentation marquée des parties crâniennes par rapport au rachis et aux membres. Les mandibules qui correspondent à la partie squelettique la plus représentée attestent la présence d'au moins 13 d'individus alors que les autres régions du squelette se 
rapportent à un nombre minimal qui ne dépasse pas 6 individus. Les ossements de chien se rapportent principalement à de jeunes animaux d'après l'état d'épiphysation des os longs. La plupart des mandibules et restes crâniens sont marqués par la présence de la dentition définitive qui est acquise à partir de 6 mois (Schmid, 1972). Des mandibules avec des dentitions lactéales sont également observées et attestent la présence de trois chiots. La majorité des premières molaires (7/13) sont non usées et se rapportent à de jeunes adultes (Horard-Herbin et al., 2014) tandis qu'un état d'usure plus marqué correspondant à un animal plus avancé en âge ne s'observe que sur une seule mandibule. Les os du squelette appendiculaire présentent en grande majorité des épiphyses soudées et indiquent également la prédominance d'individus matures. Quelques restes de jeunes chiots sont attestés par des vertèbres et une épiphyse distale de radius non soudées. Cette distribution des âges ne laisse pas transparaître une sélection très active. Mêlés aux autres catégories de vestiges, pour lesquels une durée d'accumulation assez brève, de moins d'un demi-siècle peut être avancée (Denaire, 2009 ; Boulestin et Coupey, 2015) rien ne permet d'exclure que ces reliefs de la consommation de chien ne reflètent, de la même manière que celle des humains, des pratiques très circonscrites dans le temps et correspondent à des épisodes ponctuels, et s'inscrivent dans des évènements qui ont marqué l'histoire de ce site.

L'ensemble de ces caractéristiques apparaissent très cohérentes avec des pratiques de boucherie, d'une découpe par quartiers et de la préparation de pièces de viande destinées à la consommation. Exceptionnelle dans le contexte des sociétés du Néolithique ancien, la consommation de cet animal apparait aussi hors normes dans la mesure où elle procède d'un modus operandi distinct de celui des animaux qui font traditionnellement l'objet d'une exploitation bouchère. La faible fragmentation de même que la rareté des traces de prélèvement de la viande suggèrent un partage des carcasses moins détaillé, sous forme de pièces de viande préparées entières et pour la préparation desquelles la cuisson par rôtissage semble privilégiée. La moindre dispersion de ces restes de quartiers de chien dans le fossé peut par ailleurs refléter des épisodes de rejets très ponctuels principalement circonscrits au fossé interne. Exceptionnelle et hors normes, la consommation du chien sur ce site apparaît directement liée à la fonction de cette structure et à la nature des activités particulières auxquelles elle a servi de cadre. Les restes de chien y côtoient d'autres vestiges osseux remarquables comme de nombreuses chevilles osseuses de ruminants, un dépôt de mandibules de carnivores mais surtout d'importantes accumulations d'ossements humains dont l'état de fragmentation, les nombreuses traces de désarticulation et de prélèvement des chairs, les traces de mâchonnement renvoient à des pratiques de cannibalisme (Boulestin et Coupey, 2015). L'hypothèse privilégiée dans l'état actuel des recherches est celle d'un cannibalisme guerrier, mené à une échelle assez importante, et la survenue d'une profonde crise de la société rubanée qui se traduirait par un ébranlement des valeurs avec une destruction méthodique et systématique des corps humains et des mobiliers (Boulestin et Coupey, 2015 ; Zeeb-Lanz et al., 2016).

\section{Conclusion}

11 Tant les modalités que le contexte dans lequel s'inscrit le traitement du chien sur le site de Herxheim participent à souligner le statut particulier de cet animal ainsi que l'étroitesse de ses relations avec l'homme. Comme le suggère sa discrétion sur les sites 
d'habitat où ses ossements ne se mêlent pas aux reliefs culinaires qui font l'ordinaire de la documentation accessible, sa consommation ne s'inscrit pas dans l'ordre des choses qui structure la vie quotidienne et la vie entre les hommes et les chiens sur les sites du Néolithique ancien. Concomitante avec celle de la chair humaine, la consommation du chien apparaît ainsi tout aussi transgressive et révélatrice de la déstabilisation des règles qui encadraient la relation entre l'homme et le chien, augurant probablement un nouveau chapitre de l'histoire de l'interaction entre l'homme et cet animal.

\section{BIBLIOGRAPHIE}

ARBOGAST R.-M. 1994, Premiers élevages néolithiques du Nord-Est de la France. Liège, ERAUL 67.

ARBOGAST R.-M. 2005, « Aspects de la relation au monde animal dans les sociétés du Néolithique ancien danubien », dans J. LÜNING., C. FRIRDICH. et A. ZIMMERMANN (dir.), Die Bandkeramik im 21. Jahrhundert. Symposium in der Abtei Brauweiler bei Köln (16.9-19.9 2002). Internationale Archäologie, Arbeitsgemeinschaft, Symposium, Tagung, Kongress. Bd 7, Rahden/Westf. Verlag Maria Leidorf, p. 247-258.

ARBOGAST R.-M. 2009, « Les vestiges de faune associés au site et structures d'enceinte du site rubané de Herxheim (Bade-Wurtemberg, Allemagne) », dans A. ZEEB-LANZ (ed.), Krisen Kulturwandel - Kontinuitäten. Zum Ende der Bandkeramik in Mitteleuropa. Actes de table ronde de Herxheim bei Landau (Palatinat). 14 au 17 juin 2007. Rahden/Westf. Verlag Marie Leidorf, p. 53-60.

ARBoGAST R.-M., DESCHLER-ERB S., MARTI-GRÄDEL E., PLÜSS P., HÜSTER-PLOGMANN H. et SCHIBLER J. 2005, « Du loup au "chien des tourbières". Les restes de canidés sur les sites lacustres entre Alpes et Jura », Revue de Paléobiologie, vol spéc. 10, p. 171-183.

ARBOGAST R.-M. et JEUNESSE C. 2013, « Early Neolithic pastoral traditions and cultural groups in northern France ", dans S. COLLEDGE, J. CONOLLY, K. DOBNEY, K. MANNING, S. SHENNAN (dir.), The Origins and Spread of Domestic Animals in Southwest Asia and Europe. Walnut Creek (CA), Left Coast Press, p. 271-282.

BICKLE P. et WHITTLE A. 2013, The First Farmers of Central Europe : Diversity in LBK Lifeways. Oxford, Oxbow Books, Cardiff Studies in Archaeology.

BLESL C. 2005, « Das Altneolithikum - Linearbandkeramik », dans Zeitschienen : Archäologische Funde aus 20000 Jahren, Vom Tullnerfeld ins Traisental, Fundberichte aus Österreich, Materialhefte Riehe A, Sonderheft 2, Wien, Herausgeber Bundesdenkmalamt, p. 64-68.

BOULESTIN B. et COUPEY A.-S. 2015, Cannibalism in the Linear Pottery Culture : The Human Remains from Herxheim, Oxford, Oxuniprint, Archaeopress Archaeology.

BOUlestin B., ZEeb-LANZ A., JeUnesSe C., HAACK F., ARBogAST R.-M. et DENAIRE A. 2009, « Mass cannibalism in the Linear Pottery Culture at Herxheim (Palatinate, Germany) », Antiquity, vol. 83, p. 968-982.

DENAIRE A. 2009, « Zusammensetzungen von Keramik in den Grubenringen », dans ZEEB-LANZ A. (dir.), Krisen-Kulturwandel-Kontiniuitäten - Zum Ende der Bandkeramik in Mitteleuropa, Actes 
de la table ronde de Herxheim bei Landau (Palatinat), 14 au 16 juin 2007, Rahden/Westf., Verlag Marie Leidorf, p. 70-76. (Internationale Archäologie 120)

DÖHLE H.-J. 1994. Die Linienbandkeramischen Tierknochen von Eilsleben, Börderkreis. Ein Beitag zur neolithischen Haustierhaltung und Jagd in Mitteleuropa. Halle, Veröffentlichungen des Landesamtes für archäologische Denkmalpflege Sachsen-Anhalt 47.

HACHEM L. 2011, Le site néolithique de Cuiry-lès-Chaudardes - I. De l'analyse de la faune à la structuration sociale. Rahden/Westf. Verlag Marie Leidorf, Internationale Archäologie 120.

HORARD-HERBIN M.-P., TRESSET A. et VIGNE J.-D. 2014, « Domestication and uses of the dog in western Europe from the Paleolithic to the Iron Age ». Animal Frontiers, vol. 4, p. 23-31. doi : 10.2527/af. 2014-0018.

JEUNESSE C. 1996, « Les enceintes à fossés interrompus du Néolithique danubien ancien et moyen et leurs relations avec le Néolithique récent », Archäologisches Korrespondenzblatt, vol. 26, p. 251-261.

LARSSON G. 1990, « Dogs in fraction-Symbols in action », dans P.-M. VERMEERSCH et P. VAN PEERS (dir.), Contributions to the Mesolithic in Europe. Leuwen, Leuwen University Press, p. 153-160.

SCHAEFER M. 2010a, « Archäozoologische Untersuchungen der Tierknochen aus der linearbandkeramischen Siedlung Vaihingen/Enz (Kreis Ludwigsburg D) und ihre Interpretation ", Inauguraldissertation zur Erlangung des Grades eines Doktors der Philosophie vorglegt der Philosophisch-Naturwissenschaftlichen Fakultät der Universität Basel. 4 volumes.

SCHÄFER M. 2010b, « Viehzucht- und Jagdstrategien der ersten Bauern in Süddeutschland ». dans CLASSEN E., DOPPLER T. et RAMMINGER B. (dir.), Familie - Verwandtschaft - Sozialstrukturen : Sozialarchäologische Forschungen zu Neolithischen Befunden. Fokus Jungsteinzeit, KerpenLoogh, Berichte der AG Neolithikum, Band 1, p. 107-118.

SCHMID E. 1972, Knochenatlas für Prähistoriker, Archäologen und Quartärgeologen. AmsterdamLondon- New York. Elsevier Publishing Company 159 S., 39 Abb., XXXVII Taf.

TRESSET A. et VIGNE J.-D. 2001, « La chasse, principal élément structurant la diversité des faunes archéologiques du Néolithique ancien, en Europe tempérée comme en Méditerranée », dans R.-M. ARBOGAST, C. JEUNESSE et J. SCHIBLER (dir.), Rôle et Statut de la Chasse dans le Néolithique ancien danubien (5500-4900 av. J.-C.), Rahden/Westf., Marie Leidorf, p. 129-152. (Internationale Archäologie 1)

ZEEB-LANZ A. 2009, « Gewaltszenarien oder Sinnkrise ? Die Grubenanlage von Herxheim und das Ende der Bandkeramik », dans A. ZEEB-LANZ (dir.), Krisen - Kulturwandel - Kontinuitäten. Zum Ende der Bandkeramik in Mitteleuropa, Actes de la table ronde de Herxheim bei Landau (Palatinat), 14 au 16 juin 2007, Rahden/Westf Marie Leidorf, p. 87-102.

ZEEB-LANZ A., ARBOGAST R.-M., HAACK F., HAIDLE M.-N., JEUNESSE Ch., ORSCHIEDT J., SCHIMMELPFENNIG D. et Van WILLIGEN S. 2008, « The LBK settlement with pit enclosure at Herxheim near Landau (Palatinate). First results », dans D. HOFMANN et P. BICKLE (dir.), Creating communities. New advances in central european Neolithic research, Oxford, Oxbow books, p. 199-215.

ZEEB-LANZ A., ARbOGASt R.-M., BAUER S., BOUlestin B., COUPEY A.-S., DENAIRE A., HAACK F., JEUNESSE C., SCHIMMELPFENNIG D. et TURCK R. 2016, « Human Sacrifices as “Crisis Management” ? , dans C. A. Murray (dir.), Diversity of Sacrifice. Albany, State University of New York Press, p. 171-189. 


\section{RÉSUMÉS}

L'importante représentation de vestiges osseux de chien au sein du remplissage du fossé interne du site de Herxheim (Allemagne, Rhénanie-Palatinat) daté du Rubané final est l'occasion de revenir sur la question de la place du chien au Néolithique ancien et de son rôle auprès des premiers éleveurs en Europe occidentale. L'objet de cette contribution est de présenter les caractéristiques de cet assemblage qui représente, pour le Néolithique ancien d'Europe occidentale, la série d'ossements la plus importante attribuée à cet animal. L'état de conservation et de fragmentation, les marques liées à la découpe des carcasses, les traces de cuisson par grillade suggèrent qu'il s'agit de restes d'animaux qui ont été préparés pour la consommation et qui ont fait l'objet de diverses préparations (découpe en quartiers, cuisson par rôtissage à la flamme...). Cette consommation du chien est une pratique circonscrite au fossé interne du site et semble étroitement liée à la nature des activités particulières dont il a été le cadre. Les restes de chien y côtoient d'autres vestiges osseux remarquables comme de nombreuses chevilles osseuses de ruminants, un dépôt de mandibules de carnivores, mais surtout d'importantes accumulations d'ossements humains dont l'état de fragmentation, les nombreuses traces de désarticulation et de prélèvement des chairs, les traces de mâchouillage laissent fortement soupçonner des pratiques de cannibalisme.

\section{AUTEUR}

\section{ROSE-MARIE ARBOGAST}

CNRS-UMR 7044 ARCHIMÈDE 


\title{
Ritual use of dogs and wolves in the Late Bronze and Early Iron Age in the South-Eastern Alpine region. New evidence from the archaeo(zoo)logical perspective
}

\author{
Brina Škvor Jernejčič and Borut Toškan
}

\begin{abstract}
We are thankful to Petra Vojaković and the team of Arhej LLC for allowing us to publish the not yet published archaeozoological material from the site of Tribuna in Ljubljana. We are further indebted to Mateja Belak and Tin Valoh for having prepared figures 1 and 5, to Petra KmeŤová for useful suggestions regarding the references, as well as to two anonymous reviewers for valuable advices on how to improve the manuscript. The English text has been revised by Terry T. Jackson.
\end{abstract}

\section{Introduction}

1 The dog (Canis familiaris) was the first animal to have been domesticated by the Upper Palaeolithic hunter-gatherers, with the gray wolf (Canis lupus) being regarded as its only ancestor (Vilà et al., 1997). Several large canid fossils dated to approx. 30,000 to 24,000 BC found in both Europe (Germonpré et al., 2009, 2012, 2015a) and Asia (Ovodov et al., 2011) have been interpreted as domestic dogs; however, recent analyses suggest that the first domestications only took place in the Late Glacial time bracket between 18,000 and 10,000 BC (Boudadi-Maligne and Escarguel, 2014; Morey, 2014; Perri, 2016; but see also Germonpré et al., 2015b). Initially, dogs could have been useful to man as hunting companions and protectors, possibly also by performing cleanup functions as can still be seen in indigenous societies traditionally living with these animals. Nevertheless, by far the best-attested use of early dogs in most parts of Europe is as meat-producing animals and as a source of pelts (Horard-Herbin et al., 2014, p. 28-29; and references therein). Millennia later, after stocks of other domestic animals had 
been stabilized and become consistently available, cynophagy begun to gradually lose its primary significance. This process, however, was not straightforward, as dog meat is known to have been limitedly eaten throughout prehistory (see e.g. Bartosiewicz, 1999, p. 314; Méniel, 2006; Hambleton, 2008; Vretemark and Sten, 2010; Chrószcz et al., 2013; Horard-Herbin, 2014). An almost complete cessation of the practice in Europe and the Mediterranean is presumed to have taken place with the introduction of new culinary habits of the Roman world (Bartosiewicz, 1994; Horard-Herbin et al., 2014; and references therein)0, even though consumption of dog meat continued in some European areas until mid- $20^{\text {th }}$ century or takes place even nowadays (Horard-Herbin, 2014, p. 72).

Other dog functions within past communities were more symbolic. In Europe, the most prominent manifestation of its special cultural role are several examples of individual and group burials of these animals as well as depositions of single bones as gravegoods, however, several other ritualistic uses of canids are known from archaeological records (e.g. agricultural rituals, building offerings, dogs as healing agents or associated with childbirth) (Andrałojc, 1993; Chenal-Velarde, 2006; De Grossi Mazzorin, Minniti, 2006; KmeŤová, 2006; Prummel, 2006; Trantalidou, 2006; Wilkens, 2006; Horard-Herbin et al., 2014, p. 28-29; Lazăr et al., 2016; and references therein; for wolves see e.g. Radovanović, 1999; Pluskowski, 2006, p. 288-95). A similar transition from meat (but possibly also milk; Outram et al., 2009) producing animal directly following domestication to an element with a pronounced symbolic function in latter times has been observed for the horse. Nevertheless, if ritual depositions of the latter are wellattested in the South-Eastern Alps (Mlinar, 2002; Dular, 2007) as well as in central Europe (see e.g. De Grossi Mazzorin, Minniti, 2006; KmeŤová, 2014; KmeŤová, Stegmann-Rajtár, 2014) in general, at least from the Early Iron Age onwards, similar records of dogs are much less common (Gabrovec, 1960, p. 23-25; Barth, 1969, p. 149; Riedel, 1977; Hencken, 1978, p. 61; Dular, 1991, p. 45; Tecco Hvala et al., 2004, p. 66). This is even truer for wolves, as ritual deposits of Canis lupus in Late Prehistoric and Historic Europe seem to be all but absent (see e.g. Prummel, 1992; Pluskowski, 2006). The observed scarceness might be in part linked with the problem of identification. Indeed, distinguishing between the archaeozoological remains of dogs and wolves is rather difficult and, particularly where the evidence is fragmentary and individual elements cannot be clearly identified, virtually impossible. Consequently, in cases of doubt, analysts tend to identify dog over wolf because this is what they expect to find (Pluskowski, 2006, p. 270-280 and p. 286-287). Such an approach lowers even more the already limited presence of the latter species in the European archaeological record, which is likely explainable by the apparently infrequent practice of wolf hunting and its biogeography.

3 In spite of what has been said, records of wolf ritual deposition from Iron Age Europe are not completely unknown. One of the notable examples was documented in the cave of Jama I na Prevali or Skeletna jama (Grotta delle Ossa/Knochenhöhle), which is one of the most outstanding prehistoric sites in South-Eastern Alpine region (Fig. 1). In this $46 \mathrm{~m}$ deep karst abyss at least 11 skeletons (8 male and 3 female invdivudulas) and more than 1000 animal bone remains were excaveted (Szombathy, 1913; Riedel, 1977; Merlatti, 2001). Among the latter, bones (including 11 skulls and 28 mandibles or fragments of ) and teeth belonging to at least 15 wolves and 3 dogs have been found (Riedel, 1977, p.163-181). Other peculiarities of the recovered archaeozoological 
material include a preponderance of large adult bull/oxen remains and an aboveaverage representation of horse (Riedel, 1977, p. 188-189). Numerous artefacts, namely bronze and iron weapons, bronze situlae, jewllery and fragments of pottery were also found. The site itself, together with the Velika jama na Prevali or Mušja jama (Grotta delle Mosche/Fligenhöhle) nearby (Teržan et al., 2016) was a sacred place at the "meeting point of worlds" (Teržan, 2016) where sacrificial rites and cult rituals were performed during the Late Bronze up to Late Iron Age. ${ }^{1}$

Figure 1: Geographical position of the mentioned archaeological sites in the survey area.

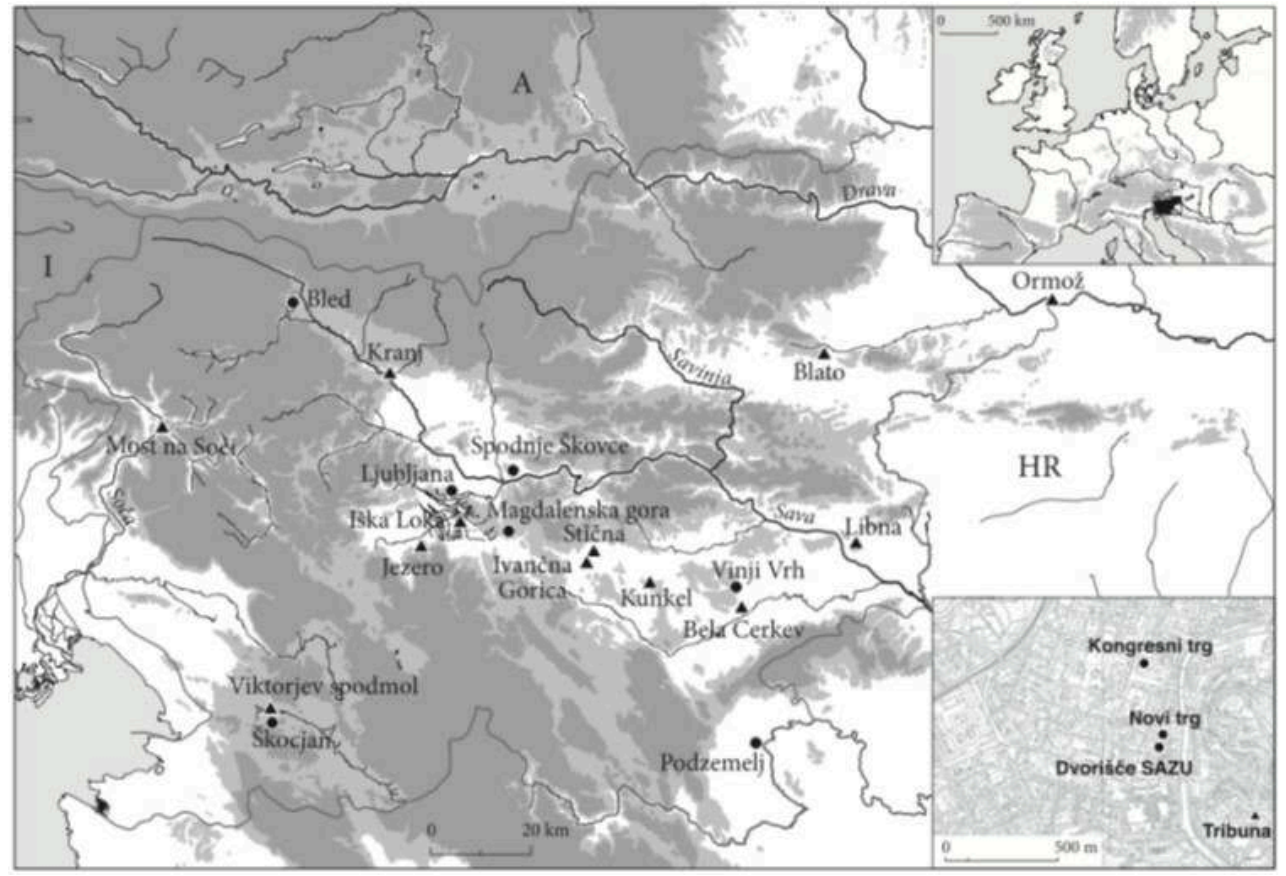

Dots $=$ cemeteries; triangles $=$ settlements. Separate sites at Ljubljana in the lower frame

Considering all of the above, the present paper aims to shed some new light on the spread of ritual depositions of dogs and - to a much lesser extent also wolves - in funerary and settlement contexts in the South-Eastern Alpine region (present-day Slovenia), focusing on the Late Bronze and Early Iron Age. The presented data are then discussed within the framework of a more general background related to Central Europe and northern Mediterranean areas.

\section{Dog and wolf remains in funerary contexts}

5 In the Late Bronze and Early Iron Age, dog skeletons or individual dog bones from funerary contexts in Central, Northern, and Eastern Europe, were relatively rare (Andrałojc, 1993, p. 67-68, fig. 5; Scheibner, 2013, p. 45, 80-83, maps 20-21; KmeŤová, 2006, p. 29-34; Ramminger, 2012, p. 234-236; see also Toškan, Štular, 2008, p. 153, 156). The research of Italian archaeozoologists reveals the same picture (De Grossi Mazzorin, 2001, p. 79-80; De Grossi Mazzorin, Minniti, 2006, p. 64; Wilkens, 2006). Remains of wolves are extraordinary. One exceptional case is represented by the Middle Bronze Age finds from the Calferi di Stenico site in Trentino, where bones of wild animals bear, wolf, wild boar, and deer - were discovered in a barrow next to human skeletons 
(Perini, Corrain, Capitanio, 1991; Riedel, Tecchiati, 1992, p. 41; Nicolis, 2001, p. 358). In Slovenia, dog or wolf bones have so far not been documented in Bronze Age graves, and finds from some Early Iron Age graves in Ljubljana and Bled are among the oldest (Tab. 1; Fig. 1 \& 3).

Tableau 1: Dog/wolf remains from the Early Iron Age graves in Slovenia.

\begin{tabular}{|c|c|c|c|c|c|}
\hline Site /context & $\begin{array}{l}\text { Dog/wolf } \\
\text { remains }\end{array}$ & $\begin{array}{l}\text { Other } \\
\text { animal } \\
\text { remains }\end{array}$ & $\begin{array}{l}\text { Burial mode, } \\
\text { age, sex }\end{array}$ & $\begin{array}{l}\text { Location of } \\
\text { dog/wolf } \\
\text { remains }\end{array}$ & Bibliography \\
\hline $\begin{array}{c}\text { Podzemelj, } \\
\text { Skrilje, } \\
\text { Barrow 1 / } \\
\text { Grave 13 }\end{array}$ & $\begin{array}{c}\text { "Skeleton } \\
\text { of a large dog" }\end{array}$ & I & Dog (?) grave & In the grave & A \& F: Barth 1969, p. 149 \\
\hline $\begin{array}{c}\text { Magdalenska } \\
\text { gora, Preloge, } \\
\text { Barrow } 7 \text { / } \\
\text { Grave } 51\end{array}$ & $\begin{array}{l}\text { Canis indet. } \\
\text { tooth with a } \\
\text { hole }\end{array}$ & I & $\begin{array}{l}\text { Inhumation, } \\
\delta ? \text { grave }\end{array}$ & In the grave & $\begin{array}{l}\text { A \& F: Hencken 1978, p. 61; } \\
\text { Tecco Hvala 2012, Fig. } 36\end{array}$ \\
\hline $\begin{array}{l}\text { Magdalenska } \\
\text { gora, } \\
\text { Preloge, } \\
\text { Barrow 13 / } \\
\text { Grave } 87\end{array}$ & $\begin{array}{l}\text { Canis familiaris } \\
\text { canine tooth }\end{array}$ & I & $\begin{array}{l}\text { Inhumation, } \\
\text { \& grave }\end{array}$ & In the grave & $\begin{array}{c}\text { A \& F: Tecco Hvala et al. } \\
\text { 2004, p. 66; } \\
\text { Tecco Hvala 2012, Fig. 36; } \\
\text { Fig. 2 }\end{array}$ \\
\hline $\begin{array}{l}\text { Ljubljana, } \\
\text { Dvorišce SAZU, } \\
\text { Grave } 275\end{array}$ & $\begin{array}{l}\text { Canis familiaris } \\
\text { os penis }\end{array}$ & Indet. spec. & $\begin{array}{l}\text { Cremation, } \\
\delta \text { adultus }+q ? \\
\text { grave }\end{array}$ & In the grave & $\begin{array}{c}\text { A: Puš 1982; } \\
\text { Skvor Jernejčč 2014; Fig. } 3 \\
\text { F: own unpublished data }\end{array}$ \\
\hline $\begin{array}{l}\text { Ljubljana, } \\
\text { Dvorišče SAZU, } \\
\text { Grave } 181\end{array}$ & $\begin{array}{c}\text { Canis indet. } \\
3 \text { vertebrae cocc. }\end{array}$ & I & $\begin{array}{l}\text { Cremation, } \\
\text { क adultus grave }\end{array}$ & In the grave & $\begin{array}{c}\text { A: Puš 1971; } \\
\text { Skvor Jernejcič 2014; } \\
\text { F: own unpublished data }\end{array}$ \\
\hline $\begin{array}{l}\text { Ljubljana, } \\
\text { Dvorišce SAZU, } \\
\text { Grave } 293\end{array}$ & $\begin{array}{l}\text { Canis familiaris } \\
\text { Radius dia } \\
\text { (dex.) }\end{array}$ & Indet. spec. & Cremation & In the grave & $\begin{array}{c}\text { A: Puš 1982; } \\
\text { Skvor Jernej飞ič 2014; } \\
\text { F: own unpublished data }\end{array}$ \\
\hline $\begin{array}{c}\text { Vinji vrh, } \\
\text { Laze nad Vinjim } \\
\text { Vrhom, } \\
\text { Barrow II / } 1880\end{array}$ & $\begin{array}{l}\text { Canis lupus? } \\
\text { mandibula }\end{array}$ & $\begin{array}{l}\text { Equus } \\
\text { caballus, } \\
\text { Indet. spec. }\end{array}$ & $?$ & $\begin{array}{l}\text { In the barrow, } \\
\text { exact location } \\
\text { unknown }\end{array}$ & A \& F: Dular 1991, p. 45 \\
\hline
\end{tabular}

Explanation of abbreviations: A - archaeological bibliography; F - faunistic bibliography. See also fig. 1.

6 An analysis of funerary contexts containing canid bones should differentiate between the cases in which bones were discovered in the grave itself, i.e. in the grave pit or in the urn, and the cases in which bones were found in the fill of the grave or in the barrow. In addition to the finds from graves, there are some examples in which bones were discovered in special "ceremonial" areas within cemeteries. No human bones were discovered there, which means these areas were not graves but rather special areas, where strictly defined funerary rituals were practiced before, during, or after the burial. Such cases are known from the Bled - Pristava site and from the more recent excavations at Novi trg in Ljubljana (Tab. 2; Fig. 1). 
Tableau 2: Dog/wolf remains from the fill of the grave/barrows and from special areas within cemeteries in Slovenia dating to the Late Bronze Age and Early Iron Age.

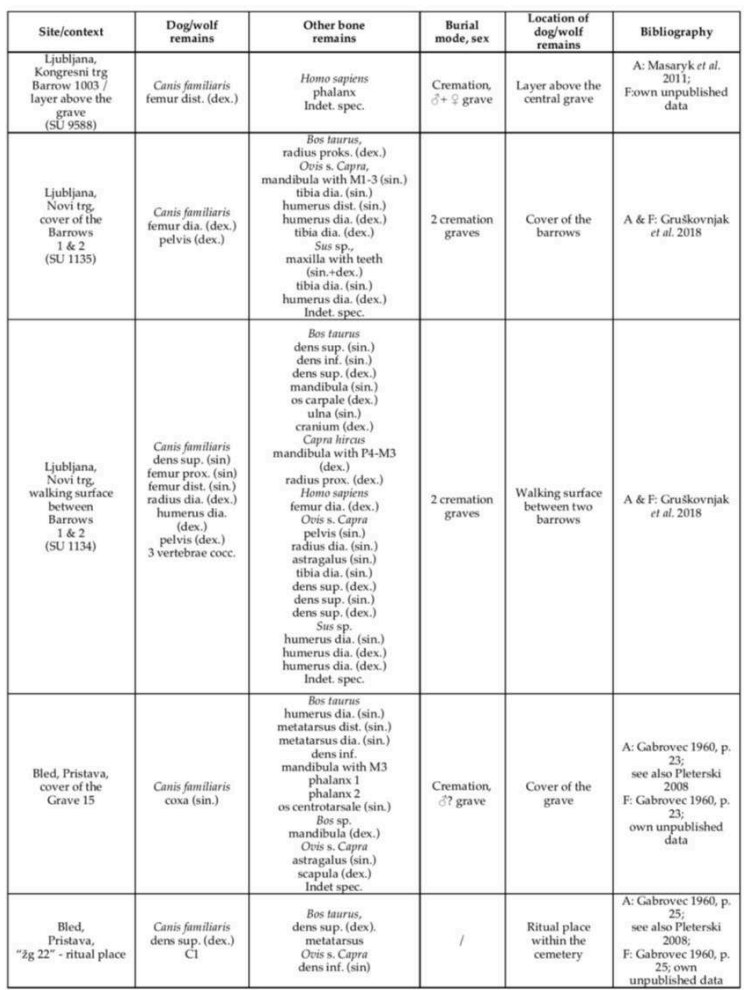

Explanation of abbreviations: dia.- diaphysis, A- archaeological bibliography; F - faunistic bibliography See also fig. 1.

7 The table with all the documented dog and possible wolf bones found within the context of Early Iron Age burials in Slovenia clearly shows that graves or grave/barrow fills practically always contained only individual teeth/bones (Tab. 1). The sole exception is the "skeleton of a large dog" (a small wolf?), designated as Grave 13, found in Barrow I in Podzemelj - Škrilje in the region of Bela krajina in south-eastern Slovenia (Barth, 1969, p. 149). In addition to the skeleton, the grave contained a clay ring, and fragments of a vessel and a bowl. ${ }^{2}$ According to the report of the excavator Szombathy, there were no human bones at that location, which means this was a dog or less likely wolf burial. ${ }^{3}$ The same barrow contained 22 other graves, both cremation and inhumation burials. In all other cemeteries, only individual dog bones - teeth, mandibula, vertebra and baculum (os penis) - were discovered (Tab. 1; Figs. 2: 4; 3:1). 


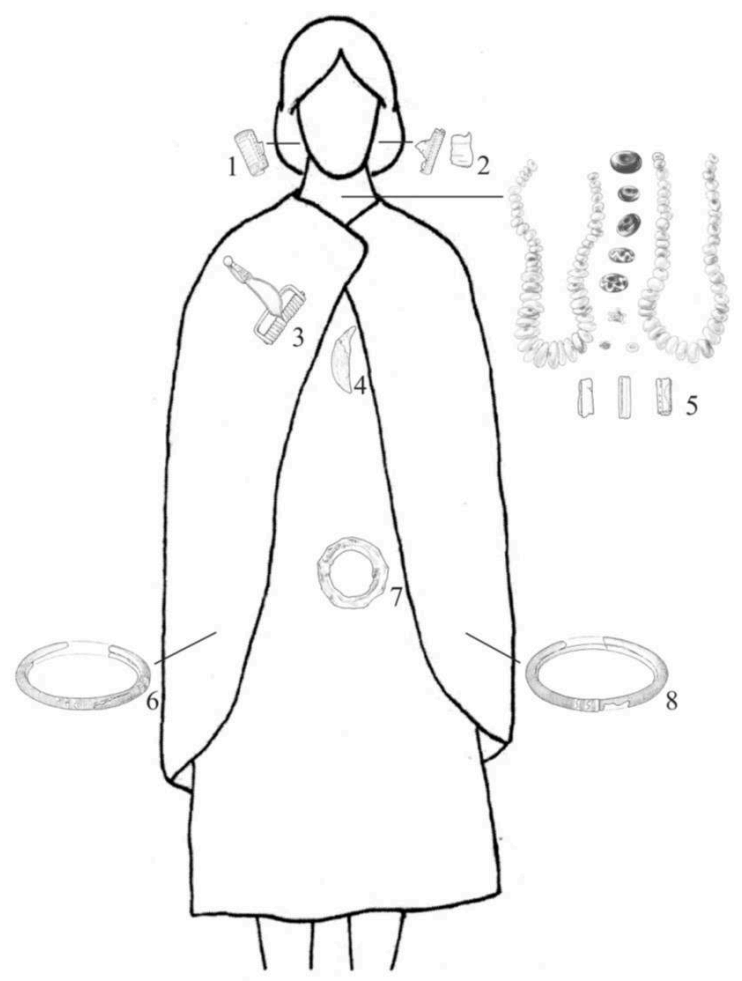

1-2: bronze earrings, 3: bronze fibula, 4: canine tooth - amulet (?), 5: amber, glass beads and bronze small tubes, 6, 8: bronze bracelets, 7: bronze ring (Modified from Tecco Hvala et al. 2004, tab. 95: A) Scale of all grave-goods $=1: 4$.

Regarding individual canid finds, we should differentiate between remains such as isolated teeth, jaws, or the baculum (os penis), and limb bones, ribs, or the pelvis. Interestingly, the remains discovered in graves were indeed teeth, jaws, a baculum and a caudal vertebra. They could be interpreted as grave-goods or apotropaion for the deceased. The tooth found in Grave VII/51 in Magdalenska gora was perforated, which means it had been used as a pendant, very likely functioning as an amulet. Dog tooth amulets were supposed to protect one against the forces of evil and to ward off diseases (Scheibner, 2013, p. 81-82). Similar was probably the significance of a possible wolf jaw from a barrow in Vinji Vrh and an unperforated dog tooth from Grave 87 of Barrow 13 in Magdalenska gora (Fig. 2: 4). Found in the chest area of a female skeleton, its very position indicates that this also was a pendant/an amulet, clearly separate from a rich amber and glass necklace worn by the deceased around her neck (Tecco Hvala et al., 2004, p. 66). A dog fang just like this one was found in Grave 16 in the Saletto cemetery in Italy (Tagliacozzo, 1998, p. 52, fig. 12:8). Another interesting case are a pig, a wolf and a dog tooth pendants/amulets found beside a skeleton at Hallstatt in Austria (Kromer, 1959, p. 61, Taf. 23: 4, 5a, 5b). Dog bones were discovered also at Este - Casa di Ricovero in northern Italy. Grave 19 contained a carpal bone in a stone chest within the grave itself, while a fragment of hemimandible and a metacarpal bone were found in its fill (Tagliacozzo, 1998, p.51, fig. 12:2-4). Another interesting case is the perforated metacarpal bones of a canid, more likely a big dog than a wolf, found in a child's grave from the Early Iron Age in the Castelleto Ticino cemetery in Italy. Archaeologists 
consider them to be pendants of a necklace or an amulet (Venturino Gambari, Gambari, 2015, p. 191).

Figure 3: Cremation grave 275 from Ljubljana - Dvorišče SAZU, Slovenia (1 drawing Tamara Korošec; 2-5 modified from Puš 1982, T. 6).

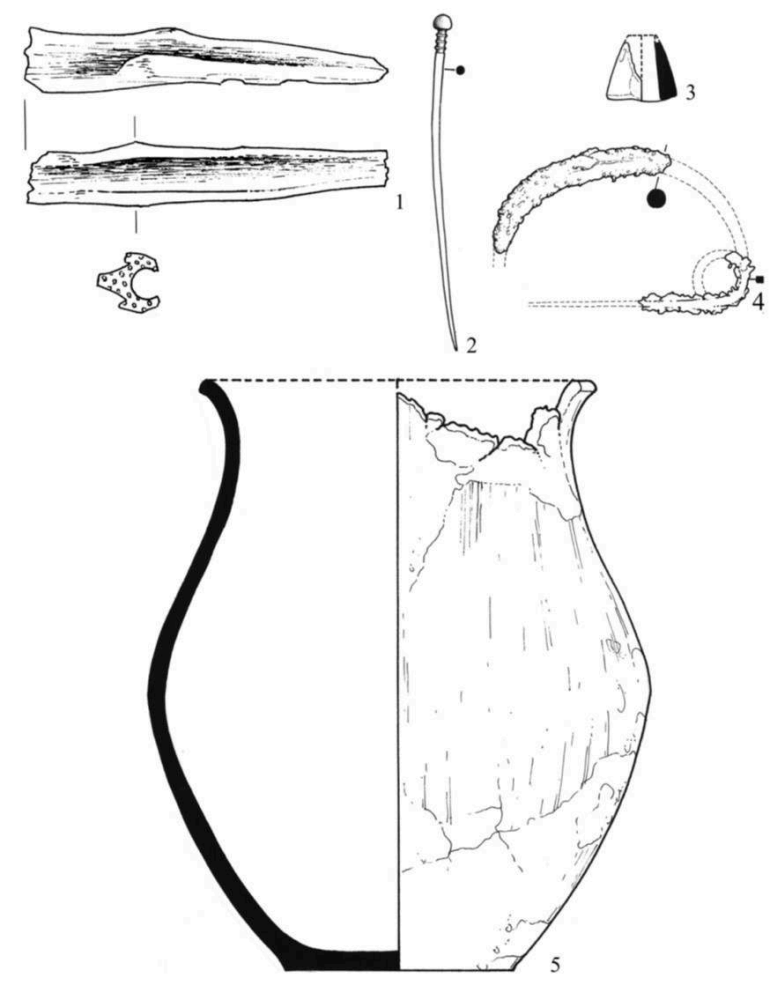

1: baculum, 2: bronze pin, 3: spindle whorl, 4: iron fibula, 5: ceramic urn. Scale 1-4 =1:2; $5=1: 4$

9 The outstanding find of a baculum is probably to be understood in a similar way. Grave 275 from the Dvorišče SAZU site in Ljubljana contained burnt human bones and an unburnt canid baculum, in addition to a clay vessel, an iron bow fibula, a bronze pin, and a spindle whorl (Fig. 1 \& 3). Considering the size of the baculum, which is believed to be related to the whole body-size (Čanády, Čomor, 2013), it could have belonged either to a large dog or a small wolf. Nevertheless, according to the results of stable isotope analysis the specimen is to be ascribed to a $\operatorname{dog}\left(\delta^{15} \mathrm{~N}=7.6 ; \delta^{13} \mathrm{C}=-17.53\right),{ }^{4}$ as the $\delta^{13} \mathrm{C}$ value exceeds the range for prehistoric as well as recent wolves (see e.g. Ewersen, Ziegler, 2010-11, Tab. 4; Kays, Feranec, 2011; Losey et al., 2011; see also: Guiry 2012). Grave 275 itself is dated to the Early Iron Age, i.e. the end of the $9^{\text {th }}$ and the $8^{\text {th }}$ century BC (Škvor Jernejčič, 2014, p. 158, fig. 6.28). Anthropological analysis showed that the grave contained an adult male, ${ }^{5}$ while pieces of jewellery as grave-goods indicate that another female person might have been buried in the same urn. In the area of Slovenia and even in Central Europe and northern Mediterranean regions, a dog baculum as a grave-good is a unique find without a proper analogy. A cave bear baculum from Križna jama cave, located approx. $20 \mathrm{~km}$ to the south of Ljubljana, is merely an indirect analogy. It is, namely, a much earlier find from the Palaeolithic and was discovered in a different context, not related to any burial (Bavdek et al., 2009, p. 22). Similar holds true for an ornamented specimen of both the same species and age from Vindija cave in the neighbouring Croatia (Malez, 1988, p. 230, fig. 5:2a-2d; see also Karavanić, Smith, 2013, 
p. 14). ${ }^{6}$ Nevertheless, there is no doubt that the dog baculum from Ljubljana had a special symbolic, apotropaic character, as finds of bacula within graves are known from different continents and chronologies (see e.g. Stearns, 1940, p. 5; Nomokonova et al., 2011, p. 35; Janssens et al., 2016, p. 569).

More intriguing is the interpretation of the caudal vertebra of either a dog or a wolf from Grave 181 at the Dvorišče SAZU site in Ljubljana. This grave also belonged to an adult person, presumably a female. In addition to the urn and a shallow bowl, the grave contained female jewellery: a two-looped bow fibula, a pin/hairpin, a ring, and some studs (Puš, 1971, T. 31, p. 5-10). The fibula dates the grave to the Early Iron Age, to the end of the $9^{\text {th }}$ and the $8^{\text {th }}$ century BC (Gabrovec, 1970; Škvor Jernejčič, 2014, p. 101). Because the only animal bones found in this grave were the three fragments of a dog/ wolf caudal vertebra, and also from the shape of the bone, it could be presumed that this again was some sort of a pendant/amulet.

11 A different pattern is indicated by the dog remains from the fill of graves or barrows, as well as by the finds not originating directly from graves but from special "ceremonial" areas within cemeteries. Here, other types of bones were discovered, the most common being limbs. At the Novi trg - Ljubljana site (Fig. 1; Gruškovnjak et al., in press), an assemblage of dog bones was found, which certainly did not belong to a single animal. The layer between two barrows, partly covering both of them, contained fragments of at least two femurs, a humerus, a radius, a pelvis, three caudal vertebras and an isolated tooth (Tab. 2). This layer was interpreted as the walking surface between the two barrows with cremation burials. In addition to numerous remains of other domesticates (cattle, pig, goat and possibly sheep), ${ }^{7}$ fragments of intentionally broken clay vessels were discovered in the same layer. Animal bones as well as the intentionally broken pottery seem to be the remains of funerary rituals, which included offerings and feasting, and took place near the graves. The dog bones could thus be the remains of sacrifices that were part of the funerary rituals.

12 A similar case is known from the Bled - Pristava site, where an Early Iron Age cemetery was excavated (Gabrovec, 1960; see also Pleterski, 2008). Animal bones were found either in the fill of the graves or in the round stone covering above them, but never in the graves themselves. Dog bones were discovered in two cases - in the fill of Grave 15 and in the "ž 22" area, where cremated human bones were absent. The latter location, 3 $\times 0,8 \mathrm{~m}$ in size, is a special area of the cemetery, where a burnt layer contained numerous fragments of pottery, charcoal, and animal remains (predominantly isolated teeth and a fragmented metatarsal bone) belonging to cattle, goats, sheep, and a dog. Again, it can be presumed that these are the remains of the funerary rituals that took place before, during and/or after the burial - sacrifices, offerings, even funerary feasting.

13 Different pattern can be observed when it comes to the analysis of dog and wolf remains found in cemeteries (either in graves or in grave fills) vs. those from special areas within the cemetery. In grave or barrow fills and in "ceremonial" areas, dog bones and teeth were always discovered together with those of other animal species. In graves, however, canid remains are the only animal finds there. The only exception is the wolf (?) mandible from Barrow II/1880 in Vinji Vrh, found together with the remains of several other species, but the data on the exact location of these bones is missing (Tab. 1). It is therefore not known whether the bones were grave-goods or belonged to the fill of the barrow. It should be mentioned that some of the bones were 
ascribed to horse and were discovered near a human skeleton. This is the only known case in Slovenia where canid and horse remains were found in the same funerary context, but, as said, their exact location within the barrow is unknown.

Horse and dog bones were discovered together in the Hungarian sites of Sütto, Százhalombatta, and Szentes - Vekerzug (Vadász, 1983, 1986; KmeŤová, 2011; Vörös, 1993; Párducz, 1952, 1954, 1955; Bökönyi, 1952, 1954; Vörös, 2015), where there are proper horse burials with entire horse skeletons interred. Next to them, dog skeletons or individual dog bones were found. Only in the Tiszavavári - Csárdapart site in Hungary (Kemenczei, 2009, p. 156, Abb. 7:41) were horse and dog bones accompanied by some individual human bones. ${ }^{8}$ Another combination of a horse skeleton, dog bones, and bones of other animals was found in cremation burial in Doroslovo, Serbia (Trajković, 2008, p. 35-36, 190; Blažić, 2008). Grave 3 from the Signal cemetery, also in Serbia, is a fascinating example of a dog burial. The dog skeleton was oriented in the same direction as human skeletons from the same stone barrow, and it had a vessel as a grave-good (Filipović, Bulatović, 2011, p. 74-76, figs. 3:1 and 4). This all seems to indicate that in the above cases of burials from the so-called Vekerzug Culture in Hungary and individual graves from Serbia, Early Iron Age burial practice was quite different from that known in Slovenia. The skeletons of horses and dogs could be interpreted as sacrificial animals, who "accompanied" their owners into their graves. Interesting in this sense are the depictions of dogs and horses on some situla art monuments, where both of these animals appear in a hunting scene accompanying a hunter. One such case is a belt buckle from Zagorje ob Savi in Slovenia (Fig. 4) (Turk, 2005 , p. 32, 57, figs. 43 and 88 ).

Figure 4: A rectangular bronze belt buckle with a partly reconstructed hunting scene from Zagorje ob Savi, Slovenia (after Turk 2005, fig. 43).

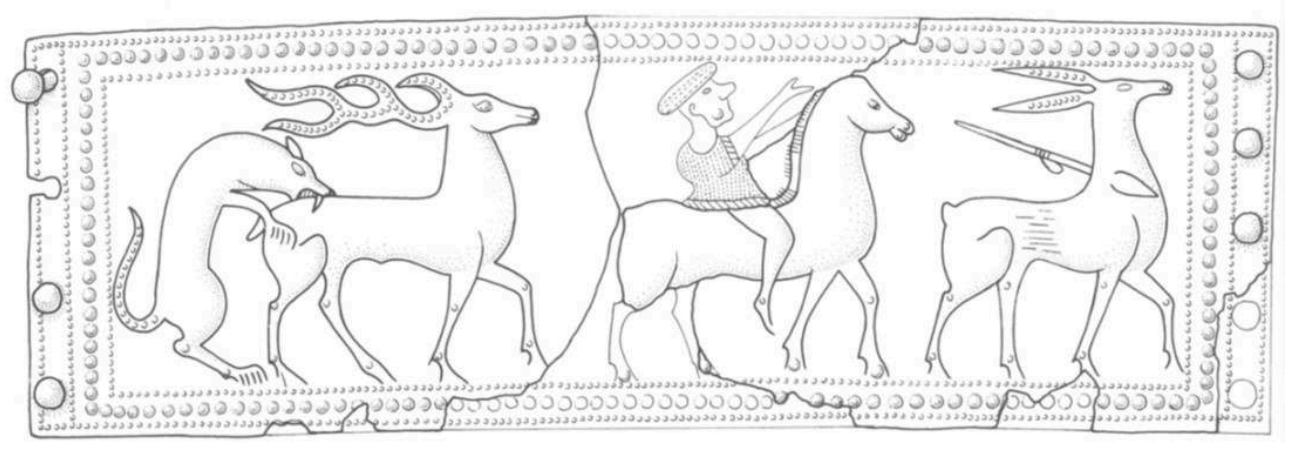

\section{Dog and wolf remains in settlement contexts}

As elsewhere in Mediterranean and Central Europe (Bökönyi, 1974, p. 337-436; Riedel, 1986, p. 89-90; 1989, Tab. 1; Bartosiewicz, 1994, Fig. 1, Tab. 3; Sanchis, Sarrión, 2004, Tab. 1; Trantalidou, 2006, Tab. 2; Horard-Herbin et al., 2014, p. 25), wolves and dogs are scantily represented in Bronze and Iron Age settlements in the South-Eastern Alps (Tab. 3; Fig. 1). This is hardly surprising considering the former's quantitative decline in the Holocene and its apparently infrequent hunting (Sommer, Benecke, 2005, p. 232; Pluskowski, 2006), combined with the latter's longstanding special status in human communities. Indeed, the dog has played the role of man's best friend, hunting and war companion, protector of domestic space, tracker of pack animals, an important 
essential element in various rituals, ceremonies, funeral practices, etc. and only occasionally also as a source of food. Consequently, the scarce number of dog remains within butchering and kitchen waste deposits in post-Neolithic contexts is fairly understandable. In addition to this, many of the forms of its secondary exploitation could be inferred exclusively from indirect information, since specimens used for work may not have even been interred within the settlement itself (e.g. hunting accidents, guard dogs kept with the herd). Indicative of the latter are extensively excavated sites containing only sporadic dog remains but revealing rather wide-spread gnawing marks (see e.g. Bartosiewicz, 1985).

16 As shown in Table 3, in the South-Eastern Alpine region no more than 15 Late Bronze and/or Early Iron Age settlements are known to have yielded canid remains. Unfortunately, in most cases, poor chronostratigraphic data prevent them from being detailedly analyzed in relation to their cultural and functional background. A notable exception is represented by the site of Tribuna, located in the central part of the Slovenian capital of Ljubljana (Vojaković, 2013, 2014), where 22 canid remains from five different constructional phases have been recovered.

Excavated in 2007 and 2008 on an area of $4,200 \mathrm{~m}^{2}$, Tribuna yielded the remains of the oldest thoughtfully planned and organised settlement in the central part of the present-day Slovenia (Fig. 5). In the early phase $\left(13^{\text {th }} / 12^{\text {th }}\right.$ century BC) it was mainly concentrated on the nearby Castle Hill, where an acropolis may be assumed, but the habitation area was also documented in Prule near the Tribuna site itself (Žerjal et al., 2014). In the $11^{\text {th }} / 10^{\text {th }}$ century $B C$, the settlement expanded to new areas - including Tribuna - forming its protourbane part, the so-called lower town or suburb (suburbium). The studied area was settled continuously between the $11^{\text {th }}$ and the $8^{\text {th }}$ centuries BC and then again for a short period in the $5^{\text {th }}$ century BC (Vojaković, 2014, p. 66-71). The recovered archaeozoological sample is fairly rich. It consists of 3,665 taxonomically identified remains of no less than 15 different animal species, including dog and possibly wolf (Tab. 3). 
Tableau 3: Number of dog and wolf remains from settlement contexts in South-Eastern Alpine region (= present-day Slovenia) covering the Late Bronze and Early Iron Age.

\begin{tabular}{|c|c|c|c|c|}
\hline Site & NISP & NISP $_{\text {dog }}$ & NISP $_{\text {wolf }}$ & Bibliography \\
\hline Bela Cerkev & 491 & 1 & - & $\begin{array}{c}\text { A: Križ } 2003 \\
\text { F: own unpublished data }\end{array}$ \\
\hline Blato (S. Konjice) & 24 & 1 & - & $\begin{array}{c}\text { A: Bricelj } 2014 \\
\text { F: own unpublished data }\end{array}$ \\
\hline Iška Loka & 45 & 1 & - & $\begin{array}{c}\text { A: Velušček } 2005 \\
\text { F: Toškan 2005; own unpubl. data }\end{array}$ \\
\hline Ivančna Gorica & 21 & 1 & - & $\begin{array}{l}\text { A: Plestenjak (Ed.) } 2013 \\
\text { F: Toškan, Dirjec } 2013\end{array}$ \\
\hline Jezero (Podpeč) & 84 & 1 & - & $\begin{array}{c}\text { A: Żorž } 2014 \\
\text { F: own unpublished data }\end{array}$ \\
\hline Kranj: Jelenov kl. & 1,742 & 24 & - & $\begin{array}{c}\text { A: Tomažinčič } 2011 \\
\text { F: own unpublished data }\end{array}$ \\
\hline Kranj: Lajh & 5,828 & 13 & 1 & $\begin{array}{c}\text { A: Urek et al. } 2015 \\
\text { F: own unpublished data }\end{array}$ \\
\hline $\begin{array}{c}\text { Kunkel } \\
\text { (Vrhtrebnje) }\end{array}$ & 282 & 13 & - & $\begin{array}{c}\text { A: Dular, Tecco Hvala } 2007 \\
\text { F: Bartosiewicz } 1991\end{array}$ \\
\hline Libna & $\mathrm{N} / \mathrm{A}$ & $>1$ & - & $\begin{array}{l}\text { A: Vojaković et al. } 2014 \text { \& RT } \\
\text { F: Vojaković et al. } 2014 \text { \& RT }\end{array}$ \\
\hline Ljubljana: Tribuna & 3,665 & $18-21$ & $1-4$ & $\begin{array}{c}\text { A: Vojaković } 2014 \\
\text { F: own unpublished data }\end{array}$ \\
\hline Most na Soči & 5,153 & 5 & - & $\begin{array}{c}\text { A: Svoljšak, Dular } 2016 \text { \& RT } \\
\text { F: Bartosiewicz } 1985\end{array}$ \\
\hline Ormož & 1,791 & 5 & - & $\begin{array}{c}\text { A: Dular, Tomanič Jevremov } \\
2010 \\
\text { F: Toškan, Dirjec } 2010\end{array}$ \\
\hline Spodnje Škovce & 86 & 4 & - & $\begin{array}{c}\text { A: Żorž, Nadbath } 2010 \\
\text { F: own unpublished data }\end{array}$ \\
\hline $\begin{array}{c}\text { Stična } \\
\text { (Phases I-III) }\end{array}$ & 3,924 & 192 & 20 & $\begin{array}{c}\text { A: Gabrovec } 1994 \\
\text { F: Bökönyi } 1994\end{array}$ \\
\hline Viktorjev spodmol & 178 & 4 & - & $\begin{array}{c}\text { A: Turk (Ed.) } 2004 \\
\text { F: Toškan, Dirjec } 2004\end{array}$ \\
\hline
\end{tabular}

The data are expressed as the Number of Identified Specimens (NISP). Explanation of abbreviations: A - archaeological bibliography; F - faunistic bibliography; \& RT - and references therein.

There are, of course, many complexities regarding canid finds from Late Bronze and Early Iron Age Tribuna, but most are not important as far as the topic of this paper is concerned. It is worth pointing out, however, that some circumstances might indeed be indicative of the local ritual use of dogs. Since animal offerings within settlement contexts are often difficult to detect, making their identification dependent on careful consideration of complete material evidence in the background, the following paragraphs inevitably include many "dull" descriptive details. By omitting them, however, the convincingness of the presented (supposedly) ritual contexts would be lost.

By chronological order, our first comment is dedicated to the skeletal element representation data for the construction phase I $\left(11^{\text {th }} / 10^{\text {th }}\right.$ century $\left.\mathrm{BC}\right)$, as left mandibles $(\mathrm{N}=4)$ were the sole dog finds there. Considering the excavating techniques (Vojaković, 2013, p. 17-19), it is improbable that such a result is due to inappropriate sampling. It might, however, be indicative of deliberate collection/placement of dog mandibles $^{9}$ as a manifestation of their possible symbolism. Noteworthy in this regard is a similar situation documented at the coeval site of Ormož, another major protourbane center some $100 \mathrm{~km}$ to the east (Dular, Tomanič Jevremov, 2010). ${ }^{10}$ As a matter of fact, three out of four recovered dog remains there were also mandibles. All of them originate from the location of Skolibrova ulica, which is characterized by the highest representation of skeletal elements from the meatiest parts of cattle and pig carcasses as well as of horse in comparison to other sectors, while the number of game finds is scantier than elsewhere (Toškan, Dirjec, 2010, p. 206-212). 
At Ormož, two out of three dog mandibles were found within the perimeters of large dwelling houses (i.e. Skolibrova ulica: Buildings 13 and 15; Dular, Tomanič Jevremov, 2010 , p. 90, 94). In contrast to this, the four mandibles from Tribuna's construction phase I apparently lay mixed to the gravel and other deposits on individual streets and lanes. This circumstance does not speak in favour of their deposition being ritual (Paulsson-Holmberg, 1997, p. 168-169), but it does not completely negate it either. As a matter of fact, several examples of dog (as well as other animal) remains found outside the exterior walls of ancient buildings have been interpreted as representing building offerings (Capelle, 1987, p. 190-192, 199, 204-205). As far as the site of Tribuna is concerned, two other assemblages of canid remains might be worth commenting on in this regard (Fig. 5). They originate from the construction phase II and are thus datable to the $10^{\text {th }}$ century BC. Both are minuscule, being composed of four and five remains, respectively. Although this does not seem to be much, it has to be stressed that only one single additional dog bone has been found among faunal remains from this construction phase on the entire site.

Considering the data on skeletal element representation and the available bone measurements (Tab. 4), the remains from the larger assemblage might all belong to a single, medium-sized specimen (De Grossi Mazzorin, Tagliacozzo, 2000). Not surprisingly, they all lay within a single basic grid unit in-between of Buildings 15 and 17, so (very) close together (Fig. 5). ${ }^{11}$ Contrary to this, bones forming the other assemblage happened to be scattered along a narrow lane between Buildings 11 and 12=13 over an area measuring between approx. 15 and $30 \mathrm{~m}^{2}$ (Fig. 5). They belong to at least two animals: a medium sized dog (right mandible) and a much larger specimen, possibly even a wolf (left mandible, radius) (Riedel, 1977; De Grossi Mazzorin, Tagliacozzo, 1997; Sansalone et al., 2015). If so, the ritual connotations of the finding only gain credibility. The isolated $\mathrm{P}_{4}$ seems to belong to the larger animal as well.

Tableau 4: Content of two small canid assemblages at the site of Tribuna in Ljubljana (Slovenia), dated to the $10^{\text {th }}$ century BC or constructional phase II (see also Fig. 5).

\begin{tabular}{|c|c|c|c|c|c|}
\hline $\begin{array}{c}\text { Assemblage } \\
\text { location }\end{array}$ & $\begin{array}{c}\text { Taxonomic } \\
\text { identification }\end{array}$ & $\begin{array}{l}\text { Skeletal } \\
\text { element }\end{array}$ & $\begin{array}{c}\text { Anatomical } \\
\text { orientation }\end{array}$ & $\begin{array}{c}\text { Part } \\
\text { preserved }\end{array}$ & $\begin{array}{c}\text { Size } \\
\text { (in } \mathrm{mm} \text { ) }\end{array}$ \\
\hline \multirow{5}{*}{ 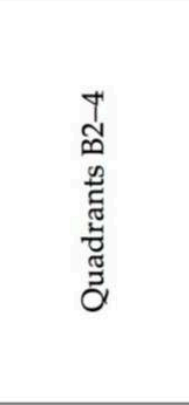 } & \multirow{5}{*}{ C. familiaris } & Femur & Right & Diaphysis & $\mathrm{SD}=11.0$ \\
\hline & & Femur & Right & Distal end & - \\
\hline & & Tibia & Left & $\begin{array}{c}\text { Proximal } \\
\text { end }\end{array}$ & $\mathrm{SD}=13.5$ \\
\hline & & Tibia & Left & Distal half & $\begin{array}{l}\mathrm{SD}=12.5 \\
\mathrm{Bd}=21.0 \\
\mathrm{Dd}=16.5\end{array}$ \\
\hline & & $\begin{array}{c}\text { Metatarsus } \\
2\end{array}$ & Left & Complete & $\mathrm{GL}=65.5$ \\
\hline \multirow{4}{*}{$\begin{array}{l}\text { م் } \\
\dot{a}\end{array}$} & C. familiaris & Mandibula & Right & Body & $M_{1}(A)=21.0$ \\
\hline & \multirow{3}{*}{ Canis sp. } & Mandibula & Left & Body & $\mathrm{M}_{1}(\mathrm{~A})=27.0$ \\
\hline & & Dens $\left(P_{1}\right)$ & Right & Complete & - \\
\hline & & Radius & Right & Diaphysis & $\mathrm{SD}=14.0$ \\
\hline
\end{tabular}

Measurement data were taken according to von den Driesch 1976. Explanation of abbreviation: $M_{1}(A)$ - length of the carnassial alveolus. 
most likely dog-related ritual manifestation at Tribuna, however, is the placement of remains in post-holes. The practice, which has clearly not been limited to the dog must have been fairly widespread from the Early Iron Age onwards (Capelle, 1987, p. 194; Paulsson-Holmberg, 1997, p. 167; Schmidt, 2001; Trebsche, 2005). Nevertheless, since remains of post-hole building offerings often do not differ at first sight from the ordinary household waste in habitational layers, they are very difficult to detect (Capelle, 1987, p. 189; Trebsche, 2005, p. 217-218). What might be of help (apart from the meticulously done field work) is the presence of bones that are incongruous or differ from the expected (e.g. presence of rare species, the predominance of certain skeletal elements). Dog remains often fall into this category, but additional indicators might be needed.

At Tribuna, dog bones have been found in fillings of two post-holes altogether: SU 4583

(related to Building $8 \mathrm{a}$ of construction phase III, i.e. $9^{\text {th }}$ century BC) and SU 1711 (related to Building 12=13 of the construction phase IV, i.e. $8^{\text {th }}$ century) (Fig. 5). The recovered bone assemblages from the two features, as well as from the related buildings in general, seem to be distinctive enough to allow for a ritual interpretation of their deposition.

Figure 5: Ground plan reconstruction of the prehistoric construction phase II at Tribuna site in Ljubljana showing its proper street layout, consisting of the main road, several streets, lanes and squares positioned perpendicularly or parallel to others. (Modified from Vojaković 2014, Figure 1).

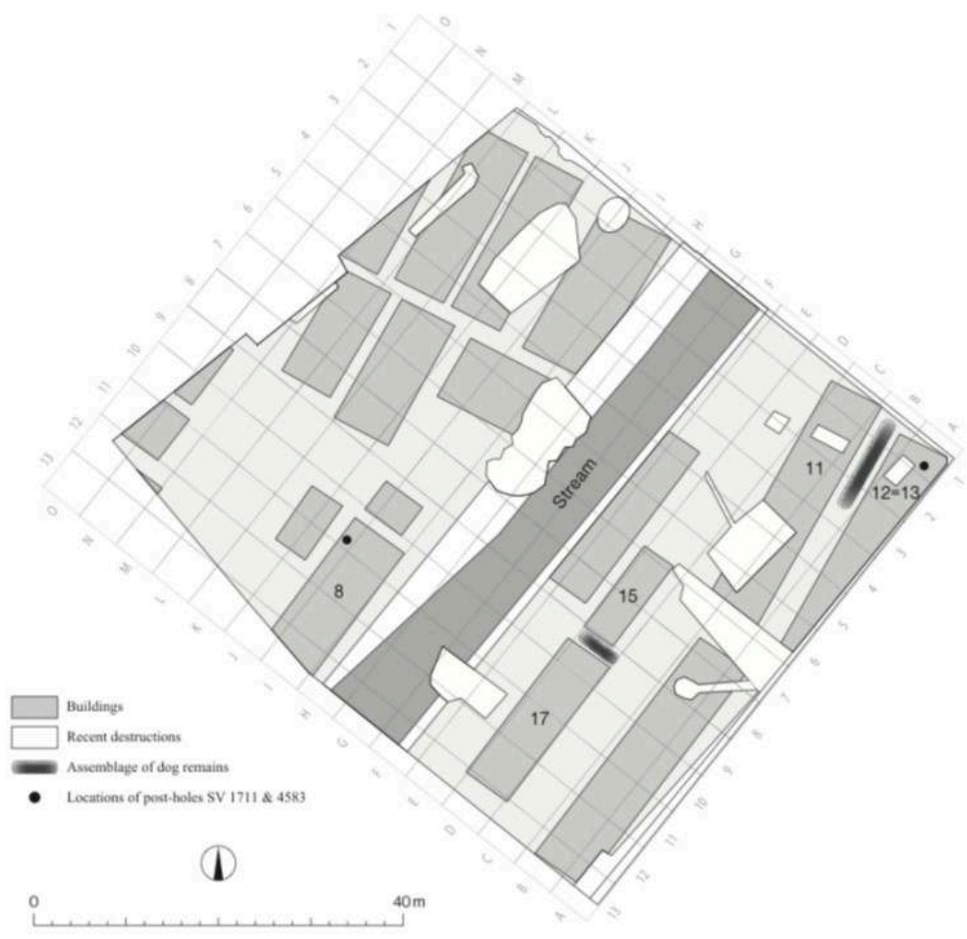

In SU 4583 (filling SU 4584), for instance, a dog mandible was found together with five taxonomically identified and an additional eight unidentified animal remains (Tab. 5). The mandible is only partially preserved (ramus and part of the body are missing). Nevertheless, as neither chop-marks nor cut-marks have been observed on the specimen, the possibility of the fragmentation being post-depositional cannot be excluded. ${ }^{12}$ If so, its presence within the post-hole filling might not be coincidental, as 
symbolic depositions of cranial skeletal elements into post-holes are well-attested (see e.g. Capelle, 1987, p. 194). After all, both the cattle mandible and humerus fragments do bear cut marks, thus probably merely represent household waste that entered the posthole accidentally.

Additional arguments for the considered dog mandible possibly representing a symbolic deposition emerge from the taxonomic richness of the coeval archaeozoological material, originating from the entire area of Building $8 \mathrm{a}(\mathrm{NISP}=61$ ). Indeed, the mentioned assemblage does not include only the omnipresent cattle, ovicaprids and pig bones, but also far more rarely represented red deer (4 fragments of worked antler; $\mathrm{NISP}_{\text {site total }}=81$ ), roe deer (unworked antler; $\mathrm{NISP}_{\text {site total }}=3$ ) and a taxonomically not better identified bird bone ( IISP $\left._{\text {site total }}=5\right)$. Interestingly enough, the roe deer antler was discovered close to (under the?) foundation of the building wall, thus probably representing a building (foundation) offering itself. This might go along well with the lead archaeologist's impression, that Building 8a was one of the two most important buildings in that part of the settlement at the time (Vojaković, 2013, p. 322). Worth noting is also the discovery of a bronze socketed axe stuck into the pavement of Building $8 \mathrm{~b}$. The latter stood just to the south of Building $8 \mathrm{a}$ during construction phase III, however, was formerly joined to it forming a single building (i.e. Building 8; Fig. 5; Vojaković, 2013, p. 136-140,325). The axe does not show any signs of usage and must thus have been deliberately driven into the pavement as yet another example of the offering (Teržan, 2006, p. 267-268; Hänsel et al., 2011, p. 27).

Tableau 5: Archaeozoological finds from the fillings of post-holes SU 1711 and 4583 at the site of Tribuna in Ljubljana, Slovenia (see also Fig. 5).

\begin{tabular}{|c|c|c|c|c|}
\hline Post-hole & Taxon & Sk. element & Part preserved & Notes \\
\hline \multirow{3}{*}{ SU 1711} & C. familiaris & Os sesamoideum & Complete & - \\
\hline & H. sapiens & Phalanx 3 & Complete & - \\
\hline & Gen. indet. & Indeterminatus & 5 small fragments & $\begin{array}{l}2 \text { fragments } \\
\text { burned }\end{array}$ \\
\hline \multirow{8}{*}{ SU 4583} & C. familiaris & Mandibula & Body (part of) & $\begin{array}{l}\text { No cut/chop- } \\
\text { marks }\end{array}$ \\
\hline & \multirow{3}{*}{ B. taurus } & Dens $\left(\mathrm{M}^{1 / 2}\right)$ & Complete & - \\
\hline & & Mandibula & Ramus (part of) & Chop-marks \\
\hline & & Humerus & Diaphysis & Chop-marks \\
\hline & \multirow{2}{*}{ Caprinae } & Dens $\left(M^{1 / 2}\right)$ & Complete & - \\
\hline & & Maxilla & Part of left side & - \\
\hline & \multirow{2}{*}{ Gen. indet. } & Costa & Body (part of) & Small ruminant \\
\hline & & Indeterminatus & 6 small fragments & - \\
\hline
\end{tabular}

As far as the post-hole filling SU 1712 (roof ridge post-hole SU 1711) is concerned, it yielded an isolated dog sesamoid bone,$^{13}$ a human distal phalanx and five taxonomically unidentified bone fragments (Tab. 5). Two of the unidentified specimens are burned. The filling has been water-sieved; thus, not much should have been missed. In addition to animal remains, an all but complete vessel together with the bases of a further three specimens have been found, which is not to be neglected.

Our first comment goes rightfully to the human phalanx, as it is the sole human bone found at the site. Nevertheless, similar examples are known from prehistoric Europe and have been convincingly interpreted as building offerings (see e.g. PaulssonHolmberg, 1997, p. 171-172). Indeed, it is hardly likely that human bones constituted a normal feature in the floor and post-hole fillings of a house, nor could they be ordinary food refuse. It is much more tempting to relate the single human - and possibly also 
dog - remain to a deliberate deposition in accordance with the wish to confer powerful protection to the building.

Moreover, the building in question (i.e. Building $12=13$ ) seems to have been especially significant. It was one of only two buildings within construction phase IV yielding the remains of a fireplace, a complete inventory of pottery (tableware, kitchenware and kitchen utensils), several spindle whorls as well as slag and bungs (Vojaković, 2013, p. 327-329). Moreover, bones of no less than nine animal species were represented among the mere 27 taxonomically identified remains collected from within the perimeters of the building. The list also includes hare and chicken, which were not detected anywhere else at Tribuna. In fact, both mentioned animals are relatively rare on Iron Age sites in general, with the chicken find being one of the oldest yet recorded in Central Europe (Kyselý, 2010; De Grossi Mazzorin, 2005; for another local early record see Hincak, 2011). Interestingly, the character of most of these early finds is believed to reflect ritual practices (Kyselý, 2010, p. 29; De Grossi Mazzorin, 2005; Sykes, 2012; Hincak, 2011).

\section{Conclusions}

29 From antiquity onward dogs played a significant role in funerary rituals, foundation offerings, purification rites, sacrifices, and were even used as healing agents (see e.g. De Grossi Mazzorin, Minniti, 2006). In this contribution, we seek to demonstrate that canids had a significant role in funerary rituals and possibly also building offerings in the South-Eastern Alpine region at least from the Late Bronze and Iron Age onward. Our analysis of dog and wolf remains in funerary contexts differentiated teeth and bones found in the graves themselves and those found in the fill of the graves or fill of the barrows, or even in specially designated places within the cemeteries, where no human bones were found. On the basis of the archaeological and archaeozoological data, we believe that these contexts require different interpretations of ritual practices.

Remains found in the fill of the graves/barrows or at "ritual" places within a cemetery were always discovered together with bones of other species (Tab. 2) and could be interpreted as the remains of funerary celebrations, which included sacrifices, offerings, and even funerary feasting. On the basis of archaeological data, it was difficult to say whether these are the remains of funerary rituals which took place before, during, or after the burial, or even in all of these cases. A different case is the dog and wolf bones discovered in the graves themselves (Tab. 1; Fig. 2 \& 3). In these contexts we are dealing with individual specimens: teeth, jaws, a baculum, a caudal vertebra; and it could be assumed that they were primarily of an apotropaic character, i.e. these bones carried a special power and protected their owners from evil, provided assistance, or healing. The baculum found in a grave in Ljubljana is an exceptional find (Fig. 3: 1), and according to the results of the analysis of the stable isotope $\delta 13 \mathrm{C}$, it can be attributed to a larger dog. There is no doubt about the special character and symbolic meaning of this bone, for which analogies are hard to find. It is somewhat surprising that burials of canids (i.e. burials of entire skeletons together with their owners or in their vicinity) are practically unknown in the South-Eastern Alpine region in the time of the Late Bronze Age and Iron Age. The closest analogies for such dog burials can be found in cemeteries in Hungary and Serbia (Vadász, 1983, 1986; KmeŤová, 2011; Vörös, 1993; Párducz, 1952, 1954, 1955; Bökönyi, 1952, 1954; Vörös, 
2015; Kemenczei, 2009, p. 156, Abb. 7:41; Trajković, 2008, p. 35-36, 190; Blažić, 2008; Filipović, Bulatović, 2011, p. 74-76, figs. 3:1 and 4; for other regions see Bill, 2003, p. 75). It is very likely that these animals "accompanied" their masters into graves as their guardians and companions.

Ritual archaeozoological features of the kind of building offerings within settlement contexts are much more difficult to detect. This is in great part ascribable to their very diverse and complicated nature (see e.g. Capelle, 1987; Paulsson-Holmberg, 1997, p. 170-172). In addition to this, their identification is dependent on careful excavation techniques and sensible treatment of animal remains, which are often lacking. One way of effectively discerning osteological offering gifts is by focusing on large, wellpreserved bones (often crania and cannon bones) of unexpected species recovered from inside or under sealed elements of construction (post-holes, wall foundations, paved floor, etc.). Of the canid remains discussed in this paper, those originating from two of Tribuna's many dug post-holes best fit these particular circumstances: the two isolated dog bones do not bear any chop- or cut-marks, were joined by several other noncommon animal species remains, including man (Tab. 5), and are related to buildings with fairly atypical archaeo(zoo)logical inventory. If the two assemblages are indeed ritual, the presence of a dog as a generally non-edible animal might be indicative of the offerings suiting into the guardian category. Both entire skeletons and isolated elements are known to have been deposited for this purpose (Capelle, 1987; PaulssonHolmberg, 1997, p. 169; De Grossi Mazzorin, Minitti, 2006, p. 65). Apparently, even a single bone has been reputed sufficient to "house" the spirit of a dead creature, called to become the guardian of the building in question. This is further corroborated by the presence of the human phalange, as single human bones recovered in such contexts likely belong to the same (= guardian) category (Capelle, 1987, p. 184-185; PaulssonHolmberg, 1997, p. 169, 172).

Our final comment goes to the chronological framework of the discussed dog and possibly also wolf remains from the settlement of Tribuna and its respective cemetery (Dvorišče SAZU, Novi trg, Kongresni trg; see Fig. 1 \& 3), as it seemingly indicates a local peak in ritualistic use of canids starting with (being limited to?) the $9^{\text {th }}$ and $8^{\text {th }}$ centuries BC (i.e. Tribuna constructional phases III and IV). Especially notable in this regard is the pairing of the two supposed examples of post-hole building offerings from Tribuna with the baculum and the caudal vertebra from Dvorišče SAZU graves 275 and 181. Also interesting, however, is the cluster of dog remains related to Barrows 1 \& 2 and to Barrow 1003 at the nearby locations of Novi trg and Kongresni trg, respectively, as both have also been preliminarily dated to the same period. In fact, most of the canid remains in funerary contexts in the South-Eastern Alpine region are dated to the initial phases of the Early Iron Age, with the only exception being represented by the site of Magdalenska gora (Tabs. 1 \& 2; Fig. 2). 


\section{BIBLIOGRAPHY}

AMBRoSE S. H. 1990, «Preparation and Characterization of Bone and Tooth Collagen for Isotopic Analysis ", Journal of Archaeological Science no 17, pp. 431-451.

ANDRAŁOJC M. 1993, The Phenomen of Dog Burials in the Prehistoric Times on the Area of Middle Europe. Ollodagos - Mémoires de la Société Belge d'Études Celtiques 1, Brüssel.

BARTH F. E. 1969, Die hallstattzeitlichen Grabhügel im Bereiche des Kutscher bei Podsemel (Slowenien). Antiquitas 3/5.

BARTOSIEWICZ L. 1985, « Most na Soči: A preliminary faunal analysis of the Hallstatt period », Arheološki vestnik, no 36, pp. 122-130.

BARTOSIEWICZ L. 1991, « Faunal material from two Hallstatt Period settlements in Slovenia ", Arheološki vestnik, no 42, pp. 199-206.

BARTOSIEWICZ L. 1994, "Late Neolithic dog exploitation: chronology and function », Acta Archaeologica Academiae Scientarum Hungaricae, nํ4, pp. 59-71.

BARTOSIEWICZ L. 1999, « Recent developments in archaeozoological research in Slovenia », Arheološki vestnik, no 50, pp. 311-322.

BAVDEK A., A. MIHEVC, B. TOŠKAN, A. VELUŠČEK 2009, « Archaeological finds from Križna jama Cave / Arheološke najdbe iz Križne jame », Arheološki vestnik, nº 60, pp. 17-31. (bilingual in Slovene and English)

BILL A. 2003, Studien zu den Gräbern des 6. bis 1. Jahrhunderts v. Chr. in Georgien unter besonderer Berücksichtigung der Beziehungen zu den Steppenvölkern. Universitätsforschungen zur prähistorischen Archäologie 96, Bonn.

BLAžÍć S. 2008, « Remains of animal bones in the graves of the Hallstatt necropolis Đepfeld », in Trajković D., Đepfeld - Early Iron Age Necropolis at Doroslovo, City Museum of Sombor, Sombor, pp. 355-376.

вÖКÖNYI S. 1952, « Les chevaux scythiques du cimetière de Szentes-Vekerzug », Acta Archaeologica Academiae Scientarum Hungaricae, nํㅡㄹ 2, pp. 173-183.

вÖкÖNYI S. 1954, «Les chevaux scythiques du cimetière de Szentes-Vekerzug. (Etude sur le matériel osseux des fouilles de 1952-1953) », Acta Archaeologica Academiae Scientarum Hungaricae, no ${ }^{\circ}$, pp. 93-114.

BÖKÖNYI S. 1974, History of domestic mammals in Central and Eastern Europe, Academiai Kiado, Budapest.

BÖKÖNYI S. 1994, « Die Tierknochenfunde », in GABROVEC S., Stična I. Siedlungsausgrabungen. Katalogi in monografije 28, Ljubljana, pp. 190-213.

BOUDADI-MALIGNE M., G. ESCARGUEL 2014, « A biometric re-evaluation of recent claims for Early Upper Palaeolithic wolf domestication in Eurasia. », Journal of Archaeological Science, nº 45, pp. 8089.

BRICELJ, M. 2014, « Slovenske Konjice / Slovenske Konjice », in TERŽAN B., M. ČREŠNAR (Eds.), Absolutno datiranje bronaste in Železne dobe na Slovenskem / Absolute dating of the Bronze and Iron Ages in Slovenia. Katalogi in monografije 40, Ljubljana, pp. 287-298. (bilingual in Slovene and English) 
CAPELLE T. 1987, « Eisenzeitlichte Bauopfer », Frühmittelalterliche Studien. Jahrbuch des Instituts für Frühmittelalterforschung der Universität Münster, $\mathrm{n}^{\circ}$ 21, pp. 182-205.

CHENAL-VELARDE I. 2006, « Food, rituals? The exploitation of dogs from Eretria (Greece) during the Helladic and Hellenistic periods ", in SNYDER L. M., E. A. Moore (Eds.), Dogs and People in Social, Working, Economic or Symbolic Interaction, $9^{\text {th }}$ ICAZ Conference, Durham, $23^{\text {rd }}-28^{\text {th }}$ August 2002 , Oxbow Books, Oxford, pp. 24-31.

CHOYKE A. 2010, "The Bone is the Beast. Animal Amulets and Ornaments in Power and Magic », in CAMPANA D., P. CRABTREE, S. D. DE FRANCE, J. LEV-TOV, A. M. CHOYKE (Eds.), Anthropological approaches to zooarchaeology: Colonialism, complexity and animal transformations, Oxbow Books, Oxford, pp. 197209.

CHRószcZ A., M. JANECZEK, Z. BIELICHOVÁ, T. GRALAK, V. onAR 2013 « Cynophagia in the Púchov (Celtic) culture settlement at Liptovská Mara, Northern Slovakia », International Journal of Osteoarchaeology, no 22(2), pp. 145-157.

ČANÁDY A., L. ČOMOR 2013, « Contribution to the knowledge of variability of the penis bone (baculum) in Canis lupus from Slovakia (Carnivora: Canidae) », Lynx, no 44, pp. 5-12.

De GROSSI MAZzorIN J. 2001, «L'uso dei cani nei riti funerari. Il caso della necropoli di età imperiale a Fidene - via Radicofani », in HEINZELMANN M., J. ORTALLI, P. FASOLD, M. WITTEYER (Eds.), Culto dei morti e costumi funerari romani. Roma Italia settentrionale e province nord-occidentali dalla tarda Repubblica all'età imperiale, Roma, 1-3 aprile 1998, Wiesbaden, pp. 77-82.

De GROSSI MAZZORIN J. 2005, « Introduzione e diffusione del pollame in Italia ed evoluzione delle sue forme di allevamento fino al Medioevo ", in FIORE I, G. MALERBA, S. CHILARDI (Eds.), Atti del $3^{\circ}$ Convegno Nazionale di Archeozoologia, Siracusa, 3-5 novembre 2000, Istituto poligrafico e Zecca dello Stato Roma, pp. 351-361.

De Grossi MAZzorin J., C. MINNITI 2006, « Dog Sacrifice in the Ancient World: A Ritual Passage ? », in SNYDER L. M., E. A. MOORE (Eds.), Dogs and People in Social, Working, Economic or Symbolic Interaction, $9^{\text {th }}$ ICAZ Conference, Durham, $23^{\text {rd }}-28^{\text {th }}$ August 2002, Oxbow Books, Oxford, pp. 62-66.

De GROSSI MAZZORIN J, A. TAGLIACOZzo 1997, « Dogs remains in Italy from the Neolithic to the Roman Period ", Anthropozoologica, nํ25-26, pp. 429-440.

De GROSSI MAZZORIN J., A. TAGLIACOZzo 2000, « Morphological and osteological changes in the dog from the Neolithic to the Roman Period in Italy ", in CROCKFORD C. J. (Ed.), Dogs through time: An archaeological perspective, $1^{\text {st }}$ ICAZ Symposium on the history of the domestic dog, Victoria, $23^{\text {rd }}$ $29^{\text {th }}$ August, Oxbow Books,Oxford, pp. 141-161.

DRIESCH A. von den 1976, « A guide to the measurement of animal bones from archaeological sites », Peabody Museum Bulletin, no 1, pp. 1-136.

DULAR A. 1991, Prazgodovinska grobišča v okolici Vinjega Vrha nad Belo Cerkvijo / Die vorgeschichtlichen Nekropolen in der Umgebung von Vinji Vrh oberhalb von Bela Cerkev. Katalogi in monografije 26, Ljubljana. (bilingual in Slovene and German)

DULAR J. 2007, « Pferdegräber und Pferdebestattungen in der halstattzeitlichen Dolenjsko-Gruppe / Konjski grobovi in pokopi konj v dolenjski halštatski skupini », in BLEČIĆ M., M. ČREŠNAR, B. HÄNSEL, A. HELlMUth, E. KAISER, C. METZNER-NEBELSICK (Eds.), Scripta Praehistorica in Honorem Biba Teržan. Situla 44, Ljubljana, pp. 737-752. (in German with Slovene summary) 
DULAR J., S. TECCO HVALA 2007, South-Eastern Slovenia in the Early Iron Age. Settlement, economy, society / Jugovzhodna Slovenija v starejši železni dobi: poselitev, gospodarstvo, družba. Opera Instituti Archaeologici Sloveniae 12, Ljubljana. (bilingual in Slovene and English)

DULAR J., M. TOMANIČ-JEVREMOV 2010, Ormož: befestigte Siedlung aus der späten Bronze- und der ältern Eisenzeit / Ormož: utrjeno naselje iz pozne bronaste in starejše železne dobe. Opera Instituti Archaeologici Sloveniae 18, Ljubljana. (bilingual in Slovene and German/English)

EWERSEN J. von, S. ZIEGLER 2011-11, « Hungrige Hunde jagen am besten. Nahrungsgrundlagen mesolithischer und neolithischer Hunde nach Isotopenverhältnissen », Offa, nº 67/68, pp. 5-26. filipović V. M., A. P. BUlatović 2011, « An Early Iron Age Necropolis in Eastern Serbia », Glasnik Srpskog arheološkog društva, no 26, pp. 73-83.

GABRovec S. 1960, Prazgodovinski Bled / The prehistory of Bled. Dela 1. razreda SAZU 12/8. (in Slovene with English summary)

GABRovec S. 1970, « Dvozankaste ločne fibule. Doprinos k problematiki začetka železne dobe na Balkanu in v jugovzhodnih Alpah / Die zweischleifige Bogenfibeln. Ein Beitrag zum Beginn der Hallstattzeit am Balkan und in den Südostalpen », Godišnjak, nº 8, Centar za balkanološka ispitivanja, no 6, pp. 5-67. (in Slovene with German summary)

GABROVEC S. 1994, Stična I. Siedlungsausgrabungen. Katalogi in monografije 28, Ljubljana.

GERMONPRÉ M., M. V. SABLIN, R. E. STEVENS, R. E. M. HEDGES, M. HOFREITER, M. STILLER, V. JAENICKEDESPRESE 2009, « Fossil dog and wolves from Palaeolithic sites in Belgium, the Ukraine and Russia: Osteometry, ancient DNA and stable isotopes », Journal of Archaeological Science, no $³ 6$, pp. 473-490. GERMONPRÉ M., M. LÁZNIČKOVÁ-GALETOVÁ, M. V. SABLIN 2012, « Palaeolithic dog skulls at the Gravettian Předmostí site, the Czech Republic », Journal of Archaeological Science, nํ39(1), pp. 184202.

GERMONPRÉ M., M. LÁZNIČKOVÁ-GALETOVÁ, R. J. LOSEY, J. RÄIKKÖNEN, M. SABLIN 2015a, « Large canids at the Gravettian Předmostí site, the Czech Republic: the mandible », Quaternary International, no 359, pp. 261-279.

GERMONPRÉ M., M. V. SABLIN, M. LÁZNIČKOVÁ-GALETOVÁ, V. DESPRÉS, R. E. STEVENS, M. STILLER, M. HOFREITER 2015b, « Palaeolithic dogs and Pleistocene wolves revisited: a reply to Morey (2014)», Journal of Archaeological Science, nº 54, pp. 210-216.

GRÖMER K., T. TOLAR, K. KOSTAJNŠEK 2017, « Textile and fur remains in Grave 6 Tumulus 1 in Pleška hosta at Molnik / Ostanki tekstila in živalskih dlak (krzna) v grobu 6 gomile $1 \mathrm{v}$ Pleški hosti na Molniku », in TECCO HVALA S. (Ed.), Molnik pri Ljubljani $v$ železni dobi / The Iron Age site Molnik near Ljubljana. Opera Instituti Archaeologici Sloveniae 36, pp. 211-219.

GRUŠKOVNJAK L., M. OMAHEN, B. TOŠKAN 2018, « Ostanki prazgodovinskega grobišča z Novega trga v Ljubljani / The prehistoric cemetery at Novi trg in Ljubljana (Slovenia) », in M. ČREŠNAR, M. VINAZZA (eds.), Srečanja in vplivi v raziskovanju bronaste in železne dobe na Slovenskem / Encounters and influences in the Bronze and Early Iron Age Archaeology in Slovenija, Ljubljana, pp. 227-261. (in Slovene with English summary)

GUIRY E. J. 2012, « Dogs as Analogs in Stable Isotope-Based Human Paleodietary Reconstructions. A Review and Considerations for Future Use », Journal of Archaeological Method and Theory, $\mathrm{n}^{\circ}$ 19, pp. 351-376.

HAMBLETON E. 2008, Review of Middle Bronze Age-Late Iron Age faunal assemblages from southern Britain. Research department report series, no 71, London. 
HÄNSEL B., B. TERŽAN, K. MIHOVILIĆ 2011, « Brončane sjekire i njihovi djelovi. Opažanja na primjeru nalaza s Monkodonje u Istri », Histria archaeologica, no 41, pp. 5-33.

HENCKEN H. 1978, The Iron Age Cemetery of Magdalenska gora in Slovenia. Mecklenburg Collection Part 2, American School of Prehistoric Research, Bulletin 32, Peabody Museum.

HINCAK Z. 2011, « Zooarheološke in antropološke analize kostnih ostankov z najdišča Kotare-Krogi pri Murski Soboti », in KERMAN B., Z. HINCAK, B. TOŠKAN, P. M. GROOTES, Kotare-Krogi pri Murski Soboti. Arheologija na avtocestah Slovenije 20, Ljubljana, pp. 128-129.

HORARD-HERBIN M.-P. 2014, « La viande de chien à l'âge du Fer. Quels individus pour quelles consommations? », Gallia, no 71(2), pp. 69-87.

HORARD-HERBIN M.-P., A. Tresset, J.-D. Vigne 2014, « Domestication and uses of the dog in western Europe from the Paleolithic to the Iron Age », Animal Frontiers, no 4(3), pp. 23-31.

JANSSENS L. A. A., M. STReET, R. MILleR, H. A. W. HAZEWinKel, L. GIEMSCH, R. SCHMitZ 2016, « The oldest case yet reported of osteoarthritis in a dog. An archaeological and radiological evaluation ", Journal of Small Animal Practice, nº 57(10), pp. 568-574.

KARAVANIĆ I., F. H. SMITH 2013, « Alternative Interpretations of the Middle/Upper Paleolithic Interface at Vindija Cave (Northwestern Croatia) in the Context of Central Europe and the Adriatic », Archaeology Ethnology \& Anthropology of Eurasia, nº 41/4, pp. 11-20.

KAYS R., R. S. FERANEC 2011, « Using Stable Carbon Isotopes to Distinguish Wild from Captive Wolves », Northeastern Naturalist, nº 18(3), pp. 253-264.

KEMENCZEI T. 2009, Studien zu den Denkmälern skythisch geprägter Alföld Gruppe. Inventaria Praehistorica Hungariae 12, Budapest.

KIRKINEN T. 2015, « The role of wild animals in death rituals. Furs and animal skins in the Late Iron Age inhumation burials in Southeastern Fennoscandia », Fennoscandia archaeologica, nº 32, pp. 101-120.

KMEŤOVÁ P. 2006, « Postavenie psa v spoločnosti doby halštatskej », Medea, no 10, pp. 7-45.

KMEŤovÁ P. 2011, « Pohreb dieŤaŤa z halštatskej mohyly v Sütto” - súvislosti a interpretácie », Zborník Filozofickej fakulty Univerzity Komenského - Musaica, no 27, pp. 261-276.

KMEŤOVÁ P. 2014, Deponovanie koní na pohrebiskách z doby halstatskej v priestore Panónskej panvy / Deposition of horses in the Hallstatt period cemeteries on the territory of Pannonian basin. Dissertationes archaeologicae Bratislavenses 2, Bratislava.

KMEŤOVÁ P., S. STEGMANN-RAJTÁR 2014, « Zur symbolischen Bestattung von Pferdeschädeln in Gräbern der späten Urnenfelder- und älteren Hallstattzeit », in TECCO HVALA S. (Ed.), Studia Praehistorica in Honorem Janez Dular. Opera Instituti Archaeologici Sloveniae 30, Ljubljana, pp. 149166.

KRIž B. 2003, « Bela Cerkev - Pod Vovkom », in Prešeren D. (Ed.), The Earth Beneath Your Feet. Archaeology on the Motorways in Slovenia, Institute for the Protection of the Cultural Heritage of Slovenia, Ljubljana, pp. 97-98.

KROMER K. 1959, Das Gräberfeld von Hallstatt. - Firenze.

KYSELÝ R. 2010, « Review of the oldest evidence of domestic fowl Gallus gallus f. domestica from the Czech Republic in its European context », Acta zoological cracoviensia, nº 53A(1-2), pp. 9-34. 
LAZĂR C., M. MĂRGĂRIT, A. BĂLĂşESCU 2016, « Dogs, jaws, and other stories. Two symbolic objects made of dog mandibles from southeastern Europe ", Journal of Field Archaeology, no 41(1), pp. 101117.

LOSEY R. J., V. I. BAZALIISKII, S. GARVIE-LOK, M. GERMONPRÉ, J. A. LEONARD, A. L. ALLEN, M. A. KATZENBERG, M. V. SABLIN 2011, «Canids as persons. Early Neolithic dog and wolf burials, Cis-Baikal, Siberia », Journal of Anthropological Archaeology, no 30(2), pp. 174-189.

MALEZ M. 1988, « Prethistorijske koštane rukotvorine iz spilje Vindije (Hrvatska, Jugoslavija) », Radovi Zavoda za znanstveni rad JAZU, nº 2, pp. 217-252.

MASARYK R., D. BADOVINAC, J. HRUSTEL, P. VOJAKOVIĆ, S. HVALEC, S. PORENTA, J. BREČIĆ, I. BEKLJANOV ZIDANŠEK, T. VERBIČ, M. BOŽINOVIĆ, R. ERJAVEC 2011, Poročilo o arheoloških raziskavah na območju gradnje parkirne hiše v Ljubljani, Kongresni trg. Unpublished report, Ministry of Culture, Republic of Slovenia, Ljubljana.

MENCEJ M. 2001, « Wolf Herdsman in the Context with the Latest Researches in Slavic Mythology », Studia Mythologica Slavica, oㅡ 4, pp. 159-188. (in Slovene with English summary).

MÉNIEL P. 2006, « Le chien en Gaule », in Curci A., D. Vitali (Eds.), Animali tra uomini e dei. Archeozoologia del mondo preromano. Ante Quem 14, Ravenna, pp. 45-52.

MERLATTI R. 2001, « Il complesso protostorico della Grotta delle Ossa a San Canziano del Carso », Atti e Memorie della Società Istriana di Archeologia e Storia Patria, nº 49, pp. 7-85.

MLINAR M. 2002, Nove zanke svetolucijske uganke: arheološke raziskave na Mostu na Soči 2000 do 2001 / Sveta Lucija - new stigma to the enigma: archaeological excavations at Most na Soči 2000-2001, Tolmin. (bilingual in Slovene and English)

MOREY D. F. 2014, «In search of Paleolithic dogs: a quest with mixed results », Journal of Archaeological Science, $\mathrm{n}^{\mathrm{0}}$ 52, pp. 300-307.

NICOLIS F. 2001, « Il culto dei morti nell'antica e media età del Bronzo », in Lanzinger M., F. Marzatico, A. Pedrotti (Eds.), Storia del Trentino. I. La preistoria e la protostoria, Il Mulino, Bologna, pp. 337-365.

NOMOKONOVA T., O. I. GORIUNOVA, R. J. LOSEY, N. A. SAVELYEV 2011, " Use of Ulan-Khada bay at Lake Baikal in the Holocene (based on faunal remains) », Archaeology Ethnology \& Anthropology of Eurasia, no $39(2), 30-36$.

O'CONNOR T. P. 2003, «Skin and bones: correlating the osteological and artefactual evidence », in MOULD Q. I. CARLISLE, E. CAMERON, (Eds.) Leather and Leatherworking in Anglo-Scandinavian and Medieval York. The Archaeology of York 17, York, pp. 3231-3235.

OUTRAM A. K., N. A. STEAR, R. BENDREY, S. OLSEN, A. KASPAROV, V. ZAIBERT, N. THORPE, R. P. EVERSHED 2009, « The earliest horse harnessing and milking », Science, nº 323(5919), 1332-1335.

ovodov N. D., S. J. CROCKFORD, Y. V. KUZMIN, T. F. HIGHAM, G. W. HODGINS, J. van der PLICHT 2011, « A 33,000-year-old incipient dog from the Altai Mountains of Siberia: Evidence of the earliest domestication disrupted by the Last Glacial Maximum », Plos One, no 6(7), [e22821].

PÁRDUCZ M. 1952, « Le cimetière hallstattien de Szentes-Vekerzug », Acta Archaeologica Academiae Scientarum Hungaricae, nำ 2, pp. 143-172.

PÁRDUCZ M. 1954, « Le cimetière hallstattien de Szentes-Vekerzug II (Les fouilles de 1952 et 1953) », Acta Archaeologica Academiae Scientarum Hungaricae, no 4, pp. 25-91. 
PÁRDUCZ M. 1955, « Le cimetière hallstattien de Szentes-Vekerzug III », Acta Archaeologica Academiae Scientarum Hungaricae, $\mathrm{n}^{\circ}$ 6, pp. 1-22.

PAULSSON-HOLMBERG T. 1997, «Iron Age building offerings. A contribution to the analysis of a diehard phenomenon in Swedish preindustrial agrarian society », Fornvännen, no 92(3/4), pp. 163175.

PERINI R., C. CORRAIN, M. CAPITANIO 1991, « La necropoli a tumulo di Stenico-Calferi (Trento)», Notizie archeologiche e studio antropologico. Archivio per l'Antropologia e la Etnologia, no 121, pp. 45-84. PERRI A. 2016, « A wolf in dog's clothing: Initial dog domestication and Pleistocene wolf variation ", Journal of Archaeological Science, $\mathrm{n}^{\circ}$ 68, pp. 1-4.

PLESTENJAK A. (Ed.) 2013, Ivančna Gorica - arheološke raziskave v letih 2008 in 2009, Arhej, Ljubljana. PLETERSKI A. 2008, Zgodnjesrednjeveški žgani grobovi v vzhodnih Alpah / Frühmittelalterliche Brandgräber im Ostalpenraum. - Frühmittelalterarchäologie in der Steiermark. Beiträge eines Fachgesprächs anlässlich des 65. Geburtstags von Diether Kramer, Schild von Steier, n 4, pp. 3339.

PLUSKOWSKI A. 2006, « Where are the wolves? Investigating the scarcity of European grey wolf (Canis lupus lupus) remains in Medieval archaeological contexts and its implications ", International Journal of Osteoarchaeology, nำ16, pp. 279-295.

PRUMMEL W. 1992, «Early medieval dog burials among the Germanic tribes », Helinium, no 32 , pp. 132-194.

PRUMMEL W. 2006, « Bronze Age dogs from graves in Borger (Netherlands) and Dimini (Greece) », in SNYDER L. M., E. A. MOORE (Eds.), Dogs and People in Social, Working, Economic or Symbolic Interaction, $9^{\text {th }}$ ICAZ Conference, Durham, $23^{\text {rd }}-28^{\text {th }}$ August 2002, Oxbow Books, Oxford, pp. 67-76.

PUŠ I. 1971, Žarnogrobiščna nekropola na dvorišču SAZU v Ljubljani. Izkopavanja v letih 1964-1965 / Nekropole der Urnenfelderkultur im Hof der Slowenischen Akademie der Wissenschaften und Künste in Ljubljana. Ausgrabungen in den Jahren 1964-1965. Razprave 1. razreda SAZU 7/1, Ljubljana. (in Slovene with German summary)

PUŠ I. 1982, Prazgodovinsko žarno grobišče v Ljubljani / Das vorgeschichtliche Urnengräberfeld in Ljubljana. Razprave 1. razreda SAZU 13/2, Ljubljana. (in Slovene with German summary) RADOVANOVIĆ I. 1999, " "Neither person nor beast" - dogs in the burial practice of the Iron Gates Mesolithic », Documenta Praehistorica, nº 26, 71-87.

RAMMINGER B. 2012, « Begleiter, Wächter, Opfertier ? Zur Bedeutung des Hundes in der Hallstattkultur », in RAMMINGER B., H. LASCH (Eds.), Hunde - Menschen - Artefakte. Gedenkschrift für Gretel Callesen. Studia Honoraria 32, Internationale Archäologie, Rahden/Westfalen, pp. 229-248. RIEDEL A. 1977, « I resti animali della Grotta delle Ossa (Škocjan) », Atti del Museo Civico di Storia Naturale, Trieste, no 30(2), pp. 125-208.

RIEDEL A. 1986, « Risultati di ricerche archeozoologiche eseguite nella regione fra la costa adriatica ed il crinale alpino (dal Neolitico recente al Medio Evo) », Padusa, no 22(1-4), pp. 1-220.

RIEDEL A. 1989, « The wild animals of the Northeastern Italy from Neolithic to Medieval times: an archaeozoological comment ", Annali del Museo Civico di Storia Naturale, Brescia, no 26, pp. 311-330. RIEDEL A., U. TECCHIATI 1992, « La fauna del Riparo del Santuario (Comune di Lasino - Trentino). Aspetti archeozoologici, paleoeconomici e rituali », Annali dei Musei Civici di Rovereto, Sezione: Archeologia, Storia, Scienze Naturali, nº 8, pp. 3-46. 
RYDER M. L. 1990, « Skin, and wool-textile remains from Halstatt, Austria », Journal of Archaeological Science, $\mathrm{n}^{\circ}$ 9(1), pp. 37-49.

SANCHIS A., I. SARRIÓN 2004, «Restos de cánidos (Canis familiaris ssp.) en yacimientos vaencianos de la edad del bronce », Archivio de Prehistoria Levantina, nํ2, pp. 161-198.

SANSALONE G., D. F. BERT, L. MAIORINO, L. PANDOLFI 2015, « Evolutionary trends and stasis in carnassial teeth of European Pleistocene wolf Canis lupus (Mammalia, Canidae) », Quaternary Science Reviews, no 110, pp. 36-48.

SCHEIBNER A. 2013, Der Hund in der mitteleuropäischen Eisenzeit. Wirtschaftliche, rituelle und soziale Aspekte. Berliner archäologische Forschungen 12, Rahden/Westfalen.

SCHMIDT V. 2001, «Tierische und menschlliche Bauopfer bei den Nordwestslawen », Studia

Mythologica Slavica, no 4, pp. 25-34.

SOMMER R., N. BENECKE 2005, « Late-Pleistocene and early Holocene history of the canid fauna of Europe (Canidae) », Mammalian biology, nº 70(4), pp. 227-241.

STEARNS R. E. 1940, The Hughes site. An Aboriginal village site on the Potomac river in Mongomery county, Maryland. Proceedings of the Natural History Society of Maryland 6, Baltimore.

SVOLJŠAK D., J. Dular 2016, Most na Soči. Gradbeni izvidi in najdbe / Most na Soči. Settlement Structures and Small Finds. Opera Instituti Archaeologici Sloveniae 33, Ljubljana. (bilingual in Slovene and English)

SYKES N. 2012, «A social perspective on the introduction of exotic animals: the case of the chicken », World Archaeology, no 44(1), pp. 158-169.

SzOMBATHY J. 1913, « Altertumsfunde aus Höhlen bei St. Kanzian im österreichischen Küstenlande ", Mitteilungen der Prähistorischen Kommission der Kais. Akademie der Wissenschaften 2/2, pp. 127-190.

ŠKVOR JERNEJČIČ B. 2014, Žarna nekropola $v$ Ljubljani in preobrazba ljubljanske skupine na prehodu iz bronaste $v$ železno dobo. Unpublished PhD thesis, University of Ljubljana. (in Slovene with English summary)

TAGLIACOZZO A. 1998, « Analisi dei resti ossei animali di Este e Saletto », in BIANCHIN CITTON E., G. GAMBACURTA, A. RUTA SERAFINI (Eds.),... Presso l'Adige ridente... Recenti rinvenimenti archeologici da Este a Montagnana, Padova, pp. 48-53.

TECCO HVALA S. 2012, Magdalenska gora. Družbena struktura in grobni rituali železnodobne skupnosti / Magdalenska gora. Social structure and burial rites of the Iron Age community. Opera Instituti Archaeologici Sloveniae 26, Ljubljana. (bilingual in Slovene and English)

TECCO HVALA S., J. DULAR, E. KOCUVAN 2004, Železnodobne gomile na Magdalenski gori / Eisenzeitliche Grabhügel auf der Magdalenska gora. Katalogi in monografije 36, Ljubljana. (bilingual in Slovene and German)

TERŽAN B. 2006, « Gurtelblech aus Grab 30, Grabhügel VI nach Herzogin von Mecklenburg bzw.

Grabhugel 55 », in GABROVEC S., Stična II/1. Grabhügel aus der ä $_{\text {lteren Eisenzeit. Katalogi in }}$ monografije 37, Ljubljana, pp. 266-269.

TERŽAN B. 2016, « Škocjan, kraj na stičišču svetov: povzetek in sklepna beseda / Škocjan, at the meeting point of worlds: summary and conclusion », in B. TERŽAN, E. BORGNA, P. TURK (Eds.), Depo iz Mušje jame pri Škocjanu na Krasu. Depojske najdbe bronaste in železne dobe na Slovenskem III / Il 
ripostiglio della Grotta delle Mosche presso San Canziano del Carso. Ripostigli delle età del bronzo e del ferro in Slovenia III, Katalogi in monografije 42, Ljubljana, 345-430. (trilingual in Slovene, Italian and English)

TERŽAN B., E. BORGNA, P. TURK 2016, Depo iz Mušje jame pri Škocjanu na Krasu. Depojske najdbe bronaste in železne dobe na Slovenskem III / Il ripostiglio della Grotta delle Mosche presso San Canziano del Carso. Ripostigli delle età del bronzo e del ferro in Slovenia III, Katalogi in monografije 42, Ljubljana, 345-430. (biilingual in Slovene and Italian)

TOMAŽINČıč Š. 2011, Poročilo o arheoloških raziskavah Jelenovega klanca na Ljubljanski cesti v Kranju. Ljubljana, unpublished report, Ministry of Culture, Republic of Slovenia.

TOŠKAN B. 2005, « Živalski ostanki iz bronastodobnih naselbin pri Iški Loki in Žlebiču / Animal remains from the Bronze Age settlement at Iška Loka and Žlebič », Arheološki vestnik, no 56, pp. 91-97. (in Slovene with English summary)

TOŠKAN B., J. DIRJEC 2004, « Ostanki velikih sesalcev v Viktorjevem spodmolu / Remains of large mammals in Viktorjev spodmol », in Turk I. (Ed.), Viktorjev spodmol in Mala Triglavca: prispevki k razumevanju mezolitskega obdobja $v$ Sloveniji / Viktorjev spodmol and Mala Triglavca: Contributions to understanding the Mesolithic period in Slovenia. Opera Instituti Archaeologici Sloveniae 9, Ljubljana, pp. 135-167. (bilingual in Slovene and English)

TOŠKAN B., J. DIRJEC 2010, « Ekonomska specializacija in socialna diferenciacija v poznobronastodobnem in zgodnježeleznodobnem Ormožu: arheozoološki pogled / Economic specialization and social differentiation of the Late Bronze and Early Iron Age Ormož (NE Slovenia): the archaeozoological perspective », in DULAR J., M. TOMANIČ-JEVREMOV 2010 (Eds.), Ormož: utrjeno naselje iz pozne bronaste in starejše železne dobe / Ormož: befestigte Siedlung aus der späten Bronze- und der ältern Eisenzeit. Opera Instituti Archaeologici Sloveniae 18, Ljubljana, pp. 99-121, 203-212. (bilingual in Slovene and English)

TOŠKAN B., J. DIRJEC 2013, « Živalski ostanki », in Plestenjak A. (Ed.), Ivančna Gorica - arheološke raziskave v letih 2008 in 2009, Arhej, Ljubljana, pp. 86-89.

TOŠKAN B., B. ŠTULAR 2008, « Pes ali volk? Analiza kanidnega skeletal iz grobišča na Pristavi / Dog or wolf? Analysis of a canid skeleton from the burial site at Pristava », in Pleterski A. (Ed.), Zgodnjesrednjeveška naselbina na Blejski Pristavi. Najdbe / Frühmittelalterliche Siedlung Pristava in Bled. Funde. Opera Instituti archaeologici Sloveniae 14, Ljubljana, pp. 153-157, 169-171. (bilingual in Slovene and English)

TRAJKOVIĆ D. 2008, Depfeld - Early Iron Age Necropolis at Doroslovo, City Museum of Sombor, Sombor. TRANTALIDOU K. 2006, « Companions from the oldest times: dogs in ancient Greek literature, iconography and osteological testimony ", in SNYDER L. M., E. A. MOORE (Eds.), Dogs and People in Social, Working, Economic or Symbolic Interaction, $9^{\text {th }}$ ICAZ Conference, Durham, $23^{\text {rd }}-28^{\text {th }}$ August 2002, Oxford, pp. 96-120.

TREBSCHE P. 2005, « Deponierungen in Pfostenlöchern der Urnenfelder-, Hallstatt- und Frühlatènezeit. Ein Beitrag zur Symbolik des Hauses ", in KARL R., J. LESKOVAR (Eds.), Interpretierte Eisenzeiten. Fallstudien, Methoden, Theorie. Tagungsbeiträge der 1. Linzer Gespräche zur interpretativen Eisenzeitarchäologie. Studien zur Kulturgeschichte von Oberösterreich N. F. 18, Linz, pp. 215-227.

TURK I. (Ed.) 2004, Viktorjev spodmol in Mala Triglavca: prispevki k razumevanju mezolitskega obdobja $v$ Sloveniji / Viktorjev spodmol and Mala Triglavca: Contributions to understanding the Mesolithic period in Slovenia. Opera Instituti Archaeologici Sloveniae 9, Ljubljana. (bilingual in Slovene and English) 
TURK P. 2005, Images of life and myth. Exhibition catalogue, Narodni muzej Slovenije, Ljubljana.

UREK M., T. PODOBNIK, Š. TOMAŽINČIČ, S. DJOKIĆ 2015, Končno poročilo o arheoloških raziskavah grobišča v Lajhu in ostankov prazgodovinske poselitve pod Savsko cesto in na sejmišču v Kranju. Ljubljana, unpublished report, Ministry of Culture, Republic of Slovenia.

VADÁSZ V. 1983, « Elözetes jelentés egy koravaskori halomsír feltárásáról Süttőn / Vorbericht über die Erschliessung eines früheisenzeitlichen Hügels in Süttő. Auszug », Communicationes Archaeologicae Hungariae, pp. 19-54.

VADÁSz 1986, « Das früheisenzeitliche Gräberfeld von Süttő », in: TöRÖK L. (Ed.), Hallstatt Kolloquium Veszprém, Archäologisches Institut der UAW, Budapest, pp. 251-257.

VELUŠČEK A. 2005, « Iška Loka - bronastodobno naselje na robu Ljubljanskega barja / Iška Loka - a Bronze Age settlement on the edge of Ljubljansko barje », Arheološki vestnik, no 56, pp. 73-89. (in Slovene with English summary)

VENTURINO GAMBARI M., F. M. GAMBARI 2015, « Non semper eodem modo. Spunti per l'interpretazione di rituali funerari particolari in necropoli a cremazione dell'età del Bronzo e dell'età del Ferro in Piemonte ", in von ELES P., L. BENTINI, P. Poli, E. RODRIGUEZ (Eds.), Immagini di uomini e di donne dalle necropoli villanoviane di Verrucchio. Atti delle Giornate di studio dedicate a Renato Peroni, Verucchio, 20-22 aprile 2011, Quaderni di Archeologia dell'Emilia Romagna 34, Firenze, pp. 187-192.

VILÀ C., P. SAVOLAINEN, J. E. MALDONADO, I. R. AMORIM, J. E. RICE 1997, « Multiple and ancient origins of the domestic dog ", Science, no 276, pp. 1687-1689.

VojAKović P. 2013, Prazgodovinska Emona: novo odkrita protourbana naselbina na Prulah in njeno mesto $v$ času in prostoru. Unpublished PhD thesis, University of Ljubljana.

VOJAKOVIĆ P. 2014, « Pre-Roman Emona in the light of new archaeological discoveries », in FERLE M. (Ed.), Emona: a city of the empire, Ljubljana, pp. 65-76.

VOJAKOVIĆ P., S. PORENTA, B. TOŠKAN 2014, « New discovery of a prehistoric dwelling below the hillfort of Sv. Marjeta on Libna », Arheološki vestnik, nº 65, pp. 101-121.

VöRös I. 1993, « Temetési étel- és állatáldozat Százhalombatta 109. sz. Halomsírjában », in POROSZLAI I. (Ed.): 4000 év a 100 halom városábán. Fejezetek Százhalombatta történetéból, Százhalombatta, pp. 35-40.

VöRös I. 2015, « Archäozoologische Untersuchungen in den präskythischen Gräberfeldern vom Mezőcsát Typ », in I. SZATHMÁRI (Ed.), An der Grenze der Bronze- und Eisenzeit. Festschrift für Tibor Kemenczei zum 75. Geburtstag, Magyar Nemzeti Múzeum, Budapest, pp. 485-499.

VRETEMARK M., S. STEN 2010, « Skeletal manipulations of dogs at the Bronze Age site of Százhalombatta-Földvár in Hungary ", in CAMPANA D., P. CRABTREE, S.D. de FRANCE, J. LEV-TOV, A. M. CHOYKE (Eds.), Anthropological approaches to zooarchaeology: Colonialism, complexity and animal transformations, Oxbow Books, Oxford, pp. 210-212.

WILKENS B. 2006, « The Sacrifice of Dogs in Ancient Italy », in SNYDER L. M., E. A. MOORE (Eds.), Dogs and People in Social, Working, Economic or Symbolic Interaction, $9^{\text {th }}$ ICAZ Conference, Durham, $23^{\text {rd }}$ $28^{\text {th }}$ August 2002, Oxbow Books, Oxford, pp. 131-136.

WILSON B. 1999, « Displayed or concealed ? Cross cultural evidence for symbolic and ritual activity depositing Iron Age animal bones », Oxford Journal of Archaeology, no 18, pp. 297-305. 
ŽERJAL T., ČERNE M., T. NANUT 2014, « Ljubljana - arheološko najdišče Prule, Ljubljana - mestno jedro, Ljubljana - Karlovško predmestje », Varstvo spomenikov. Poročila, nº 19, pp. 119-122.

ŽORŽ A. 2014, «Jezero pri Podpeči / Jezero near Podpeč », in TERŽAN B., M. ČREŠNAR (Eds.), Absolutno datiranje bronaste in Železne dobe na Slovenskem / Absolute dating of the Bronze and Iron Ages in Slovenia. Katalogi in monografije 40, Ljubljana, pp. 423-426. (bilingual in Slovene and English)

ŽORŽ A., NADBATH B. 2010, « Arheološke ostaline s Spodnjih Škovc pri Dolskem », in Omerzu S. (Ed.), $V$ deželi Jurija Vege. Zbornik občine Dol pri Ljubljani 2, Ljubljana, pp. 341-381.

\section{NOTES}

1. Unfortunately, more detailed dating of individual faunal finds is not available (Merlatti, 2001).

2. Another known case of a canid skeleton was discovered at the Bled - Pristava cemetery, but it is most likely an early medieval large dog/small wolf burial (Gabrovec, 1960, p. 47, t. 39; Toškan, Štular, 2008). The latter option is mentioned due to the size of the specimen, apparently significantly exceeding the size of (other) contemporary local dogs (Toškan, Štular, 2008), and the special role of the wolf/wolf herdsman in Slavic mythology (Mencej, 2001).

3. Unfortunately, bones are not preserved (Barth, 1969, p. 149) therefore the archaeozoological analysis is not possible.

4. The $C: \mathrm{N}$ ratio is within the acceptable range (Ambrose, 1990).

5. The anthropological analysis was made by Dr Tomazo - Ravnik Tatjana. See Škvor Jernejčič (2014, appendix 3).

6. The authors would like to thank M. Mihelič, who brought this find to our knowledge.

7. A human femur was found in the same layer (SU 1134), which might actually be associated with a cemetery, dating to the Late Antiquity, also documented at the same location.

8. For discussion and further bibliography on dogs and horses in graves see KmeŤová (2014, p. 160, 264).

9. This phenomenon was not limited to canids, alone. At Tribuna, for instance, a brown bear (Ursus arctos) mandible was found within one of the post-holes of the same constructional phase (i.e. construction phase I). See also Wilson (1999, p. 298-301).

10. For the remaining two roughly contemporaneous regional settlement centres in the Southeastern Alps skeletal representation data are not available (Bartosiewicz, 1985; Bökönyi, 1994).

11. The basic grid unit during excavations at Tribuna in 2007 and 2008 was a $4 \times 4 \mathrm{~m}$ square. Nevertheless, since it is known for the mentioned dog remains to have been found in quadrant D9 (sector 2) outside the perimeters of the nearby Buildings 15 and 17, which covered most of the same quadrant, the bones must have actually lain on an area not larger than $2 \mathrm{~m}^{2}$.

12. At Tribuna, most of the archaeozoological finds have been hand-collected, which is known to result in biased samples in favour of the larger elements. The share of isolated sheep/goat teeth in the hand-collected material (NISPCaprinae=596), for instance, falls just short of $25 \%$, while it approaches $75 \%$ if considering the remains obtained by sieving (NISPCaprinae $=79$ ). Consequently, if smaller fragments of the considered dog mandible were indeed present in the post-hole filling (of which, however, there is no direct proof), they might well have been missed by the excavators and thus discarded.

13. The small size of a skeletal element is not necessarily in contradiction with it having been used as a ritual object (see e.g. Choyke, 2010; Vretemark and Sten, 2010). Nevertheless, given the undistinctive shape of the dog sesamoid bone, its presence in the mentioned post-hole might be due to the interment of perishable animal parts (e.g. skin/fur), with the bone still attached to it 
(O'Connor, 2003; Choyke, 2010, p. 198). Such a practice has indeed been documented in local contemporary necropoles (Grömer et al., 2017; see also Ryder, 1990; Kirkinen, 2015).

\section{ABSTRACTS}

The paper explores the ritual use of dogs and wolfs in south-eastern Alpine region (Slovenia) in Late Bronze and Iron Age from different archaeological contexts: graves, settlements and hoards. Archeo(zoo)logical analysis showed that dog and wolf bones were seldom put into the Early Iron Age graves. Recent excavations on the prehistoric settlement of Tribuna (Ljubljana, Slovenia) revealed that dog bones were sometimes placed in the foundations of the prehistoric dwellings. According to the analogies from the Italian archaeological sites, we could interpret this ritual practice as foundation offerings and for the protection of the buildings. Wolf and dog bones were also found in the prehistoric hoard in Skeletna cave near fikocjan on the Kras plateau. Beside the mentioned archeo(zoo)logical records, dogs and wolfs appeared as a frequent iconographic motive on the products of the so called "situla art". As dogs were often linked with the death and underworld (graves, caves, iconography), we might interpret here presented archaeological contexts as dog sacrifices being part of the "rites de passages". Further insights into the role of canids has been inferred by stable isotope analyses $(\delta 13 \mathrm{C}$ and $\delta 15 \mathrm{~N})$ of main animal species as well as man.

Cette communication explore l'usage rituel des chiens et des loups dans les Alpes orientales (Slovénie) à l'âge du Bronze et à l'âge du Fer à partir de l'étude de différents contextes archéologiques: sépultures, implantations et dépôts rituels. Les analyses archéozoologiques montrent que les ossements de chien ou de loup sont rarement présents dans les tombes du premier âge du Fer. Les fouilles récentes du site préhistorique de Tribuna (Ljubljana, Slovénie) ont révélé que des ossements de chien étaient parfois placés dans les fondations des habitations. Par comparaison avec des sites italiens, il est proposé d'interpréter cette pratique rituelle comme une offrande de fondation ou de protection des bâtiments. Des restes de chien et de loup ont été également trouvés dans les dépôts de la grotte de Skeletna sur le plateau karstique de Škocjan. De plus, le chien et le loup paraissent avoir été un fréquent motif iconographique sur la vaisselle de bronze décorée appelée "Situla ». Comme la figure du chien est souvent liée à la mort et l'au-delà (sépultures, grottes, iconographie), nous interprétons les contextes archéologiques susmentionnés comme des sacrifices de chiens faisant partie des «rites de passage ». D'autres perspectives sur le rôle des canidés ont pu être fournies par les analyses des isotopes stables du carbone $(\delta 13 \mathrm{C})$ et de l'azote $(\delta 15 \mathrm{~N})$ des restes animaux et humains.

\section{AUTHORS}

\section{BRINA ŠKVOR JERNEJČIČ}

Department of Archaeology, faculty of Arts

University of Ljubljana

Slovenia 


\section{BORUT TOŠKAN}

Institute of Archaeology

Research center of the Slovenian Academy

of Sciences and Arts

Ljubljana

Slovenia 
Une réflexion épistémologique sur les interprétations des relations Homme-animal dans les sépultures préhistoriques issues de fouilles anciennes : l'exemple de la nécropole mésolithique de Téviec (Saint-Pierre-Quiberon, Morbihan)

\author{
Pauline Fontan
}

Je tiens particulièrement à remercier Arnaud Hurel et Amélie Vialet pour leurs conseils et leur minutieuse relecture de ce travail. Je remercie également Denis Vialou et l'association Melvan pour la mise à disposition des photographies de Marthe et Saint-Just Péquart. Ce travail a été effectué dans le cadre de mon Master (QP, MNHN) qui a bénéficié du soutien financier du programme de recherche CIMATLANTIC (Maison des Sciences de l'Homme de Bretagne) dirigé par Grégor Marchand, que je tiens également à remercier.

\title{
Introduction
}

1 En contexte archéologique, les sépultures associant des ossements humains et animaux sont des lieux privilégiés pour comprendre les différentes relations qui unissent l'Homme à l'animal, notamment sur le plan symbolique. Or, ces relations, et la place de l'animal dans les sépultures, ont reçu des interprétations différentes au cours de l'histoire des découvertes archéologiques, inhérentes aux grilles de lectures propres à chaque époque. Nous nous sommes intéressée aux toutes premières découvertes de sépultures préhistoriques, entre la fin $d u x x^{e}$ siècle et le début $d u x^{e}$ siècle, afin d'analyser l'évolution des différents statuts conférés aux restes animaux retrouvés en 
contexte sépulcral, en nous concentrant particulièrement sur l'exemple de la nécropole de Téviec (Saint-Pierre-Quiberon, Morbihan).

2 En préalable, travailler sur des collections issues de fouilles anciennes nécessite de prendre en compte que celles-ci sont le fruit d'une histoire, qu'il faut soumettre à une analyse critique, c'est-à-dire en ne considérant pas notre connaissance du site et des collections comme des faits, mais comme des constructions intellectuelles et historiques. Nous sommes donc en présence de plusieurs niveaux d'analyse: tout d'abord tenter de comprendre le site en lui-même (la démarche archéologique), replacer sa découverte dans son contexte et restituer le sens qui lui a été donné à son époque (la démarche historique et épistémologique).

De plus, en archéologie de la Préhistoire (c'est-à-dire sans sources écrites pouvant renseigner les pratiques sépulcrales), le concept de "sépulture » est extrêmement variable selon les cercles académiques, les problématiques de recherche ou les contextes archéologiques (Duday, 2009). Aujourd'hui, en France, la définition la plus largement admise est la suivante :

«Lieu où ont été déposés les restes d'un ou plusieurs défunts, et où il subsiste suffisamment d'indices pour que l'archéologue puisse déceler dans ce dépôt la volonté d'accomplir un geste funéraire; de manière plus restrictive, structure constituée à l'occasion de ce geste funéraire. » (Leclerc et Tarrête, 1988)

4 Actuellement, la reconnaissance d'une sépulture n'est pas complètement laissée à la subjectivité ou à l'expérience de l'archéologue. Elle est encadrée par une discipline qui se construit en 1982, au même moment que cette définition, (Duday et Masset, 1987) ${ }^{1}$ et qui prend la dénomination d'" archéothanatologie " (Boulestin et Duday, 2005). Elle insiste sur la place centrale du défunt lors de la reconnaissance et de la description d'une sépulture. Les ossements d'animaux, les objets associés ou l'architecture funéraire ne sont plus considérés comme des éléments suffisants pour attester de l'existence d'une sépulture. Ils font partie des informations enregistrées à titre complémentaire qui attestent de la complexité des pratiques funéraires. Reconnaître une sépulture requiert une série d'observations préalables lors de la fouille, dont l'archéothanatologie a contribué à définir une méthodologie spécifique. Ces observations concernent par ordre d'importance (Duday et al., 1990; Duday, 2005, 2009) :

- les restes ostéologiques du ou des individu(s) (position des segments anatomiques, maintien ou non des connexions labiles et chronologie de la dislocation des articulations);

- l'architecture funéraire et son influence sur le processus de décomposition du ou des cadavre(s) (décomposition en espace vide ou en espace colmaté, effets de contraintes, présence d'éléments périssables, etc.);

- le matériel funéraire (pièces d'habillement, éléments de parure ou de mobilier).

5 Notre problématique sera de questionner la place des restes animaux dans la reconnaissance des premières sépultures préhistoriques à la fin $\mathrm{du}_{\mathrm{XIX}}^{\mathrm{e}}$ et au début du $\mathrm{xx}^{\mathrm{e}}$ siècle, et la manière dont ils ont été interprétés à cette époque. Nous illustrerons notre propos grâce aux découvertes d'Aurignac, de Solutré et de Menton, qui sont des exemples emblématiques des débats qui ont alimenté la communauté des Préhistoriens au sujet de l'existence des pratiques funéraires chez les Préhistoriques (Hurel, 2016), avant de nous focaliser sur le cas emblématique de la nécropole mésolithique de Téviec. Cette dernière est, en effet, l'un des rares sites funéraires pour la Préhistoire française où différents statuts ont été attribués aux restes d'animaux: culinaire, symbolique, 
fonctionnel, etc. (Péquart et al., 1937). De surcroît, il s'agit d'un exemple exceptionnel de fouille du début du $\mathrm{Xx}^{\mathrm{e}}$ siècle, menée avec une méthodologie singulière ( $c f$. infra) et possédant une riche documentation au grand potentiel scientifique.

6 Nous ne proposerons pas dans le cadre de cet article une nouvelle étude archéozoologique de ces restes d'animaux, car cela n'est pas dans notre domaine de compétence. Nous chercherons plutôt à restituer les différentes interprétations qui ont pu en être faites suite à leur découverte dans une perspective épistémologique, c'est-àdire en proposant une réflexion sur les concepts. Nous replacerons également ces interprétations dans le contexte intellectuel de l'époque afin de mieux les comprendre aujourd'hui.

\section{La difficile reconnaissance des premières sépultures préhistoriques}

7 Nous ne questionnons pas la pertinence des interprétations ou la réalité des sépultures, mais nous essayons plutôt de comprendre le contexte scientifique et philosophique dans lequel se placent ces découvertes, sans prétention à l'exhaustivité. Ce détour par l'histoire nous permet d'identifier la place qu'a occupée l'animal dans la reconnaissance des sépultures préhistoriques et dans l'interprétation des pratiques funéraires. Les découvertes successives des sépultures d'Aurignac, de Solutré et de Menton ont été au cœur des débats de cette reconnaissance. Mais surtout, elles présentent des associations emblématiques de restes humains avec des animaux de nature variée qui ont joué une place centrale pour leur interprétation.

\section{Aurignac \& Solutré : des sépultures controversées}

Le premier cas de sépulture, pris en considération par les sciences préhistoriques, a été identifié sur le site d'Aurignac (Haute-Garonne), en 1860 par Édouard Lartet (1801-1871) (Lartet, 1861). En 1852, 17 squelettes ont été découverts fortuitement, dans une cavité scellée par une dalle de gré (Lartet, 1861, p. 180). Lorsqu'il se rend sur place en 1860, É. Lartet met au jour de nouveaux restes humains, des restes de faunes disparues, des industries lithiques et osseuses (Lartet, 1861, p.185-189). Tout en démontrant l'ancienneté de l'Homme, il affirme d'emblée le caractère sépulcral du site. Il pense que les individus ont été inhumés successivement, la dalle de gré qui fermait l'entrée de la grotte étant déplacée et remise en place après chaque nouvelle inhumation (Lartet, 1861, p. 184). Les Préhistoriques auraient partagé des repas sur le seuil de la grotte lors de chaque inhumation, comme en témoignent les restes de foyers, d'os fracturés et calcinés. Les restes animaux non fragmentés, trouvés à proximité des défunts, ont euxmêmes été interprétés comme des "provisions alimentaires » qui les accompagnaient dans la mort (Lartet et Christy, 1864, p. 254).

9 Si à Aurignac les restes de faunes ont permis à É. Lartet de justifier la présence de "rites funéraires» de type festins ou victuailles d'accompagnement, les restes de chevaux retrouvés en contrebas de la roche de Solutré (Saône-et-Loire), vont revêtir une importance tout autre pour la reconnaissance des pratiques funéraires à la Préhistoire. En 1866, Henri Testot-Ferry (1826-1869) et Adrien Arcelin (1838-1904) découvrent, au pied de la roche de Solutré, des tombeaux de pierre où gisaient des 
squelettes humains en association avec des silex taillés et des restes de rennes, ainsi qu'une quantité extraordinaire d'ossements de chevaux. Mais l'architecture de pierre si élaborée des tombeaux, alors inconnue pour "l'âge du renne", conduit Gabriel de Mortillet (1821-1898) à rapporter ces sépultures à une période plus récente, postérieure aux restes de rennes et chevaux (Mortillet, 1868, p. 107). Néanmoins, l'inventeur de ce site, argumente en faveur d'une contemporanéité des restes d'animaux avec les ossements humains, affirmant que les hécatombes de chevaux feraient partie intégrante de la cérémonie funéraire (Ferry, 1870, p. 60).

Au moment même où la Préhistoire se crée, on admet d'emblée que les Préhistoriques aient pu inhumer leurs morts. Mais, quelques années plus tard, une fois le paradigme de la haute antiquité de l'Homme parfaitement acquis, on s'interroge sur sa capacité réelle à inhumer ses morts jusqu'à la nier totalement, notamment en l'absence de contexte stratigraphique rigoureusement démontré (Hurel, 2016). Or, aujourd'hui nous savons que les sépultures d'Aurignac et de Solutré sont postérieures aux temps paléolithiques : il y a bien des restes de faunes anciennes, de silex, etc. avec des restes humains, mais ces derniers appartiennent à des époques plus récentes. Quoi qu'il en soit, ces deux sites ont le mérite d'ouvrir le débat : l'Homme préhistorique inhumait-il ses morts?

\section{Vers la reconnaissance des sépultures préhistoriques : «l'homme de Menton »}

11 La sépulture de "l'homme de Menton » est emblématique : c'est sur ce cas que le débat s'est cristallisé, et que la reconnaissance des sépultures préhistoriques a enfin été rendue possible grâce à un contexte stratigraphique suffisamment documenté et des preuves tangibles de l'inhumation. Marthe (1884-1961) et Saint-Just (1881-1944) Péquart y feront de nombreuses fois référence dans leur monographie du site de Téviec (Péquart et al., 1937, p. 57 et 78) et il s'agit, encore au début du xxe siècle, d'un modèle pour les pratiques funéraires au Paléolithique supérieur. La sépulture de l'homme - ou, selon une étude récente (Lumley, 2016), de la dame - de la grotte du Cavillon est découverte par Émile Rivière (1835-1922), le 26 mars 1872, près de la ville de Menton. Il met au jour, dans un contexte stratigraphique bien identifié, un individu en position allongée, les bras croisés sur la poitrine, la tête surélevée par une pierre et ornée d'une résille de tête en coquillages marins et craches de cerfs perforés (Rivière, 1872a, 1872b). L'individu est également accompagné de nombreux fragments de faune plus ou moins calcinés: chat sauvage, ours des cavernes, rhinocéros, chevaux, sangliers et nombreuses espèces de cervidés (Rivière, 1872b, p. 1600 et 1601). À noter également que plusieurs genres de coquilles marines (Nassa, Patella Cardium, Mytilus, etc.) sont retrouvés autour de son crâne (Rivière, 1872a, p. 1205). L'animal revêt à la fois le statut de parure funéraire et de nourriture accompagnant le défunt. La sépulture est prélevée « en bloc » puis transférée à Paris, où elle est exposée dans la galerie d'anthropologie du Jardin des Plantes (fig. 1). Pendant plus d'une vingtaine d'années, la découverte va animer de vives controverses, au sein de la communauté des Préhistoriens. 
Figure 1 : L'Homme de Menton exposé dans les galeries d'anatomie comparée et de paléontologie du Muséum national d'histoire naturelle au Jardin des Plantes (carte postale, DR).

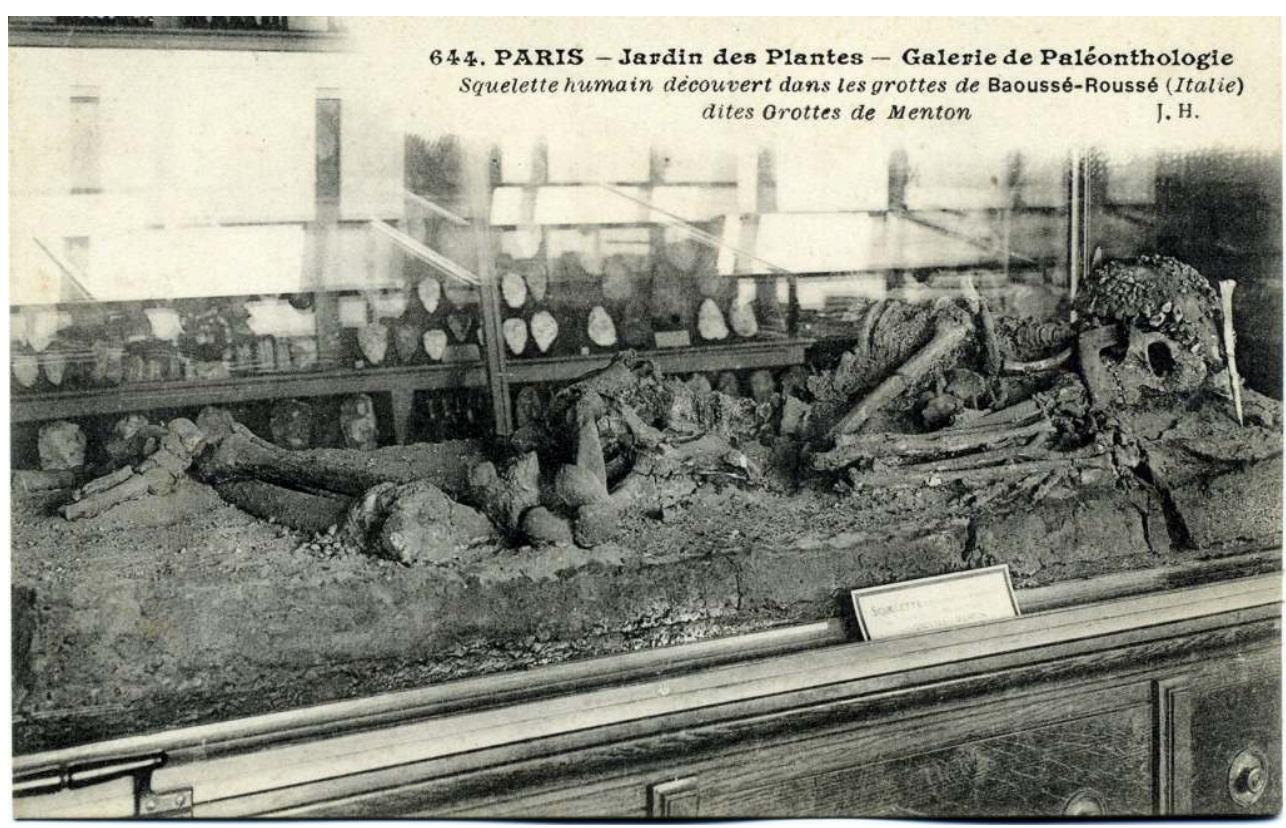

12 L'un des premiers arguments en faveur de la reconnaissance des sépultures préhistoriques à la fin $\mathrm{du} \mathrm{XIX}^{\mathrm{e}}$ siècle fut donc la présence d'ossements d'animaux associés à des squelettes humains. Au contraire, à partir de la fin du $\mathrm{xx}^{\mathrm{e}}$ siècle, les ossements d'animaux n'ont plus la primauté de la preuve, l'intérêt se déplace en faveur du défunt avec l'émergence de l'archéothanatologie. Mais, le débat sur la reconnaissance des premières sépultures a moins concerné la validité des preuves que :

«L'image des Préhistoriques que forgent alors les préhistoriens, voire sur les cadres intellectuels, philosophiques et scientifiques dans lesquels ces préhistoriens se meuvent et construisent leur science. » (Hurel, 2016)

13 En effet, l'enjeu a été davantage de savoir si ces hommes et femmes de la Préhistoire ont pu posséder les capacités cognitives qui les auraient rendus capables d'enterrer intentionnellement leurs défunts.

14 La difficile reconnaissance des sépultures préhistoriques doit être rapportée au contexte scientifique et politique de la fin de ce $\mathrm{XIX}^{\mathrm{e}}$ siècle, où le matérialisme est le paradigme dominant de la recherche scientifique, notamment dans le milieu de la Préhistoire naissante, sous l'influence de Gabriel de Mortillet (Mortillet, 1900). Les débats sur la reconnaissance des sépultures et les positions des différents acteurs scientifiques doivent être compris à la lumière des convictions personnelles, mais également à l'aune du caractère incertain des vestiges qui sont alors exhumés, et de l'absence, pour certains, de contexte stratigraphique compréhensible. La découverte de "l'homme de Menton » qui, contrairement aux autres gisements présentés, offre des preuves indiscutables d'un dépôt funéraire (un squelette entier, dans un contexte stratigraphique bien daté, en connexion, accompagné d'offrandes et d'éléments de parure en matière dure d'origine animale et dont la position laisse présager d'un traitement post-mortem) jouera un rôle majeur pour la reconnaissance des sépultures préhistoriques (Hurel, 2016). Néanmoins, certains intellectuels, dont Gabriel de Mortillet, continueront de nier l'existence de ces sépultures préhistoriques, refusant de 
reconnaître l'existence d'une pensée complexe et spirituelle chez les Préhistoriques (Mortillet, 1900).

\section{La nécropole de Téviec (1928-1930)}

\section{Présentation générale}

Situé sur une île au large du Morbihan, dans la presqu'île de Quiberon, le site de Téviec constitue la première nécropole découverte pour la période mésolithique en France (Péquart, 1928b, 1929 ; Péquart et al., 1937). Entre 1928 et 1929, M. et S.-J. Péquart mettent au jour dix sépultures à l'architecture standardisée (fosses creusées dans l'amas coquillier, surmontées d'un foyer funéraire et comblées par un monticule de pierres) renfermant vingt-trois individus (hommes, femmes et enfants) inhumés dans des positions relativement similaires (Péquart et al., 1937). Vingt-quatre foyers culinaires et domestiques sont également découverts au sein même de la nécropole (fig. 2). Les sépultures étaient constituées d'une fosse étroite globalement circulaire creusée dans l'amas coquillier. Le ou les défunt(s), y étai(en)t ensuite installé(s), assis ou allongé(s), les membres inférieurs fortement repliés, et les mains reposant de chaque côté $\mathrm{du}$ bassin ou sur le ventre (Péquart et al., 1937). Il(s) étai(en)t « accompagné(s) » d'une centaine d'éléments de parure en coquillages marins perforés, d'industries lithiques comme des lames à troncature retouchée ou osseuses comme des "stylets». La fosse était ensuite comblée par le sédiment de l'amas coquillier et protégée par des dalles (Péquart et al., 1937). Sur ces dalles, un foyer funéraire était édifié avec des pierres et renfermait parfois des mandibules de cerf ou de sanglier non calcinées. Enfin, ce foyer était comblé par un monticule de pierres qui affleurait audessus de l'amas coquillier, et qui devait signaler la présence des sépultures. Grâce à la typologie des industries lithiques (Marchand, 1999) et à une nouvelle datation réalisée en avril $2016^{2}$ sur un ossement de chevreuil par le laboratoire Beta Analytic Inc. (Floride, Beta-436330) donnant un résultat entre 6075 et 6010 cal B.C., ce site a pu être rattaché à la période du Mésolithique final. 
Figure 2 : Situation de l'île de Téviec dans le Morbihan et emplacement de la zone fouillée, au nordouest de lîle.

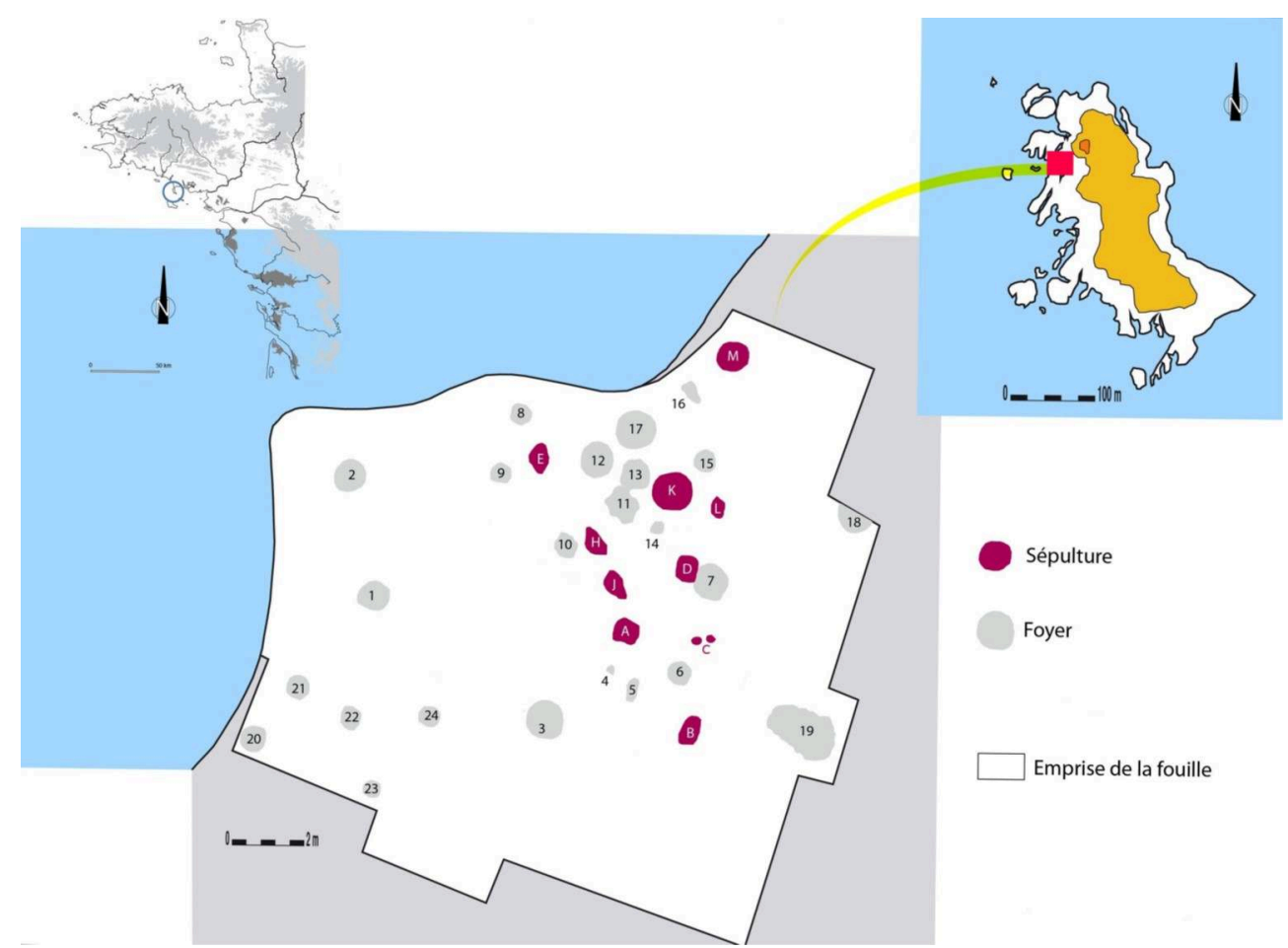

Plan de la zone fouillée avec l'emplacement des sépultures et des foyers. (DAO : J.-M. Large, d'après Péquart et al., 1937, p. 9, 14 et 17)

\section{La collection et les spécificités des méthodes de fouille}

Contrairement aux fouilles d'Aurignac, de Solutré et de Menton, pour lesquelles nous n'avons pas ou peu d'informations sur la façon dont elles ont été menées, M. et S.-J. Péquart ont théorisé une méthode de fouille (Péquart, 1928a) qu'ils appliquent pour la première fois sur le site de Téviec. Ils privilégient une approche extensive, où seules les relations entre les objets et les structures sont importantes, rejetant ainsi le simple attrait pour le «bel objet ", encore courant à l'époque. La compréhension du site passe dorénavant par l'analyse de l'agencement des structures et des objets archéologiques au sein même de celles-ci. De cette façon, l'essentiel des interprétations des structures archéologiques (sépultures et foyers dans le cas Téviec) s'effectue au moment même de la fouille. Dans le cas des sépultures, les restes squelettiques du défunt ont été positionnés au centre de l'analyse funéraire: l'observation de leur position in situ permettant à M. et S.-J. Péquart de proposer des théories sur les modes d'inhumation (Péquart et al., 1937 ; Fontan 2016, p. 10). Chacune des structures archéologiques a été soigneusement enregistrée par l'intermédiaire de relevés, et surtout de photographies retraçant chaque étape de leur dégagement. Tant pour la qualité des fouilles de M. et S.-J. Péquart, qui ont fait date dans l'histoire de l'archéologie funéraire (Duday, 2005, p. 153), que pour sa nécropole ${ }^{3}$, le site de Téviec demeure aujourd'hui une référence pour la période mésolithique. 


\section{Les restes de faune}

17 Au Mésolithique final, Téviec n'était pas une île, mais se situait sur le continent à plusieurs dizaines de mètres du rivage (Dupont, 2006, fig. 124 p. 229), dans un environnement marécageux à la confluence des biotopes marin et terrestre, avec un florilège d'espèces présentes sur le site. Dans la publication des fouilles (Péquart et al., 1937, première partie, chapitre VI), il n'est pas fait grand cas de la faune découverte. Contrairement aux ossements humains, M. et S.-J. Péquart ne donnent pas de localisation précise de ces restes, hormis pour ceux découverts dans les sépultures. Le paléontologue Marcellin Boule ${ }^{4}$ (1861-1942) a listé onze espèces de mammifères dont majoritairement des sangliers, des chevreuils et des cerfs avec une absence notable d'équidés et de bovidés, mais également vingt espèces d'oiseaux, principalement des oiseaux marins, ainsi que des restes de poissons (Péquart et al., 1937. p. 101-102). Il ne mentionne pas le nombre total de restes, ni quelles sont les parties squelettiques représentées. Les restes osseux sont aujourd'hui conservés à l'Institut de Paléontologie Humaine, à Paris. La connaissance des espèces présentes sur le site (tabl. 1), leur exploitation et leur consommation provient donc de travaux plus récents (Schulting, 1996 ; Tresset, 2003 ; Schulting et al., 2004 ; Tresset, 2005 ; Dupont, 2006 ; Tresset et Vigne, 2007; Dupont et al., 2009; Clabeau, 2016) mais avec une même difficulté: l'absence d'informations quant à leur stratigraphie.

Tableau 1 : Liste des principales espèces présentes sur le site de Téviec (d'après Dupont et al., 2009)

\begin{tabular}{|l|l|}
\hline Oiseaux & $\begin{array}{l}\text { Pingouin torda (Alca torda), grand pingouin (Alca impennis), guillemot (Uria aalge), } \\
\text { macareux moine (Fratercula arctica), bécasse des bois (Scolopax rusticola), canards } \\
\text { (Anas platyrhyncos, A. penelope, A. acuta, A. crecca) }\end{array}$ \\
\hline Mollusques & $\begin{array}{l}\text { Patelle (Patella sp.), huître plate (Ostrea edulis), moule (Mytilus edulis), coque } \\
\text { (Cerastoderma edule), bigorneau (Osilinus lineatus), murex (Ocenebra erinacea), grain de } \\
\text { café (Trivia sp.), littorine (Littorina sp.), pourpre (Nucella lapillus), nasse (Nassarius } \\
\text { reticulatus), cardium (Laevicardium crassum), coquille Saint-Jacques (Pecten maximus), } \\
\text { seiche (Sepia sp.) }\end{array}$ \\
\hline Poissons & $\begin{array}{l}\text { Vieille (Labrus sp.), dorade royale (Sparus aurata), dorade rose (Pagellus bogaraveo), } \\
\text { dorade grise (Spondyliosoma cantharus), requins (Selachimorpha) }\end{array}$ \\
\hline Mammifères terrestres & $\begin{array}{l}\text { Sanglier (Sus scrofa), chevreuil (Capreolus capreolus), cerf (Cervus elaphus), aurochs (Bos } \\
\text { primigenius) }\end{array}$ \\
\hline Mammifères marins & Phoque gris (Halichoerus grypus) \\
\hline
\end{tabular}

Si l'on ne possède pas d'informations précises sur la localisation de la faune au sein du site archéologique, M. et S.-J. Péquart ont néanmoins décrit les structures où ils l'ont découverte. Ils ont également interprété ces restes et leur ont attribué différents statuts que nous allons à présent discuter.

\section{Place et statut de l'animal dans la nécropole de Téviec}

\section{Déchets de consommation}

Grâce aux isotopes prélevés dans les ossements humains du site de Téviec, nous savons aujourd'hui que l'alimentation était constituée à $50 \%$ par des apports en protéines marines (Schulting et Richards, 2001). La nécropole de Téviec se situe, en effet, dans un amas coquillier (Péquart et al., 1937, p. 18), c'est-à-dire dans une accumulation de rejets alimentaires constituée, en grande partie, de coquilles de mollusques et d'esquilles 
osseuses dont certaines sont calcinées (Péquart et al., 1937.). Les défunts étaient donc inhumés à même ces déchets de consommation, ce qui a permis la préservation de leurs ossements de l'acidité des sols bretons grâce aux carbonates présents dans les coquilles (Péquart et al. 1937, p. 5). Lors de la fouille, M. et S.-J. Péquart ont récupéré un échantillonnage de $1,5 \mathrm{~kg}$ de coquilles qui est aujourd'hui conservé au Musée de Préhistoire de Carnac. Il a notamment été étudié en 2006 par Catherine Dupont (Dupont, 2006) qui a identifié quatorze espèces de mollusques en ce qui concerne l'alimentation (Dupont, 2006, p. 223), dont deux prédominent: la patelle (60\% de l'échantillon) et l'huître plate (27\%) (Dupont, 2006, p. 222). Sur le site de Téviec, les mollusques ont donc plusieurs fonctions: alimentation, parure (cf. infra), et indirectement - substrat pour l'inhumation des défunts.

\section{Foyers domestiques \& culinaires}

En dehors des sépultures, M. et S.-J. Péquart reconnaissent sur le site trois types de foyers, selon leur édification et leur utilisation supposée : domestiques, culinaires et rituels. Le premier type, « domestique » (fig. 3), comprend les structures dont :

«L'aménagement hâtif et peu soigné semble correspondre à l'usage qui en fut fait pour les besoins normaux, immédiats et quotidiens, de nos Mésolithiques. » (Péquart et al., 1937, p. 19)

Figure 3 : Foyer domestique $n^{\circ} 1$

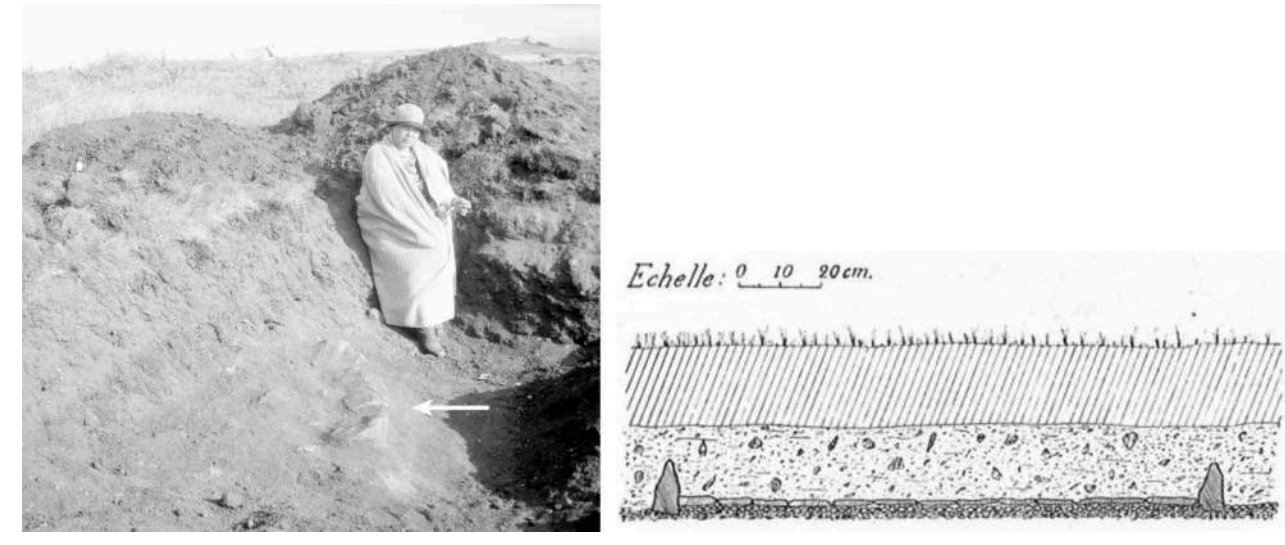

À gauche : Marthe Péquart à côté du pavement en pierres formant le foyer (Photographie de M. et S.J. Péquart, 1928, Archives MNHN). À droite : vue du foyer en coupe (Péquart et al., 1937, p. 20).

21 Certains sont aménagés avec des pierres (de chant ou à plats, ces derniers étant dénommés "foyers-bûchers») et d'autres ont été installés dans des dépressions naturelles. Certains encore ont des aires de combustion séparées de quelques dizaines de centimètres, laissant suggérer une utilisation répétée (Péquart et al., 1937, p. 20). Ces foyers auraient fait l'objet de feux intenses comme en témoignent les pierres de parement, rougies par le feu et qui se désagrègent (Péquart et al., 1937, p. 20). Quant aux restes culinaires identifiés au sein de ceux-ci, les informations sont très lacunaires. M. et S.-J. Sans citer les espèces, Péquart précisent seulement qu'ils ont trouvé :

«Des amas considérables de cendres, de coquilles entièrement pulvérisées et de fragments d'os calcinés [...] 》 (Péquart et al., 1937, p. 20)

Les foyers «culinaires» (fig. 4) se distinguent du premier type par leur architecture élaborée et leur localisation. Leur édification aurait fait l'objet d'une standardisation : 
une fosse régulière creusée dans le sol naturel, dans laquelle des pierres rectangulaires ont été placées pour constituer un parement régulier (Péquart et al., 1937, p. 21). Certains de ces foyers sont accolés aux sépultures, « Ce qui nous porte à croire que ces foyers furent aménagés à l'occasion des funérailles [...]» (Péquart et al., 1937, p. 20). Ils auraient été assez volumineux pour accueillir de « volumineux morceaux, quartiers de venaison ou autres victuailles » (Péquart et al., 1937, p. 20-21), car M. et S.-J. Péquart ont retrouvé davantage d'ossements calcinés. Leur localisation près des sépultures, ainsi que l'importante quantité d'ossements calcinés retrouvée, laissent supposer aux époux Péquart que ces foyers étaient destinés à des festins en lien avec la cérémonie funéraire (Péquart et al., 1937).

Figure 4 : Foyer culinaire $n^{\circ} 6$.
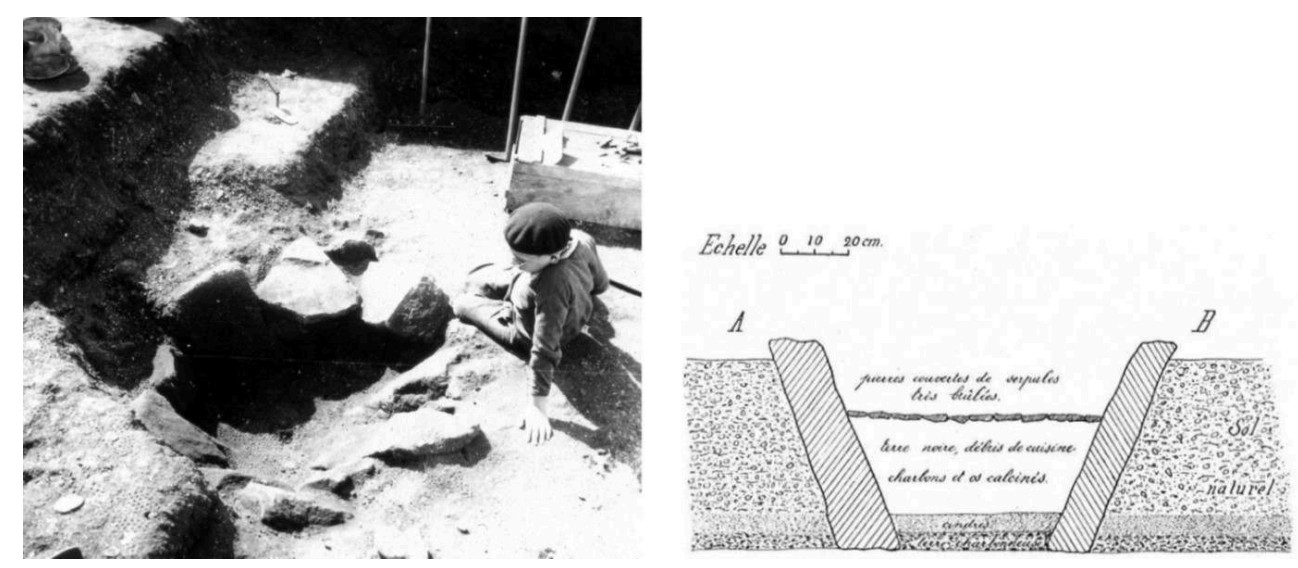

À gauche : Claude Péquart à côté des pierres formant le foyer (Photographie de M. et S.-J. Péquart, 1928, Archives MNHN). À droite : vue du foyer en coupe (Péquart et al. 1937, p. 23)

Le statut de l'animal dans la nécropole de Téviec est donc avant tout lié à l'alimentation, qu'il soit présent sous la forme de rejets composant l'amas coquillier ou d'ossements calcinés retrouvés dans les foyers. Nous ne pouvons que regretter l'absence d'informations sur les espèces animales préparées dans ces foyers. Elles nous auraient permis, en complément de l'analyse de l'architecture, d'avoir davantage d'indices quant à la fonction effective de ces foyers, et peut-être de discuter les catégorisations de M. et S.-J. Péquart. L'animal est avant tout perçu comme une composante principale de l'alimentation, qu'elle soit quotidienne, ou exceptionnelle à l'occasion des funérailles. Les interprétations de type «festin funéraire " étaient également prépondérantes lors de la reconnaissance des premières sépultures que nous avons présentées et semblent se perpétuer au début du xxe siècle. De plus, M. et S.-J. Péquart élaborent un statut du défunt en se fondant sur la présence ou l'absence de ces grands foyers funéraires ou culinaires à proximité des sépultures. Par exemple, la sépulture $\mathrm{D}$, déjà exceptionnelle pour ses bois de cerf surplombant les sujets inhumés (fig. 5), devient alors d'autant plus importante qu'ils constatent :

«La présence, autour de cette sépulture, de plusieurs grands foyers, l'intensité des brasiers qui y ont été allumés, la quantité considérable de charbon, d'os calcinés et de vestiges alimentaires dont ils sont encombrés, témoignent déjà très éloquemment du degré d'importance du sujet inhumé. » (Péquart et al., p. 36). 
Figure 5 : Sépulture D renfermant un individu adulte et un individu enfant.

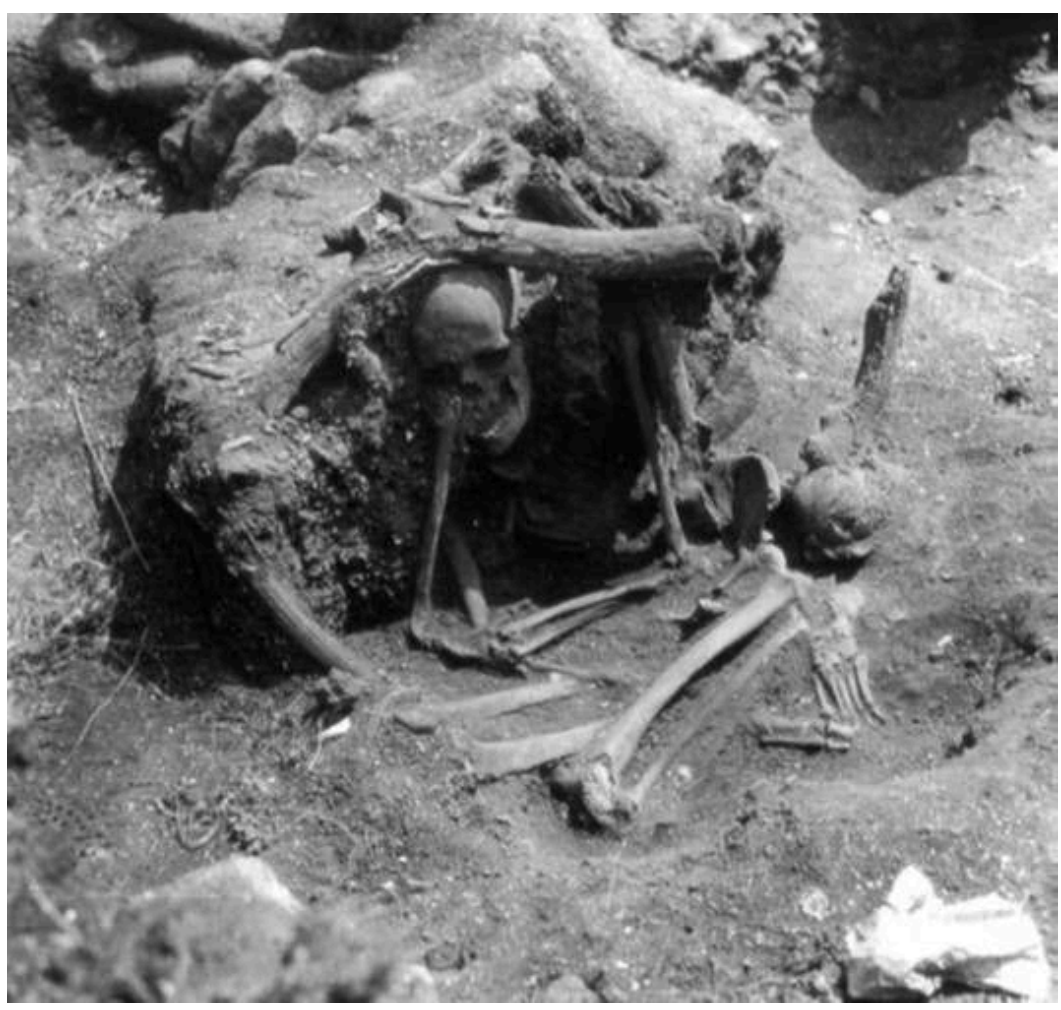

L'adulte a le haut du corps recouvert de bois de cervidés (Photographie de M. et S.-J. Péquart, 1928, Archives MNHN).

Au sein des collections de faune de l'Institut de Paléontologie Humaine, la présence d'ossements calcinés permet aujourd'hui d'identifier certaines des espèces qui ont pu être découvertes au sein de ces différents foyers (Fontan, 2015, p. 13 ; Clabeau, 2016). On retrouve, en très grand nombre, des restes de mandibules, de maxillaires et de métapodes de grands mammifères terrestres, tels que le cerf, le chevreuil et le sanglier. Ces restes ne correspondent pas aux parties consommées mais nous permettent d'appréhender les pratiques de prédation, les différentes utilisations des matières animales et la saisonnalité d'occupation du site (Dupont et al., 2009; Clabeau, 2016). Quant à l'avifaune, des études ont montré que la plupart des os étaient fracturés et brûlés, signifiant qu'ils ont été consommés rôtis, peut-être au sein de ces mêmes foyers (Tresset, 2005, p. 86 et 88).

\section{Foyers funéraires au-dessus des sépultures}

Ce dernier type de foyer se distingue des deux précédents par sa position au-dessus de chacune des sépultures (fig. 6). Ces foyers sont édifiés juste au-dessus de la fosse renfermant le défunt et sont comblés par des débris de cuisine et le sédiment de l'amas coquillier avant d'être recouverts de massifs de pierres (Péquart et al., 1937, p. 21-24). Selon M. et S.-J. Péquart, il n'y a pas de traces évidentes de combustion prolongée (Ibid., p.23). Ils suggèrent que ces foyers peuvent n'avoir été que des "foyers rituels", allumés « le temps de la cérémonie funèbre » et autour desquels « les gens de la tribu » se réunissaient (Péquart et al., 1937). Néanmoins, l'absence de marques de combustions prolongées leur fait supposer que ces foyers ne faisaient pas partie du «festin 
consécutif aux funérailles " (Péquart et al., 1937, p. 24), mais qu'ils étaient réservés à l'usage du « culte funéraire ». À l'intérieur de certains de ces foyers, une ou deux hémimandibules de cerf et de sanglier ont été mises au jour, ne présentant pas de traces de « détérioration produite par la chaleur » et qui auraient donc été déposées «[...] après l'extinction des feux rituels. » (Péquart et al., 1937). Ces dépôts de mandibules sont alors interprétés comme des « offrandes funéraires » (Péquart et al., 1937, p. 30, 34, 44, 46, 48, $52,58,64,68,69,76,77$ et 101) chargées d'accompagner les "mânes du défunt » (Péquart et al., 1937, p. 61). Leur présence est considérée comme "habituelle » ou " coutumière » par les époux Péquart. Or, si l'on se fie à leurs descriptions (Péquart et al., 1937, chapitre III, p. 25-59), seules cinq sépultures sur dix ont ce type de dépôt et les sépultures d'enfants en sont dépourvues. Cela nous amène à interroger la place de ces dépôts, et leur importance, dans l'appareil symbolique des pratiques funéraires.

Figure 6 : Foyer funéraire $n^{\circ} 4$ surmontant la sépulture $A$.

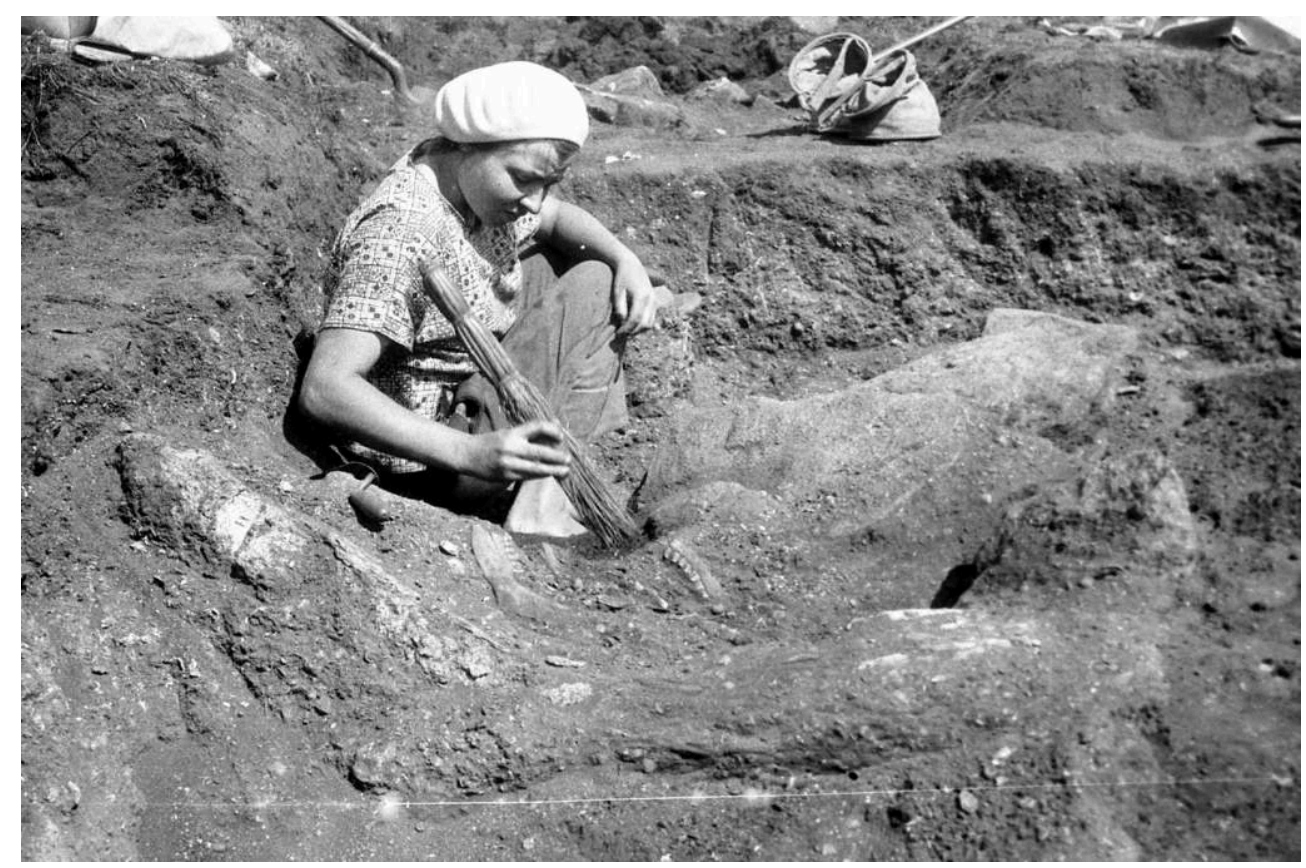

Au premier plan, un os de cétacé en forme l'une des parois. Au second plan, on peut voir Hélène Péquart dégageant une hémi-mandibule de cervidé (Photographie de M. et S.-J. Péquart, 1928, Archives MNHN).

\section{Bois de cerfs dans les sépultures}

Le cerf est d'autant plus un animal particulier au sein des sépultures qu'il est présent à même l'architecture funéraire. En effet, des bois de cerfs surplombent les défunts : dans la sépulture A renfermant deux adultes (fig. 7) et dans la sépulture D, renfermant un adulte et un enfant (fig.5). Cette modalité architecturale est cependant rare et exceptionnelle dans la nécropole de Téviec - deux sépultures sur dix - et, selon M. et S.J. Péquart reflète un statut social particulier du défunt (Péquart et al., 1937, p. 62). Dans le cas de la sépulture $\mathrm{A}$, si le squelette du premier individu mis au jour est totalement recouvert de bois de cerf (Péquart et al., 1937, p. 30), le deuxième individu, à côté du premier, ne bénéficie pas de ce type d'arrangement. Pour la sépulture $\mathrm{D}$, le crâne de l'adulte se trouve « couronné » de trois bois de cerfs (Péquart et al., 1937. p. 37-38). Ils 
constituent une véritable "clef de voûte " ou une « construction à claire-voie » dans laquelle est prise la défunte (Péquart et al., 1937. p. 37).

Figure 7 : Sépulture A renfermant deux individus adultes, dont un a le haut du corps recouvert de bois de cervidés (Photographie de M. et S.-J. Péquart, 1928, Archives MNHN).

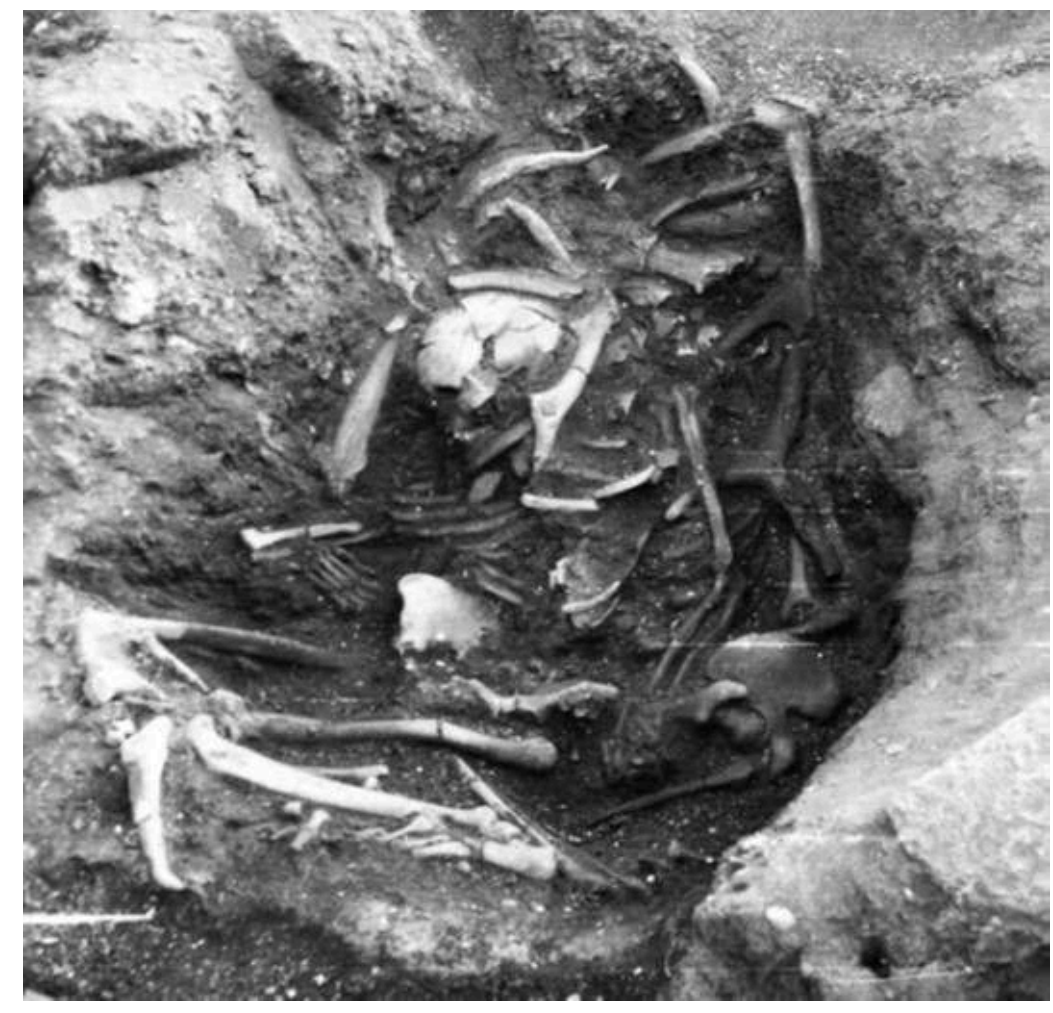

Le fait que ces bois soient tombés naturellement discréditerait leur statut de «trophées de chasse" (Péquart et al., 1937, p. 63). Une autre hypothèse leur paraît alors séduisante, celle du «sorcier» que l'on aurait «inhumé avec les attributs de sa profession» (Péquart et al., 1937). M. et S.-J. Péquart font ici référence à la représentation du «Sorcier» dans la grotte magdalénienne des Trois-Frères (Ariège). Cette représentation a été découverte, décrite et interprétée par Henri Bégouën (1863-1956) et l'abbé Henri Breuil (1877-1961), comme un sorcier, par comparaison ethnographique avec des peuples qui revêtent des têtes animales à l'occasion de rituel, soit pour honorer les divinités, soit pour favoriser la chasse (Bégouën, 1920, p. 309-310). Cette représentation était très connue au moment où $\mathrm{M}$. et $\mathrm{S}$.-J. Péquart évoquent un rapprochement avec leurs sépultures « sous bois de cerfs » et il n'est donc pas étonnant qu'ils fassent intervenir cet élément de comparaison dans leur interprétation. Dans un autre registre, ils associent également la présence du cerf à une «survivance du totémisme ancestral » (Péquart et al. 1937, p. 65). C'est-à-dire que celui-ci revêt la forme d'un "cerf-totem", d'un animal divin (Péquart et al., 1937.p. 64). La présence de ramures de cerf serait alors une tentative de "déification » du défunt (Péquart et al., 1937), idée que M. et S.-J. Péquart reprennent de l'ouvrage de Salomon Reinach ${ }^{5}$ (1858-1932), Cultes, Mythes et Religions (Reinach, 1905). Le cerf, en tant que divinité, est en effet présent à l'époque gauloise au titre d'un culte anthropomorphique du « dieucornu » (Reinach, 1905). Les époux Péquart considèrent ainsi la présence des bois de cerfs dans les sépultures comme un «palier intermédiaire » (Péquart et al., 1937, p. 64), une étape entre la représentation paléolithique du «Sorcier» de la grotte des Trois- 
Frères et les «dieux-cornus » gaulois. L'emploi du vocabulaire lié au totémisme et la référence directe à la publication de $\mathrm{S}$. Reinach sont à replacer dans un cadre de pensée où le totémisme occupe alors une place prépondérante de la recherche en ethnologie (Frazer, 1887 ; Durkheim, 1912).

\section{L'animal en tant que matière première}

De nombreux objets façonnés à partir de matières dures d'origine animale sont également retrouvés dans les sépultures. Le propos ici ne sera pas d'en proposer une liste exhaustive, nous soulignerons seulement ceux retrouvés systématiquement. Par exemple, chaque individu a été associé à un ou plusieurs "stylets ", façonnés dans des os longs de cerfs et de sangliers (fig. 8). Selon M. et S.-J. Péquart, ces «stylets » seraient soit des «répliques miniatures d'armes» (Péquart et al., 1937, p. 92-93), soit des « épingles » destinées à maintenir un vêtement (Péquart et al., 1937. p. 93).

Figure 8 : Stylet façonné dans un métatarsien ou un métacarpien de ruminant, retrouvé dans la sépulture M, d'une longueur de $14 \mathrm{~cm}$ (Péquart et al., 1937, planche XII).

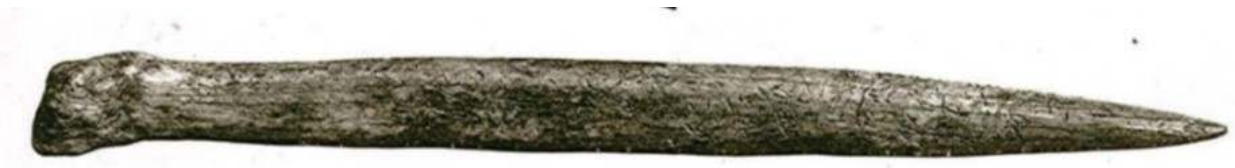

Tel est le dernier statut de l'animal que nous aborderons ici: l'animal en tant qu'élément destiné à habiller ou à parer le corps. Chaque squelette était recouvert de nombreuses petites coquilles perforées, considérées par M. et S.-J. Péquart, comme des éléments de parure. Il apparaît que ces coquilles appartiennent à des espèces de mollusques différentes de celles consommées et auraient été ramassées à l'état vide sur la plage (Dupont, 2006, p. 227 ; Fontan, 2016, p. 71). Comme pour l'alimentation, deux espèces dominent : les Trivia sp. et les Littorina obtusata (Péquart et al., 1937; Taborin, 1974, p. 158; Dupont, 2006, p. 221). On observe donc un choix préférentiel de deux espèces, qui peut être expliqué par la forme, la couleur, etc. (Taborin, 2004, p. 73) ou par la dualité homme-femme (Taborin, 1974, p. 165-169). Lors de la fouille, les époux Péquart prennent soin de relever la position exacte des coquilles sur les corps des défunts, les interprétant ainsi comme des colliers, des bracelets, des pagnes ou des résilles, faisant office de "parures funéraires" (Péquart et al., 1937, p. 77). La parure revêt alors le statut d'un "geste pieux qui honore la dépouille » et qui s'intègre au « rituel funéraire » (Péquart et al., 1937. p. 67). Néanmoins, contrairement aux bois de cerfs, M. et S.J. Péquart ne proposent pas d'interprétations symboliques de ces éléments. Cela se traduit notamment par la façon dont les coquilles sont traitées une fois la fouille terminée: M. Péquart les remonte en colliers (fig. 9), faisant fi de toute rigueur scientifique (Fontan, 2016, p. 60). 
Figure 9 : Collier probablement remonté par Marthe Péquart et composé de 305 Trivia sp., onze Nucella lapillus, une Patella, un Dentalium, une Littorina obtusa, ainsi que d'une coquille indéterminée. Celui-ci est aujourd'hui conservé à l'Institut de Paléontologie Humaine (Cliché : P. Fontan).

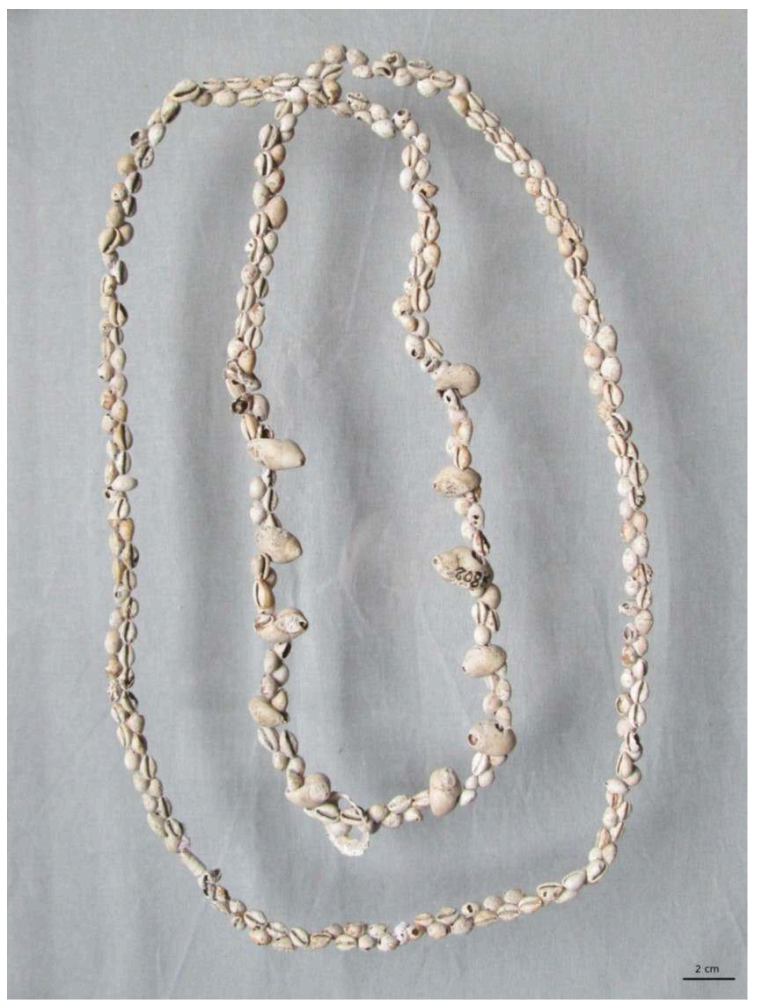

L'animal revêt ici le statut d'une matière première, que ce soit pour la fabrication d'outils (manches fabriqués à partir d'andouillers de cerfs (Péquart et al., 1937, p. 88), allènes en canines de sangliers (Péquart et al., 1937, p. 89), etc. ou d'éléments de parure («stylets» et coquilles perforées). Cette matière première ne possède ici qu'une fonction utilitaire (l'ornementation ou l'habillement du défunt) qui contraste fortement avec les interprétations symboliques des «mandibules-offrandes» et du « cerf-totem ».

\section{Conclusion}

Si à Aurignac, Solutré ou encore à Menton, les ossements d'animaux associés à des restes humains ont été considérés comme de simples preuves servant à démontrer l'existence de sépultures, pour la première fois, à Téviec, l'animal atteste davantage de la complexité des pratiques funéraires et des multiples relations qui unissent l'Homme à son environnement. Au sein de la nécropole, M. et S.-J. Péquart ont attribué les restes d'animaux à différents statuts en fonction du contexte de découverte - à l'extérieur, à côté ou à l'intérieur des sépultures - : source alimentaire (cerf, sanglier, patelle, huître plate, oiseaux, poissons...), offrandes (mandibules de cerf et sanglier), totem (bois de cerfs), objets façonnés (cerf, sanglier) et parures (Trivia, Littorina) (Péquart et al., 1937). Il y a donc un choix d'espèces provenant de la mer et de la terre, pour des destinations aussi fonctionnelles que symboliques, révélant le lien particulier que cette population mésolithique entretenait à la fois avec les deux biotopes et avec ses morts. Ce dernier point, nous amène à nous demander s'il existe une véritable différenciation, dans les usages des populations mésolithiques de Téviec, entre l'animal-consommé et l'animal- 
symbolique. Certaines espèces de mollusques sont strictement utilisées pour l'alimentation (la Patella et l'Ostrea edulis) et d'autres pour l'ornementation (la Trivia ou la Littorina). Au contraire, on observe une interpénétration de différentes sphères alimentaire, utilitaire et symbolique avec le cerf et le sanglier.

Il est nécessaire, à présent, d'affiner ces grilles de lecture, mises en place par M. et S.-J. Péquart, en appliquant nos propres problématiques et méthodes. Par exemple, la taphonomie nous permet aujourd'hui d'appréhender la façon dont les carcasses animales ont pu être traitées et découpées. De la même manière, les traces de chauffe nous renseignent sur les différents degrés de chaleur qu'ont pu subir les ossements, nous aidant ainsi à identifier leur provenance. Du point de vue des éléments de parure, l'étude techno-fonctionnelle des coquilles nous permet de discriminer les perforations intentionnelles et non-intentionnelles (Álvarez Fernández 2006; Rigaud 2011 ; Dupont et al. 2014 ; Fontan 2016). Cela permet ainsi de questionner la notion même de " parure » souvent reprise sans discussion concernant le site de Téviec (Taborin, 1974). Pourtant, cette question des parures est suffisamment problématique à bien des plans (archéologie, épistémologie, etc.) pour imposer un usage prudent. Ainsi, le remontage des patelles en collier, notamment celles où la partie amicale était absente, allait de soi pour M. Péquart. Il s'imposait comme une évidence. Or, les recherches montrent que le manque de la partie amicale est souvent le signe d'une usure naturelle, liée au ressac des vagues (Lozouet et Vigne, 1994). Il ne s'agirait donc pas d'éléments perforés intentionnellement en vue d'orner le corps, même si les Mésolithiques ont pu les utiliser comme tels. Cet exemple démontre l'obligation de questionner sans cesse nos définitions et leurs évolutions - dans ce cas, celle de la " parure » - et notre système de représentations des Préhistoriques et de leurs comportements (Moro Abadía et Nowell, 2015).

\section{BIBLIOGRAPHIE}

ÁLVAREZ Fernández E. 2006, « Los objetos de adorno-colgantes del Paleolitico superior y del Mesolitico en la Cornisa Cantabrica y en el Valle del Ebro : una vision europea », Thèse de doctorat, Université de Salamanca.

BÉGOUËN H. 1920, « Un dessin relevé dans la caverne des Trois-Frères à Montesquieu-Avantès (Ariège) », Comptes rendus de l'Académie des Inscriptions et Belles-Lettres, p. 303-310

BOULESTIN B. et DUDAY H. 2005, «Ethnologie et archéologie de la mort : de l'illusion des références à l'emploi d'un vocabulaire ", dans MORDANT C. et DEPIERRE G. (dir.), Les pratiques funéraires à l'Âge du Bronze en France, actes de la table ronde de Sens-en-Bourgogne (Yonne), Paris, CTHS, p. 17-30 CLABEAU Q. 2016, «Contribution à la connaissance de l'exploitation des animaux dans le Mésolithique breton. Nouvelles données archéozoologiques sur le site de Téviec (Morbihan) », Mémoire de Master « Quaternaire et Préhistoire », Muséum national d'histoire naturelle.

COURTAUD P. et DUDAY H. 2012, « Les sépultures plurielles au Mésolithique : l'exemple de la nécropole de La Vergne (Charente-Maritime) », dans CASTEX D., COURTAUD P., DUDAY H., Le MORT F. 
et TILLIER A-M. (dir.), Le regroupement des morts. Genèse et diversité archéologique, Bordeaux, Ausonius, p. $71-81$

DUDAY H. 2005, « L'archéothanatologie ou l'archéologie de la mort », dans VANDERMEERSH B., DUTOUR O. et HUBLIN J.-J. (dir.), Objets et méthodes en paléoanthropologie, Paris, CTHS, p. 153-205

DUDAY H. 2009, Archaeology of the Dead: Lectures in Archaeothanatology, Oxford, Oxbow Books. DUdAY H., COURTAUd P., CRUBÉzy E., SELLIER P. et TILLIER A.-M. 1990, « L'anthropologie de "terrain" : reconnaissance et interprétation des gestes funéraires », Bulletins et mémoires de la Société d' Anthropologie de Paris, T. 2, fasc. 3-4, p. 29-49

DUDAY H. et MASSET C. (dir.) 1987, Anthropologie physique et archéologie - méthodes d'étude des sépultures, actes des Colloques de Toulouse, 4 au 6 novembre 1982, Paris, CNRS.

DUPONT C. 2006, La malacofaune de sites mésolithiques et néolithiques de la façade atlantique de la France: Contribution à l'économie et à l'identité culturelle des groupes concernés, Oxford, Archeopress (BAR International Series 1571).

DUPONT C., TRESSET A., DESSE-BERSET N., GRUET Y., MARCHAND G., SCHULTING R. 2009, « Harvesting the seashores in the Late Mesolithic of north-western Europe. A view from Brittany? », Journal of World Prehistory, T. 22, fasc. 2, p. 93-111.

DUPONT C., LAPORTE L., COURTAUD P., DUDAY H., GRUET Y. 2014, « Perforated shells from an Early Mesolithic cemetery at La Vergne (Charente-Maritime, France): from acquisition to use and (sometimes) to wear » dans SZABó K., DUPONT C., DIMITRIJEVIĆ V., GASTÉLUM L. G., et SERRAND N., Archaeomalacology: Shells in the Archaeological Record, Oxford, Archeopress (BAR International Series 2666), p. 43-52.

DURKHEIM E. 1912, Les formes élémentaires de la vie religieuse : le système totémique en Australie, Paris, F. Alcan.

FERRY H. de 1870, Le Mâconnais préhistorique : mémoire sur les âges primitifs de la pierre, du bronze et du fer, en Mâconnais et dans quelques contrées limitrophes, Ouvrage posthume avec notes et additions et appendice par A. Arcelin, Mâcon, Durand, Paris, C. Reinwald.

FONTAN P. 2015, « Reconstituer l'histoire d'une collection ancienne : le site mésolithique de Téviec (Morbihan) », rapport de stage de Master 1, Muséum national d'histoire naturelle.

FONTAN P. 2016, « Une nouvelle étude des pratiques funéraires à la nécropole mésolithique de Téviec (Morbihan). Anthropologie, archéothanatologie et technologie des coquilles d'origine marine associées aux sépultures », Mémoire de Master « Quaternaire et Préhistoire », Muséum national d'histoire naturelle.

FRAZER J.-G. 1887, Totemism, Édimbourg, A. \& C. Black.

HUREL A. 2016, « Les Préhistoriques et leurs morts au regard des préhistoriens de la fin du XIX ${ }^{e}$ siècle », dans Lumley H. de (dir.) La grotte du Cavillon sous la falaise des Baousse Rousse Grimaldi, Vintimille, Italie, Paris, CNRS.

LARTET É. 1861, « Nouvelles recherches sur la coexistence de l'homme et des grands mammifères fossiles réputés caractéristiques de la dernière période géologique ", Annales des sciences naturelles, $4^{\mathrm{e}}$ série, Zoologie, T. 15, p. 177-253

LARTET É. et CHRISTY H. 1864, « Sur des figures d'animaux gravées ou sculptées et autres produits d'art et d'industrie rapportables aux temps primordiaux de la période humaine », Revue archéologique, T. 9, p. 233-267 
LECLERC J. et TARRÊTE J. 1988, « Sépulture » dans LEROI-GOURHAN A. (dir.), Dictionnaire de la préhistoire, Paris, Presses universitaires de France, p. 963-964

LOZOUET P. et VIGNE J.-D. 1994, « Les Invertébrés », dans VIGNE J.-D. (dir.), L'île Lavezzi, hommes, animaux, archéologie et marginalité (XIII $-\mathrm{XX}^{\mathrm{e}}$ siècles, Bonifacio, Corse), Paris, CNRS (Monographies du CRA 13), p. 155-164.

LUMLEY H. de 2016, La grotte du Cavillon sous la falaise des Baousse Rousse Grimaldi, Vintimille, Italie, 3 tomes, Paris, CNRS.

MARCHAND G. 1999, La néolithisation de l'ouest de la France : caractérisation des industries lithiques, Oxford, Archeopress (BAR International Series 748).

MORO Abadía O. et NOWELl A. 2015, «Palaeolithic Personal Ornaments : Historical Development and Epistemological Challenge », Journal of Archaeological Method and Theory, T. 22, p. 952-979

MORTILLET G. de 1868, « Sépultures de Solutré, Saône-et-Loire », Matériaux pour l'histoire positive et philosophique de l'homme, T. 4, p. 102-107

MORTILLET G. de 1900, Le Préhistorique. L'Antiquité de l'homme, $3^{e}$ éd., Paris, Librairie C. Reinwald.

PÉQUART M. et S.-J. 1928a, « Technique de fouilles préhistoriques », Revue des musées et Collections archéologiques, T. III, fasc. 14, p. 1-19

PÉQUART M. et S.-J. 1928b, « Un gisement mésolithique en Bretagne », L’Anthropologie, T. 38, Paris, p. $479-493$

PÉQUART M. et S.-J. 1929, « La nécropole mésolithique de Téviec (Morbihan) », L'Anthropologie, T. 39, Paris, p. 373-400

PÉQUART, M. et S.-J. 1954, Hoedic, deuxième station-nécropole du Mésolithique côtier armoricain, Anvers, De Sikkel.

PÉQUART M. et S.-J., BOULE M. et VALLOIS H.-V. 1937, Téviec : station nécropole mésolithique du Morbihan, Paris, Masson (Archives de l'Institut de Paléontologie humaine, mémoire 18).

REINACH S. 1905, «Survivances du totémisme chez les anciens Celtes », dans REINACH S., Cultes, Mythes et Religions, T. I, Paris, Ernest Leroux, p. 30-78

RIGAUD S. 2011, « La parure : traceur de la géographie culturelle et des dynamiques de peuplement au passage Mésolithique - Néolithique en Europe », Thèse de doctorat, Université de Bordeaux.

RIVIÈRE É. 1872a, « Sur le squelette humain trouvé dans les cavernes des Baoussé-Roussé (Italie), dites grottes de Menton, le 26 mars 1872 ", Comptes rendus hebdomadaires des séances de l'Académie des sciences, T. 74, p. 1204-1207

RIVIÈRE É. 1872b, « Sur l'homme fossile des cavernes des Baoussé-Roussé (Italie), dites grottes de Menton ", Comptes rendus hebdomadaires des séances de l'Académie des sciences, T. 74, p. 1597- 1601.

SCHULTING R. 1996, «Antlers, bone pins and flint blades : the Mesolithic cemeteries of Téviec and Hoëdic, Brittany », Antiquity, T. 70, fasc. 268, p. 335-350

SCHULTING R. 1999, « Nouvelles dates AMS à Téviec et Hoëdic (Quiberon, Morbihan) [Rapport préliminaire] », Bulletin de la Société Préhistorique Française, T. 96, fasc. 2, p. 203-207

SCHULTING R. et RICHARDS M. 2001, « Dating women and becoming farmers : new palaeodietary and AMS dating evidence from the Breton Mesolithic cemeteries of Téviec and Hoedic ", Journal of Anthropological Archaeology, T. 20, p. 314-344 
SCHULTING R., TRESSET A., DUPONT C. 2004, « From Harvesting the Sea to Stock Rearing Along the Atlantic Façade of North-West Europe », Environmental Archaeology, T. 9, p. 131-142

TABORIN Y. 1974, « La parure en coquillages de l'Épipaléolithique au Bronze Ancien en France », Gallia Préhistoire, T. 17, p. 307-417

TABORIN Y. 2004, Langage sans parole, la parure aux temps paléolithiques, Paris, La maison des roches, $211 \mathrm{p}$.

TRESSET A. 2003, « De la mer au bétail en domaine atlantique : unité et diversité des processus d'apparition de l'élevage à la marge nord-ouest de l'Europe », Anthropozoologica, T. 36, p. 13-35.

TRESSET A. 2005, « L'avifaune des sites mésolithiques et néolithiques de Bretagne (5500 à 2500 av. J.-C.) : implications ethnologiques et biogéographiques », Revue de Paléobiologie, T. 10, p. 83-94 TRESSET A. et VIGNE J.-D. 2007, « Substitution of species, techniques and symbols at the MesolithicNeolithic transition in Western Europe ", dans WHITTLE A. et CUMMINGS V. (dir.), Going over : the Mesolithic/Neolithic transition in NW Europe, Proceedings of the British Academy, T. 144, p. 189-210 VALENTIN B. 2015, « Paléolithique final et Mésolithique dans le Bassin parisien et ses marges. Habitats, sociétés et environnements : cinq ans de fonctionnement d'un projet collectif de recherche du ministère de la Culture ", Les nouvelles de l'archéologie, T. 139, p. 51-55.

\section{NOTES}

1. Le colloque organisé à Toulouse : «Anthropologie physique et archéologie - méthodes d'étude des sépultures » à l'initiative de Henri Duday et Claude Masset en 1982 va contribuer à définir l'objet de la discipline mais également à poser ses bases méthodologiques.

2. Précédemment, des datations radiocarbone sur ossements humains ont également été réalisées proposant une date autour de 5200 cal B.C. (Schulting et Richards, 2001) mais celle-ci se trouve aujourd'hui invalidée suite à des problèmes techniques décelés a posteriori (Schulting, com. pers.).

3. Téviec demeure encore aujourd'hui l'une des rares nécropoles connues sur le territoire français pour la période mésolithique avec celles de Hoedic (Péquart, 1954), La Vergne (CharenteMaritime) (Courtaud et Duday, 2012) et Neuilly-sur-Marne (Seine-Saint-Denis) (Valentin, 2015). Au sein de ces quatre autres nécropoles, elle est la plus vaste et la mieux conservée.

4. Directeur de l'Institut de Paléontologie Humaine de Paris de 1911 à 1942 et professeur de paléontologie au Muséum national d'Histoire naturelle.

5. Archéologue, conservateur-directeur du Musée des antiquités nationales de Saint-Germain-enLaye.

\section{RÉSUMÉS}

Les sépultures renfermant des restes d'animaux et des restes humains sont des lieux privilégiés pour comprendre les relations qui unissent l'Homme à l'animal. Cette association a notamment permis, à la fin $d u x x^{e}$ et au début $d u x^{e}$ siècle, d'établir la reconnaissance des pratiques 
funéraires à la Préhistoire. Dans une perspective épistémologique, nous tenterons de restituer les différentes interprétations qui ont été faites des restes de faune dans les sépultures, en les replaçant dans le contexte intellectuel de leur découverte. La nécropole de Téviec (Morbihan), fouillée entre 1928 et 1930 par Marthe et Saint-Just Péquart, est un exemple parfait pour cette analyse. En effet, animaux et défunts y sont intimement liés, et l'animal a été attribué à différents statuts : déchet alimentaire, élément architectural de la tombe, offrande et élément de parure. Nous interrogerons ainsi le sens donné à ces catégories et, au travers elles, nos systèmes de représentation des Préhistoriques.

\section{AUTEUR}

\section{PAULINE FONTAN}

Chercheure rattachée au Muséum national d'histoire naturelle,

UMR 7194

Histoire naturelle de l'Homme préhistorique

(CNRS - MNHN - UPVD) 


\title{
Place et rôle de l'animal dans les pratiques funéraires au Cerny : l'exemple de la nécropole néolithique de Fleury-sur-Orne (Calvados)
}

\author{
Emmanuel Ghesquière et Lamys Hachem
}

\section{Introduction}

1 La découverte de la nécropole des "Hauts de l'Orne » à Fleury-sur-Orne (Calvados) revient à J. Desloges au début des années 1990. Il y a pratiqué quelques opérations programmées, ainsi que sur la nécropole voisine de Rots "La Haute Bonny" (Calvados), qui ont été publiées pour certaines (Desloges, 1997, Arbogast et al., 2002). D'autres opérations ponctuelles de diagnostic ou de fouille ont concerné également quelques monuments (monument/mon. 10, 11 et 12, cairns, fig. 1, Flotté, 2000a, 2000b). La fouille de l'ensemble de la nécropole de Fleury-sur-Orne s'est quant à elle déroulée de mai à décembre 2014, sur une surface triangulaire de 21 hectares d'un seul tenant, après un diagnostic portant sur une surface de plus de 50 hectares (Flotté, 2013). Elle a été menée par l'Inrap sous la responsabilité d'E. Ghesquière, en association avec le CNRS (P. Chambon, UMR 7041) et une importante équipe universitaire (universités de Besançon, Bordeaux et Marseille). Elle a permis de mettre en évidence 26 monuments de type Passy, un dolmen, un cairn et trois alignements de mégalithes/ mégaxyles (fig. 1).

2 Les monuments mesurent entre 8 et $372 \mathrm{~m}$ de longueur et sont constitués de deux fossés encadrant une sépulture. Ces fossés sont formés par l'accrétion de segments de 2 à $4 \mathrm{~m}$ de longueur, respectant une direction générale est-ouest suivant un tracé assez sinueux. Leur profil est parfois étroit sous forme de tranchée (palissadée ?) ou large. Les 
seuls vestiges retrouvés dans les fossés sont quelques ossements (scapulas de bovidés en particulier) et des pics massifs en grès rouge de provenance locale.

Trois morphologies de monuments coexistent :

- les petits monuments (mon. 31, 32, 36, 37), sous forme de cercles isolés ou emboités, sont au nombre de 4 et représentent les monuments les plus courts (entre 5 et $12 \mathrm{~m}$ de longueur/ diamètre) ;

- les monuments trapézoïdaux (mon. 20, 22, 29, 33, 34) présentent un évasement très léger de leur surface interne et un élargissement important de leur fossé à leur extrémité orientale, qui leur donnent un aspect nettement évasé. Ils sont au nombre de 5 . Ils sont généralement de petite taille (moins de $20 \mathrm{~m}$ ), mais l'un d'entre eux est monumental avec $150 \mathrm{~m}$ de longueur pour $60 \mathrm{~m}$ de largeur à l'est (son tertre est préservé sous un chemin antique). Ils ne présentent pas de fossé de fermeture aux extrémités. Ces monuments sont ceux qui bénéficient des datations les plus anciennes. Leur caractère funéraire n'est toutefois pas totalement acquis puisqu'ils n'ont livré aucune sépulture.

- les monuments constitués de deux fossés parallèles sont les plus nombreux avec 17 ensembles (mon. 1, 2, 3, 4, 5, 7, 8, 10, 11, 12, 15, 18, 19, 21, 24, 25 et 26). Leurs dimensions sont très variables puisque le plus court mesure $13 \mathrm{~m}$, la plupart entre 50 et $100 \mathrm{~m}$, deux entre 150 et $200 \mathrm{~m}$ et les deux plus grands respectivement 320 et $370 \mathrm{~m}$. Ils peuvent être fermés ou ouverts à leur extrémité occidentale, ou orientale, ou les deux à la fois.

- Quatre monuments entrent difficilement dans cette typologie avec des formes intermédiaires ou déviantes (mon. 23, 28, 35 et 38).

Figure 1 : Fleury-sur-Orne « Les Hauts de l'Orne» (Calvados) - Plan masse de la nécropole néolithique, dans l'emprise de la fouille (trait continu) et à l'extérieur de celle-ci (DAO E. Ghesquière, Inrap).

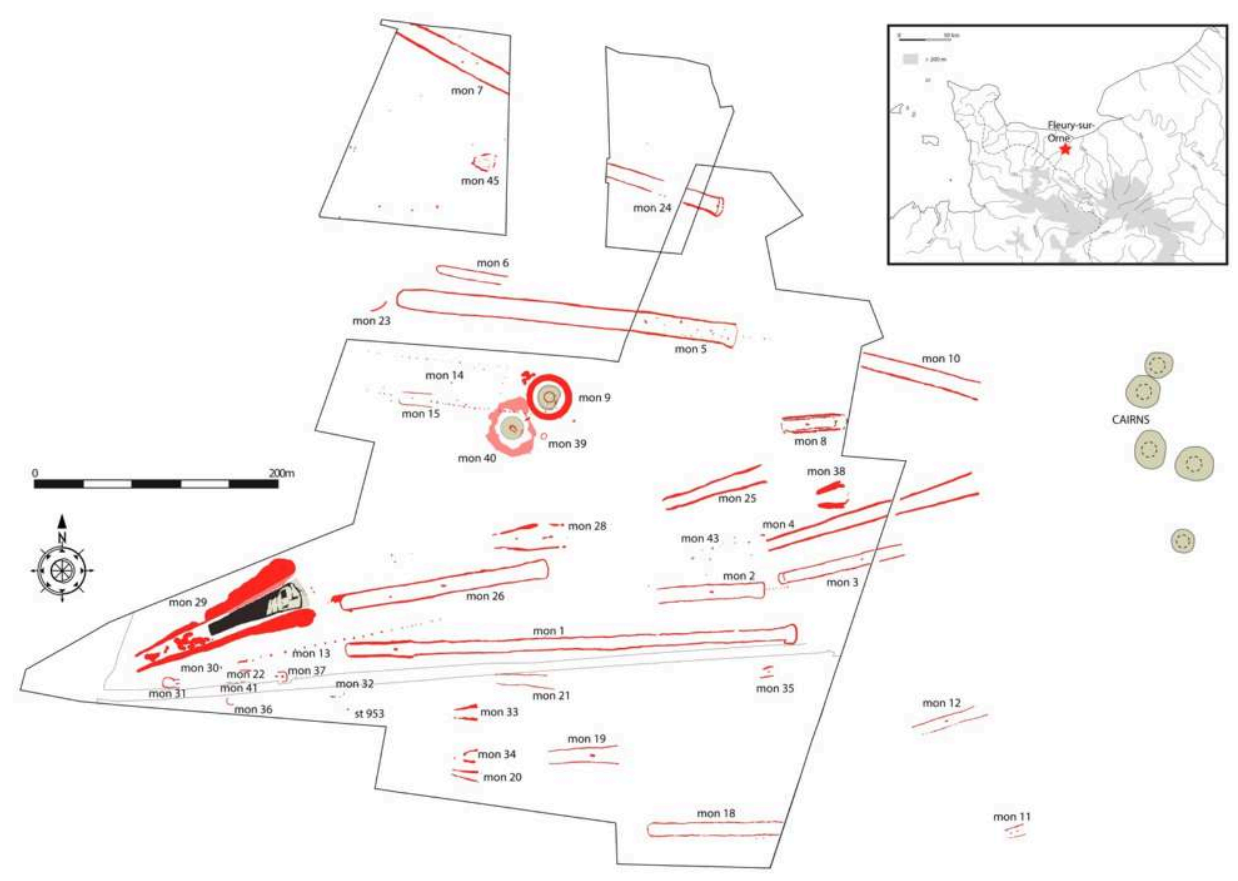




\section{Contexte chrono-culturel}

4 Trente-six datations par AMS ont été réalisées sur la nécropole de Fleury-sur-Orne (fig. 2), à partir de fragments osseux (humain ou faune). Huit monuments n'ont pas livré d'os et n'ont pas pu faire l'objet de datations. Le début de l'occupation de la nécropole correspond au Néolithique moyen I (Cerny-Videlles), avec les monuments 26 et 29 en particulier, entre 4700 et $4500 \mathrm{cal} \mathrm{BC}$. L'ensemble de l'occupation s'inscrit largement dans la phase ancienne du Néolithique moyen II, entre 4450 et $4350 \mathrm{cal} \mathrm{BC}$, période qui précède la construction des cairns collectifs (Vierville, La Hogue, La Hoguette, mon. 9 de Fleury-sur-Orne..., Chancerel et al., 1992). La surprise vient de la perduration vraisemblable de la nécropole constituée de structures de type Passy (STP) datées entre 4200 et 3900 (mon. 8 et 24), qui poursuivent une tradition funéraire dont on peut penser qu'elle correspondait à une portion particulière de la population, différente de celle enterrée dans les cairns présents au même moment sur la nécropole.

5 Les sépultures qui nous intéressent dans le cadre de cet article correspondent aux inhumations les plus anciennes. Trois d'entre elles sont datées entre 4600 et 4400 cal BC (fig. 2). La quatrième n'a pas encore été datée (2-5), tout comme les deux sépultures à caprinés de Rots. Cette nécropole «La Haute Bonny » a été découverte également par prospection aérienne, une douzaine de monuments de type STP y a pour l'instant été identifiée. Elle n'a fait l'objet que de quelques sondages et la fouille a concerné 5 sépultures (Desloges, 1997 ; Arbogast et al., 2002).

Figure 2 : Fleury-sur-Orne "Les Hauts de l'Orne" (Calvados) - Courbes de calibration des Structures de Type Passy de Fleury ; en rose, les sépultures à dépôts animaux (DAO E. Ghesquière, d'après $0 x$ Cal v4.2).

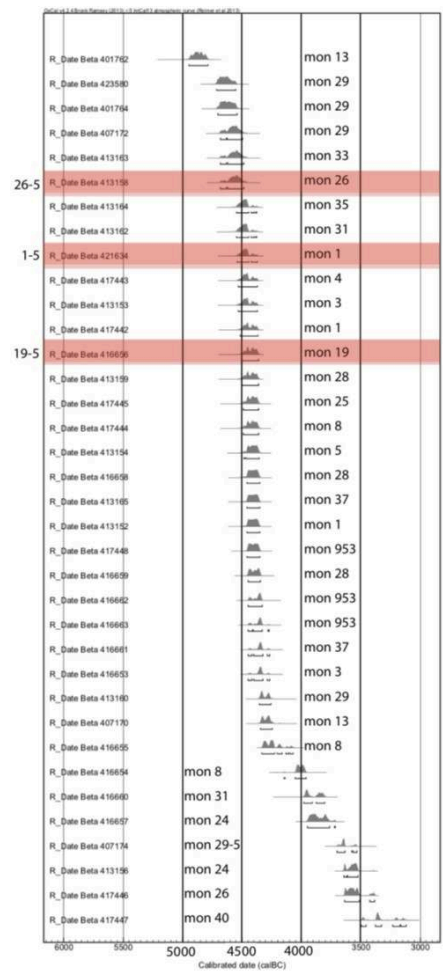

6 On peut sans réserve intégrer les monuments de Fleury-sur-Orne (et ceux de la nécropole de Rots, Desloges, 1997 et du monument de Cuverville, Fromont, DFS, 2016) 
au même phénomène que les nécropoles du bassin Seine-Yonne. En effet, la réalisation de longs tertres encadrés de fossés périphériques et surmontant vraisemblablement une unique tombe à l'origine correspond sans conteste à une même manifestation de monumentalisme funéraire. Un argument supplémentaire réside dans la terminaison des monuments, indépendante de la présence ou non d'un fossé de fermeture. La présence d'un poteau ou d'un alignement de poteaux se retrouve en effet aussi bien sur la nécropole de Fleury-sur-Orne que sur celles de Passy «La Sablonnière » et «Richebourg» (Yonne), de Balloy "Les Réaudins» (Seine-et-Marne) et d'EscolivesSainte-Camille "La Pièce de l'Étang" (Yonne) (Thomas, 2011). Des spécificités régionales viennent toutefois marquer de réelles différences dans la disposition des défunts. Ils sont en extension dans le bassin Seine/Yonne et fléchis en Normandie (à l'exception de la tombe 1-5 du site de Fleury-sur-Orne), mais cela peut avoir une dimension chronologique, les sépultures les plus tardives de Passy étant fléchies (après 4600 cal BC; Thomas, 2011). Le second élément concerne le mobilier découvert dans les tombes.

7 Si les armatures de flèche restent les objets les plus répandus dans les tombes des deux espaces géographiques, l'absence en Normandie de l'objet emblématique que constitue la pointe à ailerons en os, dite "tour Eiffel », constitue un élément de distinction. Plus significatif, toutefois, est le rôle joué par les animaux domestiques dans quatre tombes de Fleury et deux tombes de Rots, sous forme de dépôts complexes, principal objet du présent article. On conclura à un phénomène funéraire identique mais offrant des expressions légèrement distinctes. Celles-ci résultent soit d'un décalage chronologique (les sépultures de Passy les plus anciennes précèdent de deux siècles les plus anciennes de Fleury) soit de spécificités régionales liées à des pratiques propres à chacun des deux groupes humains, distants de plus de $200 \mathrm{~km}$.

8 Nous avons sélectionné plusieurs éléments significatifs pour l'analyse, en attendant qu'elle soit complétée à Fleury-sur-Orne (étude en cours). Il s'agit tout d'abord d'une étude archéozoologique réalisée par nos soins, sur d'une part, des offrandes animales retrouvées dans deux sépultures Cerny fouillées en 2014 à Fleury-sur-Orne ( $n^{\circ} 19-5$ et $\mathrm{n}^{\circ}$ 26-5), d'autre part sur les os récoltés dans les tranchées de 12 monuments de ce même site. Ensuite, nous avons mené une comparaison bibliographique avec les documents issus des fouilles plus anciennes de J. Desloges, à savoir une sépulture de Fleury-sur-Orne (M1-F1) et deux sépultures de Rots (M1-F1 et M2-F2). Enfin, nous avons élargi les comparaisons avec les sites contemporains qui ont livré de la faune, dans les départements du Calvados, de la Somme, du Pas-de-Calais, du Val-de-Marne, de l'Yonne, de l'Aube et de l'Aisne.

\section{Les sépultures de la nécropole de Fleury-sur-Orne}

Elles sont au nombre de 18. Trois d'entre elles sont des réutilisations Néolithique moyen, final et campaniforme, installées au sein des monuments. Les profondeurs de creusement sont très variables, entre 5 et $80 \mathrm{~cm}$ sous le niveau de décapage. Cette différence explique probablement qu'une partie des monuments n'ait pas livré de sépultures, ces dernières pouvant être à l'origine installées hors sol et recouvertes par le tertre. Cependant, l'absence de sépulture sous le tertre pourtant bien conservé du monument 29 nous incite à la prudence et à considérer la possibilité de "mausolées " sans tombes. 
10 Les fosses sépulcrales conservées se présentent sous la forme de creusements de plan ovalaire à rectangulaire, aux angles arrondis et de dimensions variables: les plus longues atteignent $4 \mathrm{~m}$, les plus courtes se limitent à 1,60 m. La largeur des fosses est comprise entre $0,65 \mathrm{~m}$ et $1,90 \mathrm{~m}$. Peu de sépultures ont permis la restitution de leur architecture. L'analyse taphonomique des corps s'est avérée fréquemment impossible, en raison de la médiocre conservation des ossements. C'est davantage l'étude du comblement différentiel des tombes qui offre des indices permettant une reconstitution. $\mathrm{Au}$ minimum deux types d'aménagement sépulcral ont pu être reconnus: soit des chambres quadrangulaires construites dans la fosse, soit l'aménagement de parois longitudinales prenant appui contre les bords de la fosse.

\section{Les dépôts animaux dans les sépultures de Fleury-sur- Orne}

11 Certaines sépultures contenaient des ossements d'animaux. Deux d'entre elles méritent que l'on s'y attarde en raison de l'importance des dépôts et de leurs fortes similarités, les tombes numérotées 19-5 et 26-5, fouillées lors des campagnes de 2013-2014. Les ossements animaux, en apparence bien conservés, se sont avérés très fragiles et de nombreuses extrémités articulaires avaient été endommagées par l'érosion ou se sont effritées au contact de l'air au moment de leur dégagement. De plus, les os étaient originellement entiers, mais montraient parfois des fractures anciennes, ayant été brisés sous le poids des sédiments ou d'éléments organiques maintenant disparus. En raison de ces difficultés, une partie importante du temps d'étude a été consacrée au remontage pour reconstituer l'intégrité des os provenant des deux sépultures. Néanmoins, grâce à ces remontages, plus d'un millier de mesures ont pu être prises, ce qui a permis de récolter des informations importantes et inédites non seulement sur la stature des animaux, mais aussi sur leur sexe. Ainsi la taille au garrot de moutons Cerny a pu être estimée (coefficients de Teichert, 1975 sur tibias) : deux brebis faisaient $56,5 \mathrm{~cm}$ et $57,3 \mathrm{~cm}$ au garrot et deux béliers 64,2 et $68,5 \mathrm{~cm}$. De plus, la métrique s'est révélée être un moyen efficace de distinguer les mâles des femelles, ce qui, combiné à l'identification et au relevé des parties anatomiques dès la phase de fouille, a permis de restituer a posteriori la position exacte des individus dans les fosses sépulcrales et de rassembler des éléments squelettiques parfois éparpillés. La chose n'était pas aisée sur le terrain, les ossements étant en partie fondus dans la terre ou enchevêtrés. Pour plus de facilité nous avons attribué des lettres (de A à N) aux ensembles de parties anatomiques découvertes sur le terrain, puis nous avons individualisé les animaux en laboratoire.

Ces deux tombes 19-5 et 26-5 recelaient des squelettes de moutons et des os de bovins domestiques. Une attention particulière a été portée à la distinction entre mouton et chèvre sur des critères morphologiques (Balasse et Ambrose, 2005 ; Boessneck, 1969; Fernandez 2001 ; Zeder et Lapham, 2010). Les résultats montrent qu'une seule de ces deux espèces a été choisie pour être déposée près du défunt, le mouton. La même attention a été portée à la différentiation entre bovin domestique et aurochs, qui montre que les os sont issus d'animaux domestiques. L'âge d'abattage des moutons a été effectué sur les tables dentaires, en se fondant principalement sur le référentiel de Jones G. (2006) et en complétant au besoin avec celui de Payne S. (1973). Pour les bovins, nous avons utilisé celui de Jones G. et Sadler P. (2012). 


\section{La tombe 19-5}

La fosse sépulcrale 19-5, très large, contenait un Nombre Minimal d'Individus ${ }^{1}$ de huit moutons et quatre os de bovins domestiques, outre le défunt un homme âgé de plus de 50 ans (fig. 3). Parmi les moutons trois béliers ont été répertoriés (tabl. 1, fig. 4). Les individus 1 (ensemble G-H) et 2 (ensemble F-M) ont été abattus au même âge, vers 3,5-4,5 ans (42-52 mois). L'individu 3 (ensembles L-J) est un peu plus vieux : 4,5-8 ans (54-96 mois).

Figure 3 : Fleury-sur-Orne « Les Hauts de l'Orne » (Calvados) - Vue de la sépulture 19-5. Cliché P. Chambon, CNRS.

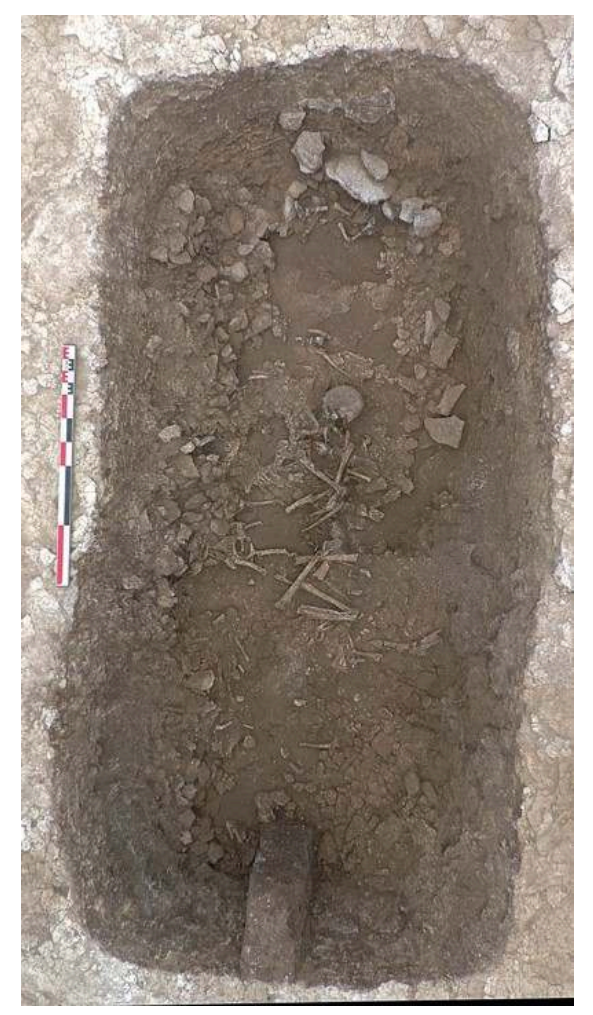

14 L'individu 1 est complet, excepté le haut du crâne et les phalanges (fig. 4), mais pour les deux autres (individu 2 et individu 3) il est difficile de trancher car leurs trains avant sont bien présents de la base du crâne jusqu'aux côtes, mais leur partie arrière n'est représentée que par quelques éléments. Il est fort possible que le reste de leur squelette ait disparu sous l'effet de perturbations dans la fosse sépulcrale (animaux fouisseurs). En effet, des mouvements de matériel en espace non colmaté sont perceptibles : les squelettes sont en connexion anatomique, mais l'individu 3, par exemple, n'est pas exempt de désordres, comme le montre une scapula positionnée à l'écart de l'humérus, ou encore un métatarse au-dessus du radius (ensemble L). 
Figure 4 : Fleury-sur-Orne « Les Hauts de l'Orne » (Calvados) - Positionnement des béliers dans la sépulture 19-5 (DAO C. Thévenet, Inrap).

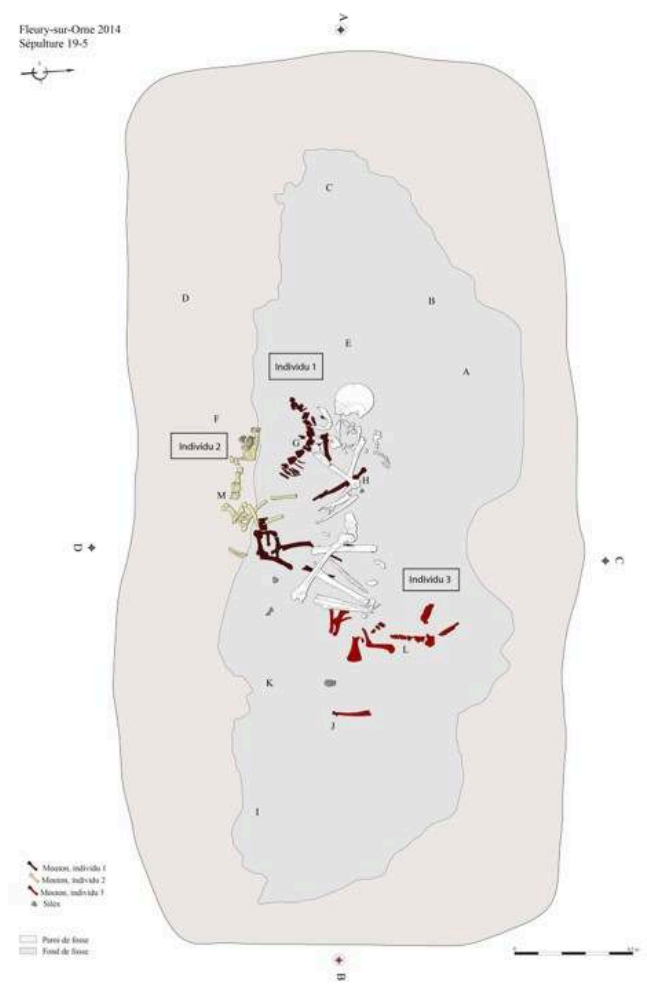

15 L'absence de chevilles osseuses dans la tombe nous intriguant, un examen minutieux des parties crâniennes a été effectué, livrant des informations intéressantes. Les os pétreux, le basi-occipital, les mandibules, les maxillaires, les vertèbres cervicales sont présentes, ce qui n'est pas le cas du haut de la boîte crânienne et du frontal. Ceci témoigne d'un prélèvement des bucranes alors que les têtes des béliers étaient encore attachées au corps, avec la volonté de garder ensemble les cornes et le frontal. Les deuxième et troisième phalanges manquent également, ce qui laisse envisager un prélèvement des peaux.

Le positionnement des animaux ne semble pas aléatoire et tient compte de l'emplacement du défunt. Ils l'entourent, les corps tournés face à lui, même s'il est probable qu'un contact direct n'ait pas eu lieu. En effet, l'étude de la répartition des pierres de comblement permet d'envisager l'existence de cloisons à l'intérieur de la sépulture et la dynamique d'effondrement du squelette montre que le défunt avait la partie supérieure de son corps en appui contre un élément rigide.

Le bélier 1 a été déposé en premier au sud du défunt, la tête à l'est, en position un peu surélevée par rapport au fond de la fosse. En partie posé sur celui-ci (vertèbres lombaires posées sur les radius), le bélier 2 a été disposé symétriquement au défunt, sa tête face à son visage, ses pattes avant et arrière passant en dessous des bras et des jambes de l'homme, qui lui, a donc été déposé en dernier. Le bélier 3 gît aux pieds du défunt, en partie recouvert par ses tibias, la tête regardant vers le nord-est.

Quatre brebis ont été décomptées (tabl. 1, fig.5). Les squelettes ont été fortement perturbés, ce qui a rendu délicate l'attribution des parties anatomiques à chaque individu. Cependant, une analyse croisée des données anatomiques et métriques permet de mettre en avant l'hypothèse de trois squelettes de brebis complets et d'un 
tibia isolé (individu 7). L'individu 4 est composé des ensembles $C$ et $E$, l'individu 5 des ensembles $\mathrm{D}$ et $\mathrm{F}$, l'individu 6 des ensembles $\mathrm{K}$ et probablement $\mathrm{I}$. Une deuxième phalange non épiphysée d'un très jeune capriné (moins de 6 mois), l'individu n ${ }^{\circ} 8$, a été recueillie parmi les ossements dispersés de la brebis $\mathrm{n}^{\circ} 6$ plus âgée. L'âge d'abattage établi sur les tables dentaires donne les résultats suivants: la brebis $n^{\circ} 4$ est âgée de 3,5-4 ans (42-54 mois) ; la brebis $n^{\circ} 5$ est âgée de 4,5-5 ans (54-96 mois) et la brebis $\mathrm{n}^{\circ} 6$ de 1,5-2 ans (18-24 mois).

Tableau 1 : Fleury-sur-Orne "Les Hauts de l'Orne » (Calvados). Liste des parties anatomiques de moutons de la sépulture 19-5.

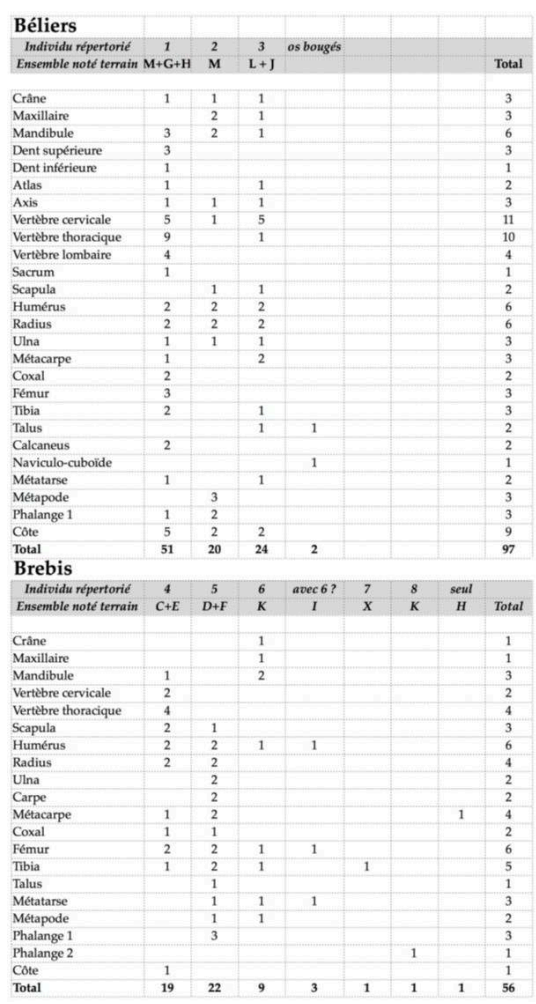


Figure 5 : Fleury-sur-Orne « Les Hauts de l'Orne » (Calvados) - Positionnement des brebis dans la sépulture 19-5 (DAO C. Thévenet, Inrap).

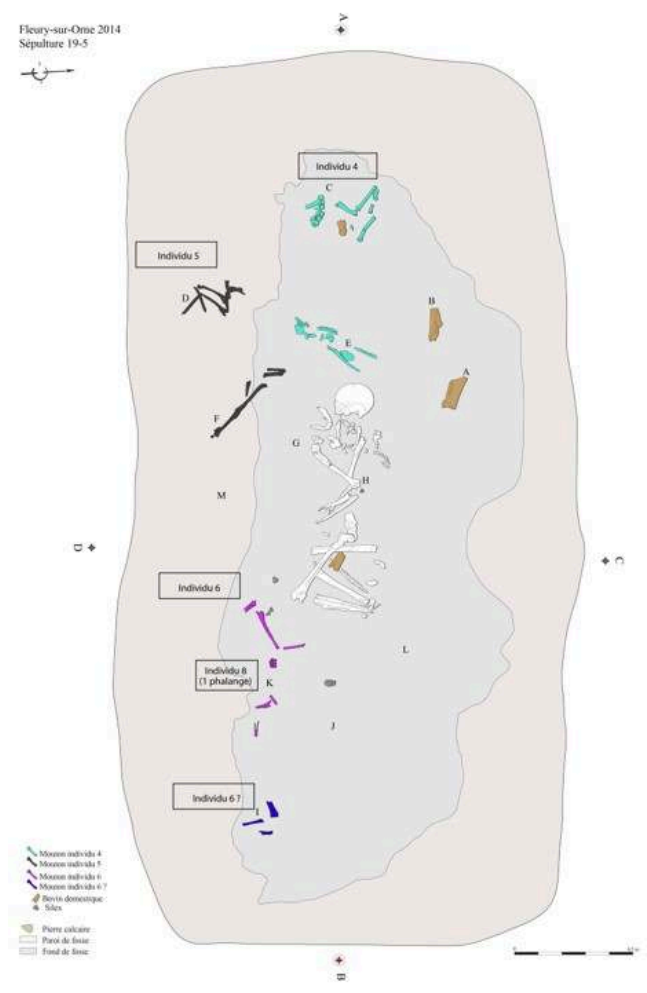

18 À l'instar des béliers, les bucranes des brebis ont été prélevés. Les chevilles osseuses sont inexistantes, mais on retrouve des mandibules et des maxillaires, ainsi que des éléments de crâne comme un os pétreux. D'autres éléments osseux comme les phalanges 3 (sabots) manquent et paraissent avoir fait l'objet d'un prélèvement. En effet, autant pour les béliers que pour les brebis, aucune phalange 3 n'est répertoriée, alors que les phalanges 1 sont présentes. Les phalanges 2 sont également absentes, excepté pour un exemplaire, mais il s'agit de la phalange du très jeune individu.

Le dépôt des brebis obéit à certaines règles. La brebis $\mathrm{n}^{\circ} 4$ est déposée au-delà de la tête du défunt dans l'axe du corps, tête à l'ouest et pattes vers le nord. La brebis $\mathrm{n}^{\circ} 5$ a également la tête placée vers l'ouest, mais pattes vers le sud. Il n'est pas possible de décrire la position précise de la brebis $n^{\circ} 6$, mais si l'on se fonde sur la connexion tibiamétatarse (ensemble K, fig. 5), l'axe du corps serait est-ouest et les pattes arrière seraient tournées vers le nord. La synthèse de ces informations amène à penser que les brebis, à l'inverse des béliers, ne sont pas tournées vers le défunt, mais dans la direction opposée.

Outre ces dépôts de moutons et de mobilier lithique (fig. 6), des os de bovins domestiques ont été placés dans la tombe. Une scapula fragmentaire de taureau, a été déposée au nord-ouest de la fosse sépulcrale du côté de la tête du défunt (fig. 6). Cette omoplate présente une fracture ancienne qui l'a éclatée en deux grands morceaux (ensemble A et B). Un fragment de base de cheville osseuse a par ailleurs été trouvé à côté de la brebis $\mathrm{n}^{\circ} 4$, l'amas d'os $\mathrm{C}$, à l'ouest de la fosse. Un fragment de dent (prémolaire) a été recueilli sans indication spatiale (os bougé). Enfin, un morceau de diaphyse distale de métacarpe a été retrouvé sur le tibia droit du défunt. Il est impossible de savoir si ces quatre os appartiennent au même individu. 
Figure 6 : Fleury-sur-Orne " Les Hauts de l'Orne » (Calvados) - Positionnement des os de bovins dans la sépulture 19-5 et dépôts de moutons complets (DAO C. Thévenet, Inrap).

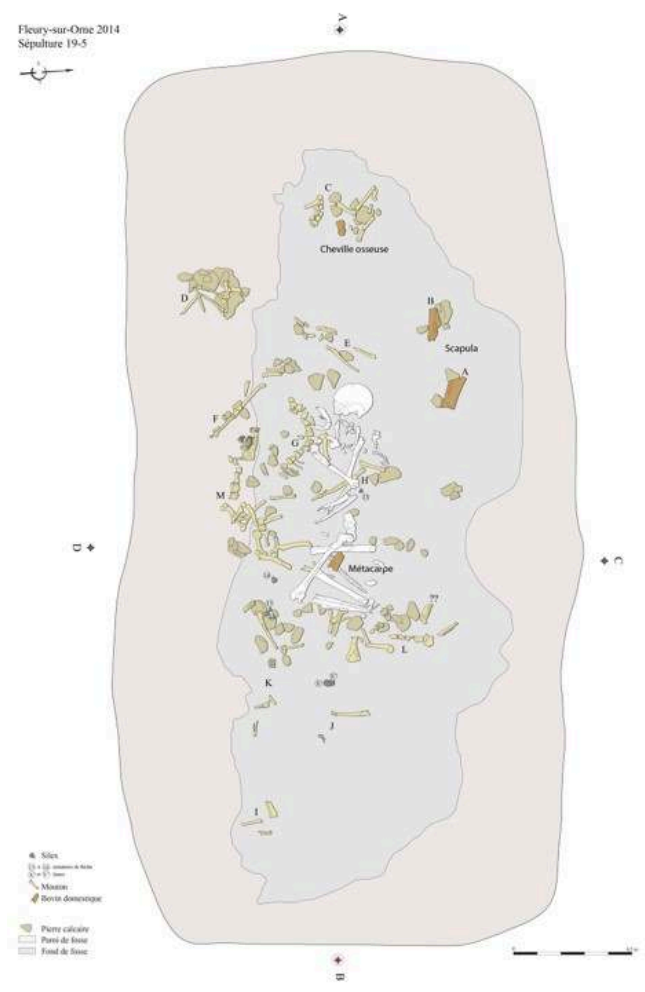

\section{La tombe $26-5$}

21 La sépulture 26.5 contient un nombre d'ossements de caprinés très important, 592 auxquels il faut ajouter 200 restes encore à enregistrer car l'étude n'est pas tout à fait achevée (fig. 7). Le nombre minimal ${ }^{2}$ de moutons abattus est de 12 , sur les os longs, et ne devrait pas évoluer d'ici l'étude complète de la tombe, car nous avons fait en sorte d'enregistrer en premier lieu les ensembles contenant des os longs et des mandibules. Les parties anatomiques répertoriées par individu montrent la présence de squelettes complets, sauf dans le niveau supérieur du remplissage, où les os ont été moins bien protégés de l'érosion qu'en profondeur ${ }^{3}$. 
Tableau 2 : Fleury-sur-Orne « Les Hauts de l'Orne» (Calvados). Taxons et parties anatomiques présents dans les monuments.

\begin{tabular}{|c|c|c|c|c|c|c|c|c|c|c|c|c|c|}
\hline Monuments & 4 & 5 & 8 & 13 & 14 & 15 & 19 & 24 & 25 & 28 & 33 & 38 & Total \\
\hline \multicolumn{14}{|l|}{ Bovins } \\
\hline Crâne & 1 & & & 1 & & & & & & & & & 2 \\
\hline Maxillaire & 8 & & & & & & & & & & & & 8 \\
\hline Dent supérieure & 1 & & & & & & & & & & & & 1 \\
\hline Dent inférieure & & & & & & & & & 1 & & & & 1 \\
\hline Dent indéterminée & 1 & & & & & & & & 1 & & & 1 & 3 \\
\hline Vertèbre cervicale & & & & & & & & & 1 & & & & 1 \\
\hline Vertèbre thoracique & 1 & & & & & & & & & & & & 1 \\
\hline Scapula & & 2 & & & 1 & 3 & 1 & 1 & 2 & 1 & & 1 & 12 \\
\hline Humérus & 1 & & 1 & & & & & & 2 & 2 & & 1 & 7 \\
\hline Radius & 1 & & & & & & & & 3 & & & & 4 \\
\hline Fémur & & & & & & & & & 2 & 1 & & 1 & 4 \\
\hline Tibia & & & 1 & & & & & & 1 & & 1 & 2 & 5 \\
\hline Côte & & & & & & & & & 1 & & & & 1 \\
\hline Métacarpe & & & & & & & & & 1 & & & & 1 \\
\hline Métapode & & & & & & & & & 1 & & & & 1 \\
\hline Métatarse & & & & & & & & & 2 & 2 & & & 4 \\
\hline Total & 14 & 2 & 2 & 1 & 1 & 3 & 1 & 1 & 18 & 6 & 1 & 6 & 56 \\
\hline \multicolumn{14}{|l|}{ Mouton } \\
\hline Scapula & & & & & & & & & & 1 & & & \\
\hline \multicolumn{14}{|l|}{ Cerf } \\
\hline Bois de mue & & & & & & & & & 1 & & & & \\
\hline Bois fragment & & & & & & & & & 1 & & & & \\
\hline
\end{tabular}

Figure 7 : Fleury-sur-Orne "Les Hauts de l'Orne " (Calvados) - Vue d'ensemble des squelettes de caprinés de la sépulture 26-5. Cliché $\mathrm{E}$. Ghesquière, Inrap.

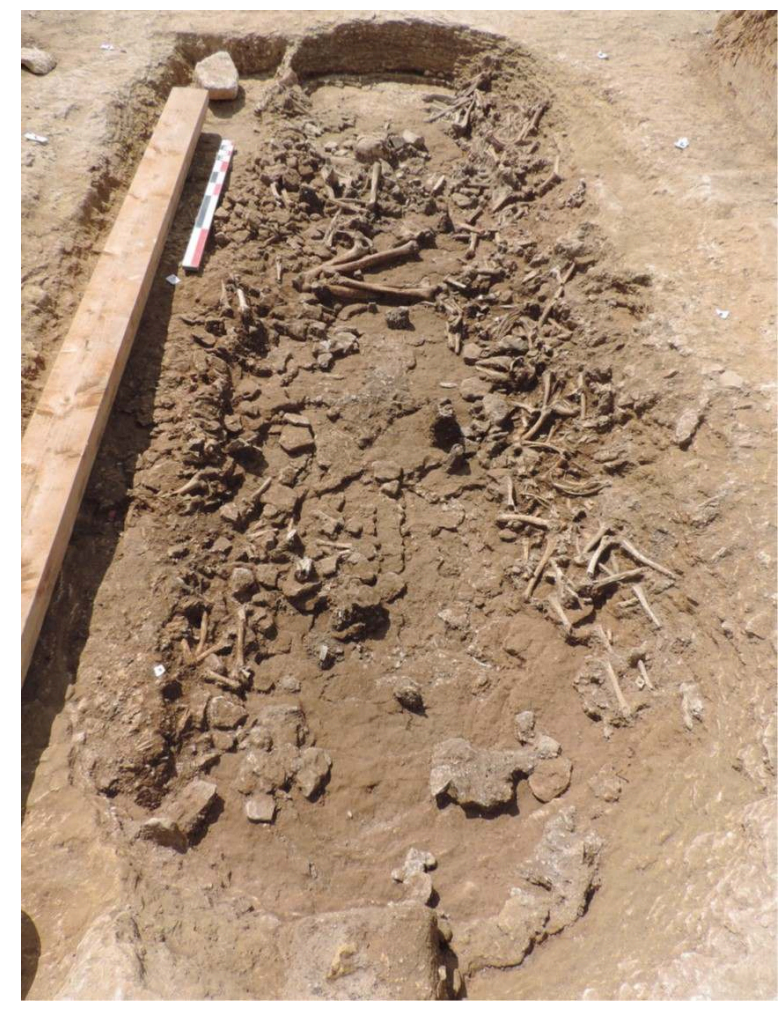

22 Six moutons ont été tués dans une fourchette d'âge qui va de 1,5 an à 3 ans, avec la forte probabilité qu'ils aient été plutôt abattus vers 18-20 mois. Deux autres ont été abattus à un plus jeune âge, il s'agit d'un agneau de 1 à 3 mois et un autre de 8-12 mois (plus proche des 8 mois). Enfin, un mouton est plus âgé, environ 3,5 à 4,5 ans. Toutes les mandibules droites et gauches de ces individus étaient présentes, ainsi que souvent le maxillaire, mais leurs branches mandibulaires étaient absentes et sectionnées 
volontairement. Quelques exemplaires de ces branches ont été retrouvés séparément. Il est possible que le sectionnement du haut des mandibules ait un lien avec la préparation des bucranes qui, comme dans la tombe 19.5, ont été prélevés. Des crânes, il subsiste la partie inférieure, à savoir le maxillaire, le bas des orbites, l'os pariétal, l'occipital, les condyles occipitaux et les bulles tympaniques. En revanche, le frontal d'où partent les chevilles osseuses (cornes) est absent (fig. 8). Alors que dans la tombe 19.5 aucune troisième phalange n'a été découverte, on en répertorie une dizaine dans la tombe 26.5. Cependant ce chiffre ne correspond pas avec le nombre qui serait nécessaire pour les pattes complètes de 12 individus, soit 96 phalanges. Cet élément ajouté à celui de la rareté des vertèbres de la queue $(\mathrm{N}=4)$ milite pour l'hypothèse, déjà évoquée, d'un prélèvement des peaux.

Figure 8 : Fleury-sur-Orne « Les Hauts de l'Orne » (Calvados) - Crâne de mouton dont il manque la partie frontale, sépulture 26-5. Cliché L. Hachem, Inrap.

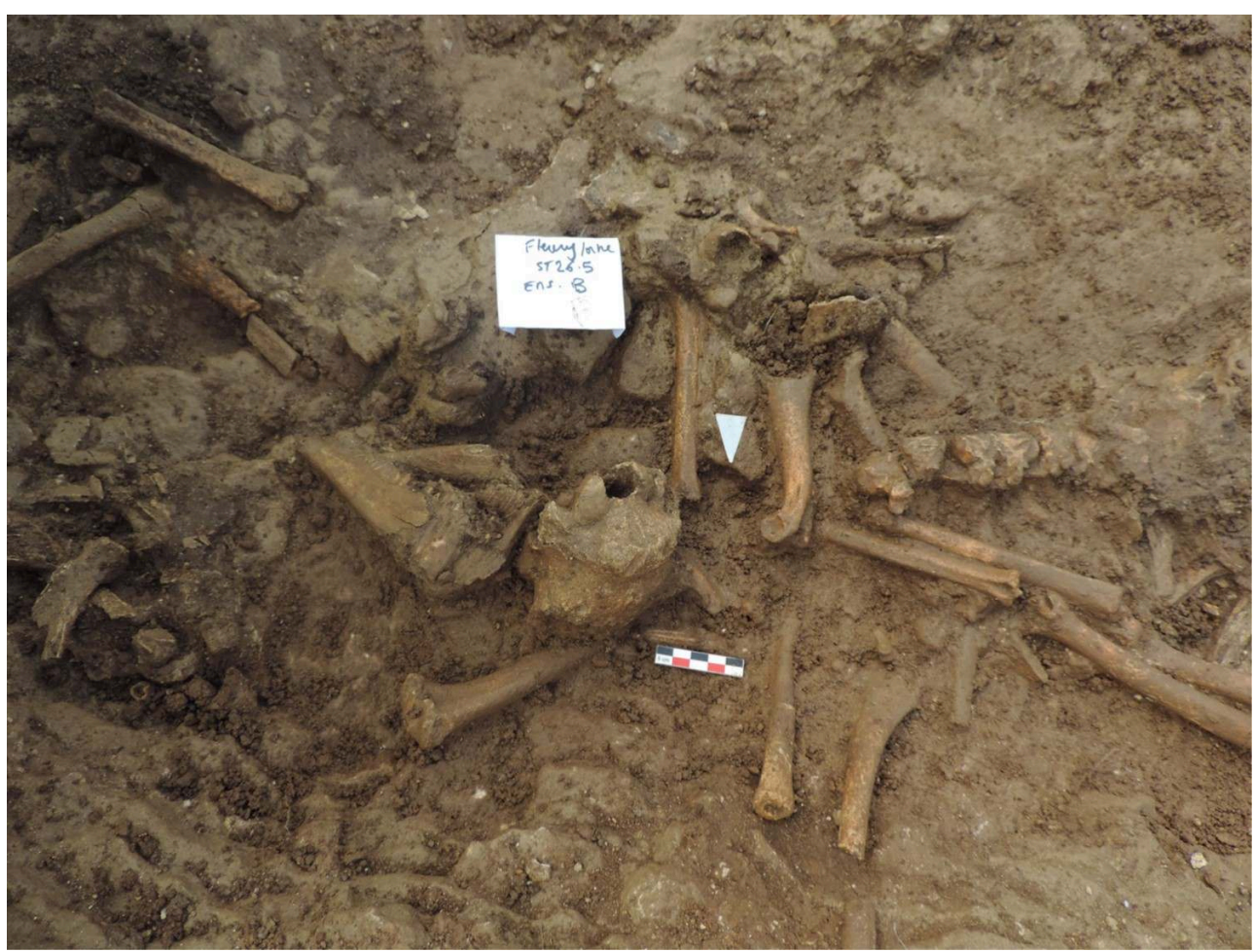

Le positionnement des animaux dans la tombe, qui dépend de la discrimination des individus, est en cours d'étude. Les carcasses de caprinés sont bien plus nombreuses du côté nord que du côté sud, elles ont glissé le long du bord nord de la fosse, ce qui induit un effondrement en espace non colmaté, mais ont été freinées avant leur chute sur le défunt par un obstacle dorénavant disparu, comme en témoigne un net effet de paroi (fig. 9). Du côté sud, les restes existent mais sont beaucoup plus rares et plus érodés, très perturbés par un petit fossé postérieur. 
Figure 9 : Fleury-sur-Orne " Les Hauts de l'Orne » (Calvados) - Effet de paroi visible sur la droite, scapula de bovin isolée sur la gauche, sépulture 26-5. Cliché E. Ghesquière, Inrap.

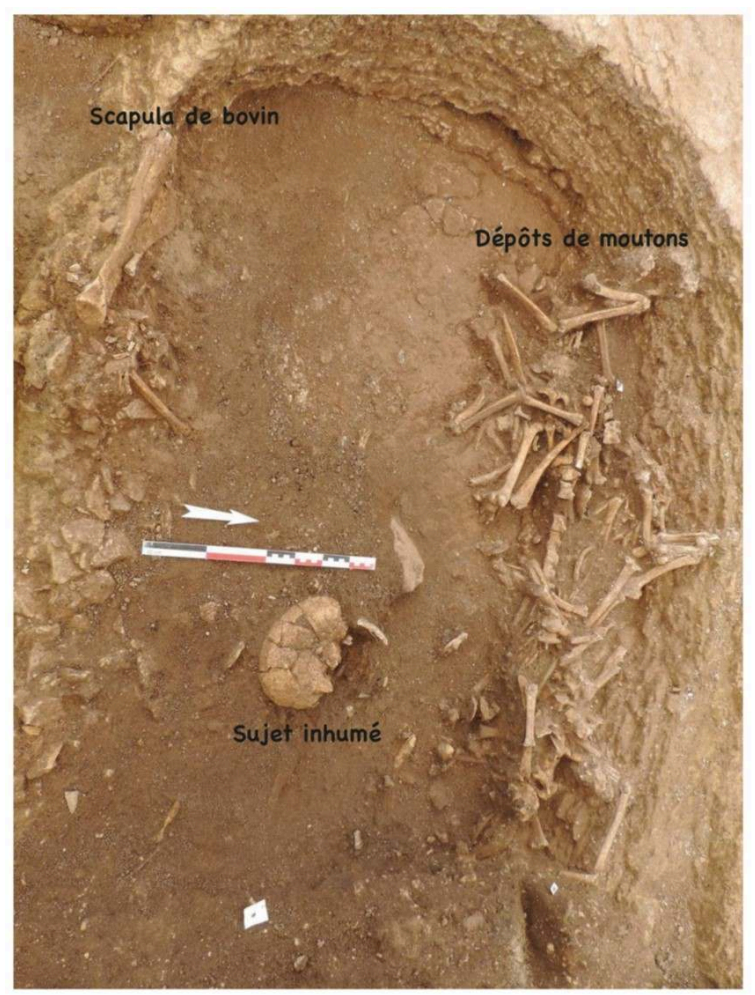

24 Trois os de bovins domestiques ont été répertoriés. Il s'agit d'une scapula, d'une épine de vertèbre cervicale et d'un fragment de cheville osseuse. L'omoplate est entière (fig. 10), mais son épine a été fracturée anciennement et l'articulation distale est érodée ce qui rend les mesures sont difficiles à prendre. Il semble cependant que cela puisse appartenir à une vache. Cette omoplate a été déposée à la tête du défunt, en position isolée, du côté inverse au plus grand nombre de moutons (fig. 9). Les morceaux de cheville osseuse et de vertèbre ne sont sans doute pas en place, mais la première est placée vers le côté nord, vers la tête du défunt, alors que la seconde est au nord-est de la sépulture. 
Figure 10 : Fleury-sur-Orne "Les Hauts de l'Orne » (Calvados) - Scapula de bovin dans la sépulture 26.5. Cliché L. Hachem, Inrap.

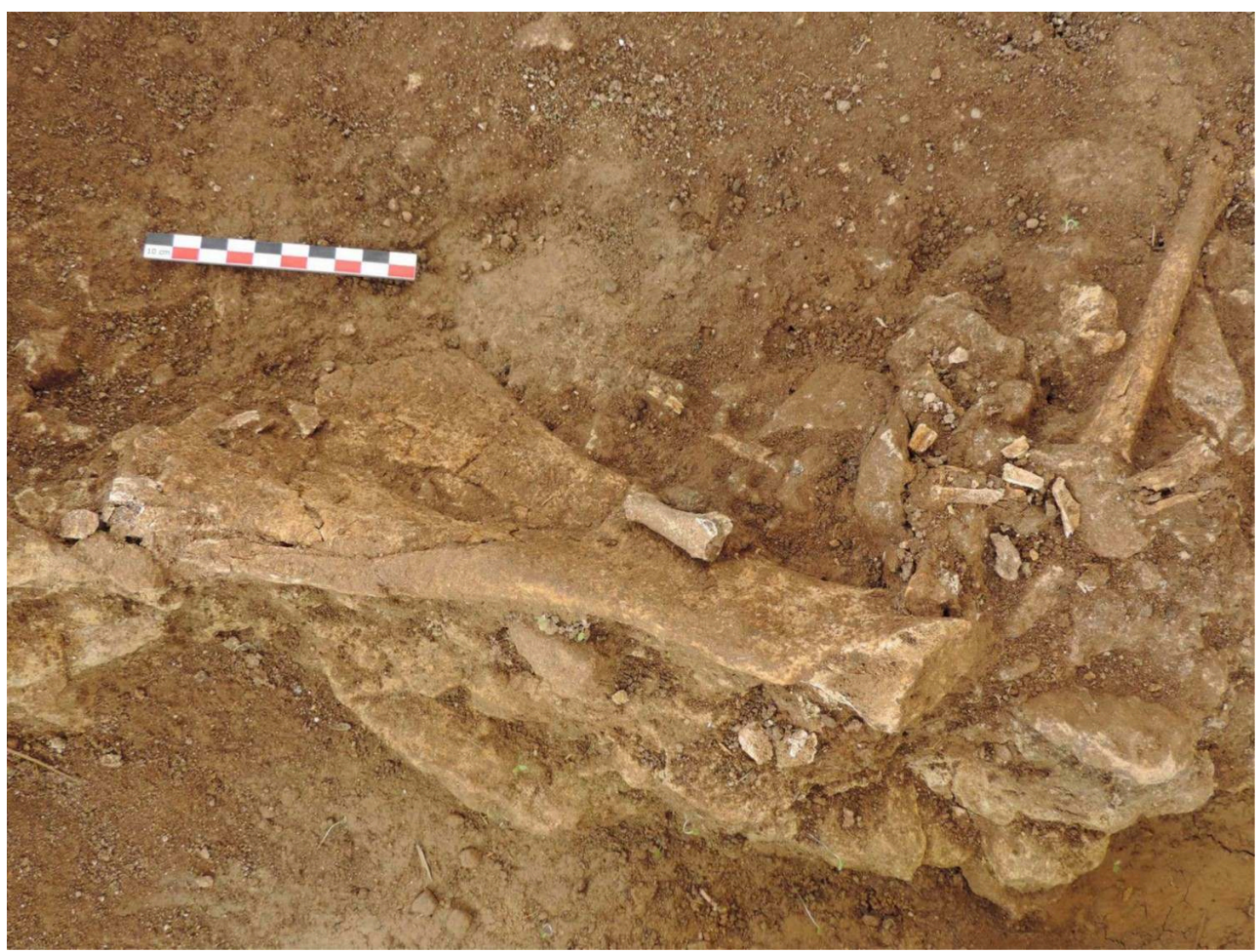

\section{Les monuments de Fleury-sur-Orne}

Les tranchées des monuments ont été entièrement fouillées, ce qui est un grand avantage, les autres nécropoles Cerny n'ayant fait l'objet que de sondages ponctuels. Ce travail fastidieux a porté ses fruits, permettant l'acquisition d'ossements qui s'avèrent être particuliers. Quatre monuments contiennent un peu plus de restes que les autres : $\mathrm{n}^{\circ} 4,25,28$ et 38 , tous situés dans la même fourchette de datation que la majorité des monuments (4500-4350 cal BC, fig. 2) (tabl. 2). Nous donnerons le détail de leur composition ci-dessous. Le monument 29 , à l'histoire plus complexe et qui a également livré des dépôts d'ossements, n’a pas encore été étudié.

\section{Monument 4}

Bien que leur nombre total soit faible $(\mathrm{NR}=14)$, les restes recueillis dans le monument 4 sont pourtant, avec ceux du monument 25 , les plus nombreux. Tous les ossements sont dans la partie sud du monument, hormis un exemplaire au nord. Une seule espèce est représentée, celle des bovins domestiques, et les os sont issus d'une sélection qui n'est pas de nature alimentaire, puisqu'il s'agit presque uniquement de parties crâniennes, en l'occurrence des maxillaires. On dénombre un minimum de six individus sur la base des $\mathrm{M}^{2}$ supérieures gauches. Il n'existe pas de référentiel pour estimer l'âge d'abattage des individus sur les dents supérieures, mais on peut dans ce cas précis déterminer la présence de deux adultes avec une usure dentaire identique (donc probablement abattus au même âge), de trois individus plus jeunes (également abattus à un âge 
similaire) et d'un dernier animal beaucoup plus jeune. Deux appariements seraient possibles, entre les maxillaires droit et gauche de deux jeunes individus.

En dehors des parties crâniennes, un humérus, un radius et une vertèbre thoracique ont été dénombrés. Les ossements n'étant pas entiers et leur surface étant très érodée, aucune mesure n'a pu être prise. Cependant leur gabarit imposant, de même que l'aspect massif des maxillaires laissent penser qu'il s'agit de sujets mâles. La répartition des os n'est pas aléatoire, on remarque une concentration des ossements sur une surface de $4 \mathrm{~m}^{2}$ de fossé.

\section{Monument 25}

Les restes trouvés dans le monument $\mathrm{n}^{\circ} 25$ sont au nombre de 20. Il s'agit d'ossements de bovins domestiques relativement variés puisque l'on décompte des os longs, des ceintures (dont deux scapulas très éloignées l'une de l'autre, l'une quasiment entière, l'autre sous forme d'un fragment) et des vertèbres. L'aspect général de ces ossements fait pencher pour un ou plusieurs bovins mâles (le NMIf ne donne qu'un seul individu ${ }^{4}$ ). Les os se répartissent équitablement entre les fossés nord et sud.

29 Les deux fragments de bois de cerf sont un fragment d'empaumure et un autre de merrain ; aucun autre bois n'a été découvert dans les autres monuments, à l'exclusion du fossé du monument 29 , non encore étudié.

\section{Monument 28}

30 Les restes recueillis dans le monument 28 s'élèvent à 7 . Ce sont des parties anatomiques variées de bovins domestiques (dont un grand morceau de scapula); le NMI est de 1 individu. Un fragment de scapula de capriné a été identifié, c'est le seul fragment d'os $(0,5$ gr. $)$ de cette espèce au sein de tous les monuments.

\section{Monument 38}

31 Six restes représentent des parties anatomiques variées de bovins domestiques (dont un fragment de scapula); mais le NMI s'élève à un seul individu.

\section{Les autres monuments}

32 La faune recueillie dans les monuments $5,8,13,14,15,19,24,33$ présente de grandes similarités (tabl. 2). On dénombre de 1 à 3 os par ensemble et, fait notoire, il ne s'agit que de scapulas de bovins domestiques exceptés pour les structures 8,13 et 33, qui sont d'ailleurs des types de structures différents. Rappelons que les scapulas sont aussi systématiquement présentes dans trois des quatre monuments dont le détail a été donné précédemment. 


\section{Synthèse sur les dépôts animaux de Fleury-sur-Orne et mise en perspective culturelle} l'hétérogénéité des contextes est importante (couches, fosses d'habitat, fossés d'enceintes, sépultures, monuments funéraires, fours, fosses particulières). Une comparaison a néanmoins été tentée afin de proposer des hypothèses sur la place que joue l'animal dans cette société.

On dénombre ainsi, en dehors du domaine funéraire :

- six enceintes: Balloy, Barbuise et Châtenay en Seine-et-Marne et dans l'Aube (Tresset, 1997) ; Maisons-Alfort dans le Val-de-Marne (Hachem, 2002) ; Gurgy en Bourgogne (Bedault, 2007) ; La Saulsotte dans l'Aube (Hachem, 2015a);

- un habitat avec des bâtiments : Conty « Zac Dunand » dans la Somme (Bostyn et al., 2016),

- une couche à proximité d'un bâtiment monumental : Beaurieux « la Plaine » dans l'Aisne (Hachem, 2010);

- un four à Cuverville «le Clos du Houx » dans le Calvados (Hachem, 2016; Fromont, DFS, 2016) ;

- des fosses isolées : Escalles « le Mont d'Hubert» dans le Pas-de-Calais (Hachem et Chombart, 2014) ; Cuiry-lès-Chaudardes « le Champ Tortu» dans l'Aisne (Colas et al., 2012) ; Vitry-surSeine « Rue du Génie » dans le Val-de-Marne (Hachem, 2015b).

On recense en contexte sépulcral :

- deux nécropoles, celles de Rots et de Fleury-sur-Orne dans le Calvados (Desloges, 1997) ;

- trois monuments funéraires, l'un à Buchères "Parc Logistique de l'Aube » dans l'Aube (Hachem, 2013 ; Riquier et al., 2015), l'autre à Beaurieux « la Plaine » dans l'Aisne (Colas et al., 2008), le troisième à Cuverville « le Clos du Houx » dans le Calvados (Hachem, 2016).

Ces analyses archéozoologiques ont permis de couvrir différents types de contextes dans des régions éloignées et de cerner ainsi différentes facettes de l'économie de ce groupe culturel et de sa gestuelle funéraire. Les enceintes du Bassin parisien révèlent une proportion d'animaux domestiques importante, avec une part dominante réservée aux bovins, des porcs comme seconde ressource carnée et un taux de caprinés insignifiant. Le taux d'animaux chassés est faible et le cerf est le principal gibier. La couche liée au bâtiment monumental de Beaurieux présente les mêmes caractéristiques que les enceintes. Néanmoins, il existe une variabilité dans la proportion ou la composition du gibier, puisque dans l'enceinte de la Saulsotte la proportion d'animaux sauvages est assez importante, ou bien encore dans l'habitat de Conty, la part du cerf est réduite, concurrencée par le sanglier.

Des fosses avec des ensembles particuliers sont par ailleurs recensées. Il s'agit de dépôts d'animaux en connexion, mais dont il manque certaines parties. Ainsi, l'une d'entre elle, située à Vitry-sur-Seine, recelait des os sélectionnés : une dizaine de côtes de cerf entières, avec la partie supérieure d'une ramure de cerf et trois os de caprinés. Une autre fosse a été découverte à Cuiry-lès-Chaudardes; très profonde $(1,70 \mathrm{~m})$, elle contenait un squelette de chevreuil. À Escalles ce sont deux fosses profondes qui ont été découvertes. La première contenait, au fond de la fosse, le squelette d'un jeune chevreuil mâle dont il manquait le train arrière et, dans le remplissage supérieur, deux empaumures de bois de cerf. La seconde contenait, au fond de la structure, un veau presque complet, mais sans connexion anatomique stricte. 
contexte de monuments funéraires, trois sites ont livré de la faune. D'abord celui de Beaurieux dans l'Aisne, une fosse sud du monument I a livré un squelette de renard en connexion anatomique stricte. Ensuite celui de Buchères dans l'Aube, une des deux fosses allongées d'un monument de type Passy (D39) a également livré des dépôts. Il s'agit d'une quarantaine d'ossements sélectionnés, essentiellement des mandibules et des maxillaires de bovins, à l'exception de deux métatarses. Six bovins domestiques sont dénombrés, ainsi que trois porcs et un capriné. À Cuverville dans le Calvados, sept os de bovins domestiques ont été trouvés au fond des fossés, composés de deux mandibules (dont une entière), deux scapulas et deux os de tarses; un os de cerf a également été répertorié.

Concernant les sépultures, une comparaison des tombes 19-5 et 26-5 peut être effectuée avec trois autres tombes qui contenaient des offrandes animales, fouillées par J. Desloges dans les nécropoles de Fleury-sur-Orne et de Rots (fig.11). Aucune étude archéozoologique n'avait été menée sur ces trois tombes, mais des éléments descriptifs ont été rapportés (Desloges, 1997 ; Arbogast et al., 2002). La conservation des ossements est décrite comme mauvaise; il est mentionné qu'il s'agit de squelettes complets de caprinés adultes et que les extrémités des membres (phalanges 3) n'ont pas été retrouvées. Nous sommes retournée au document source pour un examen attentif du relevé des tombes (Desloges, 1997, fig. 4, 5, fig. 6 et fig. 17). Le relevé de terrain montre des mandibules, des maxillaires et des phalanges premières, mais pas de phalanges $3, \mathrm{ni}$ de cheville osseuse (fig. 11). Il nous parait donc vraisemblable que les sabots, comme les bucranes, ont été prélevés, ce qui rejoint les observations faites sur les tombes que nous avons analysées.

Figure 11 : Fleury-sur-Orne «Les Hauts de l'Orne » (Calvados) - A- Nécropole de Rots, sépulture M1$\mathrm{F1}$, inhumé ; B- même sépulture (Rots $\mathrm{M1}-\mathrm{F} 1$ ) avec la répartition de la faune ; $\mathrm{C}$ - Rots, sépulture M2F2 ; D- Fleury-sur-Orne sépulture du Monument 1, d'après Desloges 1997.

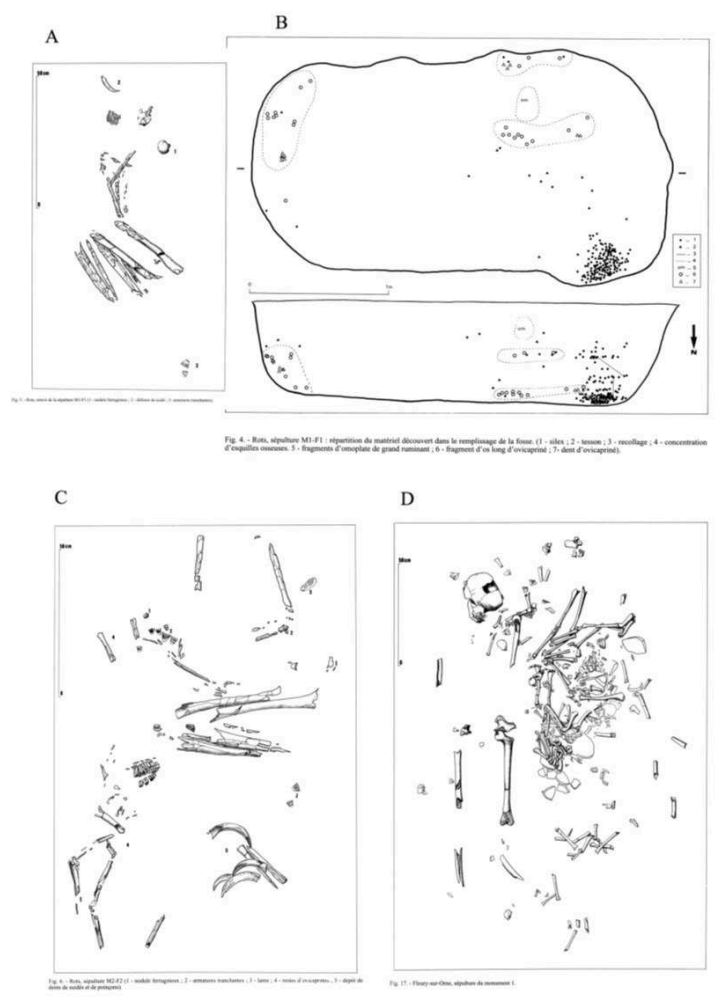



mention que la tombe du monument 1 (M1-F1) de Fleury-sur-Orne contenait cinq caprinés entassés du côté gauche du squelette humain dont ils étaient séparés par une ligne rectiligne qui évoque un effet de paroi, sauf dans la partie haute du squelette qui recouvrait en partie l'avant-train d'un animal (fig. 11). On retrouve là les mêmes éléments que dans la tombe 26-5, avec une accumulation des animaux sur un bord de la fosse et un aménagement autour du défunt.

41 À Rots, dans la tombe du monument 1 (M1-F1), des os longs de caprinés laissent supposer la présence d'au moins deux individus disposés du côté sud, vers la partie supérieure du corps de l'inhumé, ainsi que vers l'extrémité est de la fosse, c'est-à-dire à ses pieds (fig. 11). De plus, il est fait mention d'une présence de « fragments d'omoplate de grand ruminant » au sud-ouest, proche de la tête du défunt, qui rappelle le dépôt de scapulas de bovins dans les tombes 19-5 et 26-5 de Fleury-sur-Orne. Toujours à Rots, la tombe du monument 2 (M2-F2), contenait deux caprinés qui ont été découverts dans le fond de la fosse, aux pieds du défunt, côté sud-est. Le positionnement des offrandes dans les tombes M1-F1 et M2-F2 de Rots est donc similaire à celui de la tombe 19-5 de Fleury-sur-Orne que nous avons étudiée. Enfin, une information concernant de la faune trouvée dans un monument nous paraît importante. Ainsi, une mandibule de bovin a été retrouvée dans le remplissage du fossé du monument 2 de Rots (Desloges, 1997). documents publiés sans qu'il n'y ait eu d'étude archéozoologique, toutes ces ressemblances nous paraissent assez pertinentes pour envisager l'existence de pratiques funéraires identiques. La seule différence que nous avons relevée en l'état actuel de la documentation est l'absence à Fleury-sur-Orne de parure en défenses de suiné et de poinçons en os, mobilier retrouvé dans les deux sépultures de Rots (fig. 11).

Ces informations sur les aspects économiques et cultuels permettent de dégager des tendances structurelles. Ainsi, en ce qui concerne l'alimentation, on notera, malgré une variabilité certaine, des points communs aux sites livrant des rejets de consommation domestique tels que le site d'habitat et, dans une certaine mesure, les enceintes ainsi que la couche attenante au bâtiment monumental. On notera la prédominance de l'élevage sur la chasse, la proportion de bovins supérieure à celle des autres animaux, l'absence des caprinés comme des chevreuils et l'importance du porc. La place qu'occupe ce dernier s'inscrit d'ailleurs dans une tendance amorcée dès la phase moyenne du Blicquy-Villeneuve-Saint-Germain (Bedault, 2012; Bedault et Hachem, 2008) qui perdure durant tout le Néolithique moyen (Hachem, 2011).

Pour ce qui est des fosses contenant des ensembles particuliers, les espèces représentées sont peu nombreuses, il s'agit du chevreuil, du cerf et du bovin domestique. On peut poser l'hypothèse que le chevreuil, absent des rejets de consomation courante, a un statut particulier puisqu'il est à l'inverse présent dans ces structures. De même, le cerf, peut représenter dans les rejets est mis en avant par la présence de bois ou d'os en partie supérieure des fosses.

Concernant les sépultures, les espèces représentées sont aussi sélectionnées, en premier lieu les moutons, qui participent peu à l'alimentation courante, mais aussi les bovins domestiques. À Fleury-sur-Orne, les caprinés et les bovins sont traités différemment selon qu'ils soient à l'intérieur des tombes ou entre les sépultures et les fossés des monuments. Il nous parait évident au vu des éléments précédemment relevés que la même chose se produit à Rots. Dans les tombes, les moutons sont les animaux 
primordiaux, qui accompagnent le défunt ; on les dépose entiers, sans les consommer, en considérant leurs cornes et leurs toisons comme des trophées à conserver hors de la tombe. Les bovins sont au contraire mangés et seulement représentés au travers de supports qui nous paraissent devoir être reconnus pour leur portée symbolique comme les chevilles osseuses, les métapodes ou les scapulas.

La scapula de bovin joue un rôle important dans les pratiques funéraires Cerny, puisqu'on la retrouve, avec un positionnement près de la tête du défunt dans les tombes 19-5 et 26-5 de Fleury-sur-Orne, comme dans la tombe M1-F1 de la nécropole de Rots. Ce caractère symbolique est renforcé par le fait que les scapulas se retrouvent systématiquement déposées dans les fossés des monuments funéraires de Fleury-surOrne, ainsi que dans le monument de Cuverville. Dans ces derniers, ce sont les bovins qui sont les animaux fondamentaux et non pas les moutons. Les scapulas (en particulier de taureau) y sont déposées, souvent en tant qu'unique élément osseux, c'est un élément qui a une forte résonance symbolique, tout comme les mandibules et les côtes dès le début du Néolithique anatolien (Marciniak, 2008).

D'autres parties anatomiques de bovins ont aussi leur importance. Ainsi, l'extrémité occidentale du monument $n^{\circ} 4$ présente un assemblage particulier sous la forme de plusieurs maxillaires de bovins. On peut se demander pourquoi le reste du crâne (occipitaux, frontaux), les chevilles osseuses et les mandibules sont absents. Peut-être s'agit-il de témoins d'une préparation de bucranes? Les comparaisons avec d'autres sites sont rares, probablement en raison du biais induit par la fouille très partielle des fossés des monuments Cerny qui limite la découverte de restes osseux éventuels. Néanmoins, elles existent si l'on prend en considération les éléments crâniens au sens large. Ainsi, dans le Calvados, il est mentionné qu'une mandibule de bovin a été retrouvée dans le remplissage du fossé d'un des monuments de Rots (Desloges, 1997). À Cuverville, deux mandibules, dont une entière, ont été recueillies dans le fossé du monument (Hachem, 2016). De nombreux éléments crâniens sont également mentionnés dans les sites d'Ernes, d'Orville et de Saint-Sylvain (Fromont et al., 2009). En Seine-et-Marne, dans le site de Balloy (Seine-et-Marne), un fragment de crâne de bovin a été découvert à l'extrémité nord-orientale du monument V (Mordant, 1997). Enfin, en Champagne, sur le site de Buchères, les mandibules et maxillaires de six bovins ont été déposés au fond de la fosse d'un monument (Hachem, 2013). Tous ces restes crâniens devaient avoir une portée symbolique comme en témoigne, dans l'enceinte Cerny de Balloy, le dépôt de trois hémi-mandibules de bovins (deux d'un adulte et une-demi d'un veau) assemblées de manière à dessiner des cornes, le tout couvrant plusieurs ossements de bovins et quatre vases entiers (Mordant, 1992 ; Tresset, 1996, fig. 26). La présence de trois hémi-mandibules de bovins à peu de distance les unes des autres au pied du parement oriental du monument 29 de Fleury-sur-Orne évoque des pratiques similaires (Hachem étude en cours).

\section{Conclusion}

Les tombes 19-5 et 26-5 de Fleury-sur-Orne sont spectaculaires par les offrandes animales qu'elles contiennent et l'aménagement de ces dépôts en relation avec le défunt. Huit moutons, dont 3 béliers et 4 brebis, ont été déposés en offrande dans la tombe 19-5, sur le côté gauche et au pied du défunt, les mâles lui faisant face, les femelles lui étant opposées. Dans la tombe 26-5, ce sont douze moutons qui ont été 
déposés, en majorité du côté nord. Le mauvais état de conservation des os ne permet pas de dire si tous les squelettes étaient complets, mais de fortes présomptions le laissent supposer. Néanmoins, deux types de parties anatomiques sont manquants car volontairement prélevées : les bucranes avec les cornes et les phalanges.

On soulignera la portée des informations jusque-là inconnues sur les pratiques funéraires telles que les permettent les analyses archéozoologiques sur des tombes et des monuments Cerny. Ainsi, deux animaux domestiques apparaissent centraux dans le rituel funéraire : le mouton et le bovin, qui ne sont pas intégrés de la même manière au rituel puisqu'ils sont mis en opposition.

50 S'ils sont absents des fossés des monuments funéraires, les moutons sont à l'inverse déposés dans les tombes de manière ostentatoire (doublé d'une certaine mise en scène interne). Brebis et béliers sont nombreux à avoir été sacrifiés, accumulés les uns sur les autres sur un des côtés de la fosse sépulcrale, ou encore posés aux pieds du défunt ou face à lui. Ils n'ont pas été consommés alors que la masse de viande qu'ils représentaient est importante ; enfin on a prélevé leurs cornes ainsi que leur peau et l'on peut envisager que cette pratique a été faite dans le but d'exposer leur toison à l'extérieur de la tombe.

51 Inversement, les bovins sont présents dans les fossés des monuments comme dans les tombes, mais de façon discrète, ce qui n'enlève rien à leur statut symbolique. Ils ne sont visibles qu'au travers des os sélectionnés, par exemple des scapulas, des mâchoires ou des chevilles osseuses de taureau ou de vache. Ces ossements sont la plupart du temps isolés, placés dans les tombes de préférence à la tête du défunt, symétriquement aux dépôts de moutons; ou encore déposés de manière relativement espacée, dans les fossés des monuments funéraires. Leur déconnexion du reste de la carcasse laisse envisager indirectement la consommation des viandes.

Les sacrifices que ces rituels néolithiques induisent sont fréquents dans les sociétés à tradition orale et sont un moyen de communiquer avec le sacré par l'intermédiaire d'une victime (Huber et Mauss, 1899). Cependant, il est rare d'en trouver des preuves archéologiques, et la nécropole de Fleury-sur-Orne, dans laquelle de nombreux moutons ont été déposés, nous offre la possibilité d'étudier cette situation. L'intégration des caprinés et des bovins à une cérémonie funéraire rappelle celle que l'on observe dans un site contemporain de Trebur en Allemagne, où des quartiers de viande ont été déposés dans les tombes Hinkelstein et Grossgartach (Spatz, 1997 ; Spatz et Driesch, 2001). On pourra trouver un élément de comparaison également avec la sépulture de Buthiers-Boulancourt, attribuée à une phase récente du BlicquyVilleneuve-Saint-Germain, où un homme a été inhumé avec un jeune capriné entier à ses pieds et d'autres mobiliers dont une imitation de hache polie, très valorisée socialement (Samzun et al., 2012).

53 Cela rappelle également un site néolithique plus ancien, l'enceinte cérémonielle de Menneville dans l'Aisne, datée du Rubané, où des défunts (en particulier des enfants) et des animaux domestiques ont été associés (Farruggia et al., 1996; Thevenet, 2015). Comme à Fleury-sur-Orne, les moutons sont entiers ou en connexion partielle, alors que les bovins sont représentés par des os isolés : bucranes commémoratifs au-dessus d'inhumations multiples, chevilles osseuses ou autres éléments particuliers du squelette placés près des corps des défunts ou isolément. L'interprétation que nous avions alors proposée, pour cette opposition entre mouton et bœuf, était de considérer les quartiers de moutons comme des offrandes et les os de bovins comme des reliefs de 
repas funéraire, déposés lors des inhumations des défunts (Hachem in Farruggia et al., 1996, p. 166). Cette hypothèse nous paraît également pouvoir s'appliquer au cas des nécropoles de Fleury-sur-Orne et de Rots, en intégrant la dimension symbolique du support osseux, comme l'incarnent la scapula ou les éléments crâniens de bovins.

L'étude de ces restes animaux dans le rituel funéraire et la façon dont ils ont été assemblés laisse deviner leur statut et le rôle important qu'ils jouaient dans les sociétés néolithiques.

«Toute société élabore des représentations mentales: un ensemble d'idées et de valeurs propres à elle-même. Ces faits culturels ne sont pas seulement juxtaposés, ils forment des systèmes, des représentations collectives. Les classifications des espèces naturelles et des groupes sociaux, l'organisation symbolique de l'espace et les représentations du corps sont conçues comme des éléments interdépendants d'une représentation culturelle du monde. » (Boyer, 1991)

Grâce à ces offrandes animales, il est donc possible d'accéder un tant soit peu aux représentations mentales de la société du Cerny où l'on perçoit que l'animal est un élément à part entière du système social.

\section{BIBLIOGRAPHIE}

ARBOGAST R-M., DESLOGES J. et CHANCEREL A. 2002, « Sauvages et domestiques : les restes animaux dans les sépultures monumentales normandes du Néolithique » Anthropozoologica, vol. 35, p. 17-27.

BALASSE M. et AMBROSE S. 2005, « Distinguishing sheep and goats using dental morphology and stable carbon isotopes in C14 grassland environments ", Journal of Archaeological Science, vol. 32, p. 691-702.

BEDAULT L. 2007, « La faune Cerny de l'enceinte de Gurgy « le Nauzeau » dans le site de Gurgy », dans MEUNier K., CROUTSCH C., BelLini C., BonNARdin S., CARY S., CHAMBOND Ph., CHAUSSÉE Ch., CONVERTINI F., COUBRAY S., HUMBERT L., HAMON C., LABEAUNE R., LEGROS V., PARIAT J-G., PUTELAT O., RAVOIRE F. et SALANOVA L., rapport final de synthèse, SRA dîle-de-France.

BEDAULT L. 2012, « L'exploitation des ressources animales dans la société du Néolithique ancien du Villeneuve-Saint-Germain (4950 - 4650 BC.) en Bassin Parisien : synthèse et approche structurelle des données archéozoologiques », Doctorat de l'Université Paris 1, Panthéon-Sorbonne, Préhistoire-Ethnologie-Anthropologie, 2 vol. Archives HAL.

BEDAULT L. et HACHEM L. 2008, « Recherches sur les sociétés du Néolithique danubien à partir du Bassin parisien : approche structurelle des données archéozoologiques », dans BURNEZ-LANOTTE L., ILETT M. et P. ALLARD (dir.), Fin des traditions danubiennes dans le Néolithique du Bassin parisien et de la Belgique (5100-4700 BC.), Namur, 24 au 25 novembre 2006, Mémoire XLIV de la Société préhistorique française, Paris, p. 222-243.

BOESSNECK J. 1969, « Osteological differences between sheep (Ovis arie Linné) and goat (Capra hircus Linné) », dans BROTHWELL D. et HIGGS H.-S., (dir.), Science in Archaeology, $2^{\mathrm{e}}$ edition, London, p. 331-358. 
BOSTYN F., HACHEM L., JOSEPH F., HAMON C. et MAIGROT Y. 2016, « L'apport du site d'habitat de Conty «Zac Dunant » (Somme) à la connaissance de la culture Cerny », Bulletin de la Société Préhistorique Française, vol. 113, n² 2, p. 291-332.

BOYER P. 1991, « Système de représentation », dans BONTE P. et IZARD M. (dir.) Dictionnaire de l'ethnologie et de l'anthropologie, Paris, PUF, p. 626-627

CHANCEREL A., KINNES I., LAGNEL E. et KIRK T. 1992, « Le tumulus néolithique de la Commune Sèche à Colombiers-sur-Seulles (Calvados), Paysans et Bâtisseurs : l'émergence du Néolithique atlantique et les origines du mégalithisme ", actes du $17^{\text {ème }}$ colloque Interrégional sur le Néolithique, Vannes, 29 au 31 octobre 1990, p. 17-29 (Revue Archéologique de l'Ouest, supplément 5).

COLAS C. (dir.), THEVENET C., MANOLAKAKIS L., MAIGROT Y., AUXIETTE G., CHARTIER M., 2008, « BeaurieuxCuiry-lès-Chaudardes « la Plaine », Rapport de fouilles, Inrap Nord-Picardie, 2 vol.

colas C. (dir.), Le Guen P., Manolakakis L., NAZE Y., theVenet C., 2012, « Cuiry-lès-Chaudardes « le Champ Tortu », Rapport de fouilles, Inrap Nord-Picardie, 2 vol.

DESLOGES J. 1997, « Les premières architectures funéraires de Basse-Normandie », dans CONSTANTIN C., MORDANT D. et SIMONIN D. (dir.), La Culture de Cerny, nouvelle économie, nouvelle société au Néolithique, actes du colloque international de Nemours, 1994, Nemours, APRAIF p. 515-539 (Mémoires du musée de Préhistoire d'île-de-France 6).

FARRUGGIA J.-P., GUICHARD Y. et HACHEM L. 1996, « Les ensembles funéraires rubanés de Menneville "Derrière le Village" (Aisne) », dans DUHAMEL P. (dir), La Bourgogne entre les Bassins rhénan, rhodanien et parisien : carrefour ou frontière?, actes du $18^{\text {ème }}$ colloque Interrégional sur le Néolithique, Dijon, 25-27 oct. 1991, p. 119-174 (Revue Archéologique de l'Ouest, supplément 14).

FERNANDEZ H. 2001, «Ostéologie comparée des petits ruminants eurasiatiques sauvages et domestiques (genres Rubicapra, Ovis, Capra et Capreolus) : diagnose différentielle du squelette appendiculaire ", thèse de doctorat, Université de Genève, Département de zoologie et de biologie animale, 2 vol.

FLotTÉ D. 2000a, « Ifs Zac du Hoguet 14341027 AP et 14341051 », DFS de diagnostic archéologique, Caen, SRA de Basse-Normandie.

FLOTTÉ D. 2000b, « Ifs Zac du Hoguet 14341027 AP ». DFS de sauvetage urgent, Caen, SRA de BasseNormandie.

FLOTTÉ D. 2013, «Fleury-sur-Orne, Calvados “Les Hauts de l'Orne” », rapport final d'opération de diagnostic Inrap.

FROMONT N. (dir.), GERMAIN-VALLÉE C., CHARRAUD F., ARBOGAST R-M., MAIGROT Y., BONHOMME F., THIRON D., OEIL DE SALEY S., SÉHIER E., HUGOT C., KOCH N., COUTARD S. et BESNARD M., 2009, « Saint-Sylvain "Rue Vilaine/Chemin rural d'Argences" (Calvados)», rapport final d'opération, Inrap, 2 vol.

GREENFIELD H.-J. et ARNOLD E., 2007, « Absolute age and tooth eruption and wear sequences in immature sheep and goat: determining age-at-death in zooarchaeology using a modern control sample », Journal of Archaeological Science, vol. 35, p. 836-849.

HACHEM L. 2002, « La faune du site Néolithique moyen de Maisons-Alfort « Zac d'Alfort » (Val-deMarne) », dans COTTIAUX R. (dir.), Maisons-alfort ZAC d'Alfort (Val-de-Marne), sauvetages urgents 1998-2001, Document Final de Synthèse, Inrap Saint-Denis.

HACHEM L. 2010, « La faune », dans COLAS C. (dir), Un bâtiment monumental exceptionnel, Beaurieux « la Plaine ", Aisne, rapport final d'opération, Inrap, Nord-picardie, p. 75-78. 
HACHEM L. 2011, « Les faunes du Néolithique moyen dans le nord de la France : bilan et pistes de recherches ", dans BOSTYN F., MARTIAL E., PRAUD I. (dir.) Le Néolithique du Nord de la France dans son contexte européen : habitat et économie au IV ème et III İme millénaire avant notre ère, actes du $29^{\text {ème }}$ colloque Interrégional sur le Néolithique, 2 au 3 octobre 2009, Villeneuve-d'Ascq (France), p. 313-328 (Revue Archéologique de Picardie, supplément 28).

HACHEM L. 2013, « La faune Rubanée et Cerny de Buchères "Parc Logistique de l'Aube" ", dans PARESYS C. (dir.), Rapport final d'opération, responsable d'opération, Inrap. Champagne-Ardenne. HACHEM 2015a, « La faune Cerny de La Saulsotte », dans PEAKE R. (dir.) Rapport final d'opération, Inrap Centre-Ile-de-France.

HACHEM L. 2015b, « La faune et l'industrie osseuse », dans DURAND S. (dir.), Vitry-sur-Seine, Côteau Malassis, lot $n^{\circ}$ 1, Côteau Malassis 93 et 108 rue du Génie, site du Côteau Malassis, lots $n^{\circ} 3$ et 7, Rapport de diagnostic, Inrap Ile-de-France, p. 55-58.

HACHEM L. 2016, « La faune », dans Fromont N. (dir), « Le Clos du Houx » : un monument funéraire prémégalithique du Néolithique moyen dans la Plaine de Caen, Cuverville, Normandie, Calvados, Rapport de fouille préventive, Inrap Grand-Ouest, p. 174-175.

HACHEM L., GUICHARD Y., FARRUGGiA J.-P., DUBOUlOZ J. et ILETT M. 1998, « Enclosure and Burial in the earliest Neolithic of the Aisne Valley » dans EDMONDS M. et RICHARDS (dir.), Social Life and Social Change: the Neolithic Western Europe, Glasgow, Cruithne Press, p. 127-140.

HACHEM L. et CHOMBART J., avec la collab. LEDUC C., 2014, «Étude de la faune sauvage et domestique du Néolithique », dans PRAUD I. (dir.), Une enceinte du Néolithique moyen II, des fosses du Néolithique moyen I et du Bronze final sur le littoral de la Mer du Nord. Escalles " Mont d'Hubert », Nord-pas-de-Calais, Rapport de fouille préventive, Inrap, p. 163-214.

HACHEM L., BEDAULT L. et LEDUC C. 2016, « L'élevage et la chasse au Chasséen septentrional : renouvellement des connaissances d'après l'étude des enceintes de Villers-Carbonnel (Somme) et de Passel (Oise) ", dans PERRIN T., CHAMBON P., GUIBAJA J. et GOUDE G. (dir.), Le Chasséen, des Chasséens. Retour sur une culture nationale et ses parallèles, Sepulcres de fossa, Cortaillod, Lagozza, actes du colloque International, Paris 18-20 nov. 2014, Toulouse, Archives d'Écologie Préhistorique, p. 241-258.

HUBERT H. et MAUSS M. 1899, Essai sur la nature et la fonction du sacrifice, repris dans MAUSS M., Æuvres, Paris, éditions de Minuit 1968.

JONES G.-G. 2006, « Tooth eruption and wear observed in live sheep from Buster Hill, the Cotswold Farm Park an five farms in the Pentland Hills, UK », dans RUSCILLo D. (dir.), Recent Advances in Ageing and sexing Animal Bones, 9th ICAZ Conference, Durham 2002, Oxford, Oxbow Books, p. 155-178.

JONES G.-G. et SADLER P., 2012, « Age at death in cattle: methods, older cattle and known-age reference material », Environmental Archaeology, vol. 17, p. 11-28.

MARCINIAK A. 2008, «Communities, households and animals. Convergent developments in Central Anatolian and Central European Neolithic », Documenta Praehistorica, vol 35, p. 93-109.

MORDANT D. (dir.) 1992, La Bassée avant l'histoire : archéologie et gravières en petite-Seine, Nemours, Association pour la promotion de la Recherche archéologique en Ile-de-France.

MORDANT D. 1997, « Le complexe des Réaudins à Balloy enceinte et nécropole monumentale », dans C. CONSTANTIN, D. MORDANT et SIMONIN D. (dir.), La Culture de Cerny, nouvelle économie, nouvelle 
société au Néolithique, actes du colloque international de Nemours, 1994, Nemours, APRAIF, p. 449-479 (Mémoires du musée de Préhistoire d'île-de-France 6).

PAYNE S. 1973, « Kill-off Patterns in Sheep and Goats: the Mandibles from Asvian Kale », Anatolian Studies, vol. 23, p 281-303.

POPLIN F. 1976, «À propos du nombre de restes et du nombre d'individus dans les échantillons d'ossements », Cahiers du Centre de Recherches Préhistoriques, vol. 5, p. 61-74.

RIQUIER V. PARESYS C. et MEUNIER K. 2015, « Buchères, Parc Logistique de l'Aube : nouvelles données sur l'occupation du sol du Néolithique ancien au Néolithique final », dans Occupations et exploitations néolithiques : et si l'on parlait des plateaux? Actes du $31^{\text {ème }}$ colloque Internéo, 17-19 oct. 2013, Châlons-en-Champagne, Internéo et Société Préhistorique Française, p. 169-188.

SAMZUN A., PÉTREQUIN P. et GAUTHIER I. 2012, « Une imitation de hache alpine type Bégude à Buthiers-Boulancourt (Seine-et-Marne) au début du V $V^{\mathrm{e}}$ millénaire », dans De LABRIFFE P.A. et THIRAULT E., Produire des haches au Néolithique : de la matière première à l'abandon, actes de la table ronde de Saint-Germain-en-Laye, 7 au 16 mars 2007, musée d'Archéologie Nationale, Paris, Société Préhistorique Française, p. 219-234.

SPATZ H. 1997, « La nécropole du Néolithique moyen (Hinkelstein, Grossgartach) de trebur (GrossGerau, Hesse) ", dans Le Néolithique danubien et ses marges entre Rhin et Seine, actes du $22^{\mathrm{e}}$ colloque Interégional sur le Néolithique, Strasbourg, 27 au 29 octobre 1996, p. 157-170 (Supplément aux Cahiers pour la Promotion de la Recherche Archéologique en Alsace).

SPATZ H. et DRIESCH A. VON DEN 2001, « Zu den tierischenBeigaben aus dem Hinkelsteiner aund Grossgartacher Gräberfeld von Trebur, Kr. Gross-Gerau (Hesse) » in ARBOGAST R.-M., JEUNESSE C. et SCHLIBER J. (dir.), Rôle et statut de la chasse dans le Néolithique ancien danubien (5500-4900 av. J.C.), Premières rencontres danubiennes, actes de la table ronde de Strasbourg, 20 au 21 novembre 1996, International Archäologie, Arbeitsgemeimschaft Symposium Tagung Kongress 1, Verlag Marie Leidorf GmbH, Rahden/Westf., p. 113-128.

TEICHERT, M., 1975, « Osteometrische Untersuchungen zur Berechnung der Widerristhöhe bei Schafen », dans CLASON A. T. (dir.), Archaeozoological studies, North-Holland/American Elsevier, Amsterdam, p. 51-69.

THEVENET C. 2015, « The final Linear Pottery Culture Enclosure at Menneville, Dep. Aisne, France : a complex ceremonial site », dans Salzmünde. Regel oder Ausnahme?, International Tagung in Halle (Saale), 18 au 20 octobre 2012, Tagungen des Landesmuseums für Vorgeschichte Halle, Band 13.

THOMAS A. 2011, « Identités funéraires, variants biologiques et facteurs chronologiques : une nouvelle perception du contexte culturel et social du Cerny (Bassin parisien, 4700-4300 avant J.C. », thèse de doctorat, université Bordeaux 1.

TRESSET A. 1996, « Le rôle des relations homme/animal dans l'évolution économique et culturelle des sociétés des $\mathrm{V}^{\mathrm{e} m e}$ et $\mathrm{VI}^{\mathrm{e}}$ millénaires en Bassin Parisien : Approche éthno-zootechnique fondée sur les ossements animaux ", thèse de doctorat, Anthropologie-Ethnologie-Préhistoire, Université de Paris I - Panthéon-Sorbonne.

TRESSET A. 1997, «L'approvisionnement carné Cerny dans le contexte du Néolithique du Bassin Parisien », dans CONSTANTIN C., MORDANT D. et SIMONIN D. (dir.), La culture de Cerny : Nouvelle économie, nouvelle société au Néolithique, actes du colloque international de Nemours, 9 au 11 mai 1994, Paris, Association pour la Promotion de la Recherche Archéologique en Ile-de-France, p. 299-314. 
ZEDER M.-A. et LAPHAM H.-A. 2010, « Assessing the reliability of criteria used to identify postcranial bones in sheep, Ovis, and goats, Capra ", Journal of Archaeological Science, vol. 37, p. 2887-2905.

\section{NOTES}

1. Le Nombre Minimal d'Individus a été calculé en employant le NMI de combinaison (NMIc, Poplin, 1976), qui prend en compte les âges, les tailles et les sexes des animaux.

2. Le NMI employé est celui de combinaison (NMIc, Poplin, 1976), qui prend en compte les âges, les tailles et les sexes des animaux.

3. Pour preuve, les observations faites sur le terrain : les os situés en hauteur étaient cassés, une partie de leur diaphyse avait disparu. A l'inverse, une quarantaine de centimètres plus bas, les os étaient bien mieux conservés et les connexions bien visibles.

4. Le NMI de fréquence (NMIf) se base sur l'élément anatomique le plus fréquent situé sur un même côté du squelette (droit ou gauche).

\section{RÉSUMÉS}

La nécropole de Fleury-sur-Orne «Les Hauts de l'Orne » a livré 26 monuments de type Passy, un dolmen, un cairn (déjà fouillé) et trois alignements de mégalithes/mégaxyles lors de deux opérations de fouille en 2014 et 2016. Le début de l'occupation du site commence vers 4700 cal BC, au Néolithique moyen I (Cerny-Videlles), continue au Néolithique moyen II et se termine vers 3900 cal BC. Parmi les 20 tombes individuelles fouillées, quatre contenaient des associations incontestables de faune en connexion. L'article concerne plus particulièrement ici les dépôts animaux de deux tombes Cerny, l'une d'entre elle contenant huit moutons, l'autre douze. La plupart des animaux sont complets, à l'exception des bucranes et les sabots, prélevés volontairement. Des os de bovins domestiques ont également été déposés dans ces tombes, en particulier des scapulas isolées non loin de la tête de chaque défunt. La comparaison avec une tombe anciennement fouillée à Fleury-sur-Orne et deux autres à Rots montre des similitudes dans les gestes funéraires et le positionnement des offrandes animales. Les fossés des monuments funéraires ont aussi livré de la faune. Il s'agit d'ossements de bovins, principalement des scapulas et des restes crâniens. L'ensemble de ces résultats montre l'importance de l'animal au sein du système social néolithique.

\section{AUTEURS}

\section{EMMANUEL GHESQUIÈRE}

Inrap, UMR $6566 \mathrm{CReAAH}$

\section{LAMYS HACHEM}

Inrap, UMR 8215 « Trajectoires » 
Homme Vs animal : une même intention cultuelle dans les dépôts domestiques du second Âge du Fer dans le Bassin Parisien?

\author{
Valérie Delattre et Ginette Auxiette
}

\title{
L'amorce d'une réflexion pluridisciplinaire : pour en finir avec la « sépulture de relégation » laténienne
}

\section{Des silos et des humains : la lecture d'un geste récurrent}

1 Le point d'ancrage de cette réflexion, visant à associer certains humains et animaux au sein d'une même pratique cultuelle laténienne, est la proposition amorcée dans les années 1980, de la lecture d'une forme de relégation sociale, lisible grâce aux structures de stockage et aux dépôts atypiques - hors contexte détritique - qu'elles contiennent parfois.

2 Reconnus et étudiés, mis au jour en nombre considérable lors des grandes opérations de décapages préventifs réalisées depuis 30 ans dans le Bassin parisien (Delattre, 2010), ces silos délaissés peuvent livrer des squelettes humains - défunts volontairement exclus des nécropoles communautaires - dont l'éloignement funéraire est longtemps resté d'interprétation controversée : parfois adossé à la sphère sociale et hiérarchique (relégation de sujets de rangs inférieurs, parfois même d'esclaves), ce geste est désormais associé à l'inventaire foisonnant des comportements cultuels domestiques de l'âge du Fer.

3 Dans son texte fondateur, recensant notamment de nombreux cas champenois, A. Villes proposait ce terme de "sépulture de relégation", vocabulaire certes d'attente mais communément adopté, privilégiant, de fait, la marginalisation de certains défunts écartés du groupe dans la mort (fig. 1, Villes, 1987). L'expression, fondée sur une 
démonstration détaillée et un solide corpus, s'articulait autour de deux postulats : l'incongruité de cette présence humaine au sein de fosses domestiques délaissées et les circonstances, jugées forcément suspectes, de la mort de ces « relégués ».

4 Le rejet supposé injurieux dans des silos, la fréquence des postures incongrues des squelettes mis au jour, sans lien avec les agencements funéraires contemporains observés dans les nécropoles, relayés, comme le démontrait J.-L. Brunaux par les sources antiques qui invitent à " une lecture forcément barbare des us et coutumes des peuples voisins des mondes grec et romain », ont conforté cette hypothèse de quelques "pratiques de sacrifices humains ", dont l'exclusion en silo serait l'une des expressions archéologiquement accessibles (Brunaux 2005, p. 256).

De plus, ce postulat se renforçait régulièrement par la mise au jour de têtes dites " coupées », de fragments de corps humains dispersés dans toutes formes de structures, par l'observation d'impacts violents sur des os et la restitution de mises en scène humaines guerrières et macabres, comme cela a été proposé pour le sanctuaire de Ribemont-sur-Ancre en Picardie (Thiol, 2002). Ces découvertes ne pouvaient que caractériser des pratiques forcément sacrificielles!

Mais, si au second âge du Fer, les communautés ont peut-être eu recours à l'offrande humaine pour apaiser ou remercier les dieux, le sacrifice n'y a jamais été envisagé comme une pratique religieuse habituelle, récurrente et codifiée à l'instar d'autres peuples, tels les Mayas, clairement attachés à ce rituel (Johansson, 2005). Dès lors, comment décrypter raisonnablement ces gestes variés ayant l'humain et l'animal comme fil conducteur, sans surinvestir l'observation?

Figure 1 : exemple de dépôt humain individuel en silo laténien à Varennes-sur-Seine "Volstin » (Seine-et-Marne) (cliché O. Maury, Inrap).

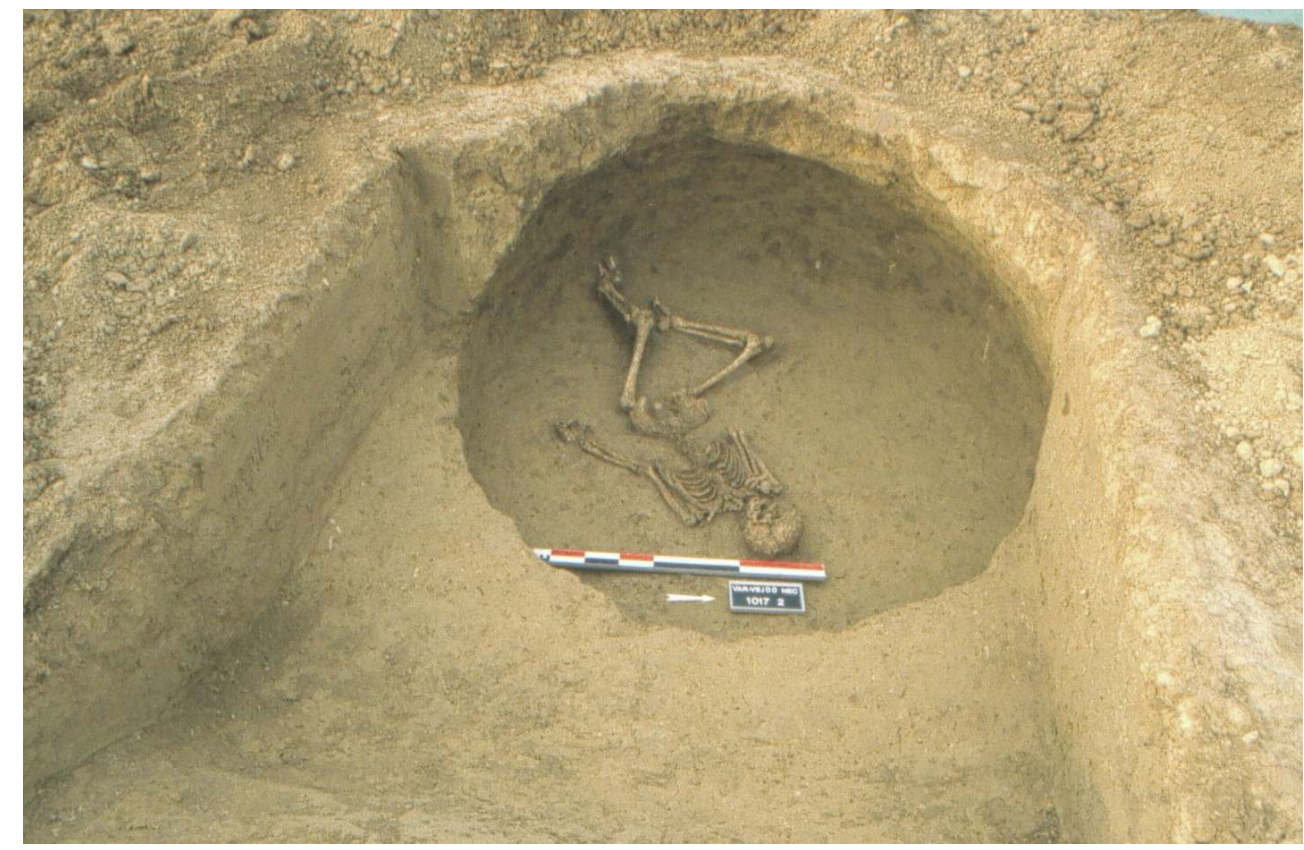

\section{Une proposition d'interprétation : une grille de lecture novatrice}

7 Exploitant pour partie les observations déjà effectuées sur le vaste site anglais de Danebury (Cunliffe, 1992), le questionnement amorcé depuis plus de 20 ans, s'est 
enrichi de nouvelles propositions, suggérant non plus un rejet de certains défunts en silo, mais leur participation codifiée à l'élaboration d'offrandes souterraines, via un séjour, définitif ou temporaire, dans une structure de stockage (Delattre et al., 2000). Bien que favorablement adoptée par la communauté scientifique et étoffée de spécificités régionales, cette partition valorisante des défunts demeure parfois assimilée à un déni péjoratif, relayant toujours l'idée d'une inhumation injurieuse de populations inférieures ne pouvant pas prétendre à une sépulture décente (Brunaux, 2006). L'option cultuelle est encore fréquemment oubliée ou volontairement niée (Brunaux 2005, p. 259) et le nécessaire débat se voit également dépossédé de sa lecture plurielle: ces associations de silos et d'humains devraient être privées de leur double caractéristique funéraire - respect et protection des corps - et cultuelle - constitution d'offrandes souterraines -, l'une devant forcément exclure l'autre (Testard, 2009).

Quoi qu'il en soit, les communautés celtiques paraissent évoluer aisément au sein de toutes leurs sphères: le domestique accueille le cultuel et le funéraire, le cultuel s'inscrit dans le funéraire, le funéraire reçoit le cultuel.

L'objection majeure à cette idée d'une relégation sociale reste que les défunts mis au jour dans les silos, et au vu de certains mobiliers qui leur sont associés, n'appartenaient évidemment pas à des populations pouvant être qualifiées d'« inférieures " (cf. supra) : les fibules et bagues de Bourges "Chemin de Gionne» (Cher) (Delattre et al., 2000), le torque du silo de la Neuville-aux-Bois «La Grande Route» (Loiret) (Josset, 2009) témoignent, s'il le fallait, que ces défunts n'ont pas, non plus, été dépouillés avant leur dépôt. Il est toutefois notable que l'activité guerrière, prégnante dans les tombes contemporaines, ne s'exprime guère à travers cette intention.

En tout état de cause et bien avant leur exaltation publique dans les grands sanctuaires communautaires à La Tène finale, s'instaure une règlementation de diverses gestuelles, qui laisse aussi le champ libre à des adaptations collectives et privées. Se met en place une sélection d'offrandes humaines, que ces groupes paysans soustraient au traditionnel monde des morts, dont ils se privent pour mieux les offrir à des divinités souterraines, via l'action de ces fosses-intercesseurs que sont les silos. Ces passages, originellement dédiés à la conservation des grains et semences, ainsi alimentés par la chair en décomposition, favorisent la communication entre les hommes et le monde souterrain :

«Un savant protocole s'installe, magnifiant la vie et la mort, la décomposition et la permanence, visant sans doute à obtenir par une gestion des dons de fertiles et durables récoltes » (Delattre 2013, p. 496).

\section{Des humains, des mobiliers spécifiques... et des animaux pour une même pratique}

11 Le dépôt humain en silo semble donc être l'expression d'un rite d'enfouissement de certains cadavres, exprimant une intention propitiatoire et/ou expiatoire se déroulant au sein de la sphère domestique et non dans un lieu dédié (Delattre et al., 2000). Mais outre l'humain, majoritaire et récurrent, il convient aussi de lister d'autres types de vestiges-offrandes, souvent réunis en des assemblages associant de la vaisselle en céramique, du mobilier métallique ou des animaux. 
animaux et divers objets, met en exergue des combinaisons de dépôts complets et massifs et des ajouts très symboliques de type pars pro toto. Bien sûr, ne sont pas considérés ici comme des dépôts stricto sensu, se cumulant aux humains et aux animaux, les éléments accompagnant directement le défunt comme ses accessoires vestimentaires et/ou les bijoux qui lui sont personnels.

\section{La présence de mobilier...} défunts, quelques rares composantes de la panoplie guerrière : fer de lance à Larchant "Les Groues", bouterolle, orles de bouclier et fer de lance à Ville-Saint-Jacques «Volstin» ou à La Grande Paroisse «La Pièce de Pincevent " (Séguier et Delattre, 2005); il faut également mentionner les deux exceptionnels fragments ployés de bandages de roues des « Rimelles » à La Grande Paroisse (Delattre et al., 2000). Peuvent aussi s'ajouter la fibule en bronze de Marolles-sur-Seine « Les Rimelles» (Delattre et al. 2000, p. 38) et celle en fer, variante du type Marzabotto, sur le site de Pithiviers «Le Bois Médor » (Loiret) (Dubuis et al., 2012-2013, p. 79 et fig. 12). De toutes évidences, la valeur intrinsèque de chaque objet en métal rend impossible leur rejet pour des communautés pratiquant un recyclage intensif. Vigne » (Champagne) où un enfant est inhumé avec une céramique (Bonnabel 2010); à Baron «Le Buisson Saint-Cyr » (Oise), une structure d'ensilage a livré un individu et un gros vase à provision de type dolium (Fémolant, 1997, fig. 6).

\section{Et des animaux}

Ces silos-réceptacles ont également la particularité de livrer des animaux dont les squelettes sont le plus souvent associés à ceux des humains. Le rôle de l'animal dans les rituels, et plus spécifiquement dans ce type de dépôts de l'âge du Fer, est encore d'interprétation très complexe alors même que sa présence dans la gestuelle funéraire n'est plus à démontrer (Auxiette in Desenne et al., 2009 ; Méniel, 1992)

En effet, l'humain, inhumé ou incinéré, est fréquemment doté de pièces de viande, le plus souvent associées à un ensemble de vases initialement garnis de denrées alimentaires. Ces dépôts carnés, assimilés à des offrandes et/ou à des viatiques, sont surtout des morceaux prélevés sur des animaux sélectionnés dans la sphère domestique et destinés à accompagner le défunt : dans un ordre décroissant, on recense le porc, le mouton, le poulet et plus rarement le bœuf. Ils peuvent être déposés isolément ou combinés (fig. 2). Quelques morceaux de viande sont préférés à d'autres : à La Tène ancienne, l'épaule de porc est le morceau le plus fréquemment déposé et à la fin de La Tène moyenne/début de La Tène finale, les crânes refendus, les épaules et les jambons sont associés dans des proportions plus ou moins similaires, alors que le dépôt de rachis, quasi absent des phases les plus anciennes, tend à se multiplier. Les pieds des trois espèces principales ne sont presque jamais déposés ; le pied de porc apparaît dans les offrandes funéraires au cours de La Tène moyenne. 
Figure 2 : portions de porcs déposées dans la sépulture 364 de la nécropole de La Tène ancienne de Bucy-le-Long « la Héronnière " (Aisne) (cliché URA 12/UMR 8215, CNRS).

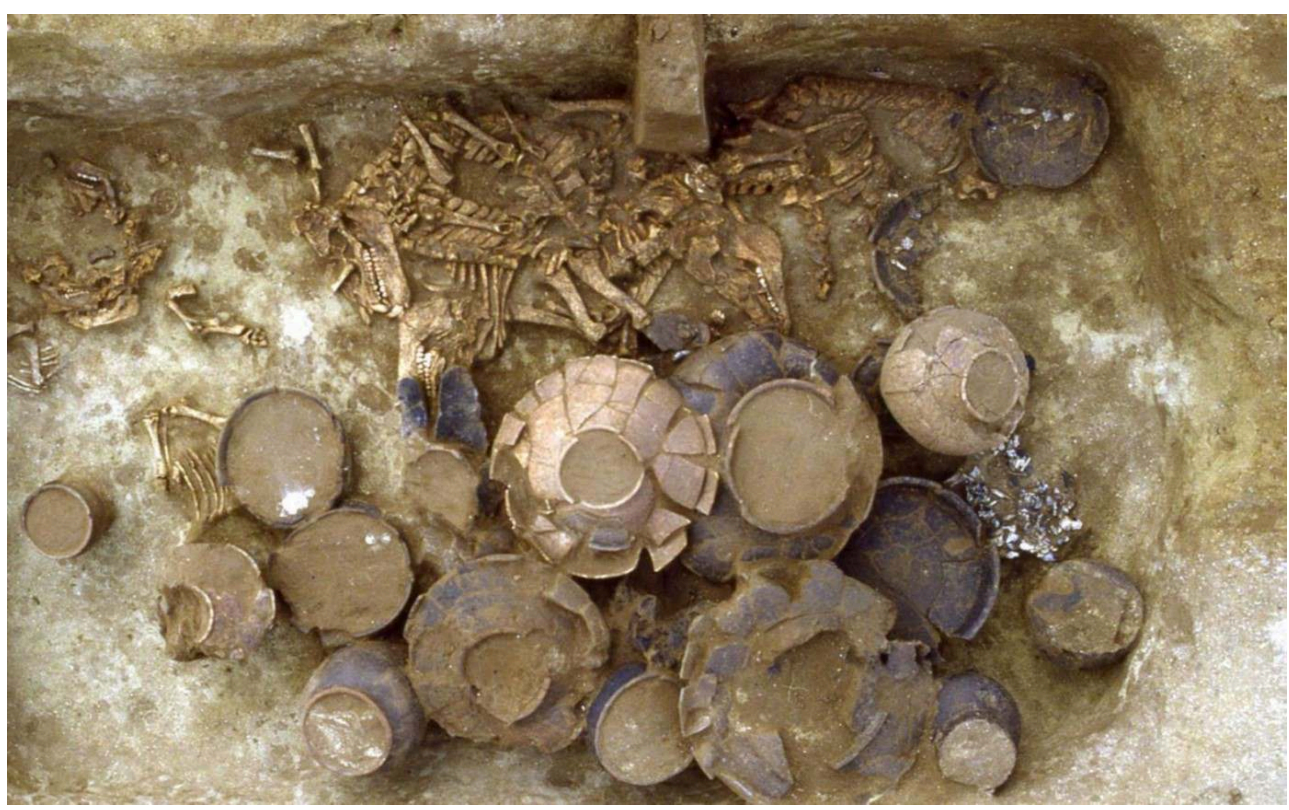

Bien sûr, les offrandes animales incinérées sont plus difficiles à appréhender ; toutefois, les témoignages dont nous disposons ne laissent pas entrevoir de pratiques distinctes des offrandes fraîches quant au choix des espèces et des morceaux.

Hommes ou femmes, enfants, adolescents ou adultes, aucune règle pouvant renvoyer à des modalités de type liturgique ne semble régir le choix de l'espèce accompagnant le défunt, pas plus que celle des morceaux (Auxiette et al., 2002; Auxiette in Desenne et al., 2009 ; Auxiette in Pinard et al. 2010; Auxiette in Bonnabel et al., 2010). Mais surtout, sont totalement exclus de la catégorie des offrandes animales éligibles dans ces contextes, le cheval et le chien, alors même qu'aucun tabou alimentaire ne frappe ces deux espèces au cours de l'âge du Fer (Auxiette 2002 ; Méniel et al., 2009).

Il est toutefois patent, dès que l'on recense ces occurrences, que cette présence animale en silo - et notamment avec le cheval et le chien - se singularise dès le Hallsttat final comme à Chilly-Mazarin «la Butte aux Bergers» (Essonne) (fig. 3, Duplessis et al., 2013) : le plus souvent, l'intérêt porté à l'animal entier ou non, retrouvé dans ce type de structure, réside en ce qu'il semble « accompagner » (à moins que ce ne soit l'inverse ?) le corps d'un humain déposé simultanément ou postérieurement. Cette combinaison, qui peut se démultiplier, attire davantage l'attention qu'un animal seul retrouvé dans une structure de stockage (Auxiette 2013). Les nombreux exemples recensés à ce jour sont souvent datés d'un large "second âge du Fer ", tels le dépôt d'un cheval et d'une femme dans un silo à Wettolsheim «Ricoh» (Haut-Rhin) (Jeunesse et Hehretsmann, 1988) ou encore les dépôts de cheval, bœuf, chien, caprinés, mouton et oiseaux des silos de Bourges «Port Sec Sud» (Cher) (Augier et al., 2012). On peut souligner qu'à Danebury (Grande-Bretagne) des couches entières de squelettes de corbeaux, animaux psychopompes s'il en est, ont été retrouvées étalées sur le fond de certains silos du site (Cunliffe, 1992). 
Figure 3 : dépôt d'un individu en position ventrale, en position supérieure du silo du Hallstatt final et sans contact direct avec les animaux sous-jacents à Chilly-Mazarin « La Butte aux Bergers » (Essonne) (cliché M. Duplessis, Inrap).

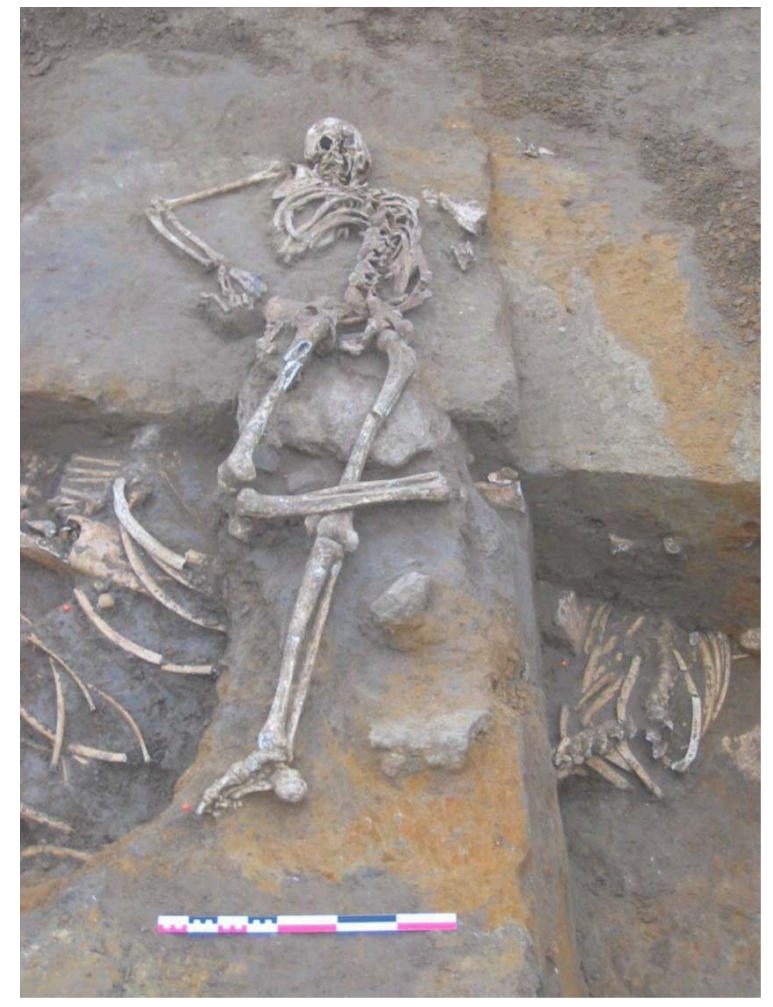

Ainsi certains animaux, et notamment le cheval pourtant absent des codes funéraires, hormis pour la courte période des sépultures à char, semblent-ils jouer un rôle déterminant dans le fait religieux protohistorique, et leur relation privilégiée avec l'homme paraît ici magnifiée dans cette « combinaison " post-mortem inédite (Méniel, 2001; Méniel, 2005). Il est toutefois très hasardeux de suggérer que le défunt est ici " accompagné » de ses animaux familiers, car il ne semble pas s'instaurer ici de hiérarchisation dans la sélection des offrandes: les animaux, comme l'humain, bénéficient des mêmes intentions et de modes de dépôt très voisins.

\section{La lecture d'une pratique similaire : des animaux pour des silos}

Humains et animaux vont donc être traités, manipulés et prélevés de la même manière, avec une intention de transformation des cadavres et des dépouilles assez similaire. L'un ne prime pas l'autre quand les dépôts sont combinés, qu'ils soient entiers ou fragmentés, que l'os isolé humain s'accompagne d'un animal entier, ou qu'un fragment d'animal s'associe au cadavre humain. La convergence de mise en dépôt est assez troublante. Dans ces duos « homme/animal » on peut donc également observer, comme pour les humains :

- des dépôts simultanés comme à Varennes-sur-Seine "Le Marais de Villeroy " (Seine-etMarne) où sont entremêlés, en un même geste, un sujet adolescent, quatre chevaux et deux chiens (Méniel, 2005) (fig. 4);

- des dépôts différés avec, le plus souvent, une séparation très nette, matérialisée par un apport sédimentaire massif, entre l'individu et l'animal comme à Wettolsheim «Ricoh » (Jeunesse et Hehretsmann, 1988). 
Figure 4 : Varennes-sur-Seine « Le Marais de Villeroy » (Seine-et-Marne) (Gif-9492 : 433-192 BC) : combinaison complexe associant des chevaux, des chiens et un humain (cliché Méniel, CNRS).

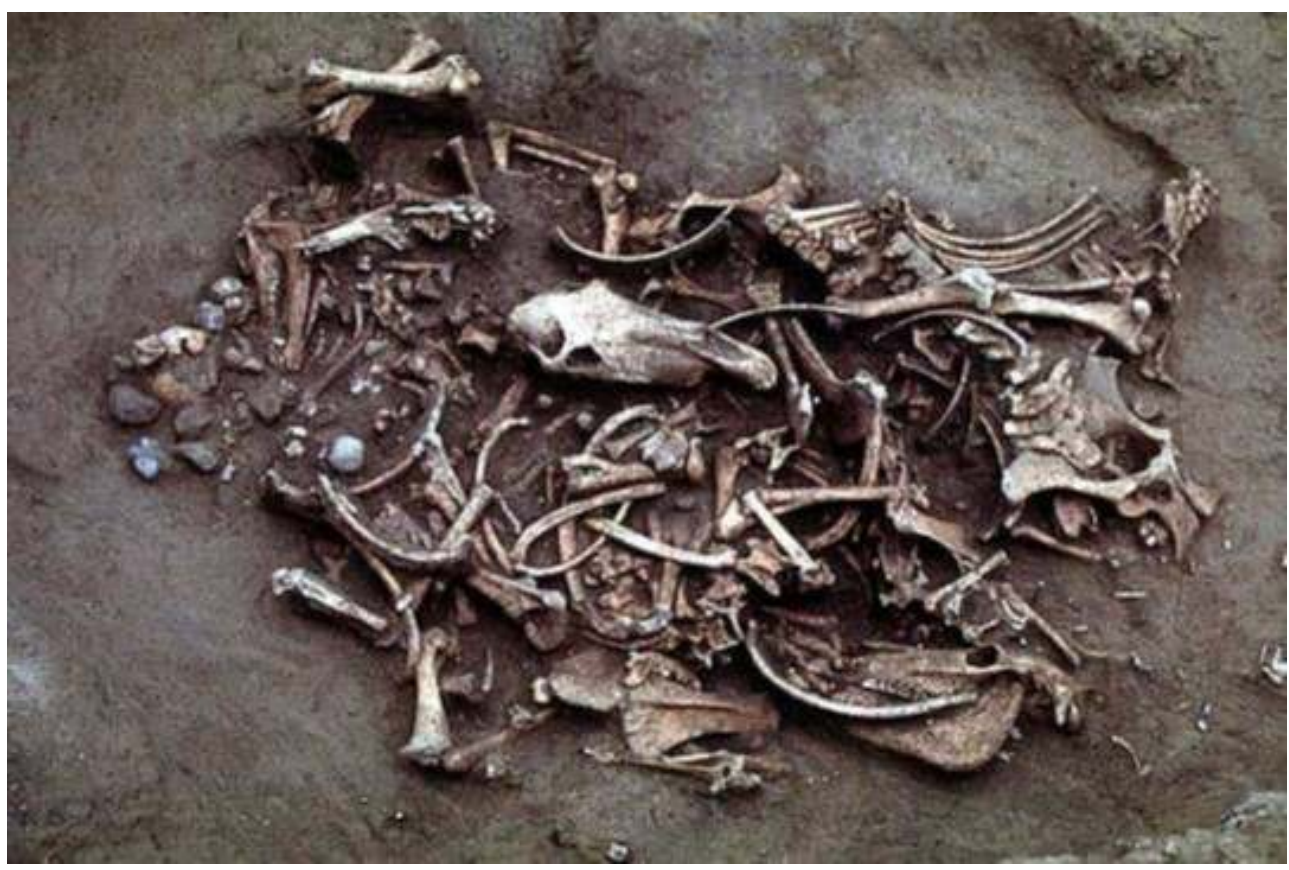

Ces installations mixtes s'organisent d'ailleurs de la même manière que les dépôts humains, oscillant entre dépôts individuels, multiples ou collectifs (Delattre, 2010). On peut toutefois observer que l'animal est rarement installé seul, même si nombre d'entre eux, non reconnus comme tels, ont probablement été ajoutés à l'inventaire des animaux issus de contextes détritiques; on peut toutefois mentionner la récente mise au jour d'une vache entière dans un silo de Milly-la-Forêt (Essonne) daté du Hallstatt final (fig. 5, Viand et al., 2008) ou l'assemblage unique des autopodes antérieurs et postérieurs d'un cheval suggérant la présence d'une peau, dans un silo de Neuville-auxBois « La Grande Route » le long du tracé de l'A19 dans le Loiret (Josset et al., 2009). 
Figure 5 : dépôt agencé d'une vache dans une structure d'ensilage du Hallstatt final de Milly-laForêt « le Bois Rond » (Essonne) (cliché A. Viand, Inrap).

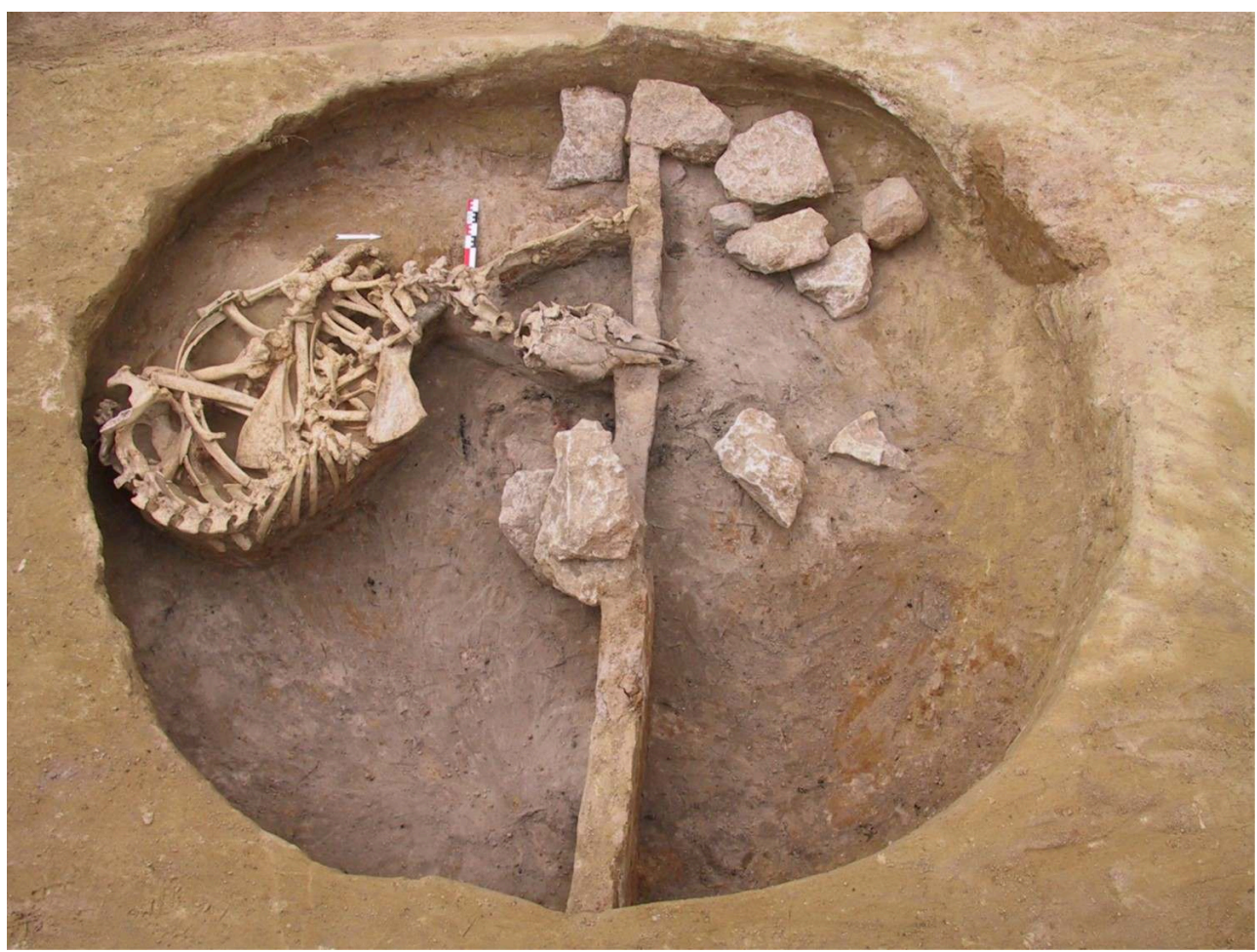

On méconnaît le laps de temps séparant les gestes, clairement identifié par un apport sédimentaire, mais il semble accentuer la volonté de séparation matérielle des cadavres. Ces superpositions ne sont pas aléatoires car elles concernent un même lieu d'accueil et recouvrent une même intention communautaire, l'humain se combinant, s'ajoutant à l'animal, sans prépondérance apparente de l'un sur l'autre.

On peut donc restituer des séquences chronologiques précises, chacune adossée à un geste commun, comme à Chilly-Mazarin «la Butte aux Bergers » qui voit se succéder, de bas en haut, selon l'ordre d'installation, un chat sauvage, un poulain de 5 mois posé sur le flanc gauche, deux lièvres, un étalon de 5,5 ans, posé sur le flanc gauche, un second étalon de plus de 9 ans, allongé sur le dos. Les deux étalons, isolés l'un de l'autre par une couche de remblai, sont suivis de plusieurs portions d'un cheval de 4,5 anspeut-être agencé dans un coffre - et probablement exposé préalablement à son ensevelissement faisant ainsi l'objet d'une sélection de morceaux destinés au dépôt. Ensuite, un lièvre et diverses autres parties d'un autre cheval ont été ajoutés en préalable au dépôt d'un cadavre humain, qui est strictement séparé des animaux qu'il recouvre en un geste ultime et unique (Auxiette et Delattre in Duplessis et al., 2013).

On peut aussi évoquer le silo de Puiseaux « Le Chemin de Paris » (Loiret) accueillant, en quatre phases, trois humains entiers et deux chevaux, l'un complet et l'autre partiel (fig. 6) (Auxiette et Delattre in Devilliers et al., 2006). Ici, une jument d'environ 24 mois a d'abord été déposée, laissée à l'air libre pour amorcer sa décomposition et permettre la reprise du crâne, puis deux adultes (une femme et un homme) l'ont rejoint avant que le tout ne soit scellé par une couche de sédiment. Sur ce remblai protecteur a ensuite été déposée, puis recouverte, une femme mature. C'est pour clôturer ce surprenant dépôt qu'ont été installées les portions d'une jument de treize ans, soit une partie de son 
crâne (occipital et mandibules), une colonne vertébrale probablement complète, la scapula droite et le bassin complet.

Figure 6 : dépôt de 3 humains et de 2 chevaux dans un silo du Hallstatt final de Puiseaux « Le Chemin de Paris » (Essonne) (cliché C. Devilliers).

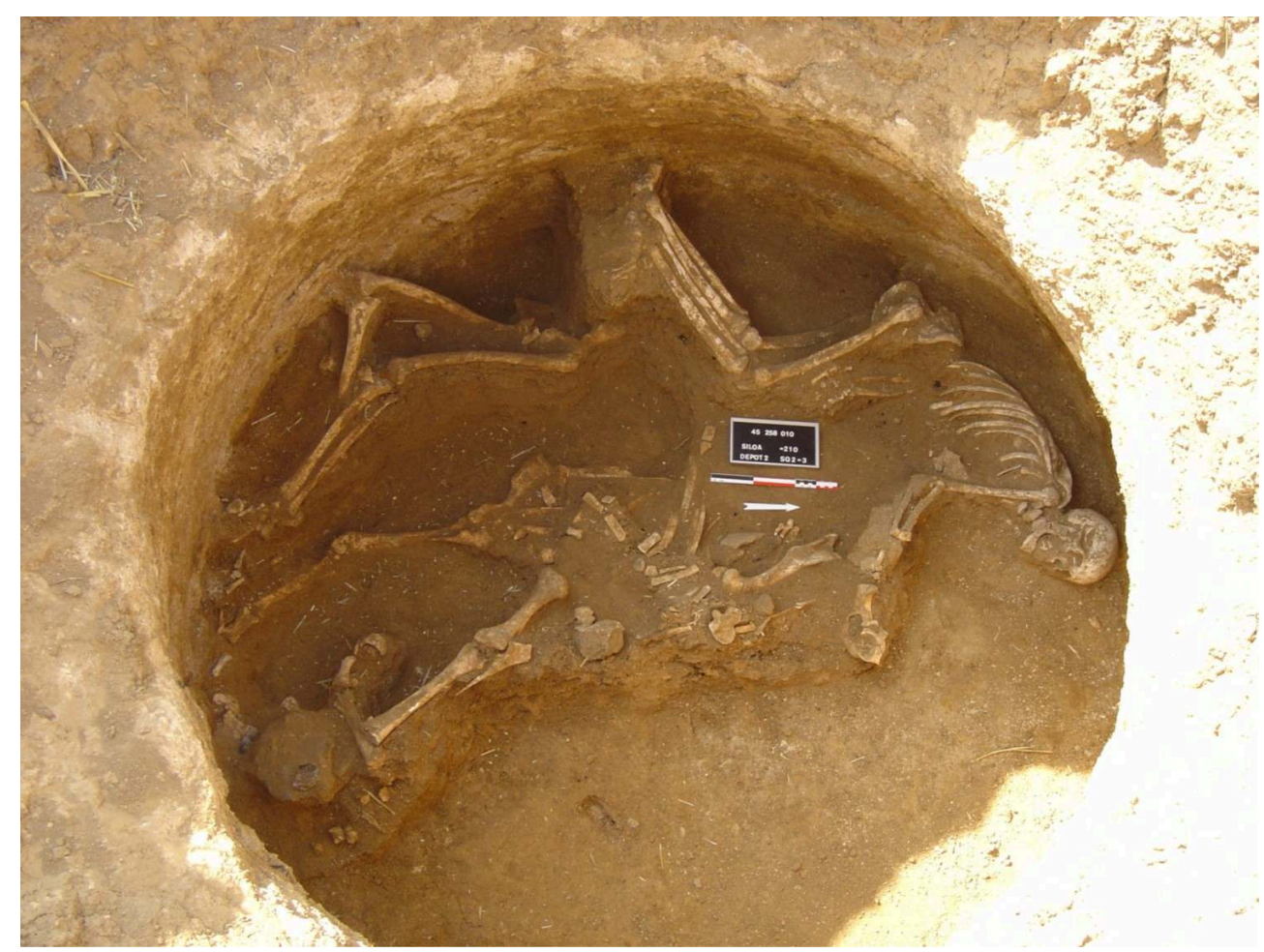

\section{De troublantes similitudes de traitement}

La multiplication des données et l'état des connaissances actuelles tendent à démontrer que l'homme et l'animal bénéficient de comportements souvent identiques, les unissant intimement dans l'expression de rituels adossés aux manipulations de cadavres.

\section{La reprise des os et/ou de portions anatomiques}

Nombre de squelettes humains issus des silos, apparaissent incomplets et présentent d'importantes lacunes ostéologiques; ces corps ont fait l'objet de reprises plus ou moins massives, et si certains d'entre eux semblent avoir été hâtivement manipulés puis éparpillés sur le fond de fosse, la fouille minutieuse de certains autres suggère surtout une connaissance anatomique précise et une aptitude exercée à ce type de geste intrusif qui ne privilégie pas systématiquement le crâne et la force symbolique qui lui est dévolue (Delattre et al., 2000)

Comme pour les humains, la manipulation des carcasses et la reprise d'ossements sur un cadavre décomposé sont aussi clairement attestées pour les animaux; en témoignent les portions et les os isolés de chevaux dans le silo de Chilly-Mazarin (Duplessis, 2013), ce dernier étant le plus emblématique de ces pratiques multiples et complexes inscrites dans le temps. Ces manipulations sont parfois si discrètes qu'il faut l'œil avisé des archéologues pour les repérer à bon escient : si un os animal isolé semble 
anecdotique dans un contexte aussi standardisé que celui d'un silo, il peut revêtir une intention bien particulière quand cette structure accueille aussi un humain, s'ajoutant dès lors à la longue liste des gestes de type pars pro toto.

En ce sens, certains silos se comportent comme des lieux d'attente où la dépouille devient peu à peu squelette, permettant l'obtention d'os secs qui, sélectionnés et repris, vont se voir affecter un lieu de dévolution définitif différé. Dans les exemples recensés dans le Bassin Parisien, on observe conjointement des squelettes humains et animaux, sur lesquels de très faibles manipulations ont été effectuées (reprise différée d'un seul os) et des squelettes très remaniés, au stade ultime des possibilités, pour lesquels il n'est pas exclu d'envisager une succession de prélèvements multiples (Delattre et Séguier, 2007).

Et comme il convient désormais d'associer l'homme et l'animal dans l'exercice d'une même pratique, on peut noter l'accumulation des discordances anatomiques du dépôt composite de Varennes-sur-Seine "Le Marais de Villeroy»: les corps de plusieurs chevaux, juments et chien sont associés en installations successives à celui d'un adolescent, sans que les dépôts intermédiaires ne soient jamais colmatés (Méniel, 2005). Si l'on songe inévitablement à l'un de ces lieux propices à l'écoulement souterrain, mais réalisé à l'air libre, des jus de décomposition, l'étude archéozoologique constate aussi des déficits osseux, des reprises répétées et des adjonctions d'os secs qui ne relèvent pas du seul prélèvement préalable de tendons ou de masse de viande.

Dans la lecture de ces rituels complexes, le dépôt des dépouilles humaines et animales n'est pas toujours une fin en soi : ces offrandes desséchées et altérées, forcément désincarnées, tendent, elles aussi, vers une seconde vie en réintégrant parfois l'habitat après cette phase de décomposition souterraine. Suite à ce nourrissage divin de forces chtoniennes par le biais de l'écoulement des jus de décomposition, certains « objets » reprennent place dans la communauté via l'érection de trophées, la confection de reliquaires ou encore l'accrochage de crânes à des palissades. Espérance de la pourriture, reprise de tout ou partie de ces offrandes dégradées mais purifiées pour une ultime exposition, sont autant de gestes qui ne figent pas le rituel et confèrent aux offrandes humaines et animales, une éternité renouvelée que la mort ne saurait corrompre.

\section{Quid du sacrifice?}

La mise à mort, le sacrifice des animaux ne font aucun doute et leurs traces sont aisément enregistrées sur le crâne ou les vertèbres cervicales : en revanche, si elles ne sont jamais perceptibles sur la faune des silos, elles le sont en contexte domestique et sur un très grand nombre d'habitats laténiens, comme à Wissous "Zone sud-ouest aéroport Orly " (Essonne) où l'on peut aisément observer des traces d'égorgement (fig. 7a) et de détachement de la tête chez un mouton (fig. 7b). 
Figure 7a: Wissous « Zone sud-ouest aéroport Orly » (Essonne), structure 1104/a : traces d'égorgement en vue ventrale (cliché G. Auxiette, Inrap).

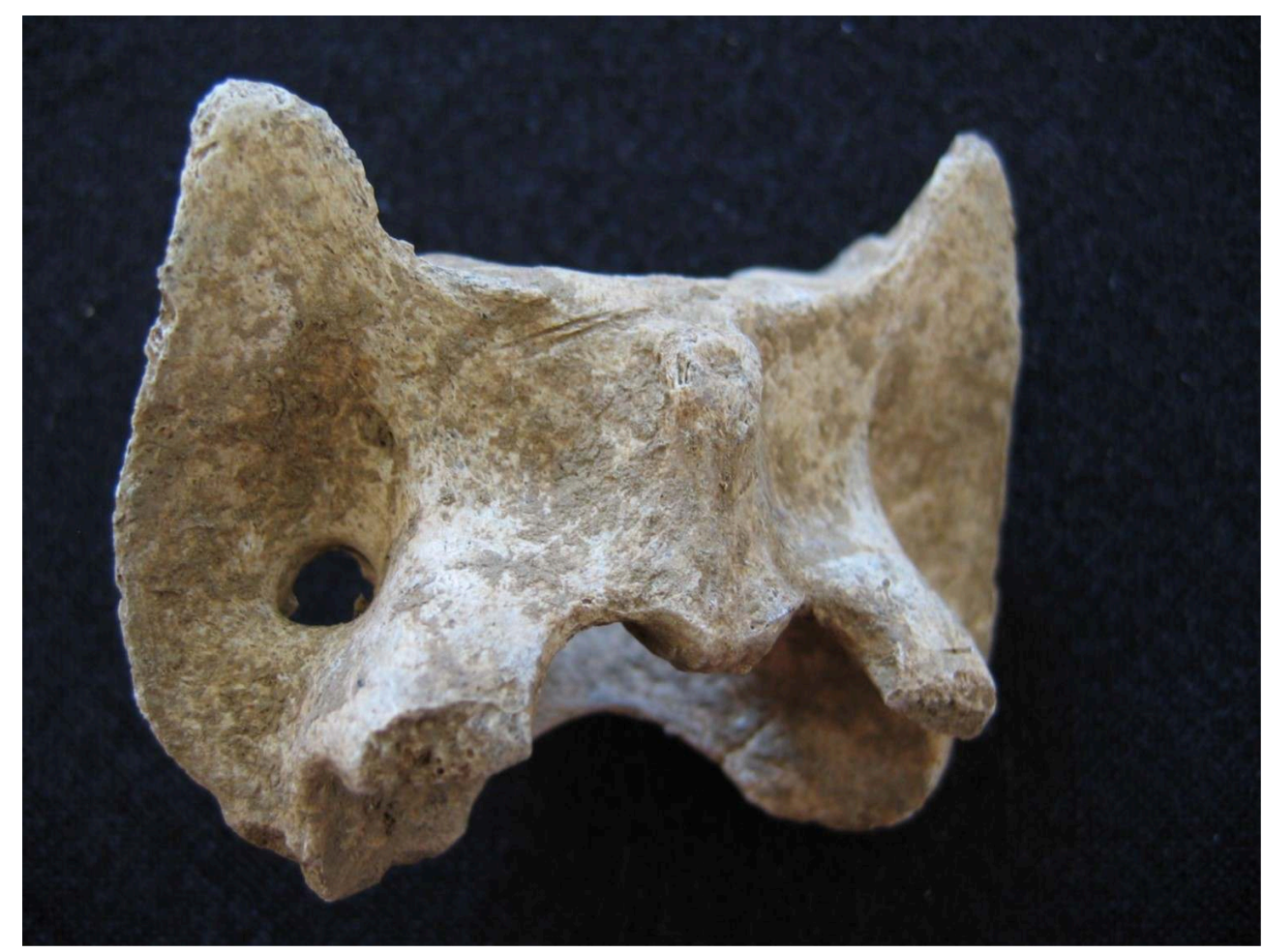

Figure $7 \mathrm{~b}$ : Wissous « Zone sud-ouest aéroport Orly » (Essonne), structure 1104/b : traces d'égorgement en vue dorsale, chez un mouton (cliché G. Auxiette, Inrap).

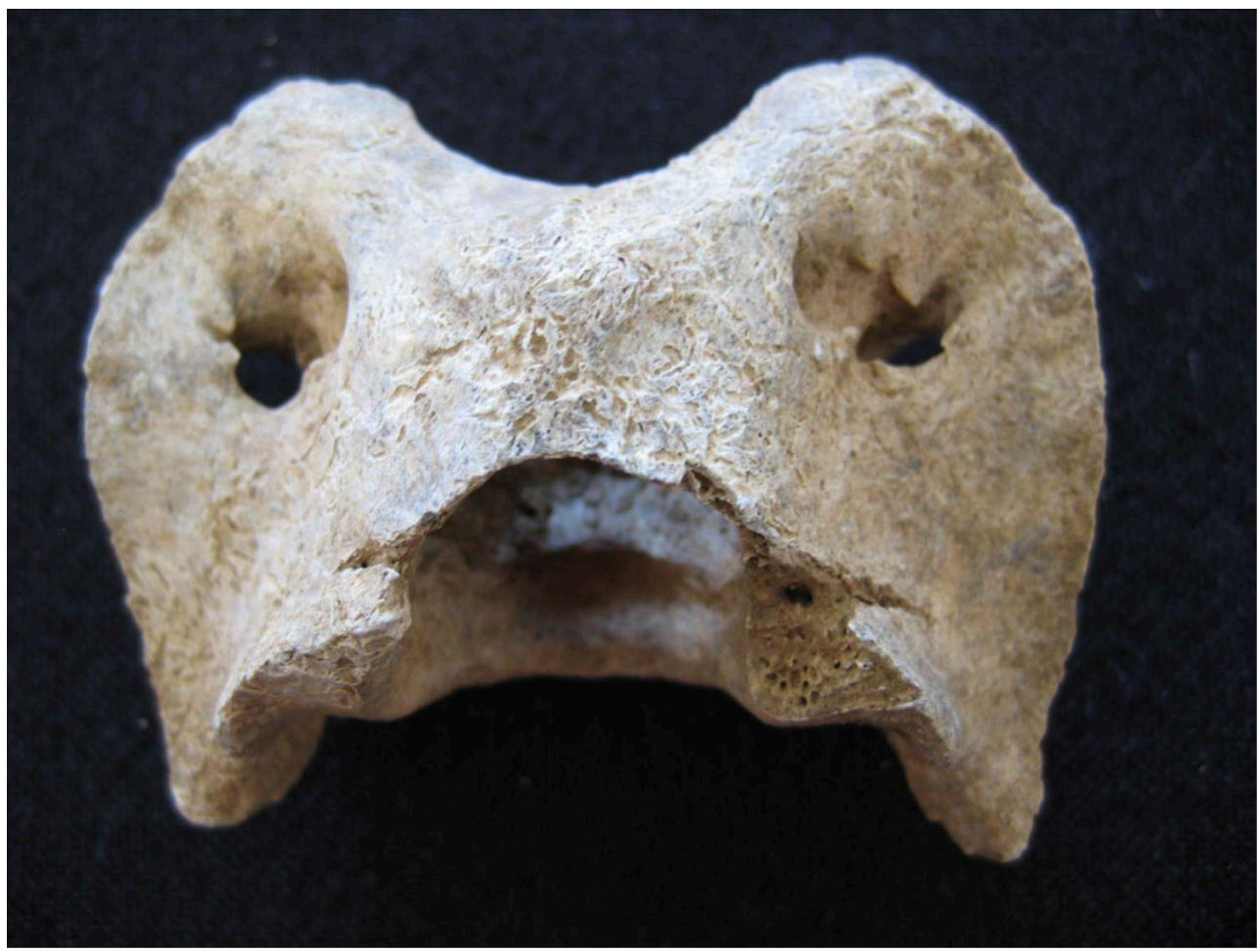

Mais en tout état de cause, le témoignage le plus récurrent de cet abattage volontaire reste celui de la lecture de l'enfoncement de la boîte crânienne, en préalable au dépôt, 
comme celui visible sur un crâne de bœuf de Braine «la Grange des Moines » (Aisne) (fig. 8).

Figure 8 : Braine « la Grange des Moines » (Aisne, La Tène D2a), enfoncement de la boîte crânienne sur un crâne de bœuf (cliché $\mathrm{G}$. Auxiette, Inrap).

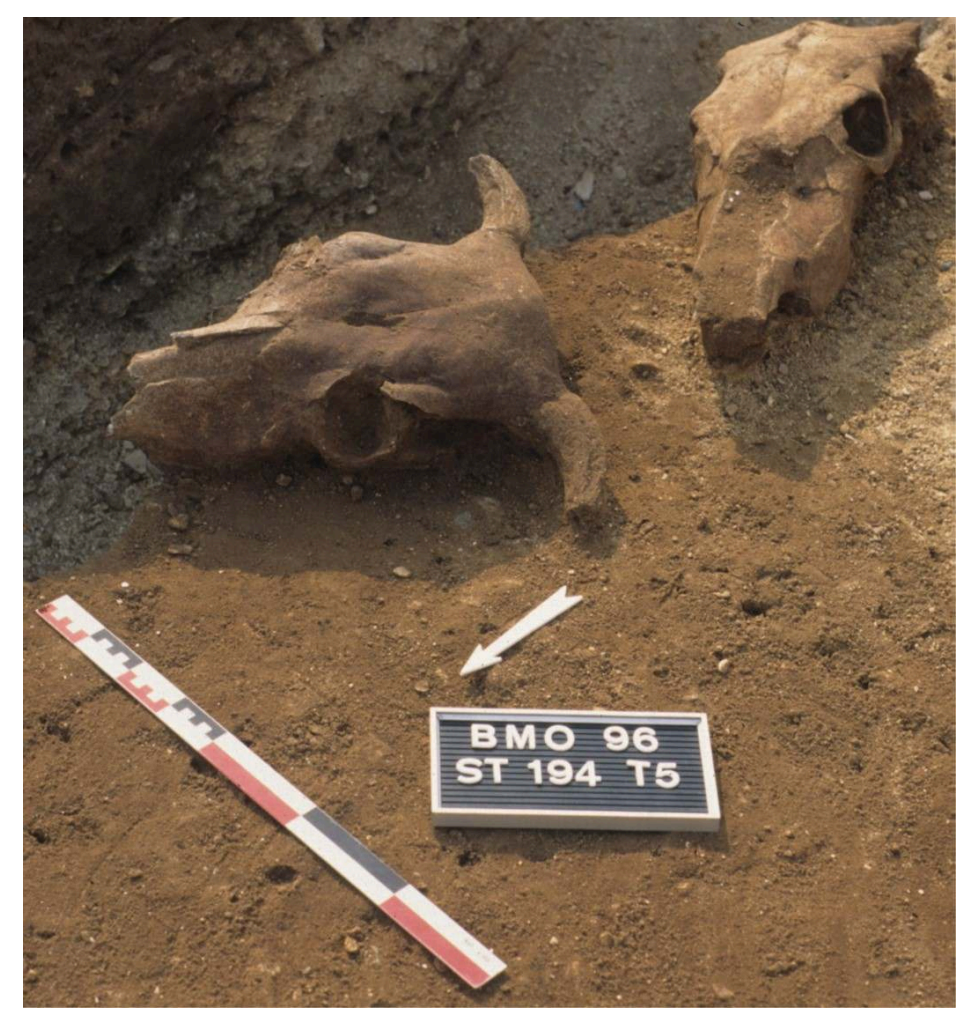

34 À noter que le prélèvement de la peau post-mortem est par ailleurs bien observé dans un certain nombre de cas, comme sur les chevaux de Chilly-Mazarin «la Butte aux Bergers » (Duplessis 2013).

Dans ce type de société, il semble que les formes que revêt l'abattage des animaux soient clairement réglementées. Si les codes de la mise à mort sont peut-être différents selon que l'animal est destiné à la consommation ou au sacrifice (comme cela doit être le cas dans les silos), ils ne sont pas tous archéologiquement perceptibles.

Chez les humains des silos, et loin de toute interprétation fantasmée du sacrifice, il existe parfois diverses traces de modifications de la surface des os pouvant s'interpréter comme des traces de coup et/ou de découpe; elles se rencontrent aussi bien en contextes domestiques que dans les sanctuaires, affectant essentiellement le squelette crânien (volonté d'accéder à la matière cérébrale ?). Leur lecture peut être multiple, parfois imputable aux aléas guerriers ou plus fréquemment, elles sont la conséquence des manipulations anthropiques post-mortem liées au démembrement ou à la décarnisation. Les modifications sont plus rares sur les autres os, touchant notamment les diaphyses par enlèvement de matière. Dans le sanctuaire de Ribemontsur-Ancre (Somme) la plupart des os du squelette post-crânien porte des traces de coup et de découpe liées au combat et au démembrement (Arcelin et Brunaux, 2003, p. 25).

37 Aucune de ces observations ne peut attester d'une mise à mort volontaire des individus. Elles confirment, si besoin était encore, le foisonnement des nombreuses manipulations 
qui concernent le cadavre humain, sitôt la mort ou bien longtemps après sa décomposition aboutie.

Dans les silos, ces particularités affectant le corps dans sa seule version squelettique ne sont pas détectables et si mise à mort il y a, elle n'a laissé aucun impact lisible sur les os. Mais qu'elle ait été donnée volontairement ne doit pas être définitivement écarté, si l'on songe aux «bog bodies» tels celui de Lindow (Grande-Bretagne, daté de -2 à 119 après notre ère), indiscutablement égorgés, étouffés ou encore empoisonnés... sans que cela ne laisse la moindre trace sur l'os (Turner, 1995).

Il ne fait aucun doute que les humains et les animaux soient investis d'une même intention quand les communautés les destinent à l'enfouissement temporaire ou définitif dans les silos. Leur décomposition semble alimenter des forces souterraines accessibles par le truchement de ces structures essentielles, en tous points, à la survie des groupes. Mais si la mise à mort volontaire des animaux est indubitable, celle des humains reste sujette à débat, de lecture archéologique encore impossible. Et si tel n'était pas le cas, il s'agirait de la seule différence de traitement à ce jour perceptible et permettant de distinguer l'humain de l'animal. Au moins dans l'intention.

\section{Conclusion}

Une grande variété de gestes et de modes opératoires définissent ainsi cette pratique du dépôt en silo, concernant aussi bien les humains que les animaux. En tout état de cause, si des référentiels peuvent être d'ores et déjà proposés, si quelques nuances de traitement et de chronologie peuvent s'observer, le questionnement principal demeure celui du décès, de la mise à mort, intentionnelle ou non. En effet, ce dépôt d'offrandes en silo doit-il s'apparenter à un "geste pacifique " ou est-il adossé à une pratique sacrificielle qui implique l'humain associant ainsi dans une même «intention propitiatoire et céréalière ", (Gransar et al., 2007) au sein des silos, des humains, des animaux et autres mobiliers de choix ? Telle est la vraie question car si l'offrande est réelle, la mise à mort est supposée.

41 Ces populations laténiennes, bien que réputées guerrières, sont surtout agricoles et sédentaires, ce qui confère au mode de stockage des grains une importance économique et symbolique. Le silo n'est pas un simple réceptacle à grains, il est aussi l'enjeu d'un échange saisonnier entre les hommes et l'invisible. Dans une lecture que l'on envisagerait ici pacifique et saisonnière, les humains et animaux en décomposition contrôlée semblent davantage invoquer les forces de fertilité/fécondité. Si les faits s'accordent sur la mise à mort intentionnelle de l'animal, on ne peut que s'interroger sur la nécessité de mettre à mort un humain, l'un des siens, dans le cadre d'une pratique visant à exalter les forces de la vie et du renouveau... Les indices probants, tels des traces d'outils, de dépeçage, de découpe... magnifient le «travail » sur l'os humain sec ou frais alors que d'indéniables impacts de mise à mort violente sont visibles chez l'animal.

Si le «fait de rendre sacré » est ici indubitable, le fait de tuer préalablement l'humain, d'une façon forcément sanglante n'est donc pas avéré et sans doute faut-il concevoir le sacrifice comme le don d'un des siens, livré à l'appétit des « dieux du dessous ». 


\section{BIBLIOGRAPHIE}

ARCELIN P., BRUNAUX J.-L., 2003, Cultes et sanctuaires en France à l'âge du Fer, Paris, CNRS Éditions, $268 \mathrm{p}$.

AUGIER L., BUCHSENSCHUTZ O., DURAND R., FILIPPINI A., GERMINET D., MACON Ph., PAULY S., PESCHER B., RALSTON I., ROURE R., SALIN M., TICHIT A., VANNIÈRE B., 2012, « Un complexe princier de l'âge du Fer : le quartier artisanal de Port Sec Sud à Bourges (Cher) », vol. 1, Analyse des structures et du mobilier, Revue Archéologique du Centre de la France, supp. 41 (Monographie 2012-1, BourgesTours), $232 \mathrm{p}$.

AUXIETTE G, DeSENNE S., POMMEPUY C., 2002, « Des viatiques et des banquets : alimentation des défunts, alimentation des vivants sur la nécropole de La Tène ancienne de Bucy-le-Long (Aisne) », actes du XXVème colloque de l'AFEAF, Charleville-Mézières 2001, Revue Archéologique Champenoise, 16, p. 317-336.

AUXIETTE G., 2013, «Évolution des dépôts du Néolithique à l'Antiquité tardive en contexte non funéraire : un premier état des lieux », dans G. AUXIETTE, P. MÉNIEL. (dir.), Les dépôts d'animaux en France, de la fouille à l'interprétation, actes de la table ronde de Bibracte, octobre 2012, Montignac, Éditions Monique Mergoil (Archéologie des plantes et des animaux, nº 4), p. 167-176.

BONNABEL L., 2010, « Dépôts de corps humains en structures réutilisées (ou détournées ?) durant la protohistoire en Champagne-Ardenne : approche comparative avec les sépultures et éléments d'interprétation ", dans L. BARAY, B. BOULESTIN (dir.), Morts anormaux et sépultures bizarres, les dépôts humains en fosses circulaires ou en silos du néolithique à l'Âge du Fer, actes de la II ${ }^{\text {ème }}$ table ronde interdisciplinaire « Morts anormaux et sépultures bizarres : questions d'interprétation en archéologie funéraire », 29 mars - $1^{\mathrm{er}}$ avril 2006, Sens, Dijon, Éditions Universitaires de Dijon (Art, Archéologie et patrimoine), p. 99-112.

BONNABEL L., MOREAU C., SAUREL M., RICHARD I., AUXIETTE G., VAUQUelin E., 2010, « Pratiques funéraires entre le Hallstatt final et La Tène moyenne en Champagne-Ardenne : un genre de point de vue, le point de vue du genre ", dans P. BARRAL, B. DEDET, F. DELRIEU, P. GIRAUD, I. Le GOFF, S. MARION, A. VILLARD-Le TIEC (dir.) Gestuelles funéraires au Second Âge du fer, actes du XXXIII ${ }^{\mathrm{ème}}$ colloque international de l'AFEAF, Caen, mai 2009, Annales Littéraires, n 883 (Environnement, sociétés et archéologie, vol. II), p. 129-154.

BRUNAUX J.-L., 2006, Les Druides, des philosophes chez les barbares, Paris, Le Seuil, 386 p.

BRUNAUX J.-L., 2005, « Sacrifices humains chez les Gaulois. Réalités du sacrifice, réalités archéologiques ", dans Le sacrifice humain en Égypte et ailleurs, J.-P. ALBERT, B. MIDANT-REYNES (dir.), Études d'Archéologie nº 6, Paris, Soleb, p. 256-273.

CUNLIFFE B., 1992, « Pits, preconceptions and propitiation in the British Iron Age », Oxford Journal of Archaeology, 11, 1, p. 69-83.

DELATTRE V., BUlARD A., GOUGe P., PIHUIT P., 2000, « De la relégation sociale à l'hypothèse des offrandes : l'exemple des dépôts en silos protohistoriques au confluent Seine-Yonne (Seine-etMarne) ", Revue Archéologique du Centre de la France, 39, p. 5-30.

DelATtRe V., 2010, « Les dépôts en silos laténiens : une pratique cultuelle ? Dépôts atypiques et manipulations de corps au second Âge du Fer : l'exemple de la confluence Seine-Yonne (Seine-etMarne) ", dans L. BARAY, B. BOULESTIN (dir.), Morts anormaux et sépultures bizarres, les dépôts humains en fosses circulaires ou en silos du néolithique à l'Âge du Fer, actes de la II ${ }^{\text {ème }}$ table ronde 
interdisciplinaire « Morts anormaux et sépultures bizarres : questions d'interprétation en archéologie funéraire », 29 mars - $1^{\mathrm{er}}$ avril 2006, Sens, Dijon, Éditions Universitaires de Dijon (Art, Archéologie et patrimoine), p. 113-126.

DELATTRE V., 2013, « Sacrifices et dépôts composites au Second âge du Fer dans le Bassin parisien : quand le défunt échappe à la nécropole et devient offrande ", L’Âge du Fer en Europe, dans S. KRAUSZ, A. COLIN, K. GRUEL, I. RALSTON, T. DECHEZLEPRÊTRE (dir.), Mélanges offerts à Olivier BUCHSENSCHUTZ, Ausonius Éditions, Mémoires 32, Bordeaux, p. 481-499.

DELATTRE V., SEGUIER J.-M., 2007, « Du cadavre à l'os sec : manipulations de corps à caractère cultuel à l'Âge du Fer dans le territoire sénon ", dans Ph. BARRAL, A. DAUBIGNEY, C. DUNNING, G. KAENEL, M.-J. ROULIÈRE-LAMBERT (dir.), L'Âge du Fer dans l'arc jurassien et ses marges. Dépôts, lieux sacrés et territorialité à l'Âge du Fer, actes du XXIX ${ }^{\text {ème }}$ colloque international de l'AFEAF, Bienne, 5 au 8 mai 2005, Besançon, Presses Universitaires de France-Comté, p. 605-620.

DESENNE S., AUXIETTE G., DEMOULE J.-P., 2009, « Dépôts, panoplies et accessoires dans les sépultures du $2^{\text {ème }}$ âge du Fer en Picardie ", dans E. PINARD, S. DESENNE (dir.), Les gestuelles funéraires au second âge du Fer, actes de la table ronde, Revue Archéologique de Picardie, vol. 3/4, p. 173-186.

DeVilliers C., Simonin D., Delattre V., Auxiette G., 2006, « Puiseaux : le Chemin de Paris », Rapport d'opération de sondage, Société archéologique de Puiseaux, SRA région Centre.

DUBUIS B., BAYLE G., GAY J.-Ph., VILLENAVE C., 2012-2013, « Une occupation de La Tène ancienne à Pithiviers « Bois Médor » (Loiret) », Revue Archéologique du Loiret, vol. 36, p. 67-92.

DUPLeSSiS M., DelATTRE V., AUXIETTE G., 2013, « Un dépôt composite et atypique d'un humain et d'animaux, le silo 27 de la Butte aux Bergers à Chilly-Mazarin (Essonne) », Revue Archéologique d'Ile-de-France, vol. 6, p. 31-54.

FÉMOLANT J.-M., 1997, « Les sépultures de La Tène D2 découvertes dans le Valois sur le tracé du TG V nord », Revue archéologique de Picardie, vol. 1-2, p. 115-126.

GRANSAR F., AUXIETTE G., DESENNE S., HÉNON B., MALRAIN F., MATTERNE V., PINARD E., 2007, « Expressions symboliques, manifestations rituelles et cultuelles en contexte domestique au $\mathrm{I}^{\mathrm{er}}$ millénaire avant notre ère dans le nord de la France ", dans Ph. BARRAL, A. DAUBIGNEY, C. DUNNING G. KAENEL, M.-J. ROULIÈRE-LAMBERT (dir.), L'Âge du Fer dans l'arc jurassien et ses marges. Dépôts, lieux sacrés et territorialité à l'Âge du Fer, actes du XXIX ${ }^{\text {ème }}$ colloque international de l'AFEAF, Bienne, 5 au 8 mai 2005, Besançon, Presses Universitaires de Franche-Comté, p. 549-564.

JEUNESSE C., HEHRETSMANN M., 1988, « La jeune femme, le cheval et le silo. Une tombe de La Tène ancienne sur le site de Wettolsheim, «Ricoh », Cahiers Alsaciens d'Archéologie d'Art et d'Histoire, vol. 31, p. 45-54.

JOHANSSON P., 2005, «Le spectacle de la mort sacrificielle chez les Aztèques », dans Le sacrifice humain en Égypte et ailleurs, J.-P. ALBERT, B. MIDANT-REYNES (dir.), Le sacrifice humain en Égypte ancienne et ailleurs, Études d'Archéologie n 6, Paris, Soleb, p. 234-247.

JOSSET D. (dir), 2009, « Commune de Neuville-aux-Bois (Loiret) « la Grande Route », Autoroute A19 - section Artenay-Courtenay », Rapport de fouille archéologique, Inrap Centre-Ile-de-France.

MÉNIEL P., 2001, Les Gaulois et les animaux : élevage, repas et sacrifice, Paris, Errance, 127 p.

MÉNIEL P., 1992, Les sacrifices d'animaux chez les Gaulois, Paris, Errance, 147 p.

MÉNIEL P., 2005, « La sépulture humaine et le dépôt d'animaux de Varennes-sur-Seine, Le Marais de Villeroy (Seine-et-Marne) », dans L'Âge de Fer en Ile-de-France, XXVI ${ }^{\text {ème }}$ colloque de l'AFEAF, Paris et Sain-Denis, Revue Archéologique du Centre de la France, 26, p. 181-191. 
MÉNIEL P., AUXIETTE G., GERMINET D., BAUDRY A., BEMILli C., 2009, « Une base de données sur les études de faunes des établissements ruraux en Gaule », dans I. BERTRAND, A. DUVAL, J. GOMEZ De SOTO, P. MAGUER (dir.), Habitats et paysans ruraux en Gaule et regards sur d'autres régions du monde celtique, actes du XXXI ${ }^{\text {ème }}$ colloque international de l'AFEAF, Chauvigny, 17 au 20 mai 2007, Chauvigny, Association des Publications Chauvinoises, vol. 33, p. 417-446.

PINARD E., DESENNE S., GAUDEFROY S., GRANSAR F., et collaborateurs, 2010, « Les gestuelles funéraires au Second Âge du fer en Picardie, dans P. BARRAL, B. DEDET, F. DELRIEU, P. GIRAUd, I. Le GOFF, S. MARION, A. VILLARD-Le TIEC (dir.), Gestuelles funéraires au Second Âge du fer, actes du XXXIII colloque international de l'AFEAF, Caen, mai 2009, Annales Littéraires, n 883 (Environnement, sociétés et archéologie, vol. II), p. 37-50.

SÉGUIER, J.-M., DELATTRE V., 2005, « Espaces funéraires et cultuels au confluent Seine-Yonne (Seineet-Marne) de la fin du $\mathrm{V}^{\mathrm{e}}$ au III $\mathrm{e}^{\mathrm{e}}$ siècle avant J.-C. », Revue Archéologique du Centre de la France, Suppl. 26, Actes du XXVI e colloque de l'AFEAF, Saint-Denis, p. 241-260.

TESTARD A., 2009, « Partir dans l'Au-delà accompagné ou le rôle des fidélités personnelles dans la genèse du pouvoir ", dans Sépultures et sociétés, Du néolithique à l'Histoire, Paris, Errance, p. 71-80.

THIOL S. 2002, Les guerriers gaulois de Ribemont-sur-Ancre (III siècle avant J.-C., Somme). Blessures au combat et traitement du cadavre. Thèse de doctorat, Université de Bordeaux 1.

TURNER R.-C. 1995, « The Lindow Bog Bodies : Discoveries and Excavations at Lindow Moss 1983-8 », dans R.C. TUNER, R.G. SCAIFE (eds.), Bog Bodies. New Discoveries and New Perspectives, London, The British Museum Press, p. 10-18.

VIAND A., AUXIETTE G., BARDEL D., 2008, « L'habitat hallstattien de Milly-la-Forêt « le Bois Rond » (Essonne) », Revue archéologique d'Ile-de-France, 1, p. 133-168.

VILLES A., 1987, « Une hypothèse : les sépultures de relégation dans les fosses d'habitat protohistorique en France septentrionale », dans H. DUDET, C. MASSET (dir.), Anthropologie physique et archéologie : méthodes d'étude des sépultures, actes du colloque de Toulouse, 4 au 6 novembre 1982, Paris, CNRS, p. 167-174.

\section{RÉSUMÉS}

Des dépôts d'animaux seuls, entiers et/ou segmentés parsèment la Gaule du second âge du Fer, sans pour autant s'apparenter à des offrandes alimentaires. Si le dépôt humain en silo relève de l'intention cultuelle et non de la relégation, le rôle de l'animal, sorte de plus-value " sacrificielle ", reste encore difficile à décrypter : parfois seul dans un silo, il peut être associé à un ou plusieurs humain(s). Toutes les combinaisons sont proposées! Certains animaux, dont le cheval, jouant un rôle déterminant dans le fait religieux celtique, semblent ici magnifier leur relation privilégiée avec l'homme. Ici, pas de hiérarchie quand les dépôts sont entiers voire lorsqu'il y a système de type pars pro toto : l'os isolé humain peut accompagner un animal entier, de même que le fragment d'animal peut s'associer au cadavre humain. Des différences apparaissent entre les humains et les animaux des dépôts, concernant la nature de leur mort, mais le traitement des cadavres comporte, en revanche, d'étonnantes similitudes, tel le pourrissement intentionnel des chairs, la reprise d'os secs, la préparation et l'exposition de fragments osseux sous forme de trophées. 
AUTEURS

\section{VALÉRIE DELATTRE}

Inrap CIF, UMR 6298 ARTeHIS-Université de Bourgogne

CRA de Croissy Beaubourg

\section{GINETTE AUXIETTE}

Inrap NP, UMR 8215 Trajectoires

De la sédentarisation à l'État

CRA de Soissons 


\title{
L'homme et l'animal dans les fosses du Mormont (Eclépens, Vaud, Suisse, vers 100 av. notre ère)
}

\author{
Patrice Méniel
}

Le site du Mormont implanté sur les communes d'Eclépens et de La Sarraz, à mi-chemin entre les lacs Léman et de Neuchâtel, sur la ligne de partage des eaux, a été découvert en 2006 (Brunetti et al., 2014); depuis il est fouillé par la société Archeodunum sur mandat de l'Archéologie du Canton de Vaud. Plus de deux cents fosses (fig. 1) ont été découvertes à proximité du sommet de cette colline calcaire sur une surface qui avoisine neuf hectares à l'issue de la campagne de 2015, sans qu'aucune limite, autres que celles imposées par le relief, n'ait encore pu être mise en évidence. Ces fosses, la plupart de forme cylindrique avec des diamètres de l'ordre du mètre (souvent de 0,80 à $1,20 \mathrm{~m}$ ), ont des profondeurs très variables, jusqu'à $6 \mathrm{~m}$, en grande partie déterminées par l'épaisseur de la moraine qui recouvre le banc calcaire. Le mobilier découvert dans ces fosses, très riche et diversifié ${ }^{1}$, assure une datation aux alentours des années 100 avant notre ère. En dehors de ces fosses, les structures sont assez rares. Il s'agit d'emplacements de foyers et de quelques trous de poteau ; certains à proximité des fosses laissent envisager des dispositifs de descente, mais aucun plan de bâtiment n'a été reconnu. En dehors de cette phase datée de la fin de l'âge du Fer, on trouve quelques structures du Hallstatt et une voie antique. Compte tenu de la nature des indices chronologiques, la durée de fréquentation de ce site est une sorte d'instantané archéologique, dont il est bien difficile de préciser, de quelques saisons à quelques années, l'ampleur. Ces indices relèvent de la typologie du mobilier céramique et métallique, mais on dispose également de quatre dates dendrochronologiques qui proviennent de bois abattus entre 107 et 102 (Hurni et Tercier, 2014). 
Figure 1 : Plan des fouilles de 2006 à 2011 sur le site du Mormont (DAO P. Méniel, d'après relevé Archeodunum), le pointillé indique la limite du décapage.

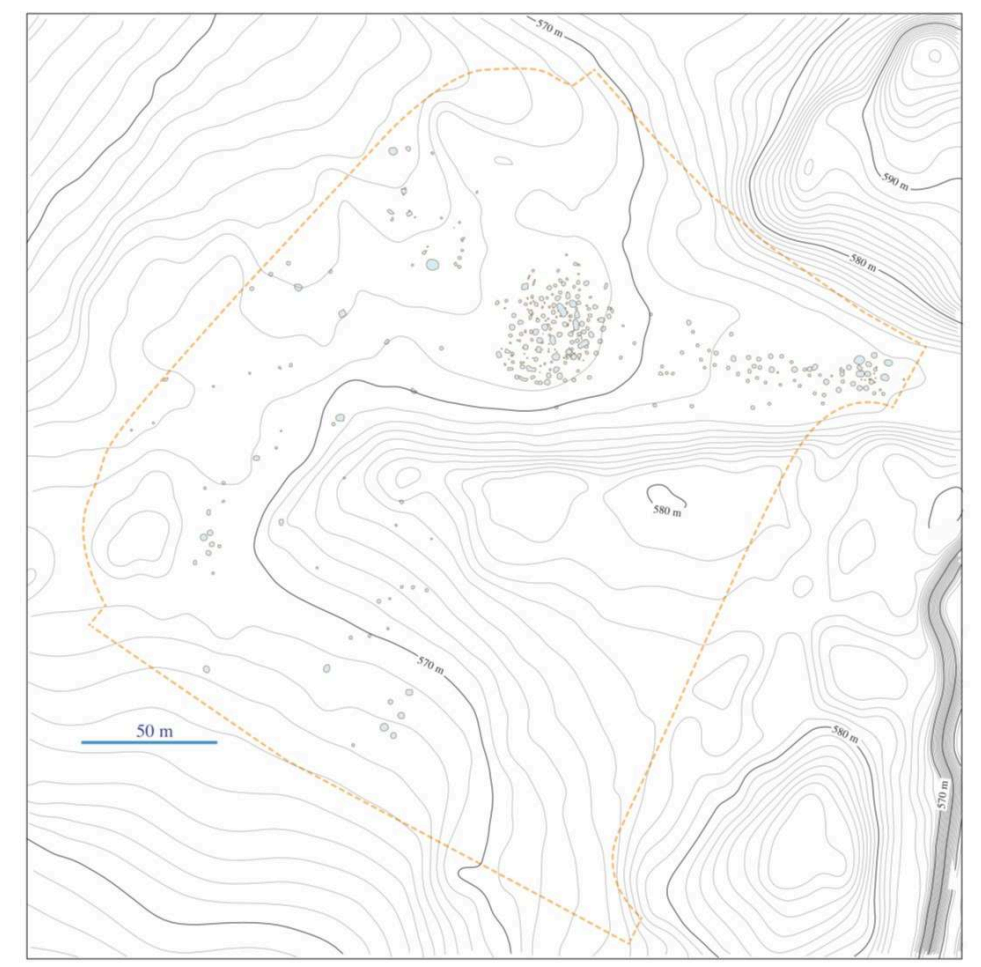

2 Nous ne connaissons pas de site analogue, aussi vaste, aussi riche et fréquenté sur une période aussi brève; la détermination de la nature de cette fréquentation est l'un des objectifs majeurs de la recherche menée par l'équipe constituée à la suite de cette découverte inattendue. Mais avant qu'une synthèse puisse être envisagée, il faut déjà que l'ensemble des études ait été mené à son terme. Or, le mobilier est en cours d'analyse et de publication, même si, compte tenu de son abondance, il a été décidé de publier les données des campagnes de 2006 à 2011, soit un peu moins de 200 fosses $^{2}$. Les restes animaux et humains ont fait l'objet d'une approche commune, que la démission de Patrick Moinat de son poste d'anthropologue a brusquement interrompu. C'est cette analyse qui est présentée ici. Elle est en grande partie inspirée de séances de travail sur les inventaires et de documents élaborés en commun, mais aucune rédaction n'avait été entreprise.

Sur les 193 fosses concernées, 185 ont livré des restes animaux et 70 des restes humains, dont une sans restes animaux (fosse 234, avec un squelette mature).

L'une des difficultés de l'approche tient aux modalités de comblement de ces fosses. Il est bien difficile de déterminer la nature des gestes (dépôt soigneux ou simple rejet) ou des circonstances (chute ou piégeage) qui ont conduit à la présence du mobilier dans les fosses; il est tout aussi difficile de déterminer les délais entre leur creusement et l'arrivée du mobilier, entre deux phases de dépôts, entre le dernier dépôt et le colmatage final. Si des niveaux de sédiments stériles séparent souvent des lots de mobiliers ${ }^{3}$, il est possible que des dépôts successifs n'aient pas bénéficié de cette forme de délimitation (fig. 2). D'autre part ces sédiments ont pu arriver rapidement ou lentement, mais faute d'analyses détaillées, il est souvent impossible de le savoir. Quoi qu'il en soit la superposition de ces ensembles mobiliers nous donne l'ordre d'arrivée 
des objets dans les fosses. C'est ainsi, qu'en règle générale, on constate que la vaisselle en bronze est enfouie plus profondément que les meules.

Figure 2 : Coupe de la fosse 256 creusée dans la moraine, avec un amas de faune à la base du remplissage (cliché Archeodunum).

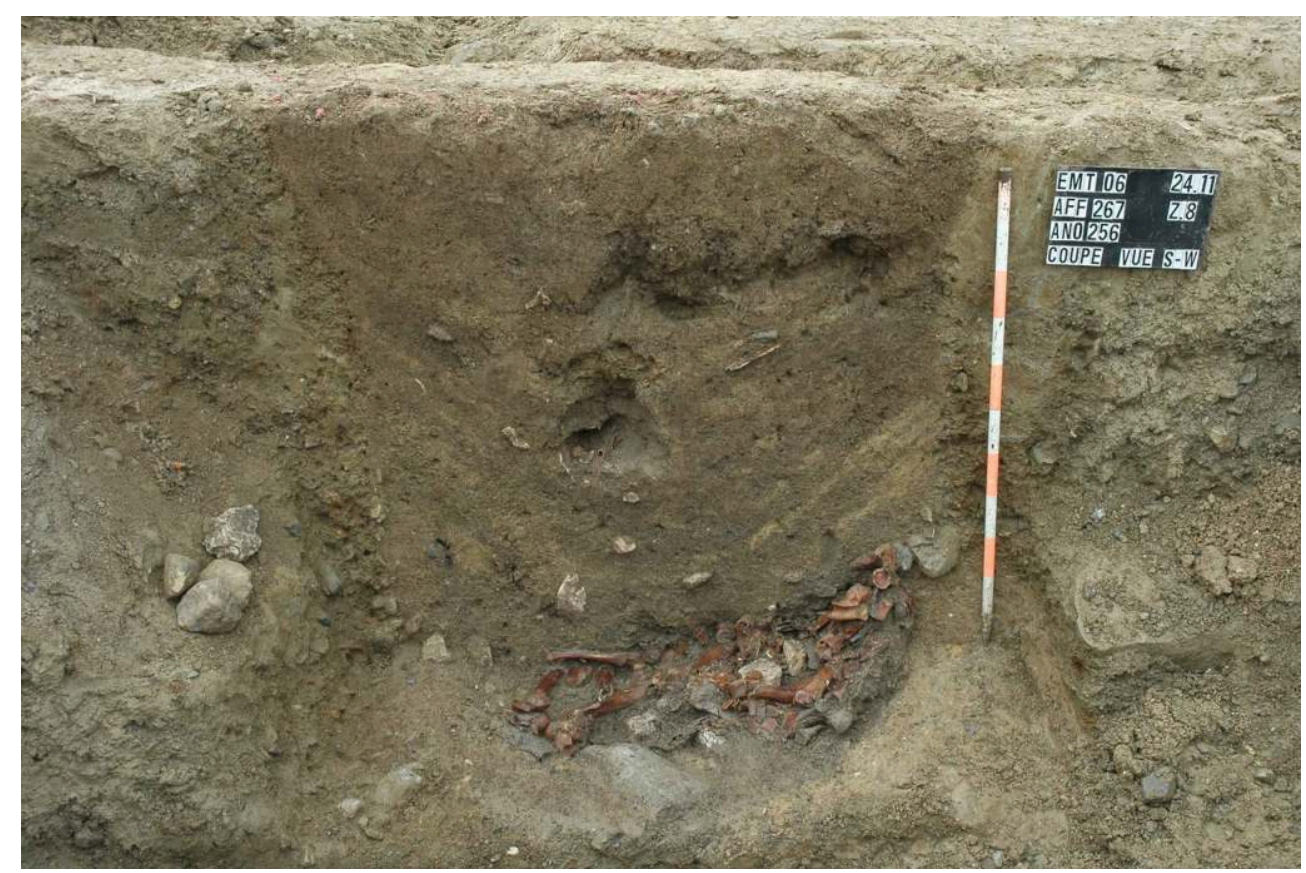

$5 \quad$ Mais ces dépôts successifs ajoutent un degré de complexité à l'approche. En effet, s'il est assez simple de conduire les analyses à l'échelle des fosses, c'est plus difficile avec les ensembles mobiliers, tant ceux-ci sont en nombre variable, jusqu'à sept par fosse, et diversifiés autant dans leur composition que leur richesse: certains n'ont qu'un vestige, d'autres plusieurs milliers. Enfin, leur superposition ne facilite pas l'approche cartographique pourtant bien adaptée à un site aussi étendu. Ces caractéristiques justifient une approche en deux temps des associations, la première au sein des fosses et la seconde au sein des ensembles mobiliers.

Les hommes et les animaux sont représentés de diverses manières : des os isolés, des ensembles anatomiques, des corps incomplets (qualifiés de carcasses pour les animaux) ou complets (squelette). Comme c'est l'usage en anatomie, nous avons distingué les crânes (os isolés) des têtes coupées (crâne avec mandibules ou cervicales attenantes).

7 Les os animaux étant publiés (Méniel, 2014), les humains étant en passe de l'être (Moinat, sous presse), il est évidemment hors de question de reprendre ici les résultats de ces monographies pour se consacrer uniquement aux associations entre l'homme et l'animal. Le point de départ de cette collaboration a été l'observation de pièces particulières, comme des scapulas et des mandibules de bœuf, mais aussi des chevilles osseuses de bovidés, associées à des ensembles anatomiques ou à des corps humains. De là est née la volonté d'établir un inventaire de ces dépôts communs afin de déceler d'éventuelles règles de dépôt (fig. 3). Ces associations revêtent des formes très diverses, qui vont d'une scapula de bœuf déposée entre les fémurs d'un squelette humain à un tibia humain portant des traces de découpe au sein d'un amas culinaire riche de plusieurs centaines de restes animaux, de bovins en particulier. En effet, ces derniers sont largement majoritaires sur le site ( $62 \%$ des restes, $51 \%$ des individus), et quelques 
catégories d'os se distinguent par leur fréquence élevée. Il s'agit des mandibules (elles proviennent d'au moins 165 sujets), puis des crânes (78 sujets), des scapulas (86 sujets) et des humérus (73 sujets); les autres os impliquent moins d'une cinquantaine d'individus (Méniel, 2014, p. 143).

Figure 3 : Tableau des associations entre les différentes catégories de vestiges humains et animaux (DAO P. Moinat), avec les numéros de fosses concernées.

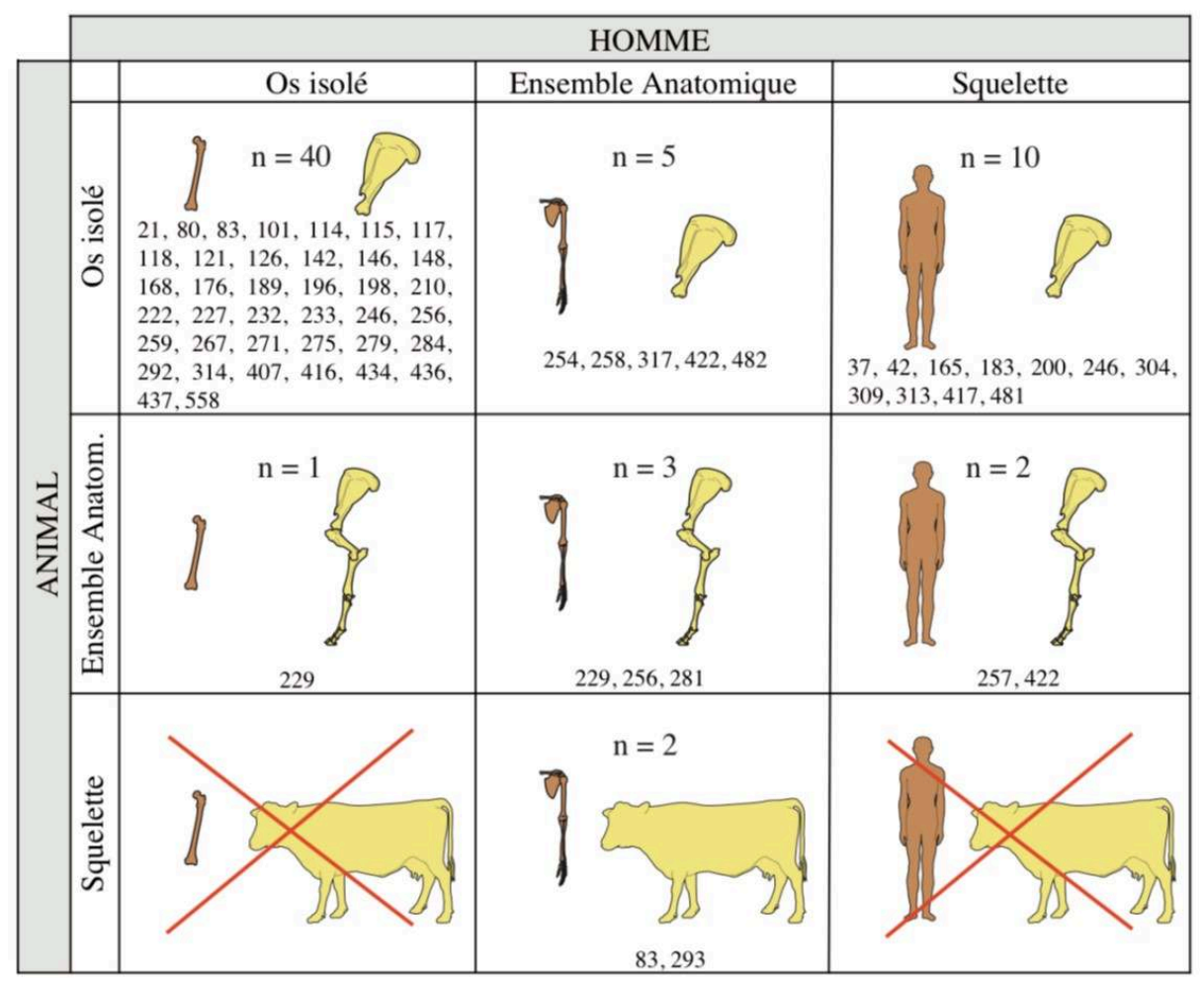

8 Les os sont souvent mal conservés et leur prélèvement ne fait qu'accentuer un état de dégradation qui s'aggrave parfois de manière dramatique lors de la dessiccation. Dans ces circonstances, l'enregistrement des observations sur le terrain, qu'il s'agisse de photos, de dessins ou d'inventaires, s'avère bien évidemment primordial. Cela donne assez régulièrement des documents spectaculaires qui témoignent de dépôts réalisés dans des circonstances assez différentes de celles en vigueur sur un dépotoir d'habitat. Cela tient à la fois à la nature des objets déposés et au fait qu'ils sont souvent peu fragmentés et parfois accumulés en grand nombre. La diversité de ces dépôts est une autre caractéristique de ce site. En effet, il est bien difficile de trouver des fosses au comblement analogue, ce qui, compte tenu de leur nombre est évidemment assez surprenant.

\section{Présentation de quelques fosses}

Des restes humains et animaux ont été trouvés dans 59 fosses (et dans 68 ensembles mobiliers), aussi cette présentation est limitée à quelques cas permettant d'illustrer ces dépôts et leur diversité.

En ce qui concerne les têtes, quatre têtes coupées et deux crânes humains, ainsi que quatre-vingt-six crânes d'animaux ont été découverts. Malgré cette abondance, 
seulement deux associations ont été observées : un crâne humain associé à celui d'un bœuf (292-EM3, fig. 4) et un autre à une tête osseuse de mouton (229-EM1). Les dix autres associations de crânes n'impliquent que des animaux ${ }^{4}$.

11 Les dépôts de corps complets ou de parties de corps se distinguent nettement de ceux des os isolés et fragmentés et nous les avons traités séparément. Lors de son étude, qui en plus de l'inventaire a comporté une longue série de mise au propre des relevés, P. Moinat a remarqué la présence récurrente de certaines catégories d'os de bœuf, comme des scapulas, des mandibules (fig. 5) et des chevilles osseuses, à ces dernières s'ajoutant parfois celles de caprinés. Par contre, il n'a pas été observé de liens directs avec les vingt squelettes ou carcasses de cheval, un seul sujet ayant été trouvé dans une fosse avec un corps humain incomplet (fosse 42). Toutefois, il faut mentionner la fosse 422 (EM2) où les restes des membres antérieurs d'un cheval (des radius aux phalanges) ont été trouvés à proximité d'un squelette humain adulte déposé au-dessus d'un premier dépôt de corps incomplet (fig. 5). Malheureusement, ces restes étaient bien mal conservés et il est difficile de préciser l'état initial de cet ensemble : il pourrait s'agir d'une carcasse de cheval.

Figure 4 : Crânes humain et bovin dans la fosse 292 (cliché Archeodunum).

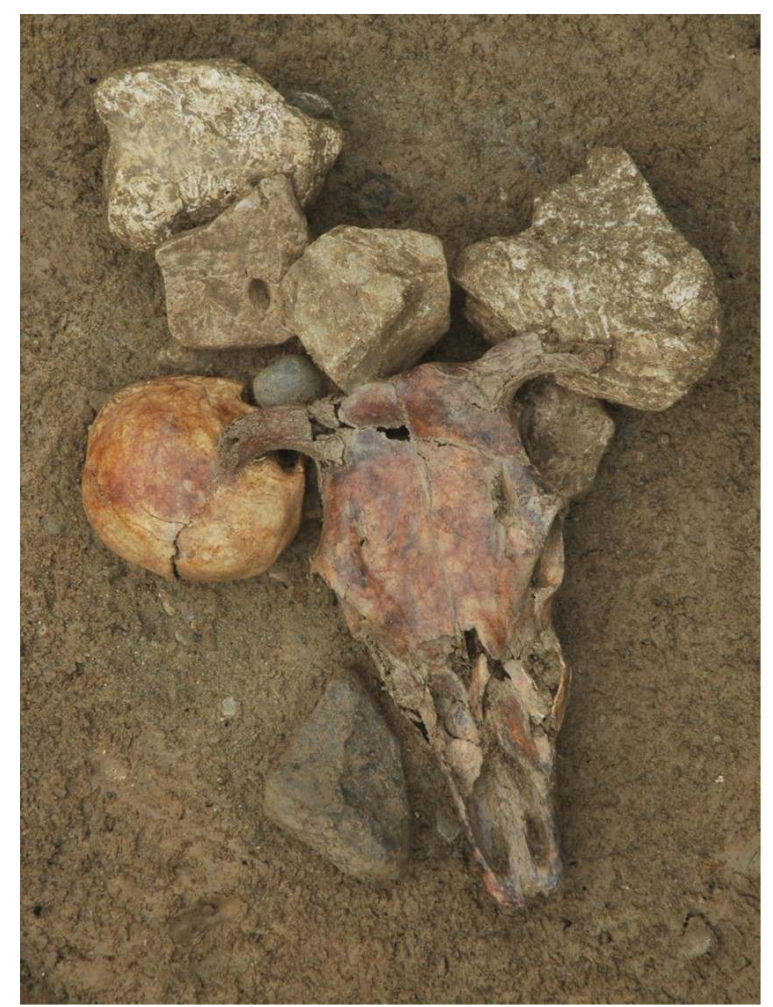


Figure 5 : Dépôt de corps incomplets au fond de la fosse 422 (EM1), avec une scapula (flèche rouge) et une paire de mandibules de bœuf (flèche verte) (cliché Archeodunum).

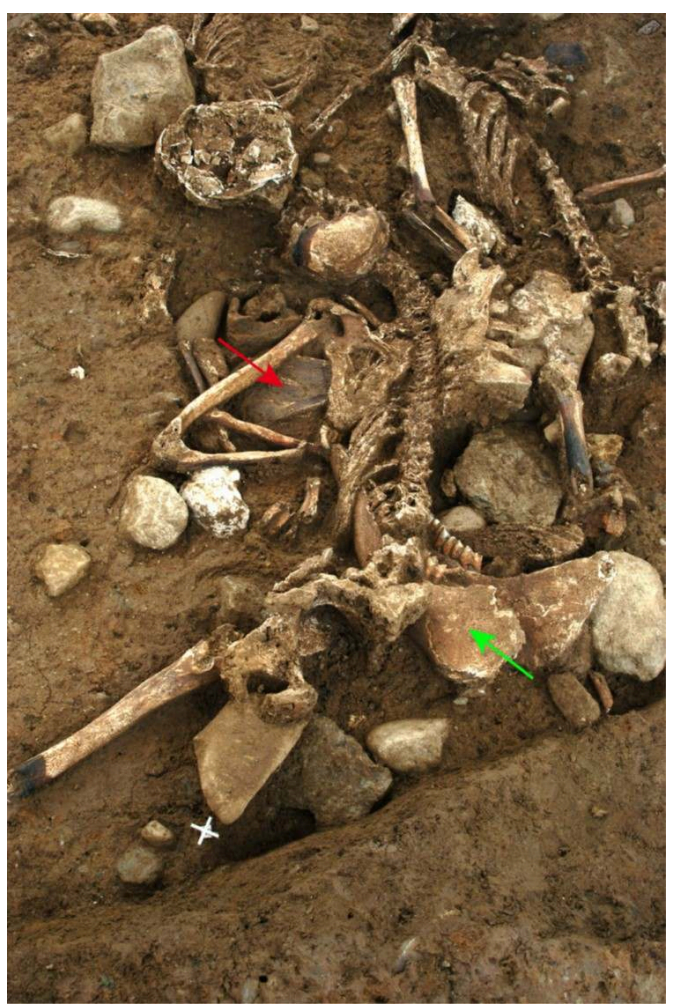

Plus fréquentes sont les associations avec les squelettes de mouton (6 squelettes et 2 carcasses) et de chèvre ( 2 squelettes, dont un sans tête). En effet, deux dépôts de trois moutons ont été découverts, le premier dans la fosse 83, recouvert par le squelette d'une vache (sans tête ?), puis par les restes d'un enfant, ces derniers difficiles à décrire $\mathrm{du}$ fait d'une fouille chaotique, et le second dans la fosse 481, d'où provient le squelette d'une femme adulte. Enfin une chèvre sans tête a été relevée dans le fond de la fosse 42 déjà citée; elle y a été recouverte par le squelette d'un cheval, puis par celui d'un enfant; dans ces trois fosses, les caprinés sont enfouis plus profondément que les humains, et ne leur sont pas associés directement.

En définitive, si la plupart (sept sur dix) des squelettes de caprinés sont associés à des corps, complets ou non, humains, il en va bien autrement pour le bœuf (un seul cas pour huit squelettes et deux carcasses) et le cheval (un ou deux cas sur dix squelettes et dix carcasses), la plupart de leurs squelettes provenant de fosses sans dépôt humain. La question de l'éventuelle association avec des squelettes de chien ne se pose pas, aucun n'ayant été découvert. Même si cette espèce est peu fréquente, sept sujets sont quand même attestés, cette absence de squelettes est un nouveau trait original de cet ensemble.

\section{Des associations homme animal volontaires ou fortuites?}

L'abondance des restes animaux fait qu'ils sont présents dans presque toutes les fosses (184 sur 194), ce qui explique qu'il n'y ait qu'une fosse avec un squelette humain sans reste animal. Il convient donc de s'interroger sur l'origine des associations, à savoir si 
elles sont le fruit d'une volonté délibérée révélatrice d'une règle ou d'une prescription, ou s'il s'agit de juxtapositions fortuites résultant de l'abondance du mobilier enfoui dans les fosses. Il s'agit de comparer les fréquences observées à la fouille à celles issues $\mathrm{du}$ calcul des probabilités de ces associations dans les 194 fosses. Cette approche a d'abord été menée pour les espèces en présence, puis pour les pièces particulières (scapula, mandibule, cheville osseuse) remarquées sur le terrain à côté des corps humains. Le seul outil à notre disposition pour ce faire consiste à tester le nombre de cas observés à celui donné par le calcul des probabilités. Il repose sur l'indépendance des séries de données : des tirages dans le «stock» des restes humains sont sans effet sur celui des animaux. Aussi la probabilité de trouver des os humains avec ceux d'une espèce animale, ou d'une catégorie d'os, est le produit des probabilités de chacun de ces deux événements. Cette probabilité permet d'estimer le nombre de fosses où l'association considérée est le fruit du jeu des effectifs en présence. La comparaison avec le nombre de cas observés peut mettre en évidence l'absence d'anomalies, et donc de choix délibérés, ou des écarts positifs (préférences) ou négatifs (exclusions).

\section{Les associations homme animal dans les fosses}

Une restriction à cette approche des associations par fosse concerne les fragments d'os isolés humains, à part les crânes. Ces restes fragmentaires ne seront considérés que dans l'approche par ensembles mobiliers.

Dans un premier temps, cette approche implique donc 24 fosses avec des ensembles anatomiques humains. Parmi ces dernières, 23 ont livré des restes de bœufs, 14 des restes de porcs, 16 des restes de caprinés, 11 des restes de chevaux et 2 des restes de chiens. Le calcul des probabilités donne, pour le bœuf ${ }^{5} 23$ fosses où cette association est attendue, ce qui est bien le nombre observé ; c'est la même chose pour le porc et le chien. Par contre, un petit écart positif apparaît pour les caprinés (16 cas observés pour 15 attendus) et un léger déficit pour le cheval (11 observés pour 13 attendus).

Dans un deuxième temps, on peut considérer les associations d'ensembles anatomiques et de squelettes. Pour les caprinés, deux faits ont été notés à la fouille : la présence simultanée de squelettes et de restes humains dans quatre fosses, et celle d'un pied de mouton dans deux autres (fosses 229 et 417). En effet, tous les squelettes de moutons, soit deux dépôts de trois sujets, et l'un des deux corps incomplets de chèvres, ont été enfouis dans des fosses qui ont livré des corps humains, un complet et deux incomplets. Pour ces ensembles anatomiques de caprinés, le nombre de fosses donné par le calcul des probabilités $(0,6)$ est cinq fois moindre que celui observé (3). Il y a là un réel écart, sans commune mesure avec ceux constatés pour les squelettes ou carcasses de bœuf (2 cas observés pour 1 attendu), de porc (1 pour 1 ) ou de cheval (3 pour 2). De même, pour les pieds de mouton l'écart n'est pas significatif (2 pour 2).

\section{Les associations homme animal dans les ensembles mobiliers}

En tout ce sont 502 ensembles mobiliers qui ont été individualisés dans les 193 fosses considérées. Nous avons testé les associations d'espèces puis la présence de mandibules 
et de scapulas de bœuf (fig. 6), et de chevilles osseuses de bœuf, mouton et chèvre, avec des squelettes ou des ensembles anatomiques humains.

Le nombre d'ensembles mobiliers où le porc est associé à l'homme est de neuf, c'est aussi l'effectif donné par le calcul statistique. Par contre, il a été trouvé plus d'ensembles mobiliers avec des restes de bovins ou de caprinés que ceux attendus (20 pour 18 pour les bovins; 12 pour 9 pour les caprinés), mais c'est l'inverse pour le cheval (4 trouvés pour 9 estimés); pour le chien l'écart est moindre (1 pour 2).

Des scapulas de bœufs sont présentes dans 75 des 504 ensembles mobiliers, et dans 6 des 26 ensembles mobiliers avec des restes humains. Cet effectif outrepasse légèrement le nombre de quatre cas, issu du calcul de probabilité (75/504 x 26). Pour les mandibules, présentes dans 130 ensembles mobiliers, l'estimation donne sept cas, l'inventaire six. Pour les chevilles, de bœuf, mouton ou chèvre, le nombre de fosses observé et estimé est de cinq. On voit, là encore, qu'il n'y a guère d'écart entre les effectifs observés et ceux donnés par le calcul des probabilités.

Figure 6 : Scapula de bœuf (flèche rouge) à proximité du corps humain de la fosse 257 (cliché Archeodunum).

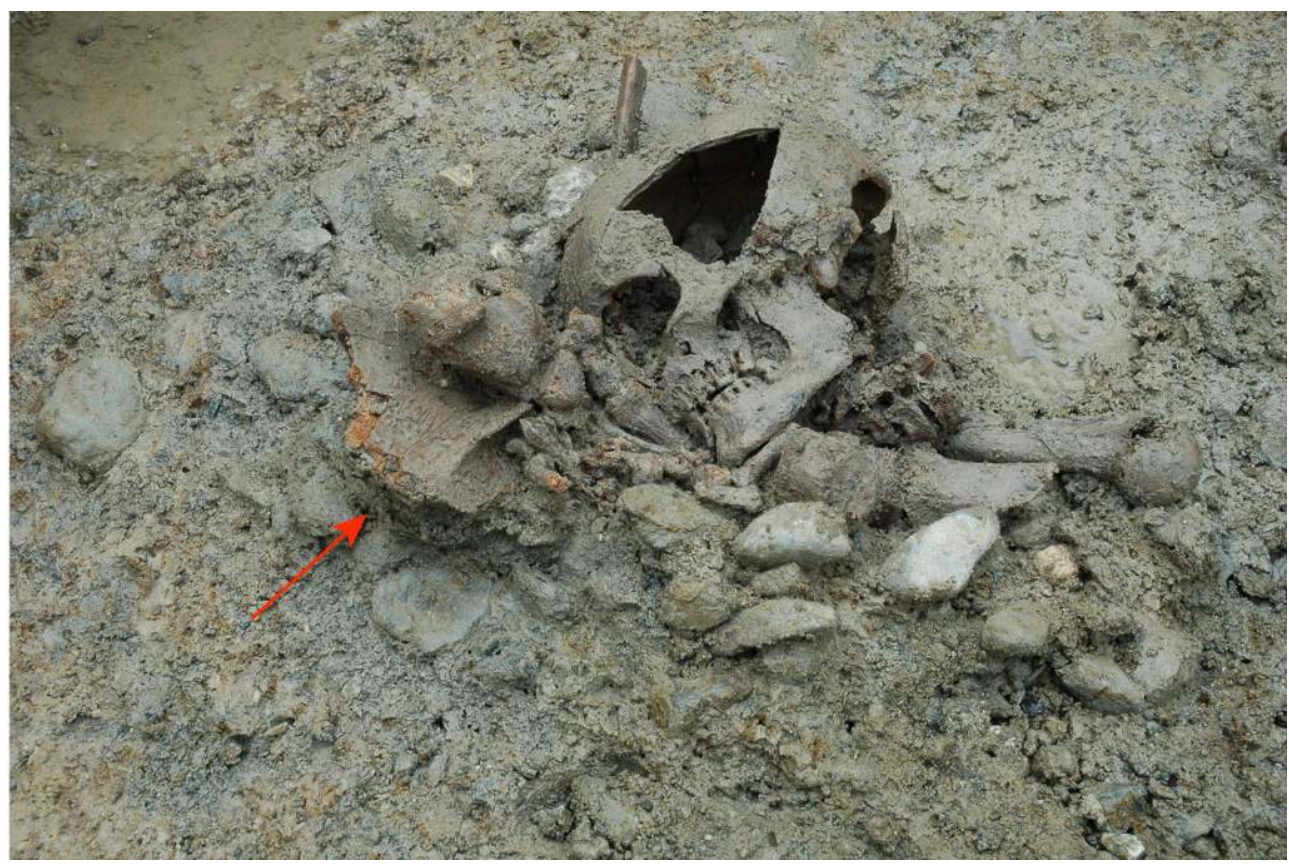

Des os humains isolés (hors crâne) ont été découverts dans 44 ensembles mobiliers dont 7 dépourvus de restes animaux. Le nombre moyen de restes animaux déterminés dans ces ensembles mobiliers est de 94 ; c'est exactement le même que pour la totalité des ensembles mobiliers du site. La comparaison des occurrences des espèces avec celles issues des probabilités (fig. 7) fait ressortir des écarts positifs, c'est-à-dire que les associations avérées sont plus nombreuses que celles issues du calcul des probabilités ; c'est pour le chien que l'écart est le moins prononcé. Huit de ces ensembles mobiliers correspondent à des amas culinaires de plus de 50 restes. Dans quelques cas, les os humains retrouvés dans ces amas portent des traces de découpe ce qui soulève la question de l'anthropophagie. Ces amas culinaires, au nombre de 46, qui comportent habituellement des tessons de céramique et des charbons de bois, ont des compositions en ossements assez diversifiées, ce qui permet de tester une autre forme d'association, 
à savoir celle qui relève de la consommation de la viande. Le sériographe ${ }^{6}$ (Desachy, 2004) de la composition de ces 46 amas (fig. 8) permet de distinguer six groupes, chacun caractérisé par une ou deux espèces animales privilégiées. Les restes humains se répartissent de manière assez inégale entre ces groupes, mais c'est avec les amas riches en caprinés que les associations s'avèrent les plus fréquentes (4 sur 13) ; à l'opposé c'est avec les amas riches en porc qu'elles sont les plus rares (1 sur 11). Les associations d'os humains avec les bœufs et les chevaux sont analogues (respectivement 5 sur 27 et 3 sur 14).

Figure 7 : Comparaison entre les nombres d'ensembles mobiliers recelant des os animaux associés à des os isolés humains et les nombres issus du calcul des probabilités (DAO P. Méniel).

nombre d'ensembles mobiliers

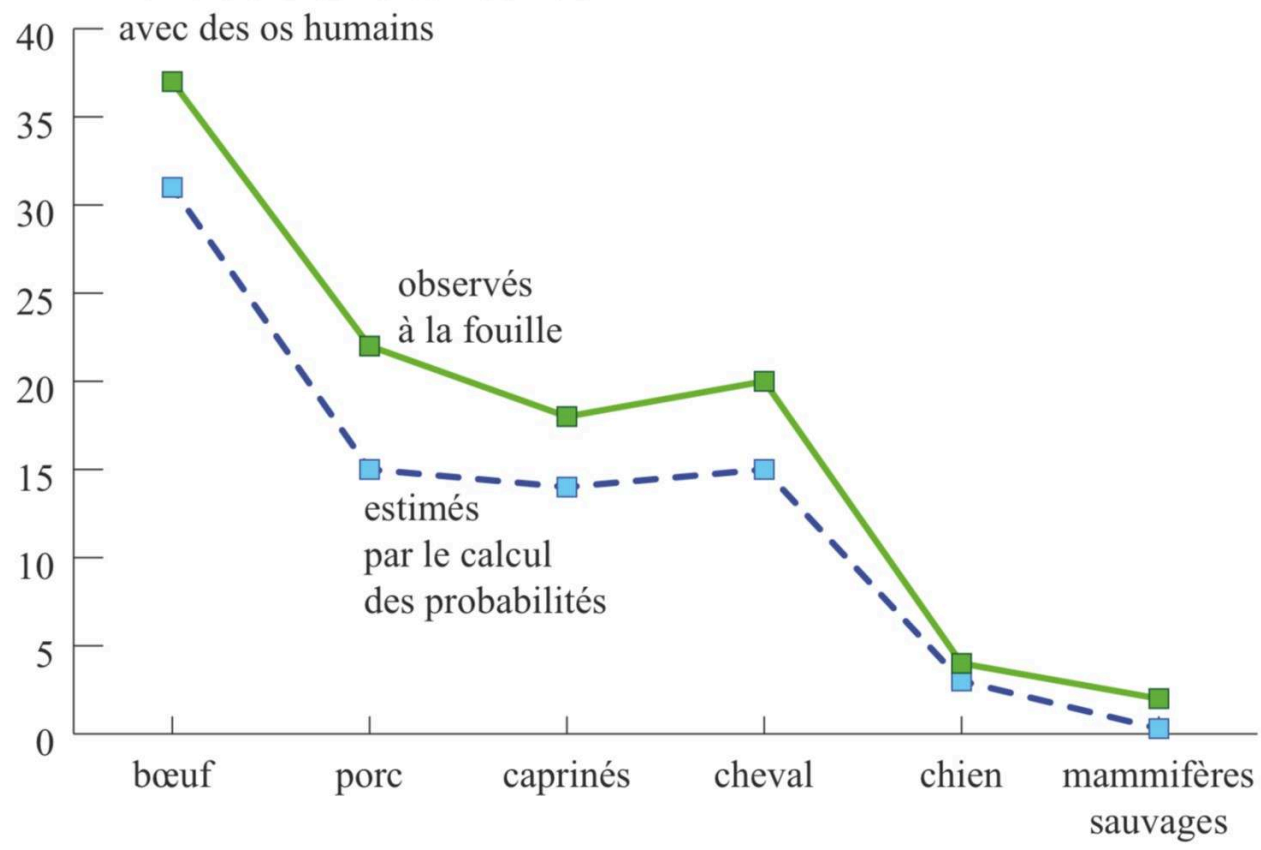


Figure 8 : Sériographe des compositions des amas culinaires contenant des os humains.

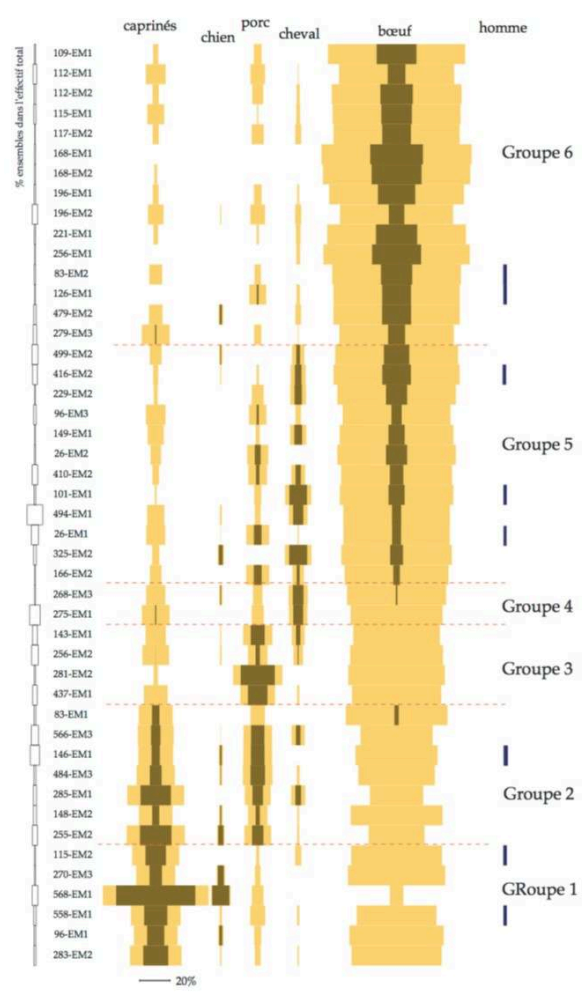

En jaune ce sont les pourcentages des espèces d'après les nombres de restes déterminés, en sombre les écarts positifs à la moyenne. Cette sériation permet de distinguer six groupes d'ensembles mobiliers dominés, du bas vers le haut, par les caprinés ( 6 ensembles), les caprinés et le porc (7 ensembles), le porc (4 ensembles), le cheval (2 ensembles), le cheval et le bœuf ( 12 ensembles) et le bœuf ( 15 ensembles du haut). Les restes humains se distribuent de façon aléatoire entre ces divers groupes, sans association privilégiée (DAO P. Méniel).

\section{Synthèse}

De cette approche, il ressort qu'une bonne partie des observations réalisées lors de la fouille, à savoir des associations entre des restes humains et animaux, impliquant diverses catégories de vestiges, s'avèrent difficiles à distinguer de juxtapositions fortuites dans les fosses. C'est le cas notamment pour les mandibules, les scapulas et les chevilles osseuses de bœuf, pour lesquelles il n'apparaît aucun lien privilégié. Seule l'association de la plupart des squelettes de caprinés, et en particulier les deux dépôts de trois moutons, avec des restes humains dans trois fosses s'avère significative. Par contre, vis-à-vis des estimations fondées sur le calcul des probabilités, un léger déficit des liens entre le cheval et l'homme apparaît.

Si cette étude des associations entre l'homme et l'animal dans ces fosses et ces dépôts ne conduit pas à la mise en évidence de règle particulière, cela ne remet évidemment pas en cause la nature particulière des mobiliers découverts dans ces fosses. Que ce soit pour l'homme ou l'animal, la juxtaposition d'ossements isolés et (peu) fragmentés, d'ensembles anatomiques, de corps complets ou non, témoigne d'une diversité de traitements qui n'a guère d'équivalents ailleurs. En effet, si des corps complets relèvent d'inhumations, les os isolés, fragmentés et parfois découpés, renvoient plutôt à la consommation de la viande. Les corps humains incomplets et les carcasses d'animaux, 
apparemment ${ }^{7}$ dépourvus de traces de découpe, ont subi une phase de décomposition préalable en dehors des fosses où ils ont été amenés avec les pertes inhérentes à ce type de transfert. Or ces trois catégories de pratiques, l'inhumation, la consommation et la décomposition (exposition?), si elles recouvrent l'essentiel des traitements applicables à des corps suite au décès ${ }^{8}$, il est rare qu'on en trouve l'expression sur un même site, et tout à fait exceptionnel qu'elles concernent toutes les espèces (sauf le chien, qui n'a été que consommé). En effet, cela signifie que des sujets ont été consommés alors que d'autres ne l'étaient pas et cette dualité fondamentale dans la définition des sacrifices animaux en Gaule (Méniel, 2008, p. 108) ne repose ni sur l'âge, ni sur le sexe.

Ce constat sur la diversité des états des corps animaux et humains peut, dans une certaine mesure, être étendu aux autres catégories de mobiliers, des objets complets côtoyant des fragments de tailles variées. Ces vestiges témoignent de traitements inhabituels, entre pratiques alimentaires, parfois d'ampleur, dont témoignent des fragments de céramique, des ossements et des charbons de bois, et des enfouissements d'objets entiers ou peu fragmentés, en quantités variables, qui résultent de gestes qui nous éloignent des pratiques du quotidien. Ces pratiques se sont déroulées pendant un temps relativement court (Brunetti et al., 2014) sur un site très étendu (9 ha explorés à ce jour), sans limites autres que naturelles et où l'essentiel des structures consiste en fosses, dont la profondeur dépend souvent de l'épaisseur de la moraine, auxquelles s'ajoutent quelques trous de poteau dont il est bien difficile de tirer un plan d'ensemble, et quelques traces de foyers. Tout cela montre que nous ne sommes pas en présence d'un habitat permanent sur ce qui aurait pu être un oppidum naturel, aucune fortification ne venant combler les quelques lacunes de la ceinture de pentes, parfois de falaises, qui en limitent l'accès de façon assez efficace. Il ne s'agit pas non plus d'un sanctuaire analogue à ceux déjà connus en Gaule (Brunaux et al. 1985; Mantel 1997; Bourgeois, 1999), beaucoup plus petits, avec des limites fossoyées et des durées de fréquentation de plusieurs siècles. Peut-être sommes-nous en présence d'un lieu de culte sur un site naturel d'un type inconnu à ce jour? Peut-être s'agit-il d'un lieu de bivouac d'une troupe en campagne, sachant que les Cimbres et les Teutons sont passés dans la région dans les dates de fréquentation révélées par la dendrochronologie?

Mais avant d'envisager ces interprétations, il convient de poursuivre l'enquête jusqu'à la synthèse des observations relatives à l'ensemble des structures et des mobiliers.

\section{BIBLIOGRAPHIE}

BOURGEOIS L. (dir.), 1999, Le sanctuaire rural de Bennecourt (Yvelines), du temple celtique au temple gallo-romain, DAF, 77.

BRUNAUX J.-L., MÉNIEL P. et POPLIN F., 1985, Gournay I : les fouilles sur le sanctuaire et l'oppidum (1975-1984), Amiens, Revue Archéologique de Picardie, numéro spécial 4.

BRUNETTI C., KAENEL G. et MÉNIEL P. (dir.), 2014, Les Helvètes au Mormont, Gollion, Archéothéma (hors-série, 7). 
BRUNETTI C. et NITU C. (dir.), sous presse, Mormont I : Site et structures, Lausanne, Cahiers d'Archéologie romande.

DESACHY B., 2004, «Le sériographe EPPM : un outil informatisé de sériation graphique pour les tableaux de comptages », Revue archéologique de Picardie, n³/4, p. 39-56.

HURNI J.-P. et TERCIER J., 2014, « Les bois du Mormont », Archéothéma, hors-série n 7, p. 76.

MANTEL E. (dir.), 1997, Le sanctuaire de Fesques « le Mont du Val aux Moines » (Seine-Maritime), Berck, Nord-Ouest Archéologie, 8.

MÉNIEL P., 2008, Manuel d'archéozoologie funéraire et sacrificielle (Âge du Fer), Gollion, Infolio, Collection Vestigia.

MÉNIEL P., 2014, Mormont II : les restes animaux. Les restes animaux du site du Mormont

(Eclépens et La Sarraz, Canton de Vaud, vers 100 avant J.-C.), Lausanne, Cahiers d'Archéologie romande, $\mathrm{n}^{\circ} 150$.

MOINAT P., sous presse, Mormont III : Les restes humains. Archéo-anthropologie du Mormont, Lausanne, Cahiers d'Archéologie romande.

\section{NOTES}

1. Il comporte de la céramique en abondance, du mobilier métallique (vaisselle, outils, ustensiles de cuisine, barres, bijoux, quelques monnaies, mais pas d'arme), des déchets d'activités métallurgiques, et une série de meules très importante.

2. Les structures (Brunetti et Nitu, sous presse), les restes animaux (Méniel, 2014) et les vestiges humains (Moinat, sous presse) sont publiés ou sous presse. Les volumes sur la céramique (C. Brunetti), le mobilier métallique et autres matériaux (G. Kaenel) sont en préparation.

3. Ces lots, qualifiés d'ensembles mobiliers (E-M), sont au nombre de 502.

4. Crânes de bœuf et de porc (117-EM3); de bœuf et de cheval (284-EM1, 288-EM3); de bœuf et de chèvre (121-EM1, 149-EM1); de bœuf, porc, mouton et cheval (566-EM2); de deux porcs (146EM1) ; de deux chevaux (256-EM3, 554-EM2); de cheval et de chèvre (275-EM1).

5. La probabilité de trouver du bœuf et de l'homme dans une fosse est le produit de la probabilité de trouver du bœuf dans une fosse (soit $n$ fosses avec bœuf/ $n$ total de fosses : 184/194) et de la probabilité de trouver de l'homme dans une fosse (n fosses avec de l'humain/n total de fosses : $24 / 194)$, soit 0,12 . Le nombre de fosses où l'on peut attendre l'association du bœuf et de l'homme est alors de $194 \times 0,12=23$ fosses.

6. Un sériographe est une représentation graphique d'une sériation basée sur les pourcentages, établis ici à partir des nombres de restes déterminés par espèce et par ensembles mobilier, qui fait ressortir les écarts positifs à la moyenne (en sombre) et qui permet de distinguer des groupes de compositions (Desachy, 2004).

7. L'état de conservation des surfaces osseuses ne facilite pas la détection des traces de découpe, ni de mise à mort. En effet, les quelques traces de saignées relevées sur des atlas concernent exclusivement des animaux consommés. On ne sait donc pas comment sont morts les animaux représentés par des squelettes ou des carcasses. En particulier, il n'a pas été observé de trace de coup de hache sur les crânes comme c'est le cas sur certains sanctuaires gaulois.

8. Sur le site du Mormont, la crémation n'a été attestée que très récemment pour l'homme (un cas sur la fouille de 2015), mais elle l'est bien pour les animaux, sauf pour le cheval. La question est de savoir si nous sommes en présence de traces d'un rite ou de traces de l'usage des os animaux comme combustible dans une situation de crise. 


\section{RÉSUMÉS}

Le site protohistorique du Mormont a été le lieu d'implantation de plusieurs centaines de fosses, la plupart cylindriques, creusées dans la moraine recouvrant le socle calcaire d'une colline qui se présente comme une place forte naturelle, mais dépourvue de fortification. À côté d'un mobilier riche et diversifié (céramique, outils en fer, bijoux, vaisselle en bronze, déchets d'activité, meules...), ces fosses recèlent des restes humains et animaux, abondants et variés, avec des os isolés, des ensembles anatomiques, des corps incomplets et des squelettes. Une approche fondée sur le calcul des probabilités des associations récurrentes notées à la fouille entre restes humains et mandibules, chevilles osseuses ou scapulas de bœuf, montre que ces associations sont fortuites et ne relèvent pas de gestes délibérés. Cela n'enlève rien au caractère particulier de ce site, dont l'analyse en cours s'efforce de préciser la nature d'une fréquentation très brève vers les années 100 avant notre ère.

\section{AUTEUR}

\section{PATRICE MÉNIEL}

Directeur de recherche CNRS,

ARTEHIS, Dijon 
Les mandibules de cheval de l'abri Duruthy (Sorde-l'Abbaye, Landes) : contexte archéologique et mise en perspective ontologique au sein $d u$ Magdalénien des Pyrénées

\author{
Clément Birouste, François-Xavier Chauvière, Frédéric Plassard et \\ Morgane Dachary
}

L'étude présentée dans cet article a été en partie financée par L'ANR MAGDATIS : que ses coordinateurs (Jean-Marc Pétillon, Mathieu Langlais, Véronique Laroulandie et Sandrine Costamagno) trouvent ici tous nos remerciements pour leur aide. Nous exprimons toute notre gratitude au Service Patrimoine du département des Landes, en particulier Sylvie Tersen et Delphine Haro-Gabay, qui nous ont autorisés à accéder aux vestiges découverts dans l'abri Duruthy. Le Service Régional de l'Archéologie d'Aquitaine nous a permis de consulter les archives de Robert Arambourou et de François Bordes : merci à Nathalie Fourment, Olivier Ferullo et Sandra Boussaguet pour leur aide précieuse.

\title{
Duruthy
}

1 Parmi les différents gisements archéologiques de la falaise du Pastou (Sorde-l'Abbaye, Landes), l'abri Duruthy s'impose comme une référence pour la connaissance du Paléolithique supérieur des Pyrénées occidentales (fig. 1 ; Arambourou, 1990 ; Dachary, 2002, 2006, 2009). Dès 1874, l'établissement d'une puissante stratigraphie et l'abondance de restes humains d'époque préhistorique mis au jour dans le fond de la cavité ont contribué à sa notoriété (Lartet et Chaplain-Duparc, 1874a, b et c ; HenryGambier, 2006). L'ensemble paléoanthropologique le plus connu (Sorde 1) était composé d'une calotte crânienne et d'os longs dont l'association avec des canines de grands carnivores, longtemps considérée comme allant de soi, ne s'avère que possible, 
après une révision récente (Chauvière, 2001). Un second ensemble était constitué d'un ossuaire d'âge holocène qui coiffait la séquence sédimentaire.

Figure 1 : Localisation de l'abri Duruthy ; vue générale de la falaise du Pastou (d'après Lartet et Chaplain-Duparc, 1874) ; plan de masse du gisement avec localisation du locus étudié (d'après Dachary, 2002).

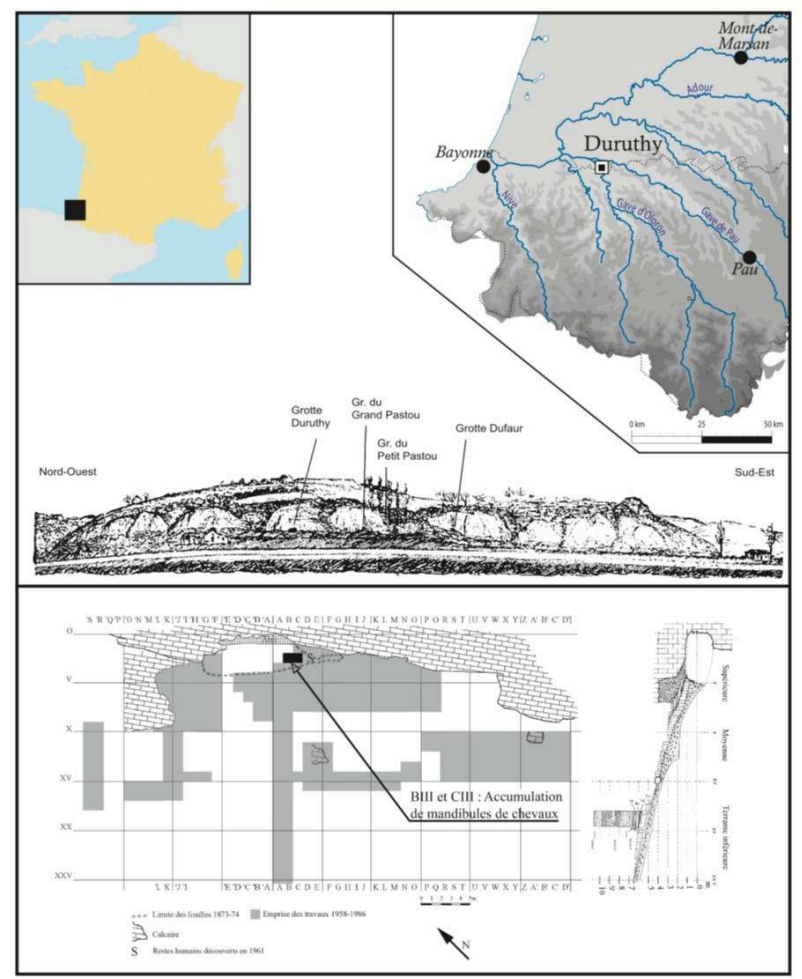

2 Menées de 1957 à 1986, les fouilles de R. Arambourou ont précisé une chronostratigraphie qui rend compte de la présence des stades moyen et supérieur du Magdalénien, d'occupations aziliennes et de pratiques sépulcrales chalcolithiques (Arambourou, 1978 ; Dachary, 2002).

En 1961, les opérations de terrain ont occasionné la découverte de vestiges exceptionnels qui ont définitivement assis la renommée de Duruthy. Il s'agit, d'une part, d'un autre ensemble de restes humains (Sorde 3) et, d'autre part, de trois sculptures de cheval attribuées au Magdalénien moyen et localisées dans un endroit bien circonscrit de l'abri (l'une est en grès, l'autre en calcaire marneux et la dernière en ivoire ; Arambourou, 1962). La présence d'une accumulation de mandibules de cheval à proximité, voire directement au contact de ces trois figurations d'équidés, accentue le caractère insolite d'un assemblage qui n'a jamais été publié en détail (Sacchi, 1990, p. 19).

4 L'inventaire d'une partie des collections de Duruthy conservées à l'abbaye d'Arthous a été l'occasion de retrouver ces vestiges exceptionnels et de procéder, sur l'instigation de l'un d'entre nous (FXC), à un retour ciblé sur l'accumulation des mandibules de cheval, suspectant un traitement original de ces éléments anatomiques. 


\section{Les mandibules de Duruthy dans leur contexte archéologique}

5 À plusieurs reprises, R. Arambourou décrit les découvertes de l'année 1961 à Duruthy. Il explicite les relations contextuelles entretenues par les mandibules de cheval avec les vestiges recueillis dans une zone à la superficie restreinte. La description qu'il présente dans la publication monographique consacrée à Duruthy résume l'essentiel de ce qu'il écrit à d'autres occasions, y compris dans ses notes de terrain :

«Cette statuette [en grès] reposait sur des fragments de mâchoire de Cheval, la partie antérieure avec les incisives, 6 en tout, serrés les uns contre les autres. Deux d'entre eux étaient superposés et formaient une sorte de coffret à l'intérieur duquel se trouvaient deux prémolaires de Loup, perforées d'un trou de suspension d'ailleurs cassé et un « couteau » façonné dans un morceau de cuirasse ferrallitique. (...) À proximité immédiate ont été recueillies une petite sagaie à section cylindroconique et biseau simple ainsi qu'une canine de Renard. » (Arambourou, 1978, p. 49)

Il ajoute plus loin (p. 50) :

«La présence de ces trois sculptures dans un espace restreint, la représentation du même animal, le contexte entourant la statuette auprès de laquelle se trouvaient aussi les restes de deux crânes de chevaux, tout fait penser à une sorte de sanctuaire rassemblant des objets dont le caractère non utilitaire est aussi évident que leur valeur de symbole. »

7 L'ensemble des vestiges est inclus au sein de la couche 4, « couche argileuse, de couleur rouge passant au beige rosé lorsqu'elle est lessivée... » (Arambourou, op. cit. p. 47).

8 L'inventaire exhaustif réalisé à la demande du Conseil Général des Landes entre 2009 et 2013 a permis de retrouver la quasi-totalité des objets décrits dans cette publication, avec l'exception notoire des "restes de deux crânes de chevaux " (Arambourou, op. cit. p. 50). Par ailleurs, la recherche systématique des archives, menée depuis 1996, a permis de collationner une partie des documents de terrain (par exemple fig. 2) et de les confronter aux descriptions faites ultérieurement.

Les choix méthodologiques du fouilleur ne permettent pas aujourd'hui de réétudier l'intégralité des vestiges présents en CIII et BIII dans la couche 4, et encore moins de discuter du lien strict que certains ont pu entretenir: les subdivisions au sein des épaisses couches d'habitat apparaissent en 1967 et seules les pièces exceptionnelles et l'outillage - en silex, sur galet ou sur matières dures d'origine animale - sont cotés; ultérieurement, il infléchira ce choix pour ajouter les éléments fauniques déterminables. Ainsi, sur le croquis de la figure 2, les chiffres associés aux mandibules ne correspondent pas à des numéros d'ordre mais à l'altitude de leur base, information qui était présente sur certains contenants lors de leur inventaire en 2012. Aucun tamisage n'a été effectué : le tout-venant de faune et de lithique ne contient donc que très rarement des éléments de petite dimension.

10 La documentation est constituée de carnets de relevé où sont parfois réalisés des relevés sommaires de coupe ou de plan (fig. 2), d'échanges épistolaires avec l'administration de tutelle et/ou des proches (F. Bordes, P. Jude, etc.) et de quelques clichés réalisés par R. Arambourou ou M. Schvoerer (fig. 2). La tenue d'un journal quotidien ne commence, en effet, qu'en 1962. 
Figure 2 : Extrait du carnet de terrain de Robert Arambourou précisant le contexte de découverte de la statuette en grès (cheval agenouillé).

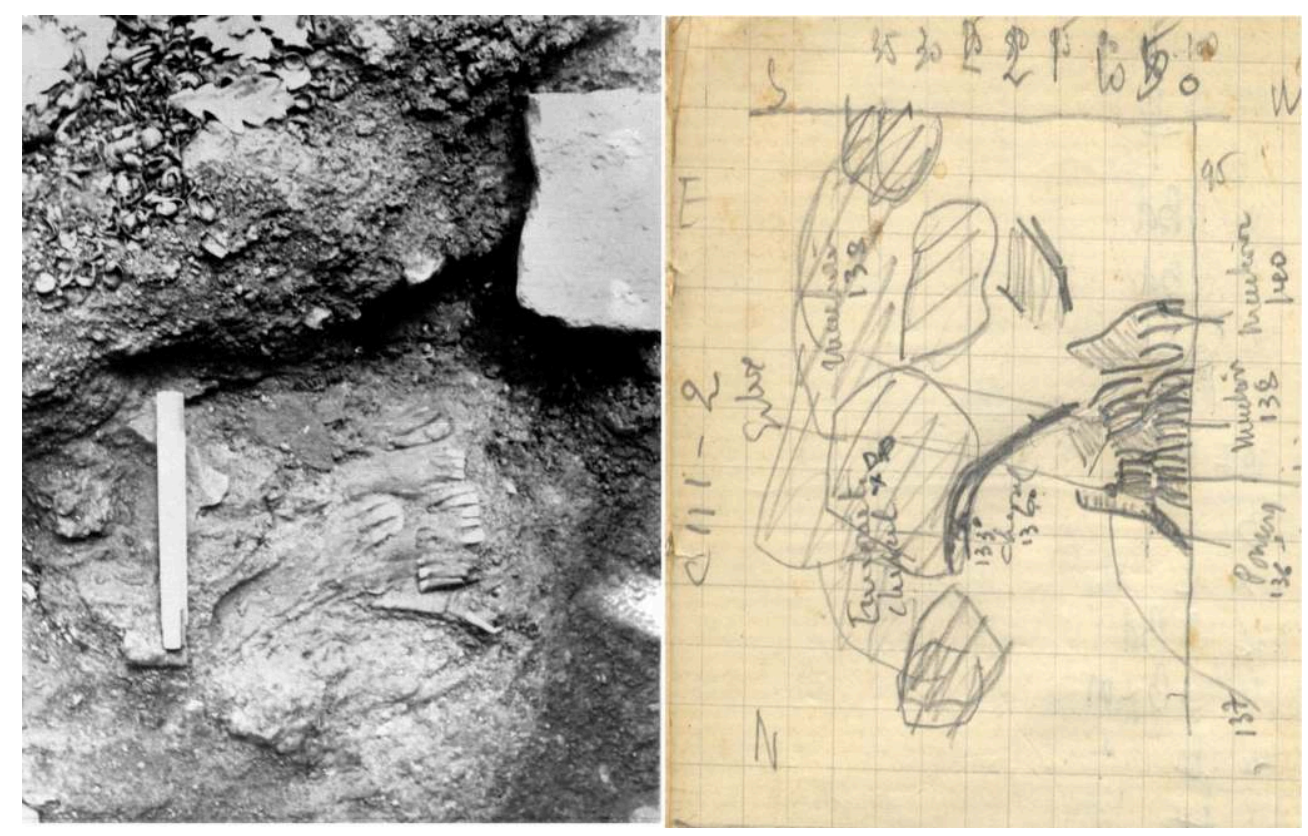

Noter la matérialisation de l'empreinte de la statuette. Cliché du même décapage (Cliché : M. Schvoerer).

11 Ces lacunes se ressentent dans la figure 3 où beaucoup de pièces "extra-ordinaires " (au sens défini dans Chiotti et al., 2009) sont positionnées dans l'espace de manière très sommaire : la face d'apparition et l'orientation des statuettes en marne et en ivoire ne sont, par exemple, pas connues. Le quart ouest du carré CIII est dans une situation différente: les deux documents de la figure 2, parfaitement complémentaires, permettent de restituer la place de 5 mandibules, de la statuette en grès (l'empreinte garde en mémoire la position de la croupe de l'animal), du racloir et de la sagaie. Chacun des éléments est visible sur la photo et sur le croquis. Certaines discordances sont malgré tout perceptibles : les coordonnées des pièces cotées montrent un décalage systématique entre le croquis et l'emplacement des vestiges: en d'autres termes, les mandibules ne sont pas au bord du carré CIII, mais en retrait de quelques centimètres. De même, R. Arambourou a isolé 9 séries d'incisives, et non pas 6 comme indiqué dans les publications ou 5 comme indiqué sur le croquis. Une mandibule, découverte dans le carré BIII - et relevée quelques semaines auparavant - n'est plus en place au moment de la réalisation des documents de la figure 2. D'autre part, le racloir est signalé comme emprisonné entre deux mandibules : la seconde n'est pas encore dégagée sur la figure 2. Deux séries dentaires n'apparaissent donc dans aucun document. 
Figure 3 : Reconstitution de la répartition spatiale des vestiges associés à la statuette en grès, à partir des archives de fouilles.

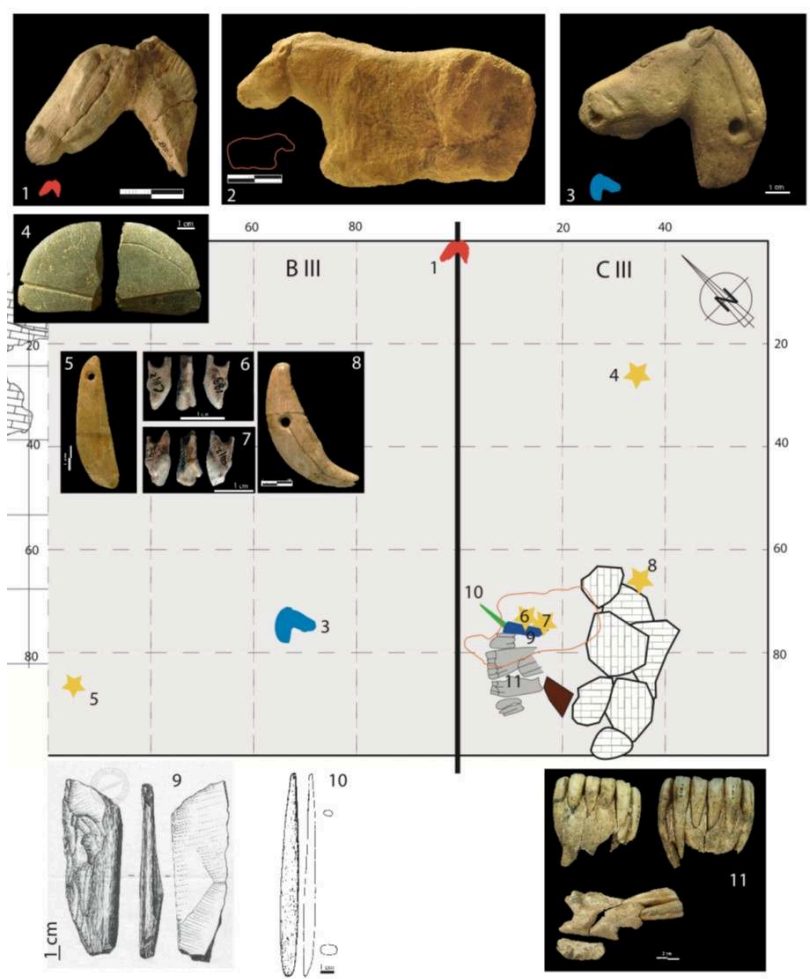

Dans le quart ouest du carré CIII, la position des vestiges est connue par leurs coordonnées et un relevé de terrain, alors que pour le reste de la zone étudiée, seules les coordonnées de vestiges sont connues. Certains fragments de mandibules proviennent du Carré BIII, sans que leur position exacte soit documentée. (Exploitation des archives : M. Dachary ; clichés : F. Plassard ; dessins : R. Arambourou).

De ces observations, il est possible de déduire que :

- Les différents vestiges sont contemporains à l'échelle de l'enveloppe sédimentaire qui les renferme, en l'occurrence la couche 4. Celle-ci est attribuée au Magdalénien moyen sur la base de l'interprétation stratigraphique, de la diagnose des vestiges lithiques et osseux et des datations radiocarbone (13510 \pm 220 BP-Ly859; 14005 \pm 65 BP-OxA 28118).

- Ces vestiges entretiennent des relations de proximité fortes puisqu'ils proviennent de deux mètres carrés contigus (BIII et CIII) et que certains étaient juxtaposés ou superposés les uns aux autres. Une telle disposition renforce encore l'association contextuelle entre certaines des mandibules et la plus grande statuette de cheval au moins (cette dernière reposant sur les premières).

13 Il est, en revanche plus difficile d'affirmer que cet assemblage d'objets "extraordinaires » est en relation avec les restes humains découverts dans le carré adjacent DIII (Birouste et al., 2016).

14 Exceptés les deux crânes de chevaux, tous les vestiges décrits dans la publication et cotés à proximité immédiate des mandibules et statuettes, d'après les carnets de fouilles, ont donc pu être replacés dans leur contexte archéologique.

15 L'essentiel des incisives et mandibules provenant des carrés CIII et BIII était déjà rangé par lots lorsque nous avons accédé à la collection. Quelques pièces étaient consolidées avec de la colle. La composition des lots était plutôt cohérente : ils ont probablement été constitués lors du prélèvement des objets sur le terrain par R. Arambourou (fig. 4). 
Le plus souvent, les propositions de remontage des incisives isolées en série étaient effectivement pertinentes. Ce classement d'origine a néanmoins été soumis à une vérification systématique de l'appariement des éléments anatomiques, et une réorientation de certaines pièces a été opérée.

Figure 4 : Ensemble des fragments de mandibules découverts à proximité de la statuette en grès. (Clichés : F. Plassard).

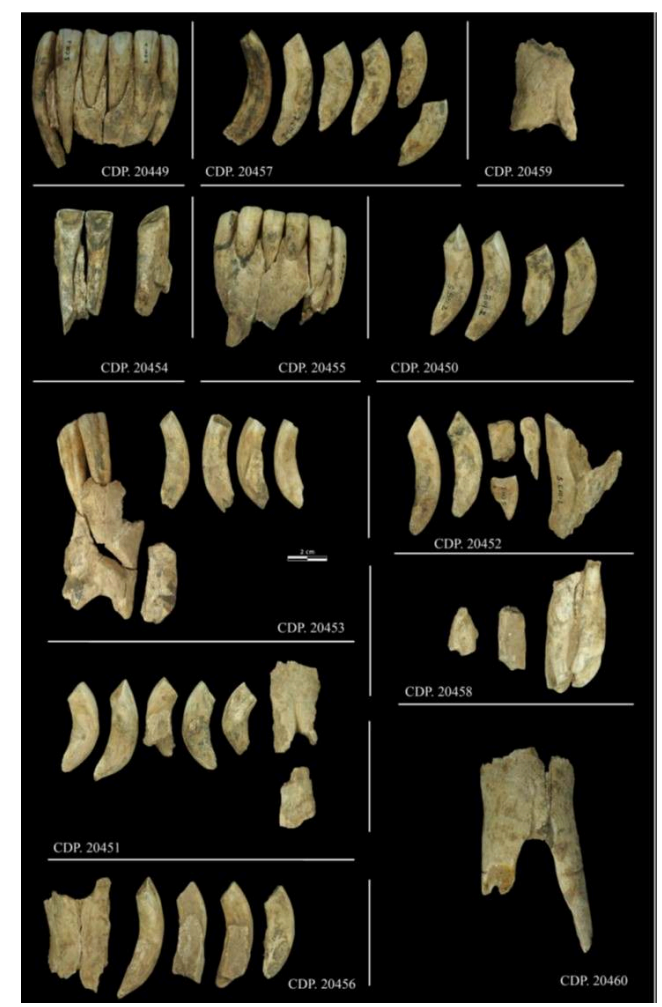

\section{Analyse}

\section{Éléments squelettiques, sexe, nombre et âge des individus}

Le tri systématique des caisses de faune associées aux carrés CIII et BIII a conduit à la découverte de quelques pièces supplémentaires. Au total, la série comporte 4 séries complètes de 6 incisives inférieures, 5 séries partielles d'incisives inférieures, 5 fragments d'os mandibulaire et 6 incisives inférieures isolées en CIII. À cela s'ajoute une série partielle d'incisives inférieures, une incisive inférieure isolée et un fragment d'os mandibulaire provenant de BIII (fig. 4). Les incisives sont parfois isolées, parfois encore liées à la partie osseuse de la mandibule.

Les incisives de cheval (Equus caballus) provenant de cette zone sont exclusivement des incisives inférieures. Plusieurs fragments de mandibule ont été également recensés, mais aucun fragment de maxillaire.

Aucune canine de cheval n'est présente dans la zone (CII ou BIII). Pour autant, ce fait ne permet pas d'attester l'absence effective de canines sur les individus et d'en tirer des conclusions sur le sexe des individus présents (les mâles portant bien plus souvent des canines que les femelles). En effet, la partie anatomique des mandibules nécessaire à la 
vérification de ce point est systématiquement absente. Néanmoins, dans l'ensemble de la collection, on ne trouve aucune canine de cheval, sauf sur la terrasse inférieure dont le matériel n'est pas pris en compte dans l'étude. En effet, ce secteur est suspecté de remaniements post-dépositionnels importants ayant affecté l'intégrité des niveaux archéologiques (Dachary, 2002).

La surreprésentation des incisives de cheval est flagrante dans le carré CIII. La plupart des restes de cheval dans ce carré sont des incisives inférieures et des mandibules. En effet, sur 60 éléments osseux de cheval provenant du carré CIII, 47 sont des fragments de mandibule ou des incisives inférieures (fig. 5a). Dans ce calcul, un fragment de mandibule comportant plusieurs dents est décompté comme un seul élément. La proportion de l'ensemble "mandibules et incisives " s'accroîtrait donc davantage si chaque incisive était considérée comme une entité à décompter.

La présence importante des incisives de cheval fait de cet animal l'espèce dominante dans le carré CIII. L'exclusion de ces pièces dans le décompte des vestiges du carré ferait des bovinés le taxon dominant, comme dans le reste de la couche 4 (selon nos propres décomptes lors de l'inventaire). Ce constat tend à souligner le caractère exceptionnel de l'assemblage des ossements de cheval dans le carré CIII. En outre, les incisives inférieures du carré CIII constituent la grande majorité des incisives (inférieures et supérieures combinées) présentes dans l'ensemble de la couche 4 . En effet, sur les 65 incisives de cheval présentes dans la couche 4 (en excluant toujours la terrasse inférieure), 49 proviennent du carré CIII.

21 Dans les carrés CIII et BIII, le calcul du Nombre Minimum d'Individus (White, 1953) pour le cheval, à partir des seuls fragments d'os mandibulaires, donne un résultat de 7 individus. Lorsque ce calcul est réalisé à partir des fragments de mandibules ainsi que des incisives (en place et isolées), le NMI passe à 10 individus. Enfin, si l'on prend en compte les âges des chevaux concernés, pour calculer un NMI de combinaison (Poplin, 1976), ce sont 11 individus qui sont décomptés. Si ce calcul du NMIc du cheval est réalisé sur l'ensemble de la couche 4 (terrasse supérieure), ce sont alors 15 individus qui sont recensés, dont 11 dans les seuls carrés CIII et BIII.

La concentration des incisives et mandibules dans les carrés CIII et BIII participe largement au nombre d'individus total pour le cheval. En effet, si le même calcul est maintenant réalisé sur la couche 4 en utilisant les seules dents jugales de cheval, alors le NMIc se réduit à 10 individus.

L'estimation de l'âge des chevaux au moment de leur mort dans l'ensemble de la couche 4 montre que nous avons affaire à une majorité de très vieux adultes (les classes d'âges sont celles employées par Bignon, 2003). Mais, il existe également une proportion relativement importante d'adultes et de juvéniles (fig. 5b). Si l'on exclut maintenant la zone CIII-BIII du calcul, il apparaît alors que la majorité des individus sont des adultes dans la pleine force de l'âge. En considérant au contraire la seule zone CIII-BIII, on constate qu'une grande majorité des individus présents appartient à la classe d'âge des vieux et très vieux adultes. Nous sommes alors en présence de 8 vieux ou très vieux adultes, de deux adultes, d'aucun sub-adulte et d'un juvénile. C'est donc bien la quantité des individus recensés dans la zone CIII-BIII, associée à la particularité de la composition des âges dans cette zone, qui font basculer le diagramme d'une majorité d'adultes dans la pleine force de l'âge à une majorité de très vieux adultes. La dent qui documente la présence d'un individu juvénile dans les carrés CIII-BIII est une dent déciduale ne correspondant à aucune des séries d'incisives de la zone, et qui ne porte 
pas les traces caractéristiques des incisives de cet ensemble (cf. infra). Par conséquent, elle apparaît intrusive par rapport à l'ensemble « cohérent » des mandibules.

Figure 5 : a/Répartition anatomique des restes de Cheval du carré CIII. b/Estimation de l'âge au décès des chevaux de la couche 4.
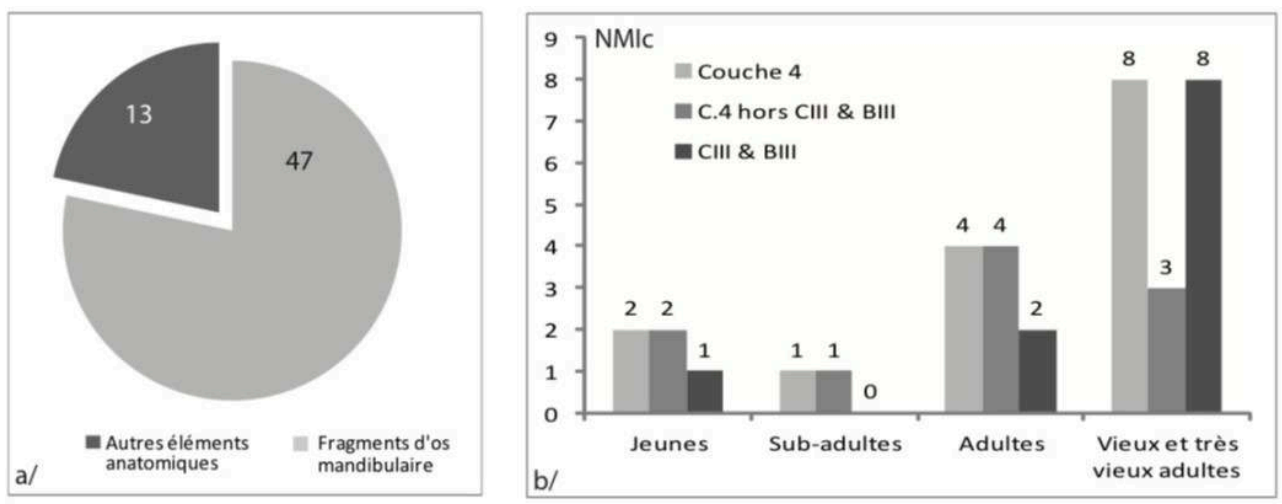

\section{Description des traces}

Différents types de traces sont visibles sur les pièces: raclage, sciage, gravure et façonnage (tab. 1).

Tableau 1 : Caractéristiques de chaque fragment de mandibule et incisive.

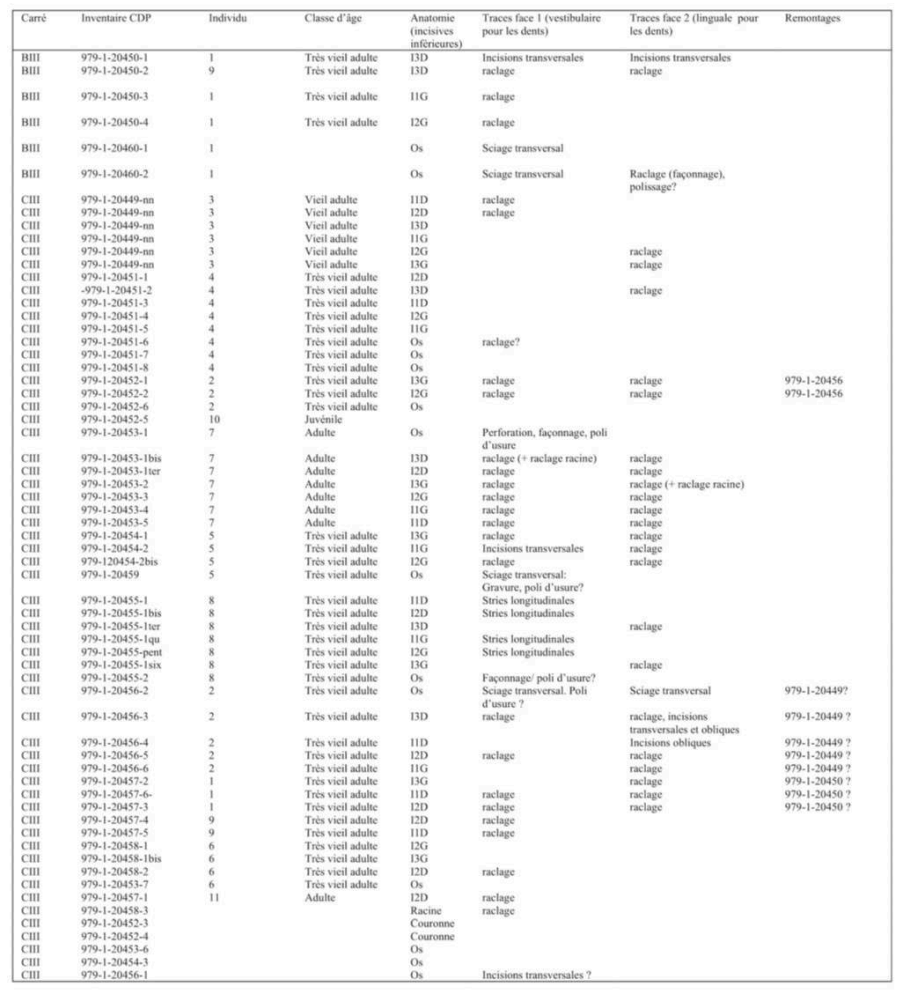

Des stries, observables sur les faces vestibulaires et linguales des incisives, correspondent à un raclage réalisé avec un outil lithique (fig. 6). Parfois profondes, dotées d'une section « en V », ces traces concernent tous les individus décomptés dans les carrés CIII et BIII, sauf le sujet identifié par la dent déciduale isolée. Ces traces ne 
sont visibles ni sur les incisives de cheval présentes dans le reste de l'assemblage, ni sur des incisives appartenant à d'autres taxons.

Figure 6 : Exemples de traces de raclage sur les incisives de Cheval (Clichés : F. Plassard).

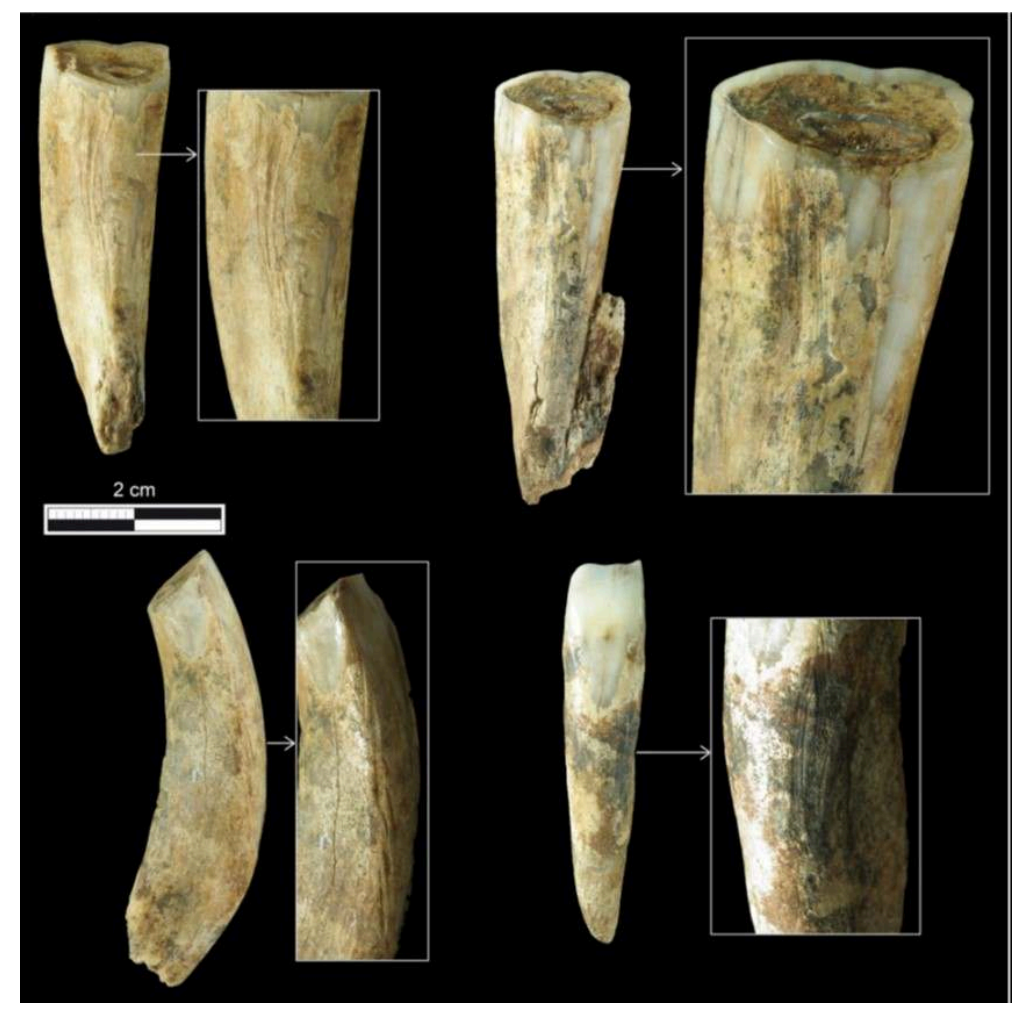

L'intensité du raclage est variable d'un individu à l'autre et d'une dent à l'autre. Il n'est pas systématiquement visible sur l'ensemble des dents de chaque série, ni sur les deux faces opposées de chaque dent. Comme dans le cas des stries de boucherie (Lyman, 1994), le but ne semble pas être de "laisser des traces ", mais plutôt d'accomplir une action qui laissera parfois des stigmates non intentionnels.

Les mandibules les mieux conservées comportent encore en place des incisives portant des stries de raclage. On y observe régulièrement une continuité des stries entre les dents juxtaposées, aussi bien sur les faces vestibulaires que linguales. Pour ces pièces, il est certain que les traces ont été produites alors que les dents se trouvaient sur les mandibules: il en est probablement de même pour les dents qui sont aujourd'hui séparées de l'os mandibulaire, comme le confirme l'absence des stries de raclage sur les faces mésiales, lesquelles ne sont pas accessibles lorsque les dents sont en place sur les mandibules. On trouve quelques traces de raclage sur les faces distales, mais uniquement sur les troisièmes incisives, appelées " coins", seules incisives dont la face distale est accessible lorsqu'elles sont en place sur les mandibules.

L'hypothèse de traces de raclage laissées lors d'une tentative d'extraction des dents hors de la mandibule semble être à écarter en raison de la relative superficialité des stigmates sur les incisives et de l'absence d'autres types de traces qui pourraient confirmer ce geste sur l'os mandibulaire. En revanche, l'emplacement récurrent de ces stries laisse supposer que ce raclage avait pour but d'ôter le tissu conjonctif jusqu'à l'os alvéolaire, peut-être pour mieux laisser apparaître les dents. 
Sur trois pièces, des traces de sciage au silex ou des incisions profondes sont observables sur les branches horizontales des mandibules, à proximité de la jonction des deux hémi-mandibules (fig. $7 \mathrm{a}, 7 \mathrm{~b}$ ). La démonstration d'une parenté entre les traces de sciage et les incisions profondes s'appuie sur leur emplacement anatomique identique et sur la nature très proche des gestes mis en jeu, même si un doute subsiste quant à la similitude des objectifs qui les sous-tendent. En effet, les incisions, bien que profondes, n'entament pas réellement la solidité des objets, alors même que la pratique du sciage a pour but de séparer les pièces en deux. Certaines mandibules ne présentent pas ces traces. Cependant, l'emplacement précis de ces stigmates étant un peu variable, il n'est pas possible de prouver l'absence totale de sciage sur les pièces qui sont fragmentées. Sur l'une des mandibules, on peut observer des traces de sciage sur les faces externe et interne de l'os. On en déduit que le sciage est intervenu en fin de chaîne opératoire, car pour accéder à la surface interne sur laquelle il est observé, il a d'abord été nécessaire de fracturer l'os et modifier la morphologie naturelle de la mandibule.

Sur une des pièces, la partie osseuse porte un rainurage profond qui découpe une forme en amande dont il est délicat de saisir l'objectif. Cette perforation ne présente pas de traces d'utilisation a priori. Sur cette même pièce, un façonnage important a modifié la conformation originelle de l'élément anatomique (fig. 7c).

Figure $7: a /$ Hypothèse sur la morphologie initiale des pièces (Dessins : C. Birouste). b/Localisation des traces (Dessins : C. Birouste). c/CDP.20453. Façonnage et perforation « en amande " par rainurage. d/CDP.20460. Incisions profondes. e/CDP.20456. Traces de sciage (Clichés : F. Plassard).

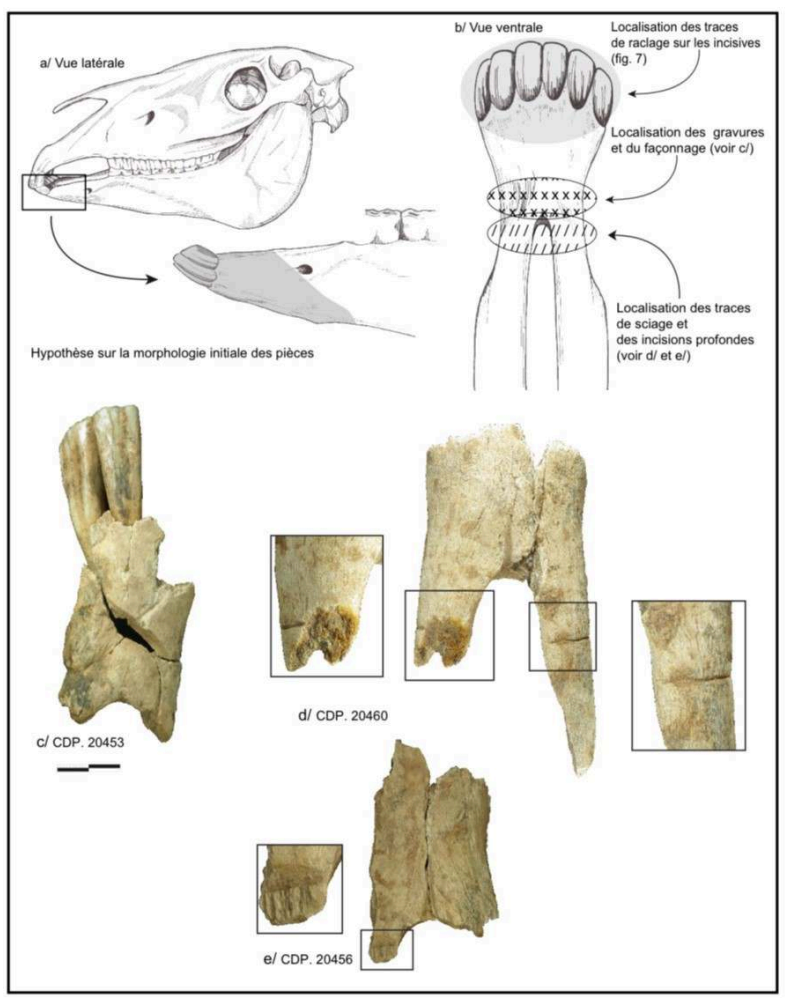

Enfin, un des fragments osseux de mandibule présente un décor gravé difficile à interpréter (fig. 8). Situés entre un bord de fracture et une extrémité sciée de l'objet, deux séries de hachures et quelques traits plus profonds sont associés pour former un motif original sans équivalent dans le registre des décors géométriques de la falaise du 
Pastou (Dachary, 2006). Il pourrait s'agir des restes très parcellaires d'une représentation figurative dans la mesure où des jeux de hachures sont couramment utilisés pour figurer des crinières, des barbes ou des fanons. Dans tous les cas, l'utilisation de l'os mandibulaire comme support de l'art mobilier au Paléolithique supérieur, bien qu'existante (Paillet, 2014; Pétillon et Sacchi, 2013; Cook, 2013), est suffisamment exceptionnelle pour que cette pièce, même très fragmentaire, soit remarquée.

Figure 8 : CDP_INV_1979.1.20459. Fragment d'os mandibulaire gravé. (Clichés et croquis : F. Plassard).

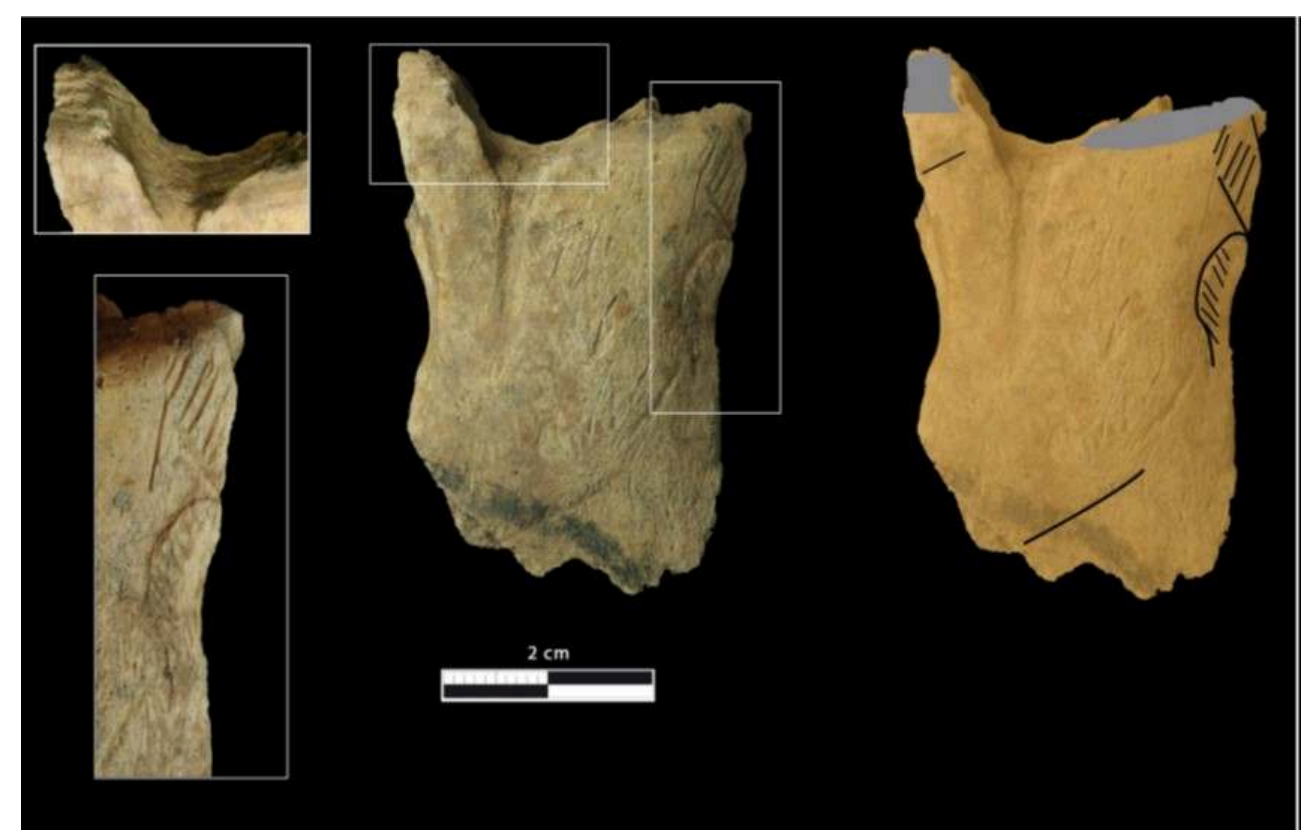

\section{Premier bilan}

La valeur de cet ensemble de mandibules paraît résider tant dans son accumulation exceptionnelle que dans le traitement des ossements.

Il est difficile d'y voir un simple entassement de déchets liés à une production technique normalisée. Il est au contraire possible de considérer cet assemblage d'incisives et de mandibules de chevaux comme un dépôt volontaire, tant ses particularismes sont nombreux : concentration exceptionnelle dans une zone limitée d'un site archéologique, élément anatomique précis, taxon unique, individus vieux ou très vieux, traitement particulier et association contextuelle avec des figurations de cheval.

La cohérence d'un tel assemblage suggère un important investissement en temps. En effet, le grand nombre de chevaux décomptés dans cet espace restreint soulève la question de l'acquisition de ces animaux vieux ou très vieux. Cette "recherche" d'objets particuliers sous-entend une organisation, qu'il s'agisse d'un tri régulier au gré des approvisionnements, d'une simple collecte au sein d'une zone de déchets culinaires, d'un ramassage sur des carcasses ou d'une chasse active concentrée sur certains individus. Les traces systématiques de raclage visibles sur ces pièces, ajoutées au 
façonnage, au sciage et à la gravure de décors sont également les preuves d'un investissement suivi et important dans la constitution de cet assemblage.

Le tri de certains éléments squelettiques provenant de crânes de chevaux âgés correspond difficilement à une simple logique d'optimisation. De la même manière, les gestes techniques appliqués à ces pièces ne correspondent pas à des objectifs économiques connus. Le dépôt de mandibules de l'abri Duruthy constitue un ensemble un peu hybride dont on ne peut pas imaginer qu'il soit purement économique, ni purement symbolique. Il ne s'agit pas exclusivement de représentation artistique, de parure ou de « déchets culinaires ", mais peut-être de tout cela à la fois.

\section{Discussion, comparaisons et hypothèses}

L'importance du cheval est actuellement nettement revalorisée pour le Magdalénien dans l'étude des vestiges osseux (Bignon, 2006) comme dans l'étude des productions graphiques (Sauvet et Wlodarczyk, 2000-2001). Nous essayons ici d'amender cette discussion en considérant le cheval au cours des phases moyenne et/ou supérieure du Magdalénien pyrénéen.

Le traitement spécial réservé à certains éléments squelettiques de chevaux, et l'association de ces éléments avec des statuettes représentant des chevaux à l'abri Duruthy, confirment la place importante qu'occupe le cheval dans le Magdalénien des Pyrénées. À l'abri Duruthy, cette espèce est en effet incontournable tant dans l'étude des productions graphiques et dans certains gestes ritualisés, que dans l'économie, puisqu'il constitue l'une des proies principalement chassées, après le renne et les bovinés (Costamagno, 2006).

Nous souhaitons interroger l'importance de cette espèce en considérant l'hybridité profonde des domaines économiques et symboliques suggérée par les vestiges découverts dans l'abri Duruthy, en essayant de prendre la mesure de ce que cela implique en termes d'interprétation. En effet, nous ne pouvons pas prétendre que toutes les collectivités anciennes partageaient les mêmes distinctions que les nôtres, à commencer par l'opposition entre nature et culture qui détermine notre approche naturaliste. Ainsi, nous souhaitons nous éloigner d'une conception qui ferait universellement des espèces animales de simples ressources utiles à l'humanité, en tant que réservoirs à calories et/ou à symboles (Overton et Hamilakis, 2014, p. 114), permettant de les réduire aux deux catégories du «bon à manger» et du «bon à penser ». Il nous semble important de garder à l'esprit que chaque culture attribue des qualités différentes à une même nature, mais que ce qui est considéré comme relevant de la nature peut également être défini différemment (Descola, 2011).

Nous essayons ainsi d'explorer les perspectives offertes par une démarche qui consisterait davantage à concevoir une « écologie symbolique » (Charbonnier, 2014), en nous intéressant plus particulièrement aux différents modes d'identification proposés par Descola (2005): le naturalisme, l'animisme, le totémisme et l'analogisme. Ces concepts anthropologiques pourraient nous apporter des outils permettant de mieux cerner la façon dont le cheval s'intégrait à la composition du monde magdalénien dans les Pyrénées. 


\section{Un lien de sens entre l'os et l'image}

40

nous semble que la juxtaposition étroite des statuettes représentant des chevaux et du dépôt des mandibules de cheval transformées constitue l'indice d'un lien sémantique entre des artefacts et des ossements. Cette association qui ne semble " pas fortuite" (Arambourou, 1962) entre "art» et "os", nous pousse à remettre en question la différence de nature parfois postulée entre écofacts et artefacts (Binford, 1964). La dichotomie entre nature et culture ou entre matière et symbole semble ici à relativiser. En effet, l'assemblage de mandibules de cheval de l'abri Duruthy montre que des ossements peu transformés, mais manifestement chargés de sens par le geste d'une concentration volontaire, peuvent être directement rapprochés de la figuration du même animal. L'évocation du cheval en tant qu'espèce pourrait ainsi concerner une sculpture comme un assemblage de mandibules, dont certaines sont à peine transformées alors que d'autres le sont plus largement. On note d'ailleurs, dans le Magdalénien pyrénéen, la présence de tous les gradients permettant de passer de la figuration de la tête de cheval à ce qui constitue physiquement la tête de cheval :

- des sculptures et gravures figurant des têtes de chevaux, principalement réalisées sur des supports en matières dures d'origine animale, (Delporte, 1990 ; Piette, 1907, par exemple) ;

- des contours découpés réalisés sur stylohyoïde (lui-même prélevé sur une tête, le plus souvent de cheval) et représentant une tête de cheval (Buisson et al, 1996; Cattelain et Bellier, 2014) ;

- des représentations de crânes décharnés de chevaux, comme au Mas d'Azil, (Péquart et Péquart, 1960 ; Piette, op. cit.) ;

- à Duruthy, des mandibules de chevaux qui sont accumulées, juxtaposées à des statuettes représentant des chevaux et traitées de manière à exacerber certaines caractéristiques anatomiques du cheval.

\section{La condition de cheval}

Il est à noter qu'à Duruthy, ce sont précisément des incisives de chevaux qui sont soulignées par leur surreprésentation dans le dépôt. Or, les dents sont des éléments dont la morphologie permet aisément de distinguer et d'identifier des espèces. Il nous semble que le choix des dents vient conforter l'importance de l'identification de la catégorie Cheval.

Nous remarquons par ailleurs que, dans la classe des mammifères, les dents ont adopté des formes en rapport avec leurs fonctions (qui n'est plus celle de simples organes de préhension comme chez les vertébrés inférieurs). Ainsi, le choix des incisives de cheval pourrait trouver son sens, non seulement dans l'identification d'une espèce en tant que catégorie de classification taxinomique, mais aussi dans la caractérisation d'un mode de vie, car la forme des dents nous renseigne directement sur le régime alimentaire des espèces animales et sur leur place dans la chaîne trophique. Le sens attaché à l'identification du cheval au Magdalénien ne se rapporterait pas forcément à une définition d'espèce suivant la logique taxinomique verticale telle que nous la connaissons dans les guides d'identification des sciences naturelles modernes (Ingold, 2011). Il pourrait tout autant renvoyer à un intérêt pour la forme du corps, vue comme le témoin du comportement de l'espèce, et d'une "place" occupée dans un 
environnement. Fréquemment, chez les peuples de chasseurs, l'animal est défini par ce qu'il fait, et il est nommé par son activité (Ingold, op. cit.).

Le raclage systématique des incisives du dépôt de l'abri Duruthy semble avoir eu pour but de mettre ces dents en valeur, suggérant fortement que ces éléments doivent être pris en compte, au-delà de leur simple forme initiale. Ainsi, si ce geste dénote bien une préoccupation liée à sa condition écologique, le cheval ne devrait pas être considéré, en ce qui concerne le Magdalénien pyrénéen, comme un pur symbole classificatoire ou une matière qui seraient déconnectés de l'environnement.

Il est à noter que l'importance de la dent de cheval est déjà largement documentée dans le Magdalénien pyrénéen, où l'on observe notamment :

- des incisives appointées et/ou multiperforées (Arudy, Isturitz, Mas d'Azil, par exemple), portant 2 à 7 trous et parfois un décor constitué de chevrons ou d'incisions obliques (Chauvière, 2006 ; Mereau, 2012).

- « les incisives de cheval sculptées en buste de femme et en visage indéterminé au Mas-d'Azil et la canine à tête humaine à Bédeilhac (Ariège) sont des œuvres exceptionnelles qui prouvent combien les dents de cheval étaient lourdes de sens dans le groupe magdalénien des Pyrénées (Taborin, 2004, p. 62).»

Plus généralement, les incisives d'ongulés (renne, mais aussi cerf, bouquetin ou bovinés) sont fréquemment retrouvées sciées et parfois conservées en série, dans certains sites magdaléniens (Desbrosse, 1972 ; Poplin 1983). L'anatomie du cheval étant différente de celle des bovidés et des cervidés (les incisives du cheval sont fortement ancrées et les racines plus solides), le sciage devrait être déplacé pour pouvoir aboutir au même but, soit la récupération de la série complète des incisives. À l'abri Duruthy, il s'agit peut-être de la même intention de récupération et de conservation de la série des incisives, mais appliquée au cheval.

Nous n'affirmons pas que les mandibules de Duruthy constituaient des parures corporelles, car bien que l'une des pièces porte une perforation, celle-ci ne semble pas avoir été portée en suspension (cf. supra). Il nous semble néanmoins que l'accent mis sur les dents dans la parure, dans certains exemples de gravures ou de sculptures, comme dans les mandibules de l'abri Duruthy, pourrait procéder d'une même intention de mettre en exergue les caractéristiques écologiques d'une espèce en isolant cet élément anatomique.

47 Ainsi, l'intérêt porté aux incisives des chevaux à l'abri Duruthy, au-delà de l'identification du cheval en tant qu'espèce telle que nous la définissons aujourd'hui, pourrait être en lien avec la condition de cheval, son comportement, et sa place vis-àvis des autres existants.

\section{L'absence d'homogénéité de l'espèce Cheval}

L'espèce Cheval est une catégorie largement mobilisée dans les pratiques que nous observons à l'abri Duruthy. Pour autant, cet intérêt pour l'espèce ne présuppose pas une stricte homogénéité de celle-ci dans les conceptions des populations que nous essayons de comprendre à travers cet assemblage. Ainsi, «le Cheval» ne semble pas être ici l'unique manière de considérer des chevaux. La conception de sous-catégories appartenant à l'espèce pourrait effectivement avoir une importance dans les pratiques observées à l'abri Duruthy. Le recrutement particulier des mandibules de chevaux dans l'assemblage que nous avons étudié, qui sont pour la grande majorité issues de la classe 
des vieux et très vieux adultes, montre un intérêt porté sur certains individus dans la catégorie des chevaux. Nous ne voyons aucune raison matérielle évidente au choix de sélectionner des chevaux âgés pour réaliser un tel dépôt. Il ne paraît pas exister de facilités particulières à collecter des ossements de chevaux âgés, et les dents des chevaux âgés ne montrent pas de propriétés physiques particulières qui pourraient être exploitées. À l'abri Duruthy, les ossements ne sont pas traités comme des symboles dont l'espèce serait le seul critère signifiant, mais ils se rapportent aussi à des individus particuliers, choisis pour leurs caractéristiques, pour leur âge ou pour une spécificité qui serait corrélée à leur âge.

Une comparaison pourrait être faite dans ce sens avec les incisives gravées connues dans le Poitou, et qui concernent uniquement de très jeunes chevaux. Cependant, dans cet exemple, un déterminant technique peut être avancé dans la mesure où la gravure est plus facile et davantage visible sur les incisives de juvéniles. Ces éléments sont chronologiquement antérieurs à ceux de Duruthy et sont attribués à la phase ancienne du Magdalénien moyen (Airvaux, 2001 ; Mazière et Buret, 2010 ; Vercoutère, 2009).

\section{Un intérêt pour la subjectivité du cheval}

Si le lien sémantique le plus évident entre les statuettes et les mandibules de l'abri Duruthy est l'identification du cheval, ce lien semble plus particulièrement s'opérer autour d'un élément précis de l'anatomie de l'animal : sa tête. Deux des trois statuettes qui sont associées à l'assemblage figurent des têtes de chevaux, et les mandibules sur lesquelles reposent ces statuettes sont des fragments de crânes de chevaux: une emphase particulière est donc portée sur des éléments se rapportant à la tête du cheval.

51 Cette insistance est confirmée dans le Magdalénien des Pyrénées par la fréquence de la figuration de la tête de cheval associée à la fréquence de la modification des crânes de chevaux (voir les exemples mobilisés antérieurement).

Il nous semble que c'est en premier lieu la question de la subjectivité des animaux qui pourrait être véhiculée dans cet intérêt pour la forme de la tête, et qui est à la fois perceptible dans la figuration et dans le traitement physique des éléments squelettiques. Ceci, dans la mesure où la tête est l'élément emblématique d'un individu, de son identité et de son intentionnalité. En effet, d'une part, c'est principalement grâce au visage que nous reconnaissons les personnes et, d'autre part, la tête est le siège de la plupart des sens, et le lieu de la prise de décision (Descola, 2008).

Dans le cas de l'abri Duruthy, la subjectivité semble particulièrement liée à l'espèce, puisque les références sont communes à la catégorie Cheval et à la zone céphalique. Or, nous remarquons que dans l'animisme ontologique au sens de Descola (2005), la subjectivité est directement liée à l'espèce, puisque c'est la forme du corps qui détermine la façon de se comporter et de percevoir le monde.

\section{Bilan des discussions}

Le dépôt de l'abri Duruthy souligne une nouvelle fois l'importance du cheval dans le Magdalénien pyrénéen, et ce dans une perspective qui peut désormais être précisée. En effet, l'étude des vestiges tend à montrer que cette espèce ne semble pas être conçue en tant qu'entité homogène, comme c'est par exemple le cas dans le totémisme (Descola 
2005 ; Ingold 2000), puisqu'il est fait référence à des sous-catégories. Par ailleurs, un intérêt particulier pourrait être porté, à l'abri Duruthy, sur la condition écologique du cheval comme sur sa subjectivité. Nous remarquons que ces deux traits sont à la fois particulièrement caractéristiques de l'animisme, et qu'ils entretiennent un lien direct l'un envers l'autre dans ce régime ontologique (Descola, op.cit.). Quant au naturalisme ontologique (Descola, op.cit.) - et sa propension à opposer «ce qui est créé par l'Homme " et "ce qui est créé par la Nature" - il semble incompatible avec les pratiques observées à Duruthy, où l'on constate au contraire une correspondance étroite, voire une équivalence, entre des ossements issus de chevaux et des figurations de chevaux. Enfin, les vestiges analysés ne montrent pas d'éléments qui soient caractéristiques d'un analogisme ontologique (Descola, op.cit.), sans que cela ne soit toutefois suffisant pour écarter cette éventualité de manière certaine.

55 À notre sens, c'est donc le mode d'identification animiste qui semble le plus pertinent pour rendre compte de la manière dont le cheval était appréhendé dans le monde magdalénien pyrénéen. Pour autant, il semble évident qu'il est nécessaire de tester cette première hypothèse en confrontant les données élaborées ici avec d'autres catégories de vestiges (art pariétal, parure corporelle, traitement des corps humains etc.), de manière à mieux définir la relation entre les humains et les animaux pendant le Magdalénien (Birouste, thèse en cours).

Dans une zone restreinte de l'abri Duruthy, l'accumulation d'éléments squelettiques sélectionnés (des mandibules et incisives inférieures de chevaux âgés), le traitement qui leur a été appliqué (raclage systématique, sciage, incisions, façonnage, gravure) et l'association avec des figurations de chevaux, font de cet assemblage un témoignage important pour la connaissance des comportements humains au Magdalénien moyen dans les Pyrénées.

Le caractère hybride de ce qui doit être considéré comme un dépôt nous a encouragé à proposer une explication alternative à la traditionnelle opposition opérée entre des «facteurs symboliques » et des « facteurs économiques".

Notre interprétation des vestiges nous a permis de confirmer un intérêt soutenu pour le cheval et différents indices laissent entrevoir la conception de cette espèce dans une perspective qui pourrait se rapporter à un animisme ontologique.

Dès lors, peut-on considérer que le dépôt de mandibules et son association directe avec des statuettes est la preuve d'un régime ontologique animiste dans le Magdalénien moyen des Pyrénées, faisant des chevaux, ou de certains d'entre eux, des personnes non-humaines?

Il reste très délicat de répondre sur la base de l'hapax documenté à l'abri Duruthy, nos hypothèses soulevant par ailleurs un nombre certain d'interrogations. La compréhension du régime ontologique des populations du Magdalénien des Pyrénées nous semble être un objectif ambitieux qui ne pourrait être entrevu qu'après la réévaluation d'un ensemble représentatif de vestiges archéologiques issus de ce contexte. Les premiers résultats auxquels nous avons pu accéder nous encouragent néanmoins à poursuivre dans cette voie. 


\section{BIBLIOGRAPHIE}

AIRVAUX J. 2001, L'art préhistorique du Poitou-Charentes, sculptures et gravures des temps glaciaires, Paris, La Maison des roches.

ARAMBOUROU R. 1962, « Sculptures magdaléniennes découvertes à la grotte Duruthy », Sordel'Abbaye (Landes). L'Anthropologie, vol. 66, p. 457-468.

ARAMBOUROU R. (Dir.) 1978, Le gisement préhistorique de Duruthy à Sorde-l'Abbaye (Landes). Bilan des recherches de 1958 à 1975, Paris, Société Préhistorique Française.

ARAmbourou R. 1990, « Préhistoire en Pays Basque Nord et Sud des Landes », Munibe, vol 42, p. 91-96.

BIGNON O. 2003, Diversité et exploitation des équidés au Tardiglaciaire en Europe occidentale Implications pour les stratégies de subsistance et les modes de vie au Magdalénien et à l'Azilien ancien du Bassin parisien, Thèse de doctorat, Université de Paris-X Nanterre.

BIGNON O. 2006, « La chasse des chevaux au Magdalénien. Interaction chasseurs-proies et implications socio-économiques ", dans SIDERA, I. (dir), La chasse, Pratiques sociales et symboliques, Paris, éd. De Boccard (Colloques de la Maison René-Ginouvès), p. 167-179.

BINFORD L. R. 1964, « A Consideration of Archaeological Research Design », American Antiquity, vol. 29 , No. 4, p. 425-441.

BIROUSTE, C., CHAUVIÈRE, F.-X., PlASSARD, F., DACHARY, M. 2016. « The horse mandibles at Duruthy rockshelter (Sorde-l'Abbaye, Landes, France) and the identification of ontological systems in the Pyrenean Magdalenian », Quaternary International, vol. 414, p. 159-173.

BUISSON D., FRITZ C., KANDEL D., PINÇON G., SAUVET G., TOSELlo G. 1996, « Les contours découpés de têtes de chevaux et leur contribution à la connaissance du Magdalénien moyen », Antiquités nationales, vol. 28, p. 99-128.

CATTELAIN P., BELLIER C. 2014, STYLOHYOÏDE, in MONS L., PÉAN S., PIGEAUD R. (Dir.), Matières d'art : représentations préhistoriques et supports osseux, relations et contraintes, Arles, Éditions Errance, Cahier de la Commission de nomenclature sur l'industrie de l'os préhistorique, vol. 13, p. 91-104.

CHARBONNIER P. 2014, La fin d'un grand partage. Nature et société, de Durkheim à Descola, Paris, CNRS éditions.

CHAUVIÈRE F.-X. 2001, « La collection Chaplain-Duparc des musées du Mans : nouveaux éléments d'interprétation pour la "sépulture Sorde 1" de Duruthy (Sorde l'Abbaye, Landes) », Paléo, vol. 13, p. 89-110.

CHAUVIÈRE F.-X. 2006, « Fonds commun et originalité du matériel dentaire travaillé dans le Magdalénien d'Arancou (Pyrénées-Atlantiques) », dans chauchat C., Préhistoire du Bassin de l'Adour : bilans et perspectives, Colloque Izpegi, CNRS, Saint-Etienne de Baigorry (France), 19 janvier 2002. Saint-Etienne-de-Baïgorry, Édition Izpegi de Navarre, p. 225-248.

CHIOTTI L., NESPOULET R., HENRY-GAMBIER D., MORALA A., VERCOUTÈre C., AGSOUS S., LENOBLE A., MARQUER L., GRIMAUD-HERVÉ D. 2009. « Statut des objets « extra-ordinaires » du Gravettien final de Pataud (Les Eyzies-de-Tayac, Dordogne) : objets abandonnés dans l'habitat ou dépôt intentionnel ?», dans BONNARDIN S., HAMON C., LAUWERS M., QUILLEC, B. (Dir.), Du matériel au spirituel : réalités 
archéologiques et historiques des « dépôts » de la Préhistoire à nos jours : actes Rencontres, 16 au 18 octobre 2008, Antibes, Éditions APDCA, p. 29-46.

CоOK J. 2013, Ice Age art. Arrival of the modern mind. London, The British Museum press.

CoSTAMAGNO S. 2006, « Archéozoologie des grands mammifères des gisements de la falaise du Pastou », dans DACHARY M. (Dir.), Les Magdaléniens à Duruthy. Qui étaient-ils ? Comment vivaientils? Catalogue d'exposition, Abbaye d'Arthous à Hastingues (7 octobre-10 décembre 2006). Conseil général des Landes, Centre Départemental du Patrimoine, p. 19-29.

DACHARY M. 2002, Le Magdalénien des Pyrénées occidentales, Thèse de Doctorat, Université de Paris X.

DACHARY M. (Dir.) 2006, Les Magdaléniens à Duruthy. Qui étaient-ils ? Comment vivaient-ils ? Catalogue d'exposition, Abbaye d'Arthous à Hastingues (7 octobre-10 décembre 2006). Conseil général des Landes, Centre Départemental du Patrimoine.

DACHARY M. 2009, « Une perception affinée du Magdalénien des Pyrénées occidentales à partir des travaux récents ", dans fULLOLA J.-M., VALDEYRON N., LANGLAIS M. (dir.), Les Pyrénées et leurs marges durant le Tardiglaciaire. Mutations et filiations technoculturelles, évolutions paléoenvironnementales, actes du XIV ${ }^{\text {ème }}$ colloque international d'archéologie de Puigcerda, novembre 2006, Hommages à Georges Laplace. Puigcerdà, Institut d'Estudis Ceretans, p. 423-460. DELPORTE H. 1990, L'image des animaux dans l'art préhistorique. Paris, Picard.

DESBRosse R. 1972, « Les dents incisées du Paléolithique », L’Anthropologie, vol. 76, p. 135-140.

DESCOLA P. 2005, Par-delà nature et culture. Paris, Gallimard, Bibliothèque des sciences humaines. DESCOLA P. 2008, « Compte rendu d'enseignement », Annuaire du Collège de France 2006-2007. DESCOLA P. 2011, L'écologie des autres. L'anthropologie et la question de la nature, Paris, Éditions Quae, coll. Sciences en questions.

HENRY-GAMBIER D. 2006, « Les sépultures de Sorde-l’Abbaye (Landes) », in DACHARY M. (Dir.), Les Magdaléniens à Duruthy. Qui étaient-ils ? Comment vivaient-ils ? Catalogue d'exposition, Abbaye d'Arthous à Hastingues (7 octobre-10 décembre 2006). Conseil général des Landes, Centre Départemental du Patrimoine, 67-73.

INGOLD T. 2000, The Perception of the Environment : Essays on Livelihood, Dwelling \& Skill, Londres, Routledge.

INGOLD T. 2011, Being Alive. Essays on movement, knowledge and description, Londres, Routledge.

LARTET L. et CHAPLAIN-DUPARC G. 1874a, « Sur une sépulture des anciens Troglodytes des Pyrénées superposée à un foyer contenant des débris humains associés à des dents sculptées de Lion et d'Ours ", Matériaux pour l'histoire primitive et naturelle de l'homme V, Xème année, $2^{\mathrm{e}}$ série, p. 101-167.

LARTET L. et CHAPLAIN-DUPARC G. 1874b, « Sur une sépulture des anciens Troglodytes des Pyrénées superposée à un foyer contenant des débris humains associés à des dents sculptées de Lion et d'Ours ». Congrès international d'anthropologie et d'archéologie préhistoriques, Compte-rendu de la $7^{\text {ème }}$ session, Stockholm, 1874. Kraus reprinte, 1969, p. 1302-310.

LARTET L. et CHAPLAIN-DUPARC G. 1874c, « Une sépulture des anciens Troglodytes des Pyrénées, superposée à un foyer contenant des débris humains associés à des dents sculptées de lion et d'ours ", Bulletin de la Société d'anthropologie de Paris, p. 516-525. 
LYMAN R.L. 1994, Vertebrate taphonomy, Cambridge, Cambridge University Press, Cambridge manuals in archaeology.

MAZIÈRE G., BURET C. 2010, « Les incisives de cheval gravées de La Marche (Lussac-les-Châteaux, Vienne). Collection Péricard, Musée Sainte-Croix, Poitiers », dans J. BUISSON-CATIL, J. PRIMAULT (éd.), Préhistoire entre Vienne et Charente, Hommes et sociétés du Paléolithique, Mém. XXXVIII, Chauvigny, p. 397-405.

MEREAU A.-L. 2012, Les dents animales perforées au Magdalénien. Nouvelles perspectives fonctionnelles. Étude de quatre sites pyrénéens : Isturitz, le Mas d'Azil, Arudy et Gourdan, Thèse de Doctorat, Université de Paris I-Panthéon Sorbonne.

OVERTON N.J., HAMILAKIS Y. 2014, « A manifesto for a social zooarchaeology. Swans and other beings in the Mesolithic », Archaeological Dialogues, vol. 20, p. $111-136$.

PAILlET P. 2014, L'art des objets de la préhistoire. Laugerie-Basse et la collection du marquis Paul de Vibraye au Muséum national d'histoire naturelle, Arles, Errance.

PÉQUART M., PÉQUART S.-J. 1960, La grotte du Mas d'Azil (Ariège). Une nouvelle galerie magdalénienne, Paris, Masson.

PÉTILLON J.-M., SACCHI D. 2013, « Deux spatules du type Pekarna dans la grotte Gazel (SallèlesCabardès, Aude, France) », dans M. De La RASILLA VIVES, F. JAVIER FORTEA PÉREZ (Eds.), Universitatis Oventensis Magister. Estudios en homenaje. Universidad de Oviedo, Mensula Ediciones, p. 305-315.

PIETTE E. 1907, L'art pendant l'Âge du renne, Paris, Masson.

POPLIN F. 1976, « À propos du nombre de restes et du nombre d'individus dans les échantillons d'ossement », Cahiers du Centre de Recherches Préhistoriques, vol. 5, p. 61-74.

POPLIN F. 1983, « Incisives de Renne sciées du Magdalénien d'Europe occidentale », dans La faune et l'homme préhistorique. Dix études en hommage à Jean Bouchud réunies par François Poplin. Paris, Société Préhistorique Française (Mémoire 16), p. 55-67.

SACCHI D. 1990, « Bases objectives de la chronologie de l'art mobilier paléolithique dans les Pyrénées septentrionales », dans CLOTTES J. (Dir.), L'art des objets au Paléolithique, tome I : l'art mobilier et son contexte, colloque international Foix-le Mas d'Azil, 16-21 octobre 1987. Paris, Ministère de la Culture, p. 13-30.

SAUVET G., WLODARCZYK A., 2000-2001, « L'art pariétal, miroir des sociétés paléolithiques », Zephyrus, vol. 53-54, p. 217-240.

TABORIN Y. 2004, Langage sans parole. La parure aux temps préhistoriques, Paris, La Maison des Roches.

VERCOUTÈRE C. 2009, « La parure », dans PINÇON G. (Ed.), Angles-sur-l'Anglin, le Roc-aux-Sorciers : art et parure du Magdalénien, catalogue numérique des collections, www.catalogue-roc-auxsorciers.fr

WHITE T.E. 1953, « A method of calculating the dietary percentage of various food animals utilized by aboriginal peoples », American Antiquity, vol. 4, p. 396-398. 


\section{RÉSUMÉS}

Les fouilles menées en 1961 par R. Arambourou dans l'abri Duruthy (Sorde-l'Abbaye, Landes) ont mis au jour trois sculptures de cheval (en grès, calcaire et ivoire) attribuées au Magdalénien moyen. L'étude du contexte archéologique montre qu'une concentration de fragments de mandibules de vieux chevaux (NMIc $=11$ ), ayant fait l'objet d'un traitement technique particulier (raclage systématique, sciage, incisions, façonnage, décor gravé), était située à proximité immédiate de ces figurations. L'analyse de ces vestiges nous a permis de confirmer un intérêt soutenu pour le cheval dans le Magdalénien des Pyrénées. Le caractère hybride du dépôt nous a encouragé à proposer une démarche alternative pour appréhender cette espèce animale. Nous soulignons l'intérêt qui est montré, à l'abri duruthy, pour certains individus parmi les chevaux. Il nous semble également qu'une préoccupation pour la condition écologique de l'animal, comme pour sa subjectivité, sont véhiculés par les vestiges. Différents indices laissent ainsi entrevoir la conception de cette espèce dans une perspective qui pourrait se rapporter à un animisme ontologique.

\section{AUTEURS}

\section{CLÉMENT BIROUSTE}

UMR 5608 TRACES,

Université Toulouse Jean Jaurès, Campus Mirail

\section{FRANÇOIS-XAVIER CHAUVIÈRE}

Office du Patrimoine et de l'archéologie de Neuchâtel - Section Archéologie, Laténium

FRÉDÉRIC PLASSARD

Université Bordeaux, UMR 5199, PACEA

MORGANE DACHARY

UMR 5608 TRACES,

Université Toulouse Jean Jaurès, Campus Mirail 


\title{
Les représentations animales de la grotte Margot (Thorigné-en- Charnie, Mayenne) : essai de synthèse
}

\author{
Tiphaine Guigon et Romain Pigeaud
}

1 L'étude des représentations pariétales peut donner des indices sur la relation particulière existant entre l'homme et l'animal, notamment pour tenter de comprendre comment les hommes préhistoriques percevaient les animaux qui les entouraient. Les représentations animales sur les parois des grottes, gravées ou peintes, permettent également d'avoir des informations sur l'environnement et son influence sur les groupes humains paléolithiques. Notre étude tend ainsi à répondre à ces problématiques, ou du moins à formuler des hypothèses, en se basant sur l'analyse d'un site, la grotte Margot, en Mayenne.

2 Après une présentation du site de la vallée de l'Erve et de ses cavités ornées, nous nous focaliserons sur les figurations animales de la grotte Margot afin d'appréhender quels animaux vivaient dans cette région et comment les groupes humains les percevaient. Nous ouvrirons notre réflexion par des comparaisons entre l'art animalier de Margot et celui des autres cavités ornées de la vallée.

\section{Présentation des grottes de la vallée de l'Erve}

Les grottes que nous allons étudier se situent en Mayenne, dans le « canyon » dit « de Saulges", une petite formation karstique sur la bordure orientale du M. assif armoricain. L'Erve, un affluent de la Sarthe, a entaillé un massif de calcaire carbonifère sur $1,5 \mathrm{~km}$. Ce « canyon » ou vallée encaissée comprend une vingtaine de cavités dont la plupart ont été fouillées dès le XIX ${ }^{e}$ siècle. Cette zone est classée Natura 2000 en raison de sa biodiversité actuelle. La vallée de l'Erve comprend deux cavernes ornées: 
Mayenne-Sciences et Margot. Nous évoquerons aussi la grotte Rochefort, située de l'autre côté de l'Erve (fig. 1).

Figure 1 : Vue aérienne du « canyon » de Saulges.

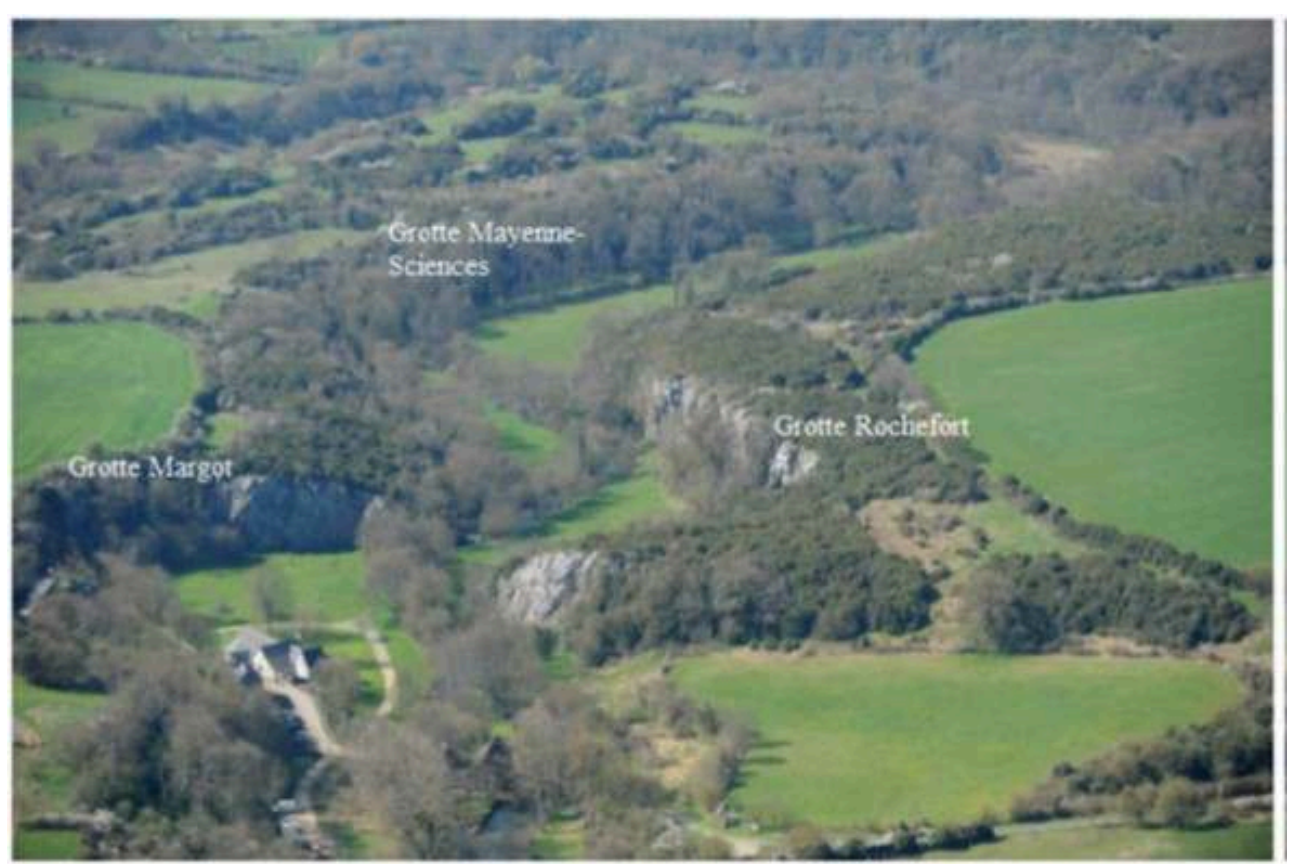

Photographie Gilles Leroux.

Mayenne-Sciences fut découverte en 1967. Elle est aujourd'hui fermée au public, car les figures peintes qu'elle renferme sont très fragiles. De plus, l'accès à cette cavité est difficile et est donc réservé aux chercheurs. L'étude menée par Romain Pigeaud au cours de sa thèse (2001) a dévoilé l'existence de 59 représentations peintes et gravées sur les parois de cette cavité. Ces figurations ont été datées gravettiennes par utilisation du Carbone 14: deux dates ont été obtenues (Pigeaud et al., 2003) : $24220 \pm$ 850 BP (Gif A 100 647) et $24900 \pm 360$ BP (Gif A 100645 ).

5 La grotte Rochefort est quant à elle dénuée de figures gravées ou peintes sur ses parois mais recèle en revanche des objets ornés paléolithiques. Cette grande cavité, fouillée par Stéphan Hinguant, a en effet livré de nombreuses plaquettes gravées dans la couche solutréenne, soit entre 19000 et 20000 BP (Pigeaud et Hinguant, 2017). Ces plaquettes présentent un décor animalier pour la plupart, mais on y trouve aussi des anthropomorphes ainsi que des signes abstraits (Pigeaud et al., 2008).

La grotte Margot est une cavité longue de $319 \mathrm{~m}$. Fréquentée et visitée depuis le Moyen Âge, elle doit peut-être son nom à une « sorcière " y pratiquant la magie noire. La cavité est classée Monument historique depuis 1926, après la découverte de squelettes médiévaux dans une de ses salles. Aujourd'hui, elle se visite pour ses concrétions, sa légende et pour les nombreuses gravures qu'elle renferme, bien que ces dernières soient, pour la plupart, extrêmement fines et donc très difficiles à voir et à lire. L'accès à la cavité est aujourd'hui aisé, ce qui n'était pas le cas au Paléolithique, période durant laquelle l'orifice de l'entrée mesurait environ $50 \mathrm{~cm}$ de diamètre. Il fallait donc ramper pour y accéder et y avancer, comme c'était le cas dans la grotte des 
Combarelles, en Dordogne. Le visiteur ne pouvait se relever qu'à 200 mètres de l'entrée, dans la partie centrale de la grotte (Pigeaud et Hinguant, 2007).

7 On imagine alors facilement que les hommes qui ont orné ces parois ont dû faire preuve d'une grande volonté et éprouver de la difficulté pour y parvenir. Les parois de Margot sont recouvertes de concrétions, en majorité de la calcite sèche orangée et par endroits du mondmilch, matière qui rend la lecture des figures encore plus compliquée. La grotte Margot est étudiée depuis 2002, dans le cadre du programme «Occupations paléolithiques de la vallée de l'Erve » de l'UMR 6566 «CReAAH» du CNRS de Rennes, avec le soutien de la Communauté de Communes des Coëvrons, du Conseil général de la Mayenne et du ministère de la Culture et de la Communication. Les premières gravures furent découvertes en 2005 par Romain Pigeaud et son équipe qui continuent d'étudier cette cavité et le décor qui orne ses parois.

\section{L'art de Margot : inventaire et analyse}

\section{Inventaire des représentations de la grotte Margot}

8 L'art pariétal de Margot est ainsi essentiellement composé de gravures. Il y a aussi quelques peintures, résiduelles pour la majorité d'entre elles. Les gravures sont de taille moyenne à petite (c'est-à-dire entre 10 et $20 \mathrm{~cm}$ ), la plus imposante devant être celle de l'équidé $\mathrm{n}^{\circ} 16$ surnommée le "Cheval Thibaut » qui mesure $40 \mathrm{~cm}$ de la tête au bout de la ligne de dos. Parmi les thèmes iconographiques représentés, on trouve une majorité d'animaux mais aussi des anthropomorphes (essentiellement des figures féminines schématiques) et des signes abstraits.

Le dernier inventaire (campagne 2016) (tab. 1) dénombre 179 unités graphiques qui se répartissent comme suit :

Tableau 1 : Dernier inventaire (campagne 2016).

\begin{tabular}{|l|c|}
\hline Représentations figuratives & 113 \\
\hline Chevaux & 19 \\
\hline Rhinocéros laineux & 9 \\
\hline Ornithomorphes & 25 \\
\hline Mégacéros & 3 \\
\hline Bovidés & 7 \\
\hline Ours & 1 \\
\hline Canidés & 1 \\
\hline Pisciformes & 2 \\
\hline Animaux indéterminés & 27 \\
\hline Anthropomorphes & 61 \\
\hline Représentations abstraites & 46 \\
\hline Signes élaborés & 15 \\
\hline Traces indéterminées (rouges et noires) & schématiques et 2 sexes féminins) \\
\hline Tracés digitaux & 5 (dont 3 mains positives et 2 mains négatives) \\
\hline Total & 179 \\
\hline
\end{tabular}


10 Nous pouvons d'ores et déjà constater que le bestiaire de Margot est très riche, une grande diversité d'animaux y étant représentés (fig. 2). On trouve une majorité de mammifères mais également des pisciformes et des ornithomorphes.

Figure 2 : Diversité du bestiaire de Margot.

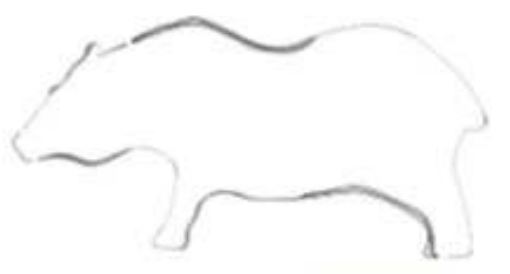

Ours 121

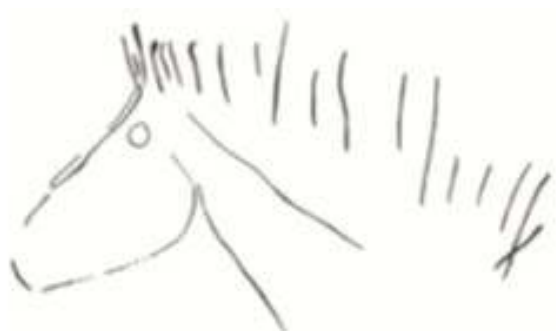

Cheval 11

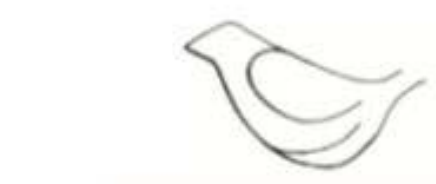

Ornithomorphe 144

\section{Pisciforme 105}

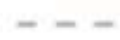

DAO Tiphaine Guigon.

11 Au sein de ce corpus, 3 thèmes animaliers principaux se distinguent: le cheval, le rhinocéros laineux et l'ornithomorphe (fig. 3). Ce corpus, pour le cheval, correspond à celui de la majorité des grottes ornées, cet animal étant la figure dominante de l'art paléolithique. Ce thème compte en effet pour plus d'un quart des représentations animalières (Tosello, 2003). De même, Margot comprend des représentations d'animaux également fréquentes dans de nombreuses cavités telles que les cervidés. Cependant, le corpus animalier de Margot est original sur plusieurs points. D'une part, cette grotte recèle des thèmes rares, à savoir des pisciformes, des rhinocéros laineux et des ornithomorphes. D'autre part, ces deux derniers thèmes sont en très grand nombre dans la cavité, ce qui est d'autant plus original. En effet, quand ces thèmes sont présents dans les grottes ornées, ils le sont la plupart du temps de manière exclusive. On peut citer les fameuses grottes de Lascaux (Soubeyran, 1995) et de Chauvet (Clottes, 2001) qui comprennent chacune un seul ornithomorphe. En Europe, très rares sont les sites ayant livré plusieurs figurations aviaires. Donnons ici simplement, avant d'y revenir par la suite, l'exemple de la grotte des Trois-Frères, en Ariège (Begouën et al., 2014), et celui du site de plein air de Gönnersdorf, en Rhénanie (Bosinski, 2011).

12 L'art de Margot est donc très riche et original. Nous reviendrons sur ses particularités, notamment lorsque nous étudierons plus en détail ses ornithomorphes. 
Figure 3 : Fréquence des thèmes animaliers dans la grotte Margot.
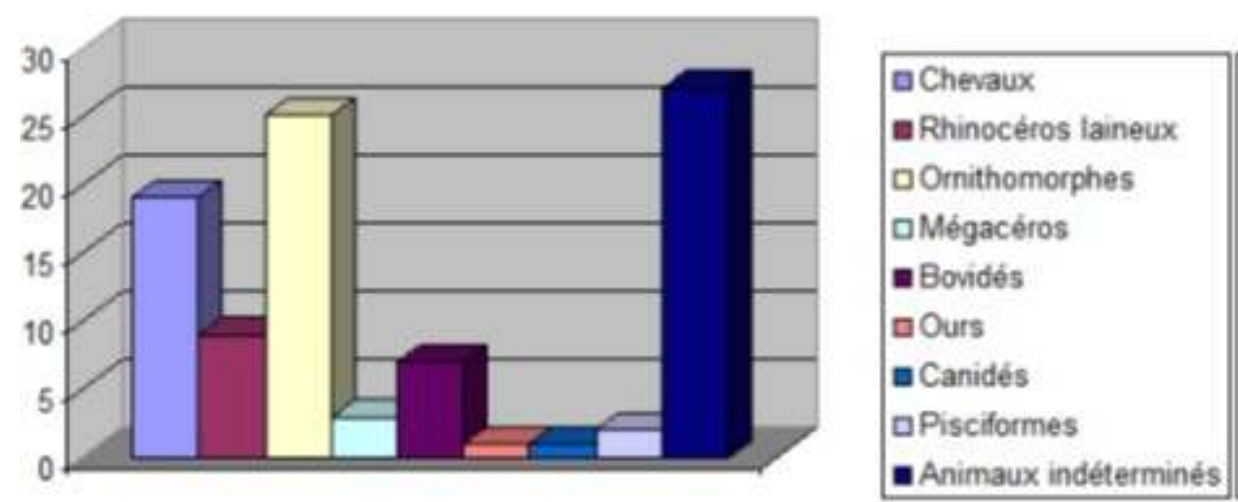

DAO Tiphaine Guigon.

\section{Analyse des figures : comment les figures animales de Margot sont- elles représentées?}

La question du style des figures animales peut être un biais pour comprendre la relation que l'Homme entretenait avec les animaux qui l'entouraient. Les a-t-il représentés de manière réaliste, ce qui suppose qu'il les observait longuement et d'une certaine manière était proche d'eux, ou bien de manière stylisée, c'est-à-dire sans chercher à dépeindre fidèlement le réel ? Dans tous les cas, cela laisse penser que l'Homme préhistorique menait une certaine réflexion sur l'animal et le faisait volontairement transparaître dans ses représentations.

\section{Méthodologie}

14 L'étude des figures, sur le terrain puis sur les relevés, s'est effectuée thème par thème avec une analyse détaillée de chaque représentation. Pour ce faire, il s'agit dans un premier temps de définir des critères d'analyse pour l'étude des figures. Tout d'abord vérifions si la figure est entière, ou si elle se résume à la représentation d'une partie du corps, comme un protomé par exemple. Cela permettra d'introduire des notions de gestes volontaires ou non, et là encore de nous pencher sur le style, une bonne partie des gravures de la cavité ne semblant pas être entières.

Il est ensuite essentiel de vérifier et noter quels sont les éléments distinctifs pour les préhistoriens qui les utiliseront afin de proposer une attribution taxinomique. Par exemple, pour les chevaux, est-ce que la gravure comporte une crinière ? Certains de ces critères sont communs à tous les thèmes et d'autres sont plus spécifiques. Les critères communs sont par exemple la présence ou l'absence d'organes sensoriels sur la représentation. Ces éléments tels que l'œil, l'oreille, la bouche ou les naseaux soulignent le niveau de précision accordé à l'œuvre. Il en va de même pour le traitement de l'extrémité des membres, quand ils sont figurés.

Tout cela nous donne des indices sur le degré de naturalisme de la figure. Il nous faut dès maintenant définir cette notion de naturalisme, qui s'oppose à celle de la stylisation, toutes deux reviendront au cours de ce travail à de nombreuses reprises. Le naturalisme est la «représentation réaliste de la nature » (Rey, 2005, p. 894). Ici une 
figure naturaliste supposera donc une volonté de l'auteur de figurer le corps de l'animal avec une « relative fidélité zoologique » (Petrognani, 2013, p. 115). À cela, nous opposerons la notion de stylisation, définie comme la «reproduction d'un objet ou d'une chose en simplifiant les formes en vue d'un effet décoratif » (Rey, 2005, p. 894). Les critères d'analyse spécifiques à chaque thème concernent surtout la présence ou l'absence d'éléments caractéristiques et la forme de certains d'entre eux. On peut citer en exemple le bout du nez en « bec de canard » des chevaux. Nous nous appuyons sur une étude statistique visant à évaluer la récurrence de ces critères pour chaque thème et leur présence ou non pour chaque figure. Cette méthode de travail, mettant en avant statistiquement les éléments et les formes les plus présents au sein de chaque thème, nous paraît la plus objective, bien que l'objectivité ne puisse être totale puisque nous avons fait le choix des critères, ce qui induit forcément une part de subjectivité dans cette analyse.

\section{Résultats de l'étude stylistique : une homogénéité au sein de chaque thème?}

\section{Les chevaux}

17 Les chevaux de la grotte Margot sont très divers, présentant ou non des détails anatomiques marqués. On peut distinguer deux groupes au sein de ce thème iconographique. En effet, 4 figures sur les 19 représentations de chevaux peuvent être, selon nos critères, qualifiées de naturalistes. Ces gravures possèdent un grand nombre de détails, alors que d'autres n'en présentent aucun. Ils sont figurés en pelage d'hiver, avec toison et barbe, et on perçoit des éléments anatomiques, comme des yeux et des oreilles par exemple (fig. $4 \mathrm{~A}$ ). 
Figure $4 \mathrm{~A}$ : Chevaux naturalistes de Margot.

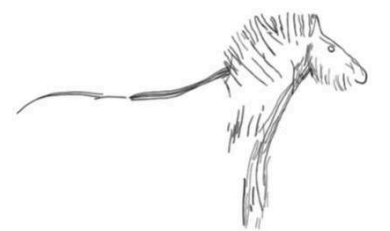

16

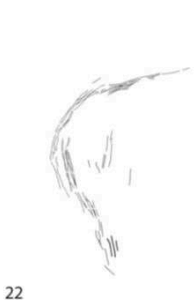

22

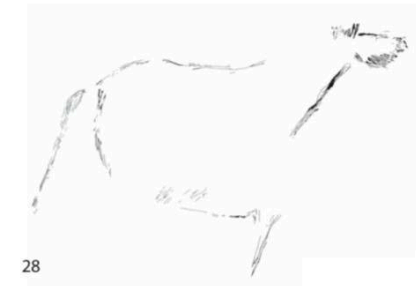

DAO Romain Pigeaud.
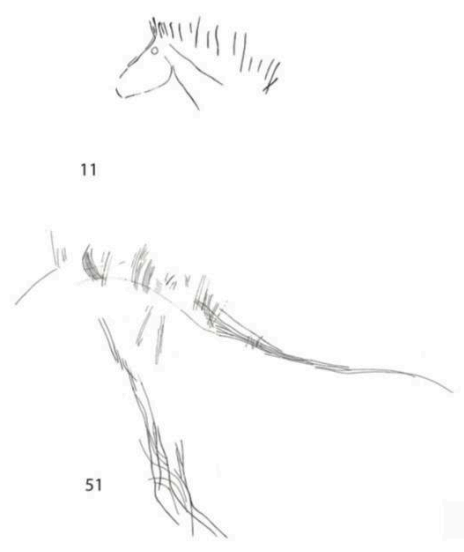

27

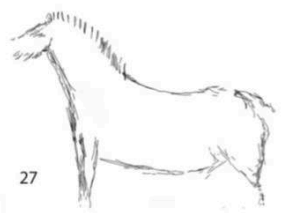

18 Les autres chevaux sont extrêmement stylisés, la gravure n'étant faite que d'un seul trait. On pourrait penser que ces gravures ont été réalisées en une fois, à main levée (fig. 4 B). Évidemment, certaines gravures sont à mi-chemin entre les chevaux naturalistes et les chevaux stylisés. Ces figures ne présentent aucun détail anatomique hormis une crinière hachurée de traits obliques. Si cela peut être perçu comme un élément naturaliste, nous ne les comptons pas parmi les autres chevaux naturalistes car la stylisation prédomine dans leur représentation. 
Figure 4 B : Chevaux stylisés de Margot.

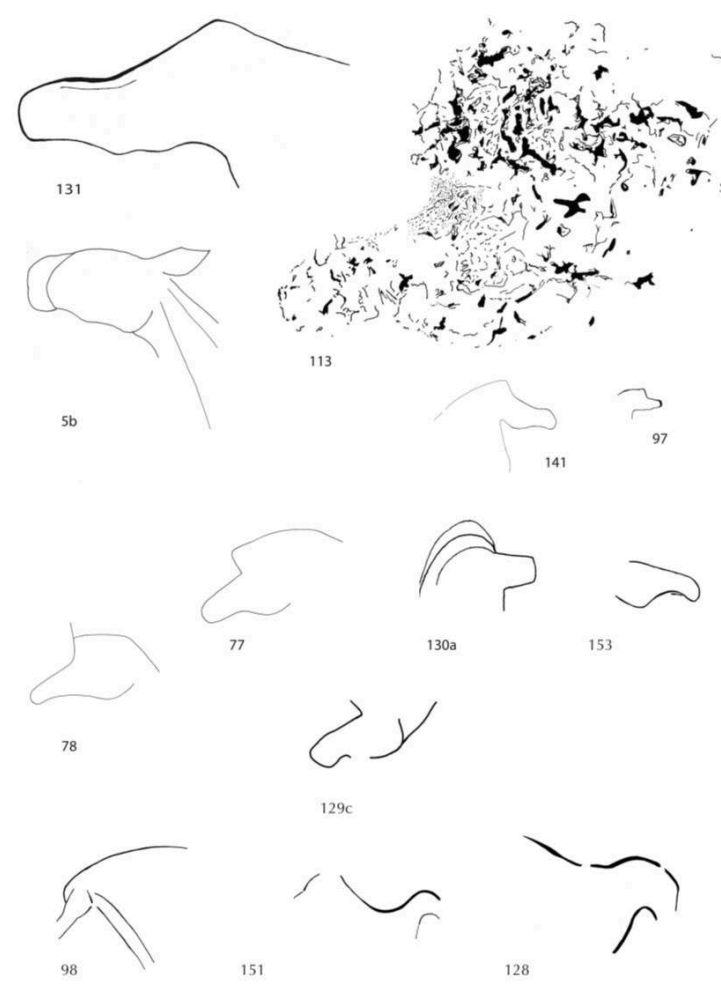

DAO Romain Pigeaud.

\section{Les rhinocéros}

Exactement comme pour le thème des chevaux, on distingue très nettement deux groupes distincts au sein du thème des rhinocéros. En effet, on perçoit la même dichotomie entre le naturalisme et la stylisation. D'une part, on trouve des rhinocéros très détaillés, représentés en pelage d'hiver bien marqué, avec des détails anatomiques tels que la figuration des deux cornes, des yeux et oreilles pour certains d'entre eux (fig. 5 A). La voussure dorsale est également très bien mise en valeur. D'autre part, on a des rhinocéros sans détail aucun, reconnaissables à leur corne unique et à leur stature lourde et basse. Comme pour les chevaux, ces rhinocéros stylisés semblent avoir été réalisés d'un seul trait (fig. 5 B). Des exceptions apparaissent pareillement. Le rhinocéros numéro 42 de l'inventaire est entre les deux groupes, ayant un contour stylisé, avec une seule longue corne et la tête peu distincte du reste du corps. Cependant, il présente des traits de pelage, ce qui le place à la limite du groupe des rhinocéros détaillés. 
Figure $5 \mathrm{~A}$ : Rhinocéros de Margot.

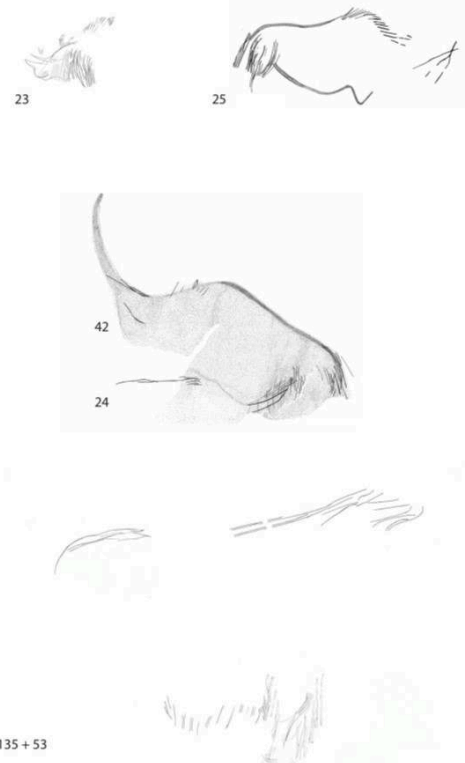

DAO Romain Pigeaud

Figure 5 B : Rhinocéros de Margot.
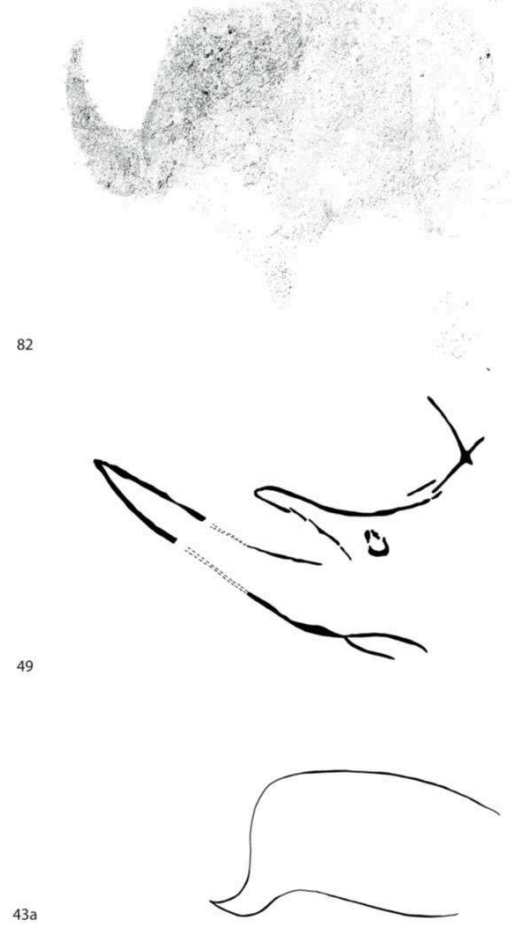

DAO Romain Pigeaud. 


\section{Les ornithomorphes}

Pour ce thème iconographique, la bipartition des figures n'est pas aussi évidente que pour les chevaux ou les rhinocéros. Ce thème est en effet plus compliqué à analyser, car les ornithomorphes étant rares dans l'art pariétal paléolithique, nous avions peu de figures sur lesquelles nous appuyer et faire des comparaisons. Comme pour les chevaux et les rhinocéros, des ornithomorphes très détaillés apparaissent et se distinguent du corpus. Nous avons d'une part les oiseaux que l'on peut aisément identifier (l'identification ne dépassant pas le genre, la détermination spécifique étant très rare et difficile à réaliser) (fig. 6 A) et d'autre part ceux pour qui cela est impossible, mais qui présentent tout de même certains détails. Ces gravures comportent par exemple un bec détaillé, un œil et parfois un plumage et des ailes (fig. 6 B, nos 115 et $46 \mathrm{c}$ ). Enfin, certaines gravures aviaires de Margot ne sont aucunement détaillées et évoquent la forme d'un oiseau très schématique (fig. 6 B).

Figure 6 A : Ornithomorphes de Margot.
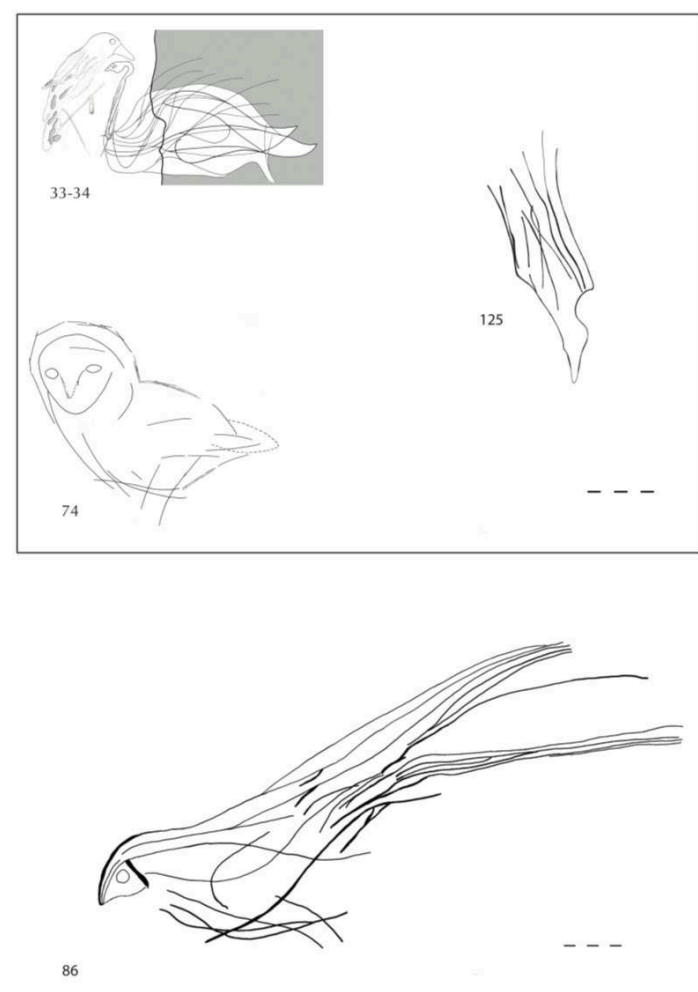

DAO Romain Pigeaud. 
Figure 6 B : Ornithomorphes de Margot.

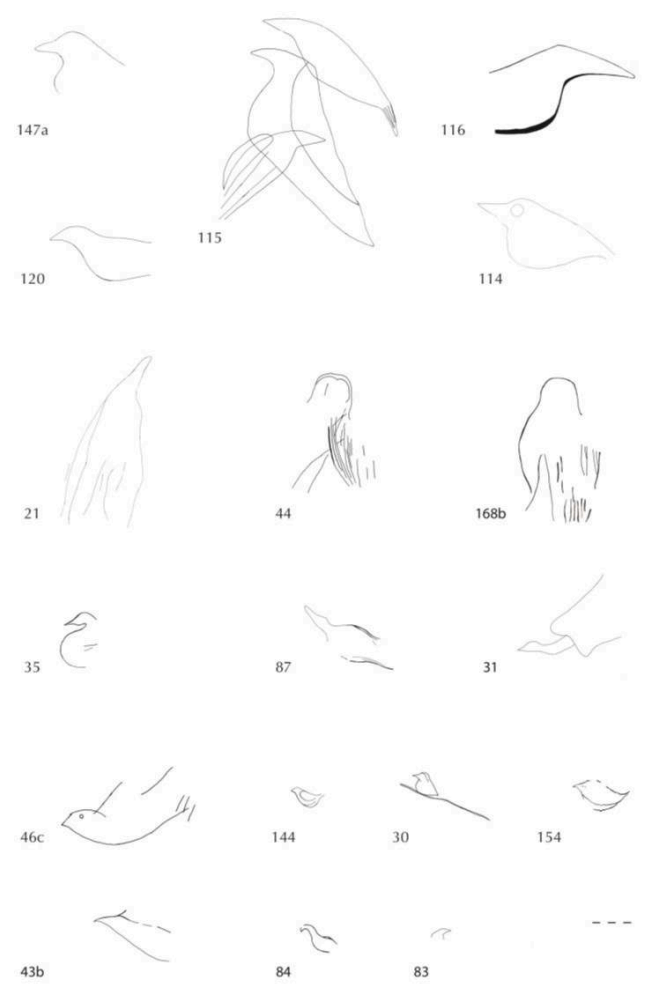

DAO Romain Pigeaud.

\section{Bilan}

21 Malgré des thèmes plus compliqués que d'autres à appréhender, on parvient tout de même à lire une bipartition des gravures. Pour chaque thème, on constate donc que se dégagent deux groupes de gravures différentes par leur représentation. Le premier est composé de gravures très détaillées, que l'on peut qualifier de naturalistes pour certaines. Le second se compose de gravures très peu, voire pas du tout détaillées et stylisées. Ces deux groupes ne sont bien sûr pas cloisonnés et étanches. Il ne faut pas tenter absolument de vouloir classer toutes les gravures et ne pas faire un effort de description si l'une d'elles ne "rentre " pas dans l'un ou l'autre groupe. Il est difficile d'évoquer les gravures trop incomplètes et pour lesquelles le doute subsiste quant à leur identification. En effet, on ne peut pas les classer dans tel ou tel groupe, le manque d'éléments nous empêchant de déterminer leur niveau.

\section{Attributions chrono-stylistiques}

Les deux styles (naturalistes vs stylisés) mis en évidence ont-ils été réalisés à des périodes différentes ? Il serait possible de conclure à deux périodes de décoration de la cavité : une première au Gravettien puis une seconde au Magdalénien (Pigeaud et Hinguant, 2007). Ces hypothèses données jusqu'alors se basent sur l'étude du style des gravures et ne peuvent donc être confirmées avec certitude, l'analyse stylistique étant à manier avec précaution. En effet, le réalisme ne signifie pas que ces œuvres sont plus récentes que les figures moins détaillées, en témoigne l'exemplaire grotte Chauvet. De 
plus, on constate que dans la vallée de l'Erve, des datations sont contradictoires. À Margot, il y a des chevaux présentant une crinière en cimier, élément traditionnellement daté aux périodes antémagdaléniennes, alors que, sur une plaquette gravée découverte dans la couche solutréenne de la grotte Rochefort, on trouve un cheval avec la crinière échevelée et réaliste (Pigeaud et Hinguant, 2017).

Il est donc délicat de proposer une attribution chronologique aux figures de Margot, les restes organiques présents dans les quelques peintures étant de plus trop résiduels pour permettre d'obtenir une datation.

\section{La place particulière des ornithomorphes}

Ce qui fait notamment l'originalité de la grotte Margot, c'est la présence d'un grand nombre de figures aviaires. Il s'agit sans doute de la cavité qui en comprend le plus, avec ses 25 représentations.

Les ornithomorphes de Margot sont très divers. En effet, si l'on s'en tient à l'ordre, on remarque que quasiment tous les ordres aviaires sont présents sur les parois de cette cavité. Ainsi, nous trouvons des Columbiformes, des Ansériformes, des Gruiformes, des Galliformes, des Strigiformes et des Passériformes. Margot comprend également un grand nombre d'indéterminés (plus de la moitié des figures). Ces dernières présentent en effet si peu de détails qu'on ne peut aller au-delà du fait qu'il s'agit d'un ornithomorphe, voire de la représentation de l'idée d'oiseau et non d'un oiseau réel. Malgré tout, cette grande diversité montre une grande capacité d'observation et d'imagination de la part des groupes humains qui ont figuré ces animaux sur les parois de cette grotte.

Nous pouvons nous demander pourquoi cette grotte recèle autant de représentations d'ornithomorphes. L'explicationss la plus fréquente est le rôle symbolique de l'oiseau. Par exemple, citons parmi les plus récentes celle de Jean Clottes, pour qui les oiseaux symbolisent l'envol de l'âme dans la mort ou lors de la transe dans de multiples cultures chamaniques, en Sibérie par exemple (Clottes, 2008). Dans la grotte Margot, ce thème iconographique est donc à plusieurs reprises associé à d'autres thèmes, animaliers ou non, tels que l'ours ou la figure féminine schématique. On ne connaît pas la signification de telles associations thématiques mais on peut supposer qu'elles sont manifestement symboliques. Ces associations se retrouvent dans d'autres grottes telles que celle des Trois-Frères (Begouën et al., 2014). Quant à la répartition des ornithomorphes dans la grotte, elle semble également symbolique. Il apparaît en effet qu'elles se situent à des points particuliers de la cavité (fig. 7). Un coup d'œil sur la topographie montre en effet que ces oiseaux se situent à des carrefours ou à des endroits où le cheminement se rétrécit ou change de direction. Cela semble se confirmer lorsque le visiteur se trouve dans la grotte. Les figurations d'ornithomorphes sont présentes sur les parois lorsqu'il doit tourner pour suivre son chemin le long des couloirs et dans les secteurs les plus décorés de la cavité. L'emplacement de ces figures aurait donc fait l'objet d'un choix précis et non anodin.

Les ornithomorphes ont donc un rôle majeur dans la grotte Margot mais également dans la vallée de l'Erve. 
Figure 7 : Répartition des ornithomorphes dans la grotte.

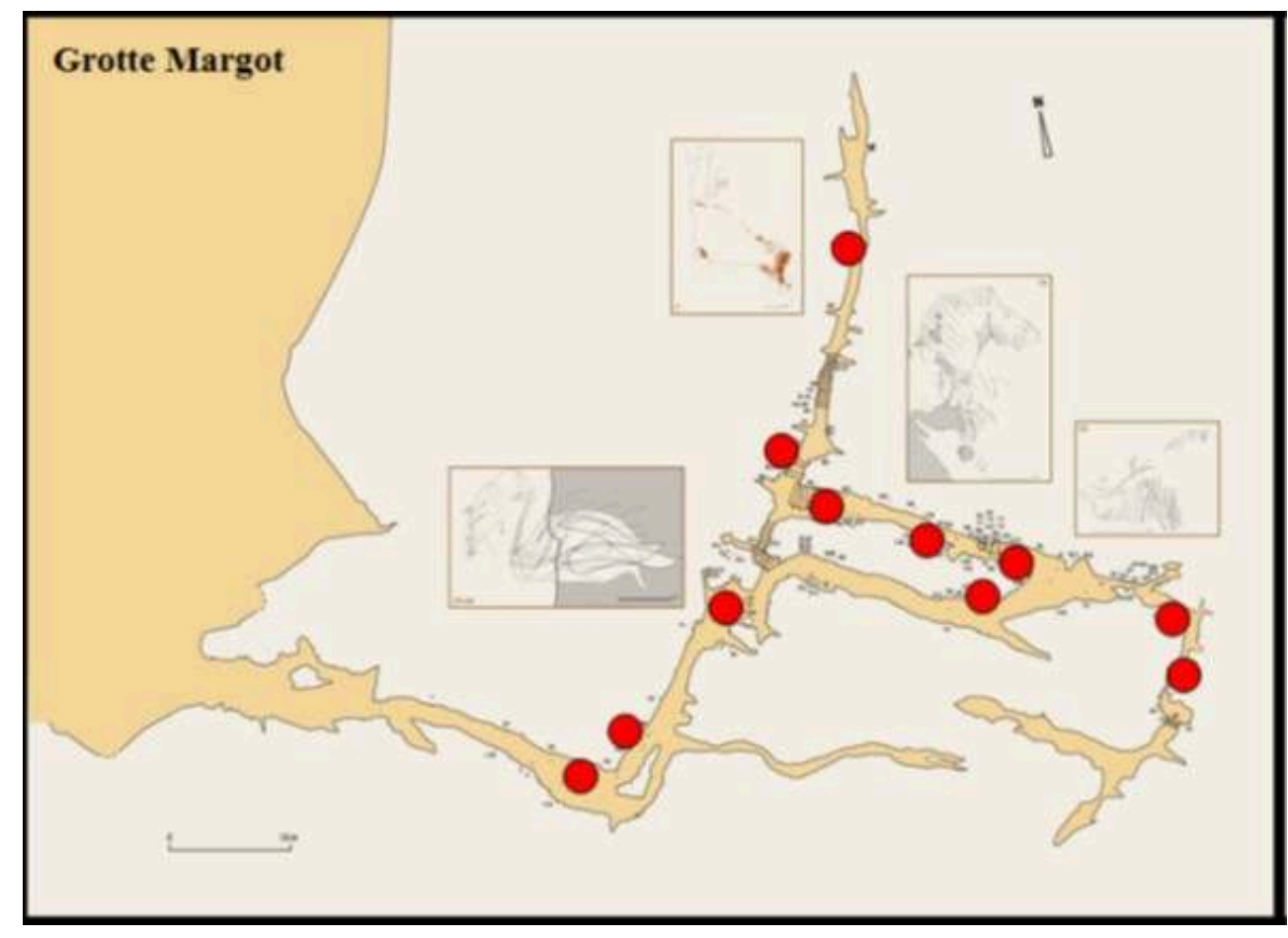

Topographie Vincent Pommier (Inrap) et Pascal Bonic (Équipe spéléologique de l'Ouest), DAO Alice Redou.

\section{Comparaisons}

\section{Margot au sein de la vallée de l'Erve}

Le bestiaire de Margot se distingue de celui des autres cavités du « canyon » de Saulges. Ces grottes ont des thèmes iconographiques communs avec Margot mais ont également leurs particularités.

Mayenne-Sciences comprend, tout comme Margot, des figures de chevaux et ces dernières sont également majoritaires dans cette grotte. Cependant, il n'y a pas de représentations de mammouths à Margot alors qu'on en trouve à Mayenne-Sciences. De plus, les rhinocéros et les ornithomorphes sont absents de ses parois.

Quant à la grotte Rochefort, si ses parois ne sont pas ornées, elle renferme de nombreuses plaquettes gravées dont le décor animalier comporte un bestiaire très varié (Pigeaud et al., 2008). En effet, on y retrouve des chevaux, des bouquetins, des mammouths et des ornithomorphes. Bien que Rochefort comprenne des représentations d'animaux absents de Margot, tels que le mammouth et le bouquetin, le thème iconographique majeur est le même que dans Margot, à savoir le cheval. Les ornithomorphes sont également présents et pourraient témoigner d'un possible lien symbolique entre Rochefort et Margot (fig. 8). 
Figure 8 : Plaquette gravée solutréenne de Rochefort présentant une gravure d'oiseau sur ses deux faces.
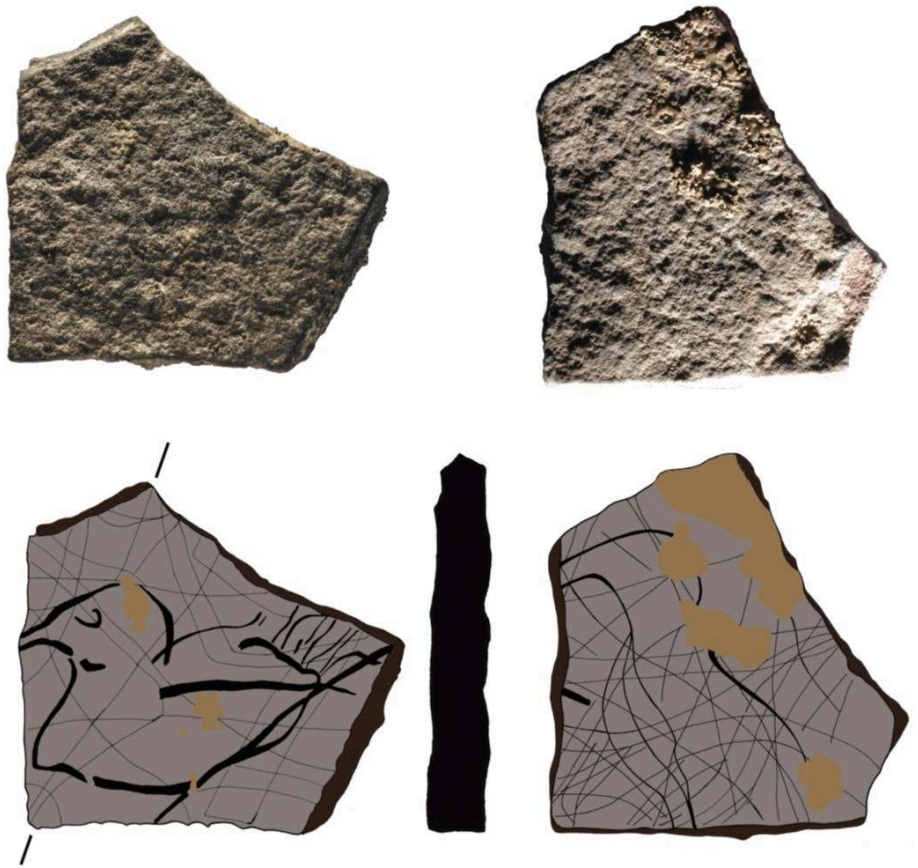

Photographie Hervé Paitier, relevés Marie Fraikin et Emma Le Vraux.

\section{Margot et d'autres cavités}

31 Il est intéressant de comparer le bestiaire de Margot avec celui d'autres cavités, plus éloignées de la vallée de l'Erve.

La grotte des Trois-Frères comprend également des représentations aviaires, au nombre de 8 (Begouën et al., 2014). Tout comme à Margot, les Strigiformes ont une place importante avec 4 représentations. Ces oiseaux sont figurés avec le corps et la tête de profil. Cette façon de dessiner se retrouve dans une autre grotte ornée des Pyrénées, Marsoulas (Fritz et Tosello, 2010) (fig. 9). 
Figure 9 : Exemples de chouettes dans l'art pariétal paléolithique.

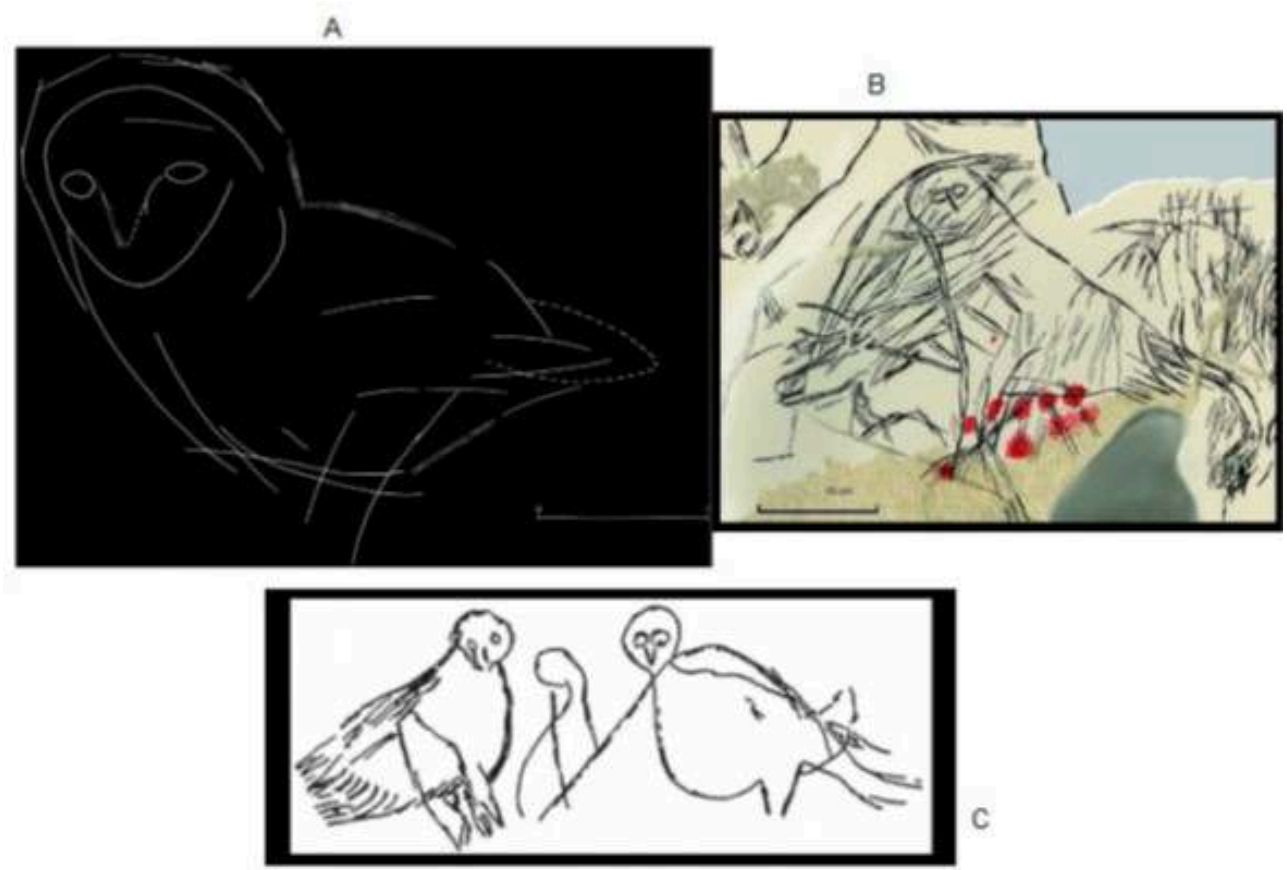

a. Chouette $n^{\circ} 74$ (grotte Margot) ; b. Marsoulas (Haute-Garonne). c. Les Trois-Frères (Ariège).

Relevés Florian Berrouet, Carole Fritz et Gilles Tosello, Henri Breuil.

Les représentations présentes sur le site de Gönnersdorf sont très semblables à celles de Margot. Bien que Gönnersdorf soit un site de plein air et non une grotte, ce dernier a livré un grand nombre de plaquettes gravées dont les thèmes iconographiques se rapprochent de ceux de Margot. En effet, les représentations aviaires y sont nombreuses avec par exemple un corvidé figuré en fuite, un cygne (fig. 10) et d'autres oiseaux probablement aquatiques.

Figure 10 : Cygne de Gonnersdörf.

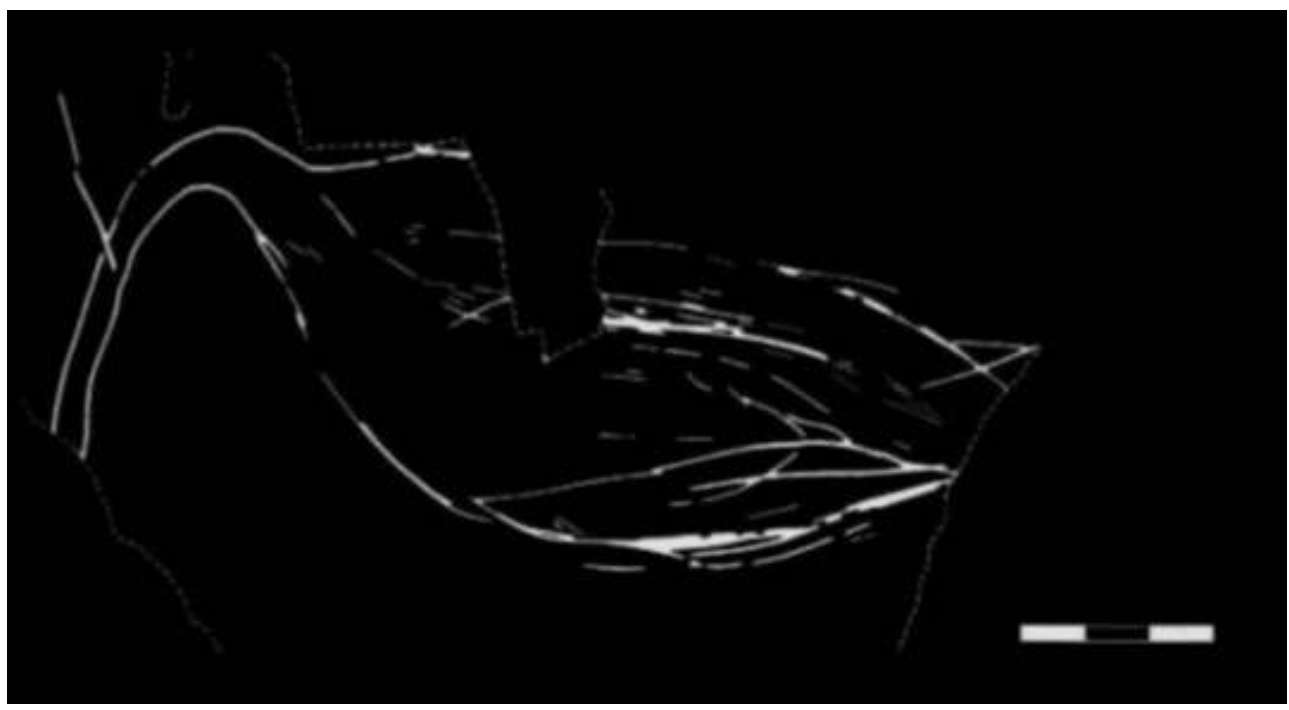

D’après Bosinski, 2011. 
représentations animales de Margot donnent donc à penser la relation entre l'homme et l'animal durant le Paléolithique. On ne peut émettre que des hypothèses quant aux raisons qui ont poussé les hommes du «canyon " de Saulges à choisir ces animaux en particulier pour décorer les parois de la grotte Margot. Cela peut-il montrer l'influence de l'environnement naturel sur les groupes humains? Si on ne peut y répondre avec certitude, on voit clairement que la diversité des animaux représentés signifie que les groupes humains les observaient avec attention et ne les ont pas choisis par hasard. Le travail sur les représentations animales pariétales est ainsi loin d'être fini et peut être étudié par d'autres biais tels que la comparaison entre le bestiaire figuré sur les parois et le spectre faunique présent dans les couches archéologiques. Pour ce qui est de la grotte Margot, cela n'est pas évident car les restes d'animaux sont peu nombreux, notamment les os d'oiseaux qui sont très fragiles et se conservent donc difficilement. Néanmoins, il serait envisageable d'utiliser les données disponibles sur d'autres sites afin d'approfondir la question des relations entre l'Homme préhistorique et les animaux qui l'entouraient.

\section{BIBLIOGRAPHIE}

ALLARD M. 1983, «État de la question sur le Paléolithique supérieur en Mayenne ; les grottes de Thorigné-en-Charnie et de Saint-Pierre-sur-Erve ", Bulletin de la Société préhistorique française, vol. 80, n 10-12, p. 322-328.

ALLARD M. 1985, « Le Solutréen de Thorigné-en-Charnie et de Saint-Pierre-sur-Erve (Mayenne) », Bulletin de la Société préhistorique française, vol. 82, n 10-12, p. 338-349.

Aujoulat N. 2013, Lascaux, le geste, l'espace et le temps, Paris, Seuil (Arts Rupestres).

AZÉMA M. 2009, L'Art des cavernes en action, T. 1, Les animaux modèles. Aspect, locomotion, comportement, Paris, Errance (Hespérides).

AZÉMA M. 2010, L'Art des cavernes en action, T. 2, Les animaux figurés. Animation et mouvement, l'illusion de la vie, Paris, Errance (Hespérides).

BEGOUËN R. (dir.) 2014, La Caverne des Trois-Frères : Anthologie d'un exceptionnel sanctuaire préhistorique, Paris, Somogy.

BOSINSKI G. 2011, Femmes sans tête. Une icône culturelle dans l'Europe de la fin de l'époque glaciaire, Paris, Errance. Traduction Romain Pigeaud.

CLOTTES J. (dir.) 2001, La Grotte Chauvet. L'art des origines, Paris, Le Seuil.

CLOTTES J. 2008, L'art des cavernes, Paris, Phaidon.

FRITZ C. et TOSELlo G. 2010, Marsoulas : renaissance d'une grotte ornée, Paris, Errance.

GRAPP (Groupe de Réflexion sur l'Art Pariétal Paléolithique) 1993, L'Art pariétal paléolithique. Techniques et méthodes d'étude, Paris, CTHS. 
HINGUANT S. et BIARD M. 2013, « Le Paléolithique supérieur ancien de la vallée de l'Erve (Mayenne) : un état des connaissances », dans BODU P., CHEHMANA L., KLARIC L., MEVEL L., SORIANO S., TEYSSANDIER

N. (dir.), Le Paléolithique supérieur ancien de l'Europe du Nord-Ouest, réflexions et synthèses à partir d'un projet collectif de recherche sur le centre et le sud du Bassin parisien, actes du colloque de Sens, 15 au 18 avril 2009, Paris, Société Préhistorique Française, p. 239-250 (Mémoire LVI).

HUME R., LESAFRE G. et DUQUET M. 2004, Oiseaux de France et d'Europe, Paris, Larousse.

LAROULANDIE V. 2004, « Exploitation des ressources aviaires durant le Paléolithique en France : bilan critique et perspectives ", s dans BRUGAL J.-P. et DESSE J. (dir.), Petits Animaux et Sociétés Humaines. Du complément alimentaire aux ressources utilitaires, actes des XXIV ${ }^{\mathrm{e}}$ Rencontres Internationales d'Archéologie et d'Histoire d'Antibes, Antibes, APDCA, p. 163-172.

LEROI-GOURHAN A. 1964, Dictionnaire de la Préhistoire, Paris, PUF (Quadrige).

MOURER-CHAUVIRE C. 1977, « Les oiseaux du Pléistocène moyen et supérieur de France », Documents des Laboratoires de Géologie de la Faculté des Sciences de Lyon, vol. 64, 2 fasc.

MULLARNEY K., SVENSSON L., ZETTERSTRÖM D. et GRANT P.-J. 1999, Le guide ornitho, Paris, Delachaux et Niestlé.

MÜLLER-BECK H. et ALBRECHT G. 1987, Die Anfänge der Kunst vor 30000 Jahren, Stuttgart, Theiss. NICOLAU-GUILLAUMET P. 2008, « Avifaune et art paléolithiques : essai pour une bibliographie exhaustive », Alauda, vol. 76, nº 6, p. 287-298.

PETROGNANI S. 2013, De Chauvet à Lascaux. L'art des cavernes, reflet de sociétés préhistoriques en mutation, Arles, Errance (Hespérides).

PIGEAUD R. 1997, « Les proportions des chevaux figurés dans l'art pariétal paléolithique : problème esthétique ou affaire de point de vue? », Paléo, vol. 9, p. 295-324.

PIGEAUD R. 2002, « La grotte ornée Mayenne-Sciences (Thorigné-en-Charnie, Mayenne) : grotte limite aux marges du monde anté-magdalénien ", L’Anthropologie, vol. 106, p. 445-489.

PIGEAUD R. 2002, « Les représentations de la grotte ornée Mayenne-Sciences (Thorigné-enCharnie, Mayenne) dans leur cadre archéologique et régional », Bulletin de la Société préhistorique française, vol. 99, $\mathrm{n}^{\circ}$ 3, p. 627-630.

PIGEAUD R. (avec la collaboration de M. Bouchard et d'É. Laval) 2004, « La grotte ornée MayenneSciences (Thorigné-en-Charnie, Mayenne) : un exemple d'art pariétal d'époque gravettienne en France septentrionale ", Gallia Préhistoire, vol. 46, p. 1-154.

PIGEAUD R. et HINGUANT S. 2007, "Grotte Margot : des graffitis de 12000 ans », Pour la Science, vol. 352, p. 64-69.

PIGEAUD R. et HINGUANT S. 2017, « Rituels familiers, pierres recyclées. Les plaquettes gravées du Solutréen de la vallée de l'Erve (Mayenne) », dans CLEYET-MERLE J.-J., GENESTE J.-M. et MAN-ESTIER E. (dir.), L'art au quotidien - Objets ornés du Paléolithique supérieur, actes du colloque international Les Eyzies-de-Tayac, 16 au 20 juin 2014, Paleo, p. 381-399 (numéro spécial, 2016).

PIGEAUd R., HingUANT S., LAdURÉE J.-R., PAITIER H., BETTON J.-P. et BONIC P. 2008, « Les grottes Margot et Rochefort. L'art préhistorique des grottes de Saulges », Maine découvertes, vol. 56, p. 5-16.

PIGEAUd R., VALLADAS H., ARNOLD M. et CACHIER M. 2003, « Deux dates carbone 14 en spectrométrie de masse par accélérateur (SMA) pour une représentation pariétale de la grotte ornée MayenneSciences (Thorigné-en-Charnie, Mayenne) : émergence d'un art gravettien en France septentrionale? », C. R. Palevol, vol. 2, p. 161-168. 
REY A. (dir.) 2005, Dictionnaire culturel en langue française, vol. III, Paris, Le Robert.

SOUBEYRAN F. 1995, « Lascaux : proposition de nouvelle lecture de la scène du puits », Paléo, vol. 7, p. $275-288$.

TOSELLO G. 2003, Pierres gravées du Périgord magdalénien. Art, symboles, territoires, XXXVI ${ }^{\mathrm{e}}$ supplément à Gallia Préhistoire, Paris, CNRS Éditions.

\section{RÉSUMÉS}

À travers une étude de cas, celle de la grotte Margot et de ses gravures pariétales, il s'agit de répondre à la question du lien entre l'Homme et l'animal et ainsi donner des éléments de réflexion sur la signification des représentations animales dans les grottes ornées. Le bestiaire de Margot est riche et original, de par la variété des animaux représentés et la rareté de ses thèmes iconographiques principaux, en particulier les ornithomorphes. L'étude du style des figures apporte des éléments sur la façon dont les artistes paléolithiques percevaient les animaux qu'ils choisissaient de représenter sur les parois des grottes. Ce bestiaire si particulier nous donne également à réfléchir sur son « rôle » au sein de la vallée de l'Erve où elle se situe et sur sa place dans l'art paléolithique.

\section{AUTEURS}

\section{TIPHAINE GUIGON}

Université de Rennes-2

ROMAIN PIGEAUD

Chercheur associé

UMR 6566 « CReAAH »,

Université de Rennes-1 


\title{
Bouquetin peint : bouquetin chassé. L'art mobilier animalier de l'Abri Dalmeri (Préalpes orientales italiennes, Épigravettien récent) dans son contexte archéologique
}

\author{
Élisa Legrand
}

\begin{abstract}
Les premières pierres peintes de l'Abri Dalmeri sont découvertes en 2001, après plus de dix années de fouilles menées par Giampaolo Dalmeri (MUSE $\left.{ }^{1}\right)$ en collaboration avec des équipes pluridisciplinaires et internationales (Dalmeri et al., 2002). Cette découverte introduisit une nouvelle dimension archéologique à cet abri-sous-roche situé à $1240 \mathrm{~m}$ d'altitude sur l'extrémité nord-oriental du Haut-Plateau de la Marcesina (Province de Trente, Préalpes vénitiennes). (Dalmeri et Bassetti et al., 2005a, 2005b; Dalmeri et Michele et al., 2005) (fig. 1).
\end{abstract}


Figure 1 : Localisation géographique de l'Abri Dalmeri.

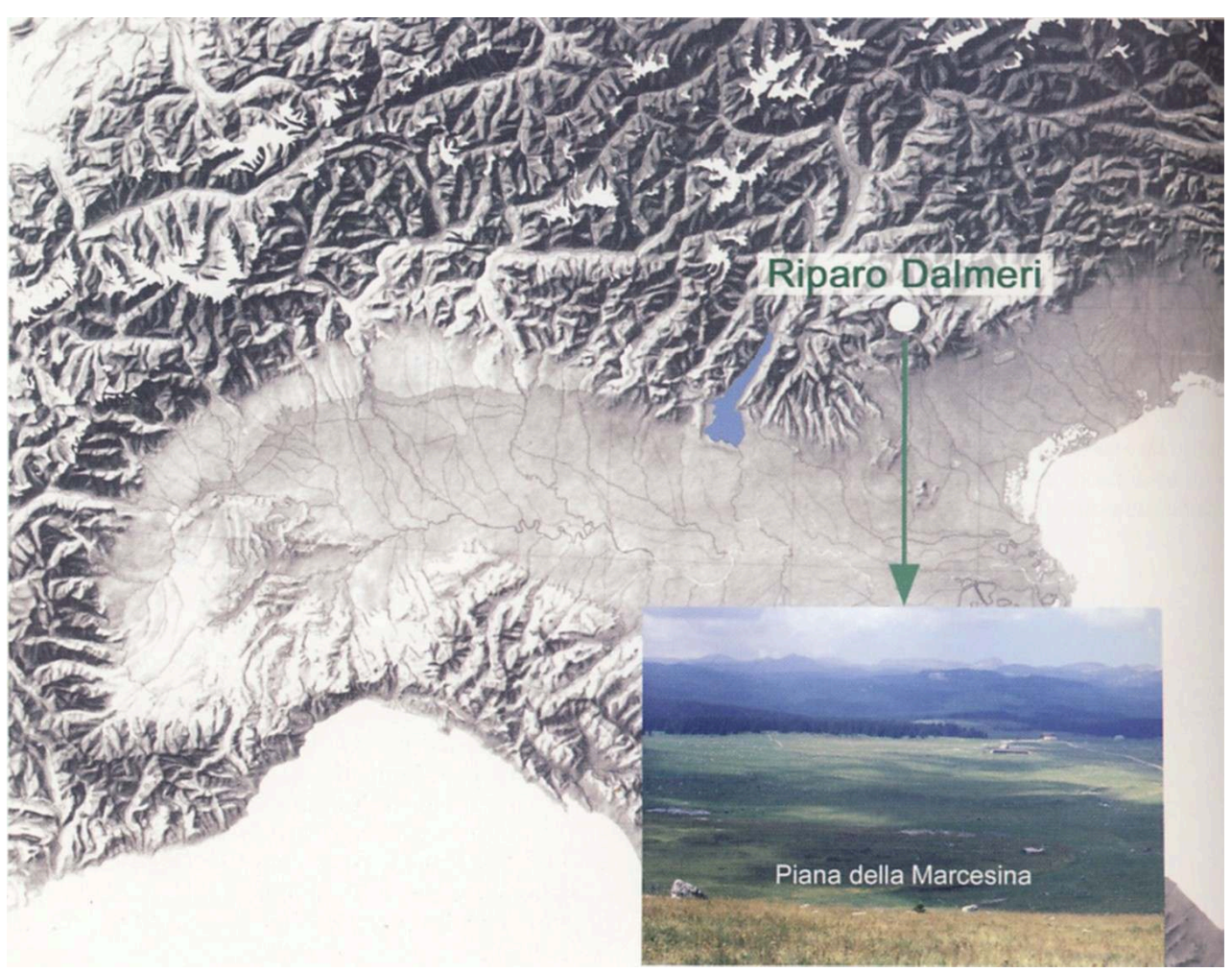

Cartographie G. Dalmeri.

2 La première occupation épigravettienne de l'abri-sous-roche a été datée dans la première phase de l'Alleröd, second interstade tempéré du Tardiglaciaire (entre 15000 et $10000 \mathrm{BP}$ pour la chronologique traditionnelle) au climat doux et tempéré. La seconde occupation s'inscrit dans l'IACP (Inter Alleröd Cold Period), période de refroidissement climatique de l'Alleröd. Elles furent considérées dans un premier temps comme les vestiges d'activités saisonnières de chasse spécialisée aux grands herbivores, dont le bouquetin en particulier (Broglio, 1992). En effet, le bouquetin représente environ $90 \%$ de restes osseux conservés. Dès les années 2000 , les fouilles s'intensifient avec la découverte des premières pierres peintes à l'ocre rouge. L'interprétation fonctionnelle du site devient plus complexe, mêlant usage économique (camp de base pour une chasse spécialisée), domestique (structures d'habitats) et symbolique avec mise au jour d'un important art peint sur pierres calcaires en connexion avec trois fosses remplies d'os d'herbivores, qui s'avèrent être en grande majorité des crânes de bouquetin (Dalmeri et al., 2009, 2011). Le relevé topographique systématique réalisé pour chacune des pierres découvertes, et la mise en évidence de connexion avec des structures domestiques et des structures de fosses, a permis de dresser l'image d'un site épigravettien exceptionnellement riche qui fait encore l'objet de publications inédites.

Dès leurs premières phases de restauration, les pierres peintes ont montré une variété de thématiques : des formes animales, des figures humaines schématisées, des signes, des dessins de doigts et des traces ocrées, tous réalisés en teinte pleine monochrome rouge. (Dalmeri et Bassetti et al., 2005c ; Dalmeri et Neri 2008). Au total, 267 pierres ont été recensées, la plus grande majorité recouverte de traces ocrées éparses. Vingt-cinq pierres ont conservé des motifs zoomorphes, se révélant être l'ensemble figuratif le 
plus important (Dalmeri, 2011) déterminant deux tendances stylistiques, naturaliste et schématique, décryptées dans un précédent travail (Legrand 2017). L'étude suivante s'est attachée à distinguer et analyser les thématiques abordées dans cet art zoomorphe qui apparaissent particulièrement originales au regard du contexte archéologique du site.

4 Art animalier, chasse spécialisée, structures de dépôt, structures domestiques, le gisement de l'abri Dalmeri se révèle riche et complexe. Que nous dit cet exemple archéologique du monde symbolique des chasseurs des derniers millénaires du Tardiglaciaire dans les montagnes italiennes?

\section{Stratigraphie et datations}

5 Le haut plateau de la Marcesina est connu pour son potentiel archéologique pour l'ÉE récent dans les Préalpes italiennes depuis les années 60 (Bertola et al., 2007). En 1990, Giampaolo Dalmeri découvre le gisement lors de prospections archéologiques menées dans le cadre de campagnes de recherche intensive sur l'implantation préhistorique sur ce haut plateau alpin, organisées par la section de Paléontologie Humaine du MUSE et l'Université de Ferrare.

Deux décennies de recherches interdisciplinaires avec la fouille systématique d'une grande partie de la zone d'occupation épigravettienne sur une superficie d'environ 200 ${ }^{\mathrm{m} 2}$ ont révélé deux occupations successives au cours de l'Alleröd et une phase d'abandon (Dalmeri et al., 2006, 2011) (fig. 2).

Figure 2 : Stratigraphie simplifiée de l'Abri Dalmeri en 2008.

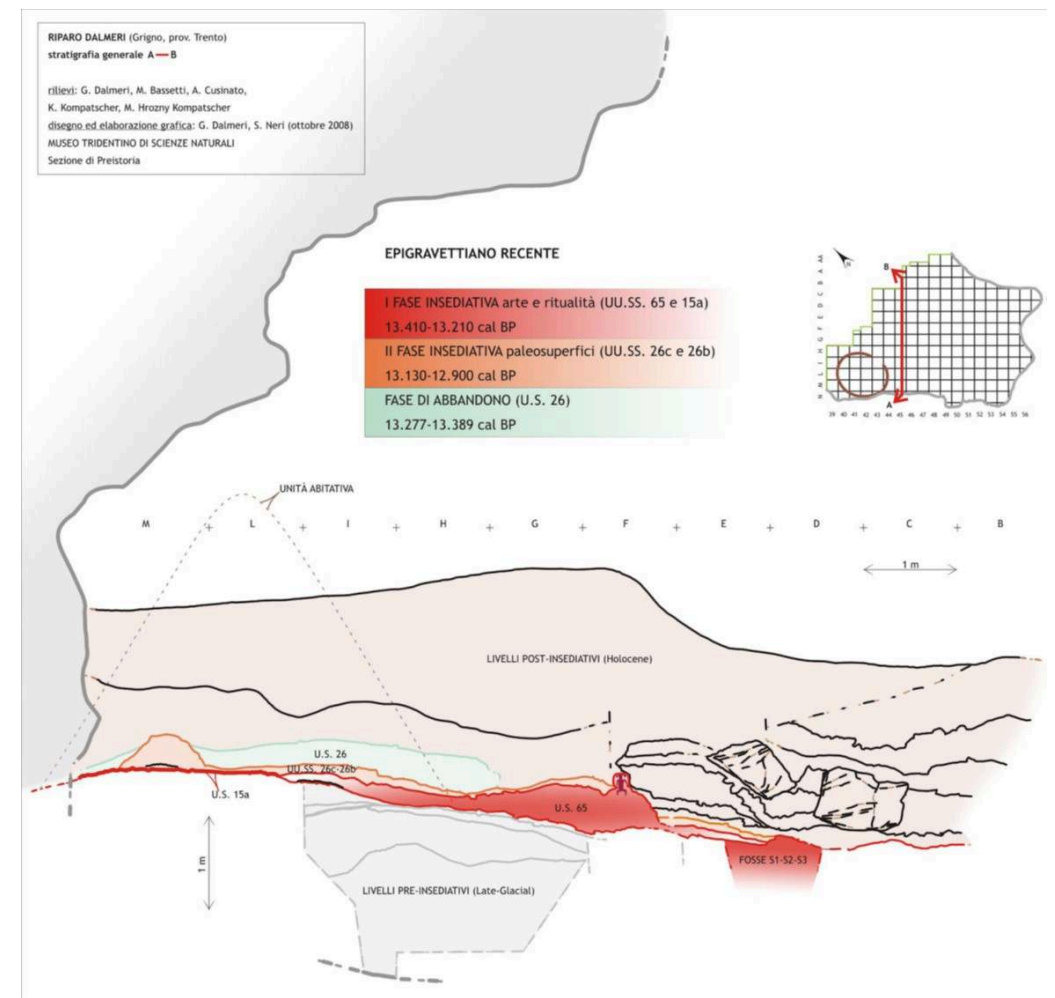


7 Cet abri-sous-roche est exposé au nord-est et s'étend sur $30 \mathrm{~m}$ en direction NNO-SSE avec une hauteur maximum de voûte d'environ $10 \mathrm{~m}$. Les données géomorphologiques ont permis d'individualiser quatre complexes stratigraphiques dont deux niveaux d'occupations principaux clairement identifiés par leur industrie lithique (Montoya, 2004, 2008) :

- une unité inférieure se composant d'une série d'éboulis cryoclastiques faisant référence à des conditions climatiques froides. Elle est datée entre 13590 et 13250 cal BP et est vierge d'occupation humaine.

- une structuration de l'espace composée des pierres peintes et des fosses. Cette phase comprend les US 74, 15a, 65, 26 d-e. L'US 65 comprend la majeure partie des pierres peintes. Elle est formée par un cailloutis à matrice organique et à fort composant anthropique (industrie lithique, restes fauniques et charbons). Cette première phase d'occupation humaine est datée entre 13410 et 13210 cal BP ou 11450 et 11340 BP, soit au cœur de l'Alleröd. L'industrie lithique recueillie se caractérise typologiquement par des armatures à dos. Elle a été déterminée dans la phase 2 du système technique élaboré par Cyril Montoya dans le cadre de sa thèse portant sur différents sites épigravettiens des Alpes italiennes et françaises (Montoya, 2004, 2008) (fig. 3).

- un second niveau anthropique formé par les US 26c, 26b-14. Il est constitué par un cailloutis cryoclastique enrichi d'une matrice fortement limoneuse, micacée, noirâtre, très organique. Ce sol possède un matériel lithique abondant, des objets en os et des restes fauniques. Les datations obtenues pour ce niveau proposent un encadrement chronologique entre 13310 et $12900 \mathrm{cal}$ BP ou 11260 et $10800 \mathrm{BP}$, qui correspond à l'IACP. Les complexes lithiques intègrent la 3ème phase de Cyril Montoya, attestant un changement dans le mode de production avec un investissement technique moindre en amont et plus axé sur la retouche (fig. 3). Le changement se produit aussi artistiquement avec la disparition des pierres peintes et la production de gravures linéaires sur des cortex de silex débités par la suite (Legrand, 2010).

- la troisième et dernière phase d'occupation du site (US 26) est elle aussi datée vers 13000 cal BP. Elle conserve des traces de fréquentations humaines très épisodiques et marque l'abandon du site (fig. 3). 
Figure. 3 : Les trois phases techno-typologiques à I'Epigravettien tardiglaciaire.

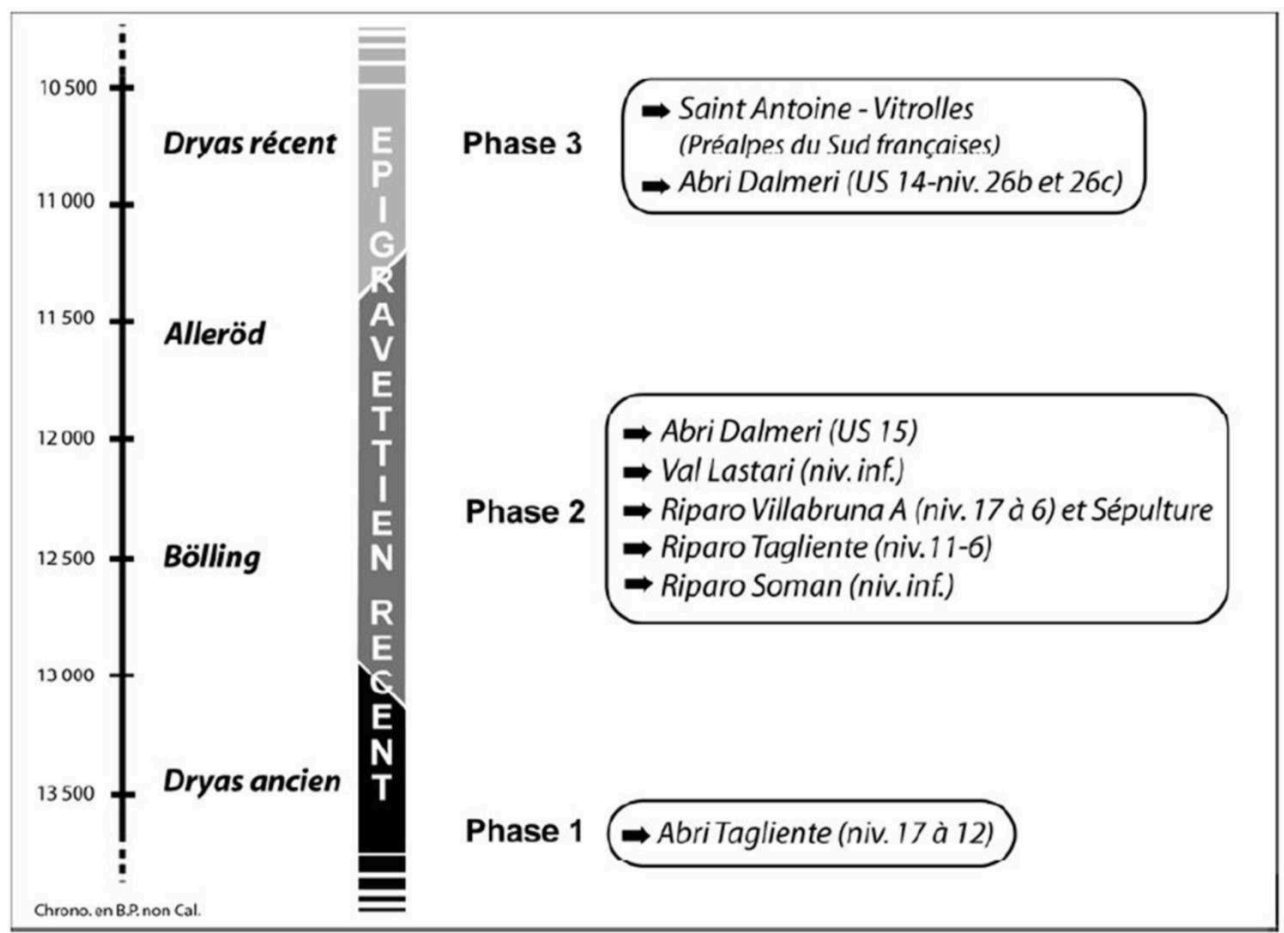

Infographie C. Montoya.

\section{Faune et paléo-environnement}

L'étude archéozoologique a révélé une économie spécialisée dans la chasse au bouquetin qui représente $90 \%$ des restes fauniques déterminables pour les UUSS $26 \mathrm{~b}$-c (Fiore et al., 2002, 2005) (fig. 4). Sur la base de l'étude, le gisement se révèle être un site de chasse spécialisée pour cet animal alpin avec une fréquentation saisonnière en été et en automne (individus jeunes, marques sur les dents des bouquetins et cerfs). D'autres animaux comme le cerf, le chevreuil et le chamois, et de façon plus sporadique l'ours, le castor, le sanglier et l'élan ont été chassés et découpés par les groupes humains qui ont fréquenté le site. De plus, des traces d'outils lithiques sur un humérus de galliforme indiquent une chasse aux oiseaux. Des restes de poissons permettent d'imaginer une activité halieutique dans le fleuve Brenta, situé en contrebas du plateau de la Marcesina.

La reconstitution paléo-environnementale du territoire de l'Abri Dalmeri, fréquenté tout au long de l'Alleröd, indique un paysage ouvert de prairie alpine avec quelques zones boisées de pins et de mélèze ainsi que des zones humides (Venzo et al., 2009). 
Figure 4 : Nombre de restes fauniques analysés (US 26c - 26b) avec indication de la saisonnalité d'occupation et la période d'abattage des ongulés.

\begin{tabular}{|c|c|c|}
\hline Taxa & NR & $\%$ \\
\hline Erinaceus & 1 & 0,01 \\
\hline Castor fiber & 17 & 0,20 \\
\hline Marmota marmota & 3 & 0,03 \\
\hline Lepus sp. & 18 & 0,21 \\
\hline Canis lupus & 5 & 0,06 \\
\hline Vulpes vulpes & 33 & 0,38 \\
\hline Meles meles & 1 & 0,01 \\
\hline Ursus arctos & 46 & 0,53 \\
\hline Carnivora & 69 & 0,80 \\
\hline Sus scrofa & 2 & 0,02 \\
\hline Cervus elaphus & 373 & 4,33 \\
\hline Capreolus capreolus & 6 & 0,07 \\
\hline Rupicapra rupicapra & 5 & 0,06 \\
\hline Capra ibex & 7445 & 86,46 \\
\hline Caprinae & 587 & 6,82 \\
\hline Mammiferi determinati & 8611 & 8,72 \\
\hline Mammiferi indeterminati & 90146 & 91,28 \\
\hline Totale Mammiferi & 98757 & 97,88 \\
\hline Aves & 86 & 0,09 \\
\hline Pisces & 2055 & 2,04 \\
\hline TOTALE RESTI & 100898 & \\
\hline NR combusti rispetto al totale NR & 20607 & 20,42 \\
\hline \multicolumn{3}{|c|}{ 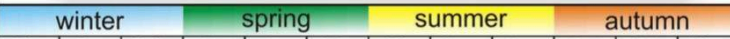 } \\
\hline \begin{tabular}{l|c|c|c|c|c|c|c|} 
Dic & Gen & Feb & Mar & Apr & Mag & Giu & Lu \\
\end{tabular} & \begin{tabular}{l|l|l|} 
& Ago & Set \\
\end{tabular} & \begin{tabular}{|l|l|} 
Ott & Nov \\
\end{tabular} \\
\hline \multicolumn{3}{|l|}{$\begin{array}{l}\text { Stagionalitad delle frequentazioni } \\
\text { e e periodo di abbattimento } \\
\text { degil ungulati }\end{array}$} \\
\hline
\end{tabular}

Tableau I. Fiore.

\section{L’habitat épigravettien (figure 5)}

Des structures domestiques ont été définies sur les niveaux d'occupations les plus anciens (US 65-15a et $26 \mathrm{c}$ et 26b-14). Une structure en forme circulaire, identifiée comme un fond de cabane, a été révélée par une légère dépression topographique circulaire de $4 \mathrm{~m}^{2}$ de diamètre, délimitée par un cordon de pierres entremêlées d'objets lithiques et des restes fauniques. Des trous de poteau ont été reconstitués.

11 En limite orientale de l'implantation anthropique du gisement sont référencées trois fosses contigües, alignées de façon parallèle à la paroi rocheuse interne. Elles ont été remplies intentionnellement par de très nombreux crânes et cornes de bouquetins, et par des lissoirs et des pierres peintes. Un premier examen n'exclut pas un usage diversifié de ces fosses. Elles sont contemporaines de la période de dépôt des pierres peintes (US 65) et appartiennent ainsi à la première phase d'occupation (Dalmeri et al., 2011, publication en préparation.)

12 L'analyse spatiale montre une disposition en éventail des pierres peintes à partir de la zone d'entrée de l'habitat subcirculaire. La répartition n'est pas homogène. La concentration des pierres est plus importante en limite orientale, proche des trois fosses, et reste plus faible dans la zone considérée comme domestique (Dalmeri et al., 2011). Les pierres ont été retrouvées en grande majorité en position horizontale ou subhorizontale avec un très faible pourcentage de pierres fragmentées au niveau du décor et dont certaines ont pu être remontées. $75 \%$ des pierres avaient la face peinte tournée vers le bas (Dalmeri et al., 2009). 
Figure 5 : Distribution spatiale des pierres peintes numérotées selon les données de 2010.

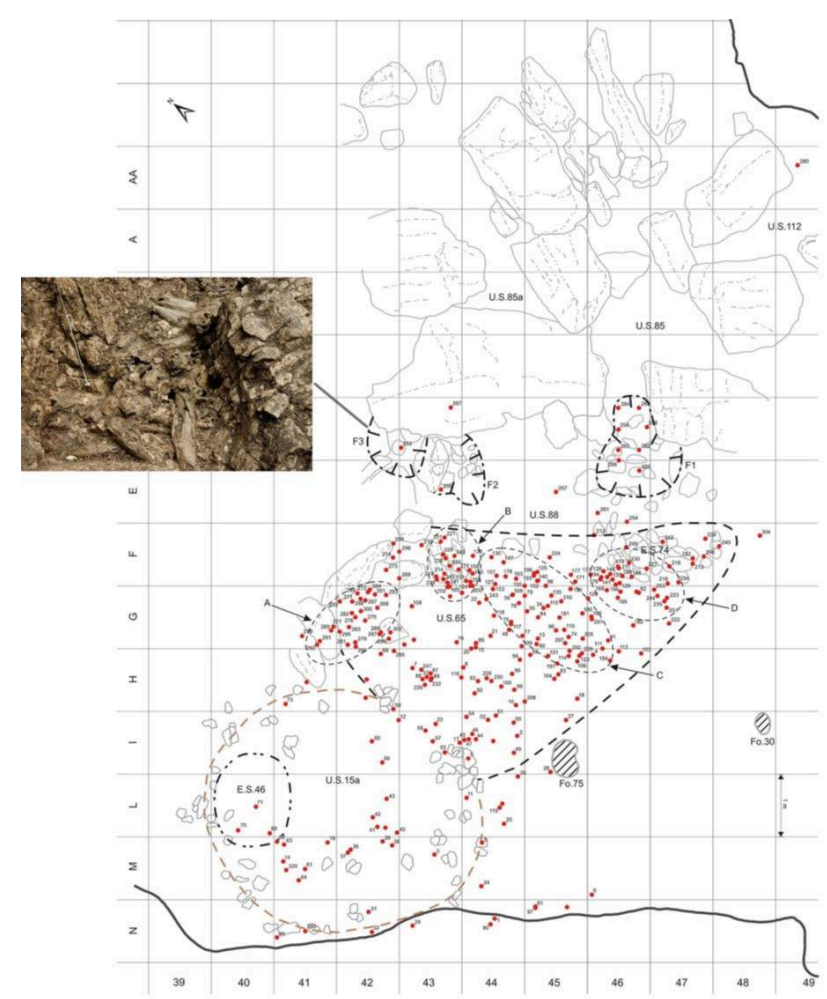

Sont représentées les trois fosses anthropiques (F1, F2, F3), les foyers Fo30 et Fo75 et les quatre zones de concentration des pierres (A, B, C, D). Photo de la fosse S3.

Photos et infographie G. Dalmeri et S. Neri.

\section{Les pierres peintes}

La collection des pierres peintes aux figures zoomorphes comprend 25 pierres, dont 24 ont pu être étudiées au MUSE ${ }^{2}$ par l'auteur. La $25^{\text {ème }}$ pierre peinte est la RD 304 restaurée après la campagne de relevé réalisée début 2010.

L'analyse des motifs s'est faite d'après l'observation directe des pierres, leur prise de vue photographiques et leur relevé graphique permettant de mettre en évidence les densités de pigmentation et les caractéristiques morphologiques des supports utilisés pour la création. Ainsi tous les relevés et toutes les photographies, sauf indication contraire, sont de l'auteur. De ces différentes documentations ont été extraites des données sur la technique et la thématique de cet art qui peuvent être synthétisées en différents points.

\section{La faible variabilité du choix du support}

Les pierres sont de dimensions et de formes variables. Toutes mesurent entre 7,5 et $20 \mathrm{~cm}$ de large, 1,2 et $36 \mathrm{~cm}$ de long, 3,8 à $10 \mathrm{~cm}$ de haut. Elles sont de type pseudoplaque ou plaque (une ou deux faces parallèles) ou en forme de bloc. Le calcaire de type oolithique provient de l'abri et présente deux aspects différents : un calcaire jaune-gris à l'aspect rugueux et aux arêtes vives et un calcaire gris à la surface lisse (fig. 6). 
L'aspect plus ou moins lisse de la surface a conduit à une conservation différente de la peinture. Ces données se retrouvent dans le reste de la collection des pierres peintes.

\section{L'homogénéité de la technique}

16 La technique de la peinture en teinte plane monochrome rouge est l'unique observable, tout comme pour le reste de la collection des pierres peintes (Dauvois 1993). La reconnaissance de la forme animale ne peut se faire que par l'observation de la silhouette, exempte d'indication anatomique interne. L'ocre rouge est de l'hématite provenant du Haut-plateau de la Marcesina (Dalmeri et al, 2005c). Plusieurs pierres montrent une bonne conservation de la peinture avec la présence de paquets de pigment. La couleur est alors d'un rouge vif. Une grande majorité conserve une pigmentation plus diffuse, avec parfois une coloration rouge-rosâtre (fig. 6). Plus rarement, la peinture est moins lisible. Toutefois, la bonne conservation générale permet la lecture des motifs, bien que certains restent indéterminés à cause de cet effet.

Figure 6 : Les deux types de calcaires avec caractérisation de la pigmentation.

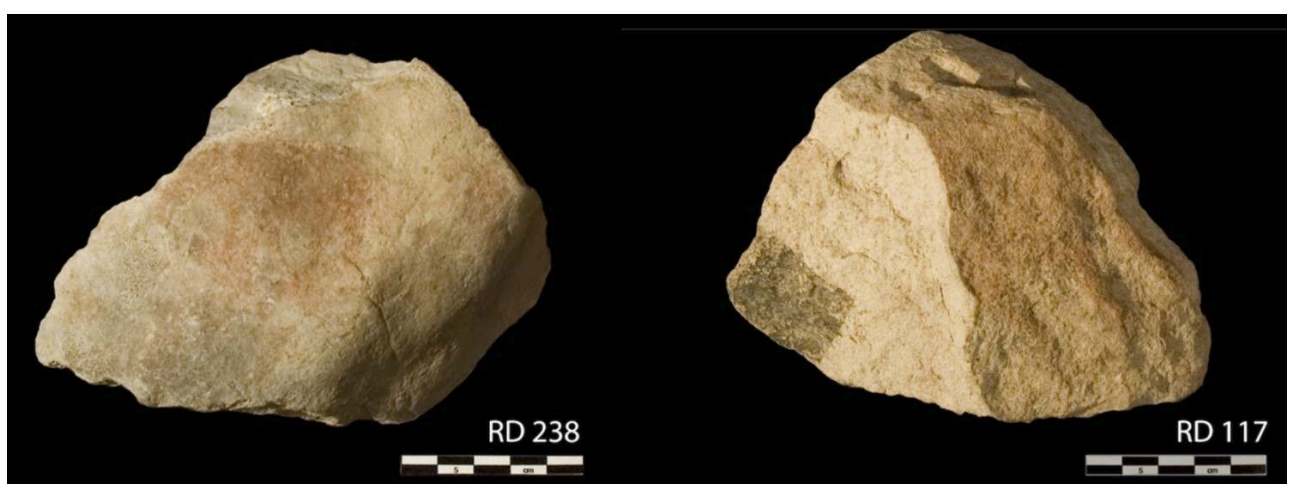

Photos Elisa Legrand.

\section{La thématique}

La technique en teinte plane monochrome induisant une lecture des motifs basée sur la silhouette, le principe de l'étude était de reconnaître des éléments anatomiques caractéristiques d'espèces animales.

La classification des critères anatomiques utilisés est tirée des travaux du GRAPP sur l'art pariétal paléolithique (Barrière, 1993a et b ; Clottes, 1993 ; Crémadès, 1993 ; Sacchi, 1993) et concerne les quadrupèdes, soit un animal représenté par 2 ou 4 pattes verticales pour un corps massif s'allongeant à l'horizontal et une tête postée à gauche ou à droite (fig. 7).

19 Ces éléments permettent de dissocier une représentation figurative (de l'ordre du monde du vivant) zoomorphe, d'une représentation anthropomorphe (caractérisée par un axe symétrique créant la frontalité) et d'une représentation abstraite (qui ne renvoie à aucune forme du vivant). 
Figure 7 : Les éléments anatomiques discriminants les espèces animales.

\begin{tabular}{||l|l|l|}
\hline \multicolumn{3}{|c|}{ DETERMINE } \\
\hline \hline \multicolumn{1}{|c|}{ BOVINE } & \multicolumn{1}{|c|}{ CAPRINE } & \multicolumn{1}{c|}{ CERVIDE } \\
\hline tête triangulaire, massive & tête triangulaire, fine & tête triangulaire, fine \\
\hline $\begin{array}{l}\text { cornes longues et recourbées } \\
\text { (en forme de lyre) }\end{array}$ & $\begin{array}{l}\text { lornes longues. Cornes très } \\
\text { longues pour le bouquetin } \\
\text { mâle. Recourbées et minces }\end{array}$ & ramure développée (mâle) \\
\hline avant-train très volumineux & $\begin{array}{l}\text { avant-train moyennement } \\
\text { volumineux }\end{array}$ & $\begin{array}{l}\text { avant-train moyennement } \\
\text { volumineux }\end{array}$ \\
\hline arrière-train carré & arrière-train arrondi & arrière-train arrondi \\
\hline queue longue et fine & queue courte & queue courte \\
\hline $\begin{array}{l}\text { pattes moyennement } \\
\text { longues, épaisses }\end{array}$ & $\begin{array}{l}\text { pattes moyennement } \\
\text { longues, peu épaisses à fines }\end{array}$ & pattes longues et fines \\
\hline
\end{tabular}

\begin{tabular}{|l|l|l|}
\hline \multicolumn{3}{|c|}{ INDETERMINE } \\
\hline \hline \multicolumn{1}{|c|}{ BOVIDE } & \multicolumn{1}{|c|}{$\begin{array}{c}\text { QUADRUPEDE } \\
\text { COMPLET }\end{array}$} & $\begin{array}{c}\text { QUADRUPEDE } \\
\text { INCOMPLET }\end{array}$ \\
\hline tête triangulaire & tête sans corne ou bois & $\begin{array}{l}\text { fragment de corps de } \\
\text { quadrupède }\end{array}$ \\
\hline cornes & corps complet & \\
\hline queue & pas de queue & \\
\hline pattes & & \\
\hline
\end{tabular}

Tableau E. Legrand.

\section{Les déterminées (figure 8)} indéterminées. Il s'agit de représentations de «boviné » (aurochs principalement), de " capriné » (bouquetin, chamois ou isard), de " cervidé » (cerf). Les différents éléments anatomiques retenus pour distinguer ces trois types d'espèces peuvent être listés en trois grandes catégories (fig. 7).

Certains éléments anatomiques sont apparus plus déterminants que d'autres (surlignés en gras). La forme de la queue par exemple, bien que cet élément reste très minoritairement représenté, est une bonne indication de l'espèce animale (ex. RD 116, fig. 8). Autrement, la forme de l'avant-train, plus volumineux pour le boviné et plus fin pour le capriné, est une caractéristique morphologique déterminante face à d'autres éléments apparaissant moins pertinents pour distinguer ces deux espèces animales (comme la forme des cornes ou de la tête). En revanche, la présence d'une ramure très développée permet une attribution relativement aisée à l'espèce « cervidé » (ex. RD 115, fig. 8). 
Figure 8 : Les figures déterminées.

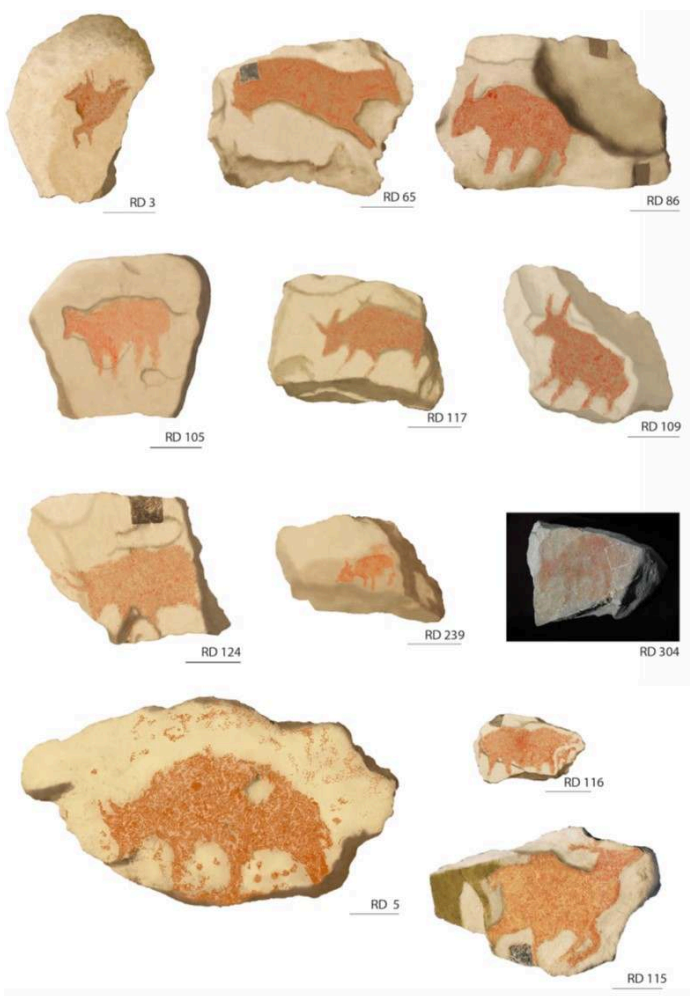

Relevés E. Legrand. Échelle $=5 \mathrm{~cm}$.

\section{Boviné : RD 5, RD 116}

La forme animale de la RD 5 est considérée comme celle d'un boviné par la présence de cornes courtes et d'un arrière-train étroit. Pour la RD 116, la longue et fine queue permet cette classification, ainsi que la masse importante de l'arrière-train tandis que le reste de la figure est illisible.

\section{Capriné : RD 3, RD 65, RD 86, RD 105, RD 109, RD 117, RD 124, RD 239, RD 304}

Une grande majorité de ces figures se distingue par la présence de longues cornes plus ou moins fines, recourbées, typique du bouquetin mâle des Alpes. La RD 109 en est une belle représentation avec les cornes relativement longues et recourbées vers l'arrière. La figure miniature RD 239 pourrait contredire cette analyse car la forme de la corne est peu lisible, mais l'arrondi de l'arrière-train rappelle le corps du bouquetin. Cette forme arrondie se retrouve d'ailleurs pour les figures RD 117 et RD 304. Des cornes courtes et verticales se dessinent sur la RD 3, ainsi que pour la RD 65 et la RD 105 avec toutefois une lecture plus difficile pour ces dernières. Serions-nous face à une représentation de chamois ou d'isard ? Toutefois la morphologie de l'avant-train étant peu discriminante, ces représentations restent proches du bouquetin.

Pour les autres représentations, l'arrière-train reste toujours arrondi. Une des représentations les plus naturalistes au niveau du corps est celle RD 65 malgré un profil absolu et l'absence de la patte arrière et de la queue. La RD 86 est l'une des rares figures 
à se présenter avec une queue. La RD 124 est sans arrière-train, la peinture s'arrête brusquement au niveau de l'arête du bord latérale.

\section{Cervidé : RD 115}

Seule la RD 115 a livré une représentation de cerf, parfaitement reconnaissable par la présence d'une ramure assez développée, de longues pattes, d'une queue courte et touffue et d'un corps assez volumineux.

\section{Les indéterminées (figure 9)}

La détermination spécifique de différentes espèces a été délicate pour certaines pierres. L'application de la grille de lecture n'a pas toujours permis de reconnaître une forme animale singulière, ce qui a entraîné la conception de catégories particulières de figures : les bovidés, les quadrupèdes complets et les quadrupèdes incomplets (fig. 7). Cette catégorie comprend des représentations entendues comme zoomorphes mais dont la forme animale est soit non clairement identifiable, soit incomplète. Le terme "bovidé » désigne une classe d'espèce qui regroupe en autres les bovinés et les caprinés. Le sens de ce vocable dans cette analyse est quelque peu différent: il désigne les figures animales dont les attributs morphologiques empruntent autant au boviné qu'au capriné. Il n'est pas possible alors de distinguer clairement l'une de ces espèces.

Les quadrupèdes correspondent aux autres figures animales dont on ne peut reconnaître une espèce. Ces figures peuvent être complètes (une tête et quatre pattes) ou incomplètes que ce soit par manque de lisibilité, par fracture du support ou encore par choix anthropique. 
Figure 9 : Les indéterminées.

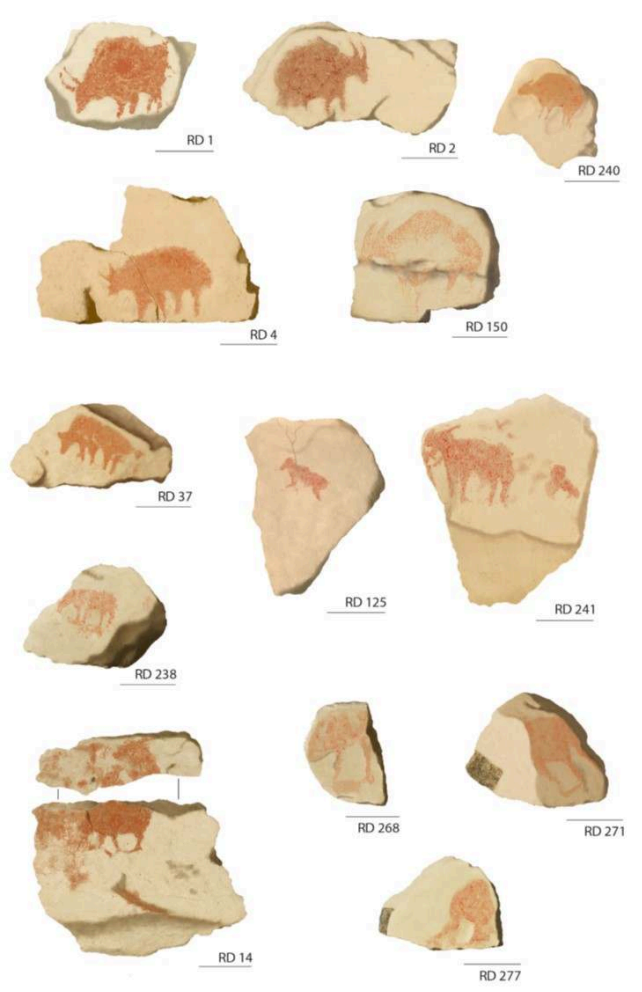

Relevés E. Legrand. Échelle $=5 \mathrm{~cm}$.

Bovidé : RD 1, RD 2, RD 4, RD 150, RD 240

Pour les figures RD 1, RD 2, RD 150 et RD 240, le quadrupède peut être considéré comme un boviné par son corps très massif. Mais cette interprétation est contrariée par la présence de longues cornes et d'un arrière-train arrondi. Autrement, la figure animale peinte sur la RD 4 a des cornes de boviné mais son corps est peu volumineux et son arrière-train arrondi.

\section{Quadrupède complet : RD 37, RD 125}

Il s'agit de quadrupède ne possédant pas de corne. S'agit-il alors du dessin originel ou bien serions-nous face à un problème de conservation ? (ce qui peut être discuté pour la $\mathrm{RD} 125$, figure miniature assez mal conservée). Une figure de carnivore peut être envisagée (les carnivores ont les oreilles arrondies). Or la RD 125 n'a pas d'oreille. Cette lecture peut être envisagée pour la RD 37 sans que, pourtant, celle-ci ne possède d'autres éléments anatomiques significatifs (queue ou pattes). Elle reste donc parmi les indéterminées.

Quadrupède incomplet : RD 14, RD 238, RD 241, RD 268, RD 271, RD 277 RD 241, la surface est recouverte par des taches ocrées notamment au niveau de la tête, 
la rendant illisible. Par contre, pour la RD 238, la tête est absente. Le cou très allongé s'interrompt au niveau d'une fissure.

Les figures RD 268, RD 271, RD 277 sont formées d'un segment de corps et de deux à trois pattes. La RD 271 et la RD 277 nous montrent un arrière-train, entier pour la RD 277, dont le dessin est interrompu par un éclatement du support pour la RD 271.

En revanche, la RD 268 a conservé une partie d'avant-train avec un cou très allongé. La tête n'a pas été représentée délibérément car la pigmentation s'interrompt avant le bord du support. La figure ne nous est pas parvenue complète, le support est fracturé au niveau du corps.

Ainsi, des trois figures, seule la RD 277 possède une silhouette continue. La forme des pattes, massive et courte, est assez différente du reste des représentations. Cette forme est plus typique de l'ours que des artiodactyles. Aussi pourrait-on imaginer une représentation d'arrière-train d'ours pour cette figure. Le problème est que la partie basse des pattes est mal délimitée, rendant difficile la lecture de pattes animales. Cette mauvaise délimitation peut aussi correspondre à une volonté de signifier une ligne de sol. Aussi, est-il prudent de considérer cette figure comme indéterminée.

\section{Considérations sur la thématique zoomorphe de l'Abri Dalmeri}

Le corpus se divise ainsi en 2 ensembles égaux quantitativement (fig. 10) :

- les espèces déterminées, soit 12 exemples. Il s'agit des figures RD 3, RD 65, RD 86, RD 105, RD 109, RD 117, RD 124, RD 239 et RD 304 pour la catégorie capriné. Les RD 5 et RD 116 intègrent la catégorie boviné.

- les espèces indéterminées, avec 13 cas, composées des bovidés (empruntant au boviné et au capriné), des quadrupèdes complets et des quadrupèdes incomplets.

Figure 10 : Nombre de figures par espèce.

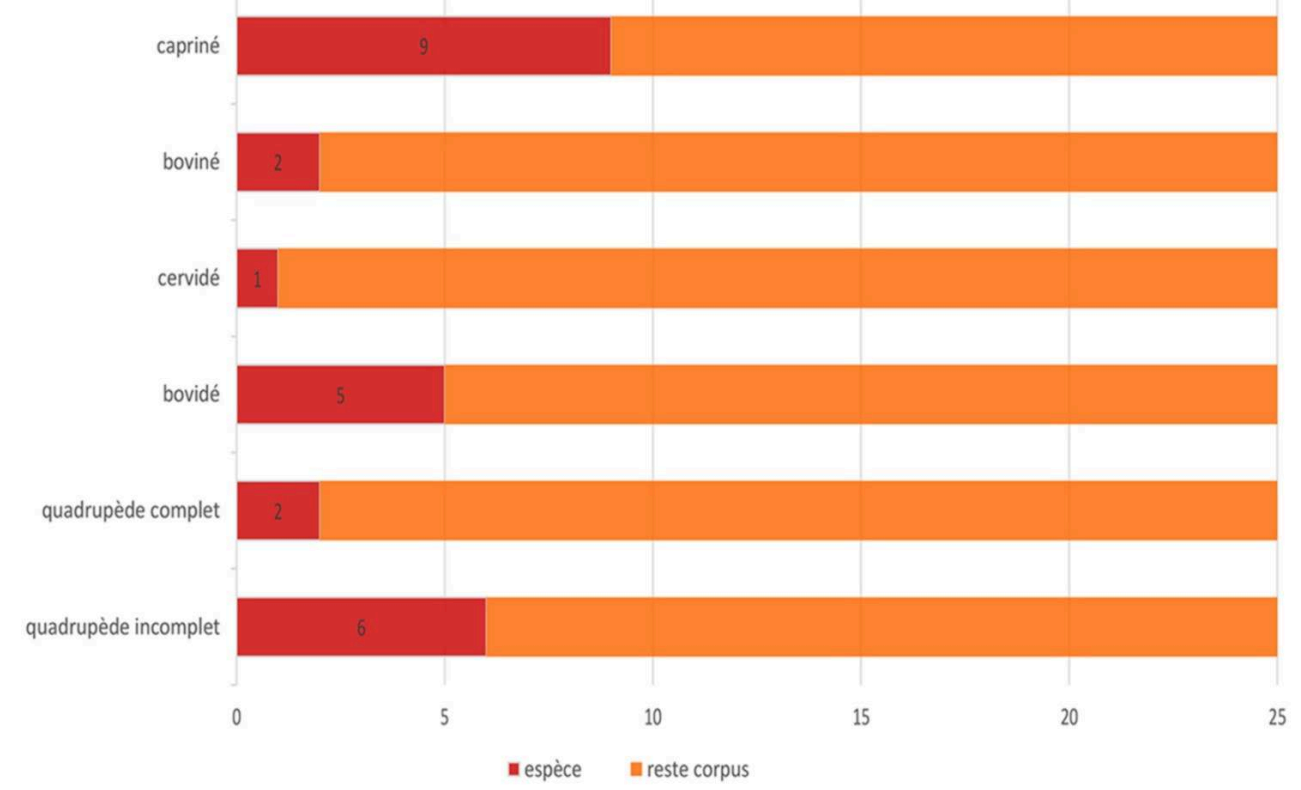

Infographie E. Legrand. 
art déterminable de cet art animalier indique des espèces d'herbivores appartenant à la faune du Tardiglaciaire d'Italie du Nord avec le bouquetin, l'aurochs, le cerf. Ainsi, la présence d'animaux de montagne de climat froid et tempéré, rappelle la nature du gisement et le paléo-environnement typique de l'interstade de l'Alleröd. Ces données permettent de proposer une vision naturaliste pour cet art épigravettien.

En contrebalancement, le nombre conséquent d'indéterminés par manque d'éléments anatomiques significatifs conduit à une expression plus schématique des figures. Il est alors difficile de distinguer des éléments caractéristiques précis, que ce soit dans la forme du corps ou encore des cornes, qui différencieraient le capriné du boviné pour les figures dites "bovidé». De même, une représentation de carnivore et une autre d'ours ont pu être envisagées. Toutefois, ces deux figures n'ont pas suffisamment d'éléments anatomiques caractéristiques pour valider ces hypothèses de lecture. Aussi est-il plus prudent de ne pas certifier ces deux thèmes. Et enfin, un grand nombre de figures restent dans la catégorie des quadrupèdes rappelant le sujet animal, avec parfois uniquement quelques parties corporelles, comme pour les quadrupèdes incomplets. prédominant de cet art épigravettien de chasseurs. La thématique du capriné est la plus importante, avec 9 figures sur 25. Peut-on extraire une relation symbolique étroite entre cette représentation animalière avec la nature du site : à savoir un site de chasse au bouquetin, avec la caractérisation du dépôt des pierres peintes et l'aménagement des fosses remplies d'ossements de bouquetin? Toutefois, l'importance de la figure du capriné et, au-delà la figure animale, reste à pondérer au vu de l'importance quantitative du reste de la collection des pierres peintes, à savoir 267 pierres, majoritairement couvertes de traces ocrées. Aussi la relation semble se faire entre le dépôt particulier de toutes les pierres peintes et la structuration de l'espace avec les fosses remplies de crânes de bouquetin.

La connexion d'un art mobilier peint mais aussi gravé avec un contexte archéologique funéraire est connue dans la culture épigravettienne des Préalpes vénitiennes. L'Abri Tagliente (Monts Lessini, Vérone), occupé entre la fin du Dryas ancien et le Bölling, a conservé une sépulture d'un homme couvert par quelques pierres de différentes dimensions. Les deux plus grandes présentent quelques fines incisions sur la face retournée vers le bas : sur l'une se profilent des traits indéterminés et sur l'autre sont gravés la figure du félin et le profil d'un boviné (Bartolomei, Broglio et al., 1974). Ces motifs gravés font partis de l'ensemble d'art mobilier de cet abri-sous-roche épigravettien "célèbre » pour son art gravé zoomorphe naturaliste (Mezzena, 1964 ; Leonardi, 1972, 1976, 1992).

L'Abri Villabruna (Vallée du Cismon) occupé lors du Bölling, a conservé une sépulture d'un homme allongé sur le dos recouvert complètement par une vingtaine de pierres locales dont certaines portent de faibles zones ocrées rouges dont quatre motifs identifiables, interprétés comme une figure anthropomorphe en attitude dynamique, une représentation hyperanthropique assez complexe (extrêmement schématisée, pouvant être interprétée comme un motif abstrait), un motif abstrait et un ensemble de bandes longitudinales plutôt irrégulières. Une cinquième pierre peinte fut découverte 
au-delà de la sépulture, avec la face peinte tournée vers le bas. Cet art peint s'est révélé être extrêmement proche de celui de l'Abri Dalmeri, au point d'en faire l'un des éléments culturels distinctifs de la culture épigravettien des interstades Bölling et Alleröd succédant à celui de l'Abri Tagliente (Dryas Ancien et début du Bölling) (Bertola et Broglio et al., 2007; Legrand, 2010 et 2017). La particularité du contexte archéologique de l'Abri Dalmeri pour le niveau le plus ancien prend ici toute sa valeur. Il serait la dernière expression d'une activité symbolique étroitement liée à l'activité artistique connue pour la culture de l'Épigravettien récent des Préalpes orientales italiennes. Ainsi cette double pratique, artistique et rituelle/funéraire, pourrait s'interpréter comme un élément culturel distinctif d'un premier Épigravettien récent dans cette région qui disparaîtrait lors de l'IACP et du Dryas récent.

\section{BIBLIOGRAPHIE}

BARRIÈRE C. 1993a, «Les figurations animales : II - Les Bovidés ; les Bovinés », dans GRAPP, L'art pariétal paléolithique, Paris, Ed. du CTHS, p. 109-122.

BARRIÈRE C. 1993b, « Les figurations animales : VII - Les Carnivores », dans GRAPP, L'art pariétal paléolithique, Paris, Ed. du CTHS, p. 165-171.

BARTOLOMEI G., BROGLIO A. et al. 1974, Una sepoltura epigravettiana nel depositio pleistocenico del Riparo Tagliente in Valpantena (Verona), Rivista di Scienze Preistoriche, n² 29, p. 101-152.

BERTOLA S., BROGLIO A. et al. 2007, « L'Epigravettiano recente nell'area prealpino e alpina orientale ", dans Martini F. (dir.) L'Italia tra 15000 e 10000 anni fa. Cosmopolitismo e regionalità nel Tardoglaciale, Firenze, Museo fiorentino di Preistoria e Protostoria, p. 39-94.

BROGLIO A. 1992, « Mountain sites in the context of the nord-east Italian Upper Palaeolithic and Mesolithic / I siti montani nel contesto del Paleolitico superiore e del Mesolitico dell'Italia nordorientale », Preistoria Alpina, n² 28, p. 293-310.

CLOTTES J. 1993, «Les figurations animales : XII - Les Animaux Indéterminés », dans GRAPP, L'art pariétal paléolithique, Paris, Ed. du CTHS, p. 193-196.

CRÉMADÈS M. 1993, « Les figurations animales : III - Les cervidés », dans GRAPP, L'art pariétal paléolithique, Paris, Ed. du CTHS, p. 137-150.

DALMERI G., BASSETTI M. et al. 2002, « Le pietre dipinte del sito epigravettiano di Riparo Dalmeri. Campagne di ricerche $2001 »$, Preistoria Alpina, n 38, p. 3-34.

DALMERI G., BASSETTI M. et al. 2005a, « The discovery of a painted anthropomorphic figure at Riparo Dalmeri and nex insights into alpine Epigravettian art ", Preistoria Alpina, n 41, p. 163-169.

DALMERI G., BASSETTI M. et al. 2005b, « Sintesi e prime ipotesi interpretative », dans BROGLIO A. et DALMERI G. (dir.), Pitture paleolitiche nelle prealpi venete : grotta di Fumane e riparo Dalmeri, Verona, Museo civico di storia naturale di Verona, p. 140-144. 
DALMERI G., BASSETTI M. et al. 2005c, « L'insieme dell' arte mobiliare », dans BROGLIO A. et DALMERI G. (dir.), Pitture paleolitiche nelle prealpi venete : grotta di Fumane e riparo Dalmeri, Verona, Museo civico di storia naturale di Verona, p. 125-139.

DALMERI G., BASSETTI M. et al. 2006, « Le site Épigravettien de l'Abri Dalmeri : aspects artistiques à la fin du Paléolithique supérieur en Italie du nord », L'anthropologie, n 110, p. 510-529.

DALMERI G., CUSINATO A. et al. 2009, « The ochre painted stones from the Riparo Dalmeri (Trento). Development of the research on the art and rituality of the Epigravettian site ", Preistoria Alpina, $\mathrm{n}^{\circ} 44$, p. 1-25.

DALMERI G., MICHELE B. et al. 2005, « Il contesto archeologico delle pietre dipinte con ocra », dans BROGLIO A. et DALMERI G. (dir.), Pitture paleolitiche nelle prealpi venete : grotta di Fumane e riparo Dalmeri, Verona, Museo Civico di Storia Naturale di Verona, p. 122-124.

DALMERI G. et NERI S. 2008, « Riparo Dalmeri : l'uomo e due stili di raffigurazione. Analisi formale di quattro pietre decorate con figure anthropomorphe ", Preistoria Alpina, n 43, p. 299-315.

DALMERI G., NERI S. et al. 2011, « Riparo Dalmeri : le pietre dipinte dell'area rituale », Preistoria Alpina, $\mathrm{n}^{\circ} 45$, p. 67-117.

DAUVoIS M. 1993, « La peinture ; Teintes plates », dans GRAPP, L'art pariétal paléolithique, Paris, Ed. du CTHS, p. 255-256.

FIORE I., TAGLIACOZzo A. et al. 2002, « Ibex exploitation in the Dalmeri Rockshelter (TN) and "specialized hunting" in the sites of the Eastern Alps during the Tardiglacial and Early Holocene ", Preistoria Alpina, n 34, p. 173-179.

FIORE I., TAGLIACOZZo A. 2005, «L'analisi dei resti faunistici : il contesto paleocologico e l'economia del sito ", dans BRoGlio A. et DALMERI G. (dir.), Pitture paleolitiche nelle Prealpi Venete. Grotta di Fumane e Riparo Dalmeri, Verona, Museo civico di storia naturale di Verona, p. 116-121.

FIORE I., TAGLIACOZZO A. 2008, « Oltre lo stambecco : gli altri mammiferi della struttura abitative dell'U.S. 26c a Riparo Dalmeri (Trento)», Preistoria Alpina, n 43, p. 209-236.

LEGRAND E. 2010, « Les pierres peintes aux figures animales de l'Abri Dalmeri (Grigno, Province de Trento) et l'art du Paléolithique supérieur terminal dans les Préalpes orientales italiennes ", mémoire de master 2 recherche en préhistoire, Toulouse, Université Le Mirail (Jean-Jaurès), BARBAZA M. (dir.), 2 vols. 109.

LEGRAND E. 2017, « Les pierres peintes aux figures animales de l'Abri Dalmeri et l'art du Paléolithique supérieur terminal dans les Préalpes orientales italiennes » Préhistoire, Art et Sociétés, $\mathrm{n}^{\circ}$ 69, p. 79-155.

LEONARDI P. 1972, Bisonte graffito e incisioni lineari e geometriche del deposito epigravettiano del Riparo Tagliente nei Lessini (Verona), Rivista di Scienze Preistoriche, n² 27, p. 272-239.

LEONARDI P. 1976, Gravures zoomorphes, géométriques et linéaires épigravettiennes du Riparo Tagliente dans les Monts Lessini près de Vérone (Italie), Congrès Préhistorique de France, $\mathrm{XX}^{\circ}$ session, Provence, p. 343-352.

LEONARDI P. 1992, « Nuove figurazioni epigravettiene del Riparo Tagliente nei Monti Lessini », L'arte in Italia dal Paleolitico all'Età del Bronzo, Atti della XXVIII Riunione Scientifica dell'Istituto Italiano di Preistoria e Protostoria, Firenze, 20 au 22 novembre 1989, p. 213-222.

MEZZENA F. 1964, « Oggetti d'arte mobiliare del Paleolitico scoperti al Riparo Tagliente in Valpantena (Verona) », Rivista di Scienze Preistoriche, $\mathrm{n}^{\circ}$ 19, p. 175-188. 
MONTOYA C. 2004, «Les traditions techniques lithiques à l'Épigravettien : analyses de séries du Tardiglaciaire entre Alpes et Méditerranée ", thèse de doctorat en préhistoire, Aix-en-Provence, Université de Provence, CHENORKIAN R. (dir.), 2 vol. , 587 p.

MONTOYA C. 2008, «Évolution des concepts de productions lithiques et artistiques à l'Épigravettien récent : analyses de collections des Préalpes de la Vénétie et des Préalpes du sud françaises », dans MUSsi M. (dir.), Il Tardiglaciale in Italia - Lavori in corso, Archeopress, British Archaeological Reports, Oxford, p. 43-53.

SACCHI D. 1993, «Les figurations animales : II - Les Bovidés ; Les Caprinés, Antilopinés, Rupicaprinés », dans GRAPP, L'art pariétal paléolithique, Paris, Ed. du CTHS, p. 123-136.

VENZO G.-A., DALMERI G. et al. 2009, « Geomorfologia e ambiente dei territori frequentati dai cacciatori-raccogliatori epigravettiani del Riparo Dalmeri nel Paleolitico superiore (Altipiano dei Sette Comuni, prov. di Trento, Italia) ", dans Atti dell'Istituto Veneto di Scienze, Lettere ed Arti, Classe di Scienze fisiche, matematiche e naturali, Venezia, $n^{\circ}$ 167, p. 1-13.

\section{NOTES}

1. Museo delle Scienze di Trento, anciennement Museo tridentino di Scienze Naturali.

2. Museo delle Scienze di Trento.

\section{RÉSUMÉS}

L'auteur interroge les données thématiques issues de l'étude techno-stylistique inédite réalisée en 2010 sur les pierres peintes aux figures zoomorphes de l'Abri Dalmeri (Grigno, Trento, Italie nord-orientale) dans leur contexte archéologique originel. L'Abri Dalmeri est l'un des principaux sites de référence sur l'Épigravettien récent des Préalpes italiennes. Il se révèle être un site de chasse spécialisée dans le bouquetin avec des structures anthropiques de dépôt d'ossements d'herbivores, en grande majorité du bouquetin. De 2001 à 2010, plus de 250 pierres peintes ont été découvertes avec un corpus original de figures zoomorphes. L'étude thématique révèle une prédominance des figures d'herbivores, en particulier le capriné. Ainsi, l'auteur questionne la mise en évidence d'une relation étroite entre cet art mobilier zoomorphe et son contexte archéologique (fosses, chasse spécialisée...) autour de la figure animale pour tenter d'affiner la définition culturelle portée sur ce groupe de chasseurs du Paléolithique terminal.

\section{AUTEUR}

\section{ÉLISA LEGRAND}

Chercheur associé TRACES UMR 5608,

Université de Toulouse-Jean Jaurès 